Editora Poisson

\title{
Gestão da Produção em Foco Volume 20
}

\author{
1a Edição
}

Belo Horizonte

Poisson

2018 
Editor Chefe: Dr. Darly Fernando Andrade

\section{Conselho Editorial}

Dr. Antônio Artur de Souza - Universidade Federal de Minas Gerais

Dra. Cacilda Nacur Lorentz - Universidade do Estado de Minas Gerais

Dr. José Eduardo Ferreira Lopes - Universidade Federal de Uberlândia

Dr. Otaviano Francisco Neves - Pontifícia Universidade Católica de Minas Gerais

Dr. Luiz Cláudio de Lima - Universidade FUMEC

Dr. Nelson Ferreira Filho - Faculdades Kennedy

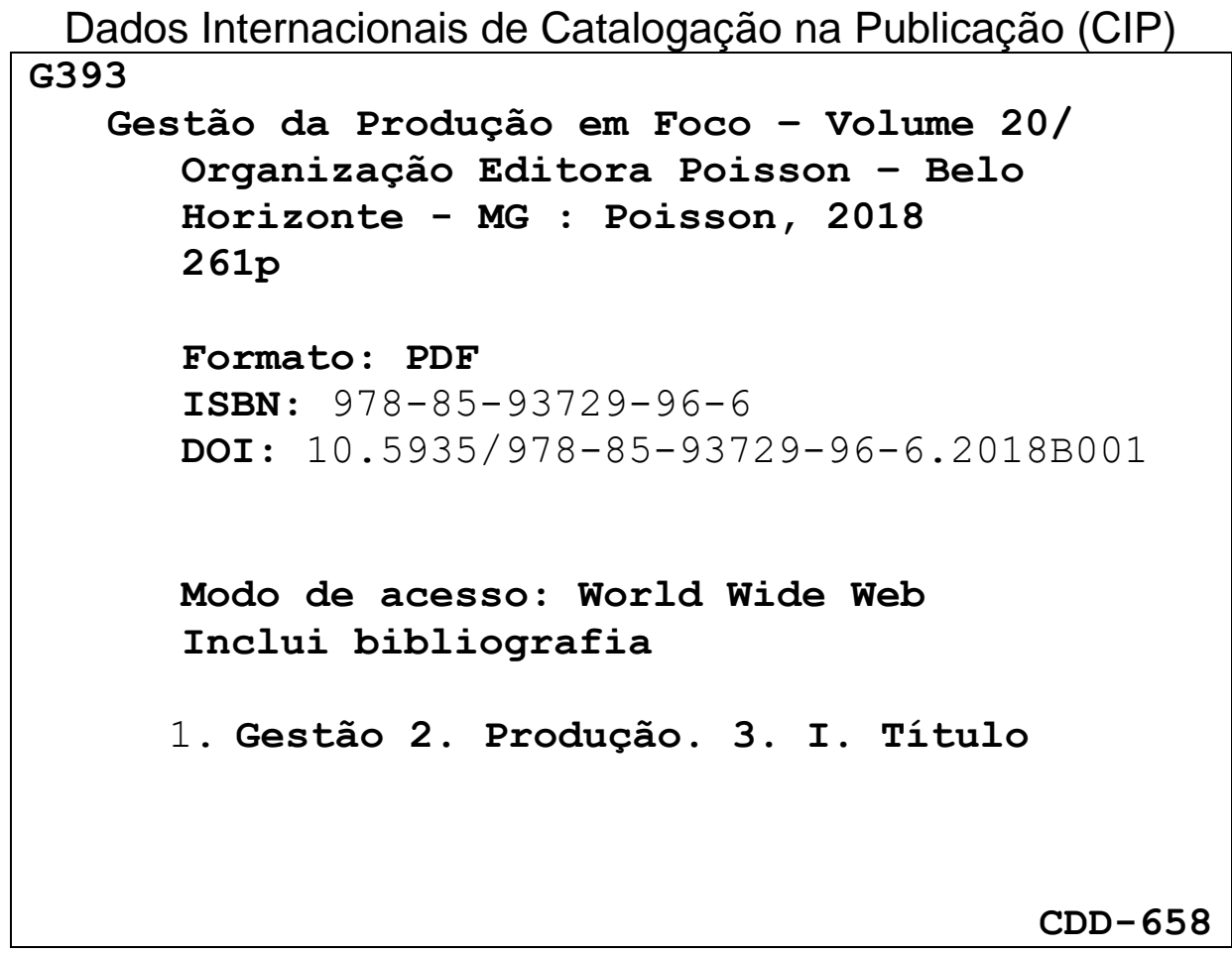

O conteúdo dos artigos e seus dados em sua forma, correção e confiabilidade são de responsabilidade exclusiva dos seus respectivos autores.

www.poisson.com.br

contato@poisson.com.br 


\section{Sumário}

Capítulo 1: Mapeamento do fluxo de valor de uma família de produtos em uma indústria de beneficiamento de vidros do sul de Santa Catarina.

Amanda de Campos, Kristian Madeira, Merisandra Cortes de Mattos, Cristina Keiko Yamaguchi, Leopoldo Pedro Guimaraes Filho, William Nunes Bittencourt

Capítulo 2: Hierarquização de projetos para desenvolvimento de produtos com uso das metodologias AHP e EVA®

Danilo Venturi, Gustavo Luiz Macedo da Silva, Pedro Alvim de Azevedo Santos

Capítulo 3: Método gestão do posto de trabalho em uma indústria de balanças no Rio Grande do Sul

Taís Oliveira da Silva Alfonso, Renata Ribeiro Silva, Layra Gabriela Gonçalves, Carolina Scherer Finkler, Luis Cláudio Ragasson

Capítulo 4: Manutenção produtiva total (TPM) e manutenção centrada na confiabilidade (RCM): Uma revisão da literatura

Leonardo Rodrigues de Freitas, Jair Rodrigues de Siqueira Neto , Thais Martins Souza,

Leticia da Silva Pires

Capítulo 5: Indicadores de desempenho para melhores resultados das extrusoras de uma indústria do ramo petrolífero.

Mateus Leite de Oliveira, Glauber Araujo Alencar Cartaxo

Capítulo 6: A utilização de simulação na avaliação de recebimento e atendimento em um armazém geral.

Germano Augusto Metzner de Andrade, Ghislaine Lury Testoni, Christiane Wenck Nogueira Fernandes, Elyelton Cesar de Souza Lima, Silvia Lopes de Sena Taglialenha

Capítulo 7: Gerenciamento do estoque de um restaurante utilizando o Método Kanban com uma planilha eletrônica

Marcela Cristina de Oliveira Rey, Gabriela Yukie Tanaka Shibao, Fernando César Cerri, Sara Santos Pereira, Gabriel Höfig de Castilho

Capítulo 8: Análise da produtividade a partir da otimização do layout: Um estudo de caso na fabricação de alçapões. 


\section{Sumárīo}

Capítulo 9: Gestão da manutenção industrial em transição para a indústria 4.0: Controle Mobile, considerações sobre esta nova tecnologia

Edson Pereira da Silva, Adriano José Correia, Gilvan Alves Ribeiro, Ricardo Luiz Ciuccio, José Benedito Sacomano

Capítulo 10: Aplicação da Tecnologia de Features da peça para simulação de um sistema de produção

Heráclito Lopes Jaguaribe Pontes, Marcos Ronaldo Albertin, Marcos Charles Pinheiro Baltazar

Capítulo 11: Estudo de caso da implementação do Método Smed no processo de compressão de uma indústria farmacêutica

Andrei Gustavo Kozan de Souza, Edson Minoru Yajima

Capítulo 12: Proposta do projeto de unidade produtiva em uma microempresa de confecção no município de Itacoatiara/AM.

Alafan Jeferson da Costa Lima, Alessandra Ferreira Reis, Ricardo Lopes de Almeida Junior, Rayson Rawkem da Silva Santos, Agberto de Castro Marinho Júnior

Capítulo 13: Piscicultura na Amazônia: Processo produtivo do Tambaqui (colossoma macropumum) Curumim

Pollyanna Menezes de Sousa, Rute Holanda Lopes, Evandro Menezes de Medeiros, Renata de Oliveira Teixeira, Marcos Antônio de Souza Queiroz, Kátia Viana Cavalcante

Capítulo 14: Identificação dos pontos críticos no processo produtivo de uma indústria do segmento de cerâmica vermelha no estado do Amazonas

Renata de Oliveira Teixeira, Rute Holanda Lopes, Renato Moreira Teixeira Júnior,

Dayanne Alves Lacerda, Roque José Paes Moraes Filho, Carlos André Esteves Leite

Capítulo 15: Filosofia Kaizen aplicada ao processo produtivo em indústria química: um estudo de caso

Camila Machado, Felipe Morais Menezes, Fabiano de Lima Nunes, Tiago dos Santos Antunes

Capítulo 16: Melhoria da produtividade com a redução do tempo de setup em uma máquina flexográfica de uma empresa de embalagens industriais

Eduardo Oliveira Paes, Hendrick Brian Rodrigues, Jeane Aparecida Castro, Mariane Merchiori 


\section{Suma์rīo}

Capítulo 17: Análise e proposta de melhoria no processo de planejamento de materiais: um estudo de caso em uma distribuidora de energia elétrica da região sul do país.

Manoel Sebastião Camargo, Tiago dos Santos Antunes, Fabio Antonio Sartori Piran

Capítulo 18: Indústria 4.0: proposta de mapa conceitual

Renan Mathias Ferreira Saltiel, Ana Claudia Silva da Silva, Fabiano de Lima Nunes, Fabio Antonio Sartori Piran, Felipe Morais Menezes

Capítulo 19: Benefícios da utilização da mineração de processos

Roquemar de Lima Baldam, Luciana de França Pestana, Paulo Cezar Thiebaut, Lourenço Costa, Thalmo de Paiva Coelho Junior

Capítulo 20: Melhoria do arranjo físico de um restaurante: Um estudo de caso.

Adriele Braga da Mota, Camila Pereira, Ingrid Moreno de Lima, Vinicius Gomes Figueiredo

Capítulo 21: Estudo de caso: Aplicação o método RKW em uma micro empresa, uma barbearia na cidade de Mossoró-RN

Antonio Jaem Estigarriga Menescal Neto, Lucas Medeiros Bezerra, Jose Helton de Azevedo, Jaine Joyce Moreira Marinho, Thiara Monik Silva Costa

Autores: 


\section{Capítulo 1}

\section{MAPEAMENTO DO FLUXO DE VALOR DE UMA FAMÍLIA DE PRODUTOS EM UMA INDÚSTRIA DE BENEFICIAMENTO DE VIDROS DO SUL DE SANTA CATARINA}

Amanda de Campos

Kristian Madeira

Merisandra Cortes de Mattos

Cristina Keiko Yamaguchi

Leopoldo Pedro Guimaraes Filho

William Nunes Bittencourt

Resumo: O sucesso de uma empresa está diretamente ligado ao fato dela responder melhor as mudanças e acompanhar o crescimento do mercado. A mudança produz efeitos de providências importantes para as organizações, que estão sujeitas as variações de fatores externos e internos. O Lean Manufacturing é uma filosofia focada na redução de perdas, melhoria na qualidade dos produtos, aprimoramento do fluxo de trabalho, melhorias no ambiente, redução de custos e principalmente ao atendimento das necessidades dos clientes. Nessa pesquisa, uma das ferramentas do Lean, o Mapeamento de Fluxo de Valor (MFV), foi aplicada com base no processo de uma família de produtos de uma indústria de beneficiamento de vidros. Iniciou-se o estudo com o mapeamento do estado atual e identificação de alguns pontos com desperdício e posteriormente desenvolvimento de um mapa de estado futuro e ideal, onde sugestão de melhorias e ações foram apontadas.

Palavras-chave: Lean Manufacturing. Ferramenta. Mapa de Fluxo de Valor. Vidro 


\section{INTRODUÇÃO}

A administração da produção vem passando por transformações através das décadas. No período da Revolução Industrial as empresas eram focadas na produção em massa e na eficiência do trabalho, a produção se tornou mecanizada e as condições humanas eram negligenciadas pelas indústrias. Logo surgiu uma nova metodologia proposta pelos japoneses, a produção enxuta, a qual era direcionada à qualidade dos produtos e principalmente no controle de desperdícios, por conta dos recursos escassos que o Japão possuía e possui até os dias de hoje.

Devido ao grande processo de globalização, a competitividade cresceu e tomou dimensões inimagináveis, tornando necessário que toda e qualquer estratégia de diferenciação disponível pudesse ser prontamente utilizada. O Lean Manufacturing é uma das principais estratégias competitivas, para as mais diversas empresas de setores distintos, estando intimamente ligada à produtividade, melhoria de resultados e aumento de lucros através de redução de perdas e do desperdício, da motivação e consequentemente, envolvimento de todos na empresa.

O Mapeamento do Fluxo de Valor é uma das ferramentas do Lean, que possibilita o melhor entendimento dos fluxos de informações e de materiais dentro de uma empresa, com ele é possível entender quais etapas agregam ou não valor ao produto, bem como propor melhorias de processos e visualizar onde é possível aplicar ferramentas para redução de desperdícios, aumento da eficiência produtiva e projetar um sistema de fluxo mais eficiente para o futuro. Inúmeras empresas, nos mais variados segmentos, vêm utilizando essa ferramenta para a visualização dos seus processos, inclusive empresas de serviços e hospitais, segundo Rother e Shook (2003).

A indústria de beneficiamento de vidros é pouco conhecida, tal como o processo de fabricação do vidro, dessa forma, esse ramo carece de mão de obra qualificada e exemplos de empresas com sistemas eficientes. Portanto, sendo o vidro um material muito utilizado em construções, é conveniente que estudos de caso sejam elaborados com a finalidade de fortalecer esse segmento.

A elaboração do presente estudo justifica-se para a aplicação de uma das ferramentas do Lean Manufacturig, o Mapeamento de Fluxo de Valor, em uma indústria de beneficiamento de vidros, localizada em Criciúma - SC. O objetivo é estudar o processo de uma família de produtos, identificar os desperdícios e falhas atuais e planejar um processo ideal, que garanta um método produtivo mais econômico, afim de eliminar desperdícios, reduzir custos, melhor a qualidade do produto final e entregar o valor desejado pelo cliente, que é de fato, o cerne de uma empresa.

\section{REFERENCIAL TEÓRICO}

\subsection{TOYOTA}

Referência na indústria automobilística e pioneira no desenvolvimento do sistema de produção enxuta, a Toyota é admirada em todos os segmentos, pela sua capacidade de conseguir empregar um sistema em diferentes fábricas pelo mundo, enquanto muitas outras empresas passam dificuldades para reproduzir o mesmo método, relatam Ritzman e Krajewski (2004).

Ainda de acordo com Ritzman e Krajewski (2004), as pessoas veem o sistema enxuto de produção como uma série de ferramentas, que implantadas trarão o resultado esperado rapidamente. Porém, a maioria não percebe que a Toyota criou um método de aprendizagem ao longo de 50 anos, para os seus funcionários. Os colaboradores Toyota, são estimulados a melhorarem $\mathrm{O}$ seu ambiente de trabalho e a utilizar o método para a resolução de problemas.

O Sistema Toyota de Produção foi desenvolvido com a finalidade de melhorar a qualidade e a produtividade, e está baseado em duas filosofias centrais à cultura japonesa: a eliminação das perdas e o respeito pelas pessoas (CHASE et al, 2006).

Liker (2005) fala sobre como os valores e ideais da família Toyoda, foram fundamentais para a fundação da Toyota. Além de idealistas e pragmáticos, os Toyoda eram grandes líderes e persistentes em buscas de suas metas. Foram anos de erros e acertos durante a implantação do Sistema Toyota de Produção (STP), fundado e conduzido por Taiichi Ohno, que foi se desenvolvendo a medida que a empresa crescia e demandava soluções para os seus desafios.

A Toyota ficou reconhecida mundialmente pela sua qualidade. Com o objetivo de proporcionar aos seus clientes a melhor experiência ao adquirir seus produtos, se 
tornou a maior em volume de vendas, confirmando ao mundo que seu método funciona e comprovou os benefícios que ele pode trazer.

\subsection{CONCEITO LEAN MANUFACTURING}

Conhecido por diferentes nomenclaturas, como Just-in-time, Sistema Toyota de Produção, Sistema Enxuto de Produção, o Lean Manufacturing, nome o qual já está muito difundido entre as empresas, é uma iniciativa que busca eliminar desperdícios durante o processo de fabricação do produto, excluindo o que não tem valor para o cliente e dando velocidade ao processo, segundo Werkema (2006).

O que estamos fazendo é observar a linha de tempo desde o momento em que o cliente nos faz um pedido até o ponto em que recebemos o pagamento. E estamos reduzindo essa linha de tempo, removendo as perdas que não agregam valor (OHNO, 1988, apud. LIKER, 2005).
De acordo com Taiichi Ohno (apud. WERKEMA, 2006) a essência do Lean, está em eliminar os sete desperdícios:

- Defeitos (nos produtos);

- Excesso de produção (mercadorias desnecessárias);

- Estoques de mercadorias (à espera no processo ou na expedição);

- Processamento desnecessário;

- Movimento desnecessário (de pessoas);

- Transporte desnecessário (de produtos);

- Espera dos funcionários (finalização do processo anterior).

A Figura 1 evidencia que a base de sustentação do Lean é a redução de desperdícios, que provoca uma melhora significativa em diversos elementos primordiais para o funcionamento da empresa, juntamente com a diminuição de itens que consomem capital, estrutura e desgaste físico.

Figura 1 - Benefícios da redução de desperdícios

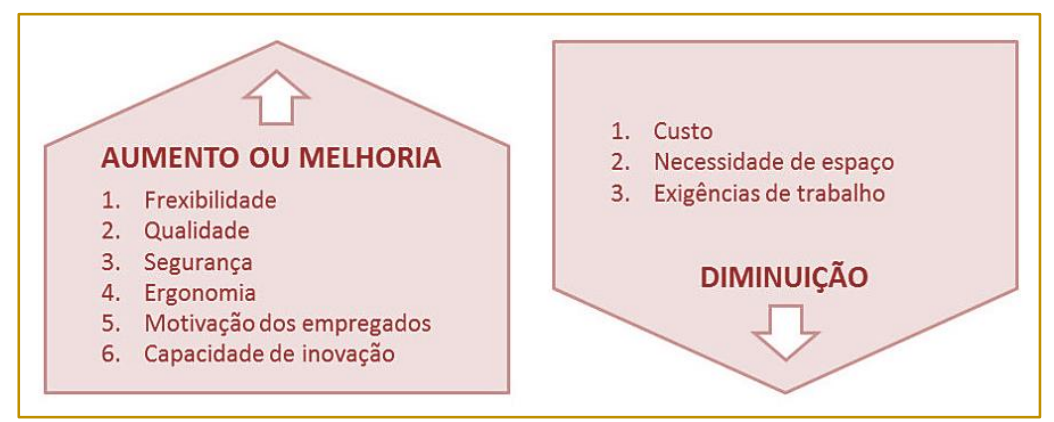

Fonte: Werkema (2006).

Segundo Werkema (2006), adotar o Lean significa adotar uma nova cultura, que representa um processo de mudança significativo. Muitas empresas vêm praticando - Lean, mas suas ferramentas não podem virar apenas painéis para decorar paredes e sim ter utilidade prática para todos e principalmente para os líderes direcionarem suas decisões.

\subsection{MAPEAMENTO DO FLUXO DE VALOR (MFV)}

O Mapeamento do Fluxo de Valor de um processo é utilizado para representar o estado atual, futuro ou ideal de um processo de implantação do sistema enxuto. De acordo com Rother e Shook (2003) o objetivo é fazer com que as empresas pensem no fluxo da produção como um todo, buscando eliminar os desperdícios e as suas causas, e não implementar métodos de melhorias isolados.

O que queremos dizer por mapeamento do fluxo de valor é simples: siga a trilha da produção de um produto, desde o consumidor até $\mathrm{o}$ fornecedor, e cuidadosamente desenhe uma representação visual de cada processo no fluxo de material e informação. Então, formule um conjunto de questões chave e desenhe um mapa do "estado futuro" de como o valor deveria fruir (ROTHER, SHOOK, 2003). 
Cohen e Fink (2003) comentam que para as organizações se manterem em equilíbrio, elas precisam fazer frequentes ajustes em sua forma de operar. As consequências para um sistema que resiste a mudanças é o gradativo decaimento, mas ao contrário disso, se uma empresa buscar uma reação muito rápida, ela pode perder o controle da sua coerência e independência. Em resumo, toda organização requer um estado de equilíbrio para manter a harmonia, ao mesmo tempo em que sofre pressões por mudanças, do ambiente que a cerca.

Rother e Shook (2003) trazem as diversas vantagens do MFV no que se refere à visualização do fluxo como um todo e não somente de processos individuais. Além disso, ele não só ajuda a identificar desperdícios, como também as suas fontes. As decisões sobre o fluxo são mais visíveis, pois tem uma linguagem clara e detalhada, mostrando a relação entre fluxo de informações e o fluxo de materiais, de forma que nenhuma outra ferramenta faz.

O Mapeamento do Fluxo de Valor consiste em seguir as seguintes etapas, segundo Rother e Shook (2003):

1-Selecionar uma família de produtos;

2-Desenhar o estado atual e futuro;

3-Plano de trabalho e implementação: Preparar um plano de implementação que descreva, como se deseja chegar ao estado futuro.

Figura 2 - Mapa de Fluxo de Valor

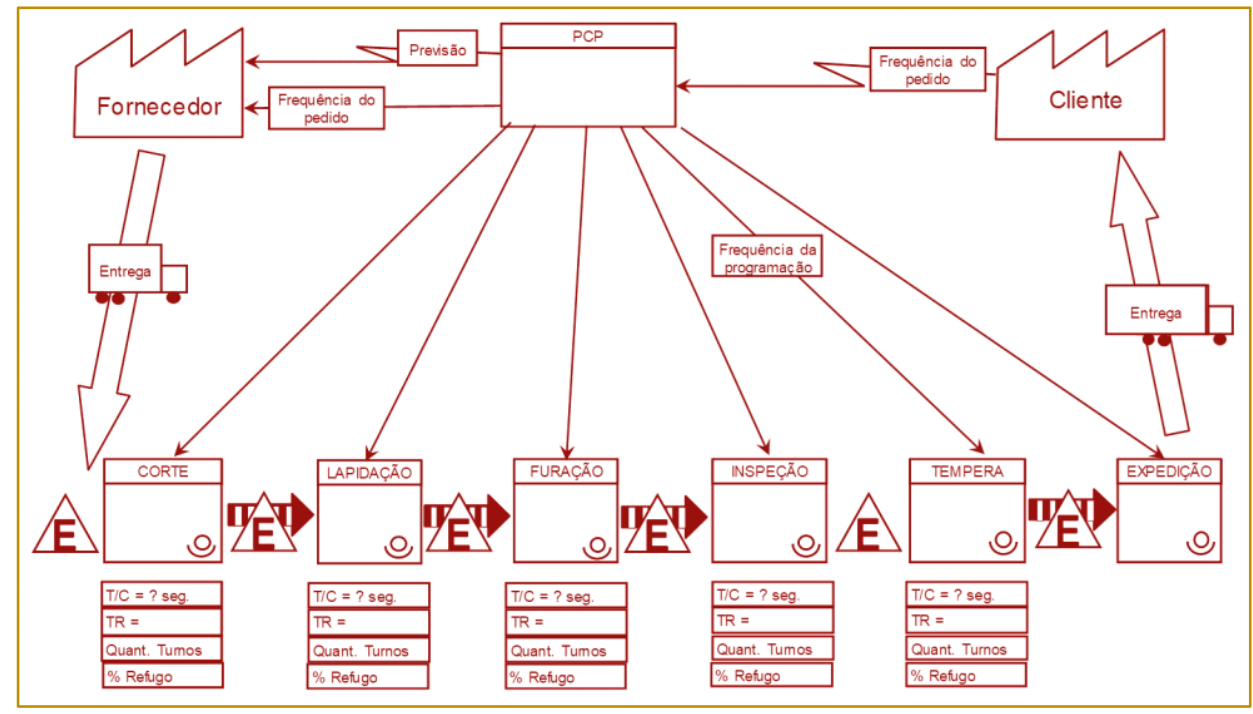

Fonte: Autora (2016)

Algumas informações básicas devem ser coletadas e incluídas no desenho. São elas:

- Tempo de ciclo (T/C): Tempo de processamento de um produto registrado em segundos.

- Tempo de troca (T/TR): Tempo de troca de ferramenta de um tipo de produto para outro, o setup.
- Índice de rejeição: Índice que determina a quantidade de produtos defeituosos provenientes do processo.

- Número de pessoas necessárias para operar o processo.

Alguns símbolos que podem ser utilizados nos mapas, segundo Rother e Shook (2003): 
Figura 3 - Ícones de fluxo de material

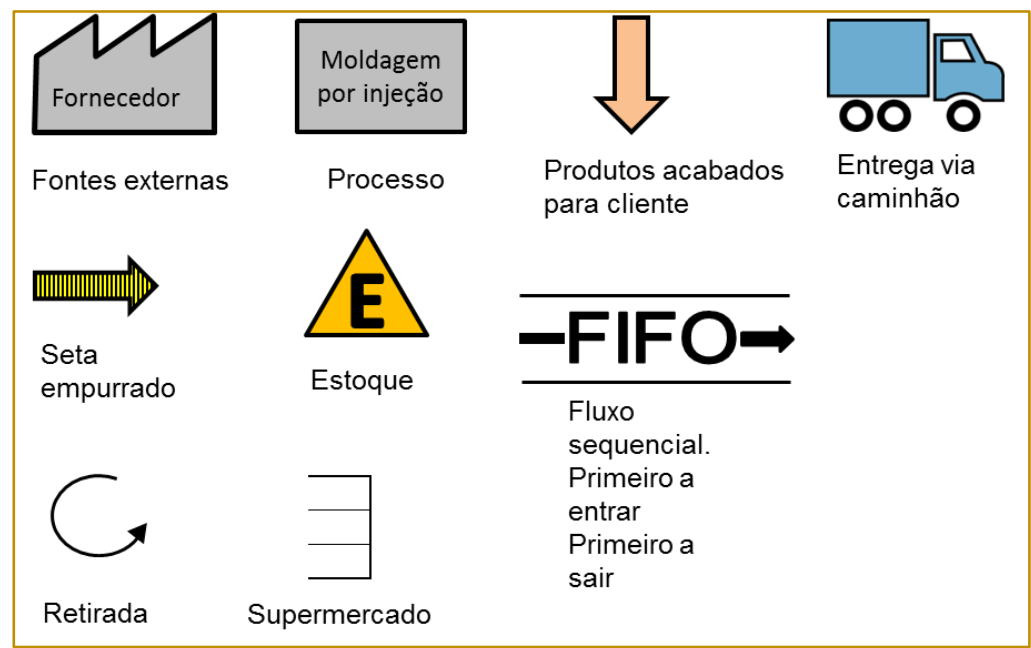

Fonte: Adaptado de Rother e Shook (2003).

Figura 4 - Ícones de fluxo de informação

$\begin{aligned} & \text { Fluxo de } \\ & \text { informação } \\ & \text { eletrônica } \\ & \text { informação } \\ & \text { manual }\end{aligned}$
$\begin{aligned} & \text { Nivelamento } \\ & \text { de carga }\end{aligned}$

Fonte: Adaptado de Rother e Shook (2003).

Figura 5 - Ícones gerais

\begin{tabular}{|c|c|c|c|}
\hline Operador & $\begin{array}{l}\text { Pulmão ou } \\
\text { estoque de } \\
\text { segurança }\end{array}$ & $\begin{array}{l}\text { Necessidade } \\
\text { de Kaizen }\end{array}$ & $\begin{array}{l}\text { Problemas de } \\
\text { qualidade }\end{array}$ \\
\hline
\end{tabular}

Fonte: Adaptado de Rother e Shook (2003). 
O Mapeamento do Fluxo de Valor ajuda na visualização dos processos individuais, a identificar os desperdícios e as suas fontes, fornece uma linguagem clara para tomar decisões de melhorias sobre o processo e segundo Rother e Shook (2003) o MFV é muito mais útil que ferramentas quantitativas $e$ diagramas de layout que produzem um conjunto de passos que não agregam valor.

\section{MÉTODO}

Nesse tópico, se pretende fornecer a proposta de abordagem metodológica de pesquisa que foi utilizada como roteiro para a realização prática do presente trabalho. Dessa forma, o estudo se qualifica como de pesquisa explicativa, a qual, segundo Lakatos e Marconi (2011, apud. PÓS- GRADUANDO, 2012) busca registrar, analisar, interpretar e identificar fatos e suas causas. Essa prática de pesquisa gera ideias através de deduções lógicas e define e estrutura modelos teóricos.

O Mapeamento do Fluxo de Valor foi desenvolvido em uma indústria de beneficiamento de vidros localizada na cidade de Criciúma-SC. Essa empresa conta com uma quantidade que varia em torno de 45 funcionários, entre mão de obra direta e indireta. A indústria funciona com pedidos personalizados e sob encomenda, é uma intermediária entre indústrias fabricantes de chaparias de vidro e vidraçarias. Por tanto, as vidraçarias são os clientes e as indústrias de produção de vidros são os fornecedores.

O processo de beneficiamento do vidro, após receber as chaparias dos fornecedores, consiste em cortar, lapidar, usinar, laminar, modelar, furar, pintar e/ou temperar. Os beneficiamentos dependem do projeto enviado pelo cliente. À vista disso, considerando que há muitas possibilidades de processar um produto, uma família de produtos foi adotada para o estudo. Essa família equivale ao processo de beneficiamento mais empregado na produção: corte lapidação, furação e tempera. A família selecionada foi denominada de Família A e engloba peças de vidro para construção civil, como portas, sacadas, muros, paredes e janelas.

Após escolhida a família de produtos, o desenho do estado atual foi elaborado a partir da coleta de informações no chão de fábrica. A coleta foi feita caminhando pela produção e fazendo as anotações, iniciando a observação da expedição e seguindo pelos processos anteriores. Com um cronômetro os tempos de ciclo $(\mathrm{T} / \mathrm{C})$ e tempo de troca de ferramenta (TR) foram medidos e marcados. As porcentagens de refugo e média de recebimento de pedidos foram obtidas através do software utilizado na empresa e com base em dados do mês de outubro de 2016, mês o qual foram feitas as medições de tempo também.

A partir do mapa de fluxo de valor do estado atual o mapa de fluxo de valor do estado futuro foi elaborado juntamente com o diretor da empresa, pois é o indivíduo com maior conhecimento sobre a produção de beneficiamento de vidros na organização. Para a elaboração do mapa, foi levado em conta algumas diretrizes e conceitos básicos do Lean Manufacturing, buscando um fluxo mais enxuto. Fontes de desperdícios foram identificadas e eliminadas na construção no mapa futuro.

Após o mapa de estado futuro pronto algumas medidas de melhorias foram apontadas para, que através de um plano, desenvolver fluxos de valor Lean e alcançar os propósitos do mapa futuro.

\section{RESULTADOS}

\subsection{MAPA DO ESTADO ATUAL}

O mapa do estado atual foi desenhado com base no processo da família $A$, que consiste nos beneficiamentos de corte, lapidação, furação e tempera. Contudo existem quatro processos que não agregam valor ao produto, mas precisam ser destacados no mapa: marcação, escariação, lavação e inspeção. 
Figura 6 - Mapa do estado atual

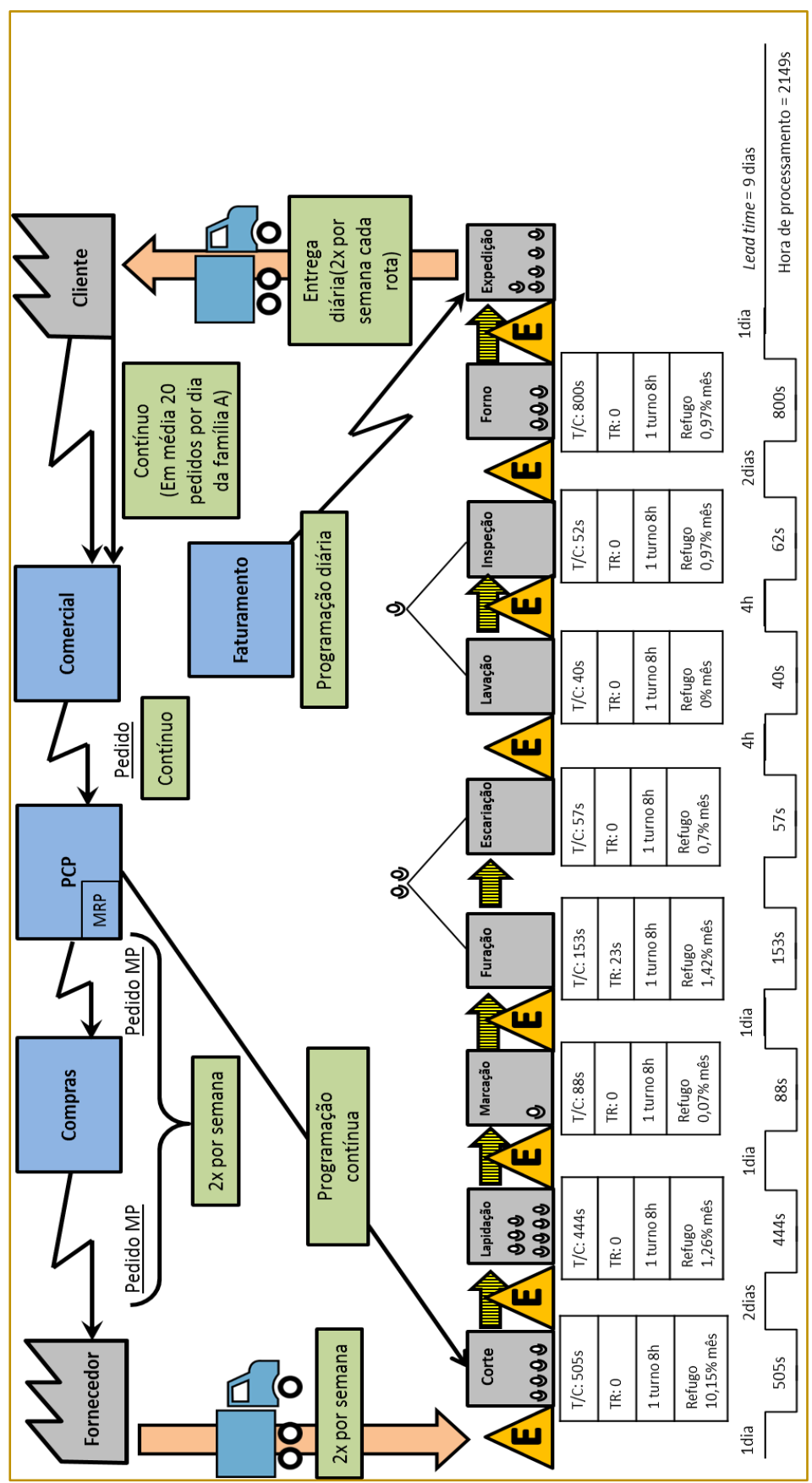

Fonte: Autora (2016).

Após o mapeamento do estado atual foi possível identificar algumas causas de desperdícios:

- Departamento comercial envia pedidos com pendências para o PCP;

- Frequente antecipação dos pedidos dos clientes;

- Constantes mudanças de programação devido a antecipações e mudanças pelo setor de vendas;
- O software da empresa apresenta várias ferramentas de controle, porém não são alimentadas e utilizadas corretamente;

- Falta de padronização nos processos;

- Fadiga dos funcionários na unidade fabril. Segundo com Martins e Laugeni (2001), além do esforço físico, as condições ambientais também interferem no cansaço dos colaboradores. Ambientes que possuem ruído acima de $80 \mathrm{~dB}$, iluminação insuficiente (abaixo de 200 lux), temperatura fora da faixa 
de 20 a 24 graus Celsius, são ambientes insalubres. De acordo com o laudo PPRA (Programa de Prevenção de Riscos Ambientais) da empresa, as condições estão fora das especificações de um ambiente agradável;

- Elevado estoque entre os processos;

- Arranjo físico confuso com má distribuição de cavaletes dos estoques entre os processos;

- Quatro processos que não agregam valor ao produto (marcação, escariação, lavação e inspeção);
- Lead time longo devido à diferença da capacidade de processamento entre os setores.

\subsection{MAPA DO ESTADO FUTURO}

O desenvolvimento estado futuro se deu a partir do mapeamento do fluxo atual da empresa. Para sua elaboração, o diretor da organização fez considerações sobre seus objetivos futuros e conduzido por fundamentos da filosofia enxuta, participou da preparação do mapa do estado futuro.

Figura 7 - Mapa do estado futuro

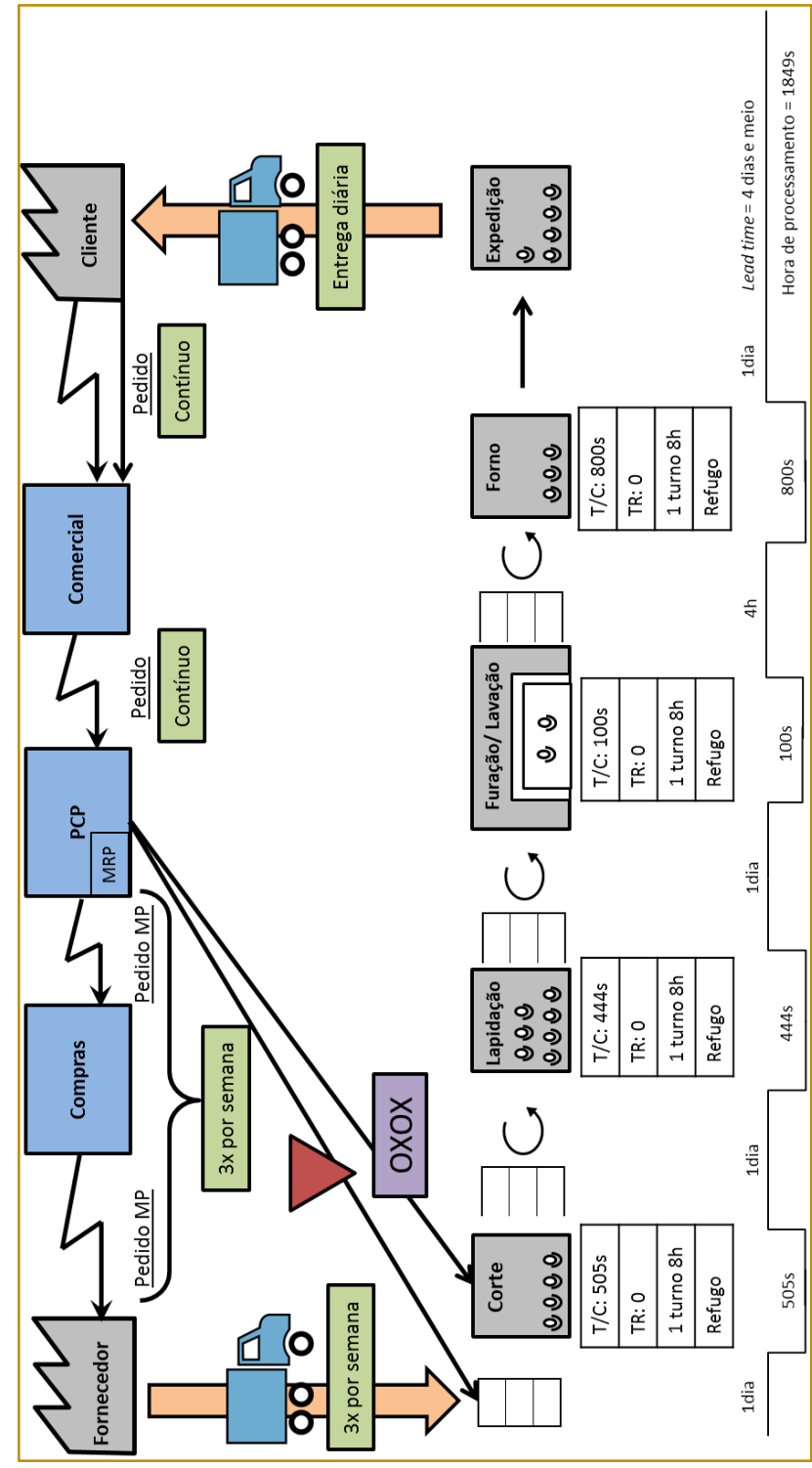

Fonte: Autora (2016). 


\subsection{COMPARAÇÃO DOS RESULTADOS}

Fazendo uma análise dos dois mapas obtidos, fica explicito, que a cadeia teve uma grande alteração de tamanho e se pode dizer que seu processo está mais enxuto. Ademais, examinando os números, é comprovado que tanto o lead time, quanto o tempo de processamento, tiveram significativas modificações.

No mapa de fluxo atual o lead time chegou a 9 dias, já no mapa de fluxo futuro o lead time caiu para 4 dias e meio. Uma queda de $50 \%$, que se deve a melhor organização da produção e principalmente na eliminação de estoques. Esse novo tempo vai interferir positivamente no prazo de entrega, fator muito importante para os clientes do setor vidreiro, de acordo com pesquisas já realizadas pela empresa.

O tempo de processamento não teve uma grande diferença, estava em 2149 segundos (em média 36 minutos) no mapa atual, e foi para 1849 segundos (em média 31 minutos) no mapa futuro, uma queda de $13,89 \%$ no tempo de processamento. Os dados de refugo no segundo mapa não foram calculados, pois dependem de treinamentos operacionais e manuseio dos produtos pelos colaboradores.

Os números obtidos são resultados de um processo mais enxuto, onde processos que não agregavam valor foram descartados. De fato, a decisão da compra de um novo equipamento fez toda a diferença no processo, pois vem com novos tempos de processamento mais rápidos (tempos disponibilizados pelo fornecedor), além disso, o novo maquinário permitiu que um fluxo contínuo fosse incluído no projeto.

Em um estudo similar de Mapeamento do Fluxo de Valor feito em uma indústria de gesso, em Nova Olinda -CE (ELIAS, OLIVEIRA E TUBINO, 2011), os resultados obtidos foram parecidos ao estudo feito na indústria de beneficiamentos de vidros. No mapa de estado futuro, os supermercados sugeridos entre os setores fizeram a diferença para um sistema puxado e não mais empurrado, com redução de $66 \%$ do lead time na indústria de gesso e o da indústria vidreira com redução de 50\%. O tempo de processamento na indústria de gesso teve uma diferença de 18 minutos do estado atual para o futuro, $18,18 \%$ de redução e a indústria de vidros com 13,89\%. Em conclusão, é importante relembrar que a indústria de vidros é um processo sob encomenda, o qual é mais restrito a grandes mudanças, porém outras melhorias podem ser exploradas para um processo ainda mais enxuto.

De acordo com Wallace e Stahl (2003) simplificar o ambiente, eliminar atividades que não agregam valor, criar fluidez, produzir apenas o que necessita e reduzir o lead time, são atitudes que ligadas às ferramentas da qualidade resultaram ao longo dos anos, não só uma evolução, mas uma revolução no mundo da manufatura. Logo, uma nova mentalidade deve ser adotada na empresa, caso ela queria alcançar esses resultados na realidade.

\subsection{MEDIDAS DE AÇÃO}

Medidas de ação foram apontadas, de acordo com princípios da produção enxuta, para o melhoramento do processo e alcance do mapa de estado futuro elaborado.

- Com base nas análises feitas em campo, é perceptível a deficiência nos departamentos por conta da falta de padronização nos processos. Portanto, é de extrema importância a padronização dos setores, segundo Antunes (2008) as empresas necessitam frequentemente adequar seus processos às exigências do mercado, pois essas mudanças geram uma grande evolução no sistema produtivo.

- Como início de um novo pensamento enxuto, é considerável que a empresa busque a aplicação de uma ferramenta simples do Lean, mas que faz diferença no envolvimento da equipe com os custos da empresa, como o Programa 5S. Segundo Campos (2014), o $5 S$ não busca somente a limpeza, mas sim uma nova maneira de pensar e de conduzir a empresa, através de comportamentos mais salubres. Além disso, é um programa para todos, desde o presidente aos operadores baseado em educação, treinamento e prática em grupo.

- Plano de treinamentos para setor comercial (fechamento de vendas), PCP e expedição (melhor aproveitamento do software da empresa) e para os colaboradores da produção (cada funcionário deve fazer a inspeção do seu próprio trabalho). De acordo com Marodin e Saurin (2015, apud. COPETTI, SAURIN, SOLIMAN, 2016) a falta de treinamento, envolvimento e autonomia para os operadores realizarem suas novas 
atribuições, pode ser uma barreira na implantação de um sistema enxuto.

- O setor de PCP deve fazer previsões de demanda para a compra de matéria-prima, pois uma demanda bem gerenciada faz melhor uso da capacidade, reduz custos e consequentemente o lucro potencial pode ser melhorado, segundo Slack, Chambers e Johnston (2007).

- De acordo com o envio da programação de produção do PCP para o corte (OXOX), o setor de lapidação terá um planejamento de processamento e não ficará sobrecarregado com estoques.

- Segundo o diretor, o próximo equipamento a ser adquirido será uma nova furadeira, a qual descarta a necessidade do setor anterior de marcação e um posterior de escariacão e nenhuma troca de ferramenta. Dessa forma, foi estudado que, uma simples adaptação entre setores pode tornar o setor de furação e lavação um fluxo contínuo.

- Os setores foram organizados de forma a funcionarem com "supermercados", os quais têm como objetivo criar um sistema puxado entre os setores de modo que o processo posterior possa ir ao seu processo antecessor e retirar as peças que precisa para o processamento. Logo, o processo que sofreu a retirada precisa produzir outro lote das peças que acabaram, segundo Rother e Shook (2003)

- O arranjo físico da produção é confuso e não auxilia na movimentação de pessoas e produtos. Uma simples realocação de máquinas e cavaletes, vai facilitar 0 deslocamento e agilizar os processos.

Um bom layout é aquele que facilita o trabalho, diminui os custos, racionaliza o espaço e possibilita rápida identificação dos materiais, bom armazenamento, facilidade de retirada do estoque e gestão focalizada [...] (MARTINS, LAUGENI, 2001).

Os problemas de fadiga podem melhorar através de ginasticas laborais e a iluminação, com a troca de algumas telhas de fibrocimento por telhas translucidas, para a

\section{REFERÊNCIAS}

[1] Antunes, J. Sistemas de produção: conceitos e práticas para projeto e gestão da produção enxuta. Porto Alegre: Bookman, 2008.

[2] Campos, Vicente F. TQC: Controle da qualidade total (no estilo japonês). 9 ed. Nova lima: Editora Falconi, 2014. iluminação natural do ambiente e economia de energia.

\section{CONCLUSÃO}

Quando uma organização tem controle total sobre suas ações, consegue se sair melhor com as mudanças rápidas de um mercado cada vez mais desenvolvido. A gestão de processos, se utilizados os métodos certos, torna a organização altamente competitiva prevenindo-a de problemas que podem vir a surgir no futuro.

Com esse estudo se buscou compreender o funcionamento das práticas do Lean Manufacturing, através da ferramenta MFV, que busca a redução de perdas, melhora na qualidade dos produtos, aprimoramento do fluxo de trabalho, melhorias no ambiente e principalmente a redução de custos.

$\mathrm{Na}$ empresa estudada, se tornou possível chegar a conclusões significativas acerca de um assunto tão debatido e estudado por organizações de vários setores: a produção enxuta. Apesar da empresa adotada não possuir a metodologia Lean aplicada, ela busca constantemente se aperfeiçoar diante das exigências de mercado.

Os próximos passos para alcançar o fluxo ideal, devem estar ligados ao trabalho coletivo, assim como preza a filosofia Lean, e na padronização dos processos na busca determinada da redução de estoques, movimentos, cumprimento de tempos e prazos e qualidade dos produtos, a qual deve estar sempre presente em todas as etapas da produção de uma empresa.

Com a elaboração do Mapeamento do Fluxo de Valor foi possível perceber a dimensão e a infinita importância de um sistema focado na eliminação de desperdícios para organizações que buscam formas de satisfação do cliente. Nessas empresas a qualidade aliada à redução de custos é fator determinante de sucesso e de bons resultados.

[3] Chase, Richard B; Jacobs, F. Roberts; Aquilano, Nicolas T. Administração da produção para a vantagem competitiva. Porto Alegre: Bookman, 2006

[4] Copetti, Filipe de A; Saurin, Tarcisio A; Soliman, Marlon. Gestão de barreiras na implantação da produção enxuta: um estudo no 
setor automobilístico. Porto Alegre: Produção Online, v. 16, p. 313-34, jan/mar. 2016.

[5] Elias, Sérgio J; Oliveira, Mauro M; Tubino, Dálvio F. Mapeamento do Fluxo de Valor: Um Estudo de Caso em uma Indústria de Gesso. Revista ADMpg Gestão Estratégica, v. 4, n. 1, 2011

[6] Liker, Jeffrey K. O modelo Toyota: 14 princípios de gestão do maior fabricante do mundo. Porto Alegre: Bookman, 2005.

[7] Martins, Petrônio G; Laugeni, Fernando P. Administração da produção. São Paulo: Saraiva 2001.

[8] Pós Graduando, As diferenças entre pesquisa descritiva, exploratória e explicativa. Disponível em: http://posgraduando.com/diferencas-pesquisadescritiva-exploratoria-explicativa/. Acesso em: 06 Dezembro 2016.
[9] Ritzman, Larry P; Krajewski, Lee J. Administração da Produção e Operações. São Paulo: Pearson Prentice Hall, 2004.

[10] Rother, Mike; Shook, John. Aprendendo a enxergar: mapeando o fluxo de valor para agregar valor e eliminar o desperdício. São Paulo: Lean Institute Brasil, 2003.

[11] Slack, Nigel; Chambers, Stuart; Johnston, Robert. Administração da produção. 2 ed. São Paulo: Atlas, 2007.

[12] Wallace, Thomas F; Stahl, Robert A. Planejamento moderno de produção. São Paulo: IMAM, 2003.

[13] Werkema, Maria Cristina C. Lean Seis Sigma: Introdução às Ferramentas de Lean Manufacturing. 1 ed. Belo Horizonte: Werkema Editora,

2006. 


\section{Papítulo 2}

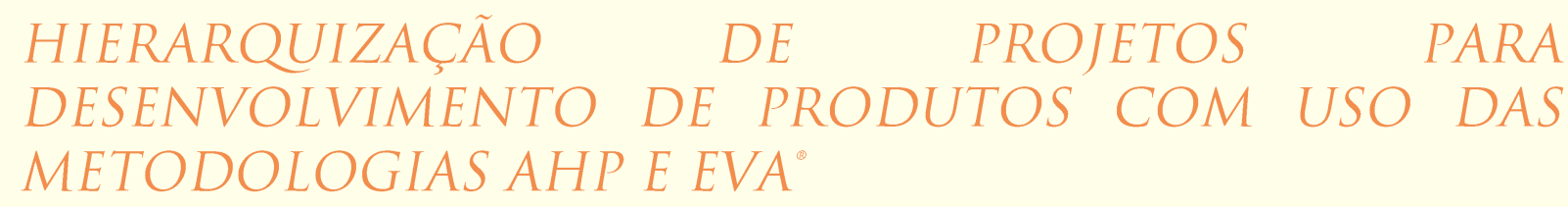

Danilo Venturi

Gustavo Luiz Macedo da Silva

Pedro Alvim de Azevedo Santos

Resumo: O presente projeto de pesquisa possui como objetivo a aplicação de duas ferramentas para o auxílio à tomada de decisão no processo hierarquização de projetos, para desenvolvimento de produtos. A aplicação destas metodologias, é baseada em um estudo de caso em uma empresa metal mecânica situada no norte de Santa Catarina, no qual será analisado os parâmetros quantitativos e qualitativos de cinco projetos disponíveis para o desenvolvimento de novos produtos. Efetuar a priorização de projetos apenas considerando critérios quantitativos e desconsiderando os critérios qualitativos, por vezes pode limitar o processo decisório de hierarquização na seleção dos projetos, gerando atrasos no lançamento e gastos adicionais com uma escolha apenas baseada em indicadores econômico-financeiros. Utilizar critérios quantitativos e qualitativos engrandecem a análise, pois a avaliação não apenas considerará os critérios financeiros, mas também critérios técnicos tão importantes no desenvolvimento de novos produtos. Para execução do processo de hierarquização, o presente projeto de pesquisa constrói uma planilha de cálculo para aplicação da ferramenta AHP - Análise Hierárquica de Processos, bem como uma planilha para ferramenta EVA® - Valor Econômico Agregado. Através de entrevistas com decisores-chave da empresa, será realizada a hierarquização dos projetos realizando a comparação entre essas duas ferramentas. Para tanto, foram definidos cinco projetos, utilizando cinco critérios, com a avaliação de quatro decisores de áreas distintas da empresa. A ferramenta AHP mostrou que a priorização ficou dívida entre os projetos $A, B$ e C. Já na aplicação da ferramenta EVA®, apenas o projeto $C$ foi selecionado com um $E V A \otimes=R \$ 1.046 .34,04$. Para avaliar a resposta do AHP frente à variação nas decisões tomadas por dois dos cinco decisores, foi utilizado uma análise de sensibilidade, que aplicada aos decisores 2 e 4 mostrou que ao variar o peso de critérios selecionados, alterará a sequência de hierarquização dos projetos. Com isso, a análise de sensibilidade quantificou a variação do peso de um determinado critério necessário para obter-se uma decisão distinta. O trabalho conclui que ambas as ferramentas foram capazes de hierarquizar os projetos, entretanto, a utilização de apenas critérios econômico-financeiros pela ferramenta EVA® torna a hierarquização restrita a um resultado algébrico, enquanto o AHP mostrou-se mais completo e abrangente para contemplar interesses de decisores de áreas diferentes. Por fim, o trabalho sugere aplicação conjunta de ambas as ferramentas AHP e EVA®, atreladas a uma análise de sensibilidade, capaz de contemplar critérios quantitativos e qualitativos, bem como relativizar o resultado ao considerar cenários de decisões distintas.

Palavras-Chave: Hierarquização de projetos. AHP. EVA®. Análise de Sensibilidade. 


\section{INTRODUÇÃO}

A presente pesquisa realiza um estudo da aplicação e utilização das ferramentas AHP Análise Hierárquica de Processos e EVA® Valor Econômico Agregado, na seleção e hierarquização de um portfólio de projetos para desenvolvimento dentro de uma empresa multinacional do ramo de refrigeração, situada no norte de Santa Catarina. O objetivo desta análise visa aplicar as duas ferramentas em um estudo de caso, afim de estabelecer a hierarquização de cinco projetos disponíveis para desenvolvimento dentro de um portfólio de produtos.

A aplicação da ferramenta AHP será mediante a avaliação de cinco critérios com características qualitativas e quantitativas, avaliados por quatro decisores de áreas distintas da empresa. O resultado será a hierarquização de cinco projetos reais, selecionados para esse estudo de caso. Já a aplicação da ferramenta EVA® será mediante a avaliação de dados econômico-financeiro, mensurando e comparando a lucratividade dos projetos.

Para verificação do resultado apresentado pela ferramenta AHP, utilizando o resultado da avaliação feita por dois dos cinco decisores, será realizada uma análise de sensibilidade, que mostrará o impacto na hierarquização ao variar o peso de critérios selecionados. Por fim, será realizada uma análise comparativa dos resultados das duas ferramentas, afim de identificar e demonstrar suas diferenças no processo de hierarquização de projetos.

Com este cenário, este trabalho busca através de um estudo de caso possibilitar o aperfeiçoamento do processo de gestão e tomada de decisão dentro de um portfólio de projetos. Vale ressaltar que, embora as empresas que gerenciem portfólios de projetos de acordo com a teoria da carteira de projetos, sem uma metodologia consistente para tomada de decisão os projetos podem fracassar com atrasos, indisponibilidade de recursos e falta de visão geral com os objetivos da empresa (BLICHFELDT, 2008).

\section{GESTÃO DO PORTFÓLIO DE PROJETOS E PRODUTOS}

Todo e qualquer produto ou serviço entregue a um cliente necessita de um processo para sua realização (SALGADO; MELLO, 2005). A gestão do portfólio de projetos e produtos, alinhada ao desenvolvimento de novos projetos, são etapas essenciais no processo de manutenção e geração de receita. Rozenfeld et al. (2006), afirma que o portfólio de produtos e projetos consiste em todos os produtos atualmente comercializados pela empresa e projetos de novos desenvolvimentos em andamento ou ainda não iniciados. O GUIA PMBOK (2014), afirma que um portfólio se refere a projetos, programas, subporfólios e operações gerenciadas como um grupo para atingir objetivos estratégicos.

A gestão do portfólio de projetos consiste na seleção e priorização dos projetos que estão para serem desenvolvidos, afim de avaliar os custos, prazos e a complexidade do desenvolvimento, avaliando se existe alguma superposição de projetos, já a gestão do portfólio de produtos consiste em avaliar os custos, ganhos dos produtos em fabricação, afim de analisar os projetos que serão descontinuados e descartados da carteira de produtos da empresa. A Figura 1 apresenta uma breve explicação da diferença entre portfólio de projetos e portfólio de produtos pelo ponto de vista dos autores:

Figura 1 - Diferença entre Portfólio de Projetos Vs. Portfólio de Produtos

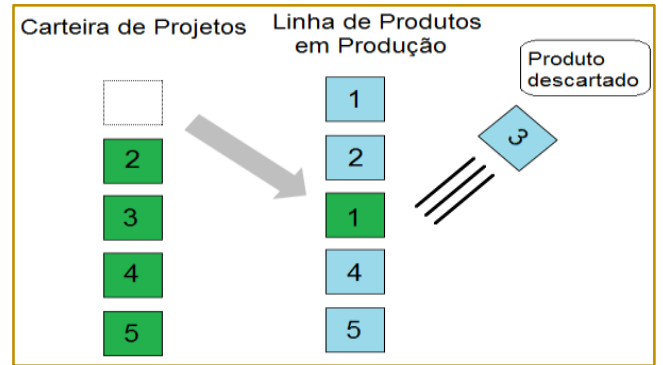

Fonte: Do autor, 2016 
A coluna da esquerda "Carteira de Projetos" representa os projetos que estão hierarquizados para o desenvolvimento e que compreendem a gestão do portfólio dos projetos. A coluna da direita "Linha de Produtos em Produção" refere-se aos produtos atualmente comercializados pela empresa e que compreendem a gestão do portfólio de produtos.

Identificar dentro da carteira de projetos qual o projeto momentaneamente mais atrativo para a empresa e que possa se tornar um produto rentável, é uma tarefa de muitos obstáculos. Descontinuar um produto em produção, substituindo-o por um projeto previamente rentável, onde os custos, prazos, riscos e complexidades ainda não foram totalmente validados, aumenta a relevância de uma metodologia como o AHP ou EVA para os decisores.

\section{AHP - ANÁLISE HIERÁRQUICA DE PROCESSOS}

No método AHP, proposto por Thomas L. Saaty em 1980, primeiramente um problema é estruturado como uma hierarquia e, posteriormente sofre um processo de hierarquização. Saaty (2006), afirma que o AHP ajuda o tomador de decisão a enxergar melhor seu problema em níveis hierárquicos, determinando com clareza, e por meio da síntese dos valores dos agentes de decisão, uma medida para cada uma das alternativas, priorizando-as ou classificando-as ao finalizar o método.

Para a modelagem de um problema, o ponto inicial é estabelecer qual é o foco principal, qual o objetivo central que deverá ser avaliado. O AHP divide o problema geral em critérios e subcritérios, conforme apresentado na Figura 2.

Figura 2 - Exemplo da Estrutura do AHP

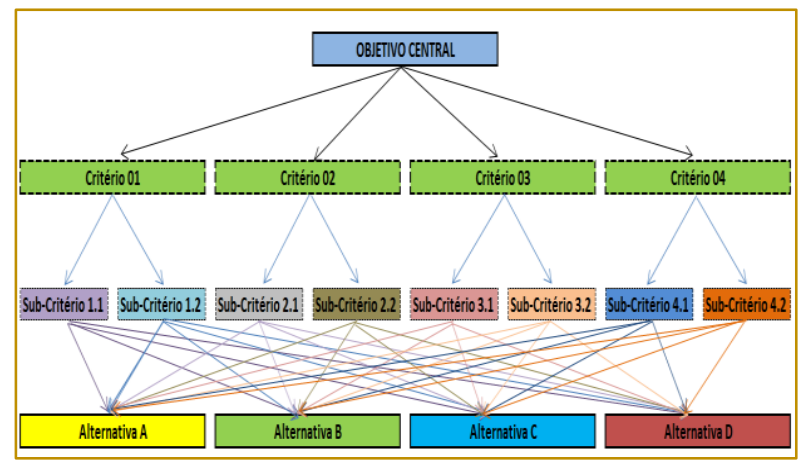

Fonte: Do autor, 2016

Para a avaliação da importância dos critérios e subcritérios conforme apresentado na Figura 2, utiliza-se a escala fundamental de
Saaty para julgamentos comparativos, sendo essa escala de valores que variam de 1 a 9 , apresentada na Tabela 1.

Tabela 1 - Escala Fundamental de Saaty para julgamentos comparativos

\begin{tabular}{|c|c|c|}
\hline $\begin{array}{c}\text { Intensidade da } \\
\text { Importância }\end{array}$ & Definição & Explicação \\
\hline 1 & De mesma importância & $\begin{array}{l}\text { As duas alternativas contribuem igualmente } \\
\text { para o objetivo }\end{array}$ \\
\hline 3 & $\begin{array}{l}\text { Importância pequena de uma } \\
\text { sobre a outra }\end{array}$ & $\begin{array}{l}\text { A experiência e o julgamento favorecem } \\
\text { levemente uma atividade em relação à outra } \\
\text { atividade. }\end{array}$ \\
\hline 5 & $\begin{array}{l}\text { Importância grande ou } \\
\text { essencial }\end{array}$ & $\begin{array}{l}\text { A experiência e o julgamento favorecem } \\
\text { fortemente uma atividade em relação à outra } \\
\text { atividade. }\end{array}$ \\
\hline 7 & $\begin{array}{l}\text { Importância muito grande ou } \\
\text { demostrada }\end{array}$ & $\begin{array}{l}\text { Uma atividade é fortemente favorecida em } \\
\text { relação à outra; sua dominação de importância } \\
\text { é demonstrada na prática. }\end{array}$ \\
\hline 9 & Importância absoluta & $\begin{array}{l}\text { A evidência favorece uma atividade em relação } \\
\text { à outra com o mais alto grau de certeza }\end{array}$ \\
\hline $2,4,6,8$ & $\begin{array}{l}\text { Valores Intermediários entre os } \\
\text { valores adjacentes }\end{array}$ & $\begin{array}{l}\text { Quando se procura uma condição entre duas } \\
\text { definições. }\end{array}$ \\
\hline
\end{tabular}

Fonte: Adaptado de Saaty, 1991 
A realização da comparação pareada gera matrizes recíprocas quadradas positivas $(n \times n)$, onde $n$ representa o número de critérios. O número na linha i e na coluna j dá a importância do critério $\mathrm{Ai}$ em relação ao critério $\mathrm{Aj}$, realizando a comparação entre os critérios conforme apresentado na Equação 1:

$$
\mathbf{A}=[\mathbf{a i j}] \mathbf{n x n}
$$

Cada julgamento representa a dominância de um elemento da coluna à esquerda sobre um elemento da linha, conforme Saaty (1994). Sendo assim, no elemento aij do vetor da linha da matriz dominante, representa a dominância da alternativa Ai (da linha) sobre a alternativa Aj (da coluna). Após a realização da comparação dos critérios e coleta dos julgamentos de valor, se faz necessário a formação da matriz de comparação para cada nó de julgamento. A próxima etapa é a obtenção do Auto Vetor.

Para cada julgamento de hierarquia, em cada nó se faz necessário calcular o auto vetor, os cálculos utilizados nesse estudo de caso são detalhados por Venturi (2016). Após a obtenção dos valores do Auto Vetor, se faz necessário normalizar o Auto Vetor, que consiste em realizar o cálculo do Auto Valor (Kmax). O cálculo do Auto Valor (Kmax), é obtido através do somatório dos julgamentos atribuídos aos critérios de cada coluna. Após essa etapa, o somatório dos julgamentos atribuídos aos critérios de cada coluna é multiplicado pelo Auto Vetor de cada linha gerando o resultado do Auto Valor (Kmax) (VENTURI, 2016).

Se o tomador de decisão é consistente em suas escolhas e classificações, cada medida de consistência será igual ao número de alternativas do problema. Para determinar se há inconsistência, devem ser realizados os cálculos do Índice de Consistência (IC) e Razão de Consistência (RC). Para o cálculo do Índice Consistência (IC), utilizamos a Equação 2:

$$
I C=\frac{(\lambda \max -n)}{(n-1)}
$$

Para o cálculo Razão de Consistência (RC) se faz necessário a utilização do Índice Randômico (IR). O valor do IR é tabelado conforme (TZENG; HUANG,2011), e o seu respectivo cálculo é apresentado na Equação 3:

$$
R C=\frac{I C}{I R}
$$

Nesse caso quanto maior for o RC, maior é a inconsistência. Se os valores de RC forem: para $\mathrm{n}=1$ é nulo; $\mathrm{n}=2$ é nulo; quando o $\mathrm{n}=$ 3 deve ser inferior a 0,05 ; e quando for $n=4$ o $R C$ deve ficar abaixo de 0,08 , quando o $n \geq 5$ o RC deve ficar abaixo de 0,10.

\section{EVA® - VALOR ECONÔMICO AGREGADO}

O valor econômico agregado (EVA®, do inglês Economic Value Added) foi introduzido incialmente por Alfred Marshall em 1890 nos Estados Unidos. Segundo Lovata (2002), o EVA® basicamente mede a diferença entre o retorno sobre o capital de uma empresa e o custo deste capital, e foi introduzido definitivamente no âmbito da administração financeira a partir da década de 80 . O EVA $®$ da empresa é apenas uma medida do retorno incremental que o investimento ganha sobre a taxa de retorno do mercado. Em termos simples, pode-se afirmar que o EVA® mede a rentabilidade líquida do custo de capital. Segundo Wernke (2000), o EVA® é uma forma real de medir a lucratividade de uma operação ou empreendimento, e essa analogia é o que distingue essa ferramenta das demais. Malvessi (2000) define o EVA® conforme apresentado na Equação 4: 
Sendo:

- NOPAT (Net Operating Profit After Tax): é o lucro operacional produzido pelo capital utilizado pela empresa, independente de como este capital tenha sido financiado, após o pagamento de impostos;

- C\%(TC): Representa o custo de oportunidade composto por duas parcelas;

- C\%: É o custo de capital da empresa, calculado como uma média ponderada entre o custo de capital de terceiros e o custo do capital próprio WACC (Weighted Averege Cost of capital) que significa Custo médio Ponderado de Capital.

- TC: Representa o quanto foi investido na empresa para produzir o NOPAT.

Segundo Lovata (2002), O custo do capital é, portanto, o aspecto mais importante da EVA $\Theta$. Nos métodos tradicionais, a maioria das empresas parecem ser rentáveis, enquanto que, na realidade, não o são. A utilização do EVA® no estudo de caso resultará em uma comparação análoga entre duas ferramentas distintas, uma econômico-financeira em relação a uma ferramenta multicritério.

\section{APRESENTAÇÃO DO ESTUDO DE CASO}

O estudo de caso foi realizado em uma empresa multinacional de grande porte, atuante no mercado de refrigeração doméstica e comercial situada no norte de Santa Catarina. Por se tratar de uma empresa líder no mercado e estar na vanguarda do desenvolvimento voltado para tendências do ramo de refrigeração, sua estrutura de gestão de recursos para o desenvolvimento de novos projetos já está bem delimitada, em comparação a empresas de médio e pequeno porte. Dessa forma concentrando grande parte dos seus recursos de engenharia, vendas e marketing no desenvolvimento e gestão do portfólio de produtos e projetos.

Porém gerir a demanda oriunda dos cinco continentes de atuação, despende a utilização de muitos recursos. O objetivo de utilizar uma empresa multinacional de grande porte nesse estudo de caso, é demostrar que até grandes empresas que possuem muitos recursos, tem dificuldades em gerenciar e direcionar seus recursos em projetos para desenvolvimento.

\subsection{PERFIL DOS DECISORES}

A maioria das empresas de médio e grande porte, o processo de tomada de decisão referente aos projetos que devem ser priorizados e desenvolvidos, é realizado através de um grupo de profissionais que desempenham função de gestão. Em geral, grande parte das decisões são tomadas exclusivamente a partir do retorno financeiro previsto por cada projeto. Na maioria dos casos, vários fatores são desconsiderados na análise dos projetos. Existem particularidades exclusivas de cada projeto, como: complexidade, risco, quais os clientes e mercados são estratégicos, qual a melhor janela de mercado para o lançamento, etc. Que antes do período de desenvolvimento do projeto são apenas lacunas que podem dificultar a tomada de decisão. Essas características específicas podem inviabilizar investimentos e sobrecarregar as equipes responsáveis pelo desenvolvimento dos projetos. Nesse contexto, para a seleção dos profissionais que avaliaram os projetos e definirão critérios, foi selecionado quatro profissionais tomadores de decisão de áreas distintas, conforme apresentado a seguir:

- Decisor №1 - Especialista em Marketing: Responsável pelo planejamento e implementação das ações de marketing, monitorando indicadores de performance dos produtos internos e dos concorrentes;

- Decisor №2 - Especialista em Marketing Estratégico: Responsável em realizar o processo de entrada/saída de linhas de produtos no mercado, auxiliando no processo de elaboração das propostas de valor dos produtos. Realiza a análise de mercado de um produto ou serviço, definindo o mercadoalvo, ajudando na quantificação do preço;

- Decisor №3 - Analista em Vendas: Responsável pelo processo de vendas, desenvolve e administra relatórios de pedidos e volume de faturamento. Acompanha indicadores para suporte em ações estratégicas;

- Decisor №4 - Especialista de Projetos: Responsável por gerenciar os fluxo e implementação dos projetos, sendo eles de: homologação, desenvolvimento e testes 
integrados de softwares. Faz a abertura, planejamento, execução e encerramento do projeto, controle de cronograma, escopo e financeiro do projeto.

O objetivo na escolha de quatro decisores no processo de avaliação dos projetos é tornar a priorização mais assertiva e menos subjetiva. Os decisores selecionados para este estudo de caso são peças importantes dentro da empresa, no processo de definição do mercado, especificação do projeto e venda.

\subsection{CRITÉRIOS SELECIONADOS}

No processo de hierarquização de projetos, a seleção dos critérios de avaliação é de suma importância, e deve estar diretamente relacionada a visão e missão da empresa, conforme comentado por Kerzner (2009). Desta forma para cada empresa que pretende aplicar ferramentas multicritério para a hierarquização de projetos, e que necessitem de critérios e subcritérios para avaliação, deve-se tomar muito cuidado na seleção dos critérios utilizados para avaliação dos projetos. Muitas empresas atuam em segmentos e ramos que são totalmente diferenciados, sendo assim para cada segmento de atuação é necessário definir os critérios que são mais importantes para a análise e elaboração do processo de hierarquização. Para a seleção dos critérios na avalição dos projetos dentro do portfólio da empresa, foi selecionado um dos segmentos de atuação da empresa no qual seria comumente aplicado o processo de hierarquização dos projetos.

Os critérios apresentados na Figura 3 foram selecionados através da ferramenta Brainstorming em conjunto com os decisores. Não foi utilizado subcritérios na avaliação, os mesmos não influenciariam na decisão deste estudo de caso.

Figura 3 - Diagrama dos critérios selecionados

\begin{tabular}{||c|l||}
\hline Critérios: & \multicolumn{1}{c|}{ Definição: } \\
\hline Complexidade & $\begin{array}{l}\text { Muitas partes inter-relacionadas variadas e que pode ser operacionalizada em termos de } \\
\text { diferenciação e interdependência (BACCARINI, 1996). }\end{array}$ \\
\hline Janela de Mercado & $\begin{array}{l}\text { Periodo de tempo em que a oportunidade está disponivel para a entrada de um novo produto } \\
\text { no mercado. }\end{array}$ \\
\hline Riscos & $\begin{array}{l}\text { Á medida que o desconhecimento de um futuro projeto é maior, consequentemente, o risco e } \\
\text { a incerteza tenderão na mesma proporção (PERREIRA, 2010). }\end{array}$ \\
\hline $\begin{array}{c}\text { Valor Presente } \\
\text { Liquido }\end{array}$ & $\begin{array}{l}\text { Soma dos valores presentes de cada um dos fluxos de caixa (positivos ou negativos) que } \\
\text { ocorrem ao longo da vida do projeto. }\end{array}$ \\
\hline Cliente estratégico & $\begin{array}{l}\text { São as pessoas ou entidades que compram seus produtos e serviços e fornecem sua receita } \\
\text { (SIMONS, 2010). }\end{array}$ \\
\hline
\end{tabular}

Fonte: Do autor, 2016

Os critérios Complexidade e Riscos foram quantificados para facilitar o processo de tomada de decisão dos decisores, transformando-os esses critérios tradicionalmente qualitativos em qualiquantitativos. A metodologia utilizada para a quantificação desses critérios e a definição dos demais critérios é detalhada por Venturi (2016).

\subsection{CARACTERÍSTICAS DOS PROJETOS}

$\mathrm{Na}$ seleção dos projetos para tomada de decisão, optou-se pela avaliação de cinco projetos com diferentes características, afim de demostrar as diversas oportunidades que um gestor possui no processo de tomada de decisão. A Tabela 2 apresenta as principais características financeiras e de mercado dos cinco projetos disponíveis para desenvolvimento. 
Tabela 2 - Características Financeiras dos projetos

\begin{tabular}{|c|c|c|c|c|c|c|}
\hline Projeto & $\begin{array}{c}\text { Volume peças por } \\
\text { ano }\end{array}$ & $\begin{array}{c}\text { Margem de } \\
\text { contribuição } \\
\text { Unitário }\end{array}$ & $\begin{array}{c}\text { Margem de } \\
\text { Contribuição Total }\end{array}$ & Custo Total do Projeto & Mercado & Aplicação \\
\hline $\mathrm{A}$ & 5877 & $\mathrm{R} \$ 26,00$ & $\mathrm{R} \$ 851.337,37$ & $\mathrm{R} \$ 53.479,64$ & Americano & Doméstico \\
\hline $\mathrm{B}$ & 1763 & $\mathrm{R} \$ 84,65$ & $\mathrm{R} \$ 831.538,83$ & $\mathrm{R} \$ 6.959,68$ & Americano & Comercial \\
\hline $\mathrm{C}$ & 18220 & $\mathrm{R} \$ 10,32$ & $\mathrm{R} \$ 1.047 .679,53$ & $\mathrm{R} \$ 13.054,89$ & Todos & Comercial \\
\hline $\mathrm{D}$ & 2057 & $\mathrm{R} \$ \mathbf{7 8 , 6 0}$ & $\mathrm{R} \$ 900.833,73$ & $\mathrm{R} \$ 256.409,22$ & Todos & Comercial \\
\hline $\mathrm{E}$ & 2351 & $\mathrm{R} \$ 4,23$ & $\mathrm{R} \$ 55.435,92$ & $\mathrm{R} \$ 11.904,71$ & Latino & Comercial \\
\hline
\end{tabular}

Fonte: Do autor, 2016

Conforme a Tabela 2, o projeto $\mathrm{C}$ apresenta o maior volume anual de peças em comparação aos demais projetos, com um custo de projeto relativamente baixo. Outra característica do projeto $C$ é possuir a segunda menor margem de contribuição unitária. Já o projeto D apresenta o menor volume anual de peças em comparação aos demais projetos, com 0 maior custo de projeto. Além dos aspectos econômico-financeiros apresentados na Tabela 2, os decisores necessitam ponderar sobre os demais critérios para cada um dos projetos, o que poderá alterar a escolha baseada apenas nestes dados.

Por solicitação da empresa os dados sigilosos utilizados nesse estudo de caso foram multiplicados por um fator aleatório afim de camuflar seus verdadeiros dados mantendo a integridade e proporcionalidade das informações, sem prejudicar os verdadeiros objetivos dessa análise.

\section{RESULTADOS E DISCUSSÕES}

\subsection{MÉTODO AHP}

A partir da apresentação dos projetos e das suas características, pode-se aplicar a ferramenta AHP com cada decisor, afim de hierarquizar os cinco projetos apresentados. O Gráfico 1 apresenta o peso da decisão dos quatro decisores na avaliação dos cinco projetos. As planilhas de cálculo são detalhadas em Venturi (2016).

\section{Gráfico 1 - Peso dos critérios atribuídos por cada decisor}

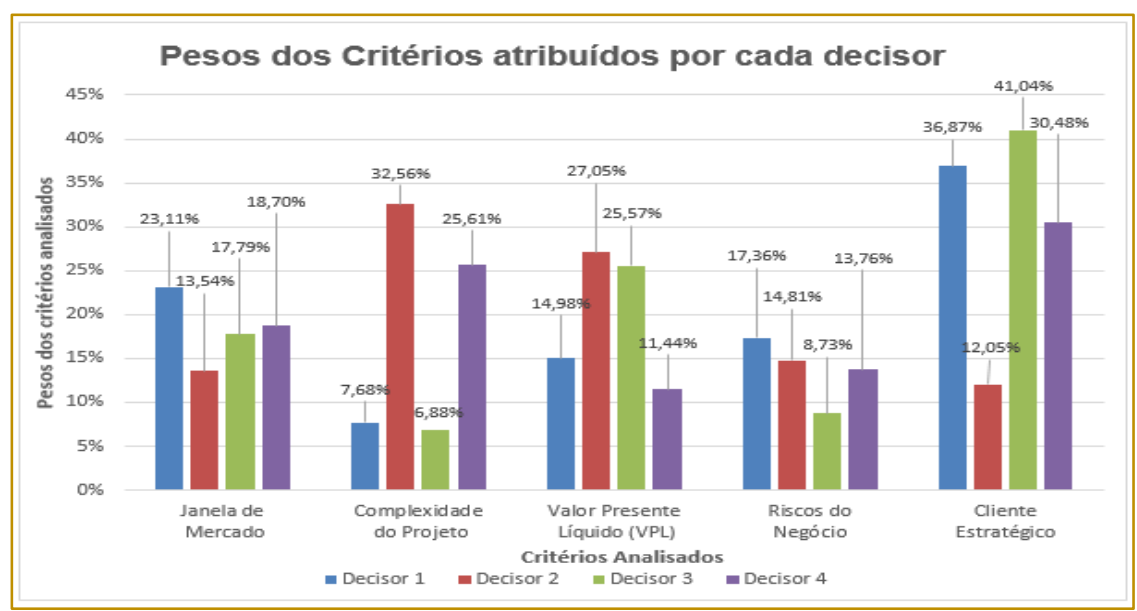

Fonte: Do autor, 2016.

O Gráfico 1 mostra que para os decisores número 1,3 e 4 o critério com maior importância foi o " Cliente Estratégico". Para o decisor número 2 o critério com maior importância foi a "Complexidade do Projeto". Dessa forma pode-se observar que ao utilizar decisores de áreas diferentes encontrou-se disparidades na seleção da importância dos critérios selecionados, e essa disparidade impactará diretamente na hierarquização dos projetos.

O Gráfico 2 apresenta a decisão dos quatro decisores a respeito da ordem de hierarquização dos projetos selecionados. 
Gráfico 2 - Priorização dos projetos atribuídos a cada decisor

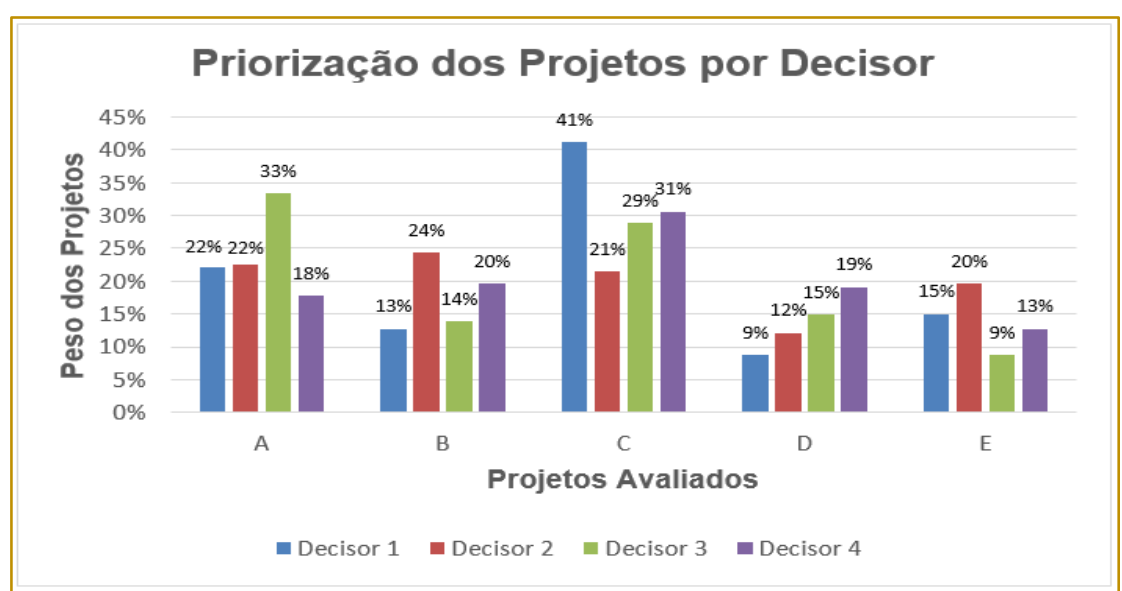

Fonte: Do autor, 2016

O Gráfico 2 mostra que para os decisores número 1 e 4 , o projeto selecionado foi o projeto $\mathrm{C}$. Para o decisor número 2 o projeto selecionado foi o projeto $\mathrm{B}$, e para o decisor número 3 o projeto selecionado foi o projeto A. Dessa forma pode-se observar que ao utilizar decisores de áreas diferentes encontrou-se disparidades nas escolhas dos projetos.

O método AHP apresentou através da decisão dos decisores, uma hierarquização não trivial e intuitiva, pois foram utilizados na análise critérios qualitativos e quantitativos, que estimularam o senso crítico dos decisores a avaliar os projetos por várias perspectivas, sendo elas: Técnica, financeira e de mercado. A utilização destes critérios distintos mostrou a não proporcionalidade dos resultados.

A presença de quatro decisores de áreas diferentes possibilitou diferentes hierarquizações para os cinco projetos selecionados, mostrando que existem disparidades nas decisões por conta das experiências pessoais e profissionais de cada decisor.

O processo decisório, ligado ao lançamento e gestão de novos produtos, habitualmente empoderado apenas pelos critérios financeiros, foi posto à prova nesse estudo de caso. Pois a hierarquização sofreu uma grande modificação quando considerado critérios técnicos como "Complexidade" e critérios de mercado como "Risco" em sua avaliação.

Os projetos de naturezas diferentes tornaram o processo decisório mais complexo, pondo à prova a análise dos decisores, pois decisores sem experiência técnica utilizada no desenvolvimento de projetos avaliaram critérios como "Complexidade" e "Riscos", e decisores sem experiência de mercado julgarem critérios como "Cliente Estratégico" e "Janela de Mercado".

\subsection{ANÁLISE DE SENSIBILIDADE}

A análise de sensibilidade se faz necessária, uma vez que possa existir subjetividades nas definições dos pesos e valores atribuídos por cada decisor. A subjetividade pode ser provocada pelas pequenas diferenças de entendimento dos critérios, ou mesmo, pela diferença de pensamento natural a cada participante do processo decisório. $\mathrm{Na}$ análise de sensibilidade aplica-se a variação de algum parâmetro, mantendo os demais parâmetros na condição original. O cálculo da análise de sensibilidade inicia através da obtenção da matriz de decisão do método AHP, como apresentado por Venturi (2016).

Os resultados obtidos através do método AHP, serão submetidos a uma análise de sensibilidade. A análise de sensibilidade será aplicada aos decisores 2 e 4, variando um critério por decisor. Para o decisor 2, serão variados os critérios" Complexidade" e para o decisor 4, será variado os critérios "Cliente Estratégico". O Gráfico 3, apresenta a variação do critério " Complexidade do Projeto" através da matriz de decisão do decisor 2: 
Gráfico 3 - Variação do critério "Complexidade do Projeto" Decisor 2

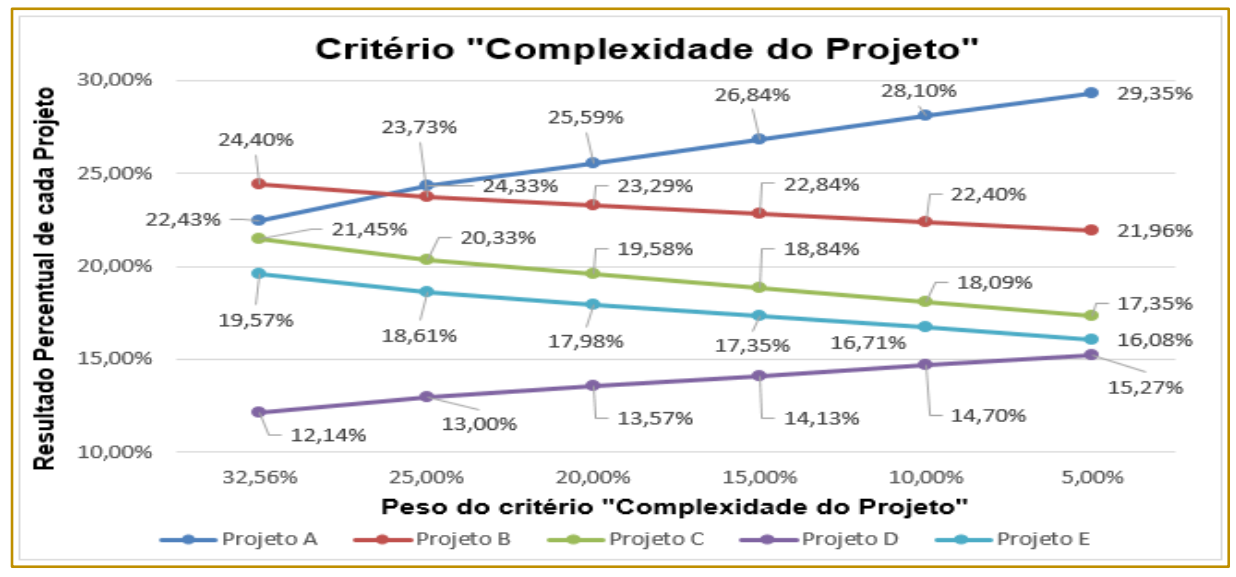

Fonte: Do autor, 2016.

Conforme apresentado no Gráfico 3, observase que ao variar o peso do critério "Complexidade do Projeto" de 32,56\% para $25 \%$ já se obteve variação na decisão do projeto de B para A, logo se houver uma variação menor que $10 \%$ em seu peso o projeto A será o escolhido, sendo assim para o decisor 2 o critério "Complexidade" é altamente sensivel. Dessa forma pode-se concluir que quanto maior o coeficiente angular das retas dos gráficos de sensibilidade, maior será a sensibilidade dos critérios à luz da avaliação do decisor.

O Gráfico 4, apresenta a variação do critério "Cliente Estratégico" através da matriz de decisão do decisor 4. Neste caso pode-se observar um comportamento inverso ao anterior.

Gráfico 4 - Variação do critério "Cliente Estratégico" do Decisor 4

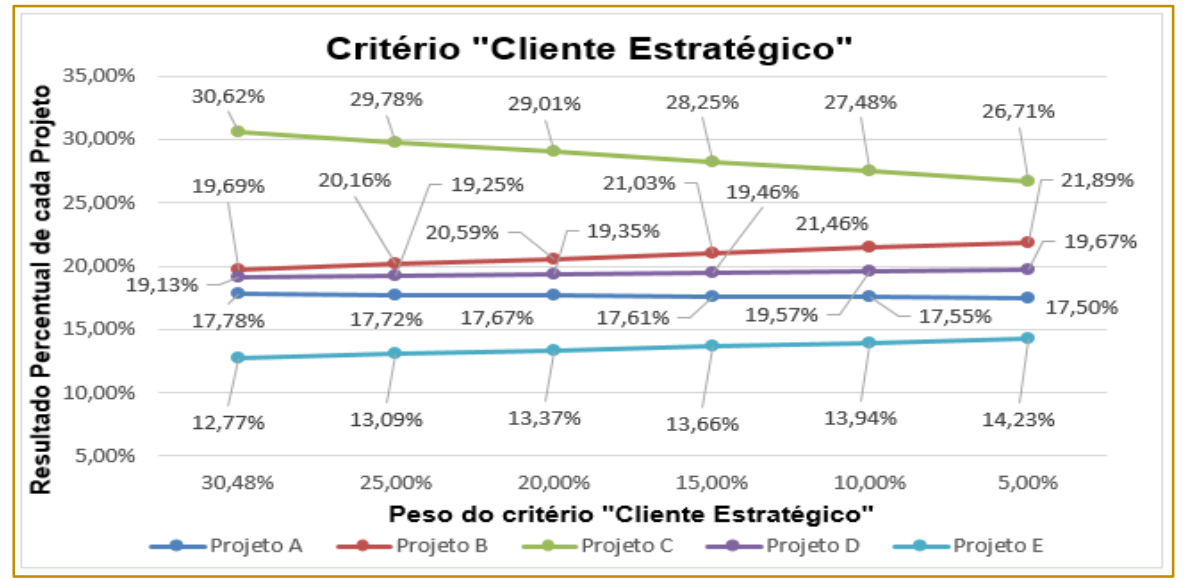

Fonte: Do autor, 2017

Conforme apresentado no Gráfico 4, pode-se observar que diminuindo o peso do critério "Cliente Estratégico" atribuindo 5\% do peso dos critérios, não se obteve variação do projeto selecionado, e isso deve-se ao fato de que para o decisor 4 a pontuação atribuída aos projetos à luz do critério "Cliente Estratégico" foram muito parecidas, conforme apresentado na Tabela 3. 
Tabela 3 - Avaliação AHP critério "Cliente Estratégico", decisor 4

\begin{tabular}{|c|c|c|c|c|c|}
\hline \multicolumn{7}{|c|}{ 1 - Análise Pareada das Alternativas } \\
\hline $\begin{array}{c}\text { Cliente } \\
\text { Estratégico }\end{array}$ & $\begin{array}{c}\text { Projeto } \\
\text { A }\end{array}$ & $\begin{array}{c}\text { Projeto } \\
\text { B }\end{array}$ & $\begin{array}{c}\text { Projeto } \\
\text { C }\end{array}$ & $\begin{array}{c}\text { Projeto } \\
\text { D }\end{array}$ & $\begin{array}{c}\text { Projeto } \\
\text { E }\end{array}$ \\
\hline Projeto A & 1 & 5 & $1 / 5$ & $1 / 3$ & 5 \\
\hline Projeto B & 0,20 & 1 & $1 / 5$ & $1 / 3$ & 5 \\
\hline Projeto C & 5,00 & 5,00 & 1 & 3 & 3 \\
\hline Projeto D & 3,00 & 3,00 & 0,33 & 1 & 1 \\
\hline Projeto E & 0,20 & 0,20 & 0,33 & 1,00 & 1 \\
\hline Total & 9,40 & 14,20 & 2,07 & 5,67 & 15,00 \\
\hline
\end{tabular}

Fonte: Do autor, 2016.

Conforme apresentado na Tabela 3, observase que a avaliação do decisor 4 à luz do critério Cliente Estratégico apresentou inconsistente $(R C=0,38)$. Para atingir a consistência na análise, o RC deveria ficar abaixo de 0,10. Essa inconsistência foi provocada, pois não houve interferência no juízo de valor atribuído pelo decisor ao avaliar os critérios e projetos.

\subsection{MÉTODO EVA®}

Após aplicar o método EVA® para os cinco projetos analisados, e a partir dos resultados obtidos de cada projeto pode-se realizar a hierarquização, conforme apresentado no Gráfico 5.

Gráfico 5 - Hierarquização dos projetos através do método EVA®

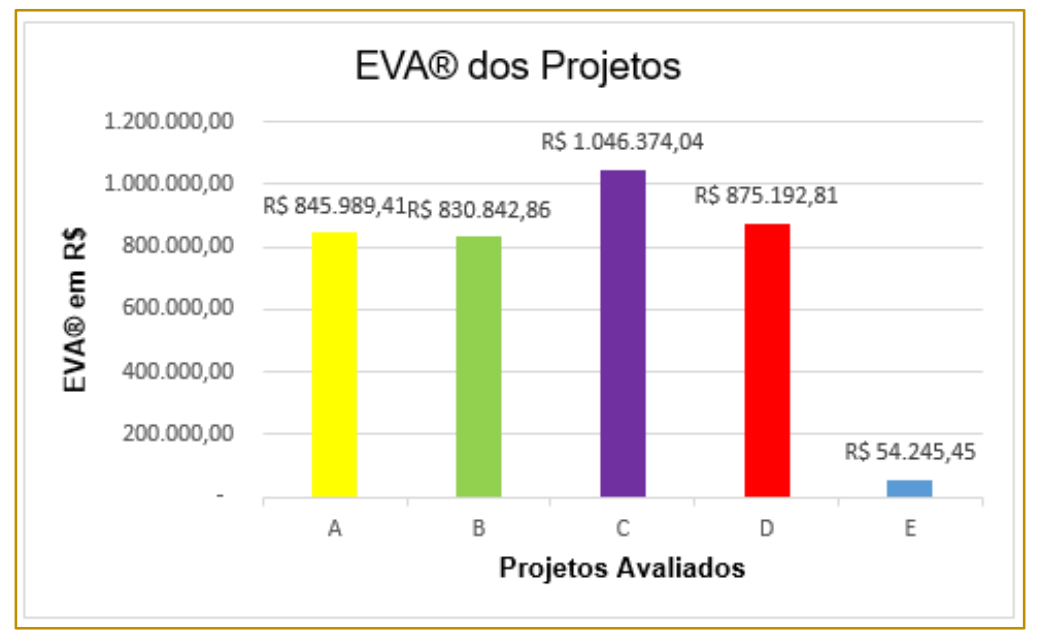

Fonte: Do autor, 2016

Conforme apresentado no Gráfico 5, observase a hierarquização alcançada através do uso da ferramenta EVA®. Sequenciamento $O$ projeto $C$ foi o selecionado, pois apresentou ser o projeto mais rentável, seguido pelos projetos $\mathrm{D}, \mathrm{A}, \mathrm{B}$ e E nessa análise econômicofinanceiro. Ao analisar os resultados do AHP e EVA em conjunto, através dos gráficos 2 e 5 , respectivamente, nota-se que o projeto $\mathrm{C}$ foi escolhido por 2 dos 4 decisores e também obteve o maior EVA. Contudo, o Projeto D obteve o segundo maior EVA, porém não foi selecionado por nenhum dos decisores pelo AHP.

\section{CONSIDERAÇÕES}

Uma gestão assertiva do portfólio de projetos e produtos, facilita o processo de tomada de decisão e gestão dos recursos empreendidos pela empresa no processo de desenvolvimento. Envolver no processo de hierarquização de projetos profissionais com o cunho técnico, melhoram a assertividade do processo de tomada de decisão.

Ao utilizar duas ferramentas qualiquantitativos para tomada de decisão, uma multicritério (Ferramenta AHP), e outra econômico-financeiro (Ferramenta EVA®), o resultado da hierarquização apresentou-se análogo. Ao utilizar a ferramenta AHP pode-se 
tangibilizar critérios tradicionalmente qualitativos em quantitativos (Complexidade, Risco, Cliente Estratégico e Janela de Mercado), e na ferramenta EVA® apenas foram contabilizados os dados econômicofinanceiro na análise.

Através desses resultados comparativos, conclui-se que um projeto que possua alto retorno de investimento, muitas vezes apresenta alta complexidade, risco e não possui uma janela de mercado e cliente estratégico devidamente definida. Dessa maneira, é mais comumente priorizar projetos que possuam um retorno de investimentos menor e que apresentem menos riscos,

\section{REFERÊNCIAS}

[1] Baccarini, David. The concept of project complexity-a review. International Journal of Project Management, v. 14, n. 4, p. 201-204, 1996.

[2] Blichfeldt, Bodil Stilling; ESKEROD, Pernille. Project portfolio management-There's more to it than what management enacts. International Journal of Project Management, v. 26, n. 4, p. 357-365, 2008.

[3] Guia Pmbok. Um Guia de gerenciamento de projetos. 5. ed. São Paulo: Saraiva, 2014.

[4] Kerzner, Harold. Gerenciamento de Projetos: Uma abordagem sistêmica para planejamento programação e controle. 1. ed. São Paulo: Blucher, 2009.

[5] Lovata, Linda M.; Costigan, Michael L. Empirical analysis of adopters of economic value added. Management Accounting Research, v. 13, n. 2, p. 215-228, 2002.

[6] Malvessi, Oscar. Criação ou destruição de valor ao acionista. Revista Conjuntura Econômica, v. 1, p. 1-6, 2000.

[7] Pereira, Sérgio Luiz Pinto. Utilização do método multicritério Prométhée para definição da ordem de desenvolvimento de programas de indicadores de negócio. XXXVI - SBPO, São João del Rei: 2004

[8] Rozenfeld, Henrique et. al. Gestão de Desenvolvimento de Produtos - Uma referência para melhoria de processo. 1. ed. São Paulo: Saraiva, 2006. complexidade, do que projetos que apresentem alto retorno, e que não se possua conhecimento suficiente para desenvolve-los.

No contexto apresentado acima, conclui-se que o processo de gestão do portfólio de produtos e projetos aliado, a ferramentas multicritério para tomada de decisão, torna o processo de lançamento, gestão de investimentos e custos dos projetos mais assertivos. Dessa forma contribuindo para agilizar o processo de desenvolvimento de projetos para novos produtos.

O trabalho, por fim, sujeita a utilização da metodologia desenvolvida em outros tipos de empresas, portfólios de projetos e produtos.

[9] Salgado, Eduardo Gomes; Mello, Carlos Henrique Perreira. Mapeamento dos processos em serviços: estudo de caso em duas pequenas empresas da área de saúde. Anais do ENEGEP 2005, 2005.

[10] Saaty, Thomas Lorie. Fundamentals of decision making and priority theory. 2. ed. Pittsburgh: RSW Publications, 2006.

[11] Saaty, Thomas Lorie. How to Make a Decision: The Analytic Hierarchy Process. The Institute for Operations Research and the Management Science. Interfaces, v.24, n.6, pg.1943, 1994.

[12] Saaty, T. L. Método de análise hierárquica. Tradução e revisão técnica Wainer da Silveira e Silva. São Paulo: Makron Books, 1991

[13] Simons, Robert. Choosing the right customer. Harvard Business Review, v. 92, n. 3, p. 48-55, 2014.

[14] Tzeng, Gwo-Hshiung; HUANG, Jih-Jeng. Multiple attribute decision making: methods and applications. New York: CRC

\section{[15] Press. Taylor \& Francis Group, 2011.}

[16] Venturi, Danilo. Hierarquização de projetos para desenvolvimento de produtos com uso das metodologias AHP e EVA®. Trabalho de conclusão de curso. Centro Universitário Católica de Santa Catarina.2016.

[17] Wernke, Rodney; Lembeck, Marluce. Valor econômico adicionado (EVA). Revista Brasileira de Contabilidade, Brasília, ano XXIX, n. 121, p. 84-90, 2000. 


\section{Capítulo 3}

\section{MÉTODO GESTÃO DO POSTO DE TRABALHO EM UMA INDÚSTRIA DE BALANÇAS NO RIO GRANDE DO SUL}

\section{Taís Oliveira da Silva Alfonso}

\section{Renata Ribeiro Silva}

\section{Layra Gabriela Gonçalves \\ Carolina Scherer Finkler \\ Luis Cláudio Ragasson}

Resumo: São cada vez mais claras as mudanças mercadológicas e o crescente acirramento da competitividade entre empresas dentro de um mercado globalizado. Assim, é fundamental que as empresas compreendam o ambiente econômico onde estão inseridas e ssejam ágeis e capazes de realizar mudanças necessárias para atingir seus objetivos e manterem-se competitivas no mercado. Este artigo trata de um estudo de caso na empresa Balanças Saturno, localizada em Canoas - RS. A questão abordada é: sob a ótica da produção enxuta, como aumentar a produtividade do posto de trabalho através do método gestão do posto de trabalho (GPT)? Nosso objetivo é implantar o método GPT em uma indústria de balanças. Para tal, buscou-se implantar um instrumento de coleta de dados de forma a analisar as peculiaridades do posto de trabalho e propor um plano de ação para o aumento da produtividade do mesmo. Ao final do estudo e análise dos dados, foi possível demonstrar a viabilidade de implantar novas metas e a construção de um plano de ação capaz de orientar os esforços necessários visando o aumento da produtividade do posto estudado através da elevação dos índices de disponibilidade, desempenho e qualidade, possibilitando maior aderência da empresa diante da atual realidade competitiva do mercado. 


\section{INTRODUÇÃO}

As relações comerciais entre as nações vêm mudando ao longo do tempo. No Brasil, a queda das barreiras alfandegárias gerou uma transformação no comportamento das nossas organizações. Empresas, produtos e tecnologias consolidadas se dissipam para dar lugar a novos modelos de negócio e de gestão. Tem-se claramente um acirramento da competitividade, que deixa de ser local para se tornar global (ANTUNES, 2013).

Conforme Oliveira (2004), as empresas precisam entender o ambiente econômico no qual estão inseridas, que varia de país para país. A ideia é que, a partir do ambiente econômico, haja uma adequação dos processos de produção a esta nova realidade. Entende-se processo de produção como a transformação de capital investido no valor recebido após a venda dos bens manufaturados, através da agregação de valor. Dessa forma, faz-se necessário reduzir o tempo de atravessamento e maximizar o uso dos ativos fixos, principalmente no Brasil, onde as taxas de juros (que impactam no capital de giro) são maiores do que as dos Estados Unidos, Japão e Alemanha. (ANTUNES, 2013).

Portanto, um ponto crucial da estratégia de gestão consiste em aumentar a utilização dos recursos escassos (ANTUNES, 2013). No caso do Brasil, o recurso mais caro vem a ser os ativos fixos, sendo que a maximização destes pode ser obtida por meio do aumento das suas eficiências operacionais. Conforme o mesmo autor, a abordagem que trata do aumento desta eficiência é o método gestão do posto de trabalho (GPT). O GPT melhora a eficiência operacional dos equipamentos, implantando ações de melhoria para aumentar a capacidade e a flexibilidade da produção, alavancando assim os resultados da empresa (ANTUNES, 2013; KLIPPEL, 2003).

Partindo da necessidade de aumento de eficiência, a pesquisa apresentada neste trabalho tem por objetivo implantar o método GPT em uma indústria de balanças. Para tal, buscou-se implantar um instrumento de coleta de dados de forma a analisar as peculiaridades do posto de trabalho e propor um plano de ação para o aumento da produtividade do mesmo.

A fim de alcançar estes resultados, esta pesquisa está estruturada da seguinte forma: esta introdução; após, na segunda seção, conceitos de sistemas produtivos, produtividade e gestão do posto de trabalho; na seção três apresenta-se uma síntese da metodologia utilizada além da descrição da empresa; na seção quatro descreve-se o caso estudado e, por fim, destacam-se algumas considerações sobre o estudo.

\section{REFERENCIAL TEÓRICO}

\subsection{SISTEMAS PRODUTIVOS}

Para Harding (1981), um sistema de produção "é um conjunto de partes inter-relacionadas, as quais, quando ligadas, atuam de acordo com padrões estabelecidos sobre inputs (entradas) no sentido de produzir outputs (saídas)". Um sistema de produção reúne e transforma recursos de uma forma controlada, a fim de agregar valor, de acordo com os objetivos empresariais. É importante ressaltar, que um sistema de produção está sempre se comunicando com os outros sistemas componentes da empresa, fazendo assim, parte de um sistema maior (MONKS, 1987).

Conforme Slack (2009), existe um modelo genérico para descrever qualquer tipo de sistema de produção. O mesmo consiste em entradas, o processo de transformação em si e as saídas. O modelo de transformação (produção) caracteriza-se como sistêmico, ou seja, os recursos representam as entradas no sistema, que são processados ou transformados, obtendo-se as saídas do sistema, que são os produtos ou serviços. A Figura 1 traz 0 processo de input, transformação e output.

Figura 1 - Processo input - transformação - output

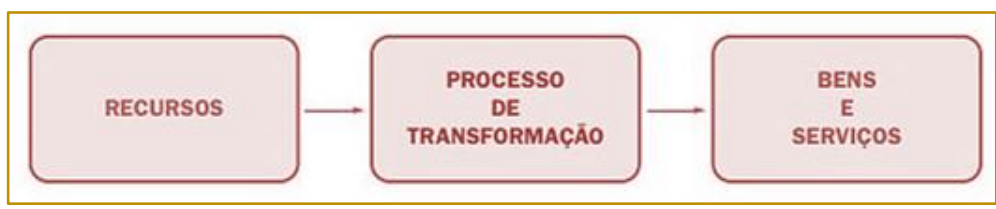

Fonte: Slack (2009) 
Segundo as classificações vistas por Harding (1981), Monks (1987) e Moreira (1996), os sistemas de produtivos são compostos por diversos subsistemas, sendo que os principais elementos são:

a) Entradas: para Chiavenato (2001), "o sistema recebe entradas (inputs) ou insumos para poder operar. A entrada de um sistema é tudo o que o sistema importa ou recebe de seu mundo exterior". De outra forma, assinala, Slack (2009) "estes [inputs] são os recursos que são tratados, transformados ou convertidos de alguma forma".

b) Processo de transformação: é o processo de conversão, que altera o formato das matérias-primas ou a composição e a forma dos recursos. Essa conversão cria novos bens ou serviços, que possuem um valor maior para os consumidores que os custos de processamento e aquisição dos insumos para a empresa. Em serviços, não há propriamente transformações: o serviço é criado (SLACK, 2009; MOREIRA, 1986; MONKS, 1987).

c) Saídas: trata-se do produto final. Pode haver basicamente duas: fabricação ou manufatura de bens ou serviços. Após a concluída esta etapa do processo, o bem/serviço está pronto para ser fornecido ao mercado (SLACK, 2009).

De acordo com Harding (1981), há mais dois subsistemas vitais na operacionalização da produção: o sistema de planejamento, responsável pela qualidade, quantidade e tempos de produção; e o sistema de controle, que assegura que as programações sejam cumpridas. Ambos gerenciam a produção e são responsáveis pela obtenção dos resultados desejáveis, em termos de quantidade, qualidade e tempo.

\subsubsection{CLASSIFICAÇÃO DOS TIPOS DE PRODUÇÃO}

Conforme Slack (2009), cada tipo de processo em manufatura implica uma forma diferente de organizar as atividades das operações com diferentes características de volume e variedade. A Figura 2 traz os tipos de processos de manufatura existentes.

Figura 2 - Tipos de processos de operações de manufatura

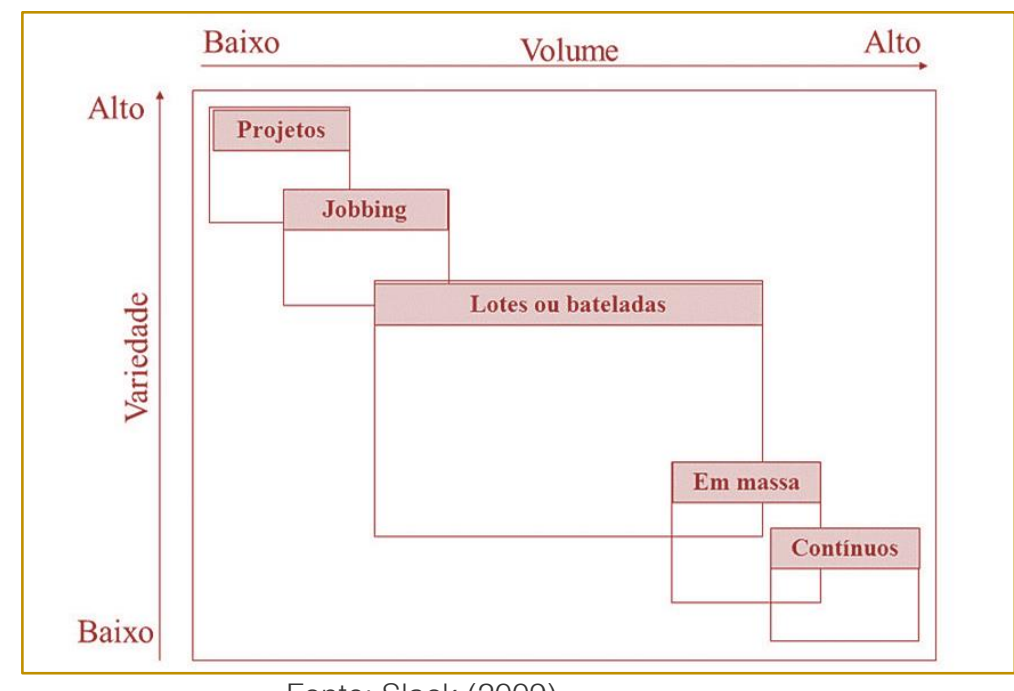

Fonte: Slack (2009)

a) Produção de projetos: trabalha com grandes projetos e envolve produtos discretos, normalmente bastantes customizados, com baixo volume de produção, alta variedade de produtos e tempos bastante longos de produção. As atividades envolvidas neste tipo de processo podem se apresentar mal definidas e muitas vezes incertas, modificando-se durante 0 processo de produção (SLACK, 2009). b) Jobbing: opera com o compartilhamento de recursos de operação com diversos outros processos, trabalhando também com alta variedade, baixo volume de produção e baixo grau de repetição. Assim, os recursos de produção processam uma série de produtos, mas, embora todos os produtos exijam mesmo tipo de atenção, diferem entre si pelas suas necessidades particulares (SLACK, 2009). 
c) Produção em lotes: produz sempre mais do que uma unidade do mesmo item por vez. Este tipo de produção possui entendimentos parecidos com os processos de jobbing, porém não possuem o mesmo grau de variedade (SLACK, 2009).

d) Produção em massa: produz bens em alto volume com pouca variedade. Esse modo de produção possibilita altas taxas de produção por colaborador e ao mesmo tempo disponibiliza produtos a custos e preços baixos. Entretanto, oferta aos consumidores reduzidas opções de produtos e com pequeno grau de diferenciação (SLACK, 2009; GROOVER, 1987).

e) Produção contínua: opera em volumes ainda maiores que a produção em massa e geralmente com variedade ainda mais baixa. Esses processos são contínuos, no sentido de que os produtos são inseparáveis, pelo processo ser em um fluxo ininterrupto, e também pelo fato de a operação ter que suprir os produtos sem uma parada (SLACK, 2009).

\subsection{PRODUTIVIDADE}

As operações procuram manter os seus custos tão baixos quanto sejam possíveis, dentro de uma lógica de respeito aos níveis de qualidade, velocidade, confiabilidade e flexibilidade de acordo com a demanda do consumidor (SLACK, 2009). A medida mais usada para indicar o sucesso em relação a estes quesitos é a produtividade. Produtividade é a razão do que é produzido (outputs), pelo que é necessário para essa produção (inputs). (SLACK, 2009).

Conforme Falconi (2001), a produtividade pode ser aprimorada, por exemplo, de duas formas: reduzindo o custo de inputs, mantendo os outputs e por meio de um melhor uso de inputs na operação. Ressaltase que todas as organizações estão cada vez mais preocupadas em cortar desperdícios, sejam eles de materiais, de tempo de funcionários ou derivados da subutilização das instalações. Assim, o caminho para o crescimento da organização é a produtividade (SLACK, 2009; FALCONI, 2001).

\subsection{GESTÃO DO POSTO DE TRABALHO}

Segundo Antunes (2013): "o método gestão do posto de trabalho é um modelo geral que propõe a reordenação e reconceituação das práticas existentes em três sentidos básicos: visão sistêmica, integração/unificação e foco nos resultados". Assim, os recursos ficam subordinados às melhorias propostas de forma ordenada. Ademais, as ações propostas pelo método devem ser executadas pelo grupo multidisciplinar envolvido no projeto, articulando para que as mudanças promovidas nos indicadores dos postos de trabalho sejam visíveis nos resultados econômico-financeiros da empresa. (ANTUNES, 2013).

Ainda segundo o autor, para que a aplicação da gestão do posto de trabalho seja bemsucedida, é necessário utilizar métodos para que a mesma seja feita de uma forma sistêmica. Há um método gerencial - e de resolução de problemas - chamado PDCA (plan-do-check-act, ou planejar-agir-executaragir), que é amplamente utilizado (FALCONI, 2009). Dessa forma, o PDCA é o pano de fundo para o método da gestão do posto de trabalho (ANTUNES, 2013; FALCONI, 2009).

\subsection{1. ÍNDICE DE RENDIMENTO OPERACIONAL GLOBAL (IROG) E SEU DESDOBRAMENTO}

Conforme Antunes (2013), o índice de rendimento operacional global (IROG) é o indicador que mede a eficiência operacional de um equipamento. $O$ cálculo se dá conforme equação: $\mu$ global $=\mu 1 \times \mu 2 \times \mu 3$ (ANTUNES, 2013).

Assim, o resultado da equação vem a partir da multiplicação de três outros índices: o índice de disponibilidade $(\mu 1)$, o índice de desempenho $(\mu 2)$ e o índice de qualidade $(\mu 3)$. O índice de disponibilidade ( $\mu 1)$ está relacionado com os tempos de paradas dos equipamentos, por exemplo, setup e horário de almoço. O índice de desempenho ( $\mu 2)$ é a relação entre o tempo de produção total e o tempo real de operação, estando relacionado com a queda de velocidade do equipamento durante a operação e as pequenas paradas (ou perdas não registradas). Já o índice de qualidade $(\mu 3)$ é a relação entre a quantidade de itens conformes manufaturados e a quantidade total de itens, ou seja, contando os itens fora de especificação (ANTUNES, 2013).

Ainda segundo o autor, o IROG também pode ser tratado como o somatório dos tempos de ciclo multiplicados pela quantidade de itens 
bons produzidos, dividido pelo tempo disponível. Assim, o índice assume o conceito de TEEP (total effective equipment productivity, ou produtividade efetiva total do equipamento) quando o posto de trabalho é restritivo. Neste caso, o tempo disponível para a produção corresponde ao tempo de calendário (total de tempo disponível para produção, sem desconto algum). Para os postos de trabalho que não são restritivos, utiliza-se o conceito de OEE (overall equipment effectiveness, ou índice de eficiência global do equipamento). Nessa situação, o tempo disponível para a produção se dá descontando-se o tempo total de paradas programadas do tempo de calendário (ANTUNES, 2013; ANTUNES e KLIPPEL, 2001). A Figura 3 representa a relação entre os tempos e índices de eficiência.

Figura 3 - Relação entre índices e tempos de eficiência

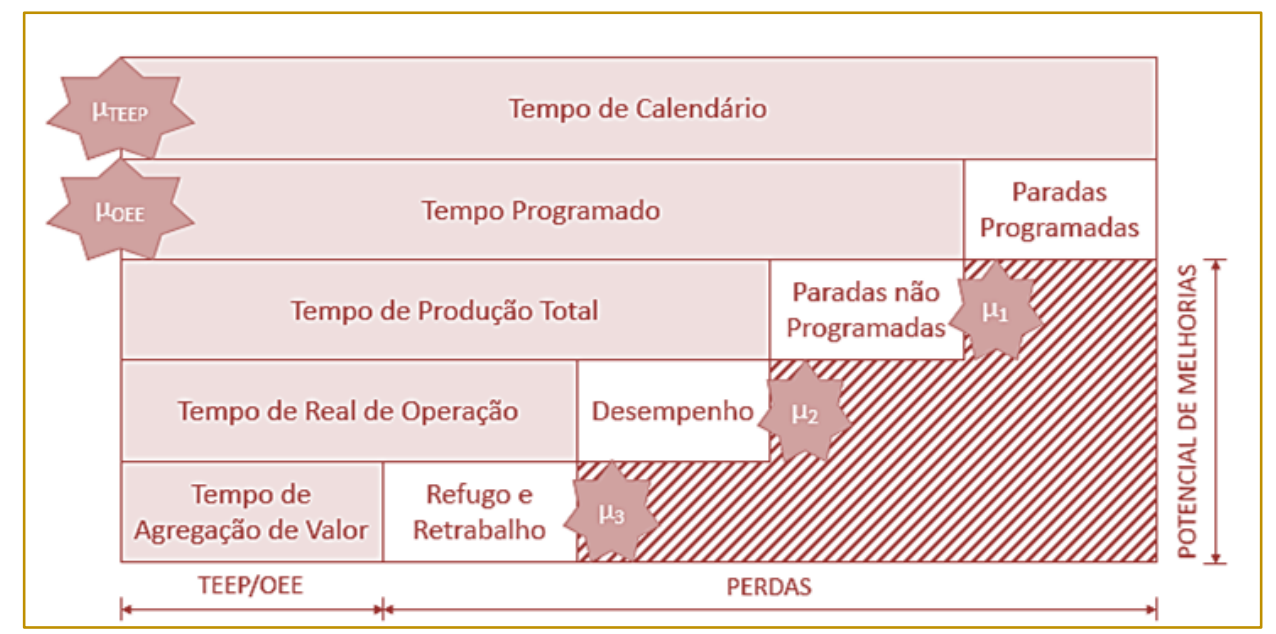

Fonte: Antunes (2013)

Segundo Antunes (2013), a figura mostra as diferentes perdas ao longo do processo produtivo, reduzindo o tempo de calendário até atingir o tempo de agregação de valor. Observa-se que cada redução de tempo corresponde a um dos índices de eficiência componentes do IROG. Assim, a diferença entre o tempo de calendário (ou do tempo programado para produzir, no caso de recurso não restritivo) e o tempo de agregação de valor é o potencial de melhorias possíveis de serem realizadas.

\subsubsection{IMPLEMENTAÇÃO, MANUTENÇÃO E MELHORIAS}

A implementação do método de gestão do posto de trabalho se dá por meio de uma releitura do ciclo PDCA (FALCONI, 2009), conforme Figura 4. 
Figura 4 - Método PDCA para implementar o método GPT

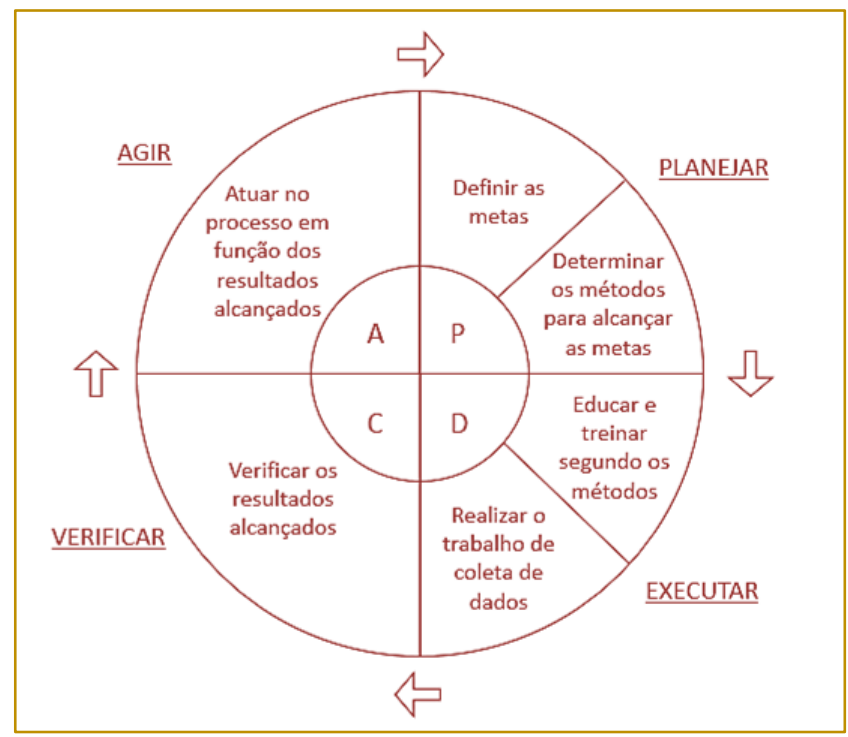

Fonte: Adaptado de Falconi (2009)

Assim, conforme Antunes (2013), na etapa de planejamento do PDCA os seguintes passos devem ser executados: (1) determinar os colaborares que participarão da implantação do método GPT e construir a matriz de responsabilidades, (2) criar tipologia de paradas, (3) definir ferramenta para coleta de dados, (4) eleger ferramenta para registro de dados, (5) escolher os postos de trabalho que serão monitorados, (6) definir rotina de coleta e (7) definir o método GPT como método a ser usado nos postos de trabalho monitorados. $\mathrm{Na}$ etapa de execução, (8) treinam-se os colaboradores envolvidos no GPT, (9) registram-se as anotações do dia a dia na ferramenta de coleta de dados e (10) digitamse os dados coletados. Na etapa de verificação (11) obtêm-se e analisam-se os valores iniciais do IROG a partir de planilha eletrônica. Por fim, na etapa de ação, (12) implementa-se a gestão visual, (13) estabelecem-se metas para os valores de eficiência operacional, (14) elabora-se um plano de ação a fim de aumentar o IROG e (15) implementam-se as ações de melhoria (ANTUNES, 2013).

Ainda segundo o autor, após elevar o valor inicial do IROG até a meta estabelecida, esse valor se mantém ao longo do tempo pela padronização dos procedimentos operacionais. Para tal, aplica-se o SDCA, onde o P (plan, ou planejar) é substituído pelo $\mathrm{S}$ (de standard, ou padrão).

\section{METODOLOGIA}

O método utilizado foi o estudo de caso, sob uma abordagem quantitativa. Conforme Yin (2010), usa-se o estudo de caso quando há necessidade de entender um fenômeno da vida real em profundidade, desde que as condições textuais estejam englobadas. Trata-se de uma investigação contextualizada, principalmente quando não há definição clara entre o contexto e o fenômeno. Ou seja, é uma investigação empírica sobre o tema, de modo a permitir que características integrais e significativas sejam preservadas (YIN, 2010).

A empresa em que este estudo foi realizado é uma indústria fabricante de balanças rodoviárias, ferroviárias, industriais e modulares. De base familiar, a mesma conta com 70 colaboradores aproximadamente, dispostos em uma planta na cidade de Canoas-RS. Optou-se por realizar a implantação do método GPT no posto de trabalho "corte plasma", o qual, em épocas de alta demanda, torna-se o recurso restritivo (gargalo). O trabalho na empresa se deu conforme a Figura 5. 
Figura 5 - Fluxo de trabalho

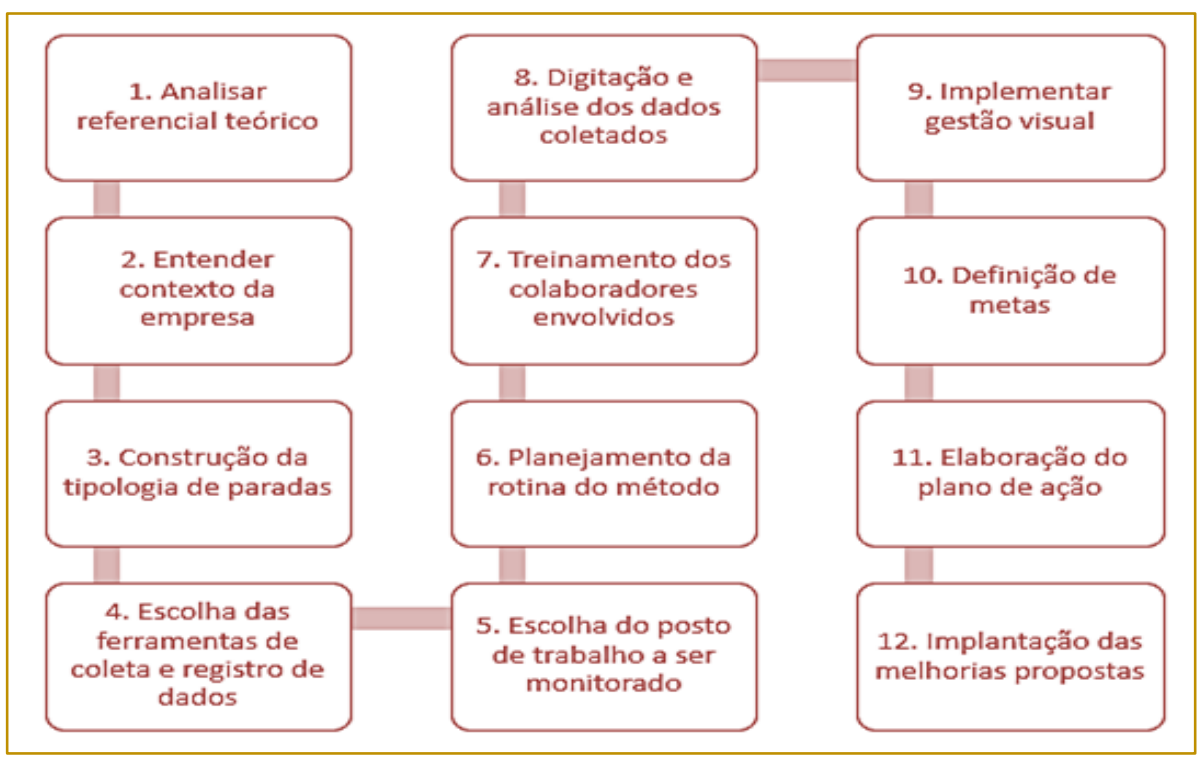

Fonte: Autores

Este método de trabalho baseia-se no método GPT proposto por Antunes. (2013). O objetivo da abordagem é aumentar os índices de eficiência operacional dos postos de trabalho monitorados por meio da elevação dos índices de disponibilidade, desempenho e qualidade (ANTUNES, 2013).

\section{RESULTADOS}

Este estudo de caso refere-se à implementação do método GPT no posto de trabalho corte plasma em uma indústria de balanças, situada em Canoas - RS. Buscouse implantar o GPT por meio da construção de um instrumento de coleta de dados, analisando as peculiaridades do posto de trabalho e propondo um plano de ação de modo a promover o aumento da produtividade no posto.

Primeiramente a ideia da pesquisa foi levada à direção. Após sensibilização da alta administração para a importância do monitoramento da eficiência de equipamentos restritivos, o grupo de trabalho alinhou suas ações com o gerente da planta. Neste contato, foi ressaltado que o posto já havia sido monitorado anteriormente, mas, devido à falta de continuidade, o projeto de controle de eficiência foi abandonado. Os dados do monitoramento anterior não foram localizados, assim, decidiu-se neste encontro iniciar o processo metodológico do início.

Após revisão de bibliografia e filmagens para entender o funcionamento do posto, partiu-se para a construção da tipologia de paradas. Esta etapa foi construída pelo grupo de trabalho desta pesquisa juntamente com o gerente da planta, sendo validada em um segundo momento pelo operador do posto. $\mathrm{Na}$ validação, acrescentou-se o código 24, conforme Tabela 1: 
Tabela 1 - Tipologia de Paradas

\begin{tabular}{|c|c|c|}
\hline Código & Parada & Descrição \\
\hline 11 & Manutenção corretiva & $\begin{array}{c}\text { Quando a máquina está aguardando manutenção ou } \\
\text { ajustes ou sendo consertada. }\end{array}$ \\
\hline 12 & Aguardando ponte rolante & Quando a ponte rolante não está disponível. \\
\hline 13 & Ausência de operador & $\begin{array}{l}\text { Quando o operador tem que se deslocar para outro } \\
\text { posto. }\end{array}$ \\
\hline 14 & Falha operacional & $\begin{array}{l}\text { Quando o operador realizou algum procedimento } \\
\text { incorreto, danificando o equipamento. }\end{array}$ \\
\hline 15 & Falta de matéria-prima & $\begin{array}{l}\text { Quando falta a matéria-prima necessária para o } \\
\text { corte das peças. }\end{array}$ \\
\hline 16 & Manutenção preventiva & $\begin{array}{c}\text { Quando é feita manutenção antes que a máquina } \\
\text { estrague. }\end{array}$ \\
\hline 17 & Refeição & Quando o operador vai para o almoço ou refeição. \\
\hline 18 & Trocar desenho (setup) & $\begin{array}{l}\text { Quando é necessário trocar o desenho para o corte } \\
\text { de uma nova peça. }\end{array}$ \\
\hline 19 & Troca de consumível (setup) & Quando é necessário a troca de bico ou oxigênio. \\
\hline 20 & Troca de chapa (setup) & $\begin{array}{l}\text { Quando é necessário trocar a chapa que está sendo } \\
\text { utilizada por outra. }\end{array}$ \\
\hline 21 & Treinamento/Palestra/Curso/Reunião & Quando o operador está em algum destes eventos. \\
\hline 22 & Retirada de Material & $\begin{array}{l}\text { Quando é necessário retirar materiais prontos e já } \\
\text { cortados no plasma. }\end{array}$ \\
\hline 23 & Retrabalho & $\begin{array}{l}\text { Quando é necessário retrabalhar peças que tenham } \\
\text { algum defeito. }\end{array}$ \\
\hline 24 & Redefinir ponto inicial de corte & $\begin{array}{l}\text { Quando é necessário redefinir o ponto inicial de } \\
\text { corte. }\end{array}$ \\
\hline
\end{tabular}

Fonte: Autores

Para a construção da tipologia, optou-se por decompor o setup em três: troca de desenho, troca de chapa e troca de consumível, por ser o vocabulário já utilizado na planta. Também se definiu que a descrição da parada, que acompanha o diário de bordo, deveria ser a mais clara e simples possível.
Posterior a isso, partiu-se para a definição e construção da ferramenta de coleta. Seguindo uma proposta de baixo investimento na implantação das primeiras etapas do método, optou-se pelo diário de bordo manual, o foi recolhido todas as manhãs. O layout do diário de bordo foi definido conforme figura 6 . 
Figura 6 - Diário de bordo

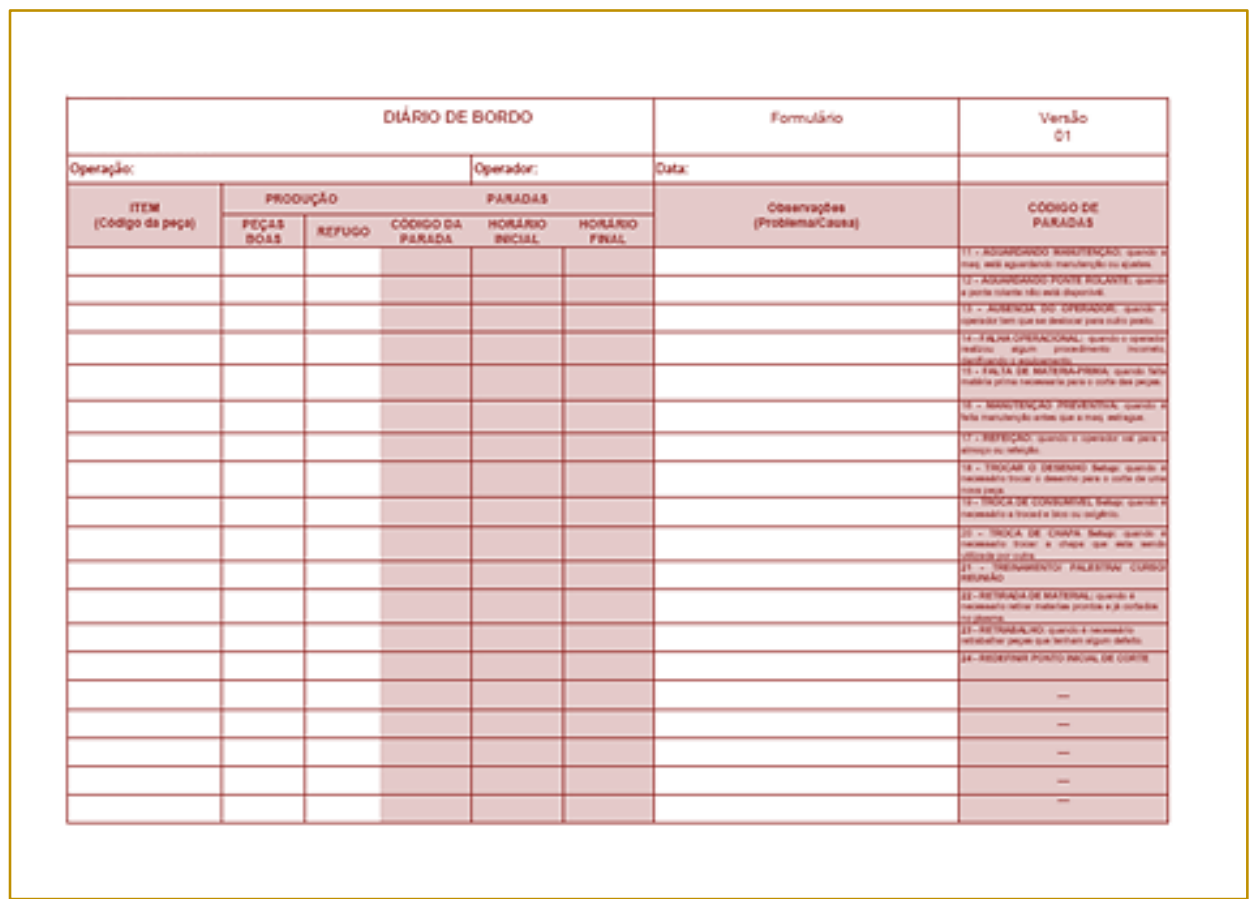

Fonte: Autores

O treinamento do operador foi realizado no próprio posto de trabalho. O propósito desta etapa foi promover uma pesquisa piloto, entretanto, ressalta-se a importância de transmitir estes conhecimentos e técnicas de forma estruturada para todos os colaboradores da empresa, com o intuito de criar um ambiente sistêmico de melhoria.
A implantação do método GPT concentrou-se no plasma, posto que corta tanto os módulos das balanças fabricadas quanto as peças adicionais que acompanham 0 kit de montagem. Os resultados trazidos na Tabela 2 são resultado de três semanas de coleta. Recomenda-se que novos ciclos de análise sejam feitos, valendo-se de um período de tempo maior.

Tabela 2 - Índices de eficiência

\begin{tabular}{|c|c|}
\hline Índices de eficiência & $\%$ \\
\hline$\mu$ TEEP & $32 \%$ \\
\hline$\mu \mathrm{OEE}$ & $37 \%$ \\
\hline$\mu 1$ & $59 \%$ \\
\hline$\mu 2$ & $55 \%$ \\
\hline$\mu 3$ & $99 \%$ \\
\hline
\end{tabular}

Fonte: Autores

No que tange aos motivos de parada, tem-se que a parada por manutenção corretiva é a mais representativa, sendo responsável por mais de $50 \%$ do tempo em que o posto não está produzindo. A figura 7 ilustra, por meio do Gráfico de Pareto, as paradas. 
Figura 7 - Pareto de paradas

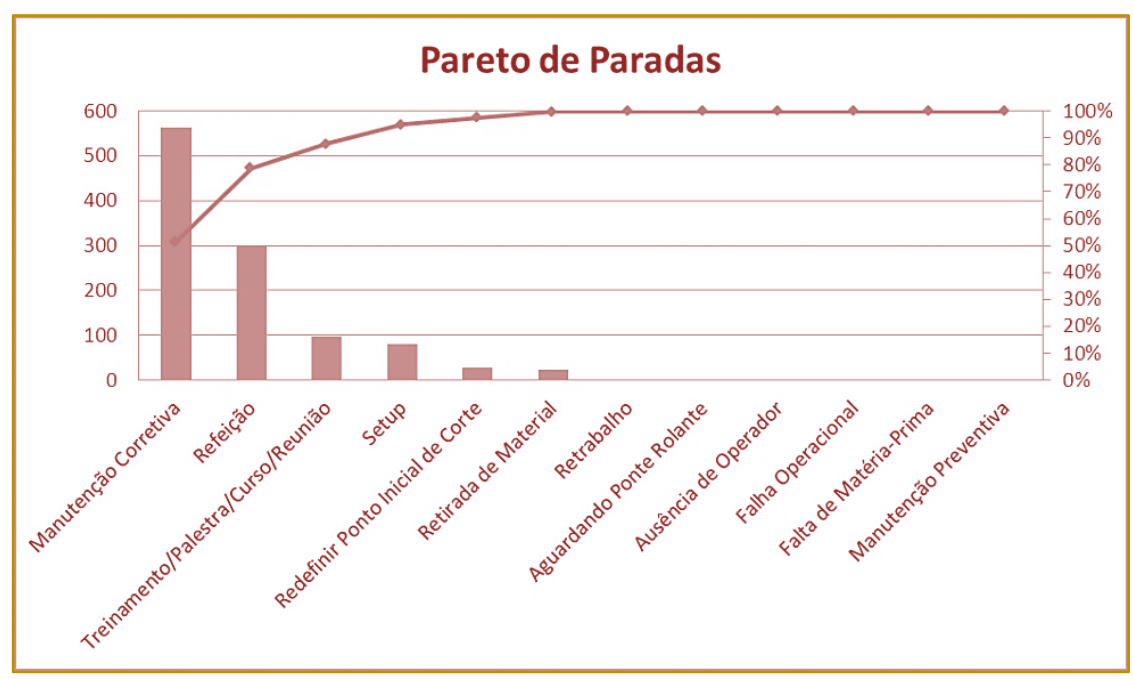

Fonte: Autores

A análise dos dados demonstrou a viabilidade de estabelecer como meta para o posto um TEEP de 65\%. Para tanto, propôs-se o plano de ação apresentado na Tabela 3, visando aumentar a produtividade do posto. O plano contempla uma ação de aperfeiçoamento no preenchimento do diário de bordo, a fim de garantir a precisão dos dados coletados. Também se sugere a aplicação ou construção de algum método que contemple a manutenções preventivas, haja vista que a maior causa de paradas no posto monitorado é pela quebra do equipamento.

Tabela 3 - Plano de ação

\begin{tabular}{|c|c|c|c|c|c|}
\hline What (O quê) & Why (Por quê) & Who (Quem) & $\begin{array}{c}\text { When } \\
\text { (Quando) }\end{array}$ & $\begin{array}{l}\text { Where } \\
\text { (Onde) }\end{array}$ & How (Como) \\
\hline $\begin{array}{l}\text { Aperfeiçoar o } \\
\text { preenchimento do } \\
\text { diário de bordo }\end{array}$ & $\begin{array}{c}\text { Melhorar a } \\
\text { precisão dos } \\
\text { dados coletados }\end{array}$ & $\begin{array}{l}\text { Supervisor, } \\
\text { líder e } \\
\text { operador. }\end{array}$ & $\begin{array}{l}20 \text { dias } \\
\text { após início } \\
\text { do plano }\end{array}$ & $\begin{array}{c}\text { Sala de } \\
\text { Treinamento }\end{array}$ & $\begin{array}{l}\text { Treinar envolvidos } \\
\text { sobre o } \\
\text { preenchimento } \\
\text { correto do Diário de } \\
\text { Bordo e suas } \\
\text { implicações }\end{array}$ \\
\hline $\begin{array}{l}\text { Aplicar método } \\
\text { SMP (Sistema de } \\
\text { Manutenção } \\
\text { Planejada) }\end{array}$ & $\begin{array}{c}\text { Promover } \\
\text { confiabilidade do } \\
\text { equipamento }\end{array}$ & $\begin{array}{l}\text { Manutenção } \\
\text { e operador }\end{array}$ & $\begin{array}{l}50 \text { dias } \\
\text { após início } \\
\text { do plano }\end{array}$ & Plasma & $\begin{array}{l}\text { Conhecimento do } \\
\text { ciclo operativo do } \\
\text { equipamento, } \\
\text { construção de rotina, } \\
\text { realização de } \\
\text { registros e instruções } \\
\text { de funcionamento. }\end{array}$ \\
\hline $\begin{array}{l}\text { Desenvolver } \\
\text { planilha própria } \\
\text { para cálculo de } \\
\text { eficiência }\end{array}$ & $\begin{array}{l}\text { Dar continuidade } \\
\text { ao método GPT }\end{array}$ & Qualidade & $\begin{array}{l}20 \text { dias } \\
\text { após início } \\
\text { do plano }\end{array}$ & Qualidade & $\begin{array}{l}\text { Construir fórmulas } \\
\text { para cálculo de } \\
\text { eficiência e sitio para } \\
\text { armazenar os diário } \\
\text { de bordo de forma } \\
\text { eletrônica. }\end{array}$ \\
\hline
\end{tabular}

Fonte: Autores 
Após a implementação do plano, recomendase a padronização do novo estado obtido com as melhorias, visando que as mesmas não se percam. Conforme o método se consolida na empresa, novos ciclos de análise são feitos. Observa-se também que outros indicadores podem ser utilizados para acompanhar a evolução da eficiência do posto, como por exemplo, tempo médio de setup e tempo de atravessamento.

\section{CONSIDERAÇÕES FINAIS}

A abordagem GPT não é apenas uma ferramenta que pode ser implementada de forma isolada em uma organização, mas sim, de uma forma sistêmica envolvendo desde a alta administração até o operador no chão de fábrica, decorrente da mudança cultura e comportamental que se faz necessária neste processo. Deste modo, o papel da alta administração torna-se fundamental para o sucesso e a implementação efetiva do GPT, atuando como agentes de mudanças e promotores dos conceitos, princípios e técnicas relacionados a esta metodologia.

A presente pesquisa foi desenvolvida com o

\section{REFERÊNCIAS}

[1] Antunes, J. A. V.; Klippel, A. F.; Klippel, M; Seidel, A. Uma revolução na produtividade. Porto Alegre: Bookman, 2013.

[2] Antunes, J. A. V.; Klippel, M. Uma abordagem metodológica para o gerenciamento das restrições dos sistemas produtivos: a gestão sistêmica, unificada/integrada e voltada aos resultados do posto de trabalho. Anais do XXI Encontro Nacional de Engenharia de Produção (ENEGEP). Salvador, 2001

[3] Chiavenato, I. Introdução a teoria geral da administração. Rio de Janeiro: Elsevier, 2001.

[4] Falconi, V. O Verdadeiro Poder. Nova Lima: INDG, 2009.

[5] Falconi, V. Gerenciamento da rotina do trabalho do dia-a-dia. Belo Horizonte: DG, 2001.

[6] Groover, M. P. Automation, production systems and computer integrated manufacturing. Pretice - Hall, Cop., 1987.

[7] Harding, H. A. Administração da produção. São Paulo: Atlas, 1981. objetivo de implantar o método GPT em uma indústria de balanças. Para tal, buscou-se implantar um instrumento de coleta de dados de forma a analisar as peculiaridades do posto de trabalho e propor um plano de ação para o aumento da produtividade do mesmo.

$\mathrm{Na}$ indústria em questão, foi demonstrado que o $\mu_{\text {TEEP }}$ do posto monitorado é de $32 \%$. Verifica-se que a maior causa de parada nesse posto é a manutenção corretiva, correspondendo a mais de 50\% do tempo total em que o equipamento fica parado.

A aplicação do método GPT permite aumentar os índices de eficiência operacional dos postos de trabalho através da elevação dos índices de disponibilidade, desempenho e qualidade. Dessa forma, o método possibilita maior aderência da empresa frente a atual realidade competitiva.

\section{AGRADECIMENTOS}

A Débora Petersen e Rafael Pieretti, pela parceria e apoio para a construção deste trabalho.

[8] Klippel, A. F.; Antunes, J. A. V.; Klippel, M; Jorge, R. R. Estratégia de Produção dos Postos de Trabalho - Um Estudo de Caso na Indústria de Alimentos. Anais do XXIII Encontro Nacional de Engenharia de Produção (ENEGEP). Ouro Preto, 2003.

[9] Monks, J. G. Administração da produção. São Paulo: Mc Graw Hill, 1987.

[10] Moreira, D. A. Introdução à administração da produção e operações. São Paulo: Pioneira, 1996.

[11] Oliveira, J. C. A; Klippel, A. F. Aumento da Eficiência Operacional através da Abordagem de Gestão dos Postos de Trabalho (GPT): um estudo de caso na indústria de medicamentos. Anais do XXIV Encontro Nacional de Engenharia de Produção (ENEGEP). Florianópolis, 2004.

[12] Slack, N.; Chambers, S.; Johnston, R. Administração da produção. São Paulo: Atlas, 2009.

[13] Yin, R. K. Estudo de caso: planejamento e métodos. Porto Alegre: Bookman, 2010. 


\section{Capítulo 4}

\section{MANUTENCEAOO PRODUTIVA TOTAL (TPM) E MANUTENÇÃO CENTRADA NA CONFIABILIDADE (RCM): UMA REVISÃO DA LITERATURA}

\section{Leonardo Rodrigues de Freitas}

\section{Jair Rodrigues de Siqueira Neto}

\section{Thais Martins Souza}

\section{Leticia da Silva Pires}

Resumo: A gestão da manutenção tem se apresentado como uma das áreas de grande importância nas organizações devido ao contexto de aumento de competitividade entre as empresas e aos avanços tecnológicos, que tem modificado os sistemas de produção, tornando-os cada vez mais automatizados e modernos. Dessa forma, assume-se como indispensável abordar os sistemas de gestão da manutenção que tem sido mais utilizados nas empresas hoje em dia, sendo esta a motivação para a execução deste estudo. Portanto, este artigo tem objetivo fazer uma revisão da literatura acerca dos sistemas de gestão da manutenção: Manutenção Produtiva Total (TPM) e Manutenção Centrada na Confiabilidade (RCM). Por fim, conclui-se que o objetivo do trabalho foi alcançado, uma vez que a literatura sobre o tema fora revisada e se fomentou a discussão sobre o referido tema; e sugere-se que, a partir do conhecimento repassado neste estudo, novos trabalhos sejam executados futuramente com a aplicação destes sistemas em organizações que busquem alcançar um diferencial competitivo através da utilização dos mesmos.

Palavras-chave: Gestão da Manutenção, Sistemas de Gestão da Manutenção, TPM, RCM, Revisão da Literatura. 


\section{INTRODUÇÃO}

Com o aumento da competitividade entre as empresas e por conta dos avanços tecnológicos, os sistemas de produção vêm passando por mudanças, com a introdução de equipamentos mais modernos, automação de sistemas e processos. Dessa maneira a gestão da manutenção tem se tornado uma das áreas de grande importância dentro das organizações, de acordo com Gomes et al (2011) ela proporciona redução de custos e garantia da disponibilidade de máquinas e pessoas, gerando uma otimização que reflete tanto na qualidade, confiabilidade e custos, se mostrando assim fundamental para a estratégia de uma empresa que busca diferencial no mercado.

Dada a importância da gestão da manutenção, este artigo tem por objetivo apresentar uma revisão da literatura sobre os sistemas de gestão da manutenção que tem despontado e se apresentado recentemente como os mais utilizados nas organizações, desenvolvendo o conhecimento geral sobre o tema, sendo estes: a Manutenção Produtiva Total (TPM), que segundo Kardec e Nascif (2009) promovem uma melhora na qualificação das pessoas e dos equipamentos dentro de uma organização, aumentando assim a eficácia da mesma; e a Manutenção Centrada na Confiabilidade (RCM), desenvolvida para auxiliar as empresas nas tomadas de decisão referentes à manutenção, através do estudo detalhado dos equipamentos, permitindo identificar desempenho e funcionalidade operacional dos mesmos (KARDEC; NASCIF, 2009).

O referido trabalho está estruturado de modo que a seção 2 apresenta o estado da arte dos sistemas de manutenção, promovendo a visão geral sobre o assunto e disponibilizando os conhecimentos pertinentes sobre 0 mesmo, enquanto na seção 3 são feitas as conclusões sobre o estudo.

\section{SISTEMAS DE GESTÃO DA MANUTENÇÃO: ESTADO DA ARTE \\ 2.1. MANUTENÇÃO PRODUTIVA TOTAL (DO INGLÊS TOTAL PRODUCTIVE MAINTENANCE - TPM)}

A manutenção produtiva total é uma abordagem nascida nos anos 1970, nos quais o cenário socioeconômico era cada vez mais rigoroso com o mercado, fazendo as empresas para sobreviver. Para isso, foram obrigadas a eliminar desperdícios, obter o melhor desempenho dos equipamentos, reduzir as paradas de produção por quebra de maquinário, redefinir o perfil de conhecimento e habilidade dos empregados da produção e manutenção e modificar a sistemática de trabalho.

Kardec e Nascif (2009) descrevem que o objetivo da TPM é a eficácia da empresa através da melhora da qualificação das pessoas e melhoramentos introduzidos nos equipamentos. Em TELECURSO 2000 PROFISSIONALIZANTE, O TPM é a melhoria da estrutura da empresa em termos materiais (máquinas, equipamentos, ferramentas, matéria-prima, produtos etc.) e em termos humanos (aprimoramento das capacitações pessoais envolvendo conhecimentos, habilidades e atitudes). A meta a ser alcançada é o rendimento operacional global.

A aplicação da TPM é tida como uma verdadeira filosofia de trabalho dentro de uma empresa e, de acordo com Dennis (2008), a TPM promove uma mudança profunda na mentalidade ao qual afirma que o operador apenas trabalha na operação da máquina e o pessoal da manutenção quando o equipamento tiver problema, para a mentalidade que mostra que todos são responsáveis pelos equipamentos, pela fábrica e o pelo futuro da organização.

\subsubsection{AS GRANDES PERDAS}

Quando se trata de perdas, a TPM foca nas 6 grandes perdas (MARTINS; LAUGENI, 2005):

1a Perda - Quebra: a quantidade de itens que deixa de ser produzida porque a máquina quebrou. É a mais conhecida e mais facilmente calculada. Deve ser combatida com uma manutenção preventiva eficaz;

2a Perda - Ajuste (setup): a quantidade de itens que deixa de ser produzida porque a máquina estava sendo preparada e/ou ajustada para a fabricação de um novo item. Deve ser combatida com técnicas de redução de setup (trocas rápidas);

3 - Perda - Pequenas pardas/ Tempo ocioso: a quantidade de itens que deixa de ser produzida em decorrência de pequenas parada no processo para pequenos ajustes, ou por ociosidades, como bate-papo do operador;

4 Perda - Baixa velocidade: a quantidade de item que deixou de ser produzido em 
decorrência do equipamento estar operando a uma velocidade mais baixa do que a nominal especificada pejo fabricante.

5a Perda- Qualidade insatisfatória: é a quantidade de itens que é perdida (para todos os efeitos, é como se eles não tivessem sido produzidos) por qualidade insatisfatória, quando o processo já entrou em regime;

6 ${ }^{\underline{a}}$ Perda - Perdas com start-up: é a quantidade de itens que é perdida (para todos os efeitos é como se eles não tivessem sido produzidos) por qualidade insatisfatória, quando o processo ainda não entrou em regime. No start-up ou partida, o índice de perda é em geral maior.

\subsubsection{QUEBRA ZERO}

Na filosófica da TPM, o conceito da quebra zero é tratado sobre a relação do operário com a máquina, onde o homem é responsável pela máquina que está operando. Uma vez que a máquina foi projeta para não dá defeito, é obrigatório conceder as melhores condições e soluções para atingir esse objetivo (KARDEC; NASCIF, 2009).

Kardec e Nascif (2009) ainda salientam que a quebra zero, sendo o cuidado da máquina para que não venha dá defeito no período no qual foi programada para não dá defeito, é totalmente diferente de que a máquina nunca pode quebrar. Algumas medidas são fundamentais para obter a quebra zero (KARDEC; NASCIF, 2009):
- Limpeza da área, asseio, lubrificação e ordem;

- Operar os equipamentos dentro das condições e limites estabelecidos;

- Recuperar o equipamento por problemas de envelhecimento e evitar quebras futuras;

- Eliminar as causas de envelhecimento dos equipamentos;

- Restaurar os equipamentos, periodicamente, retornando-os as condições originais;

- Ter domínio das anomalias que provocam a degradação dos componentes internos;

- Corrigir eventuais deficiências do projeto original;

- Fazer previsões da vida media através de técnicas de diagnostico;

- Capacitação e desenvolvimento do elemento humano, de modo que ele possa perceber, diagnosticar e atuar convenientemente.

\subsubsection{OS 8 PILARES DA TPM}

Segundo Souza (2013) a divisão das atividades de uma TPM é baseada em 8 diretrizes que estabelecem um sistema para se atingir a maior eficiência produtiva, os denominados "pilares", que tem esse nome por serem os responsáveis pela sustentação da metodologia da TPM. Figura 1 ilustra os 8 pilares da TPM:

Figura 1 - Os 8 pilares da TPM

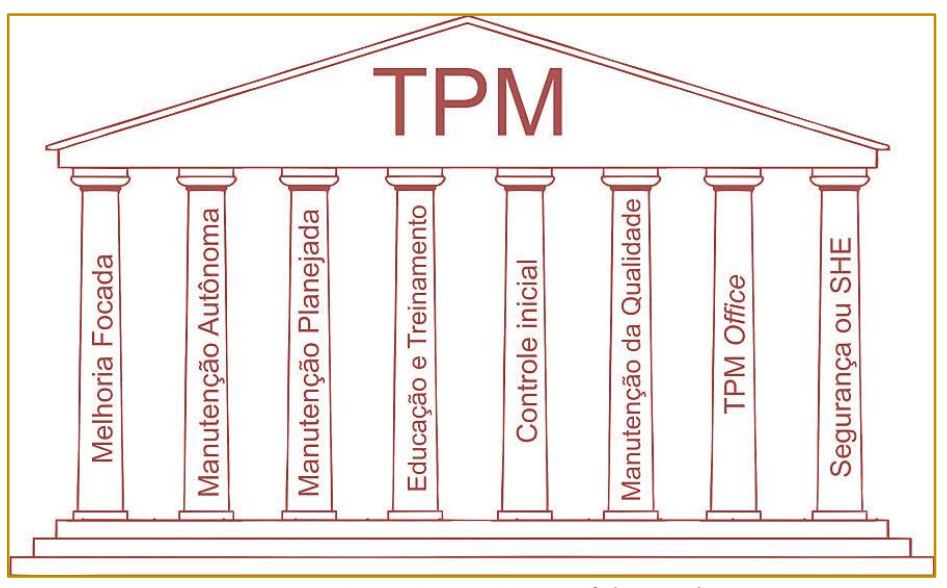

Fonte: Kardec e Nascif (2009)

Cada pilar tem sua definição (KARDEC; NASCIF, 2009):
- Melhoria Focada: como o nome sugere, é a diretriz negocio. Desse modo, procura-se 
reduzir os problemas $\square$ focadas na melhoria global do para melhorar o desempenho;

- Manutenção Autônoma: Autogerenciamento e controle, liberdade de ação, elaboração e cumprimento de padrões, conscientização da filosófica da TPM;

- Manutenção Planejada: Significa ter realmente o planejamento e o controle da manutenção, o que implica treinamento em técnicas de planejamento (software), utilização de um sistema mecanizado de planejamento da programação diária e do planejamento de paradas;

- Educação e Treinamento: Ampliação da capacitação, gerencialmente comportamental do pessoal de manutenção e operação;
- Controle Inicial: Estabelece um sistema de gerenciamento de fase inicial para novos projetos/equipamentos;

- Manutenção da Qualidade: Estabelece um programa de zero quebra

- TPM office: Estabelece um programa de TPM nas áreas administrativa, visando o aumento de sua eficiência;

- Segurança ou SHE: Estabelece um sistema de saúde, segurança e meio ambiente.

\subsubsection{IMPLANTAÇÃO DA TPM}

Para a implantação da TPM, normalmente, segue um esquema de 12 passos. O Quadro 1 foi adaptado de Kardec e Nascif (2009):

Quadro 1 - 12 passos para a implantação da TPM

\begin{tabular}{|c|c|c|c|}
\hline Fase & Passo & Etapa & Ações \\
\hline \multirow{5}{*}{ Preparo } & 1 & Comprometimento da alta administração & $\begin{array}{l}\text { Divulgação da TPM em todas as áreas da empresa; } \\
\text { Divulgações através de jornais internos. }\end{array}$ \\
\hline & 2 & Divulgação e treinamento & $\begin{array}{l}\text { Seminário interno dirigido a gerentes de níveis superior e } \\
\text { intermediário; } \\
\text { Treinamento de operação. }\end{array}$ \\
\hline & 3 & $\begin{array}{l}\text { Definição o Órgão ou Comitê } \\
\text { responsável pela implantação }\end{array}$ & Estruturação e definição das pessoas do comitê de implantação. \\
\hline & 4 & Definição da politica e metas & Escolha das metas e objetivos a serem alcançados. \\
\hline & 5 & $\begin{array}{l}\text { Elaboração do plano diretor de } \\
\text { implantação }\end{array}$ & Detalhamento do plano de implementação em todos os níveis. \\
\hline Introdução & 6 & $\begin{array}{l}\text { Outras atividades relacionadas com a } \\
\text { introdução }\end{array}$ & Convite a fornecedores, clientes e empresas controladas. \\
\hline \multirow{5}{*}{ Implantação } & 7 & Melhorias em maquinas e equipamento & $\begin{array}{l}\text { Definição de áreas e/ou equipamentos e estrutura das equipes de } \\
\text { trabalho. }\end{array}$ \\
\hline & 8 & Estruturação da manutenção autônoma & $\begin{array}{l}\text { Implementação da manutenção autônoma, por etapas, de acordo } \\
\text { com o programa; } \\
\text { Auditoria de cada etapas. }\end{array}$ \\
\hline & 9 & $\begin{array}{l}\text { Estruturação do setor de manutenção e } \\
\text { condução da Manutenção Preditiva }\end{array}$ & $\begin{array}{l}\text { Condução de Manutenção Preditiva; } \\
\text { Sobressalentes, ferramentas e desenhos. }\end{array}$ \\
\hline & 10 & $\begin{array}{l}\text { Desenvolvimento e capitação de } \\
\text { pessoal }\end{array}$ & $\begin{array}{l}\text { Treinamento de pessoal de operação para desenvolvimento de } \\
\text { novas habilidades relativas a manutenção; } \\
\text { Treinamento de pessoal de manutenção para analise, diagnostico } \\
\text { e entre outros; } \\
\text { Formação de lideres; } \\
\text { Educação de todo o pessoal. }\end{array}$ \\
\hline & 11 & $\begin{array}{l}\text { Estrutura para controle e gestão dos } \\
\text { equipamentos numa fase inicial }\end{array}$ & $\begin{array}{c}\text { Gestão do fluxo inicial; } \\
\text { LCC (Life cycle cost) - Análise de custo do clico de visa. }\end{array}$ \\
\hline Consolidação & 12 & $\begin{array}{l}\text { Realização da TPM e seu } \\
\quad \text { aperfeiçoamento }\end{array}$ & $\begin{array}{l}\text { Candidatura ao prêmio TPM; } \\
\text { Busca de objetos mais ambiciosos. }\end{array}$ \\
\hline
\end{tabular}

Fonte: Adaptado de Kardec e Nascif (2009) 
2.2. MANUTENÇÃO CENTRADA NA CONFIABILIDADE (EM INGLÊS RELIABILITY CENTERED MAINTENANCE - RCM)

A Manutenção Centrada na Confiabilidade (RCM) é uma ferramenta de auxilio a tomada de decisão, "é uma metodologia que estuda um equipamento ou um sistema em detalhes, analisa como ele pode falhar e define a melhor forma de fazer manutenção de modo a prevenir a falha ou minimizar as perdas recorrentes das falhas" (KARDEC; NASCIF, 2009, p. 140).

Seixas (2012) ainda reforça ao dissertar que a RCM identifica o desempenho ou a funcionalidade operacional requerido pelo equipamento, em seguida identifica os modos, as causas prováveis, os efeitos e as consequências das falhas, permitindo assim avaliar a criticidade das falhas e onde podemos identificar consequências significantes que afetam a segurança, a disponibilidade ou custo. Desta forma, a RCM é capaz de aplicar a melhor estratégia de manutenção para um determinado equipamento ou sistema.

Segundo Kardec e Nascif (2009), tal prática proporciona uma série de benefícios às empresas que a adotam, como o aprimoramento de desempenho operacional, já que sua aplicação fornece o tipo de manutenção mais eficaz para cada máquina em cada situação. Para Moubray (2000) a qualidade do produto também melhora com a implantação da manutenção centrada em confiabilidade. Esta metodologia traz o maior custo $x$ beneficio, pois os investimentos com manutenção serão empregados onde o impacto é maior, tendo uma redução significativa nas tarefas rotineiras de manutenção e nos trabalhos de emergência (KARDEC; NASCIF, 2009).

Conforme Kardec e Nascif (2009), outro fato importante é que a RCM prioriza a análise das consequências sobre a segurança e o meio ambiente em relação às consequências da falha no aspecto operacional, possibilitando desta forma uma melhoria nas condições ambientais e de segurança. Além disso, a análise pela equipe multidisciplinar permite a obtenção de um excelente banco de dados, possibilitando a criação de uma memória disponível a todos (Manutenção, Operação e Inspeção), facilitando "a adaptação de planos existente e, função de modificações ou adaptações no processo, nos sistemas ou nos equipamentos" (KARDEC; NASCIF, 2009, p. 155).

Ainda nesse sentido, Meneghini e Zaions (2010) afirmam que a metodologia da RCM é descrita através de quatro principais características: (I) preservar as funções; (II) identificar os modos de falha que podem interferir nas funções; (III) priorizar a função do equipamento ao invés da condição; e (IV) selecionar apenas as tarefas aplicáveis e eficazes ao sistema. O que permite dizer que esta metodologia prioriza as necessidades e concentra os recursos nas tarefas que promovam confiabilidade ao sistema.

\subsubsection{AS ETAPAS DO RCM}

De acordo com Raposo (2004), a RCM pode ser sistematizada em sete questões sobre o item, equipamento ou sistema, como listado abaixo:

1-Quais as funções e os padrões de desempenho do item no seu contexto operacional atual?

2-De que forma ele falha em cumprir as funções?

\section{3-O que causa cada falha operacional?}

4-O que acontece quando ocorre cada falha?

5-De que forma cada falha tem importância?

6-O que pode ser feito para prevenir cada falha?

7-O que deve ser feito, se não for encontrada uma tarefa preventiva apropriada?

Em seguida, conforme Raposo (2004) é possível abordar os passos para a utilização da RCM:

Passo 01: determinar as funções primarias e secundarias no contexto operacional de cada item e o padrão desempenho desejado.

Passo 02: identificar as falhas funcionais de cada item, as quais são a incapacidade de realizar o desempenho padrão desejado ou a impossibilidade de cumprir sua função. Sendo as falhas divididas em o modo como o item pode falhar e o que pode causar cada perda de função.

Passo 03: Identificar todos os modos de falhas (eventos) que são prováveis de causar cada perda de função, considerando as falhas já ocorridas, que estão sendo prevenidas e que podem possivelmente vir a 
ocorrer, incluindo até as falhas causadas por erros humanos.

Passo 04: Listar os efeitos provocados por cada modo de falha, resultando em informações fundamentais para avaliar as consequências da falha: evidências da ocorrência da falha, o que afetado pela ocorrência e o tipo de reparo necessário. Desta forma é possível conhecer como as falhas afetam a organização ou quais os tipos de consequências resultam em cada modo de falha. Existem quatro grupo de consequências: Falhas ocultas, não evidentes para pessoal de operação; Consequências para segurança e meio ambiente; Consequências operacionais; Sem consequências operacionais: envolve somente o custo de reparo.

Passo 05: Projetar a estratégia de manutenção a ser adotada para cada modo de falha a fim de eliminá-lo ou reduzir suas consequências, através de um plano de manutenção, buscando o gerenciamento das falhas e não apenas prevenção indiscriminada de todas elas.

Os dois últimos passos descritos por Raposo (2004) são dissertados por Kardec e Nascif (2009), da seguinte forma: com os registros dos efeitos de falha é possível identificar o nível de importância de cada falha, ou seja, se a falha não provoca qualquer efeito ou se tem um efeito sem importância, o grau de prevenção será pequeno, ao contrário, se a falha provoca consequências sérias demandará ações na tentativa de evitar sua ocorrência e para isso, há três formas de atuação: a manutenção preditiva ou manutenção sob condição; manutenção preventiva com tarefas programadas de restauração; manutenção preventiva com tarefas programadas de descarte. A Figura 2 ilustra as etapas de utilização da RCM.

Figura 2 - Diagrama de etapas da RCM

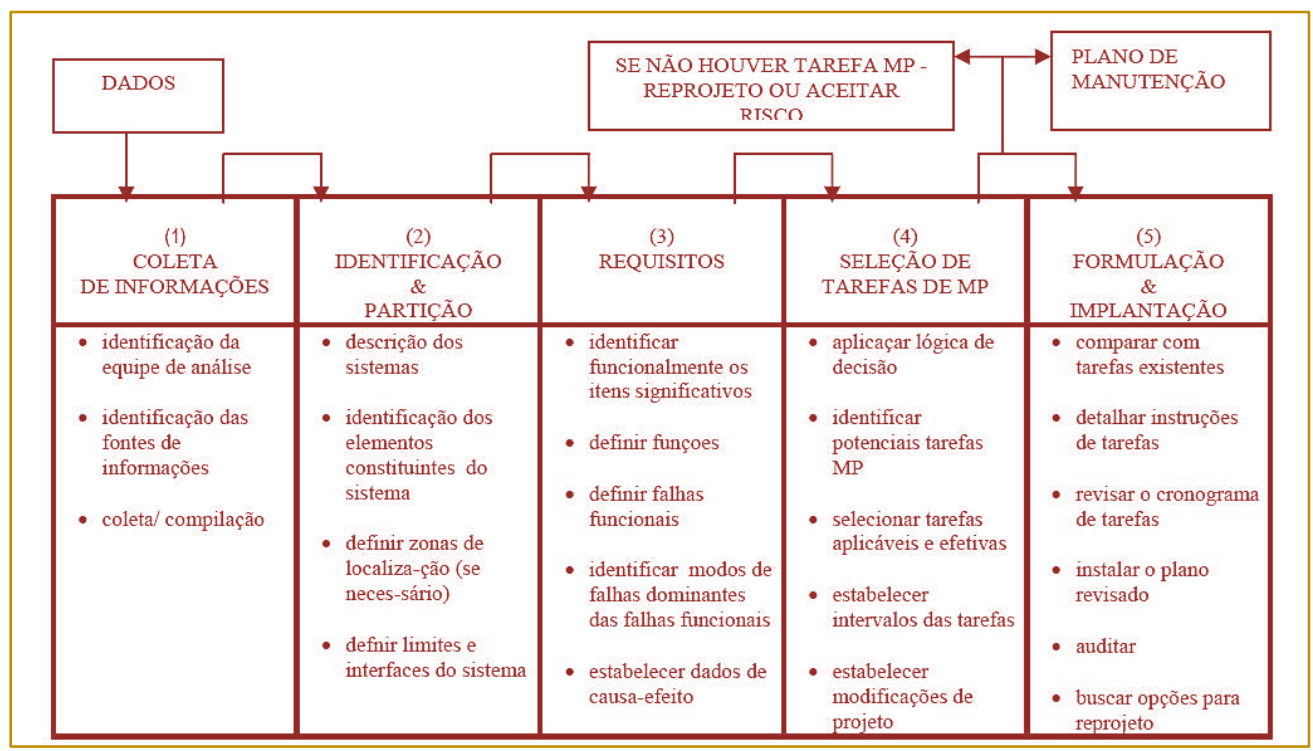

Fonte: Relatório EPRI NP-4795 (1986) apud Raposo (2004) 


\subsubsection{TIPOS DE CURVAS DE FALHAS}

Figura 3 - Tipos de curvas de falhas

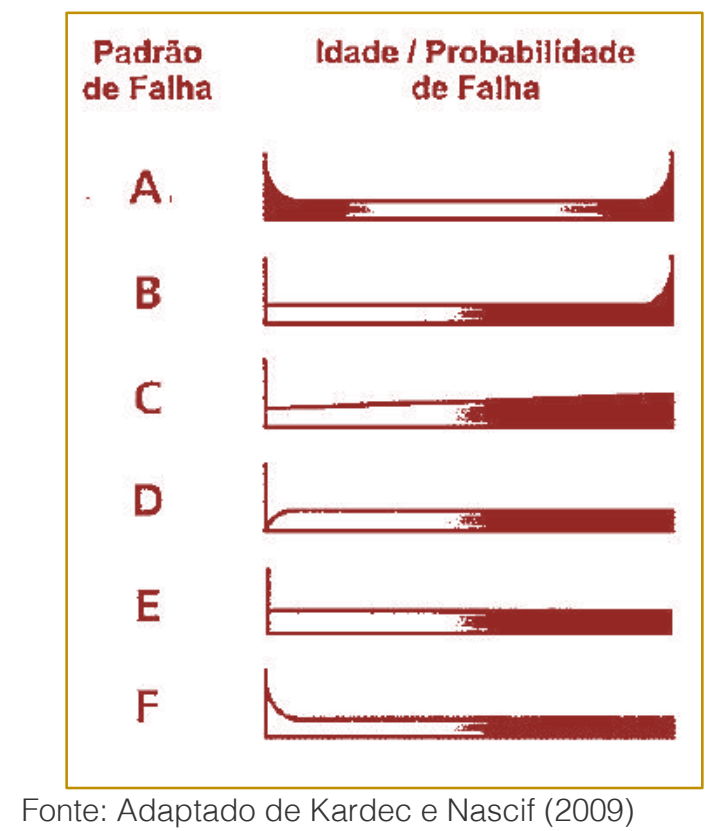

Como apresentado na Figura 3 e segundo um estudo em aeronaves mostrado por Kardec e Nascif (2009) foi identificado seis tipos de curvas de falhas, os quais são utilizados para caracterizar a vida dos equipamentos:

Padrão A - elevada ocorrência de falhas no inicio de operação do equipamento (mortalidade infantil);

Padrão B - probabilidade constante de falha seguida de uma zona de desgaste ao final da vida útil;

Padrão C - não há idade definida e ocorre o aumento lento e gradual na probabilidade de falha;

Padrão D - há uma baixa probabilidade de falha em equipamentos novos seguida de um rápido aumento para um patamar de probabilidade de falha constante;

Padrão E - o equipamento apresenta falha aleatória tendo probabilidade constante em qualquer idade do item;

Padrão F - existe alta probabilidade de falhas no inicio da operação do equipamento (mortalidade infantil) e cai para uma situação de probabilidade constate para as demais idades ou um aumento lento e gradual.

$O$ resultado do estudo mostrou que a minoria dos componentes apresentam o Padrão A (3 e $4 \%$ ) e a maioria (77 a 92\%) demonstra
Padrões D, E e F, os quais são falhas típicas em equipamentos complexos como hidráulicos ou eletrônicos (KARDEC; NASCIF, 2009).

\subsubsection{RESULTADOS DA ANÁLISE PELA RCM}

Como citado por Kardec e Nascif (2009), a implantação da análise pela RCM gera quatro resultados principais:

- Melhoria e aumento da compreensão do funcionamento do equipamento ou sistema por parte dos participantes de especialidades diversas.

- Desenvolvimento do trabalho em equipe, com resultados positivos na análise, solução de problemas e estabelecimentos de programas de trabalho.

- Definição de como um item pode falhar e suas causas, elaborando mecanismos para evitar falhas não programadas ou causadas por atos humanos.

- Elaboração de planos para garantir o funcionamento e o desempenho do item em um índice de performance desejado, englobando: Planos de manutenção, procedimentos operacionais e lista de modificações ou melhorias. 


\section{CONSIDERAÇÕES FINAIS}

A gestão da manutenção propicia redução de custos e garantia da disponibilidade de máquinas e pessoas, o que reflete tanto na qualidade, confiabilidade e custos. Dessa maneira observa-se a importância dessa gestão para a estratégia de uma empresa que busca ser competitiva e pretende ter um diferencial no mercado.

Nesse sentido, o objetivo do presente artigo de apresentar uma revisão da literatura sobre os sistemas de gestão da manutenção que tem despontado e se apresentado recentemente como os mais utilizados nas organizações, foi alcançado, pois houve o

\section{REFERÊNCIAS}

[1] Dennis, Pascal. Produção lean simplificada. Porto Alegre: Bookman, 2008.

[2] Electric Power Research Institute. Use of Reliability-Centered Maintenance for the McGuire Nuclear Station Feedwater System. Relatório EPRI NP-4795, 1986 apud RAPOSO, José Luis Oliveira. Manutenção centrada em confiabilidade aplicada a sistemas elétricos: uma proposta para uso de análise de risco no diagrama de decisão. Salvador, 2005.

[3] Gomes, I. C. M., et al. Análise e otimização da gestão da manutenção em uma empresa do setor de transporte urbano do interior potiguar. In: XXXI ENCONTRO NACIONAL DE ENGENHARIA DE PRODUCAO, Belo Horizonte - MG, 2011.

[4] Kardec, Alan; Nascif, Júlio. Manutenção: Função estratégica. 3a edição, Rio de Janeiro: Qualitymark: Petrobras, 2009.

[5] Martins, Petrônio G.; Laugeni, Fernando P. Administração da produção. 2a edição, São Paulo: Saraiva, 2005.

[6] Meneghini, Cristiano. Zaions, Douglas. A manutenção centrada em confiabilidade aplicada a desenvolvimento do conhecimento geral sobre o tema, focando a Manutenção Produtiva Total (TPM) e a

Manutenção Centrada na Confiabilidade (RCM), cabendo à organização que pretenda implementar a gestão de manutenção definir quais métodos serão mais adequados e possíveis para a sua estratégia.

Assim, para trabalhos futuros, sugere-se a execução de algum desses métodos em uma empresa que se mostre aberta para esse tipo de modelo de manutenção, já que o artigo em questão não se propôs a realizar uma aplicação prática dos mesmos.

um sistema de embalagem de presunto de uma indústria alimentícia. Joaçaba: UNOESC, 2010. 16 p. Trabalho de Conclusão de Curso - Curso de Engenharia de Produção Mecânica, Universidade do Oeste de Santa Catarina, Joaçaba, 2010.

[7] Moubray, John. Manutenção Centrada em Confiabilidade. São Paulo: Aladon Ltds. 2000, 426 p.

[8] Raposo, José Luis Oliveira. Manutenção centrada em confiabilidade aplicada a sistemas elétricos: uma proposta para uso de análise de risco no diagrama de decisão. Salvador, 2005.

[9] Souza, Valdir Cardoso de. Organização e Gerência da Manutenção: Planejamento, Programação e Controle da Manutenção. 5a edição, São Paulo: All Print Editora, 2013.

[10] Seixas, Eduardo de Santana. Manutenção centradana confiabilidade. 2012. Disponível em:<http://migre.me/wrEei>. Acessado em: 15 de abr. 2017.

[11] Telecurso 2000 Profissionalizante. Manutenção. São Paulo. 284p. 


\section{Bapítulo 5}

\section{INDICADORES DE DESEMPENHO PARA MELHORES RESULTADOS DAS EXTRUSORAS DE UMA INDÚSTRIA DO RAMO PETROLIFERO}

\section{Mateus Leite de Oliveira}

\section{Glauber Araujo Alencar Cartaxo}

Resumo: O presente artigo aborda como temática a busca de dados reais a partir de indicadores de desempenho em extrusoras de uma indústria do ramo petrolífero. Para tanto, utilizou-se de uma pesquisa quantitativa, qualitativa - descritiva, através do método de estudo de caso, utilizando como instrumento a observação dos dados para que esses sejam analisados e interpretados. Como resultado esperado pretendeu-se compreender o motivo pelo qual a quantidade do produto final não condizia com a planejada.

Palavras-chave: Indicador de desempenho, Extrusora, PPCP. 


\section{INTRODUÇÃO}

A busca pela eficiência e eficácia dos recursos produtivos para maximização do rendimento operacional torna-se crucial para maiores ganhos econômicos e sustentação da competitividade perante o mercado.

Este conceito auxilia no desenvolvimento dinâmico, comprovado através de menores prazos e maior qualidade de seus produtos e serviços. Assim, elementos de análise da situação organizacional (gestão da produção) incidem diretamente no incremento do gerenciamento da rotina do sistema produtivo.

Segundo Porter (2005), o planejamento estratégico torna-se uma ferramenta para gerar competitividade em empresas de produtos e serviços, além de projetar perspectivas de crescimento e desenvolvimento em setores de áreas técnicas, tecnológicas e humanas.

Diante desta realidade, monitorar o desempenho dos fatores críticos de sucesso de uma empresa pode guiar seus caminhos rumo à melhoria de atuação, à medida que baixos desempenhos apontam para a necessidade de otimização de suas atividades em curto, médio ou longo prazo (RECHULSKI, 2004).

Para tanto, os indicadores de desempenho são ferramentas de gestão, fundamentais nas atividades de monitoramento e avaliação das organizações, pois constituem, aferem e registram tarefas básicas do cotidiano. E são utilizados como instrumento estratégico em projetos, programas e políticas, $\mathrm{o}$ que permite acompanhar o alcance das metas, identificar avanços, melhorias de qualidade, correção de problemas, necessidades de mudanças etc.

A pesquisa teve como finalidade aplicar os indicadores de desempenho para auxiliar nas análises hierárquicas do baixo rendimento do equipamento, em vista da obtenção de melhorias contínuas para o mesmo e consequentemente para o processo.

Desta forma, para atingir o objetivo proposto, foi realizada uma investigação da real situação da linha de produção e dos recursos produtivos a fim de equacionar as ações táticas e estratégicas do setor estudado.

Sendo assim, a justificativa para o proposto trabalho, caracteriza-se pela busca do aumento da produtividade do equipamento no processo industrial. Assim, a aplicação dos indicadores de desempenho torna-se essencial, para realizar a confrontação e mensuração das informações entre o planejamento e controle do sistema produtivo, o que promove a identificação das possíveis causas da baixa produtividade.

O artigo está dividido em três etapas. Primeiramente, estão evidenciados os caminhos trilhados para elucidar (metodologia) e amparar (fundamentação teórica) esta pesquisa. Em seguida, foi abordado o estudo de caso, apresentando a empresa estudada, a coleta de dados e identificação e análise do cenário. Por fim aplicação dos conceitos (indicadores) e análise do novo cenário e resultados.

\section{METODOLOGIA}

A pesquisa foi qualitativa descritiva, através do "modelo conceitual e operativo" estudo de caso, no qual, foram feitas observações e anotações, in loco, dos painéis eletrônicos de duas extrusoras; quantitativa, no que diz respeito ao levantamento de dados possíveis de quantificar através dos apontamentos diários dos valores das velocidades de extração de tubo/mangueira, para realizar a análise de dados interpretativa e comparativa (entre os dois objetos de pesquisa, o histórico da empresa e o referencial teórico) (GIL, 2002, p. 43; 54-55).

Os dados foram obtidos através da documentação direta e indireta. A direta ocorreu nos setores de planejamento tático Planejamento, Programação e Controle da Produção (PPCP) e operacional (chão de fábrica) da indústria estudada $e, \quad a$ documentação indireta, classifica-se por fontes e dados coletados pelos demais setores, encontrados no sistema integrado de gestão empresarial Enterprise Resource Planning (ERP), Totvs da empresa.

As documentações foram analisadas com base nos conceitos de gestão da produção, e com isso, os indicadores de desempenho foram aplicados como auxílio ao estudo e análise hierárquica de todo 0 processo produtivo. 


\section{FUNDAMENTAÇÃO TEÓRICA}

\subsection{GESTÃO DA PRODUÇÃO}

Gestão da Produção é a atividade de gerenciamento de recursos escassos e processos que produzem e entregam bens e serviços, visando a atender as necessidades e/ou desejos de qualidade, tempo e custo de seus clientes. Toda organização, vise ela ao lucro ou não, tem dentro de si uma função de produção, pois gera algum valor agregado para seus clientes que inclui algum composto de produtos e serviços, mesmo que, dentro da organização, a função de produção não tenha este nome (LOPES, SIEDENBERG e PASQUALINI, 2010).

Portanto, Gestão da produção apresenta-se como o conjunto de processos interligados, relacionados ao desenvolvimento do produto ou serviço até sua comercialização, com ênfase no relacionamento clientesfornecedores.

Pode-se dizer que a gestão da produção é, acima de tudo, um assunto prático que trata de problemas reais, pois tudo o que vestimos, comemos e utilizamos passa de alguma maneira por um processo produtivo (SLACK et al., 2008).

\subsubsection{PLANEJAMENTO, PROGRAMAÇÃO E CONTROLE DA PRODUÇÃO (PPCP) \\ O setor de planejamento, programação e controle da produção assinala-se de grande importância para um bom desenvolvimento da}

Gestão da Produção. Concretiza-se devido ao departamento ser o núcleo de concentração das informações-chave que futuramente serão encaminhadas para cada área competente realizar suas atividades com eficácia.

Para Martins e Laugeni (2001), a finalidade da área de PPCP é liderar o processo produtivo, com o objetivo de transformar informações de vários setores em ordens de produção e compra, desempenhando as funções de planejamento, programação e controle, de maneira a satisfazer os clientes com produtos e serviços, assim como os acionistas com resultados econômicos positivos.

$\mathrm{Na}$ área de PPCP ocorrem as atividades relacionadas às análises críticas dos projetos, com atenção aos prazos de entrega dos produtos fabricados pela necessidade do cliente, os recursos produtivos disponíveis e o estudo de demanda/capacidade da organização.

Este departamento encarrega-se em gerir a liberação de execução das atividades via sistema Enterprise Resource Planning (ERP), software de gerenciamento de necessidades de compras de insumos e matéria-prima (suprimentos), revisões dos equipamentos e recursos produtivos (manutenção), previsão de demandas e projeção de vendas (marketing), confirmação de prazos (engenharia de produto e processos), avaliação dos inputs e outputs (qualidade) etc., evidenciado pela Figura 1.

Figura 1 - Influência de outras áreas no PPCP

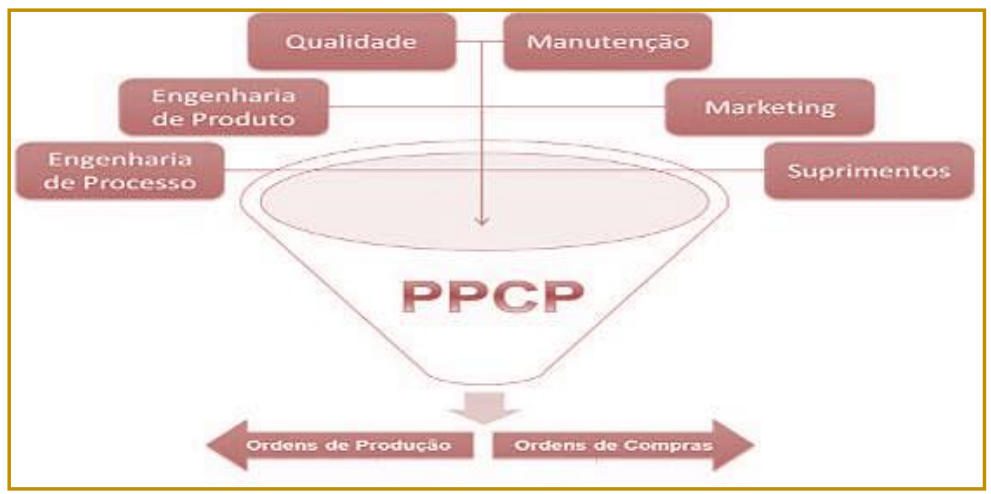

Fonte: SANTOS (2014) 
As informações sistemáticas obtidas através do sistema possibilitam a seção ratificar $e$ disponibilizar para o setor de fabricação as Ordens de Produção (OP's) e as Ordens de Compras (OC's).

Diante disso, para Costa (2010), o PPCP é um elo importante entre as estratégias da empresa e o seu sistema produtivo, no qual, é possível garantir que os processos da produção ocorram com melhor fluidez ao alcance das metas.

\subsection{PROCESSO DE EXTRUSÃO}

Figura 2 - Exemplo de plastificação no processo de extrusão

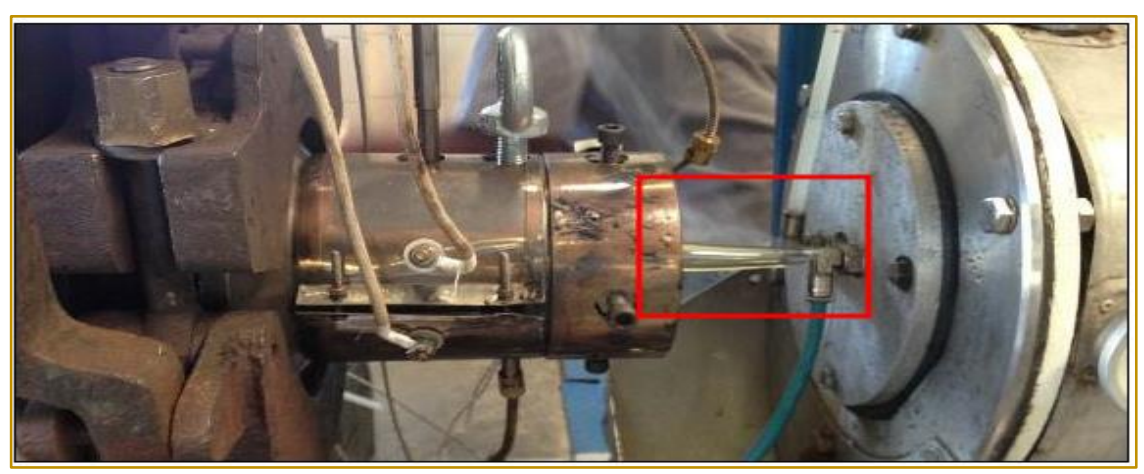

Fonte: Elaborado pelo autor (2015)

O processo de extrusão caracteriza-se pela conformação plástica de um determinado material, no qual um corpo é compelido a passar através de um cilindro aquecido em situação controlada, por meio da ação
Segundo Carvalho (2013), o processo de extrusão é utilizado comercialmente desde o século XIX. No entanto, com o advento da Segunda Guerra Mundial, passou-se a ter uma maior necessidade neste procedimento, devido à importância de possuir perfis extrusados em grandes quantidades para serem utilizados em componentes aeronáuticos.

A fabricação de tubos pelo processo de extrusão passou a substituir a laminação, pois tornou-se mais econômica e competitiva para comprimentos relativamente curtos e em pequenas quantidades (CHITKARA e ALEEM, 2001).

Figura 3 - Exemplificação do processo de extrusão

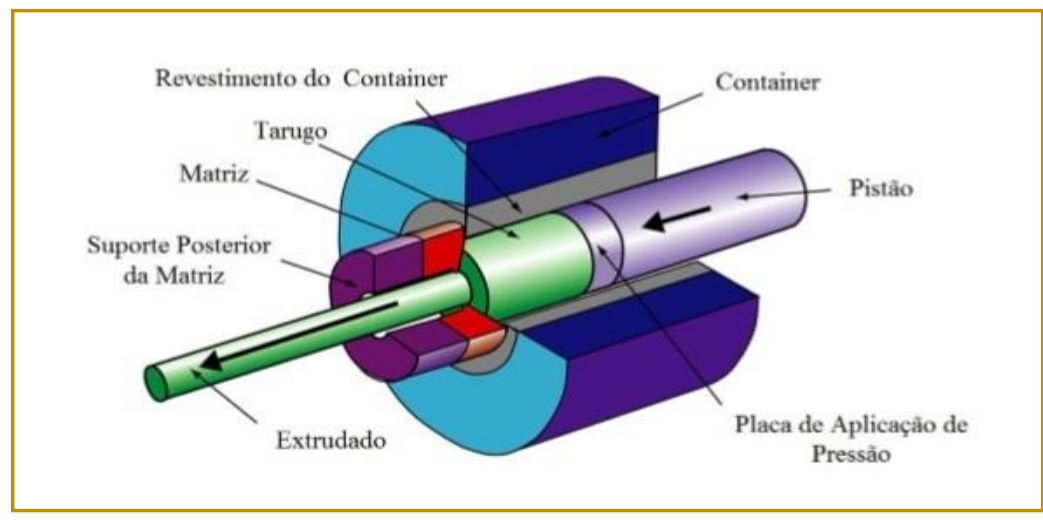

Fonte: CARVALHO (2013) 
No orifício de saída do cilindro, o material é comprimido contra um conjunto de ferramentais (matriz, nariz, tela etc.), que possuem estreitas tolerâncias dimensionais e grandes relações de comprimento, diâmetro e adquire 0 formato da seção transversal desejado (Figura 3). Cada tarugo é extrusado individualmente, o que caracteriza a extrusão como um processo semi-contínuo.

\subsection{IMPORTÂNCIA DOS INDICADORES DE DESEMPENHO}

Segundo Dias (2007), a medição é uma propriedade utilizada para mensurar algo através da comparação com um padrão. No entanto, o indicador aborda o conjunto de medições que viabilizam o acompanhamento da evolução do item avaliado. Desta maneira, os indicadores de desempenho são um conjugado de elementos que colaboram para a avaliação das entradas, saídas, processamentos e produtividade da empresa. Esses componentes compreendem critérios de desempenhos, padrões e medições que permitem à organização satisfazer seus clientes e atingir seus objetivos.

Para Hronec (2001), os indicadores de desempenho são sinais vitais da instituição. Eles são responsáveis por qualificar e quantificar todo o mapeamento das atividades ou outputs de um procedimento até atingirem as metas que foram propostas.
Para Moreira (2008), o indicador de produtividade, associado ao de qualidade, são utilizados como ferramenta gerencial, no qual auxiliam no monitoramento das metas e objetivos e comparam os mesmos de forma sistemática e detalhada dos desempenhos e potencializa e engloba todas as outras medidas de monitoramento de satisfação, aferindo a produtividade ao mesmo tempo em que se conservam os indicadores de eficácia (qualidade).

\subsubsection{INDICADOR DE QUALIDADE}

Os indicadores da qualidade, ou indicadores da satisfação dos clientes, medem como o produto (ou serviço) é percebido pelo cliente e a capacidade de atender às expectativas dos clientes. Podem ser aplicados para a empresa toda, para um processo específico ou para uma área da empresa (SEBRAE, 2015).

Segundo o SEBRAE (2015), o índice calcula a razão entre os produtos conformes (produção com ausência de anomalias) pelos produtos não conformes (produção fora das especificações técnicas, perdidos durante o processo ou retrabalhados), somados aos produtos conformes novamente, como visto na Equação 1.

$$
\text { Indicador de Qualidade }=\left(\frac{\text { produtos conformes }}{\text { produtos conformes }+ \text { produtos não conformes }}\right) \times 100
$$

(Eq.1)

Com a aplicação do indicador de qualidade, busca-se um índice elevado de satisfação da organização e do cliente, a resultante da medida do indicador é a mesma da eficácia.

Indicadores de qualidade medem o total de erros, não conformidades ou desvios que acontecem em um processo em relação ao total que foi produzido. A comparação do resultado obtido na medição de um indicador de qualidade com o índice-padrão de aceitação definido para um determinado processo (ou seja, índice desejado) é chamada de eficácia (SEBRAE, 2015).

\subsubsection{INDICADOR DE PRODUTIVIDADE}

O aumento continuado da produtividade gera uma série de benefícios que atingem a empresa, os trabalhadores e a sociedade como um todo. Por isso o estudo dos indicadores, e o monitoramento da produtividade são importantes, pois as medidas são usadas como ferramenta gerencial (MARTINS e LAUGENI, 2001).

A produtividade caracteriza-se pela diminuição do tempo consumido para a composição de um produto ou serviço, acrescido dos níveis de qualidade sem o acréscimo de mão-de-obra ou recursos 
produtivos. Para Moreira (2008), ela pode ser determinada pela razão entre os outputs alcançados e inputs consumidos (Equação 2).

$$
\text { Indicador de Produtividade }=\frac{\text { output }}{\text { Input }}
$$

(Eq. 2)

Mede-se a produtividade para detectar problemas e verificar o acerto de decisões tomadas no passado sobre mudanças na organização, nos processos de produção, no arranjo físico etc.; mede-se a produtividade também para atestar a utilidade de programas de treinamento em setores ou atividades específicas, o acerto na introdução de novos produtos, de políticas de investimentos, entre outros (MOREIRA, 2008).

Os indicadores de produtividade possuem a finalidade de corroborar para que todos os colaboradores da empresa compreendam o andamento dos processos e qual a sua real contribuição para o fortalecimento produtivo e alcance dos objetivos e as metas indicadas.

\subsubsection{PROCESSO DE APLICAÇÃO DO INDICADOR DE PRODUTIVIDADE \\ O processo de aplicação baseia-se nos resultados encontrados em função da quantidade de recursos gastos, evidenciado na Figura 4.}

Figura 4 - Lógica de aplicação do indicador de produtividade

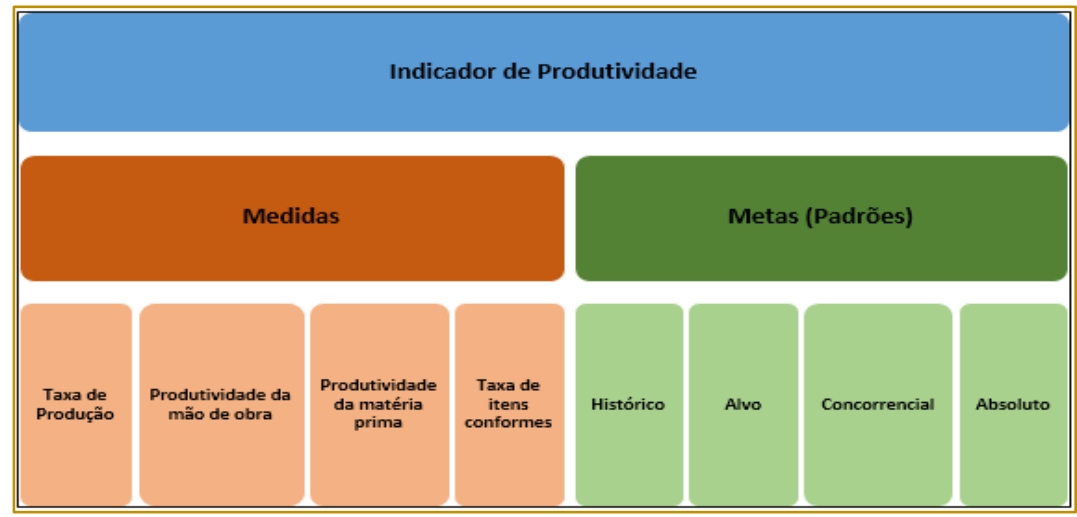

Fonte: Elaborado pelo autor (2015)

Portanto, de acordo com o plano proposto, esta pesquisa adotou a taxa de produção como medida de produtividade e o padrão histórico de performance como variáveis de avaliação do desempenho dos processos estudados.
Em todo processo e recurso consumido durante a fase produtiva deve-se eleger as medidas de produtividade mais adequadas e avaliar o seu desempenho. Este momento é evidenciado pela "taxa de produção", de acordo com detalhamento na Tabela 1. 
Tabela 1 - Detalhamento das medidas de produtividade

\begin{tabular}{|c|c|c|c|c|}
\hline \multicolumn{5}{|c|}{ Medida de produtividade } \\
\hline Análises & Taxa de produção & $\begin{array}{l}\text { Produtividade da } \\
\text { mão de obra }\end{array}$ & $\begin{array}{c}\text { Produtividade da } \\
\text { matéria prima }\end{array}$ & $\begin{array}{l}\text { Taxa de itens } \\
\text { conformes }\end{array}$ \\
\hline Resultados & $\begin{array}{c}\text { Quantidade de } \\
\text { componentes } \\
\text { produzida }\end{array}$ & $\begin{array}{l}\text { Quantidade } \\
\text { produzida }\end{array}$ & $\begin{array}{l}\text { Quantidade } \\
\text { produzida }\end{array}$ & $\begin{array}{l}\text { Quantidade de } \\
\text { itens conformes } \\
\text { produzida }\end{array}$ \\
\hline $\begin{array}{l}\text { Recursos } \\
\text { utilizados }\end{array}$ & Tempo gasto & $\begin{array}{l}\text { Tempo gasto e } \\
\text { número de } \\
\text { operadores }\end{array}$ & $\begin{array}{l}\text { Quantidade de } \\
\text { MP utilizada }\end{array}$ & Tempo gasto \\
\hline Forma de cálculo & $\begin{array}{c}\text { Quantidade / } \\
\text { tempo }\end{array}$ & $\begin{array}{l}\text { Quantidade / } \\
\text { (tempo x No de } \\
\text { operadores) }\end{array}$ & $\begin{array}{l}\text { Quantidade } \\
\text { produzida / Kg de } \\
\text { MP utilizada }\end{array}$ & $\begin{array}{l}\text { Quantidade } \\
\text { conforme / } \\
\text { tempo gasto }\end{array}$ \\
\hline Observações & $\begin{array}{l}\text { Utilizada em } \\
\text { processos de } \\
\text { produção } \\
\text { discretos }\end{array}$ & $\begin{array}{l}\text { Utilizada quando } \\
\text { o processo é } \\
\text { intensivo em uso } \\
\text { de mão de obra }\end{array}$ & $\begin{array}{l}\text { Utilizada quando } \\
\text { o custo de MP é } \\
\text { significativo }\end{array}$ & $\begin{array}{l}\text { Utilizada para } \\
\text { processos com } \\
\text { alta variação de } \\
\text { conformidade }\end{array}$ \\
\hline
\end{tabular}

Fonte: Adaptado de NORTEGUBISIAN (2015)

Além disso, a definição de metas a serem atingidas é um fator essencial para um bom desempenho produtivo, ratificada pelo "histórico", conforme a Tabela 2.

Tabela 2 - Detalhamento das metas e padrões

\begin{tabular}{|c|c|c|c|c|}
\hline \multicolumn{5}{|c|}{ Metas (Padrōes) } \\
\hline Registro & Histórico & Alvo & Concorrencial & Absoluto \\
\hline $\begin{array}{l}\text { Características } \\
\text { principais }\end{array}$ & $\begin{array}{c}\text { Mede a } \\
\text { produtividade e } \\
\text { compara os } \\
\text { valores obtidos } \\
\text { com os períodos } \\
\text { anteriores }\end{array}$ & $\begin{array}{c}\text { Mede a } \\
\text { produtividade e } \\
\text { verifica o "gap" } \\
\text { entre o valor } \\
\text { obtido e o "alvo" } \\
\text { especificado }\end{array}$ & $\begin{array}{c}\text { Mede a } \\
\text { produtividade e } \\
\text { avalia o resultado } \\
\text { comparando-o } \\
\text { com empresas } \\
\text { concorrentes ou } \\
\text { processos } \\
\text { semelhantes } \\
\end{array}$ & $\begin{array}{c}\text { Mede a } \\
\text { produtividade e } \\
\text { avalia o resultado } \\
\text { de acordo com os } \\
\text { limites teóricos } \\
\text { (matemáticos) da } \\
\text { grandeza }\end{array}$ \\
\hline Observações & $\begin{array}{l}\text { Permite avaliar a } \\
\text { evolução do } \\
\text { indicador, mas } \\
\text { não dá ideia de } \\
\text { satisfação. }\end{array}$ & $\begin{array}{l}\text { Análise subjetiva } \\
\text { e dependente } \\
\text { dos critérios para } \\
\text { fixação do "alvo" }\end{array}$ & $\begin{array}{c}\text { Permite } \\
\text { comparar } \\
\text { desempenho, } \\
\text { mas não dá ideia } \\
\text { de satisfação }\end{array}$ & $\begin{array}{c}\text { Avalia de acordo } \\
\text { com referencial } \\
\text { teórico absoluto, } \\
\text { sem vínculo com } \\
\text { condição real }\end{array}$ \\
\hline
\end{tabular}

Fonte: Adaptado de NORTEGUBISIAN (2015)

\subsection{EFICIÊNCIA OPERACIONAL}

A eficiência operacional (Equação 3) apresenta-se como um método inerente à aplicação do cálculo do indicador de produtividade. Através do conhecimento prévio dos tempos de processamento de cada produto, realiza-se uma confrontação do tempo de fabricação com o tempo efetivamente gasto.

$$
\text { Eficiência Operacional }=\frac{\text { Medida de produtividade }}{\text { Grau de utilização }}
$$

(Eq. 3)

\section{ESTUDO DE CASO}

\subsection{CARACTERIZAÇÃO DA ORGANIZAÇÃO}

O estudo de caso foi realizado em uma indústria fornecedora de cabos umbilicais utilizados no processo de extração de petróleo em alto mar. Os cabos são conjuntos de elementos, utilizados na exploração Offshore (afastado da costa), no qual, exercem funções de controle hidráulico, suprimentos de energias, controle dos equipamentos, injeção de fluídos químicos e interliga o poço submerso a uma plataforma em alto mar (Figura 5). 
Figura 5 - Ilustração de cabos umbilicais conectados a plataforma

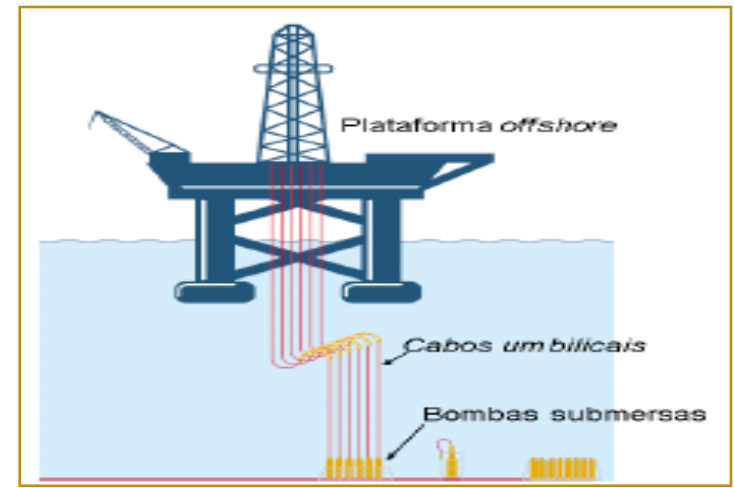

Fonte: SOUZA (2014)

A estrutura do umbilical (Figura 6) pode ser bem complexa e diferente para cada aplicação. Geralmente são compostas por elementos ópticos, mangueiras hidráulicas acionadas por comando de válvulas, mangueiras de injeção químicas, cabos elétricos de alta tensão, armadura e capa interna e externa.

Figura 6 - Exemplo da estrutura do cabo umbilical

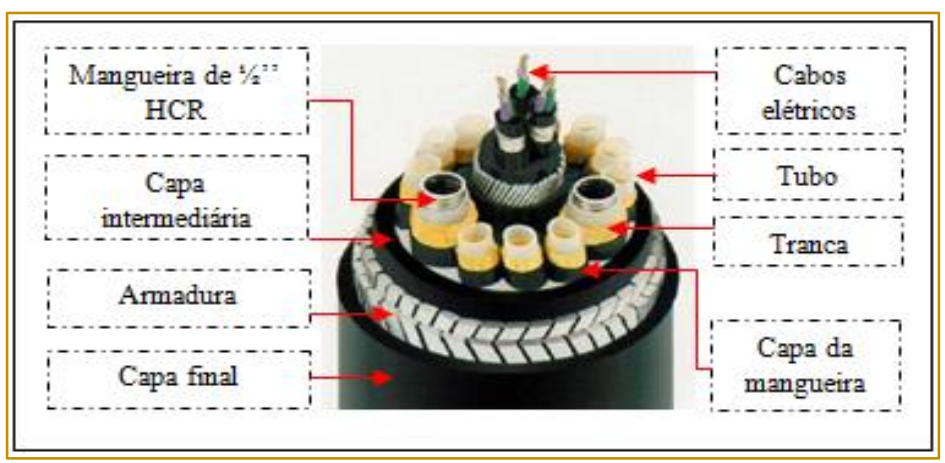

Fonte: SOUZA (2014)

No Gráfico 1, pode-se compreender todas as etapas dos processos produtivos da empresa, com destaque para as etapas que foram analisadas.

Gráfico 1 - Fluxo do processo de fabricação do umbilical

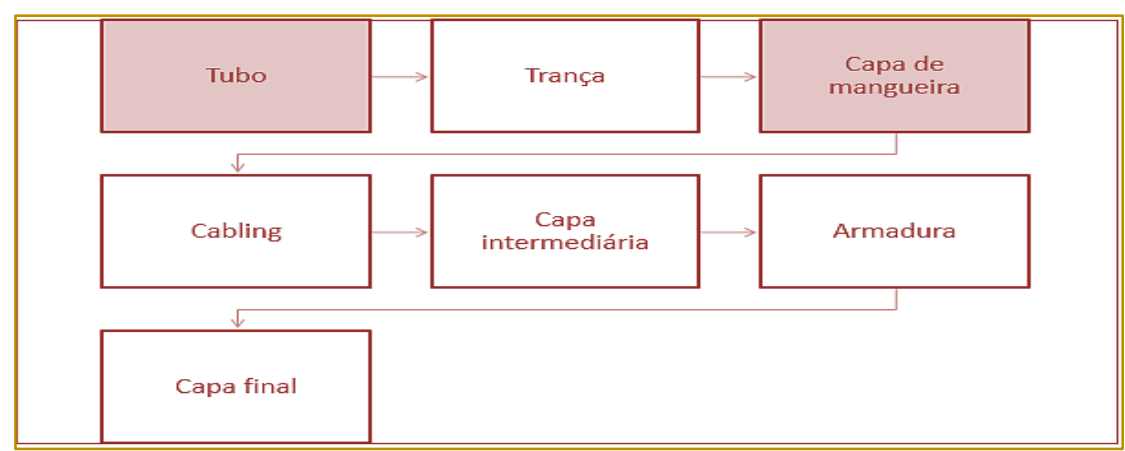


Esse fluxo permite demonstrar as etapas de fabricação do produto. Os processos em destaque caracterizam-se, respectivamente, como início e término do ciclo de fabricação de uma mangueira, elemento que constitui o umbilical.

\subsection{COLETA E ANÁLISE DE DADOS}

Segundo Nortegubisian (2015), grande parte das atividades operacionais de uma indústria, a medida de produtividade denominada por "taxa de produção" e a adoção do padrão histórico de performance podem levar a ponderações erronias sobre o desempenho dos processos.
Um fator que explica esse equívoco é o "mix" de produtos mensais/anuais produzidos pela empresa, que sofrem diversas variações (quantidades, velocidades e diversidade de itens), prejudicando a comparação eficaz dos resultados.

Na empresa estudada, este "mix" de produtos ocorre com bastante frequência, reverberando em dificuldades nas delimitações dos parâmetros de análise dos equipamentos (extrusoras).

Assim, foi realizado um estudo referente aos tipos de produtos fabricados e suas velocidades lineares para cada extrusora (TR60 e SD-70), como pode ser visto nas Tabelas 3 e 4 .

Tabela 3 - Tipos de produtos e suas velocidades na TR-60

\begin{tabular}{|c|c|c|c|c|}
\hline \multicolumn{5}{|c|}{ EXTRUSORA TR-60 } \\
\hline Velocidades & Antes do estudo & Depois do estudo & Antes do estudo & Depois do estudo \\
\hline Tipos & Tubo & Tubo & Capa de mangueira & Capa de mangueira \\
\hline $1 / 2^{\prime \prime} H C R$ & $630 \mathrm{~m} / \mathrm{h}$ & $612 \mathrm{~m} / \mathrm{h}$ & $612 \mathrm{~m} / \mathrm{h}$ & $600 \mathrm{~m} / \mathrm{h}$ \\
\hline $1 / 2^{\prime \prime} 8 \mathrm{M} 9$ & $840 \mathrm{~m} / \mathrm{h}$ & $720 \mathrm{~m} / \mathrm{h}$ & $1000 \mathrm{~m} / \mathrm{h}$ & $900 \mathrm{~m} / \mathrm{h}$ \\
\hline $1 / 2 " 8 \mathrm{M} 10$ & $840 \mathrm{~m} / \mathrm{h}$ & $720 \mathrm{~m} / \mathrm{h}$ & $1020 \mathrm{~m} / \mathrm{h}$ & $1000 \mathrm{~m} / \mathrm{h}$ \\
\hline 1/4" 4M8 & $1100 \mathrm{~m} / \mathrm{h}$ & $1044 \mathrm{~m} / \mathrm{h}$ & $920 \mathrm{~m} / \mathrm{h}$ & $840 \mathrm{~m} / \mathrm{h}$ \\
\hline 1/4" 4M10 & $1020 \mathrm{~m} / \mathrm{h}$ & $1000 \mathrm{~m} / \mathrm{h}$ & $1020 \mathrm{~m} / \mathrm{h}$ & $1000 \mathrm{~m} / \mathrm{h}$ \\
\hline $3 / 4 " \mathrm{HCR}$ & $612 \mathrm{~m} / \mathrm{h}$ & $522 \mathrm{~m} / \mathrm{h}$ & - & - \\
\hline $3 / 8$ " $6 \mathrm{M} 9$ & $1020 \mathrm{~m} / \mathrm{h}$ & $1000 \mathrm{~m} / \mathrm{h}$ & $920 \mathrm{~m} / \mathrm{h}$ & $840 \mathrm{~m} / \mathrm{h}$ \\
\hline $3 / 16^{\prime \prime} 3 \mathrm{M} 8$ & $1100 \mathrm{~m} / \mathrm{h}$ & $1020 \mathrm{~m} / \mathrm{h}$ & $920 \mathrm{~m} / \mathrm{h}$ & $840 \mathrm{~m} / \mathrm{h}$ \\
\hline
\end{tabular}

Fonte: Elaborado pelo autor (2015)

Tabela 4 - Tipos de produtos e suas velocidades na TR-70

\begin{tabular}{|c|c|c|c|c|}
\hline \multicolumn{5}{|c|}{ EXTRUSORA SD-70 } \\
\hline Velocidades & Antes do estudo & Depois do estudo & Antes do estudo & Depois do estudo \\
\hline Tipos & Tubo & Tubo & Capa de mangueira & Capa de mangueira \\
\hline 1/2" HCR & $920 \mathrm{~m} / \mathrm{h}$ & $900 \mathrm{~m} / \mathrm{h}$ & $612 \mathrm{~m} / \mathrm{h}$ & $600 \mathrm{~m} / \mathrm{h}$ \\
\hline $1 / 2$ " $8 \mathrm{M} 9$ & $840 \mathrm{~m} / \mathrm{h}$ & $720 \mathrm{~m} / \mathrm{h}$ & $840 \mathrm{~m} / \mathrm{h}$ & $720 \mathrm{~m} / \mathrm{h}$ \\
\hline $1 / 2^{\prime \prime} 8 \mathrm{M} 10$ & $920 \mathrm{~m} / \mathrm{h}$ & $840 \mathrm{~m} / \mathrm{h}$ & $840 \mathrm{~m} / \mathrm{h}$ & $720 \mathrm{~m} / \mathrm{h}$ \\
\hline 1/4" 4M8 & $1100 \mathrm{~m} / \mathrm{h}$ & $1020 \mathrm{~m} / \mathrm{h}$ & $1020 \mathrm{~m} / \mathrm{h}$ & $1000 \mathrm{~m} / \mathrm{h}$ \\
\hline 1/4" 4M10 & $1100 \mathrm{~m} / \mathrm{h}$ & $1020 \mathrm{~m} / \mathrm{h}$ & $1020 \mathrm{~m} / \mathrm{h}$ & $1000 \mathrm{~m} / \mathrm{h}$ \\
\hline 3/4" HCR & - & - & $320 \mathrm{~m} / \mathrm{h}$ & $240 \mathrm{~m} / \mathrm{h}$ \\
\hline $3 / 8$ " $6 \mathrm{M} 9$ & $1020 \mathrm{~m} / \mathrm{h}$ & $1000 \mathrm{~m} / \mathrm{h}$ & $1100 \mathrm{~m} / \mathrm{h}$ & $1020 \mathrm{~m} / \mathrm{h}$ \\
\hline $3 / 16^{\prime \prime} 3 \mathrm{M} 8$ & $1020 \mathrm{~m} / \mathrm{h}$ & $1000 \mathrm{~m} / \mathrm{h}$ & $1100 \mathrm{~m} / \mathrm{h}$ & $1020 \mathrm{~m} / \mathrm{h}$ \\
\hline
\end{tabular}

Fonte: Elaborado pelo autor (2015) 
Com a determinação dos novos parâmetros de processo, verificou-se que os tempos para cada produto, utilizados no momento do planejamento da programação, não eram assertivos.
Outro aspecto importante é o estudo das perdas inerente a cada processo para a verificação do tempo necessário de utilização do equipamento em análise. Portanto, o Tabela 5, evidencia as principais perdas para cada tipo de produto fabricado.

Tabela 5 - Registro de perdas para cada produto

\begin{tabular}{|l|c|c|c|c|c|c|c|c|}
\hline \multicolumn{10}{|c|}{ Extrusora TR-60 $\mathrm{SD}-70$} \\
\hline \multicolumn{1}{|c|}{ Mangueiras } & $\begin{array}{l}1 / 2^{\mathrm{I}} \\
\mathrm{HCR}\end{array}$ & $\begin{array}{c}1 / 2^{\prime \prime} \\
8 \mathrm{M} 9\end{array}$ & $\begin{array}{c}1 / 2^{\prime \prime} \\
8 \mathrm{M} 10\end{array}$ & $\begin{array}{c}1 / 4^{\prime \prime} \\
4 \mathrm{M} 8\end{array}$ & $\begin{array}{c}1 / 4^{\prime \prime} \\
4 \mathrm{M} 10\end{array}$ & $\begin{array}{c}3 / 4^{\prime \prime} \\
\mathrm{HCR}\end{array}$ & $\begin{array}{c}3 / 8^{\prime \prime} \\
6 \mathrm{M} 9\end{array}$ & $\begin{array}{c}3 / 16^{\prime \prime} \\
3 \mathrm{M} 8\end{array}$ \\
\hline $\begin{array}{l}\text { Derdas } \\
\text { equipanibilidade do }\end{array}$ & $12 \mathrm{~h}$ & $12 \mathrm{~h}$ & $12 \mathrm{~h}$ & $12 \mathrm{~h}$ & $12 \mathrm{~h}$ & $12 \mathrm{~h}$ & $12 \mathrm{~h}$ & $12 \mathrm{~h}$ \\
\hline Setup & $4 \mathrm{~h}$ & $2 \mathrm{~h}$ & $2 \mathrm{~h}$ & $2 \mathrm{~h}$ & $2 \mathrm{~h}$ & $2 \mathrm{~h}$ & $2 \mathrm{~h}$ & $2 \mathrm{~h}$ \\
\hline Troca de ferramenta & $1 \mathrm{~h}$ & $1 \mathrm{~h}$ & $1 \mathrm{~h}$ & $1 \mathrm{~h}$ & $1 \mathrm{~h}$ & $1 \mathrm{~h}$ & $1 \mathrm{~h}$ & $1 \mathrm{~h}$ \\
\hline Ajustes de dispositivo & $0,5 \mathrm{~h}$ & $0,7 \mathrm{~h}$ & $0,7 \mathrm{~h}$ & $0,7 \mathrm{~h}$ & $0,7 \mathrm{~h}$ & $0,7 \mathrm{~h}$ & $0,7 \mathrm{~h}$ & $0,7 \mathrm{~h}$ \\
\hline Testes de conformidade & $0,5 \mathrm{~h}$ & $0,3 \mathrm{~h}$ & $0,3 \mathrm{~h}$ & $0,3 \mathrm{~h}$ & $0,3 \mathrm{~h}$ & $0,3 \mathrm{~h}$ & $0,3 \mathrm{~h}$ & $0,3 \mathrm{~h}$ \\
\hline \hline
\end{tabular}

Fonte: Elaborado pelo autor (2015)

Como pode ser visto no quadro acima, o elevado mix de produtos acaba por requerer tempos de processamento específicos. Esses tempos influenciam diretamente no diagnóstico do desempenho, devido a sua variação.

\subsection{IDENTIFICAÇÃO E ANÁLISE DO CENÁRIO}

Com os estudos e análises realizados através de levantamento de dados do chão de fábrica e, em seguida, confrontados com os números do setor de Planejamento, Programação e Controle da Produção (PPCP), foi identificado que as extrusoras (TR-60 e SD-70) estavam produzindo com atrasos (baixa produtividade) em relação às programações realizadas, como pode ser visto na Gráfico 2.

Gráfico 2 - Comparação entre planejado x realizado

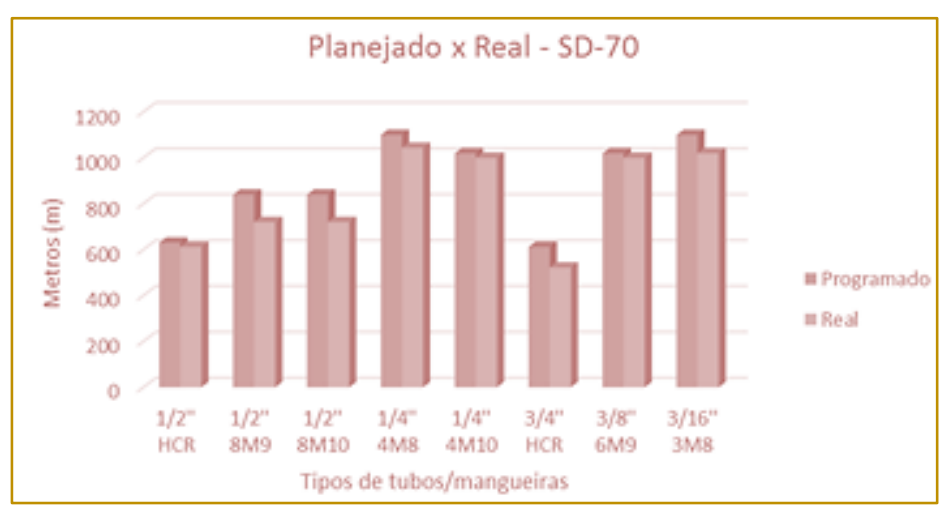

Fonte: Elaborado pelo autor (2015)

Posteriormente aos diagnósticos concretizados, no período de janeiro a maio de 2015, foi realizado um estudo minucioso da produtividade dos equipamentos, conforme Gráfico 3. 
Gráfico 3 - Controle da produtividade de janeiro a maio de 2015

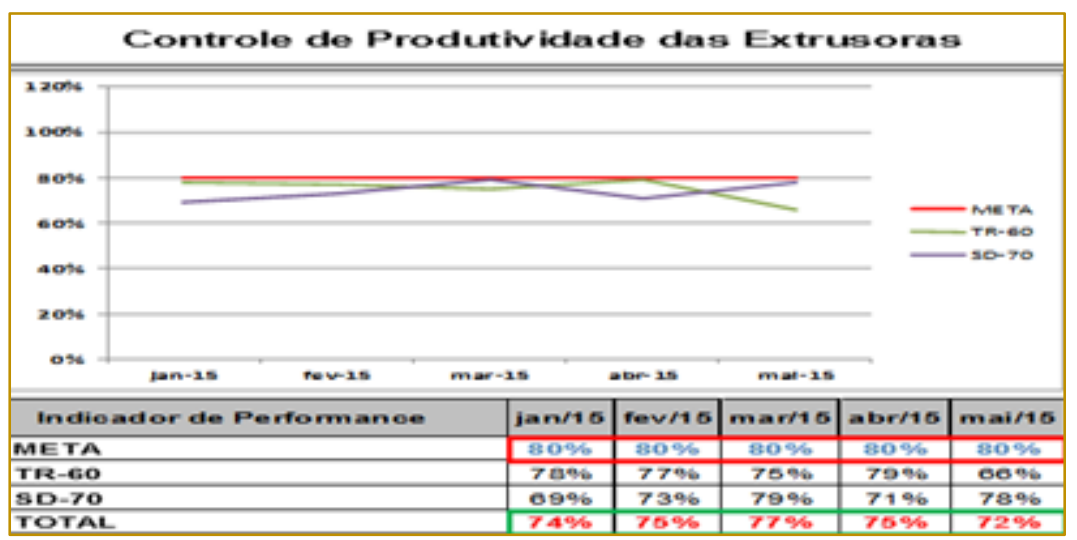

Fonte: Elaborado pelo autor (2015)

A carta-controle acima demonstra que as extrusoras além de não estarem conseguindo atingir, com frequência, a meta de $80 \%$, estipulada pelo departamento de PPCP, existia uma oscilação muito grande dos valores encontrados nos produtos em análise.
Desta forma, foi elaborado o Diagrama de Ishikawa (Gráfico 4), como ferramenta para auxiliar na orientação e identificação das possíveis causas do problema.

Gráfico 4 - Diagrama de Ishikawa

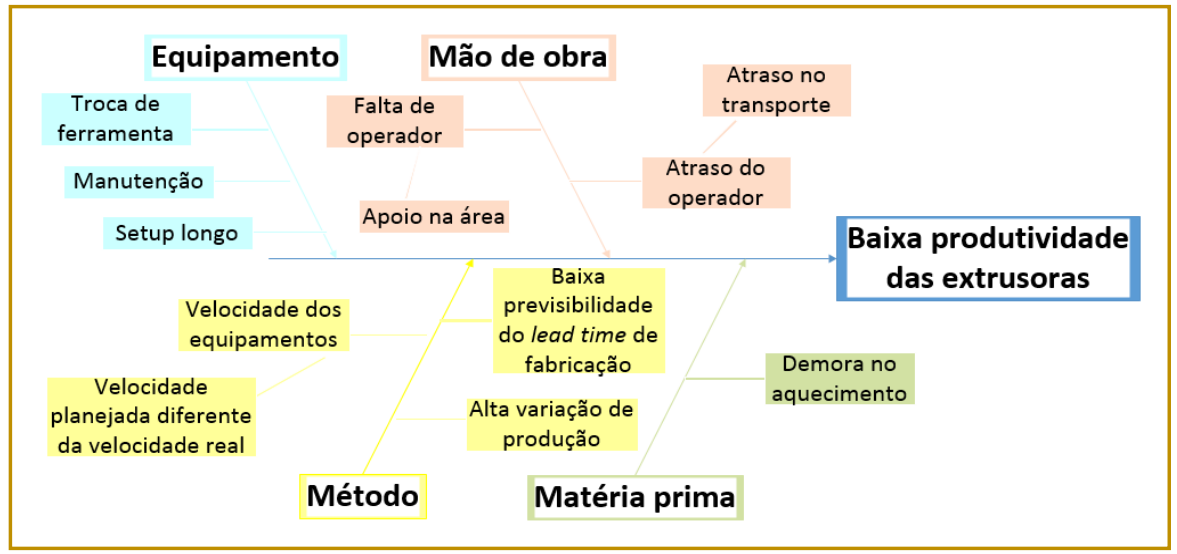

Fonte: Adaptado de SOUZA (2014)

Com a avaliação abrangente dos principais recursos que envolvem o processo de extrusão, foi possível identificar no diagrama, permitindo ao estudo focalizar que o problema central estava relacionado à baixa produtividade das extrusoras.

De posse da coleta, análise e identificação das possíveis causas do problema central verificado no Diagrama de Ishikawa, foi realizado um plano de ação (Figura 7), no qual são definidas as ações estratégicas, comumente estabelecidas em curto prazo, a serem tomadas a fim de solucioná-lo.

O plano de ação é uma ferramenta de planejamento estratégico extremamente importante para a aplicação de medidas de correção e/ou prevenção de problemas. 
Figura 7 - Plano de Ação realizado

\begin{tabular}{|c|c|c|c|}
\hline \multicolumn{4}{|c|}{ PLANO DE ACCAO } \\
\hline & Oque? & Porque? & Como? \\
\hline 1 & $\begin{array}{c}\text { Verificar as velocidades lineares } \\
\text { de cada } \\
\text { produto nas extrusoras e } \\
\text { confrontar com as adotas pelo } \\
\text { setor de PPCP }\end{array}$ & $\begin{array}{c}\text { Inconsisténcia entre os valores } \\
\text { plancjados } \\
\text { com os realizados }\end{array}$ & $\begin{array}{c}\text { Acompanhar na área todos os } \\
\text { tipos de projetos através da } \\
\text { mediça de velocidade do } \\
\text { puxador }\end{array}$ \\
\hline 2 & $\begin{array}{c}\text { Ajustar o horário do transporte } \\
\text { do turno }\end{array}$ & $\begin{array}{c}\text { Atraso de produça por conta } \\
\text { do transporte }\end{array}$ & $\begin{array}{c}\text { Entrar em contato com o setor } \\
\text { de RH - Responsavel pelo } \\
\text { transporte da empresa }\end{array}$ \\
\hline 3 & $\begin{array}{c}\text { Criar um planejamento de } \\
\text { preventivas para os } \\
\text { equipamentos }\end{array}$ & Evitar paradas por manutenç\$o & $\begin{array}{l}\text { Realizar uma manutensła } \\
\text { mersal para cada extrusora }\end{array}$ \\
\hline 4 & $\begin{array}{c}\text { Atualizar as Instruçes de } \\
\text { Trabalho com as ferramentas } \\
\text { corretas a serem utilizadas em } \\
\text { cada projeto }\end{array}$ & $\begin{array}{l}\text { Diminuir o tempo de setup } \\
\text { gasto no processo }\end{array}$ & $\begin{array}{c}\text { Dimensionar as ferramentas } \\
\text { existentes para cada tipo de } \\
\text { projeto }\end{array}$ \\
\hline 5 & $\begin{array}{c}\text { Analsar cartera anualde } \\
\text { pedidos e verificar jurto ao } \\
\text { PPCP as ordens de programac\$o } \\
\text { des produtcos }\end{array}$ & $\begin{array}{l}\text { Programaça da produç\$o sem } \\
\text { considerar o mix de produtos }\end{array}$ & $\begin{array}{l}\text { Corsiderar influencia do mix } \\
\text { combinando os dados do } \\
\text { padrà historico com o absoluto }\end{array}$ \\
\hline 6 & $\begin{array}{l}\text { Compreender todas as etapas } \\
\text { do processo de fabricacto }\end{array}$ & $\begin{array}{l}\text { Atividades manuais sem } \\
\text { padronleacào e sem controle de } \\
\text { tempo, altamente dependentes } \\
\text { dahabilidade pesscal }\end{array}$ & $\begin{array}{l}\text { Implantaça de trabaho } \\
\text { padronizado e tempos padrà } \\
\text { de operaçes, introduçà de } \\
\text { fatores de ritmoe fadiea }\end{array}$ \\
\hline
\end{tabular}

Fonte: Elaborado pelo autor (2015)

O plano de ação auxiliou no desdobramento das estratégias para resolução do problema através de iniciativas que visaram o alcance dos objetivos definidos.

\subsection{APLICAÇÃO DOS CONCEITOS \\ 4.4.1 INDICADOR DE QUALIDADE}

$\mathrm{O}$ indicador de qualidade por caracterizar-se como um parâmetro de satisfação dos clientes com o produto ou serviço está diretamente associado a todos os processos de fabricação. Portanto, o cálculo mais apropriado para este estudo, foi a razão entre os produtos sem anomalias pelo total de produtos fabricados (Figura 8).

Figura 8 - Cálculo da qualidade

\begin{tabular}{|c|c|c|c|c|c|}
\hline \multicolumn{7}{|c|}{ Cálculo da Qualidade } \\
\hline Extrusora & Tipo do produto & Produç̃o total & $\begin{array}{c}\text { Produção } \\
\text { com defeito }\end{array}$ & $\begin{array}{c}\text { Produç̃o } \\
\text { sem defeito }\end{array}$ & Qualidade \\
\hline TR-60 & $1 / 2$ HCR & $20.000 \mathrm{~m}$ & $800 \mathrm{~m}$ & $19.200 \mathrm{~m}$ & $\begin{array}{c}\text { Qual }=(\text { Prod sem defeito/ Prod total })^{* 100} \\
\text { Qual }=(19.200 \mathrm{~m} / 20.000 \mathrm{~m}){ }^{*} 1000=96 \%\end{array}$ \\
\hline
\end{tabular}

Fonte: Elaborado pelo autor (2015)

A aplicação deste índice auxiliou na avaliação indireta dos demais indicadores de desempenho.

\subsubsection{INDICADOR DE PRODUTIVIDADE}

Os indicadores de produtividade são ferramentas utilizadas para mensurar 0 rendimento e a eficiência dos processos.
Portanto, sua aplicação define-se pela quantidade de recursos que as empresas utilizam para originar um determinado produto ou serviço.

Para elucidar esta questão, o Figura 9 demonstra o cálculo da produtividade e considera uma amostragem do mix de produtos que a empresa possui. 
Figura 9 - Cálculo da produtividade

\begin{tabular}{|c|c|c|c|c|c|}
\hline \multicolumn{6}{|c|}{ Cálculo da Produtividade } \\
\hline Situaç̆o & Mx Possivel & Mix do Periodo & Produção (unidades) & Tempo disponivel (h) & Produtividade (uni/ $\mathrm{h}$ ) \\
\hline A & $\begin{array}{c}1 / 2^{\prime \prime} \text { HCR, 1/2" } \\
8 \mathrm{MLO}, 1 / 4^{\prime \prime} 4 \mathrm{M} 8, \\
3 / 8^{\prime \prime} 6 \mathrm{M} 9\end{array}$ & $1 / 2^{\prime \prime}$ HCR & 20.000 & 120 & $\begin{array}{l}\text { Produt }=\text { Produçฐ̃o/tempo } \\
\text { Produt }=20.000 / 120=166,67\end{array}$ \\
\hline B & $\begin{array}{c}1 / 2^{\prime \prime ~ H C R, ~} 1 / 2^{\prime \prime} \\
8 \mathrm{MCO}, 1 / 4^{4} 4 \mathrm{M} 8, \\
3 / 8^{\prime \prime} 6 \mathrm{Mg}\end{array}$ & $\begin{array}{c}1 / 2^{\prime \prime} \mathrm{HCR}, 1 / 2^{\prime \prime} \\
8 \mathrm{M} 10,1 / 4^{\prime \prime} \\
4 \mathrm{M} 8,3 / 8^{\prime \prime} 6 \mathrm{M} \theta\end{array}$ & 18.000 & 120 & $\begin{array}{l}\text { Produt }=\text { Produçajo/tempo } \\
\text { Produt }=18.000 / 120=150,00\end{array}$ \\
\hline
\end{tabular}

Fonte: Elaborado pelo autor (2015)

No mix de produtos fabricados na situação B, o tempo disponível é mais afetado por perdas improdutivas como setup, trocas de ferramentas, ajustes de dispositivo e testes de conformidade, do que na situação A.
Deste modo, para que haja confiabilidade no cálculo da produtividade, foram descontadas as perdas improdutivas (Tabela 5) de cada situação, como visto na Figura 10.

Figura 10 - Cálculo da produtividade descontando as perdas improdutivas

\begin{tabular}{|c|c|c|c|c|c|}
\hline \multicolumn{6}{|c|}{ Cálculo da Produtividade } \\
\hline Situação & Mx Possivel & Mix do Periodo & Produção (unidades) & Tempo disponivel (h) & Produtividade (uni/h) \\
\hline A & \begin{tabular}{|c}
$1 / 2^{\prime \prime}$ HCR, $1 / 2^{\prime \prime}$ \\
$8 \mathrm{M10}, 1 / 4^{\prime \prime} 4 M 8$, \\
$3 / 8^{\prime \prime} 6 \mathrm{Mg}$
\end{tabular} & $1 / 2^{\prime \prime} H C R$ & 20.000 & 114 & $\begin{array}{l}\text { Produt }=\text { Produção/tempo } \\
\text { Produt }=20.000 / 114=175,44\end{array}$ \\
\hline B & $\begin{array}{c}1 / 2^{\prime \prime} \text { HCR, } 1 / 2^{\prime \prime} \\
8 \mathrm{M} 10,1 / 4^{\prime \prime} 4 \mathrm{MB}, \\
3 / 8^{\prime \prime} 6 \mathrm{Mg}\end{array}$ & $\begin{array}{c}1 / 2^{\prime \prime} \mathrm{HCR}, 1 / 2^{\prime \prime} \\
8 \mathrm{M} 10,1 / 4^{\prime \prime} \\
4 M 8,3 / 8^{\prime \prime} 6 \mathrm{MO}\end{array}$ & 18.000 & 102 & $\begin{array}{l}\text { Produt }=\text { Produção/tempo } \\
\text { Produt }=18.000 / 102=176,47\end{array}$ \\
\hline
\end{tabular}

Fonte: Elaborado pelo autor (2015)

Após o abatimento, percebeu-se que houve um aumento significativo da produtividade em ambas as situações e que o tempo disponível da situação $B$ mesmo inferior a situação $A$, devido ao grande mix de produtos, a produtividade apresentou-se superior.

\subsubsection{EFICIÊNCIA OPERACIONAL}

O cálculo da eficiência operacional (Figura 11) de cada processo deve ser analisado considerando a decorrência da variação do mix fabricado e os tempos de processamento (velocidade linear) distintos que cada produto exige.

Figura 11 - Cálculo da eficiência operacional

\begin{tabular}{|c|c|c|c|c|c|}
\hline \multicolumn{6}{|c|}{ Cálculo da Eficiência Operacional } \\
\hline \multicolumn{2}{|c|}{ Capacidade } & \multicolumn{2}{|c|}{ Produção } & \multicolumn{2}{|c|}{ Produtividade } \\
\hline $\begin{array}{c}\text { Ex.: Tubo de } 1 / 2^{\prime \prime} \\
\text { HCR na TR-60 }\end{array}$ & Disponibilidade: $24 \mathrm{~h}$ & $\begin{array}{c}\text { Ex.: Tubo de } 1 / 2^{\prime \prime} \\
\text { HCR na TR- } 60\end{array}$ & Disponibilidade: $24 \mathrm{~h}$ & $\begin{array}{c}\text { Ex.: Tubo de } 1 / 2^{\prime \prime} \\
\text { HCR na TR-60 }\end{array}$ & Disponibilidade: $24 \mathrm{~h}$ \\
\hline \multicolumn{2}{|c|}{$\begin{array}{l}\text { Cap }=\text { vel. linear } * \text { disponib. } \\
\text { Cap }=612 \mathrm{~m} / \mathrm{h} * 24 \mathrm{~h}=14.688 \mathrm{~m}\end{array}$} & \multicolumn{2}{|c|}{$\begin{array}{l}\text { Prod }=\text { vel. linear } * \text { (disponib. }- \text { setup }) \\
\text { Prod }=612 \mathrm{~m} / \mathrm{h}^{*}(24 \mathrm{~h}-6 \mathrm{~h})=11.016 \mathrm{~m}\end{array}$} & \multicolumn{2}{|c|}{$\begin{array}{c}\text { Produt }=(\operatorname{Prod} / \mathrm{Cap})^{*} 100 \\
\text { Produt }=(11.016 \mathrm{~m} / 14.688 \mathrm{~m}))^{*} 100=759\end{array}$} \\
\hline
\end{tabular}

Fonte: Elaborado pelo autor (2015) 
O cálculo demonstra que o desempenho do equipamento em análise foi influenciado diretamente pelo tempo necessário de uso, ou seja, o desconto das perdas produtivas está atrelado ao índice de produtividade, que neste caso, apresenta-se em $75 \%$.

\section{ANÁLISE DO CENÁRIO E RESULTADOS}

Conforme ilustra Gráfico 5, percebe-se que no início da pesquisa (janeiro a maio de 2015), quando foi feito o levantamento e análise dos dados para compreender o real motivo da baixa produtividade das extrusoras, a avaliação realizada demonstra uma variação dos índices no intervalo de $72 \%$ a $77 \%$, considerado como não satisfatório para as metas estipuladas.

Gráfico 5 - Controle da produtividade de janeiro a outubro

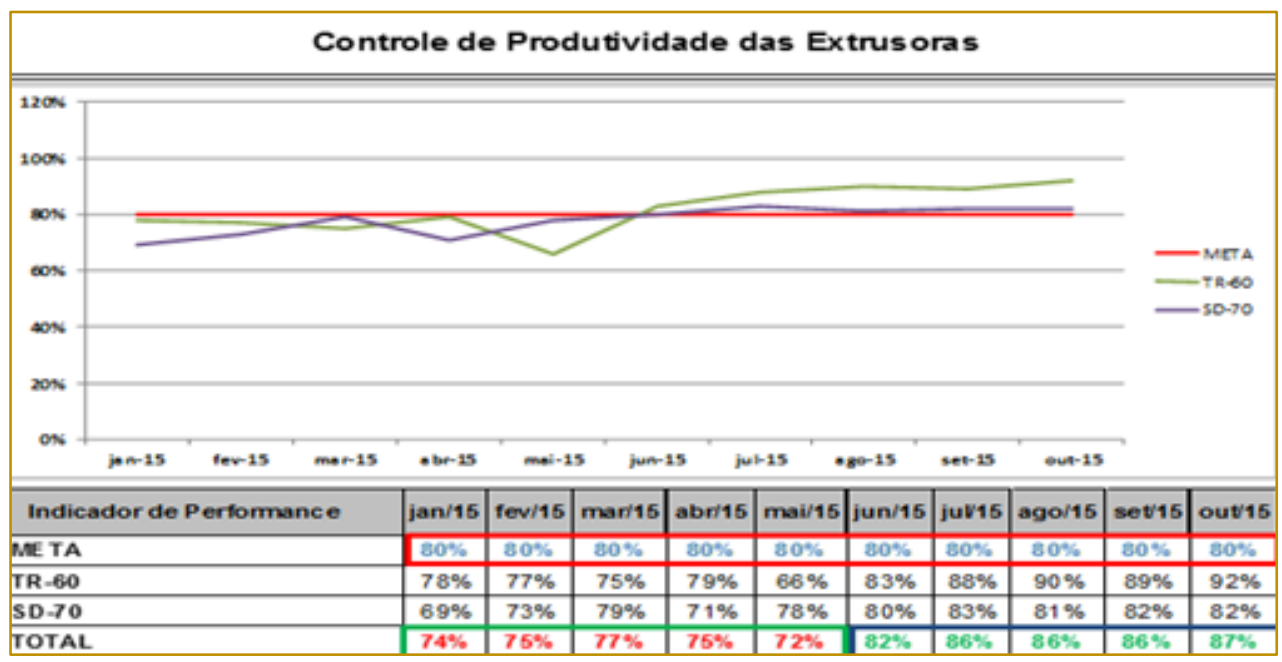

Fonte: Elaborado pelo autor (2015)

No entanto, com o verdadeiro entendimento do problema e com os métodos desenvolvidos para resolvê-lo, a partir do mês de junho de 2015, os índices passaram a suplantar a meta estabelecida.

\section{CONSIDERAÇÕES FINAIS}

O modelo operacional implantado teve como objetivo principal, o aumento da produtividade das extrusoras em análise, através da aplicação dos conceitos e técnicas da Gestão da Produção em uma empresa do ramo petrolífero.

Com a coleta de dados foi possível realizar o levantamento para determinação e monitoramento de tempos padrão, o balanceamento do tempo das operações e a divisão das etapas de montagem.

A etapa de identificação e análise do problema, evidenciou a grande influência do histórico dos dados utilizado pelo setor de Planejamento, Programação e Controle da Produção (PPCP) para realização do cálculo da programação de fabricação dos produtos e monitoramento da gestão do indicador de produtividade do equipamento.

Desta maneira, deve-se levar em consideração toda e qualquer perda por tempos improdutivos (setups, ajustes, qualidade, manutenção) na produção. Deste modo, a aferição dos tempos disponíveis e a monitoração da eficiência operacional do equipamento forneceram uma análise mais adequada e confiável do comportamento e desempenho de cada processo.

Com aplicação do indicador de desempenho (produtividade), houve a possibilidade de uma avaliação mais legitima do cenário e desempenho produtivo das extrusoras. Esta adoção culminou na identificação de oportunidades de melhorias contínuas.

A Engenharia de Processos da empresa passou a oferecer um suporte maior no monitoramento das medições, foram realizados treinamentos com os colaboradores para adoção das novas rotinas de trabalho padronizado, atualização das 
instruções de trabalho e implantação de um quadro de gestão à vista, o que proporcionou índices, que no início do estudo eram baixos e inconstantes, mais expressivos e constantes.

Portanto, o desafio da empresa foi garantir que os envolvidos no desenvolvimento dos

\section{REFERÊNCIAS}

[1] Carvalho, Francianne Santos Gonzaga de. Extrusão a quente de tubos: análise experimental da distribuição de tensões residuais na parede do tubo. São João Del Rei, 2013.

[2] Chitkara, N.R.; Aleem, A. Extrusion of AxiSymmetric Tubes From Hollow Solid Circular Billets: a Generalized Slab Method of Analysis and Some Experiments. International Journal of Mechanical Sciences, v. 43, n.7, p.1661-1684. 2001.

[3] Costa, Edmilson Ferreira da. Diretrizes para elaboração de um manual para planejamento e controle da produção de empresas de pequeno e médio porte. 2010. Trabalho de conclusão de curso (Graduação em Engenharia de Produção) Universidade Federal de Juiz de Fora, Juiz de Fora. Disponível em: <www.ufjf.br/ep/files/2011/02/Modelo_Qualificacao _TCC-edmilson1pdf>. Acesso em: 20 set. 2015.

[4] Dias, S. L. V.; Caulliraux, H. M.; Antunes, J. A. V.; Lacerda, D. P. Alinhamento entre sistemas de produção, custo e indicadores de desempenho: um estudo de caso. Revista Produção, v. 7, n. 2, 2007.

[5] Gil, A. C. Como elaborar projetos de pesquisa. 4 ed. São Paulo: Atlas, 2002.

[6] Hronec S. M. Sinais vitais. São Paulo: Makron Books, 2001.

[7] Lopes, Alceu de Oliveira; Siedenberg, Dieter; Pasqualini, Fernanda. Gestão da Produção, 2010.

[8] Martins, Petrônio G.; Laugeni, Fernando P. Administração da produção. São Paulo: Saraiva, 2001. processos fabril entendam a importância do monitoramento constante de todas as atividades inerentes aos procedimentos de fabricação, como as perdas por tempos improdutivos e a conservação da alta eficiência operacional, para manutenção da produtividade nos patamares desejados, encontrados nesta pesquisa.

[9] Moreira, D. A. Administração da produção e operações. São Paulo: Pioneira Thompson Learning, 2008

[10] Nortegubisian Consultoria Empresarial e Treinamento (Brasil, São Paulo, Campinas). Medindo a produtividade para processos industriais. 2015. Disponível em: $<$ http://www.nortegubisian.com.br/component/cont ent/article/10-noticias/256-produtividade>. Acesso em: 10 set. 2015.

[11] Porter, Michael E. Estratégia competitiva: técnicas para análise de indústrias e da concorrência. 2. ed. Rio de Janeiro: Campus, 2005.

[12] Rechulski, Denise Kaufman. Sistema de indicadores de produtividade e qualidade para uma empresa de distribuição de GLP. 2004.

[13] Santos, Michelle Raimundo dos. Planejamento, Programação e Controle da Produção (PPCP). São Paulo: Sebrae, 2014. Disponível em: <http://pt.slideshare.net/michellesantos908/palestra -planejamento-programao-e-controle-da-produo>. Acesso em: 13 out. 2015.

[14] Sebrae Nacional. O que são indicadores. $2015 . \quad$ Disponível em: <http://www.sebrae.com.br/sites/PortalSebrae/artig os/MPE:- indicadores-para-controle-egerenciamento-da-ind\%C3\%BAstria>. Acesso em: 30 abr. 2015

[15] Slack, N. et al. Administração da produção. São Paulo: Atlas, 2008.

[16] Souza, Marcela Carvalho M. de. Aplicação do indicador OEE (Overall Equipment Effectiveness) em uma indústria fornecedora de cabos umbilicais. Salvador: Universidade Salvador (Unifacs), 2014. 


\section{Bapítulo 6}

\section{A UTILIZAÇ̃̃o DE Simulaç̃̃o NA AVALIAC̄̃O DE RECEBIMENTO E ATENDIMENTO EM UM ARMAZÉM GERAL}

\section{Germano Augusto Metzner de Andrade}

\section{Ghislaine Lury Testoni}

\section{Christiane Wenck Nogueira Fernandes \\ Elyelton Cesar de Souza Lima \\ Silvia Lopes de Sena Taglialenha}

Resumo: Devido ao desenvolvimento constante no setor industrial e aos crescentes problemas logísticos causados pela competitividade de mercado, a utilização de análises computacionais dentro das organizações acaba atraindo olhares de pequenos e grandes empresários devido à redução dos custos, fidelidade dos valores durante análises e maior eficiência na produção. Através de análises estocásticas e do software de simulação ARENA, visa-se analisar três casos de um problema de maximização de atendimento em um armazém geral retroportuário da empresa. Através das análises obtidas ficou claro que tendo uma modificação pequena na taxa de atendimento entre os casos estipulados, houve uma redução no número de clientes na fila de sete clientes para aproximadamente zero eliminando a fila e tempo de espera de 24 minutos para 2 minutos. 


\section{INTRODUÇÃO}

Sabe-se hoje que as organizações evoluíram suas proporções físicas e operacionais de maneira nunca antes vista. Se séculos atrás o desenvolvimento industrial era limitado a pequenos polos industriais, atualmente a palavra intercontinentalidade nunca esteve mais presente. Mas, assim como o avanço da indústria cresceu progressivamente, o processo de gestão e administração ocorreu da mesma maneira. Por esse motivo a necessidade de engenheiros com embasamentos teóricos, vivência prática, e conhecimento de diversos sistemas e modelagens, tornou-se fundamental para gerir os diversos núcleos presentes nas grandes empresas.

Esses engenheiros constantemente se deparam com situações onde devem ser feitas tomadas de decisões que podem ser cruciais para o desenvolvimento da empresa. Tais decisões podem ser simples, sem que haja necessidade de um estudo ou elaboração de inúmeras hipóteses, porém outros casos podem se tratar de problemas complexos onde a utilização de modelos matemáticos e tecnologia se torna indispensável. Neste contexto é que surgem as análises de Processos Estocásticos (P.E.).

Segundo Hillier e Lieberman (2013), P.E. é uma coleção de variáveis aleatórias que, em geral, são utilizadas para estudar a evolução de fenômenos (ou sistemas) que são observados ao longo do tempo. Assim, ao invés de se descrever o sistema através de equações determinísticas, que dado uma condição inicial, conhecemos toda a evolução do sistema e suas várias consequências, utilizar-se-á de processos estocásticos, para o qual, dada uma condição inicial, ainda tem-se diversas trajetórias possíveis para a evolução do sistema. . É através dessa ideia que este relatório tem como objetivo apresentar uma introdução e usabilidade processo estocástico em nosso cotidiano.

Para Taha (2008) a simulação é o segundo melhor procedimento depois da observação de um sistema real pois permite acompanhar o passo a passo do movimento dos clientes no sistema, medindo o seu desempenho.

A simulação permite ao analista realizar estudos sobre os correspondentes recursos do sistema, sem que o sistema sofra qualquer interferência, além de possibilitar o estudo e experimentação de complexas interações internas e permiti verificar como algumas variações no meio ambiente podem interferir no sistema. Serve como teste para se traçar novas regras para operação, antes de experimentá-lo no sistema real. Sendo uma importante ferramenta para tomada de decisão e planejamento de uma empresa (ANDRADE, 2009).

Os objetivos de uma organização correspondem aos resultados que a organização persegue, e centram-se nos precursores de desempenho que possibilitem a verificação dos resultados organizacionais, como, por exemplo, a participação no mercado, satisfação do cliente e ganhos com os investimentos (MAXIMIANO, 2008).

Além desta introdução, este trabalho conta com um breve embasamento teórico do assunto, seguido da explicação a respeito do estudo feito e análise de resultado após análise.

\section{PROCESSOS ESTOCÁSTICOS}

Constantemente, consideram-se situações em que devem ser feitas observações quanto a um período de tempo, situações essas influenciadas por efeitos não determinísticos, não só em um único momento, mas em todo um intervalo de tempo ou sequência de tempos em que se está a considerar. Essa situação é denominada um Processo Estocástico.

De maneira geral, processo estocástico é um evento que varia em algum ponto de forma aleatória à medida que o tempo passa. A imprevisibilidade, nesse caso, acarreta em que valores de entrada idênticos geram valores de saída e ou atendimentos diferentes.

Assim, a experiência aleatória determina o comportamento de algum sistema para uma sequência ou intervalo de tempo inteiro. Isto é, o resultado da experiência aleatória é uma sequência ou série de valores, uma função, e não apenas um único número (CLARKE; DISNEY, 1979).

A fila é caracterizada por um processo variável de chegadas de pessoas a uma unidade de serviço formada por uma ou mais unidades de atendimento. Segundo Fogliatti e Mattos (2007), um sistema com fila é qualquer processo aonde usuários oriundos de uma determinada população chegam para receber um serviço pelo qual esperam, se for 
necessário, saindo do sistema assim que o serviço é completado.

De um modo geral, uma fila pode ser definida como uma linha de espera formada por entidades que demandam um determinado serviço em uma estação que realize este serviço. (MIRSHAWKA, 1981).

Segundo Andrade (2009), a presença de filas em um serviço é um dos principais sintomas que indicam que o funcionamento de um processo está deficiente. As filas existem devido à procura por um determinado serviço ser maior do que a capacidade de atendimento desse sistema, isto é, o sistema não está conseguindo suprir toda demanda por seus serviços, pelo menos, durante um determinado espaço de tempo.

Figura 1- Exemplo de modelo estocástico na flutuação de valores no mercado de ações

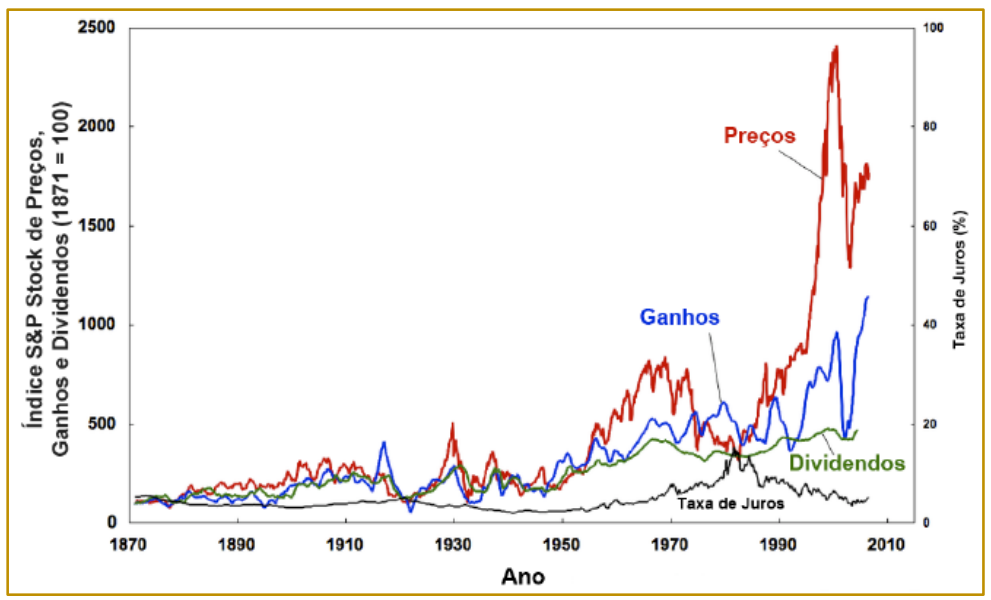

Fonte: https://pt.wikipedia.org/wiki/Processo_estoc\%C3\%A1stico

\section{CONTEXTUALIZAÇÃO}

A gestão de operação dentro dos armazéns é realizada por um setor que acompanha diariamente o registro de novas demandas, realiza a programação de estufagem, recebe as mercadorias no sistema Warehouse Management System - WMS, como também controla o estoque de mercadoria depositada nos armazéns, analisa e organiza as descargas agendadas pelo setor comercial da empresa. As operações realizadas nos armazéns são as seguintes:

- Desova: retirada do produto dentro dos contêineres, esta operação geralmente é associada ao processo de importação;

- Estufagem: inserção dos produtos definidos pelos clientes dentro do contêiner, operação geralmente associada ao processo de exportação;

- Carregamento: operação de embarque de carga em algum caminhão, operação associada a processos de importação;

- Descarga: operação de desembarque de carga de algum caminhão que realizou o transporte, geralmente associado ao processo de exportação.
Porém cada processo deste não é um evento isolado, depende de outras variáveis para executar corretamente. Neste presente estudo serão consideradas somente operações que envolvem o processo de exportação. Assim levam-se em consideração as operações que envolvem descarga e estufagem realizadas nos processos operacionais de exportação.

\section{PROBLEMÁTICA}

O processo abordado para elaboração de um modelo e posteriormente sua simulação, foi definido o de exportação dentro de um armazém geral retroportuário. Este é constituído pela descarga no armazém e posteriormente a estufagem da carga no contêiner para o envio do mesmo ao terminal portuário. Este tipo de operação é executado durante dois turnos diários, de segunda a sábado, sendo constituído por duas equipes a cada turno.

Assim, como mostra a figura 2, é definido o modelo de simulação adotado no presente capítulo: 
Figura 2 - Modelo de simulação adotado

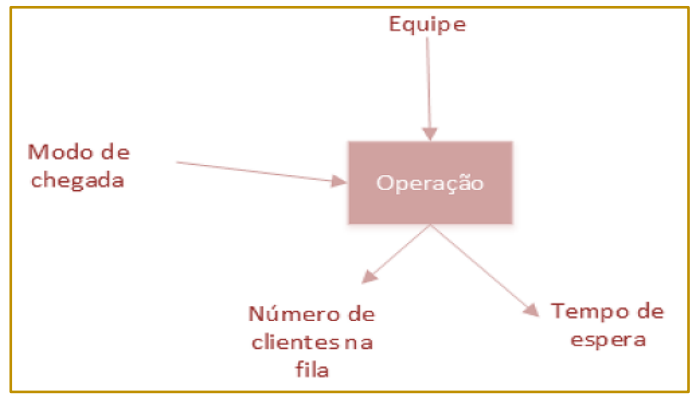

Fonte: Autores

A equipe disponível para realizar esta operação é definida como recurso desta operação, a informação de entrada no modelo é o modo de chegada de cada cliente que realizará a descarga, já a informação de saída durante a simulação do modelo será o número de clientes na fila e o tempo de espera na fila.

Com a utilização do software ARENA foi elaborado o modelo e realizada a simulação. Assim foram definidos três cenários de simulação:

- Cenário 1: Implementar no Arena os dados e ajustar o processos para que os valores fiquem condizentes com o processo real;

- Cenário 2: Implementar no Arena um aumento de $11 \%$ nos dados de chegada representando um possível contrato com um novo cliente e verificando seus valores de saída;

- Cenário 3: Modelar um possível aumento no tamanho da equipe para proporcionar um melhor atendimento no "Caso 2".
Estes cenários foram propostos para realizar uma previsão de como seria o comportamento do sistema simulado, no caso o processo de exportação de um armazém, com eventualmente picos de demanda e aumento de uma equipe. Antes de obter os resultados, são necessárias algumas análises como taxa de atendimento.

\subsection{TAXA DE ATENDIMENTO}

A taxa de chegada dentro do software foi simulada através do subprograma "Input Analyzer", sendo que os valores retirados são provenientes de tempos reais registrados por um operador logístico. Por questão de preservação dos clientes os valores não serão mostrados neste trabalho. Os valores colocados dentro do programa resultaram nos dados apresentados no gráfico 1 e na Figura 3:

Gráfico 1 - Valores de tempo entre chegadas e respectiva curva ajustada (linha azul escura)

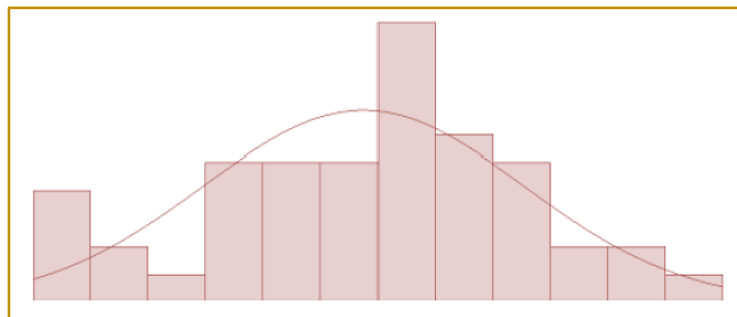

Fonte: Autores 
Figura 3 - Dados da curva ajustada pelo software Arena

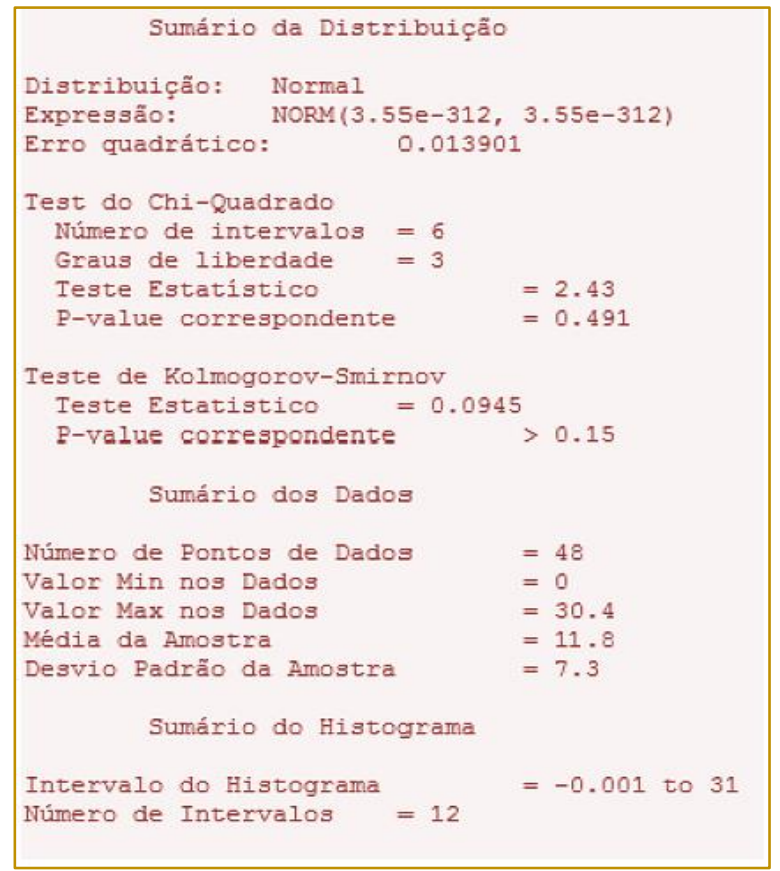

Fonte: Autores

Mediante aos dados apresentados pelo software Arena pode-se observar que a curva ajustada (linha azul) mais idêntica ao problema inicial foi uma "Normal" com valores de média 11,8 e desvio padrão de 7,3. Mesmo sendo possível melhorar ainda mais o ajuste através de outros programas não haveria necessidade para tanto, pois a partir do teste de Kolmogorov-Smirnov e do ChiQuadrado observamos uma alta taxa de correspondência, $\quad 15 \% \quad$ e $\quad 49,1 \%$ respectivamente, comparados aos 10\% que normalmente se usa para reconhecer um padrão aceitável.

Para o Caso 2 e 3 onde não se conhece a distribuição entre chegadas de diferentes veículos, foi estimado um aumento previsto de $11 \%$ no aumento do número de chegadas, neste caso o valor entre as chegadas sofreu uma redução de mesma porcentagem para que o programa pudesse realizar uma média aproximada.

Figura 4 - Expressão adicionada ao software para realizar a simulação entre chegadas dos veículos no Caso 1

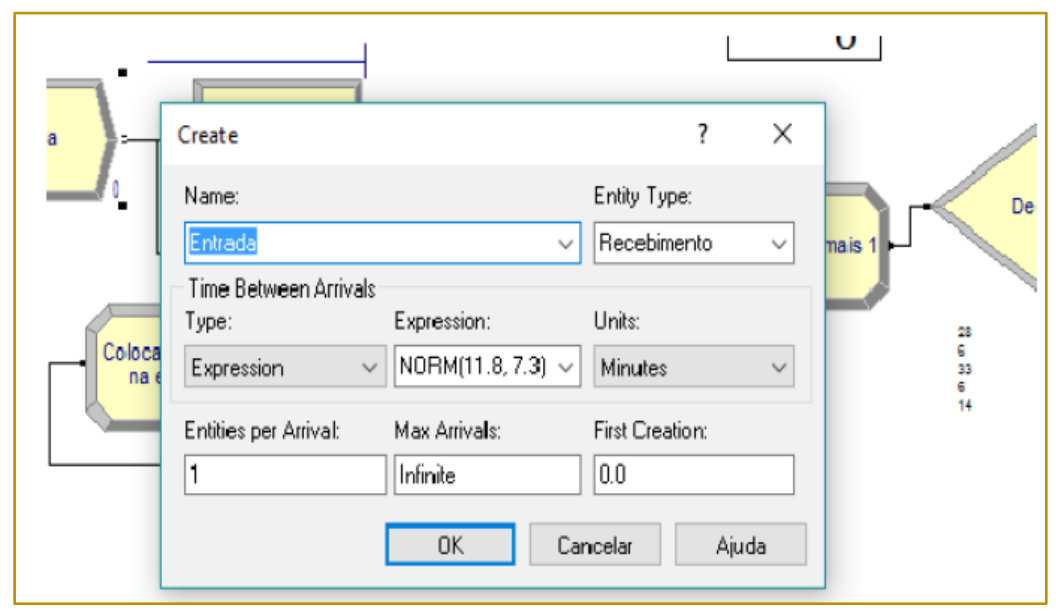

Fonte: Autores 


\subsection{MONTAGEM DO SISTEMA}

Para que o modelo digital fosse compatível com o sistema real algumas condições precisavam ser atendidas, as principais são:

- Fator de atendimento por horário de chegada FIFO (First In First Out);

- Limite de 2 equipes por atendimento (Caso 1 e 2) ou 3 equipes (Caso 3);

- Classificação de tipo de atendimento.

No modelo real o atendimento aos clientes é feitos através do sistema de tickets, os quais são entregues para cada um no momento de sua chegada. No entanto o software Arena funciona com ações definidas por tempos determinados ou atributos. No caso do atendimento digital foi escolhida a abordagem de atributos, semelhante a um contador, na qual a cada 5 minutos é verificado se há ou não vaga disponível para atendimento, em caso de resposta negativa o primeiro cliente da fila recebe um atributo na qual the dá uma prioridade contra os demais, no presente caso esse atributo é chamado "Pressa" e foi implementado através de um bloco Assign.

Figura 5 - Ciclo de execução para determinar se o cliente pode ou não ser atendido naquele momento

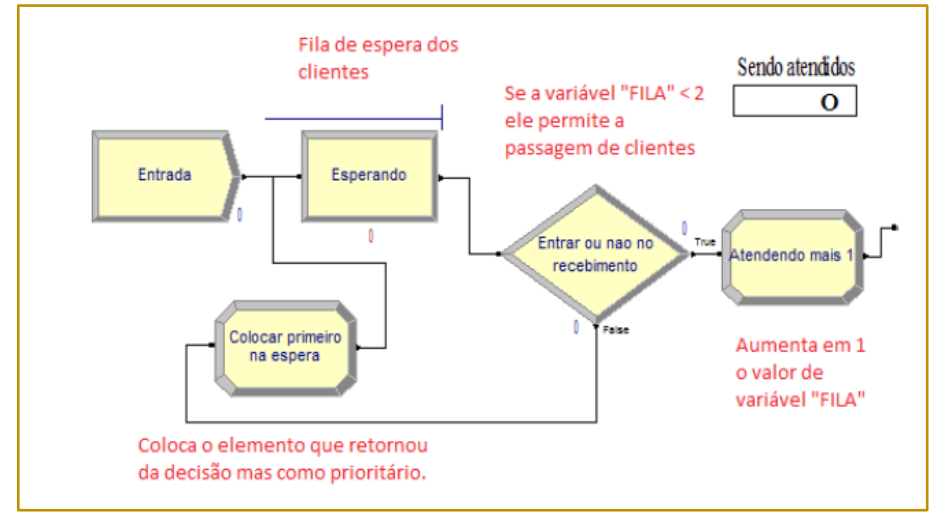

Fonte: Autores

Para criar um limite se pode ou não permitir a passagem de clientes para atendimento. Foi estipulado dois blocos também Assign, mas que aumentavam ou diminuíam a variável "Fila". Caso a variável fosse menor que 2 era permitida a passagem, senão o veículo era forçado a voltar para a fila, porém com prioridade. Estes blocos são denominados "Atendendo mais 1" e "Atendendo menos 1" e estão representados nas figuras 6 e 7:

Figura 6 - Representação da condição de entrada para atendimento

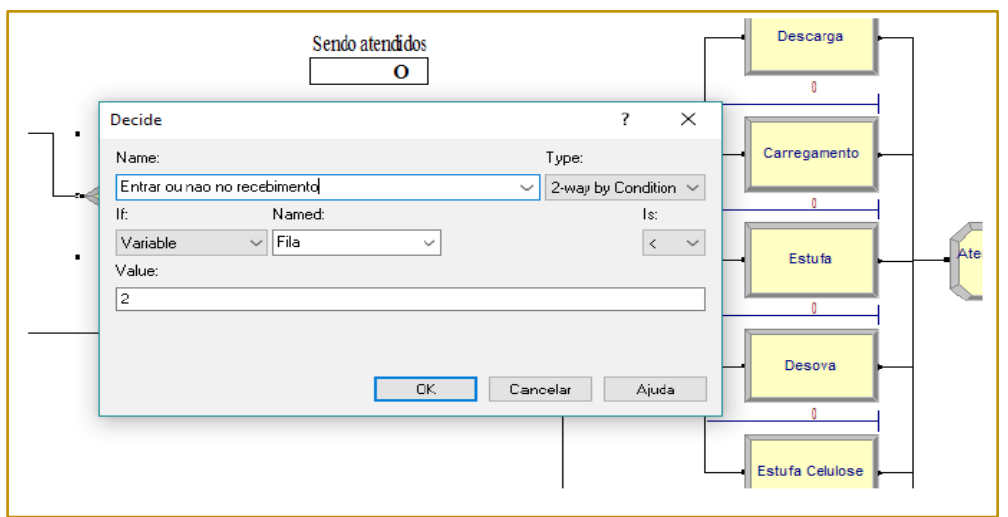

Fonte: Autores 
Figura 7 - Representação das possibilidades de atendimento e execução do bloco Assign que diminui o número de clientes sendo atendidos

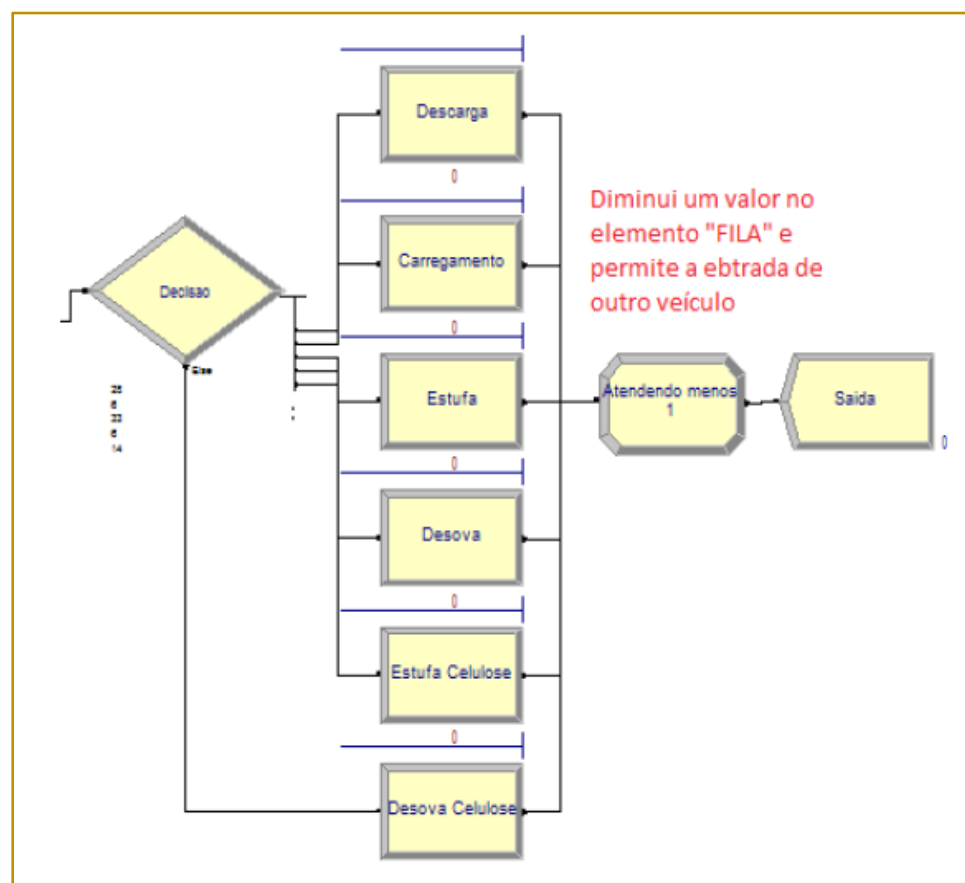

Fonte: Autores

Para criar as condições dos tipos de atendimento foi criado um bloco de decisão com as respectivas porcentagens de atendimento, estes valores de porcentagem foram tirados com base no somatório de todos os atendimentos do mês de agosto de 2016, e o tempo, em média, de cada um dos atendimentos. Segue a figura $8 \mathrm{com}$ os respectivos valores:

Figura 8 - Valores de tempo por tipo de atendimento

\begin{tabular}{|c|c|c}
\hline \hline Tipo de atendimento & Porcentagem de cada tipo de atendimento & Tempo médio de processamento \\
\hline \hline Descarga & $28 \%$ & $\operatorname{Triangular}(25,30,35)$ \\
\hline Carregamento & $6 \%$ & $\operatorname{Triangular}(25,30,35)$ \\
\hline Estufa & $33 \%$ & $\operatorname{Triangular}(25,30,35)$ \\
\hline Desova & $6 \%$ & $\operatorname{Triangular}(25,30,35)$ \\
\hline Estufa Celulose & $14 \%$ & $\operatorname{Triangular}(22,15,18)$ \\
\hline Desova Celulose & $13 \%$ & $\operatorname{Triangular}(22,15,18)$ \\
\hline
\end{tabular}

Fonte: Autores

\section{ANÁLISE DE RESULTADOS E} CONCLUSÃO

Após a elaboração do modelo e executada a simulação, nos relatórios gerados pelo software é possível analisar o tempo de espera na fila e o número de clientes esperando na mesma. Foram executados os três cenários propostos, e obtiveram-se os seguintes resultados apresentados na figura 9: 
Figura 9 - Tempo de espera na fila e número de clientes esperando

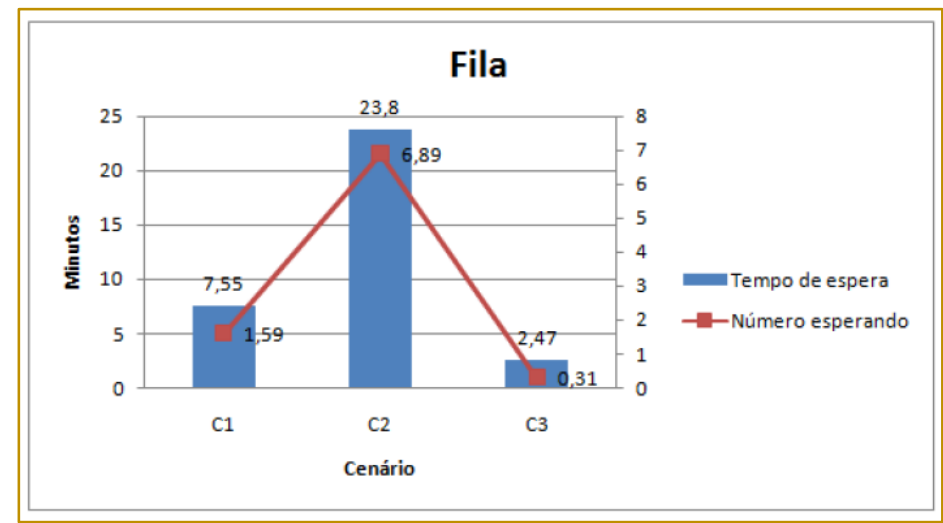

Fonte: Autores

No cenário um que é a atual operação realizada obtém-se aproximadamente dois clientes na fila, esperando em média oito minutos para serem atendidos. Enquanto no cenário dois que há um pico nas atividades, tem-se como resultado sete clientes na fila, esperando vinte quatro minutos para serem atendidos. E no cenário três, com a adição de mais uma equipe, o tempo de espera diminui para dois minutos e aproximadamente zero clientes em fila, aguardando atendimento.

Analisando o cenário dois, quando há o incremento de $11 \%$ nas operações, o tempo de espera na fila tem um aumento de 19 minutos, e o número de clientes esperando na fila tem um aumento de cinco clientes. Neste cenário nota-se, que com tempo estimado de atendimento, um incremento não tão expressivo já afeta a dinâmica deste processo

\section{REFERÊNCIAS}

[1] Andrade, Eduardo Leopoldino de. Introdução à Pesquisa Operacional. 4. ed. Rio de Janeiro: LTC, 2009

[2] Clarke, A. Bruce.; Disney, L. Ralph.: Probabilidade e Processos Estocásticos. Livros Técnicos e Científicos. Editora S.A., Rio de Janeiro, 1979.

[3] Fogliatti, M. \& Mattos, N. Teoria de filas. Ed. Interciência. p.7, 2007.

[4] Hillier, Frederick S.; Lieberman, Gerald J.. Introdução á Pesquisa Operacional. 9. ed. Porto Alegre: AMGH, 2013. simulado com os recursos disponíveis. Com isso foi adotada a estratégia de adicionar mais uma equipe para analisar 0 comportamento da fila no sistema com este incremento de $11 \%$, tendo uma redução no número de clientes na fila de sete clientes para aproximadamente zero, eliminando a fila e tempo de espera de 24 minutos para 2 minutos.

Então com este tipo de análise percebe-se como uma boa estimativa de demanda e oferta de serviço pode afetar ao modo de atendimento e como é realizado o processo. Nesta simulação executada, percebe-se que com o incremento de operações se afeta o resultado negativamente, aumentando 0 tempo de espera e clientes na fila, ao contrário do que, de um modo geral, se deseja para um serviço de atendimento.

[5] Maximiano, Antonio Cesar Amaru. Teoria geral da administração. 1. ed. São Paulo: Atlas, 2008.

[6] Mirshawka, Victor. Aplicações de Pesquisa Operacional, v. 2. São Paulo: Editora Nobel, 1981. Processo estocástico. Wikipédia. Disponível em $<$ https://pt.wikipedia.org/wiki/Processo_estoc\%C3 \%A1stico> Acesso em: 26 nov. 2016.

[8] Taha, Hamdy A.. Pesquisa Operacional. 8. ed. São Paulo: Pearson, 2008. 


\section{Capítulo 7}

\section{GERENCIAMENTO DO ESTOQUE DE UM RESTAURANTE UTILIZANDO O MÉTODO KANBAN COM UMA PLANILHA ELETRÔNICA}

\section{Marcela Cristina de Oliveira Rey}

Gabriela Yukie Tanaka Shibao

Fernando César Cerri

\section{Sara Santos Pereira}

\section{Gabriel Höfig de Castilho}

Resumo: O mercado de restaurantes vem crescendo a taxas surpreendentes nos últimos anose, devido à enorme viabilidade do setor, a concorrência tornou-se grande requisito para a sobrevivência destas empresas, fazendo com que métodos como o gerenciamento de estoque sejam empregados para diminuir o custo de produção e reduzir o preço final do produto, gerando crescimento no número de vendas e aumento significativo do lucro. O objetivo deste trabalho é propor uma forma de gerenciamento de estoque, empregando o método Kanban através de uma planilha eletrônica, sendo objeto de estudo o Bomboniere e Restaurante Castelinho Ltda, localizados na cidade de Lorena,interior do estado de São Paulo. A coleta de dados para a aplicação na planilha ocorreu durante um mês e envolveu 11 produtos. Ao término do estudo, obteve-se uma economia que representou $9,8 \%$ do valor gasto com as reposições desses produtos no período. Sendo assim, os resultados mostram a importância de uma boa gestão de estoque para aumentar a competitividade dos restaurantes no mercado. 


\section{INTRODUÇÃO}

Atualmente, no Brasil, existem cerca de 800 mil restaurantes (NUCLEORA, 2017). O setor alimentício é um dos mais promissores, já que a industrialização, o crescimento demográfico e a urbanização mudam o consumo e o estilo de vida, fazendo com que a sociedade busque maneiras de adequar-se ao ritmo acelerado do dia a dia (ABREU et al. 2001). Sendo assim, as refeições fora de casa deixaram de ser apenas momentos de lazer e tornaram-se hábitos de quase todos os membros de uma família (RIBEIRO, 2012). De acordo com a Associação Brasileira das Indústrias de Alimentação, o segmento de Food Service cresce à taxa de $14,7 \%$ ao ano, três vezes maior que o Produto Interno Bruto (PIB) brasileiro nos últimos cinco anos (PORTAL BRASIL, 2016). Este setor representa $33 \%$ das despesas com alimentos e bebidas, além de ter movimentado cerca de 300 bilhões de reais no final do ano de 2015 (TERZIAN, 2017).

A partir dessa crescente viabilidade do setor alimentício, a concorrência, definida por Kotler e Keller (2006) como "... todas as ofertas e substitutivos rivais, reais e potenciais que um comprador possa considerar", torna-se cada vez mais um motivo para o desenvolvimento das empresas do setor, pois faz com que elas busquem maneiras de oferecer melhor atendimento, menor preço e maior qualidade, a fim de atrair e reter consumidores. Uma das maneiras encontradas para diminuir o custo de produção e, consequentemente, o preço final do produto é um adequado controle de estoque.

Gerenciar estoques é relevante, uma vez que estes absorvem grande parte do orçamento operacional de uma organização e não agregam valor aos produtos, pois quanto menor o nível dos estoques, mais eficiente será o sistema produtivo, reduzindo os tempos, diminuído os custos e melhorando a qualidade (ALMEIDA; LUCENA, 2006). Mesmo com a relevante importância do gerenciamento de estoques, grande parte dos restaurantes brasileiros não possui um controle eficiente, sendo que muitos ainda usam a forma intuitiva para mapear os suprimentos (SANTOS; AZEVEDO; BENTES, 2012).

Diante da realidade, portanto, este artigo propõe um método de gerenciamento de estoque para restaurantes, utilizando o método Kanban, aliado a uma planilha eletrônica.

Para atingir o propósito, foi realizado estudo em um tradicional restaurante à La Carte, localizado na cidade de Lorena, estado de São Paulo. Os proprietários e funcionários alegaram falhas no gerenciamento do estoque, mostrando a necessidade de estudos e de busca por soluções.

\section{FUNDAMENTAÇÃO TEÓRICA}

\subsection{GESTÃO DE ESTOQUE}

O Japão foi o primeiro país a dar importância ao planejamento do estoque da matéria prima ao abordar o sistema just in time. Com o principal intuito de reduzir os desperdícios dos processos, o sistema foi criado pelo fundador da Toyota Motor Company, Kiichiro Toyoda, em supermercados norteamericanos, onde a reposição nas prateleiras ocorria à medida que os produtos eram comprados (FAVONI; GAMBI; CARETA, 2013). Esse sistema, posteriormente, foi implementado pelo engenheiro Taicchi Ohno em uma linha de produção industrial, na Toyota, em que os próprios montadores repunham a matéria prima de acordo com a produção, o que gerou resultados significativos, como a redução do estoque e, consequentemente, a diminuição de desperdícios (AGUIAR; PEINADO, 2007).

Os estoques são tanto matérias primas, utilizadas para abastecer uma linha de produção, como produtos acabados antes da serem vendidos, e sua principal função é atender a demanda (MOREIRA, 2000). Contudo, para administrá-lo, é necessário entender o processo de cada material específico (GIANESI; BIAZZI, 2011).

Gianesi e Biazzi (2011) propõem uma equação básica para calcular a quantidade necessária de suprimentos, que é dada por:

$$
S=D+E f-E i(1)
$$


Em que:

$S$ representa a quantidade de suprimentos;

$D$ representa a demanda prevista;

Ef representa o estoque final desejado;

Ei representa o estoque inicial.

Por meio da equação (1), percebe-se que, para controlar a quantidade de suprimentos, é fundamental conhecer o estoque inicial da produção, estimar a demanda futura de cada item e atender, por meio de ferramentas de controle de estoque, à demanda necessária, minimizando perdas de materiais por excesso de estoque (GIANESI; BIAZZI, 2011).

Conclui-se que, além de monitorar, prever e suprir a demanda de forma constante, a gestão do estoque contribui para o controle do fluxo financeiro da empresa, por meio de cálculos matemáticos e utilização de softwares, possibilitando a diminuição das despesas de compra, manutenção e armazenagem (RODRIGUES; SOARES, 2015).

\subsection{LEAN MANUFACTURING}

O Lean Manufacturing é uma abordagem ampla do sistema Toyota de produção. Traz como proposta alinhar sequência de produtividade, qualidade e desenvolvimento de produtos de forma dinâmica e eficaz (VENANZI; LAPORTA, 2015). Desta forma, segundo Rezende et al. (2016), Lean Manufacturing é utilizado em linhas contínuas de produção com a finalidade de reduzir desperdícios, assegurar maior qualidade dos produtos e reduzir o tempo de entrega ao cliente, produzindo mais com cada vez menos.

Desta forma, o Lean Manufacturing aparece como um sistema que, segundo Dumitrescu e Dumitrache (2011), melhora o fluxo do processo, removendo os resíduos e as operações desnecessárias. Para isso, dispõese de algumas ferramentas, como o VSM (Value Stream Map) e o sistema Kanban (REZENDE et al.,2016).

\subsection{SISTEMA KANBAN}

O termo Kanban, em japonês, significa sinal visual e, de acordo com Knibeg (2009), possui apenas três prescrições, sendo a primeira a necessidade de ressaltar que o fluxo de trabalho a ser analisado é o que, de fato, ocorre dentro da empresa, não o previamente estipulado pela organização. A segunda limita o fluxo do trabalho, determinando o Kanban como um sistema puxado; a terceira é responsável por analisar os problemas encontrados e, dessa forma, propor formas de resolvê-los.

Ademais, Pinto (2008) também assegura que a ênfase deste sistema está no output, ou seja, o fluxo de operações que é comandado pela linha de montagem final. Assim, a linha de montagem recebe o programa de produção e, de acordo com o consumo das peças, alerta os centros de trabalho antecedentes para que eles voltem a fabricar as peças necessárias.

Suas principais vantagens são a maior interação entre os postos de trabalho, devido à grande dependência de todos os centros, melhor serviço para os clientes, uma vez que diminui os prazos de entrega, e a diminuição dos estoques (PINTO, 2008).

\section{METODOLOGIA}

O método de pesquisa escolhido foi o estudo de caso. Segundo Miguel (2007), estudo de caso é um estudo de natureza empírica que tem como objetivo analisar um ou mais objetos (casos) dentro de um contexto real, visando estimular a compreensão para solucionar o problema observado. Esse método é indicado quando se busca descobrir o "como" e "por que" das situações encontradas e quando o controle do investigador sobre os eventos é muito reduzido (YIN,2001).

Ou ainda, como cita Voss et al (2002), esse método de pesquisa é uma técnica de investigação qualitativa, que possui enfoque indutivo para a análise de dados e foco descritivo para a apresentação de resultados.

Trata-se de um estudo de caso único, de natureza exploratória, que buscou coletar e analisar dados da gestão de estoque, propondo a utilização do método Kanban através de uma planilha eletrônica. O estudo foi realizado em um restaurante de porte médio, uma empresa gerida por uma família, que tem como suas principais atividades um restaurante de comida por quilo, serviços à La carte, atuando também como choperia e bomboniere.

Numa primeira fase, pesquisas foram realizadas com os temas: Gestão de Estoque, Lean Manufacturing, Sistema Kanban e 
utilização de planilhas eletrônicas. Os dados utilizados foram extraídos de diversas teses, dissertações e artigos científicos encontrados principalmente dos bancos de dados Web of Science e Scielo, sendo selecionados os documentos mais relevantes.

Numa segunda fase, uma entrevista não estruturada foi realizada com a auxiliar administrativa do restaurante. Desta, foram obtidas informações sobre o funcionamento do estabelecimento, a frequência com que ocorrem os pedidos de reabastecimento, bem como os principais fornecedores e os locais de armazenamento dos produtos. As informações foram organizadas em forma de quadros, de maneira a facilitar o entendimento dos processos do restaurante.

Uma planilha eletrônica disponível na internet, criada pela empresa FM2S Treinamentos e Projetos (VIRGILIO e MURILO, 2016), baseada no método Kanban e com o objetivo de controlar estoques, foi usada como base para a criação de uma planilha para a gestão de estoques do restaurante. Essa planilha criada foi adaptada às necessidades específicas do restaurante, a fim de que os dados coletados fossem usados para aprimorar o processo de compra de mercadoria e gestão de estoques. Foi alimentada com 11 produtos escolhidos pela gerente do estabelecimento, devido ao fato de referirem-se aos de maior consumo.

Estes produtos foram monitorados durante um mês, a fim de se analisar a eficiência do controle de estoques que havia no restaurante, e, em todas as terças-feiras, foram coletadas as quantidades em estoque de cada um deles e cadastrados na planilha.

\section{A PROPOSTA DE UMA FERRAMENTA PARA GESTÃO DE ESTOQUES}

A planilha criada tinha como objetivo auxiliar o monitoramento da quantidade de suprimentos em estoque, e assim possuir maior controle sobre a quantidade de compra de cada mercadoria. Essa planilha é baseada em comandos básicos do Excel. É composta por duas tabelas numa mesma tela: a Tabela 1, denominada "Dados dos produtos em estoque", e a tabela 2, denominada de "Quantidade a ser comprada".

Essas tabelas encontram-se nas figuras 1 e 2 , respectivamente, onde estão descritos o objetivo de cada uma das colunas que as compõem.

Figura 1 - Tabela "Dados dos produtos em estoque"

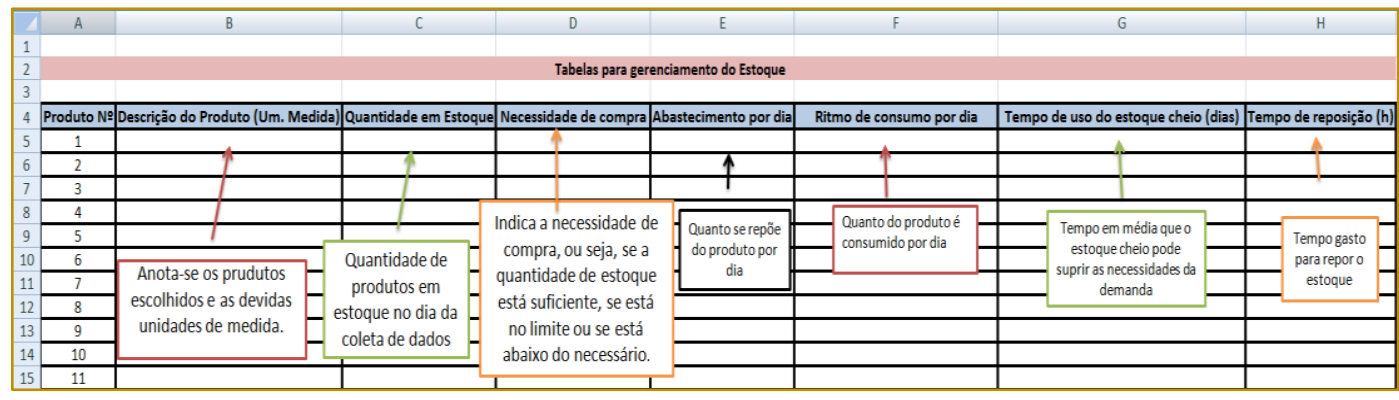

Fonte: Do autor (2017)

Um detalhamento dos campos de cada uma das colunas da tabela "Dados dos produtos em estoque" é feito a seguir:

- "Produto №”, que atribui um código para os produtos utilizados;

- "Descrição do produto/Unidade de Medida"; apresenta uma descrição para cada um dos produtos, bem como a suas unidades de medida;

- "Quantidade em estoque"; contém os valores referentes à quantidade de produtos existentes no estoque no dia da coleta de dados;

- "Necessidade de compra"; mostra com as palavras "sem necessidade", "alerta" e "urgente" a situação da quantidade do produto no estoque, indicando, respectivamente, se ele está em quantidade suficiente, no limite ou se é urgente a reposição da mercadoria; 
- "Abastecimento por dia";quantidade de produtos reposta no estoque quando os fornecedores entregam as mercadorias;

- "Ritmo médio de consumo por dia"; quanto se consome na média do produto por dia;

- "Tempo de uso do Estoque Cheio" indica o tempo médio gasto para consumir toda a quantidade de um determinado produto a partir de seu estoque cheio.

- "Tempo de reposição" mostra o tempo de entrega dos fornecedores para repor o estoque.

A quarta coluna ("Necessidade de Compra") mostra a situação da quantidade de produto no estoque, através dos termos "SEM
NECESSIDADE", "ALERTA" e "URGENTE". Essa classificação é feita de acordo com intervalos que consideram as quantidades de produtos máximas e mínimas.

Os intervalos são classificados da seguinte maneira:

Quantidade $\geq X \rightarrow$ Estoque Suficiente;

$X \geq$ Quantidade $\geq Z \rightarrow$ Estoque em Alerta;

Quantidade $<Z \rightarrow$ Estoque de Segurança (Estoque Mínimo),

onde "Quantidade" representa a quantidade atual em estoque, $X$ é o número máximo de cada produto em estoque e $Z$ o número mínimo:

Figura 2 - Tabela "Quantidade a ser comprada"

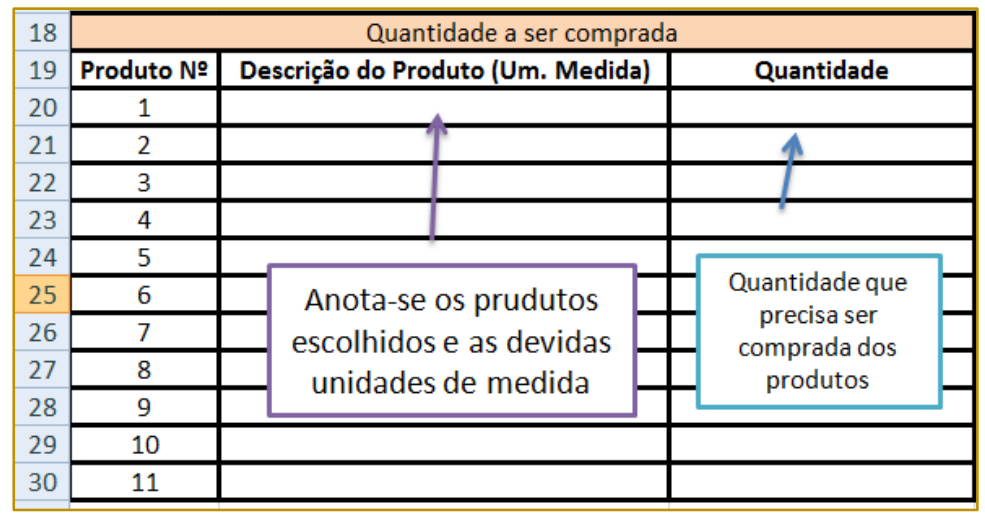

Fonte: Do autor (2017)

A Figura 2 apresenta a tabela "Quantidade a ser comprada", tendo nas colunas o código do produto, sua descrição, e a quantidade que deve ser comprada para reabastecer o estoque, respectivamente.

O cálculo da quantidade que deve ser comprada para reabastecer o estoque é feito com a subtração dos valores da coluna 3 (Quantidade em estoque) da tabela "Dados dos produtos em estoque", das quantidades de estoque cheio (valores fixos e préestabelecidos apresentados na figura 3).
A quantidade de estoque cheio, apesar de não ser apresentada na planilha, foi um dado coletado e utilizado na programação da tabela 2,"Quantidade a ser comprada". Esta programação pode ser generalizada pela equação (2):

Quantidade a ser comprada $=$ Quantidade do estoque cheioQuantidade atual em estoque(2)

Equação de programação da coluna "Quantidade de estoque cheio" da tabela 2 
Figura 3 - Quantidade do estoque cheio

\begin{tabular}{|c|c|}
\hline Produto & $\begin{array}{c}\text { Quantidade } \\
\text { quando estoque } \\
\text { está cheio }\end{array}$ \\
\hline Arroz & $150 \mathrm{kgs}$ \\
\hline Arroz Integral & $8 \mathrm{kgs}$ \\
\hline $\begin{array}{c}\text { Macarrão } \\
\text { Espaguete }\end{array}$ & $9 \mathrm{kgs}$ \\
\hline $\begin{array}{c}\text { Macarrão } \\
\text { Penne }\end{array}$ & $9 \mathrm{kgs}$ \\
\hline $\begin{array}{c}\text { Macarrão } \\
\text { Cabelo de Anjo }\end{array}$ & $9 \mathrm{kgs}$ \\
\hline $\begin{array}{c}\text { Açúcar } \\
\text { Trigo de }\end{array}$ & $40 \mathrm{kgs}$ \\
\hline $\begin{array}{c}\text { Farinha } \\
\text { Chocolate em } \\
\text { Barra }\end{array}$ & $4 \mathrm{kgs}$ \\
\hline $\begin{array}{c}\text { Leite } \\
\text { condensado }\end{array}$ & $57 \mathrm{kgs}$ \\
\hline Creme de Leite & $15 \mathrm{kgs}$ \\
\hline \begin{tabular}{c} 
Manteiga \\
\hline \hline
\end{tabular} & $6 \mathrm{kgs}$ \\
\hline Fonte: Do
\end{tabular}

Fonte: Do autor (2017)

A planilha foi alimentada com os seguintes 11 produtos:

- Arroz branco;

- Arroz integral;

- Macarrão espaguete;

- Macarrão pene;

- Macarrão cabelo de anjo;

- Açúcar;

- Farinha de trigo;

- Chocolate em barra;

- Leite condensado;

- Creme de leite;

- Manteiga

A figura 4 apresenta um exemplo de ambas as tabelas da planilha devidamente preenchidas, numa situação em que o estoque estava completo: 
Figura 4 - Planilha preenchida com o estoque completo

\begin{tabular}{|c|c|c|c|c|c|c|c|}
\hline hasenes: & 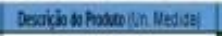 & 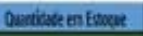 & 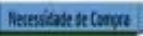 & Maxivettor & 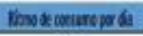 & 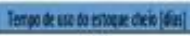 & Terposa kwicioly. \\
\hline 1 & 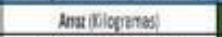 & 非 & Gellextiosor & 75 & 8.1 & 21.6 & 24 \\
\hline 2 & 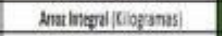 & $\underline{L}$ & Sentermighe & 11 & 10 & 8 & 4 \\
\hline 3 & 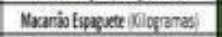 & I & Genlenencade & 06 & 08 & 12 & 24 \\
\hline 4 & Neanib fer KCoranasi & in & Senteesuadr & 86 & 18 & 18 & 2 \\
\hline 5 & 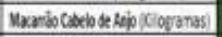 & 2 & Pequictuante & 0.3 & 0.5 & 2) & 2 \\
\hline 6 & 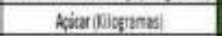 & $\bar{c}$ & Staliecentind & 43 & 5.1 & 8 & 24 \\
\hline 7 & 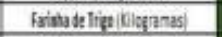 & es & Enlienaside & 57 & 12 & 6 & 24 \\
\hline 8 & 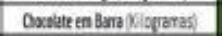 & 6 & 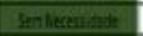 & 06 & 0,5 & 8 & 2 \\
\hline 9 & 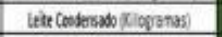 & SI & Sen fortusede & 69 & 9 & 7 & 2 \\
\hline 18 & 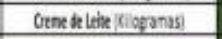 & 亚 & Gethensiad & 21. & 20 & 7 & 24 \\
\hline 11 & Unaria X(cyanas) & $i$ & Genterasaber & 09 & 10 & 6 & 24 \\
\hline \multicolumn{3}{|c|}{ Osuriticte ser congon } & & & & & \\
\hline Aodites & 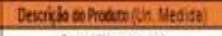 & Oarcins & & & & & \\
\hline 1 & Ame Klibpranas & 0 & & & & & \\
\hline 2 & 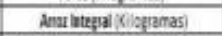 & 0 & & & & & \\
\hline 3 & 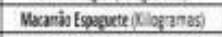 & 8 & & & & & \\
\hline 4 & 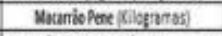 & 0 & & & & & \\
\hline 5 & 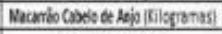 & 0 & & & & & \\
\hline 6 & Avica filistanes: & 8 & & & & & \\
\hline 7 & 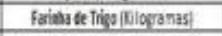 & 8 & & & & & \\
\hline 8 & 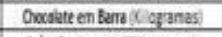 & $\theta$ & & & & & \\
\hline 9 & Léte Costeos & 0 & & & & & \\
\hline 10 & 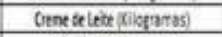 & 8 & & & & & \\
\hline \pm & Memaipilioganes & 0 & & & & & \\
\hline
\end{tabular}

Fonte: Do autor (2017)

A figura 5 apresenta uma situação com dados reais, em que se evidencia na tabela "Dados dos produtos em estoque" a necessidade de compra de alguns produtos.

Figura 5 - Primeira tabela preenchida após um tempo de uso

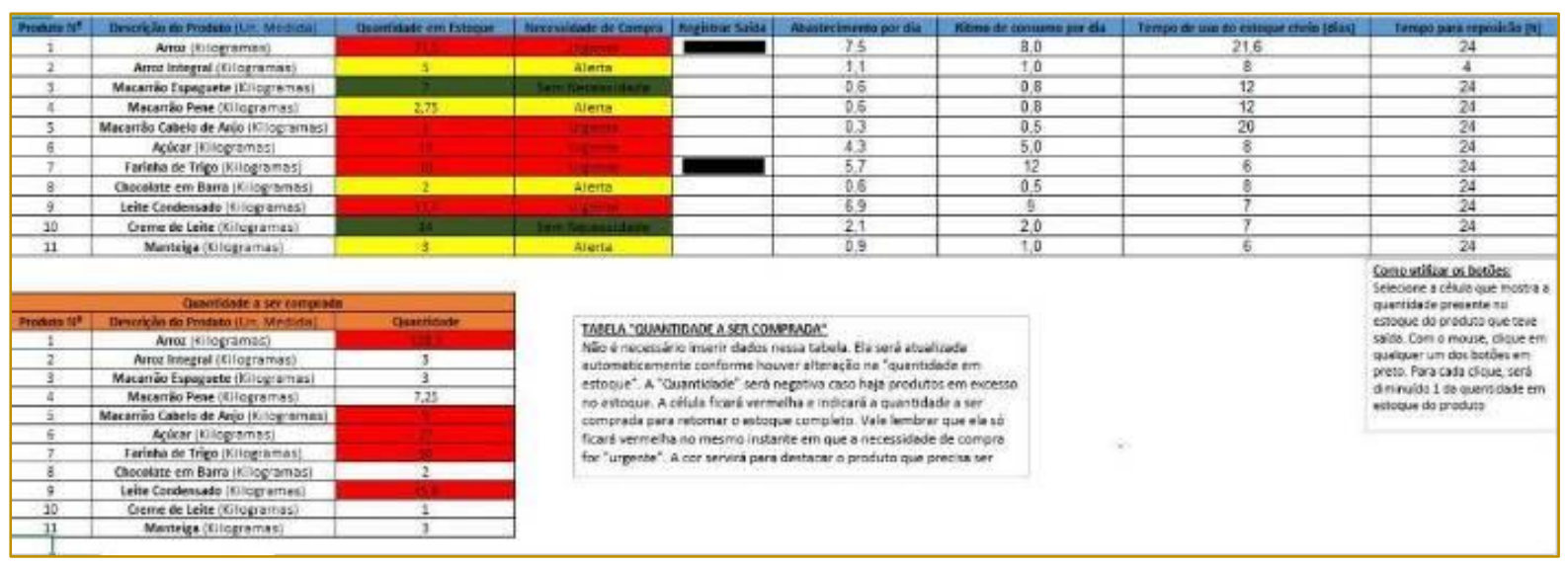

Fonte: Do autor (2017)

A primeira tabela ("Dados dos produtos em estoque") foi programada para que as cores mudem à medida que diminui a quantidade de estoque. Essa programação foi dada por comandos aplicados nas colunas "Quantidade em estoque" e "Necessidade de compra".

Na terceira coluna ("Quantidade em estoque") da tabela "Dados dos produtos em estoque" foi utilizado o comando de "Formatação Condicional" - que tem como objetivo realçar informações importantes em uma planilha, bem como criar novas regras para células selecionadas em função do valor ou dos resultados que elas possuem. As cores escolhidas na "Formatação Condicional" são: (i) - Verde, para enfatizar quantidades acima ou igual ao estoque suficiente; (ii) - Amarela, para estoque em alerta (quando a quantidade está entre o estoque máximo e mínimo), e (iii) - Vermelha, quando a quantidade está abaixo do estoque mínimo de segurança.

Um exemplo dessa aplicação é mostrado na Figura 6 para o produto "chocolate em barra", cujo estoque a ser controlado deve respeitar as seguintes quantidades: 
- Valores maiores a $4 \rightarrow$ Estoque Suficiente (preenchimento em verde);

- Valores iguais a $2 \rightarrow$ Alerta (preenchimento em amarelo);
- Valor menor ou igual a $1 \rightarrow$ Estoque de segurança (preenchimento em vermelho).

Figura 6 - Comando da formatação condicional para o produto "chocolate em barras"

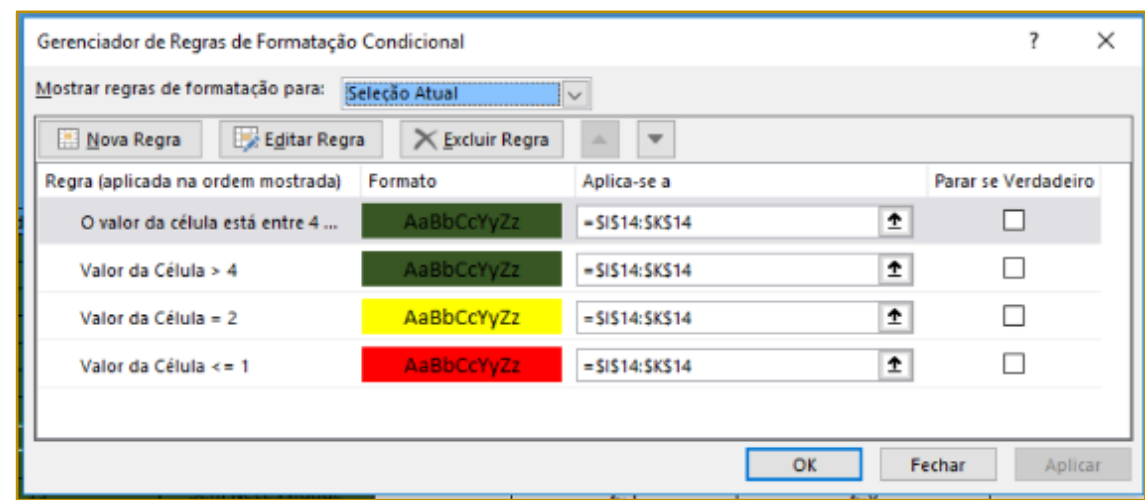

Fonte: Do autor (2017)

$\mathrm{Na}$ quarta coluna ("Necessidades de Compra") da tabela "Dados dos produtos em estoque, foram relacionadas as informações da quantidade de produtos e da necessidade de compra. Para isso, foi utilizada a Função
SE do Excel, que realiza testes lógicos e retorna valores (números ou letras) para uma condição verdadeira e uma falsa. Esse comando se dá na seguinte forma:

\section{$=S E($ teste_lógico, $[$ valor_(se_verdadeiro $)],[$ valor_(se_falso $)])$}

Equação Sintaxe da Fórmula SE do Excel

A estrutura apresentada na equação (3) é composta de 3 argumentos, sendo eles:

- Teste lógico: condição em que será testada por esta função;

- Valor se verdadeiro: define o valor a ser retornado, caso a condição seja verdadeira;

- Valor_sefalso: define o valor a ser retornado, caso a condição seja falsa.
$\mathrm{Na}$ coluna "Necessidade de Compra", a função SE foi utilizada de forma composta, chamada SE dentro de SE. Ou seja, no argumento "Valor_se_falso", foi colocada outra função SE, pois, o valor a ser retornado dependia de mais de uma condição (BORGES, 2017).

Portanto, a programação das células da coluna "Necessidade de compra" para o produto "Chocolate em barra" foi escrita da seguinte forma:
Equação da "Necessidade de Compra" para o chocolate em barra

Concomitantemente, foi utilizada a "Formatação condicional", com o mesmo sistema de cores, porém, de acordo com o texto apresentado na célula: Vermelho para o texto "Urgente", amarelo para "Alerta" e verde para "Sem Necessidade", como mostra a Figura 7. 
Figura 7 - Comando da Coluna "Necessidade de Compra" para o produto "chocolate em barras"

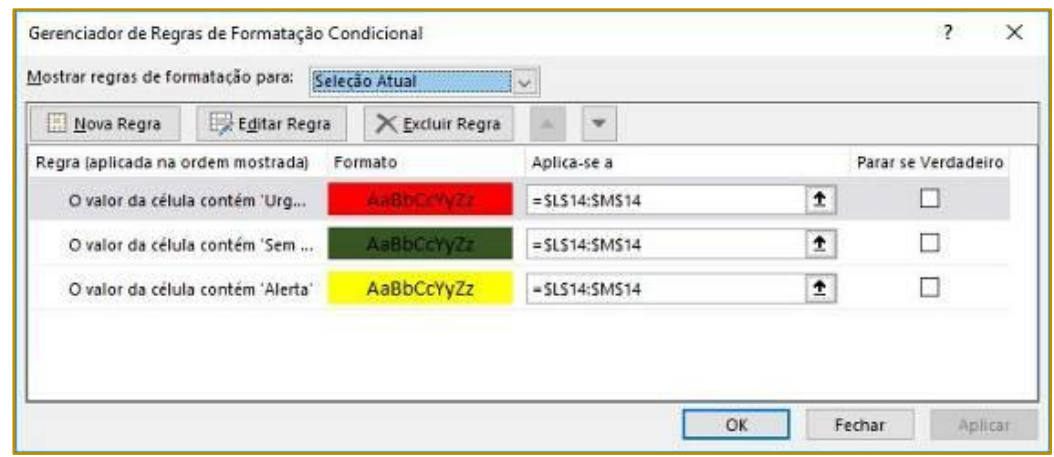

Fonte: Do autor (2017)

Esses comandos apresentados foram aplicados em todos os 11 produtos, de forma a se obter a planilha demonstrada na figura 5 ("Primeira tabela preenchida após um tempo de uso").

A segunda tabela da planilha criada ("Quantidade a ser comprada") também foi programada com a "Formatação Condicional", de maneira a destacar a quantidade estocada quando esta atinge a faixa mínima de segurança, que é evidenciada através da célula preenchida pela cor vermelha, como mostra na figura 8.

Figura 8 - "Quantidade a ser comprada" preenchida

\begin{tabular}{|c|c|c||}
\hline \multicolumn{3}{|c|}{ Quantidade a ser comprada } \\
\hline Produto No & Descrição do Produto (Un. Medida) & Quantidade \\
\hline 1 & Arroz (Kilogramas) & 5 \\
\hline 2 & Arroz Integral (Kilogramas) & 1 \\
\hline 3 & Macarrão Espaguete (Kilogramas) & 0 \\
\hline 4 & Macarrão Pene (Kilogramas) & 0 \\
\hline 5 & Macarrão Cabelo de Anjo (Kilogramas) & 34 \\
\hline 6 & Açúcar (Kilogramas) & 20 \\
\hline 7 & Farinha de Trigo (Kilogramas) & 0 \\
\hline 8 & Chocolate em Barra (Kilogramas) & 27 \\
\hline 9 & Leite Condensado (Kilogramas) & 9 \\
\hline 10 & Creme de Leite (Kilogramas) & 0 \\
\hline 11 & Manteiga (Kilogramas) & \\
\hline
\end{tabular}

Fonte: Do autor (2017)

\section{RESULTADOS E DISCUSSÃO}

Os primeiros resultados obtidos foram informações sobre o funcionamento do estabelecimento, a frequência com que ocorrem os pedidos de reabastecimento, os principais fornecedores e também os locais de armazenamento dos produtos. Esses dados foram compilados no quadro 1. 
Quadro 1 - Dados gerais

\begin{tabular}{|c|c|c|c|c|c|c|}
\hline Produto & Pedido & Entrega & Tempo & Local & Saida & Fornecedor \\
\hline Verduras: & $\begin{array}{c}\text { Terça, quinta e } \\
\text { sábado }\end{array}$ & $\begin{array}{c}\text { Terça, quinta e } \\
\text { sábado }\end{array}$ & \pm 2 dias & $\begin{array}{c}\text { Refrigeradores } \\
\text { na garagem da } \\
\text { casa }\end{array}$ & $\begin{array}{c}\text { Restaurante e } \\
\text { Choperia }\end{array}$ & 3 \\
\hline Massas & A cada 2 meses & A cada 2 meses & \pm 2 meses & \begin{tabular}{|c|}
$\begin{array}{c}\text { Refrigeradores } \\
\text { na garagem da } \\
\text { casa }\end{array}$ \\
\end{tabular} & Choperia & 1 \\
\hline Laranja & Diário & Diário & Diário & \begin{tabular}{l|l} 
Sem lugar \\
especifico
\end{tabular} & \begin{tabular}{|c|}
$\begin{array}{c}\text { Restaurante e } \\
\text { Choperia }\end{array}$ \\
\end{tabular} & 1 \\
\hline $\begin{array}{c}\text { Alimentos não } \\
\text { pereciveis e } \\
\text { embalagens }\end{array}$ & $\begin{array}{l}\text { Segunda e } \\
\text { quinta }\end{array}$ & Terça e sexta & Semanal & Área do estoque & $\begin{array}{c}\text { Restaurante e } \\
\text { Choperia }\end{array}$ & $\begin{array}{l}\text { Depende da } \\
\text { pesquisa de } \\
\text { mercado }\end{array}$ \\
\hline $\begin{array}{c}\text { Comidas } \\
\text { congeladas e } \\
\text { carnes }\end{array}$ & $\begin{array}{l}\text { Segunda e } \\
\text { Quinta }\end{array}$ & Terça e sexta & \pm 2 dias & $\begin{array}{c}\text { Cámara fria; } \\
\text { Freezer na } \\
\text { cozinha interna } \\
\text { com salgados }\end{array}$ & $\begin{array}{c}\text { Restaurante e } \\
\text { Choperia }\end{array}$ & JBS \\
\hline $\begin{array}{c}\text { Bebidas sem } \\
\text { álcool (20 a } 25 \\
\text { fardos) } \\
\end{array}$ & Terça & Quarta & Semanal & \begin{tabular}{|c|}
$\begin{array}{c}\text { Pequeno } \\
\text { estoque na área } \\
\text { da casa; }\end{array}$ \\
\end{tabular} & $\begin{array}{c}\text { Restaurante e } \\
\text { Choperia }\end{array}$ & Coca-cola \\
\hline $\begin{array}{l}\text { Bebidas } \\
\text { Brahma }\end{array}$ & Terça & $\begin{array}{l}\text { Segunda, } \\
\text { quinta e } \\
\text { sábado }\end{array}$ & \pm 3 dias & $\begin{array}{l}\text { Área da casa; } \\
\text { câmara fria; } \\
\text { Freezers }\end{array}$ & $\begin{array}{c}\text { Restaurante e } \\
\text { Choperia }\end{array}$ & Brahma \\
\hline Sorvete & Segunda & Segunda & Semanal & \begin{tabular}{|c|} 
Sem estoque, \\
freezer próprio \\
\end{tabular} & Restaurante & $\mathrm{MR}$ \\
\hline Polpas & Quarta & Quinta & Semanal & Camara fria & \begin{tabular}{|c|}
$\begin{array}{c}\text { Restaurante e } \\
\text { Choperia }\end{array}$ \\
\end{tabular} & 1 \\
\hline
\end{tabular}

Fonte: Do autor (2017)

Após a elaboração do quadro 1, outros dados foram coletados, visando a elaboração da planilha proposta. Estes estão apresentados no quadro 2.

Quadro 2 - Dados para a planilha

\begin{tabular}{|c|c|c|c|c|c|c|c|c|}
\hline Produto & $\begin{array}{c}\text { Quantidade } \\
\text { quando estoque } \\
\text { estă cheio }\end{array}$ & $\begin{array}{l}\text { Faixa de Estogue } \\
\text { Sufciente }\end{array}$ & $\begin{array}{c}\text { Faixa de Estogue } \\
\text { cm alerta }\end{array}$ & $\begin{array}{l}\text { Faisa de } \\
\text { Estoque de } \\
\text { Sezuranga }\end{array}$ & $\begin{array}{c}\text { Abastecimento por dia } \\
\text { (Quanto de produto se } \\
\text { repöe por dia) }\end{array}$ & $\begin{array}{l}\text { Aitumo de consumo (quanto } \\
\text { do produto e consumido } \\
\text { por dila) }\end{array}$ & $\begin{array}{c}\text { Tempo de uso do } \\
\text { estoque chelo } \\
\text { (dias) }\end{array}$ & $\begin{array}{l}\text { Tempo de } \\
\text { reposiçăo do } \\
\text { produto }\end{array}$ \\
\hline Arroz & $150 \mathrm{kgs}$ & $>100 \mathrm{kes}$ & \begin{tabular}{|c|} 
Entre $100 \mathrm{KgS}$ e 50 \\
KgS
\end{tabular} & $<50 \mathrm{kgs}$ & 7,5 & 8 & 21,6 & 24 \\
\hline Arroz integral & $8 \mathrm{kgs}$ & $>6 \mathrm{~kg}$ & Entre $6 \mathrm{e} 2 \mathrm{kgs}$ & $<2 \mathrm{kgs}$ & 1,1 & 1 & 8 & 4 \\
\hline $\begin{array}{l}\text { Macarrâo } \\
\text { Espaguete }\end{array}$ & $9 \mathrm{kgs}$ & $>4 \mathrm{kgs}$ & Entre 4 e $2 \mathrm{kgs}$ & $<2 \mathrm{Kg} 5$ & 0,6 & 0,8 & 12 & 24 \\
\hline $\begin{array}{l}\text { Macarrố } \\
\text { peine }\end{array}$ & $9 \mathrm{kgs}$ & $>4 \mathrm{kgi}$ & Entre 4 e $2 \mathrm{kgs}$ & $<2 \mathrm{Kg} 5$ & 0,6 & 0,8 & 12 & 24 \\
\hline $\begin{array}{c}\text { Macarrão } \\
\text { Cabelo de Anjo }\end{array}$ & $9 \mathrm{kgs}$ & $>4 \mathrm{kgs}$ & Entre 4 e $2 \mathrm{kgs}$ & $<2 \mathrm{Kgs}$ & 0,3 & 0,5 & 20 & 24 \\
\hline Açücar & $40 \mathrm{kgs}$ & $>20 \mathrm{kgs}$ & Entre $20 \mathrm{e} 15 \mathrm{kgs}$ & $<15 \mathrm{kgs}$ & 4,3 & 5 & 8 & 24 \\
\hline $\begin{array}{c}\text { Farinha de } \\
\text { Trigo }\end{array}$ & $60 \mathrm{~kg} 5$ & $>30 \mathrm{kgs}$ & Entre 30 e $15 \mathrm{kgs}$ & $<15 \mathrm{kgs}$ & 5,7 & 12 & 6 & 24 \\
\hline $\begin{array}{c}\text { Chocolate em } \\
\text { Barra }\end{array}$ & $4 \mathrm{kgs}$ & $>2 \mathrm{~kg}$ & $2 \mathrm{kgs}$ & $1 \mathrm{~kg}$ & 0,6 & 0,5 & 8 & 24 \\
\hline $\begin{array}{c}\text { Leite } \\
\text { concensado } \\
\end{array}$ & $57 \mathrm{~kg}$ & $>35 \mathrm{kgs}$ & Entre 35 e $20 \mathrm{kgs}$ & $<20 \mathrm{kgs}$ & 6,9 & 9 & 7 & 24 \\
\hline Creme de Leite & $15 \mathrm{~kg}$ & $>7 \mathrm{~kg}$ & Entre 7 e $5 \mathrm{kgs}$ & $<5 \mathrm{~kg}$ & 2,1 & 2 & 7 & 24 \\
\hline Manteiga & $6 \mathrm{kgs}$ & $>3 k g 5$ & Entre 3 e $2 \mathrm{kgs}$ & $<2 \mathrm{~kg} 5$ & 0,9 & 1 & 6 & 24 \\
\hline
\end{tabular}

Fonte: Do autor (2017) 
A análise dos dados coletados e dos relatos semanais passados pela auxiliar administrativa do local possibilitou evidenciar uma falha no reabastecimento do estoque, pois o mesmo era realizado sem que houvesse uma avaliação da sua necessidade real naquele momento, o que, para alguns produtos, gerava estoque em excesso. Isso ocorria devido à falta de uma ferramenta de controle que monitorasse o estoque dos produtos utilizados ao longo da semana, tornando, portanto, o controle passível de erros.

Após o monitoramento dos gastos do restaurante em 4 semanas, foi possível calcular o gasto total das compras dos 11 produtos presentes no quadro 2, como é mostrado na figura 9.

Figura 9 - Gasto bruto de reposição pelo antigo método do gerenciamento

\begin{tabular}{|c|rr|}
\hline & Gasto Bruto & \\
\hline Semana 1 & R\$ & $1.055,71$ \\
\hline Semana 2 & R\$ & 652,84 \\
\hline Semana 3 & R\$ & 711,23 \\
\hline Semana 4 & R\$ & $1.481,07$ \\
\hline Gasto mensal: & RS & $3.900,85$ \\
\hline
\end{tabular}

Fonte: Do autor (2017)

Devido a essas falhas, identificou-se uma oportunidade de melhoria através da aplicação de conceitos do Lean Manufacturing, particularmente do conceito de Kanban. Por meio da planilha, após a primeira semana de acompanhamento, os resultados encontrados estão na figura 10.

Figura 10- Planilha com estoque após uma semana de uso

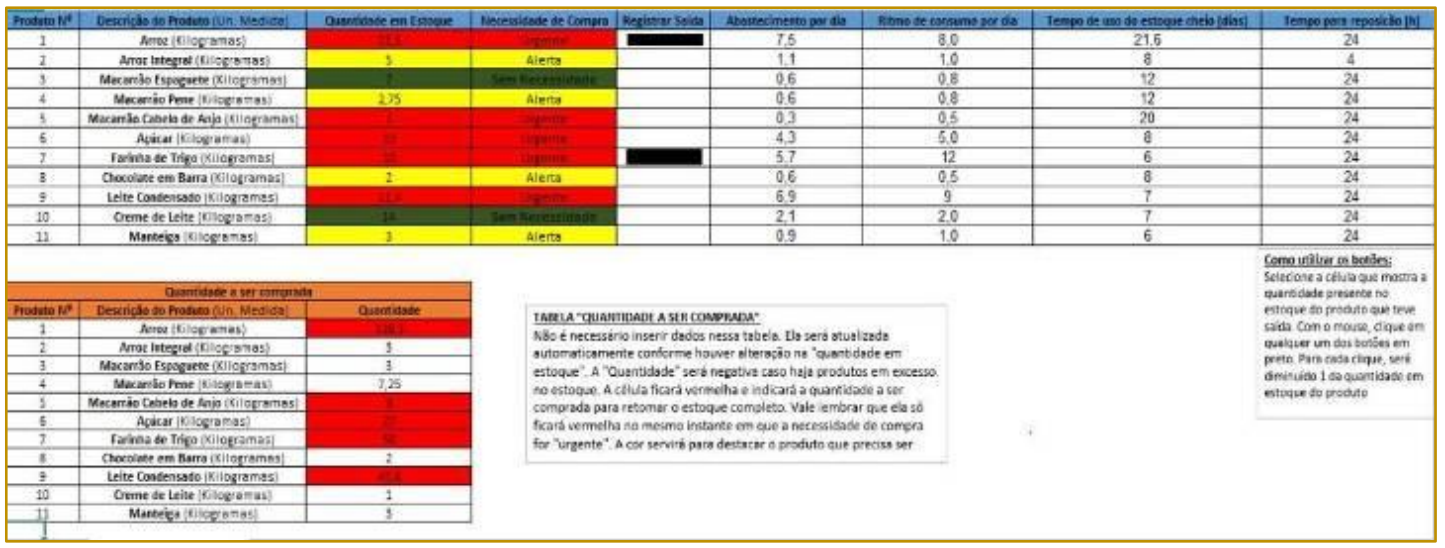

Fonte: Do autor (2017)

Estes resultados permitem perceber que alguns produtos não apresentaram necessidade urgente de compra, indicando que não precisariam ser adquiridos no pedido seguinte. Dessa forma, os produtos que não fossem comprados acarretariam em uma retenção de custos, a economia semanal. O cálculo desta está apresentado no quadro 3. 
Quadro 3 - Economia da primeira semana

\begin{tabular}{|c|c|c|c|}
\hline Produto & $\begin{array}{c}\text { Quantidade } \\
\text { Economizada (Kg) } \\
\end{array}$ & Preço Unitário (R\$) & Economia \\
\hline Arroz Integral & 3 & 3,20 (Pacote $1 \mathrm{~kg}$ ) & $\mathrm{R} \$ 9,60$ \\
\hline $\begin{array}{l}\text { Macarrăo } \\
\text { Espaguete }\end{array}$ & 3 & 4,04 (Pacote de $0,5 \mathrm{~kg}$ ) & $\mathrm{R} \$ 24,25$ \\
\hline Macarrāo Penne & 7,25 & 4,04 (Pacote de 0,5 kg) & $\mathrm{R} \$ 58,61$ \\
\hline Chocolate em Barra & 2 & 28,35 (Pacote de $1 \mathrm{~kg}$ ) & $\mathrm{R} \$ 56,71$ \\
\hline Creme de Leite & 1 & $\begin{array}{c}10,50 \text { (Embalagem de } 0,5 \\
\mathrm{~kg} \text { ) }\end{array}$ & $\mathrm{R} \$ 21,00$ \\
\hline Manteiga & 3 & 4,60 (Embalagem de $0,2 \mathrm{~kg}$ ) & $R \$ 69,00$ \\
\hline \multicolumn{3}{|c|}{ Economia Total } & R\$ 239,17 \\
\hline
\end{tabular}

Fonte: Do autor (2017)

Percebe-se que a utilização da planilha permitiu "poupar" um valor de $\mathrm{R} \$ 239,17 \mathrm{em}$ apenas uma semana, com um acompanhamento de somente 11 produtos. Devido ao fato de o restaurante possuir demanda variável, sendo difícil determinar a quantidade exata de produto necessária, decidiu-se realizar um acompanhamento mensal, com o intuito de calcular a economia real que um efetivo controle de estoque, por meio dessa planilha, poderia render ao estabelecimento em um mês.

Com isso, os produtos acompanhados passaram por uma simulação como se fossem repostos apenas ao atingirem o estoque de segurança. Essa quantidade foi definida para cada produto (juntamente com a auxiliar administrativa do estabelecimento), de acordo com o ritmo de consumo e possíveis imprevistos, e é apresentada na coluna cinco do quadro 2, mostrado anteriormente.

Durante as quatro semanas, foram calculados os gastos com reposições. Este cálculo foi realizado considerando que estas ocorreram apenas quando os produtos atingiram a quantidade mínima de segurança (estoque de segurança).

Posteriormente, obteve-se o valor da economia das quatro semanas- utilizando-se o cálculo apresentado no quadro 3 - e subtraiu-se deste a soma dos gastos. Desta forma, foram obtidos saldos semanais que, somados, resultaram em uma economia mensal, conforme mostra a figura 11.

Figura 11 - Economia mensal

\begin{tabular}{|c|c|c|c||}
\hline \multicolumn{5}{|c|}{ Economia Mensal } \\
\hline SEMANA N & Economia (E) $^{\circ}$ & Gasto com reposição (G) & Saldo (E - G) \\
\hline 1 & $\mathrm{R} \$ 239,16$ & $\mathrm{R} \$ 0$ & $\mathrm{R} \$ 239,16$ \\
\hline 2 & $\mathrm{R} \$ 675,45$ & $\mathrm{R} \$ 441,93$ & $\mathrm{R} \$ 233,52$ \\
\hline 3 & $\mathrm{R} \$ 188,12$ & $\mathrm{R} \$ 358,83$ & $-\mathrm{R} \$ 170,71$ \\
\hline 4 & $\mathrm{R} \$ 465,30$ & $\mathrm{R} \$ 385,23$ & $\mathrm{R} \$ 80,07$ \\
\hline & SALDO FINAL & $\mathrm{R} \$ 382,04$ \\
\hline
\end{tabular}

Fonte: Do autor (2017)

Obtidos os dois valores, o do gasto bruto (Figura 10) e o de economia mensal (Figura 11), calculou-se a porcentagem do segundo em relação ao primeiro, a fim de comparar o quanto a economia refletiria no gasto que o estabelecimento teve no mês com os 11 produtos escolhidos, ilustrado na figura 12. 
Figura 12 - Porcentagem da economia sobre o gasto

\begin{tabular}{|l|rr|}
\hline Economia: & RŞ & 382,04 \\
\hline Gasto Bruto & RS $3.900,85$ \\
\hline Porcentagem & $9,8 \%$ \\
\hline
\end{tabular}

Fonte: Do autor (2017)

Portanto, no mês em que o estabelecimento foi acompanhado, a planilha proposta possibilitaria um saldo de $R \$ 382,04$, que representa $9,8 \%$ do valor gasto com as reposições dos 11 produtos observados no período.

\section{CONCLUSÃO}

A utilização do método Kanban adaptado para uma planilha do Excel permitiu a economia de $\mathrm{R} \$ 382,04$ em um mês, reduzindo $9,8 \%$ do total gasto com as reposições dos 11 produtos analisados. Com a implantação do método proposto, atingiu-se

\section{REFERÊNCIAS}

[1] Abreu, EdeliSimioni de et al. Alimentação mundial: uma reflexão sobre a história.Saúde soc., São Paulo, v. 10,n. 2,p.3-14,Dec.2001 <http://www.scielo.br/scielo.php?script=sci_arttext \&pid=S0104-

$12902001000200002 \& \operatorname{lng}=e n \& n r m=i s o>$. Acesso em 03 Mar. 2017.http://dx.doi.org/10.1590/S010412902001000200002

[2] Almeida, D.; Lucena, M. Gestão de estoques na cadeia de suprimentos. Revista Ecco. Revista da Faculdade de Economia e Ciências Contábeis da Universidade Metodista de São Paulo, n. 1, p. 34-49, 2. sem. 2006.

[3] André, M. E. (maio de 1984). Estudo de Caso: Seu potencial na Educação. Cadernos de pesquisa, p. 51-54. Disponível em <http://www.fcc.org.br/pesquisa/publicacoes/cp/ar quivos/528.pdf>. Acesso em: 20 jan. 2017.

[4] Borges, Leandro.Função SE Excel. Disponível em: <http://blog.luz.vc/excel/funcao-se-excel/> Acessoem: 20 jan. 2017.

[5] Dumitrescu C.; Dumitrache M.ThelmpactofLeanSixSigmaonthe Overall Results of Companies.Diponível em: htmldo arquivo http://www.management.ase.ro/reveconomia/20112/26.pdf. Acesso em: 19 março 2017

$\begin{array}{llll}\text { [6] Favoni, } \quad \text { Célio; } & \text { Gambi, Lillian do } \\ \text { Nascimento; Careta, } & \text { Catarina } & \text { Barbosa. }\end{array}$ o objetivo de desenvolver um modelo eficaz de gerenciamento de estoque, uma vez que a falha na administração destes produtos era uma das principais queixas da auxiliar administrativa do local.

Assim, o uso constante da ferramenta para controle de estoque, abrangendo o máximo de produtos possíveis, trará resultados ainda mais significativos, contribuindo para a contenção de despesas e redução do tempo da visualização do estoque, fatores que possibilitam ao estabelecimento ser mais competitivo e destacar-se no setor alimentício do município.

Oportunidades de implementação de conceitos e ferramentas de produção enxuta visando melhoria da competitividade de empresas do APL calçadista de Jaú/SP.Revista Produção Online, Florianópolis, v. 13, n. 3, p. 1118-1142, ago. 2013. ISSN 16761901. Disponível em: <https://producaoonline.org.br/rpo/article/view/140 4/1060>. Acesso em: 20 jan. 2017. http://dx.doi.org/10.14488/1676-1901.v13i3.1404.

[7] Gianesi, Irineu Gustavo Nogueira; Biazzi, Jorge Luiz de. Gestão estratégia dos estoques. Revista de Administração, [s.l.], v. 46, n. 3, p.290304, 14 set. 2011. Business Department, School of Economics, Business \& Accounting USP. http://dx.doi.org/10.5700/rausp1013.

[8] Kniberg, H., Kanban vs. Scrum: Makingthemostofboth, 2009, http://www.crisp.se/henrik.kniberg/Kanban-vsScrum.pdf [18-Março-2017].

[9] Kotler, Philip. Administração de Marketing. São Paulo: Prentice Hall, 2000.

[10] MIGUEL, Paulo Augusto Cauchick. Estudo de caso na engenharia de produção: estruturação e recomendações para sua condução. Produção. São Paulo, p. 216-229. abr. $2007 . \quad$ Disponivel em: <http://www.scielo.br/pdf/prod/v17n1/14.pdf>. Acesso em: 15 nov. 2016.

[11] Moreira, Daniel Augusto. Administração da Produção e Operações. São Paulo: Cengage Learning, 2008. 
[12] Nucleora (Org.). Quero Montar um Restaurante. Disponível em: <http://www.nucleora.com.br/publicacoes/guiagourmet-foodie-edicao-n1-brasil-o-pais-dosgourmets.html>. Acesso em: 19 jan. 2017.

[13] Ohno, T. O Sistema Toyota de Produção. Porto Alegre: Bookman, 1997.

[14] Pinto, João Paulo. Leanthinking.ComunidadeLeanThinking, p. 1-8, 2008.

[15] Portal Brasil (Ed.)Alimentação em bares e restaurantes cresce no Brasil. Disponível em: $<$ http://www.brasil.gov.br/turismo/2014/06/alimenta cao-em-bares-e-restaurantes-cresce-no-brasil> Acesso em: 15 nov. 2016.

[16] Ribeiro, Cilene da Silva Gomes. TUDO PRONTO: O COMER FORA E O PRAZER REINVENTADO - CURITIBA (1970-2000). 2012. 250 f. Tese (Doutorado) - Curso de História, Universidade Federal do Paraná, Curitiba, 2012.

[17] Rodrigues, Gisele Pereira; SOARES, Leandro. As Estratégias de Gestão de Estoque Aplicadas ao Cotidiano de Drogarias.CadernosUnisuam.Rio de Janeiro, p. 1026. nov. 2015. Disponível em: <http://apl.unisuam.edu.br/revistas/index.php/cade rnosunisuam/article/view/856/662>. Acesso em: 19 jan. 2017.

[18] Santos, Eduardo Bezerra dos; Azevedo, Pedro Henrique Bueno Meirelles de; Bentes, Ramiro Isaac. Análise da Utilização de Ferramentas de Gestão de Estoque em uma Empresa Produtora
De Bebidas, Como Auxílio à Gestão da Logística de Materiais em um Cenário de Demanda Variável. In: Encontro Nacional de Engenharia de Produção, 32., 2012, Bento Gonçalves. Anais eletrônicos. Bento Gonçalves: Abepro, 2012. p. 1 - 8. Disponível em: $<$ http://www.abepro.org.br/biblioteca/enegep2012_ tn_stp_157_914_20007.pdf>. Acesso em: 19 jan. 2017

[19] Santos, Virgilio F. M. dos; Santos, Murilo F. M. dos. (Planilha de base) Empresa FM2S Treinamentos E Projetos. Disponível em <http://www.fm2s.com.br/portfolio/planilha-degestao-de-estoque/>. Acesso em: 04 Out. 2016.

[20] Terzian, Françoise. Mesmo com crise, o setor de alimentação continua a crescer no Brasil. Disponível em: <http://www.forbes.com.br/negocios/2015/06/mes mo-com-crise-setor-de-alimentacao-continua-acrescer-no-brasil/>. Acesso em: 19 jan. 2017.

[21] Venanzi, Délvio; Laporta, Bruna Pires. Lean Six Sigma. - South American DevelopmentSociety Jornal. São Paulo, p. 66-84. jun. 2015. Disponível em: Acesso em: 23 jan. 2016

[22] VOSS, C. et al. Case Research in Operations Management. InternationalJournalofOperationsandProduction Management, v. 22, n. 2, p. 195-219, 2002.

[23] YIN, R. K. Estudo de Caso - Planejamento e Método. 2. ed. Porto Alegre: Bookman, 2001 


\section{Bapítulo 8}

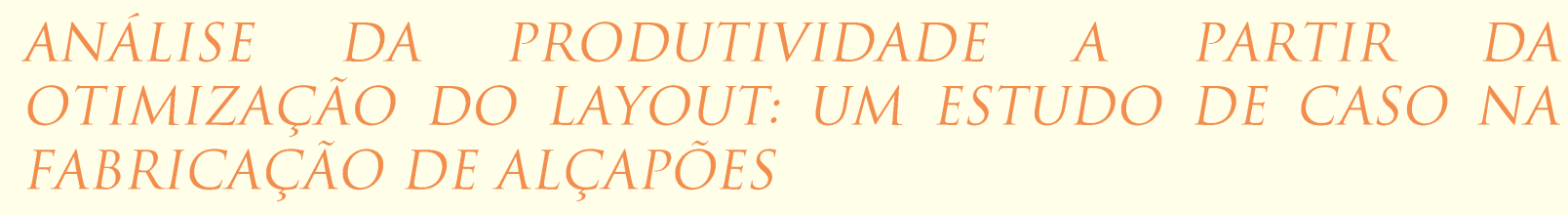

\section{Tiago Lisboa Mattos}

\section{Larissa dos Santos Rosa}

\section{Alexandre Paranhos Bastos}

Resumo: A proposta do trabalho, é dimensionar a produtividade em relação ao espaço físico, definindo ferramentas, métodos de análise e estudo como um veículo para a otimização. Buscando em cima de um sistema produtivo já existente, foi realizado uma reforma no processo, visando sanar as deficiências e aprimorar a produção, contribuindo para a qualidade e o ganho de produtividade no setor de alçapão de uma fábrica de pré-moldados. 


\section{INTRODUÇÃO}

Empresas que não se atualizam e não caminham por evoluir, acabam ficando para trás na corrida mercadológica, as que se mantêm fiel a filosofia de que sempre pode haver progresso, acabam encontrando boas posições em relação aos competidores.

Fomentar a economia da construção civil, vem por diversas vezes, através do investimento em novas pesquisas e tecnologias. Sua industrialização encontra-se em desenvolver novos métodos de produção, reduzindo custos, aprimorando a qualidade e diminuindo perdas faz parte de uma economia saudável e empreendedora. A construção civil, por meio do advento de peças pré-moldadas, sofre esses constantes processos de industrialização e conforme Mamede (2001), através deste processo se consegue reduzir desperdícios e aumentar a produtividade e rapidez da obra.

$\mathrm{Na}$ busca por melhorias que sejam econômicas, de baixo custo e que não afetem negativamente a economia da empresa, a otimização do espaço físico é apresentada como uma possibilidade viável de ser implantada e de possuir retornos rápidos em relação à produtividade da empresa e logo, seus possíveis ganhos financeiros e boa colocação no mercado.

A partir da decisão de otimizar o espaço, o presente estudo de caso é feito sobre um layout já existente, onde foi levantado informações, estudado e apresentado uma otimização no setor de alçapão em gesso de uma empresa de perfilados.

\section{REFERENCIAL TEÓRICO}

\subsection{MAPEAMENTO DE PROCESSOS}

\subsubsection{FLUXOGRAMA}

O fluxograma nada mais é do que a representação de atividade através de símbolos gráficos que descrevem passo a passo a natureza e o fluxo de todo um processo. O objetivo dele se constitui em apresentar de forma descomplicada a sequência de informações e elementos do sistema operacional a ser executado.

Segundo Barnes (1977), a American Society Mechanical Engenieers ASME, apresentou um padrão para a aplicação de 05 símbolos, conforme apresentado na Figura abaixo.

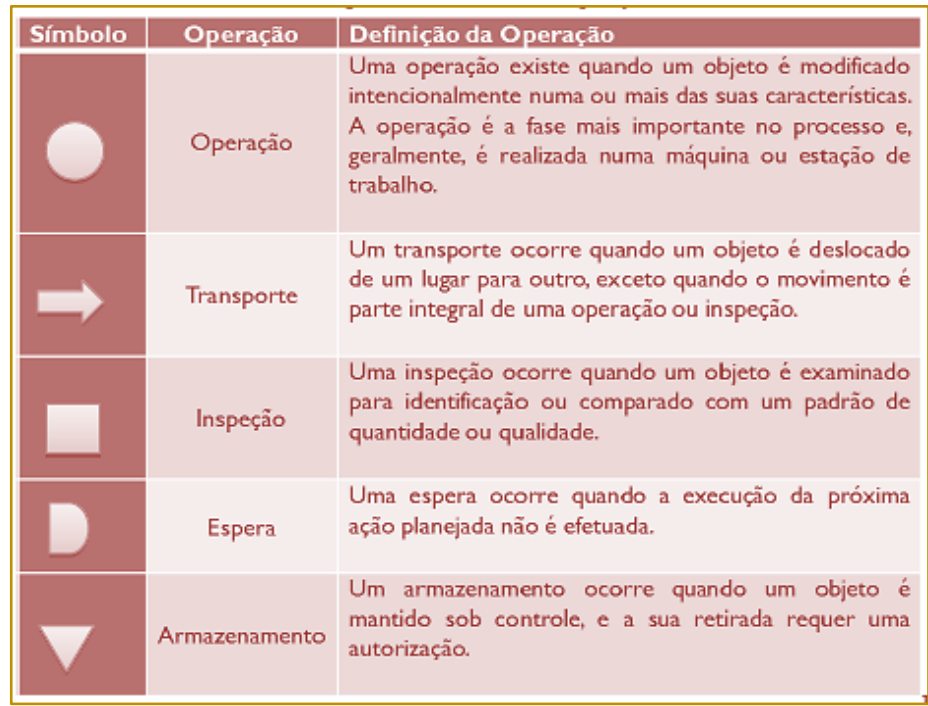

Fonte: Barnes (1977)

\subsubsection{MAPOFLUXOGRAMA}

O mapofluxograma representa toda movimentação física de um item, através dos centros de processamento dispostos no arranjo físico de uma instalação produtiva. Assim, o mapofluxograma do processo tornase importante a partir do momento que 0 deslocamento se torna parte relevante no processo (CORREIA et al, 2002).

O curso ou rota física do item, que pode ser produto, material, formulário ou pessoa, é apresentado por linhas gráficas, que indicam movimento sobre a planta baixa em escala da instalação envolvida. 
A trajetória ou rota física do item, que pode ser produto, material, formulário ou pessoa, é desenhado, por meio de linhas gráficas com indicação de sentido de movimento, sobre a planta baixa em escala da instalação envolvida.

O mapofluxograma fornece uma visão geral do processo detalhado no fluxograma sobre o layout da empresa, gerando a percepção das operações ocorridas em cada local (TARDIN, 2013).

\subsubsection{DIAGRAMA DE ESPAGUETE}

Corresponde como um mapa de fluxo que permite desenhar e analisar a movimentação de pessoas e dos materiais em processo de uma determinada instalação.

O diagrama de mapa de fluxo (ou diagrama de espaguete) possibilita a análise de movimentação das pessoas e dos materiais de uma determinada área, com esse tipo de gráfico é possível a aproximação de postos de trabalho para reduzir movimentação (SILVA, 2009).
Com a utilização dessa ferramenta capaz de medir os deslocamentos dos operadores em uma determinada operação, através dessas distancias melhora a capacidade de identificar a necessidades de resenhar o fluxo, deslocando os operadores e minimizados os espaços entres os processos (FAVERI, 2013).

\subsection{SISTEMAS PRODUÇÃO}

Sistema de produção é um conjunto de atividade e operações inter-relacionadas, envolvidas na produção de bens ou serviços, segundo Moreira (2002). Podem ser nomeados em quatro tipos: continuo repetitivo em massa, repetitivo em lotes e projeto.

Associados ao volume de produção e grau de variedade é possível assimilar a definição do tipo de layout a ser escolhido. Por diversas vezes, baseado no nível de complexidade do processo, pode haver vários tipos de sistemas de produção num único layout. A tabela abaixo demonstra uma maneira de entender a classificação de um processo.

Tabela 1 - Características dos sistemas de produção

\begin{tabular}{|c|c|c|c|c|}
\hline & Contínuo & $\begin{array}{c}\text { Repetitivo em } \\
\text { massa }\end{array}$ & $\begin{array}{l}\text { Repetitivo em } \\
\text { lotes }\end{array}$ & Projeto \\
\hline Volume de produção & Alto & Alto & Médio & Baixo \\
\hline Variedade de produtos & Pequena & Média & Grande & Pequena \\
\hline Flexibilidade & Baixa & Média & Alta & Alta \\
\hline Qualificação da Mão de Obra & Baixa & Média & Alta & Alta \\
\hline Layout & Por produto & Por produto & Por processo & Por processo \\
\hline Capacidade ociosa & Baixa & Baixa & Média & Alta \\
\hline Lead times & Baixo & Baixo & Médio & Alto \\
\hline Fluxo de informações & Baixo & Médio & Alto & Alto \\
\hline Produtos & Contínuos & Em lotes & Em lotes & Unitários \\
\hline
\end{tabular}

Fonte: Gerlach (2013)

Na figura abaixo, Slack (2009) posiciona a decisão de um arranjo físico correlacionando com o tipo de processo, variedade $\mathrm{e}$ quantidade, apresentando quatro tipos de layouts: arranjo físico posicional, por processo, celular e por produto. 
Figura 2 - Tipos básicos de layout

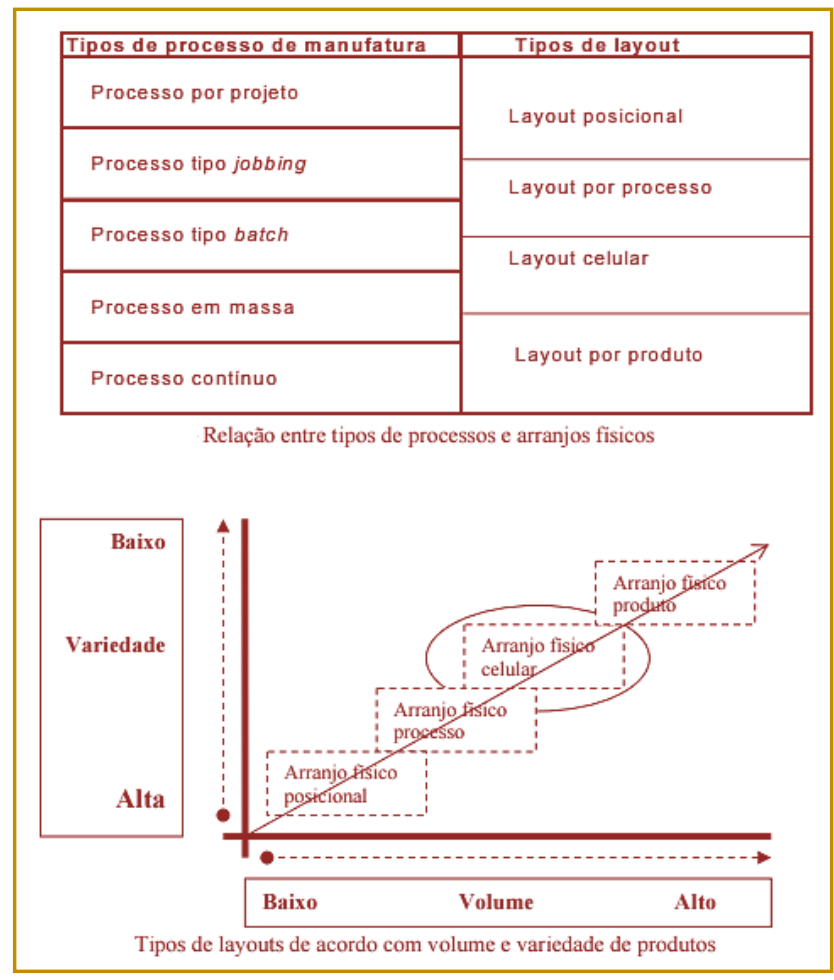

Fonte: Slack (2009)

- Arranjo físico posicional: quem sofre o processamento fica estacionário, enquanto o maquinário, equipamento, instalações e pessoas movem-se na medida do necessário, é apropriado para ambientes, onde tenhamos baixo volume de produção e alta variedade de produtos;

- Arranjo físico por processo: é assim chamado, pois, as necessidades e conveniências dos recursos transformadores que constituem o processo é que dominam a decisão sobre o layout, ou seja, processos similares são postos juntos, está situado em zonas mediadas de volume e variedade;

- Arranjo físico celular: corresponde a células de trabalho, onde todos os recursos transformadores necessários para atender a demanda estão disponíveis, situado em zonas mediadas de volume e variedade;

- Arranjo físico por produto: os recursos transformadores estão distribuídos de acordo com a conveniência do recurso a ser transformado, está ligado a alto volume de produção e baixa variedade de produtos.

\subsubsection{DIAGRAMA DE RELACIONAMENTO}

Uma ferramenta quantitativa que mede a proximidade entre os setores de produção. Desenvolvido por Muther (1961), o diagrama apresenta o grau de importância e compatibilidade entre dois setores. A Figura abaixo exemplifica o diagrama: 
Figura 3 - Diagrama de relacionamento

\begin{tabular}{|c|c|c|c|c|c|c|c|}
\hline \multicolumn{6}{|c|}{ Setor A } & Cód. & Proximidades \\
\hline A & \multicolumn{5}{|c|}{ Setor B } & A & Absolutamente Importante \\
\hline $\mathrm{u}$ & 1 & \multicolumn{4}{|c|}{ Setor C } & $\mathrm{E}$ & Especialmente Importante \\
\hline $\mathrm{A}$ & $\mathrm{I}$ & A & \multicolumn{3}{|c|}{ Setor D } & $\mathrm{I}$ & Importante \\
\hline $\mathrm{O}$ & $\mathrm{x}$ & $\mathrm{x}$ & $\mathrm{E}$ & \multicolumn{2}{|c|}{ Setor E } & 0 & Pouco Importante \\
\hline 1 & 0 & o & $\mathrm{U}$ & $\mathrm{u}$ & Setor $\mathrm{F}$ & $\mathrm{u}$ & Sem Importância \\
\hline 0 & 0 & $u$ & I & 1 & \begin{tabular}{l|l} 
A & Setor G
\end{tabular} & $\mathrm{x}$ & Não desejável \\
\hline
\end{tabular}

Fonte: Muther (1961)

\subsubsection{ASPECTOS ERGONÔMICOS}

A Ergonomia (ou Fatores Humanos) é uma disciplina científica relacionada ao entendimento das interações entre os seres humanos e outros elementos ou sistemas, e à aplicação de teorias, princípios, dados e métodos a projetos a fim de otimizar o bemestar humano e o desempenho global do sistema.

De maneira geral, domínios de especialização da ergonomia são ergonomia: física, cognitiva e organizacional.

\section{. 3 PRODUTIVIDADE}

Paranhos (2008) posiciona que produtividade é a eficiência do rendimento produzido. que pode ser definido como um alicerce da produtividade que se baseia em produzir com eficiência de maneira eficaz, onde uma operação feita com eficiência, e carente de eficácia para a conclusão de determinado plano, passa a ser inútil, pois não agregará nada de substancial, por mais bem feito que tenha sido executado. Toda atividade que foi gerada em prol de uma meta principal é atribuída a definição de produtiva.
Analisar as metas da empresa e focar em resultados, atividades e processos que realmente interessem a essas metas, contribuiu para o ganho da produtividade dentro da organização. Manter um equilíbrio entre eficiência e eficácia torna-se um desafio nunca eliminado dos empreendimentos e que deve ser sempre aprimorado.

\subsection{ALÇAPÃO}

Um alçapão é uma peça utilizada na construção civil para acionar outra área, sem comprometer a estética e a harmonia do ambiente. Podem ser encontrados principalmente em tetos. O alçapão do estudo é feito de gesso acartonado, composto por uma tampa e uma moldura.

Seu acesso ao teto é feito empurrando-se a tampa removível, e em seguida, descansando-a lateralmente perto da abertura do compartimento ou até mesmo removendo a tampa através da abertura.

O alçapão agrega como uma solução viável arquitetônica que permite a flexibilização entre determinadas áreas do projeto, mantendo o conforto acústico e ganho do espaço.

Figura 4 - Embalagem do alçapão

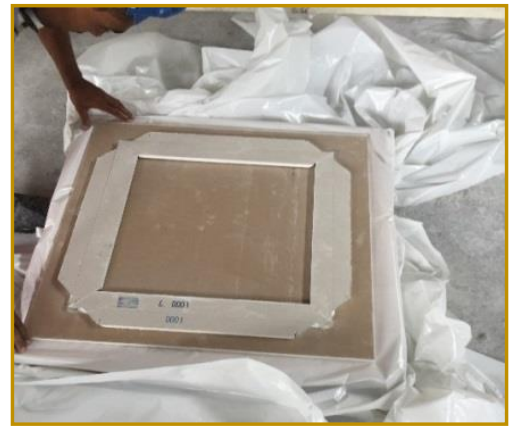

Fonte:.Elaborado pelo autor (2016). Extraído da empresa 
Figura 5 - Alçapão instalado

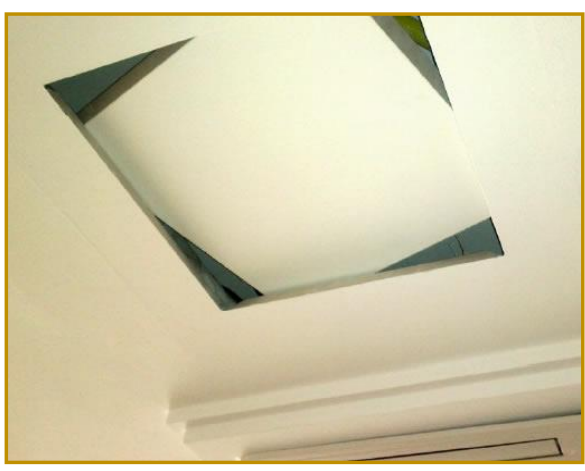

Fonte: Empresa.

\section{METODOLOGIA APLICADA}

As ferramentas apresentadas na fundamentação teórica auxiliaram na construção do antigo e novo layout, para representar o processo visualmente e facilitar a identificação de gargalos produtivos e áreas críticas.

O levantamento de dados ( 1 - etapa do estudo de caso), durante 6 meses, baseou-se em conhecer as características da empresa, seus colaboradores, matérias primas, produtos, equipamentos, processos utilizados e o arranjo físico atual.

Após a primeira fase. Foi mapeado todo o processo de fabricação do alçapão e realizado encraves para a visualização do processo:

a) Representar o layout encontrado

b) Construir fluxograma e mapofluxograma do primeiro layout

c) Desenvolver o diagrama de espaguete

Tendo os dados da situação atual, foi possível realizar um diagnóstico e propor uma otimização no espaço físico, foram construídas novas ferramentas que ajudassem a visualização do novo processo proposto:

a) Novo fluxograma

b) Diagrama de relacionamento

c) Novo layout

d) Novo mapofluxograma

e) Novo diagrama de espaguete

Possuindo as duas situações que foram, ao final, comparadas e analisadas, ocorreu o exame dos dados e resultados da pesquisa.

\section{ESTUDO DE CASO}

\subsection{DESCRIÇÃO DO PROCESSO}

O alçapão é constituído de 2 peças: tampa e tela, Figura 6. É obtido através de corte e montagem, sendo a primeira parte, realizada por uma máquina e a segunda, atividade manual.

Figura 6 - Peças que compõe o alçapão

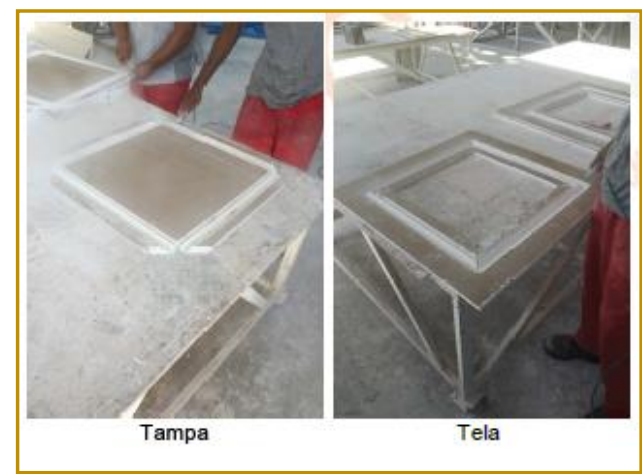


Suas é etapas são divididas em: Fabricação, Limpeza, Montagem e Embalagem. A figura abaixo representa o processo mais detalhado:

Figura 7 - Fluxo de fabricação de um alçapão simples

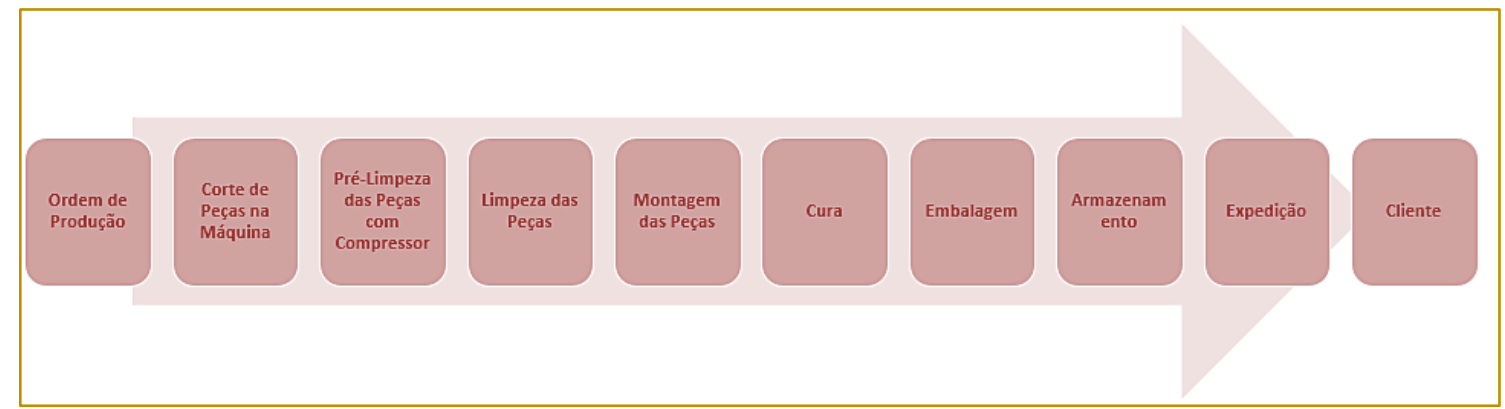

Fonte: Elaborado pelo autor (2016)

A etapa de corte é abastecida por uma placa de gesso acartonado, com dimensões de $2400 \mathrm{~mm}$ por $1200 \mathrm{~mm}$. A máquina que realiza o corte das peças é automatizada e através de um software, manipula desenhos e cálculos para cortar alçapões de diversas formas e tamanhos.

A limpeza fica por conta dos operadores, feita manualmente e em duas etapas. A primeira como uma pré -limpeza realizada com um compressor de ar que remove o pó e os dejetos deixados pelo corte. $\mathrm{Na}$ segunda parte, uma limpeza mais pesada é feita, retirando rebarbas e acertando os cortes.

A montagem também é feita manualmente, aonde é realizada a colagem e união das peças que foram tratadas pelas limpezas. Quando necessário ou quando solicitado pelo cliente, após o processo de limpeza, dobradiças e puxadores são colocados. Os orifícios de instalação também são cortados pela máquina.

O processo de embalagem corresponde ao empacotamento do lote de alçapões prontos para a expedição, também feito de forma manual.

O modelo mais demandado é o de dimensões $50 \mathrm{~cm} \times 50 \mathrm{~cm}$, devido a isso, será o produto analisado no estudo.

\subsection{LAYOUT ENCONTRADO}

Os postos de trabalho foram decompostos e numerados para fácil visualização:

1-Armário de ferramentas;

2-Área de armazenamento de placas de gesso acartonado para alimentação da máquina:

3-Máquina de corte de placas de gesso;

4-Bancada de limpeza de peças cortadas;

5-Bancada de montagem de peças cortadas;

6-Bancadas de apoio, utilizadas para armazenamento de produto pronto;

7-Área de armazenamento de sobras de placas cortadas;

8-Toneis de lixo;

9-Bancadas de armazenamento de produtos interrompidos;

10-Mostruário de peças;

11-Área de estoque de placas de gesso acartonado;

12-Acesso por onde entra a empilhadeira quando necessário;

13-Área de estocagem do pallet com os produtos prontos e embalados;

A figura 8 descreve o layout antigo, um galpão de 13 metros por 19 metros com os postos apresentados: 
Figura 8 - Layout encontrado

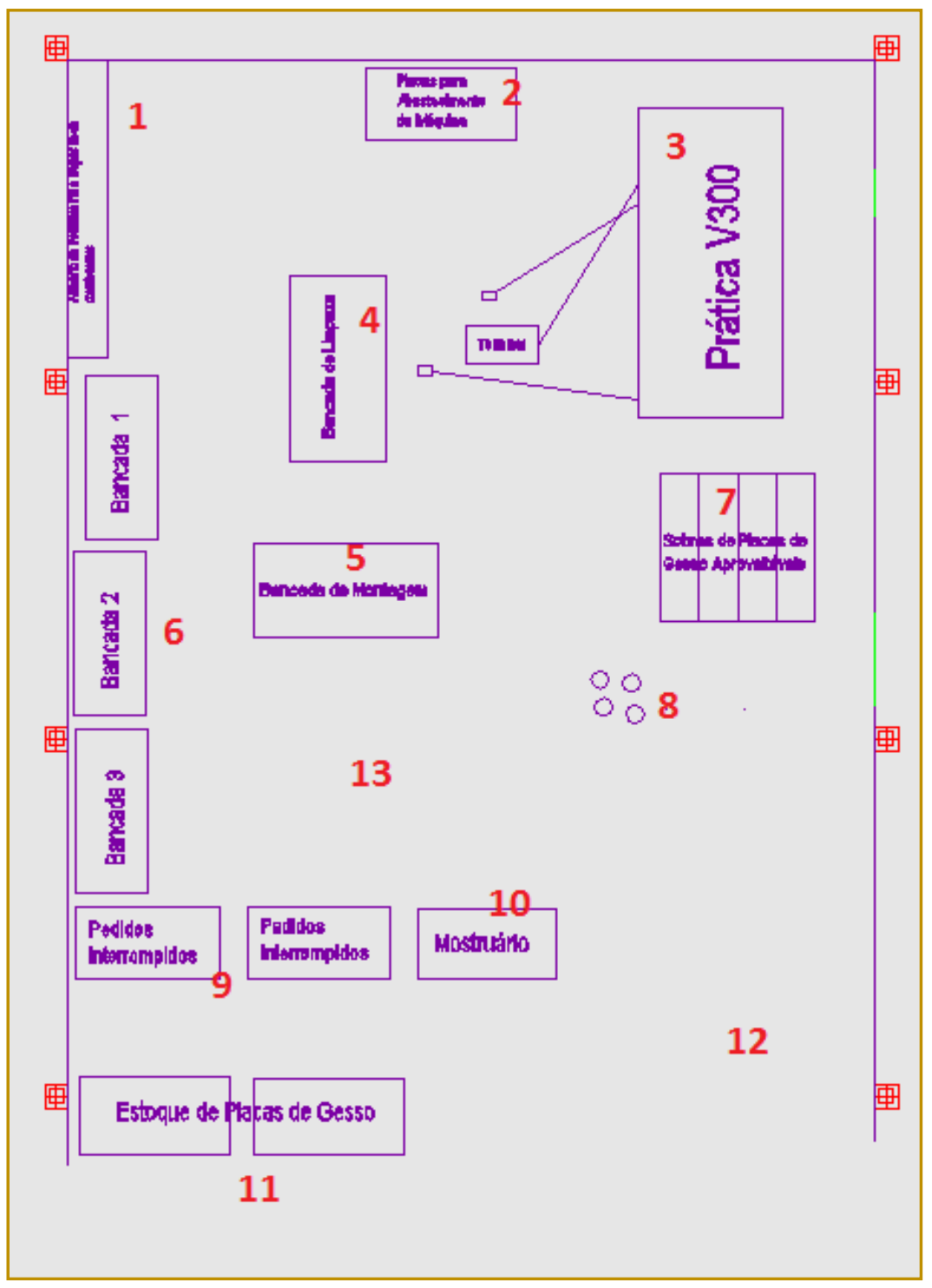

Fonte: Elaborado pelo autor (2016)

\subsection{FLUXOGRAMA}

Com a unidade de fabricação funcionando foi elaborado um fluxograma detalhado de todo o processo com 57 tarefas, de acordo com a literatura. Todo o caminho do operador para processar o produto foi desenhado. A Figura 9 ilustra apenas parte dele, devido ao tamanho, porem o mesmo está disponível no Apêndice A. 
Figura 9 - Fluxograma do processo produtivo

\begin{tabular}{|c|c|c|c|}
\hline Tarefa & $\begin{array}{l}\text { Distância percorrida } \\
\text { (m) }\end{array}$ & Símbolos & Operação \\
\hline 1 & & & Colocar EPI's; \\
\hline 2 & 40 & & Pegar a Ordem de Produção; \\
\hline 3 & 20 & & $\begin{array}{l}\text { Preparapar o Posto do trabalho: Ligar máquina de Corte, } \\
\text { Compressor e filtro; }\end{array}$ \\
\hline 4 & 15 & & $\begin{array}{l}\text { Efetuar rotinas de manutenção dos equipamentos conforme } \\
\text { periodicidade; }\end{array}$ \\
\hline 5 & 8 & & Verificar as ferramentas e material de trabalho; \\
\hline 6 & 8 & & Pegar materiais no estoque ; \\
\hline 7 & 40 & & $\begin{array}{l}\text { Solicitar ao operador de empilhadeira o reabastecimento de } \\
\text { placas de gesso acartonado novas; }\end{array}$ \\
\hline 8 & 6 & & $\begin{array}{l}\text { Afastar bancadas de limpeza e montagem para entrada da } \\
\text { empilhadeira; }\end{array}$ \\
\hline 9 & & & $\begin{array}{l}\text { Receber o estoque de placas de gesso acartonado da } \\
\text { empilhadeira; }\end{array}$ \\
\hline 10 & & & $\begin{array}{l}\text { Retornar a posição original das bancadas de limpeza e } \\
\text { montagem; }\end{array}$ \\
\hline 11 & & & Programar o pedido; \\
\hline 12 & 9 & & Abastecer a máquina com placa nova; \\
\hline 13 & & & Travar a máquina pisando no pedal \\
\hline 14 & & & Iniciar o corte, iniciando o ciclo; \\
\hline 15 & & & Destravar a máquina; \\
\hline 16 & 4 & & $\begin{array}{l}\text { Retirar as partes que não foram cortadas de cima para baixo, } \\
\text { segregando-as em local apropriado de acordo com a } \\
\text { possibilidade de reutilização; }\end{array}$ \\
\hline 17 & 15 & & $\begin{array}{l}\text { Retirar as peças cortadas uma a uma e coloca-las sobre a } \\
\text { bancada de limpeza; }\end{array}$ \\
\hline
\end{tabular}

Fonte: Elaborado pelo autor (2016)

\subsection{MAPOFLUXOGRAMA}

O mapofluxograma (Figura 10) foi construído para gerar uma visão mais clara do comportamento do processo produtivo em operação, ou seja, alocando cada operação do fluxograma na região específica do layout. 
Figura 10 - Mapofluxograma do processo produtivo

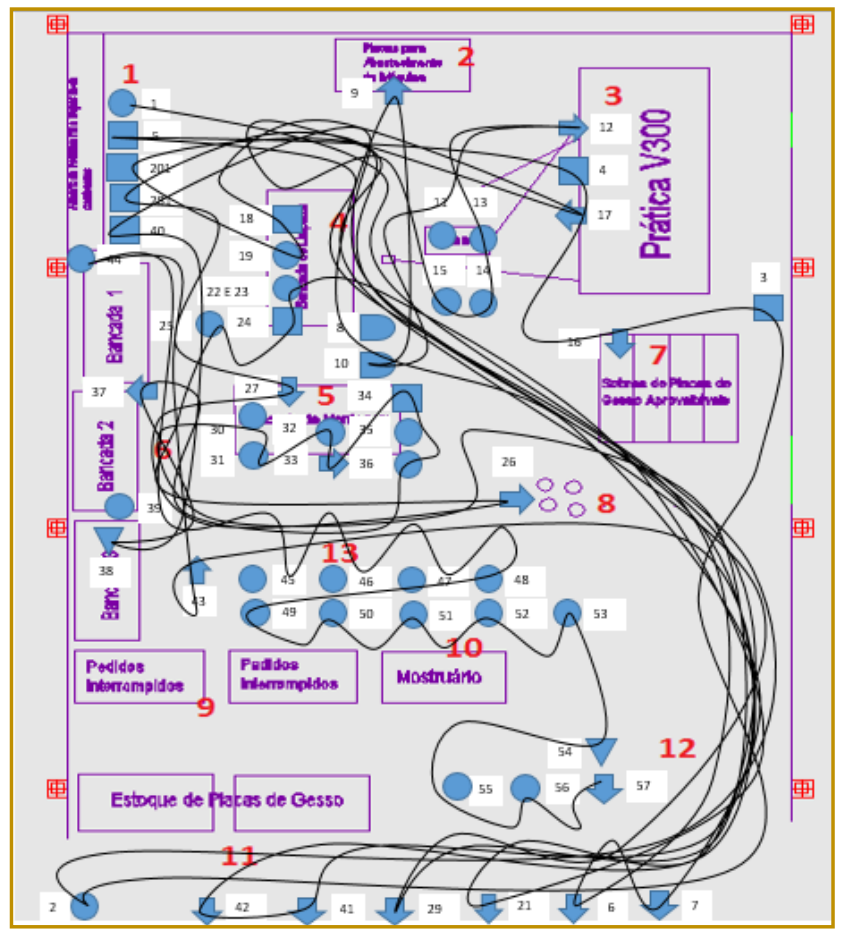

Fonte: Elaborado pelo autor (2016)

\subsection{DIAGRAMA DE ESPAGUETE}

A Figura 11 demonstra dois fluxos que ocorrem no processo produtivo, de azul o fluxo do processo de fabricação do produto e de laranja a movimentação de carga através da utilização da empilhadeira para apoiar as atividades necessárias.

Figura 11 - Diagrama de espaguete no layout encontrado

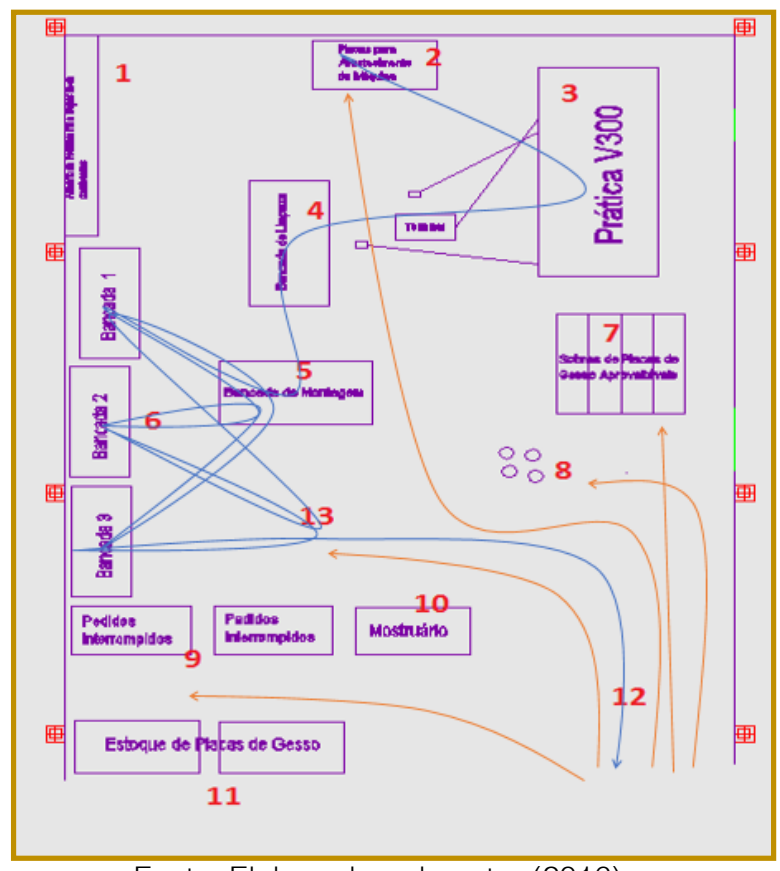

Fonte: Elaborado pelo autor (2016) 


\subsection{DIAGNÓSTICO \\ DA SITUAÇÃO}

\section{ENCONTRADA}

Pela descrição das atividades, e com auxílio das figuras 8 e 10 pode-se afirmar que o tipo de processo utilizado pela empresa é em lotes, distribuído em um layout por processo, embora sua divisão de processos não seja a ideal.

Nenhum estudo de layout havia sido realizado antes, portanto, a própria distribuição das máquinas e postos de trabalho foram escolhidos pelo "olho".

$\mathrm{Na}$ figura 10, captamos rapidamente que havia uma poluição visual e um fluxo desordenado de produção. É possível identificar e ter noção da distância espacial dos postos de trabalho e a distância percorrida pelo operador é exagerada, devido a quantidade de voltas que ele tem que dar para processar um único lote.

A figura 11 captura o processo de abastecimento e movimentação de materiais. Um congestionamento pode ser previsto, devido ao tamanho que a empilhadeira necessita para levar e recolher materiais, passando por meio de todo processo e interrompendo algumas funções como as etapas de limpeza (área 4) e montagem (área
5) que acabam tendo que dar passagem à empilhadeira, deslocando-se para possibilitar tal acesso.

Nota-se, que as operações de limpeza, não condizem muito bem com seus espaços ocupados, como por exemplo, o setor de limpeza, que por natureza, gera muita poeira e resíduos, que acaba se localizando no meio do galpão. Para os operários limparem a área por acúmulo de pedaços de peças do processo de limpeza, precisavam se deslocar, várias vezes, até os toneis para efetuarem o descarte.

Pode ser percebido que não existe áreas de estoques delimitadas e livres para operação sem interferências, o que pode gerar mais movimentação de carga para liberação de espaços para trânsito.

\subsection{OTIMIZAÇÃO DO LAYOUT}

O primeiro passo para o planejamento do layout, deve-se verificar o grau de relacionamento entre todos os postos de trabalho, como mencionado no referencial teórico, utilizaremos o diagrama de relacionamento para definir sua relação de proximidade entre si.

Figura 12 - Diagrama de relacionamento

\begin{tabular}{|c|c|c|c|c|c|c|c|c|}
\hline \multicolumn{7}{|c|}{ Corte - Linha de Produção } & Cód. & Proximidades \\
\hline A & \multicolumn{6}{|c|}{ Limpeza - Linha de Produção } & A & Absolutamente Importante \\
\hline $\mathrm{E}$ & A & \multicolumn{5}{|c|}{ Montagem - Linha de Produção } & $\mathrm{E}$ & Especialmente Importante \\
\hline $\mathrm{o}$ & $\mathrm{E}$ & A & \multicolumn{4}{|c|}{ Cura - Linha de Produção } & 1 & Importante \\
\hline $\mathrm{u}$ & 0 & $\mathrm{E}$ & A & \multicolumn{3}{|c|}{ Embalagem } & 0 & Pouco Importante \\
\hline $\mathrm{I}$ & $\mathrm{u}$ & $\mathrm{u}$ & $\mathrm{u}$ & A & Esto & & $\mathrm{u}$ & Sem Importância \\
\hline $\mathrm{u}$ & $\mathrm{u}$ & & 1 & $\mathrm{E}$ & A & Expedição & $\mathrm{x}$ & Não desejável \\
\hline
\end{tabular}

Fonte: Elaborado pelo autor (2016)

Observando a Figura $X$, a proximidade entre os setores segue a sequência de cima para baixo.

Respeitando a dificuldade de locomoção da máquina de corte e para melhor disposição dos espaços, o melhor arranjo dos processos é a construção do layout em formato de "U", segue figura abaixo: 
Figura 13 - Disposição das áreas na fábrica quanto a proximidades

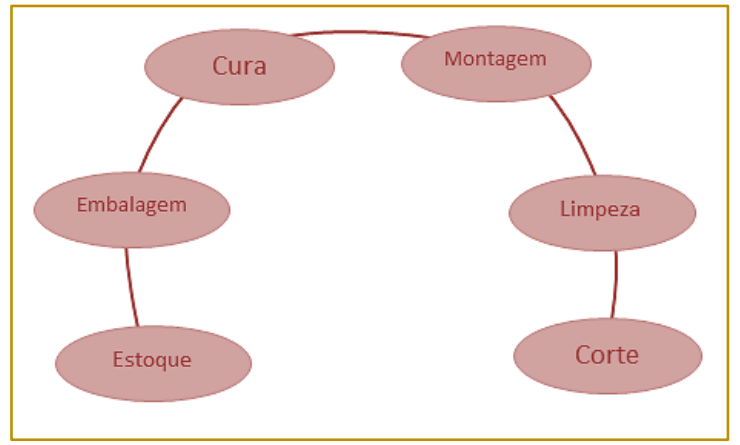

Fonte: Elaborado pelo autor (2016)

Foi elaborado um layout visando solucionar os problemas:

- Melhor aproveitamento dos espaços;

- Redução das distâncias percorridas;

- Organização visual;

- Área de fluxo de máquinas identificada;
- Fluxo de pessoas, máquinas e produtos mais seguro;

- Respeitar as diretrizes da NR-12;

- Aproximação das áreas de processo.

\subsubsection{NOVO LAYOUT}

Figura 14 - Layout proposto

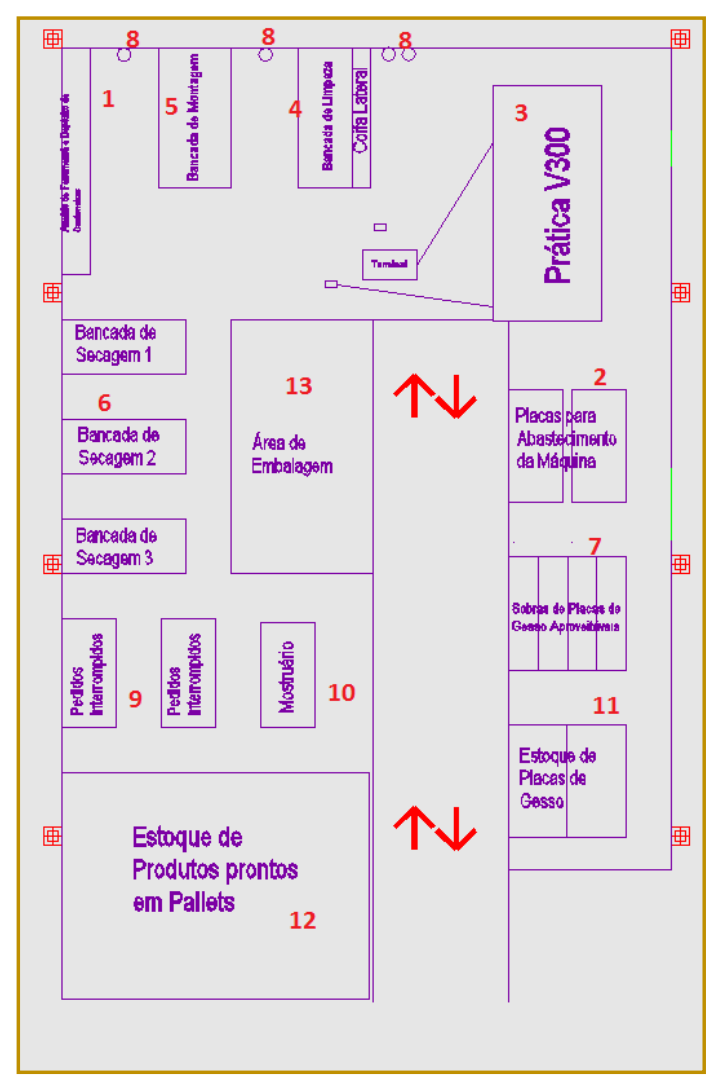

Fonte: Elaborado pelo autor (2016) 
As mudanças em evidência foram:

- Uma área delimitada para movimentação de máquinas e materiais, facilitando o acesso e segurança do setor;

- Lugar de abastecimento modificado, onde procurou não causar interferência nos outros processos ao alimentar a máquina;

- $\quad$ Bancada de Limpeza (área 4), com ganho de coifa para aspirar melhor as partículas suspensas e posicionada estrategicamente ao lado da etapa seguinte;

- Toneis de lixo (área 8) bem posicionados às áreas de utilização, reduzindo deslocamentos;

- A Bancada de montagem ganhou rodinhas visando facilitar o deslocamento para as áreas de cura;

- As bancadas (área 6), antes usadas como apoio, passaram a ser utilizada para cura ou secagem das peças;

- A área de embalagem, 13, foi demarcada e posicionada em local fixado a frente das bancadas de cura ou secagem junto com acesso a área de movimentação das máquinas;

- Área de estoque de produtos acabados (área 12), retirada anteriormente do centro da produção juntamente com a área de embalagem e deslocado para a parte mais externa da área da fábrica e também com acesso a área de movimentação de máquina.

\subsection{AVALIAÇÃO DOS RESULTADOS}

As atividades e aplicações das ferramentas de fluxograma e mapofluxigrama foram responsáveis por dar instância e visibilidade no processo, ganhando estratégias de padronização, redução de deslocamentos desnecessários, agrupar atividades afins e excluir outras que não agregam valor. Os resultados foram listados e comparados na Figura abaixo:

Figura 15 - Ganhos com a otimização do layout

\begin{tabular}{|c|c|c|c|c|c|c|c|c|c|c|c|c|c|}
\hline \multirow{2}{*}{\multicolumn{2}{|c|}{ VISÃO POR OPERAÇÃO }} & \multicolumn{4}{|c|}{ GANHO } & \multicolumn{4}{|c|}{ DEPOIS } & \multicolumn{4}{|c|}{ ANTES } \\
\hline & & \multicolumn{2}{|c|}{ Distância percorrida } & \multicolumn{2}{|c|}{ Operações } & \multicolumn{2}{|c|}{ Distância percorrida } & \multicolumn{2}{|c|}{ Operações } & \multicolumn{2}{|c|}{ Distância percorrida } & \multicolumn{2}{|c|}{ Operações } \\
\hline Símbolo & Operação & \multirow{2}{*}{$\begin{array}{l}\text { (m) } \\
-80\end{array}$} & $\%$ & \multirow{2}{*}{$\begin{array}{c}\text { (qtde) } \\
-2\end{array}$} & \multirow{2}{*}{$\begin{array}{c}\% \\
7,14 \%\end{array}$} & \multirow{2}{*}{$\begin{array}{c}\text { (m) } \\
1\end{array}$} & \multirow{2}{*}{$\begin{array}{c}\% \\
1 \%\end{array}$} & \multirow{2}{*}{$\begin{array}{c}\text { (qtde) } \\
26\end{array}$} & \multirow{2}{*}{$\begin{array}{c}\% \\
58 \%\end{array}$} & \multirow{2}{*}{$\begin{array}{l}\text { (m) } \\
81\end{array}$} & \multirow{2}{*}{$\begin{array}{c}\% \\
26 \%\end{array}$} & \multirow{2}{*}{$\begin{array}{c}\text { (qtde) } \\
28\end{array}$} & \multirow{2}{*}{$\begin{array}{c}\% \\
49 \%\end{array}$} \\
\hline 0 & Operação & & $98,77 \%$ & & & & & & & & & & \\
\hline$\Rightarrow$ & Transporte & -81 & $58,70 \%$ & -5 & $31,25 \%$ & 57 & $51 \%$ & 11 & $24 \%$ & 138 & $45 \%$ & 16 & $28 \%$ \\
\hline & Inspeção & -19 & $30,65 \%$ & -3 & $33,33 \%$ & 43 & $38 \%$ & 6 & $13 \%$ & 62 & $20 \%$ & 9 & $16 \%$ \\
\hline 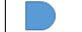 & Espera & -6 & $100,00 \%$ & -2 & $100,00 \%$ & 0 & $0 \%$ & 0 & $0 \%$ & 6 & $2 \%$ & 2 & $4 \%$ \\
\hline$\nabla$ & Armazenamento & -10 & $47,62 \%$ & 0 & $0,00 \%$ & 11 & $10 \%$ & 2 & $4 \%$ & 21 & $7 \%$ & 2 & $4 \%$ \\
\hline & & -196 & $63,64 \%$ & -12 & $21,05 \%$ & 112 & $100 \%$ & 45 & $100 \%$ & 308 & $100 \%$ & 57 & $100 \%$ \\
\hline \multicolumn{2}{|c|}{ VISÃO POR ÁREA } & \multicolumn{4}{|c|}{ GANHO } & \multicolumn{4}{|c|}{ DEPOIS } & \multicolumn{4}{|c|}{ ANTES } \\
\hline \multirow{2}{*}{\multicolumn{2}{|c|}{ Área de Operação }} & \multicolumn{2}{|c|}{ Distância percorrida } & \multicolumn{2}{|c|}{ Operaç̄os } & \multicolumn{2}{|c|}{ Distância percorrida } & \multicolumn{2}{|c|}{ Operaç̄oses } & \multicolumn{2}{|c|}{ Distância percorrida } & Oper & \\
\hline & & (m) & $\%$ & (qtde) & $\%$ & (m) & $\%$ & (qtde) & $\%$ & (m) & $\%$ & (qtde) & $\%$ \\
\hline Linha de $\mathrm{Pr}_{\mathrm{r}}$ & rodução & -74 & $45,12 \%$ & -6 & $16,67 \%$ & 90 & $80 \%$ & 30 & $67 \%$ & 164 & $53 \%$ & 36 & $63 \%$ \\
\hline Estoque & & -71 & $89,87 \%$ & -5 & $83,33 \%$ & 8 & $7 \%$ & 1 & $2 \%$ & 79 & $26 \%$ & 6 & $11 \%$ \\
\hline Embalagem & & -51 & $78,46 \%$ & -1 & $7,14 \%$ & 14 & $13 \%$ & 13 & $29 \%$ & 65 & $21 \%$ & 14 & $25 \%$ \\
\hline Expedição & & 0 & $0,00 \%$ & 0 & $0,00 \%$ & 0 & $0 \%$ & 1 & $2 \%$ & 0 & $0 \%$ & 1 & $2 \%$ \\
\hline & & -196 & $63,64 \%$ & -12 & $21,05 \%$ & 112 & $100 \%$ & 45 & $100 \%$ & 308 & $100 \%$ & 57 & $100 \%$ \\
\hline
\end{tabular}

Fonte: Elaborado pelo autor (2016).

Conforme pode ser visto na Figura 15, a padronização de atividades juntamente com o estudo do novo layout, proporcionou uma redução de distâncias de 196m ou 63,64\%, dados significativos de esforço reduzido.
Na Figura 26, foi possível comparar os layouts e verificar que a proposta de modificação serviu implementando o processo em cadeia, respeitando seu fluxo, dando espaço e segurança necessários à produção, ganhando uma visão organizada da fábrica. 
Figura 16 - Comparação entre layouts

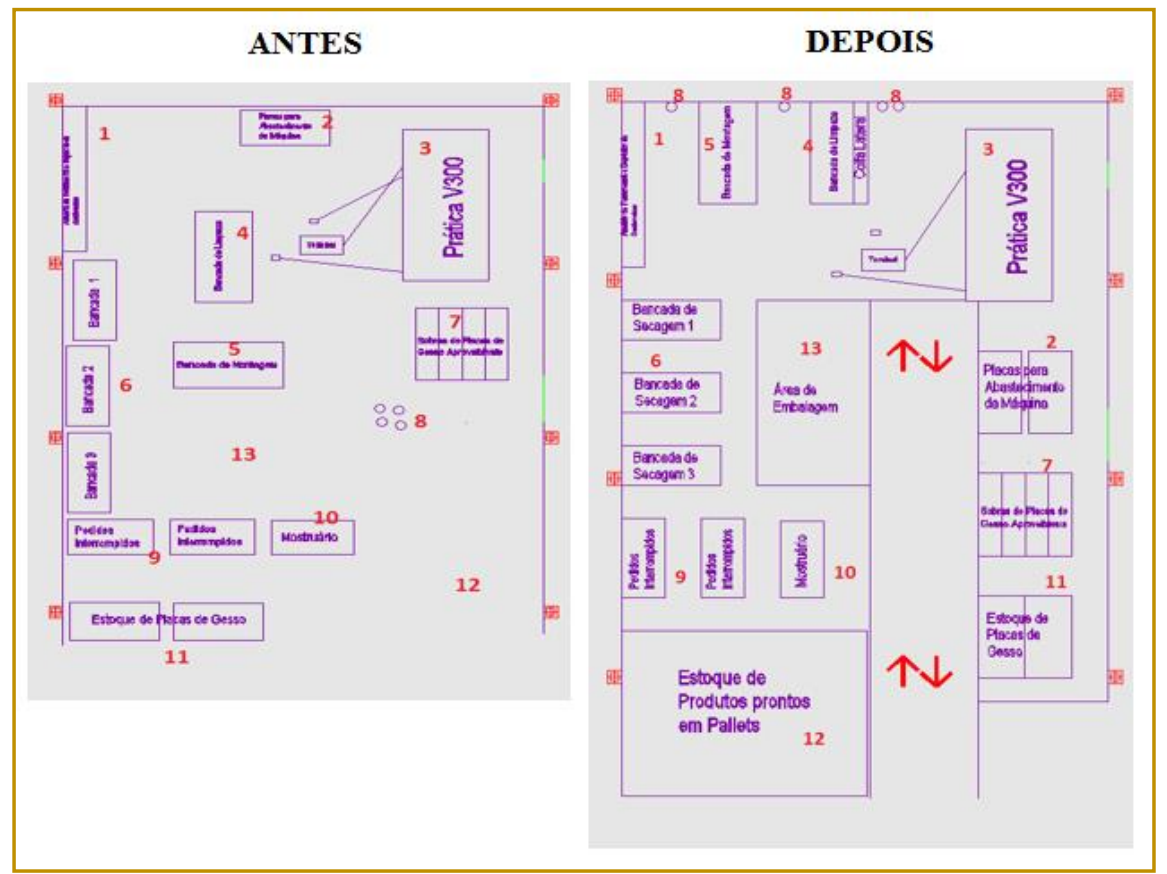

Fonte: Elaborado pelo autor (2016)

Pode ser percebido que as modificações promoveram:

- Espaços existentes anteriormente foram melhor distribuídos e aproveitados;

- O arranjo de processos foi modificado com a aplicação do diagrama de relacionamento, produzindo uma redução das distancias entre processos;

- A criação de uma rua para tráfego da empilhadeira e a alocação das áreas que necessitam desse apoio juntas, possibilitou a circulação isolada da máquina, gerando maior segurança, eliminando interferências e aumentando a velocidade no escoamento da produção.

Após a construção da otimização do layout, foi realizado um novo mapofluxorama para analisar e verificar como os processos iam se comportar no novo ambiente:

Figura 17 - Comparação do Mapofluxograma

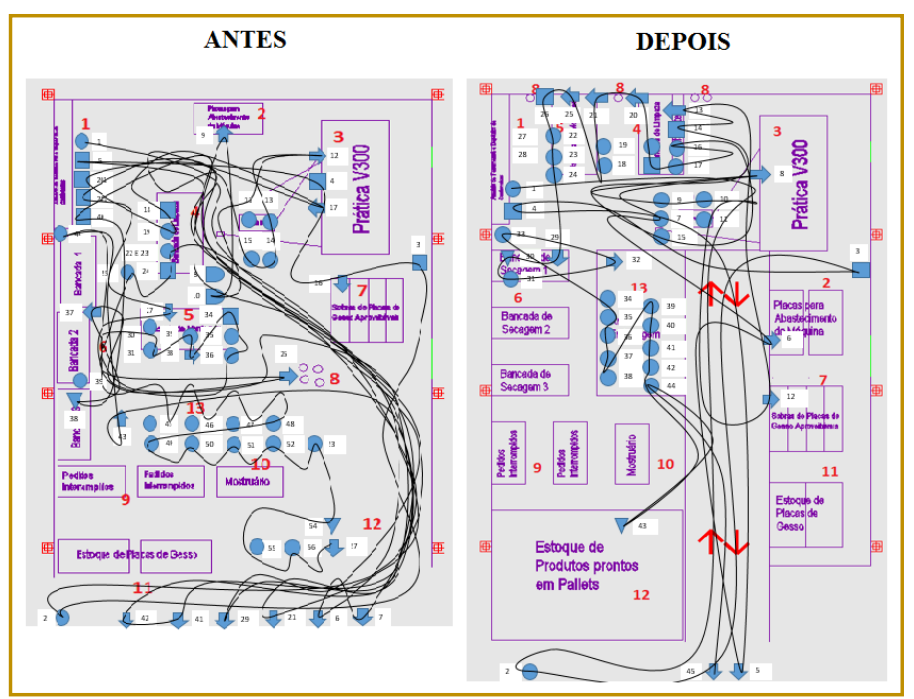

Fonte: Elaborado pelo autor (2016). 
Fica claramente visível a limpeza de atividades no novo layout, devido também a remoção de atividades desnecessárias, que contribuiu para descongestionar as áreas de maior fluxo.

O diagrama de espaguete providenciou uma visualização ainda melhor do resultado obtido, notando apenas o fluxo de movimentação, afirmando o comentário acima e cumprindo com a facilidade no escoamento da produção. (Figura 18)

Na nova situação proposta, não existe mais interrupção das atividades para reabastecimento de matéria prima na máquina de corte, uma vez a área de movimentação de carga foi posicionada de forma a atender as demandas sem interferir nos processos em andamento. (Figura 17)

Figura 18 - Comparação do diagrama de espaguete

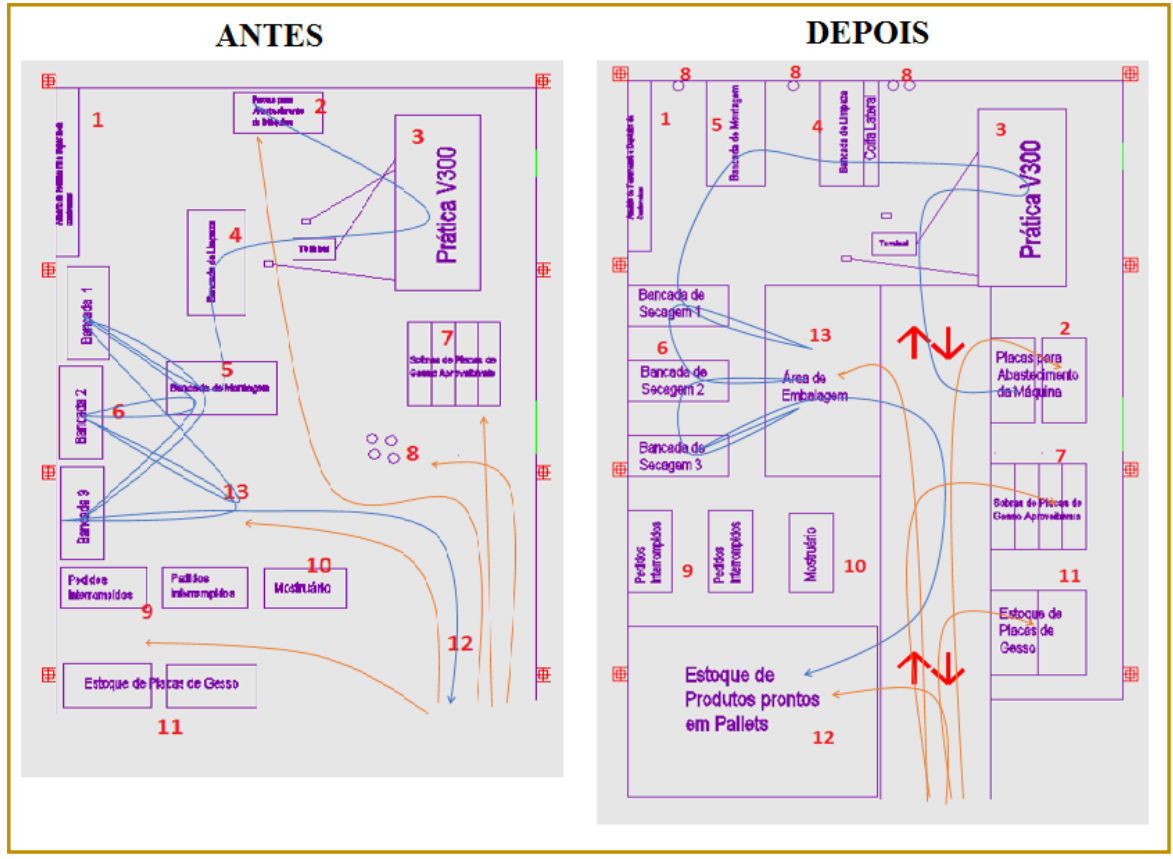

Fonte: Elaborado pelo autor (2016).

\section{CONCLUSÕES}

A abertura deste trabalho segue em analisar uma situação com deficiências e estudar formas de amparar e dar assistência a essas falhas, que muitas vezes, podem ser solucionadas no arranjo físico, proporcionando uma alternativa acessível, em comparação ao aumento da produtividade pela aquisição de máquinas e grandes investimentos, que não necessariamente sanariam as deficiências.

O estudo foi segmentado em três partes: a primeira se constitui em registrar com ferramentas da engenharia de métodos o layout existente, analisar e encontrar falhas. A segunda, em prover as mudanças, com base no diagrama de relacionamento, caracterizando os postos que deveriam ser posicionados de maneira estratégica, retirando processos desnecessários e alavancando o fluxo do processo. Já a terceira, e não menos importante, a comparação entre os dois layouts existentes a partir das mesmas ferramentas e métodos utilizados na feitura do primeiro layout.

Todos os processos de uma fábrica são impactados sob o meio que os limitam (arranjo físico). Elaborando um sistema inteligente, é possível ter os postos de trabalho bem posicionados de maneira que um processo não interfira no outro de forma negativa. Aproximando o bom fluxo de processos com o ganho de qualidade, afinal, com processos bem definidos e padronizados, é possível se detectar essa qualidade, logo, naturalmente a produtividade e o ganho menor de tempo para se produzir um alçapão é trazido em questão.

Não tão só com o ganho da produtividade, o fechamento do trabalho prova a relevância de estudar e conhecer os processos internos, analisar e comparar com novos cenários 
possíveis melhorias a serem implantados e organizando processos para possibilitar fluxos de produção mais harmônico e sequenciais.

\section{REFERÊNCIAS}

[1] Barnes, R. M. Estudo de movimentos e de tempos: Projeto e medida do trabalho. São Paulo: Edgard Blücher, 1977.

[2] Bastos, Alexandre Paranhos. Fatores que interferem na Produtividade: Uma análise comparada de quatro unidades de diferentes países de uma mesma transacional. Ufrj, 2008.

[3] Correia, K. S. A.; Leal, F.; Almeida, D. A. Mapeamento de Processos: Uma Abordagem para Analise de Processos de Negocio. XXII Encontro Nacional de engenharia de Produção - Enegep. Curitiba - PR, 2002

[4] Faveri F. Identificação dos Desperdícios em um Serviço de Emergência com a Utilização da Metodologia Lean Thinking, 2013. Disponivel em: < http://biblioteca.asav.org.br/vinculos/00000c/00000 c03.pdf>. Acesso em 22/04/2017.

[5] FBF Sistemas. O que é ergonomia? Portal Economia do Trabalho, 2000. Disponível em: <http://www.ergonomianotrabalho.com.br/ergonomi a.html> Acesso 04 maio 2017.

[6] Gerlach, Gustavo Proposta de melhoria de layout visando a otimização do processo produtivo
Ficando provado que um bom arranjo físico atribuiu grandes ganhos à empresa.

em uma empresa de pequeno porte. Fahor-RS, 2013.

[7] Moreira, D. A. Administração da produção e operações - São Paulo: Pioneira Thomson Learning, 2002.

[8] Muther. R. Systematic Layout Plannin. Boston, 1961.

[9] Silva, Alessandro L. da Desenvolvimento de um modelo de análise e projeto de layout industrial, em ambientes de alta variedade de peças, orientado para produção enxuta. USP-SP, 2009.

[10] Slack, N; Chambers, S; Johnston, R. Administração da Produção. 3 Ed. São Paulo:Atlas, 2009.

[11] Souto, M. S. M .L. Engenharia de Métodos. Curso de especialização em Engenharia de Produção. PPGEP/UFPB, 2004.

[12] Tardin, Matheus G.; Elias, B. R.; Ribeiro, P. F.; Ferreguette, C. R. Aplicação de conceitos de Engenharia de Métodos em uma panificadora. Um estudo de caso na panificadora Monza. Enegep, Salvador, n. XXXIII, out. 2013. 
APÊNDICE A - FLUXOGRAMAS DE PROCESSO

Fluxograma de Processo da Situação Encontrada

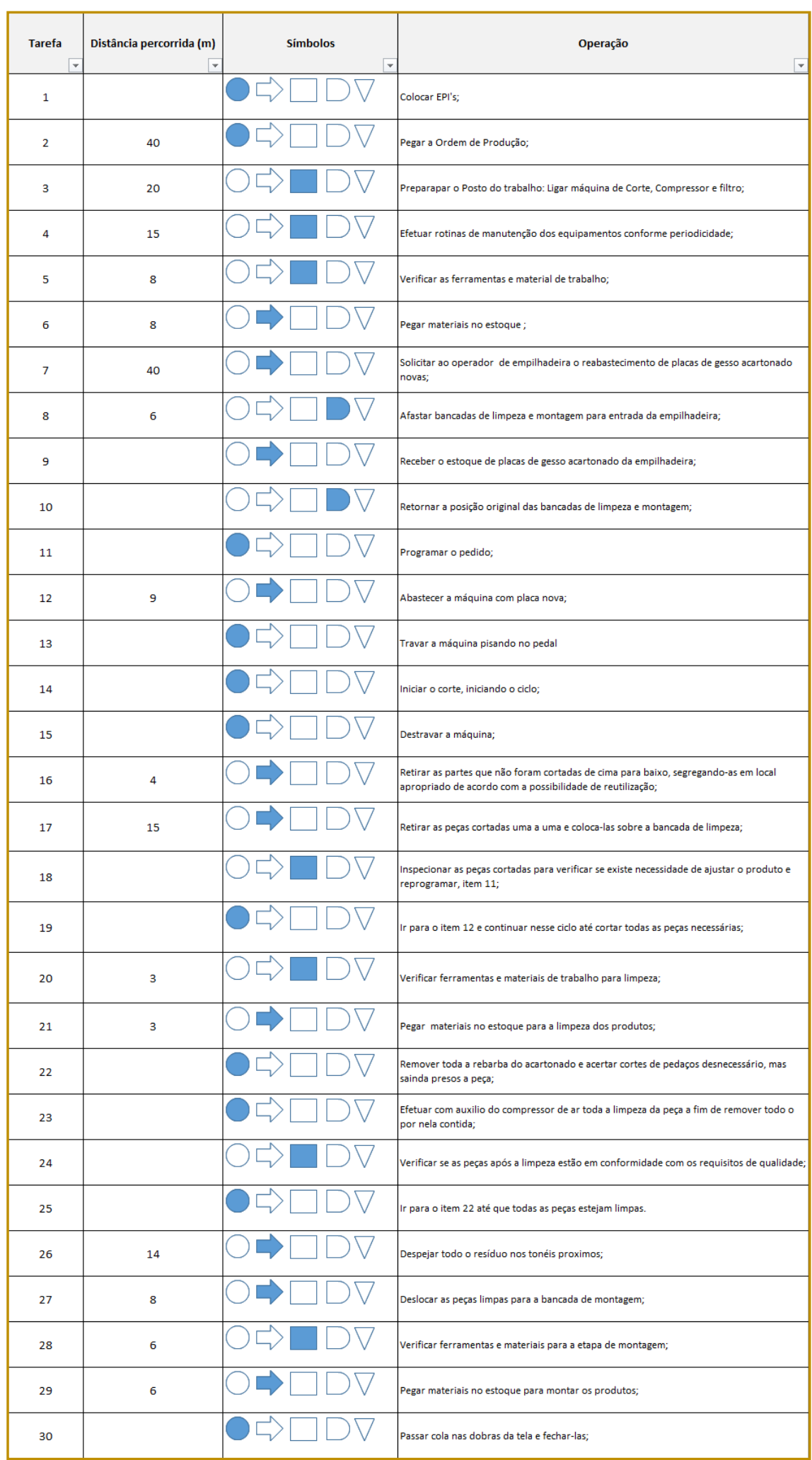




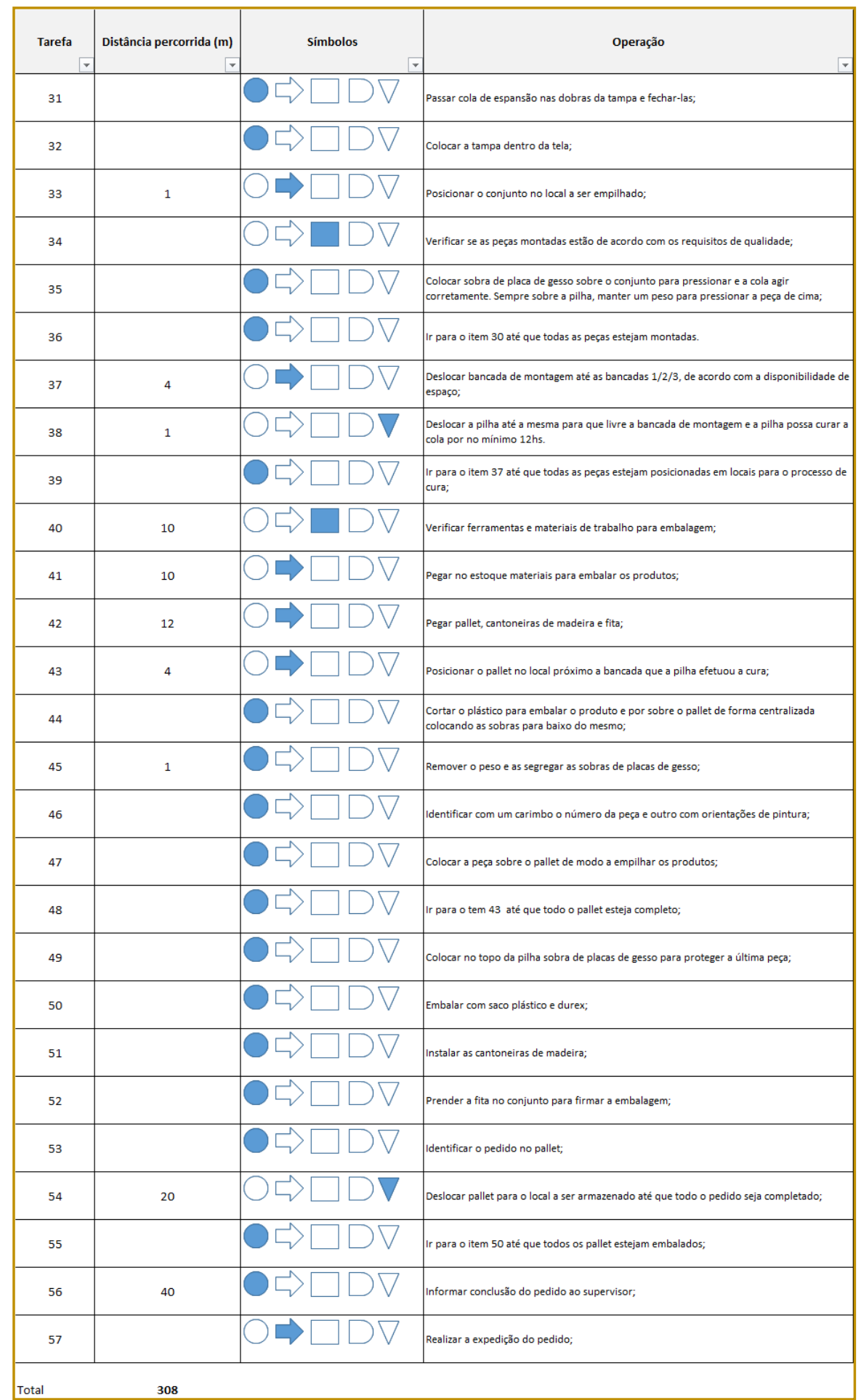


Fluxograma de Processo da Situação Proposta

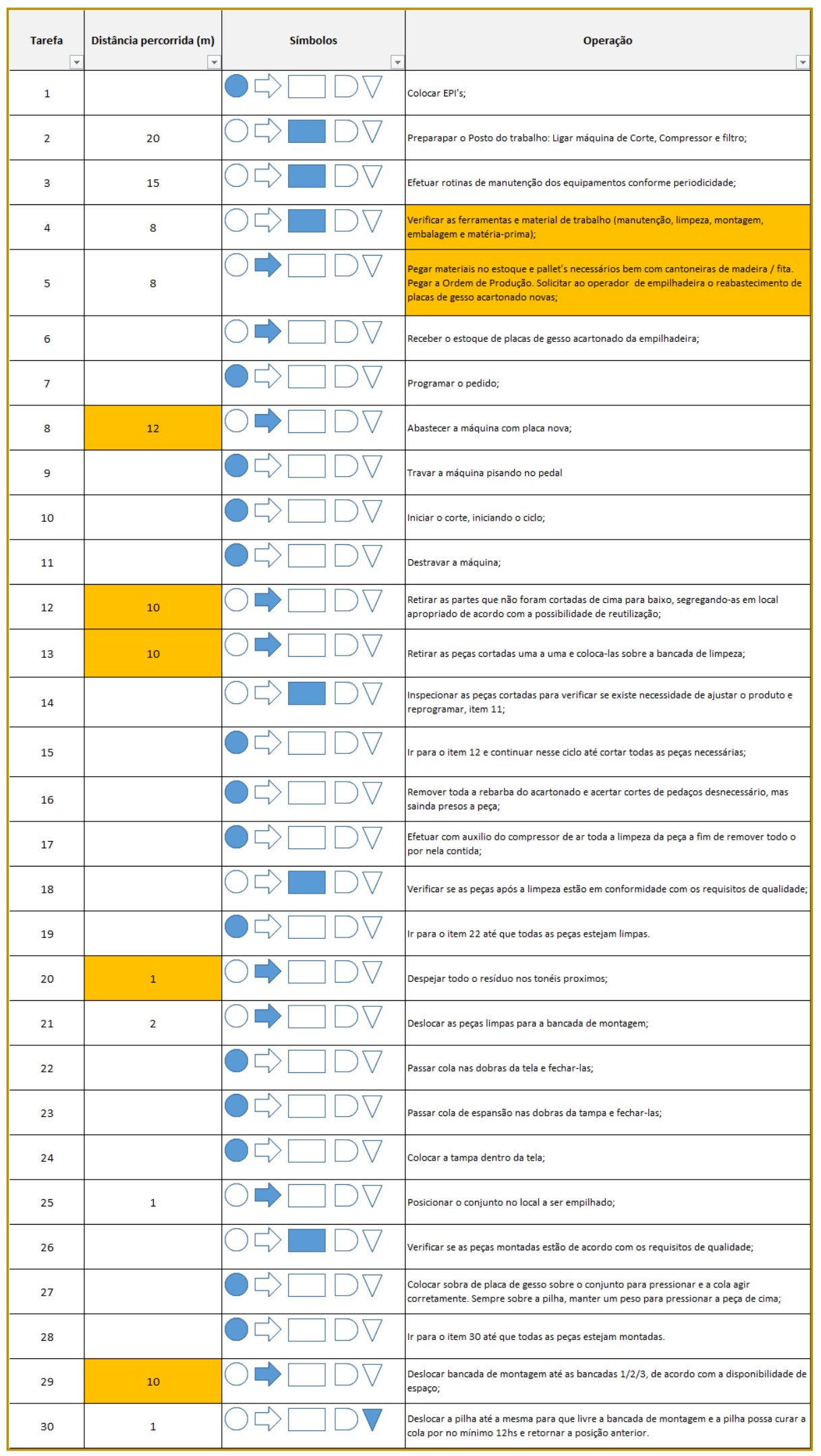




\begin{tabular}{|c|c|c|c|}
\hline Tarefa & Distância percorrida (m) & Símbolos & Operação \\
\hline 31 & & $>$ & $\begin{array}{l}\text { Ir para o item } 37 \text { até que todas as peças estejam posicionadas em locais para o processo de } \\
\text { cura; }\end{array}$ \\
\hline 32 & 3 & & Posicionar o pallet no local próximo a bancada que a pilha efetuou a cura; \\
\hline 33 & & & $\begin{array}{l}\text { Cortar o plástico para embalar o produto e por sobre o pallet de forma centralizada } \\
\text { colocando as sobras para baixo do mesmo; }\end{array}$ \\
\hline 34 & 1 & & Remover o peso e as segregar as sobras de placas de gesso; \\
\hline 35 & & & Identificar com um carimbo o número da peça e outro com orientaç̃oes de pintura; \\
\hline 36 & & & Colocar a peça sobre o pallet de modo a empilhar os produtos; \\
\hline 37 & & & Ir para o tem 43 até que todo o pallet esteja completo; \\
\hline 38 & & & Colocar no topo da pilha sobra de placas de gesso para proteger a última peça; \\
\hline 39 & & & Embalar com saco plástico e durex; \\
\hline 40 & & & Instalar as cantoneiras de madeira; \\
\hline 41 & & & Prender a fita no conjunto para firmar a embalagem; \\
\hline 42 & & & Identificar o pedido no pallet; \\
\hline 43 & 10 & & Deslocar pallet para o local a ser armazenado até que todo o pedido seja completado; \\
\hline 44 & & & Ir para o item 50 até que todos os pallet estejam embalados; \\
\hline 45 & & & Realizar a expedição do pedido; \\
\hline Total & 112 & & \\
\hline
\end{tabular}

Obs: Itens em laranja sinalizam modificação. 


\section{Papítulo 9}

\section{GESTÃO DA MANUTENCCÃO INDUSTRIAL EM TRANSIÇÃO PARA A INDÚSTRIA 4.0: CONTROLE MOBILE, CONSIDERAÇÕES SOBRE ESTA NOVA TECNOLOGIA}

\section{Edson Pereira Silva}

\section{Adriano José Correia}

Gilvan Alves Ribeiro

Ricardo Luiz Ciuccio

\section{José Benedito Sacomano}

Resumo: A Indústria 4.0, novo paradigma de produção, promete aumento de produtividade e customização em massa, com redução de custos. A gestão de manutenção tem agora a tecnologia mobile, que apoiada na Internet se propõe a melhorar esta gestão, reduzindo custos, aumentando a produtividade, qualidade e confiabilidade de seus serviços, de forma sustentável. Este artigo, utilizando metodologia de pesquisa bibliográfica, aborda os requisitos técnicos, funcionalidades, vantagens e desvantagens, sugerindo metodologia de implantação da tecnologia mobile, de interesse para a indústria e academia, uma ferramenta para a gestão da manutenção industrial em transição para a Indústria 4.0. Muitas são as vantagens possibilitadas pelo uso desta tecnologia, contudo algumas barreiras como a segurança das informações, resistência à adoção desta tecnologia, e mau uso da mesma, ainda são pontos para melhorias.

Palavras chave: Gerenciamento de manutenção, Indústria 4.0, inovação, indicadores, mobilidade, custo, tecnologia, sustentabilidade. 


\section{INTRODUÇÃO}

Qualidade e confiabilidade são determinantes nas operações de manutenção nas indústrias (ASSOCIAÇÃO BRAŞILEIRA DE MANUTENÇÃO E GESTÃO DE ATIVOS ABRAMAN, 2017; COLTRO, 1996; SELLITTO, 2005); isto para dar sustentação de forma que as indústrias possam inovar e desenvolver soluções, a fim de participar de forma competitiva e sustentável no mercado (BARBIERI, 2010).

A inovação não se dá apenas em produtos, mas também nos modelos produtivos. A denominada Quarta Revolução Industrial, ou Indústria 4.0, é identificada pela digitalização e integração entre produtos e processos produtivos, cadeia de suprimentos e principais stakeholders em grau crescente (CHOI et al., 2016; CONFEDERAÇÃO NACIONAL DA INDÚSTRIA - CNI, 2016; DE MORAIS; MONTEIRO, 2016). Indústria 4.0 é a completa transformação de toda a esfera de produção industrial através da fusão de tecnologias digitais apoiadas na Internet, com a indústria convencional (EUROPEAN PARLIAMENT, 2015).

Com o uso da Internet como meio de troca de informações, um número ilimitado de dispositivos podem ser conectados, compartilhando informações, o que passou a se chamar Internet das Coisas, ou Internet of Things (IoT, da sigla em inglês) (CNI, 2016).

No que se refere aos requisitos para uma empresa ter um processo estabelecido nos moldes sugeridos da Indústria 4.0 o setor de manutenção deverá sofrer profundas mudanças em seus processos, e o uso da tecnologia mobile como suporte de manutenção deverá se difundir cada vez mais na Indústria 4.0.

O setor de Planejamento e Controle de Manutenção (PCM) continuará sendo o elo entre a máquina e o homem no que tange às atividades de manutenção, contudo a dinâmica do mesmo deverá passar por transformações, desde a coleta de informação e identificação de sinais de falha, até o direcionamento e execução da manutenção (SOUZA, 2009).

O propósito deste estudo é pesquisar o uso da tecnologia mobile como suporte à gestão de manutenção, vantagens e desafios, de interesse para a indústria e academia, neste momento de transição para a Indústria 4.0, objeto de escassos estudos acadêmicos.

\section{O SISTEMA DE CONTROLE MOBILE NA} INDÚSTRIA 4.0

Este trabalho se baseia em pesquisa bibliográfica, com base em referências publicadas em livros, periódicos, sites e anais de congressos (MARTINS; THEÓPHILO, 2009).

O modelo de produção passou por várias fases, com novas práticas e tecnologias sendo aplicadas à manufatura, visando a aumentar sua eficiência e eficácia (MENDES; SAMPAIO, 2016). Na Indústria 4.0, o mundo físico se funde com o virtual; baseados na Internet, produção, manutenção, fornecedores, compradores, distribuidores e até mesmo produtos e máquinas são integrados e conectados digitalmente, proporcionando uma cadeia de valor integrada como jamais visto antes (HERMANN; PENTEK; OTTO, 2015; FEDERAÇÃO DAS INDÚSTRIAS DO ESTADO DO RIO DE JANEIRO - FIRJAN, 2016; KAGERMANN; WAHLSTER; HELBIG, 2013).

A manutenção industrial no Brasil faz uso reduzido de softwares nos processos de gestão da manutenção, e limitado é o número das indústrias que utilizam sistema de gestão totalmente informatizado. Há um gap na dinâmica entre o planejamento da manutenção, sua execução e controle e, uma vez que a coleta e inserção das informações para gestão das atividades desta área são realizadas pelo uso de planilhas e controles impressos na realização da maioria das atividades da rotina do setor de manutenção, sendo preenchidos à mão, para posteriormente serem digitalizadas e lançados no sistema do software de gestão da manutenção, possibilitando falhas no fluxo da informação, podendo prejudicar os resultados e até mesmo onerando os custos gerais dos serviços realizados.

Para aprimorar o gerenciamento departamento de manutenção, melhor controlar o almoxarifado de peças de manutenção e reduzir o gap entre execução e inserção de dados no sistema, foram desenvolvidos dispositivos móveis de controle, ou seja, acesso ao software de manutenção via aplicativos em dispositivos moveis - mobile.

Os softwares de gestão da manutenção com modulo mobile são desenvolvidos em plataformas que usam aplicativos de fácil compreensão tendo característica intuitiva e atrativa, facilitando a implantação do sistema, 
trazendo uma tecnologia que contribui para o aumento da qualidade e desempenho do processo como um todo. Inovar aperfeiçoando tanto as ferramentas de controle quanto sua aplicação é estrategicamente importante para promover o aumento de produtividade com maior qualidade e confiabilidade da manutenção (CORREIA; RIBEIRO; CIUCCIO, 2015).

\subsection{MÓDULOS DE CONTROLES PORTÁTEIS}

A tecnologia mobile pode ser utilizada nos seguintes dispositivos: Palm, Pocket PC, Smartphones e Tablets, operando no sistema Android e iOS. Os dispositivos móveis portáteis possibilitam acesso de forma flexível ao software de manutenção em qualquer localidade da empresa, possibilita rápida entrada de dados e acesso imediato às informações nas operações de manutenção, possibilitando executar abertura, fechamento e cancelamento de ordens de serviço e coleta acumulativa de dados (CORREIA; RIBEIRO; CIUCCIO, 2015).

Informações registradas no aparelho móvel são registradas de forma imediata ou a posteriori no banco de dados do software de manutenção ampliando a eficiência do processo. Há também módulos para controles em campo, controle sobre materiais de almoxarifado, inspeções periódicas, cadastros básicos e históricos.

Essas soluções trabalham em ambiente web, ou seja, pela Internet, permitindo realizar consultas a diversos dados, aumentando de forma significativa a eficiência do processo, pois viabiliza a inserção imediata, em tempo real, das informações recolhidas.

\section{REQUISITOS TÉCNICOS PARA INSTALAÇÃO}

As soluções móveis estruturadas para possibilitar as operações de controle da manutenção, podem utilizar os sistemas operacionais: Android 2.3 ou superior Windows Mobile 5.0 ou superior (Fig. 1) ou Palm OS 3.5 ou superior. Alguns softwares de manutenção possuem versões para sistemas como IOS 7.0 ou superior. Os aparelhos requerem reduzidos pré-requisitos de hardware, bem como tela de tamanho conveniente, e câmera com resolução que possa atendar as necessidades básicas. Naturalmente os fabricantes do aplicativo sugerem sistemas operacionais e modelos mais adequados às necessidades e funcionalidades requeridas conforme cada cliente.

Figura 1. Alguns sistemas operacionais

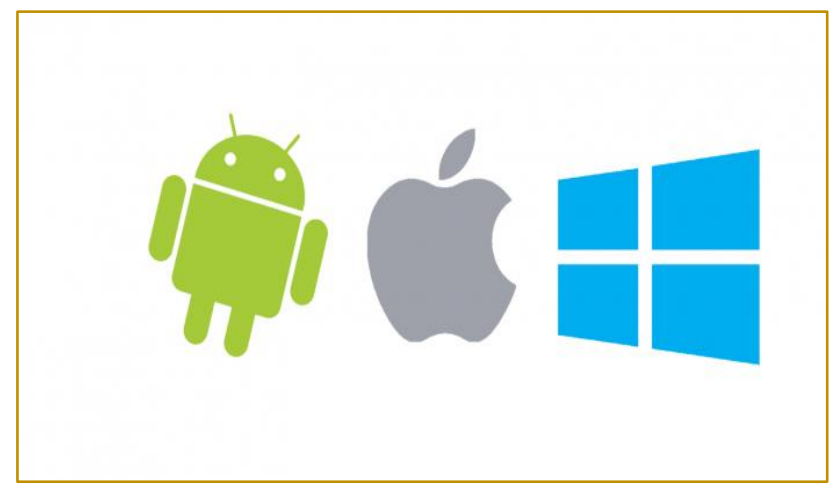

Fonte: Arena 4G (2016)

Em loja virtual ou pelo Google Play é possível fazer o download dos aplicativos para a qual o software esteja disponível, utilizando-se do próprio aparelho móvel de origem (figura 2). Há aplicativos padrões, com um banco de dados mínimo, para potenciais clientes poderem conhecer gratuitamente como os softwares funcionam. O cliente uma vez autorizado terá acesso a todas as funcionalidades, podendo utilizar o serviço em sua rotina de trabalho, gerando e processando informações a fim de serem armazenadas e utilizadas, tudo conforme as licenças e planos de serviços previamente adquiridos por sua empresa. 
Figura 2. Dispositivos móveis

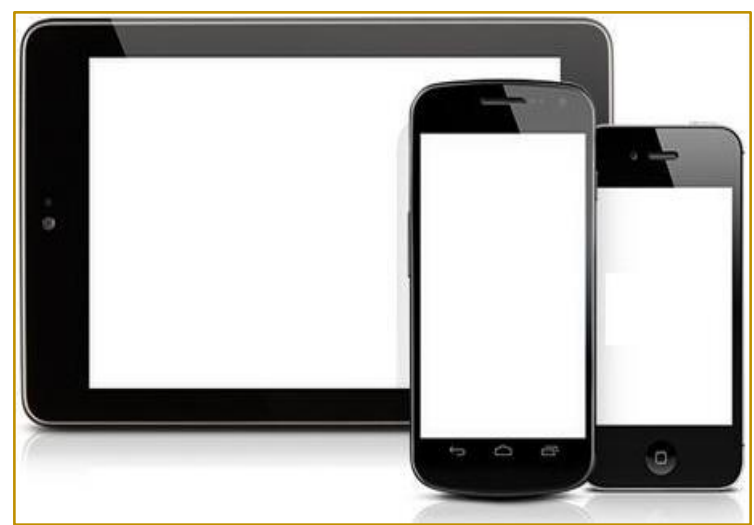

Fonte: Engeman (2016)

\section{CARACTERÍSTICAS E FUNCIONAMENTO}

\subsection{DIGITAÇÕES DE SERVIÇOS REALIZADOS}

Na manutenção, o fluxo de informação se dá em vários níveis e a velocidade em que ocorre - processamento dessas informações interfere na confiabilidade e qualidade das ações de manutenção, tanto na sua execução quanto no planejamento. A utilização dos dispositivos móveis reduz o tempo e facilitam a coleta das informações oriundas da execução, assim como a tratativa, apropriação e entrega das informações tornadas disponíveis pelo planejamento da manutenção, graças à eliminação de algumas etapas do processo propiciada pela utilização destes dispositivos. A inclusão das informações é direta e em tempo real, implantadas no sistema por digitação no dispositivo, que é sincronizado ao ERP ou Software de suporte à gestão da manutenção. A tela de consulta às atividades a serem realizadas pelo profissional da manutenção é apresentada na Figura 3.

Figura 3. Tela de consulta às atividades

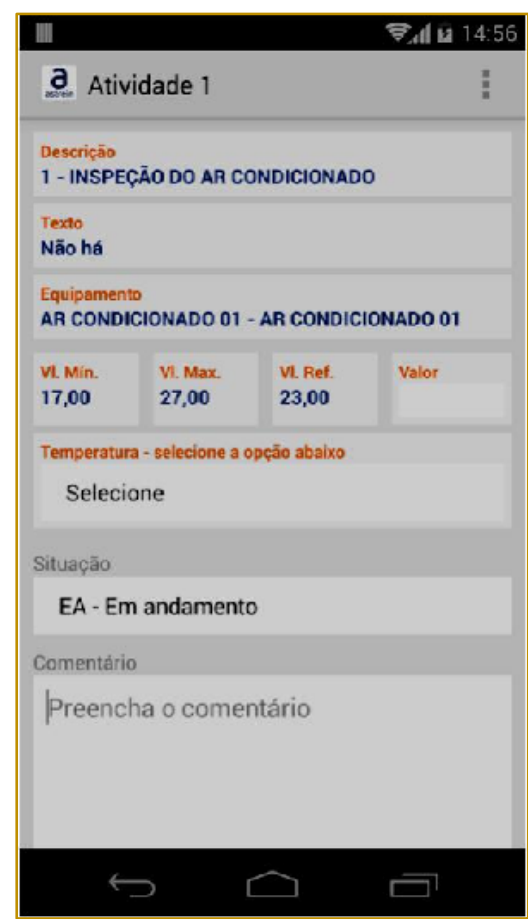

Fonte: Astrein (2016) 


\subsection{COLETAS DE DADOS NO PLANEJAMENTO E CONTROLE DE MANUTENÇÃO}

O PCM planeja suas atividades em função das informações provenientes das necessidades de manutenção, oriundas tanto das inspeções preventivas quanto das necessidades comunicadas por seus clientes internos, bem como do fluxo de insumos, como os materiais de reposição (PINTO, 2013). A tecnologia mobile possibilita a redução do tempo de coleta destas informações.

\subsection{IMPORTAÇÃO DE SERVIÇOS REALIZADOS}

O banco de dados da tecnologia mobile permite a verificação de pendências em serviços anteriores e até mesmo verificar quais materiais foram utilizados, facilitando e aperfeiçoando o processo, pois a disponibilidade do histórico é imediata, vide Figura 4.

Figura 4. Tela de O.S. para execução

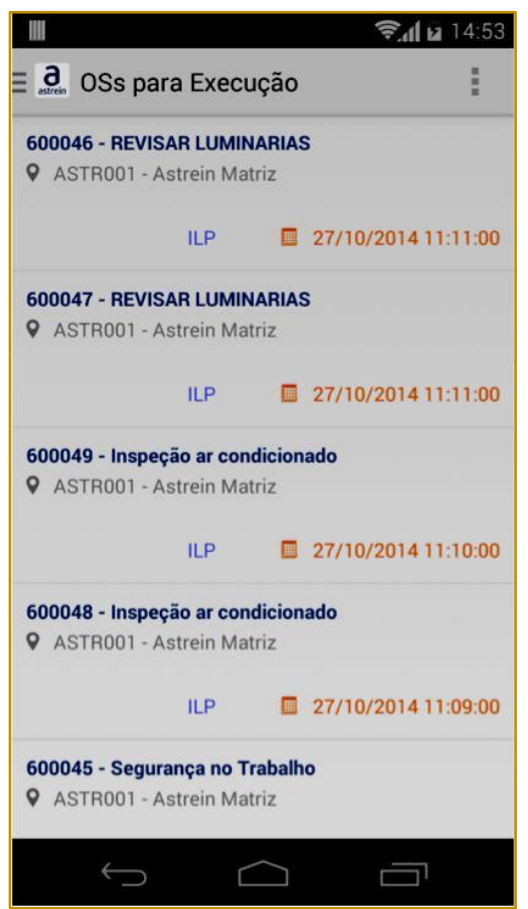

Fonte: Astrein (2016)

\subsection{FECHAMENTOS, ENCERRAMENTO E CANCELAMENTO DE ORDENS DE SERVIÇO (OSS)}

A tecnologia mobile permite estender a todos da equipe, a execução, fechamento ou encerramento e cancelamento quando necessário das ordens de serviço (OSs), realizando esta atividade em tempo real no campo, sem a necessidade do preenchimento de documentos impressos para posterior inserção no sistema.

A tecnologia mobile reduz o processo de fluxo de informação com vantagens, como a redução do backlog, eliminando o conflito entre OSs que já foram executadas em campo e constam ainda pendentes no sistema, ou emitidas em duplicidade, minimizando a necessidade de reuniões de acerto.

\subsection{CONSISTENNCIAS DOS DADOS COLETADOS}

A inclusão de dados em tempo real no encerramento das ordens de serviço pela tecnologia mobile gera consistência dos dados, dado que minimiza conflitos gerados pela falta de anotação e apropriação de horários entre outros verificados nas ordens de serviço. 


\subsection{LEITORES DE CÓDIGO DE BARRAS INTEGRADO À CÂMARA DO DISPOSITIVO MÓVEL}

O modulo almoxarifado da tecnologia mobile permite realizar controle do almoxarifado de manutenção de forma rápida e eficaz, melhorando gestão de manutenção. É possível utilizar a câmara do dispositivo móvel para realizar a leitura do código de barras do item a ser pedido e retirado do almoxarifado. As tecnologias de conexão utilizadas nas plataformas mobiles podem ser vistas na Figura 5.

Figura 5. Tecnologia agregada

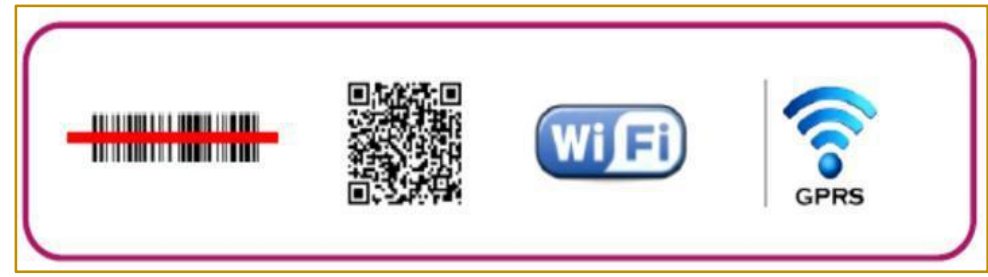

Fonte: Engeman (2016)

\subsection{ADIÇÕES DE ANEXOS ÀS OSS}

A tecnologia mobile não sofre as limitações quanto à inserção de informações qual nos processos convencionais de documentação impressa. Como os cheklists e as ordens de serviço e de controle e inspeção de materiais de estoque ficam disponíveis nos dispositivos móveis, é possível anexar imagens e até vídeos mostrando o progresso da tarefa em execução. A inclusão desses anexos pode ser por meio de arquivos nas mais diversas extensões, conforme Figura 6.

Figura 6. Tela para anexar arquivos

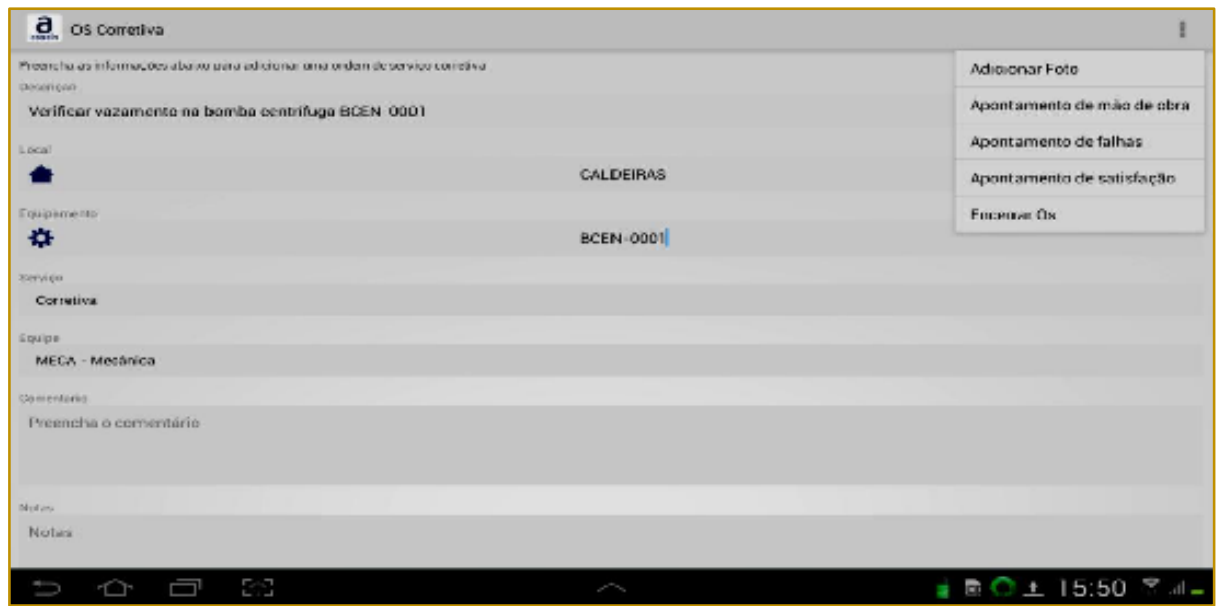

Fonte: Astrein (2016).

\subsection{INCLUSÕES DE OSS DIRETAMENTE NO DISPOSITIVO MÓVEL}

Em ambiente não digital, a abertura de uma ordem de serviço se dá por uma solicitação via anotações ou rascunhos ou até mesmo via software. Posteriormente esta solicitação será analisada pelo planejador de manutenção gerando uma ordem de serviço. Na tecnologia mobile este procedimento acontece em tempo real, utilizando-se o próprio dispositivo para gerar a ordem de serviço. A figura 7 mostra exemplo de tela de abertura de solicitação de manutenção. 


\section{III}

Figura 7. Tela Solicitação de Serviços

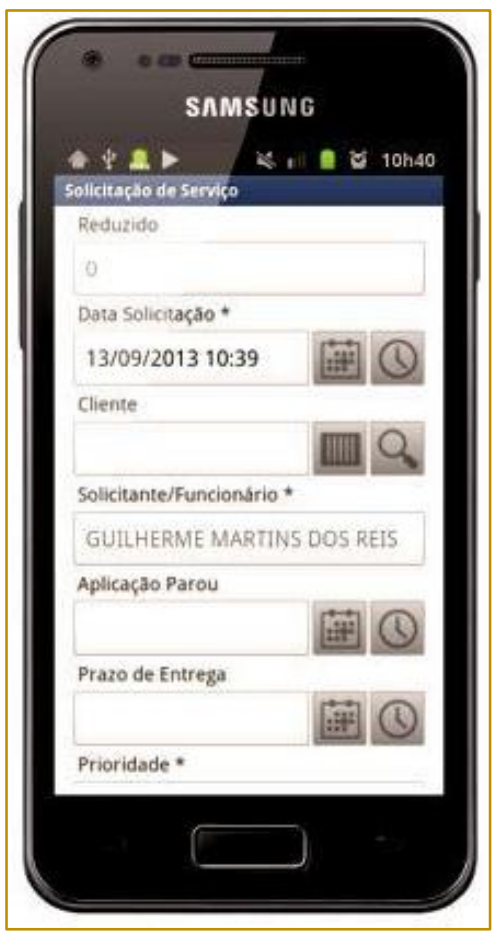

Fonte. Engeman (2015)

\subsection{ALERTAS DE NOVAS OSS GERADAS PARA O DISPOSITIVO MÓVEL}

As solicitações de serviço de manutenção ou chamados são gerados pelo cliente ou pelo planejamento da manutenção, sendo analisados e enviados aos líderes, supervisores, ou coordenadores, por meio de documento impresso ou e-mail. O fluxo dessas informações pode gerar problemas para a realização do serviço solicitado, como duplicidades de OSs, quando a execução da manutenção e a gestão de planejamento não são centralizadas. Com a tecnologia mobile, o processo é feito de forma mais eficaz, possibilitando ao programador remeter a solicitação de serviço diretamente para o executante, permitindo também acesso estendido a todos os envolvidos na execução da atividade.

\subsection{FUNCIONAMENTO EM MODO ONLINE E OFF-LINE}

A utilização dos módulos portáteis pode se dar nos modos online e off-line. Online - os dados já são remetidos ao servidor e ficam disponíveis no software de manutenção imediatamente. Off-line - os dados ficam armazenados no próprio dispositivo mobile, sendo posteriormente sincronizados e enviados ao sistema quando houver uma conexão disponível.

\subsection{PERSONALIZAÇÕES NA TECNOLOGIA MOBILE}

Há opções de personalização dos softwares de manutenção com aplicação por meio de dispositivos mobile, assim o layout de ícones pode ser alterado conforme gosto e necessidades dos usuários, possibilitando alterações nas configurações básicas, dentre elas, o idioma do sistema. A figura 8 apresenta exemplos de personalização de idiomas do aplicativo. 
Figura 8. Configuração de idiomas

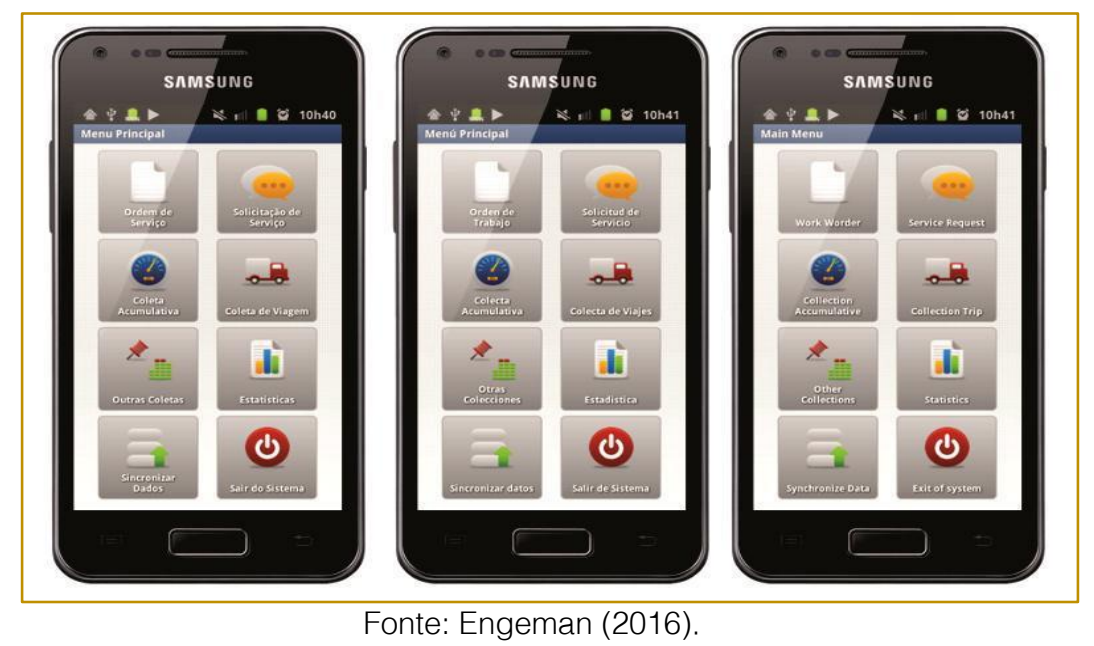

\section{VANTAGENS EM RELAÇÃO AOS} CONTROLES MANUAIS

A tecnologia mobile apresenta vantagens sobre os controles manuais.

Possibilita maior rastreabilidade das informações, uma vez que as informações e registro histórico das atividades de manutenção são inseridos no sistema em tempo real, garantindo-se cumprir diversas normas e indicadores que 0 setor de manutenção precisa seguir.

Propicia a reduzir a burocracia quando da distribuição das atividades, melhorando o indicador de tempo médio de reparo (TMR), aumentando a disponibilidade dos ativos da empresa, e tornando ágil a circulação de informações, pois após a seleção das ordens de serviço envia-se a mesma diretamente para os dispositivos portáteis sem a necessidade de passar pela coordenação e supervisão da execução dos grupos de manutenção.

O aplicativo do módulo de estoque para almoxarifado na tecnologia mobile melhora a eficiência na retirada e controle de peças. Através de suas câmaras digitais, os dispositivos móveis têm o recuso de leitor de códigos de barras, possibilitando retirar de material do almoxarifado, registrando diretamente pelos dispositivos sem necessidade de preenchimentos manuais das solicitações de materiais, aprimorando a rastreabilidade das informações e tornando simples a realização dos inventários. A figura 9 ilustra a aplicação do leitor de código de barras.

Figura 9. Módulo de almoxarifado / Código de barras

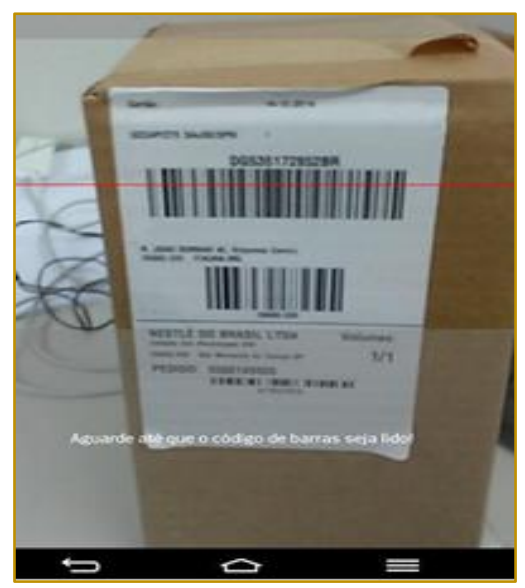

Fonte: Astrein (2016) 
A preocupação com o desenvolvimento sustentável tem crescido no setor industrial, assim como em vários outros setores da economia, com a conscientização sobre os impactos ao meio ambiente (ACSELRAD, 1999; BARBIERI et al., 2010). A sustentabilidade está apoiada no desenvolvimento econômico, que possa respeitar o meio ambiente, e gerar o desenvolvimento social (Elkington, 2004). A tecnologia mobile com os dispositivos móveis é uma solução que possibilita minimizar do uso de documentos impressos, reduzindo o impacto ao meio ambiente.

\section{PROCESSO DE IMPLANTAÇÃO}

O processo de implantação da tecnologia mobile requer atenção, pois a introdução de novo método de trabalho traz a quebra de paradigmas já estabelecidos, portanto este processo deve ser feito de forma cuidadosa, para que uma possibilidade de melhoria não gere transtornos ou até inviabilize a sua implantação. A mudança de cultura possivelmente provoque reações de resistência na equipe envolvida, assim é preciso sensibilizar a equipe para as vantagens que este novo modelo de trabalho vai proporcionar.

Não é incomum na composição da equipe de colaboradores do setor de manutenção haver colaboradores antigos na empresa que venham a entender o uso da tecnologia mobile na manutenção como forma de redução do quadro de funcionários, e por consequência o medo do desemprego pode se tornar uma séria barreira a se transposta. Sugerem-se os passos abaixo, para a implantação da tecnologia mobile, de forma que seja minimizado o efeito negativo relacionado à rotina de trabalho da equipe como um todo.

\subsection{PROJETO PILOTO}

Recomenda-se no desenvolvimento da implantação, a utilização de um projeto piloto. Separa-se uma parte da linha de produção, equipamento ou processo para ali ser implantada em escala piloto à ferramenta mobile, possibilitando realizar comparativos de produtividade e mensurar indicadores de disponibilidade e desempenho.

O projeto piloto também pode ser iniciado anteriormente aos demais departamentos da empresa pelo almoxarifado, este setor tem muita movimentação de funcionários da manutenção em geral, assim, o uso desses controles acaba despertando a curiosidade da equipe. Utilizando-se a ferramenta inicialmente na rotina diária de entrada, saída de materiais e gestão do inventário, a facilidade de seu uso passa a despertar o interesse e tornar o almoxarifado um exemplo a ser seguido pelos membros das equipes de manutenção.

Sugere-se usar colaboradores chave, ou seja, funcionários que se destacam dentro do setor e demonstram certa facilidade de adaptação a novas tendências e tecnologias. Isso possibilitará mostrar para o restante da equipe a facilidade da utilização do software. Recomenda-se que essa fase dure um limitado espaço de tempo, a ser usada como uma demonstração do potencial da ferramenta mobile, evitando-se assim possíveis conflitos dentro da própria equipe, ou entre equipes.

Os gestores precisam ter cuidado especial, quando a mudança iniciar em sua totalidade, para que as equipes não se percam utilizando os outros programas presentes nos celulares ou tabletes. Sugere-se ao gestor o monitoramento das atividades e desempenho individual dos membros das equipes.

Para tentar minimizar os problemas de segurança, dado toda troca de informação ser feita via Internet, os softwares tem acesso controlado por senha, assim qualquer alteração ou simples ingresso no sistema só pode se dar por pessoal devidamente cadastrado e autorizado, procurando-se reduzir assim possíveis acessos indevidos ou manipulações de dados. A figura 10 apresenta a tela com o pedido de confirmação de senha do usuário, visando aumentar a segurança do sistema. 
Figura 10. Acesso de usuários

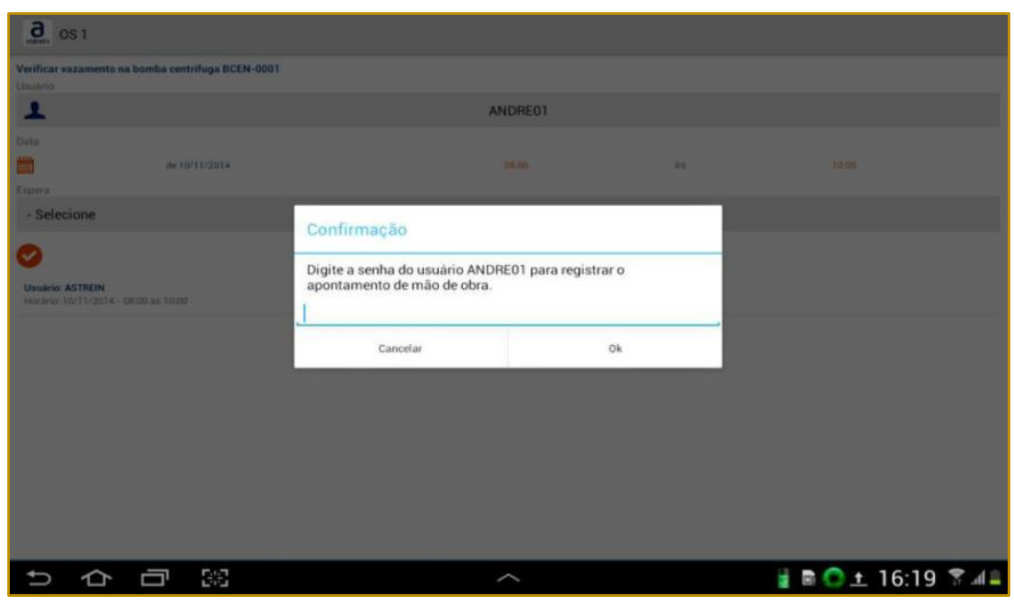

Fonte: Astrein (2016)

\subsection{TREINAMENTO}

É crucial o investimento em tempo inicial de treinamento dos usuários e/ou executantes, quando será possível identificar os colaboradores que possuem mais facilidade em absorver essa melhoria, e verificar os possíveis problemas de funcionamento do sistema quando de sua implantação. É importante que as equipes sejam treinadas, para garantir uma melhor assimilação dessa nova forma, além de disseminar a utilização do software. Os fabricantes ministram os treinamentos de homologação e uso geral do sistema, e na maioria dos casos está incluído no pacote de aquisição da ferramenta (CORREIA; RIBEIRO; CIUCCIO, 2015).

O receio de utilização da tecnologia mobile para o gerenciamento da manutenção é suprimido com o seu uso de forma regular. Tem-se observado a valorização da mão de obra que a utiliza (SOUSA et al., 2016), por estar alinhada á tendência da digitalização de tarefas, modernizando e facilitando das suas atividades, propiciando continua melhoria dos indicadores de manutenção e por consequência os de produção, importante ferramenta para a gestão de manutenção industrial em transição para a Indústria 4.0.

\section{CONCLUSÃO}

A indústria 4.0 é caracterizada pela digitalização e integração em grau crescente entre produtos e processos produtivos, cadeia de suprimentos e principais stakeholders, propiciada pelo uso da Internet como meio de troca de informações, quando um número ilimitado de dispositivos podem ser conectados, compartilhando informações.

O uso da tecnologia mobile para a gestão e controle da manutenção industrial alinha-se a este novo paradigma de produção, onde dispositivos móveis, tais como: Palm, Pocket PC, Smartphones e Tablets, utilizam softwares que possibilitam minimizar o tempo dedicado às tarefas burocráticas e/ou que não acrescentam valor às atividades de manutenção, ao mesmo tempo em que reduz custos despendidos com controles manuais e uso intensivo de papel, colaborando para a sustentabilidade.

A tecnologia mobile possibilita melhor rastreabilidade, registro das informações, e até a melhor instrumentação do profissional de manutenção para a execução das suas atividades, pela possibilidade de incorporar fotos e filmes da execução das tarefas, além da rápida disseminação das informações entre os membros das equipes de manutenção. Com isto a tecnologia mobile propicia aumento da produtividade e maior disponibilidade dos ativos da empresa para a operação, em alinhamento com o paradigma da Indústria 4.0.

A inserção da tecnologia mobile para a gestão da manutenção é vista de maneira positiva, pelas melhorias advindas, trazendo qualidade, confiabilidade e agilidade para as intervenções da manutenção, um importante passo para a inserção das empresas na Indústria 4.0.

Geram preocupações a segurança de dados, por ser uma tecnologia apoiada na web, precisando ser melhorada para dar maior confiabilidade; o uso indevido dos celulares e 
tabletes pelos funcionários para fins particulares, e a resistência à sua implantação.

Sugere-se que futuras implantações da tecnologia mobile possam utilizar este estudo por base, gerando futuros trabalhos acadêmicos complementando esta pesquisa e trazendo novos conhecimentos ao meio acadêmico e empresarial.

\section{REFERÊNCIAS}

[1] Arena 4G. Qual sistema operacional mais inovou em 2015? [ENQUETE]. Disponível em: < https://arena4g.com/qual-sistema-operacionalmais-inovou-em-2015-enquete/>. Acesso em 27 abr. 2017.

[2] Associação Brasileira de Manutenção e Gestão de Ativos - Abraman. Congresso Brasileiro de Manutenção e Gestão de Ativos. Disponível em: $<$

http://www.abraman.org.br/sidebar/congresso/cbm :> Acesso em 16 abr. 2017.

[3] Acselrad, Henri. Discursos da sustentabilidade urbana. Revista Brasileira de Estudos Urbanos e Regionais, v. 1, n. 1, p. 79-90, 1999.

[4] Astrein. ILP-Mobile. Disponível em: <http://www.astrein.com.br/solucoes/gestao-deativos/ilp-mobile>. Acesso em: 13 mai. 2016.

[5] Barbieri, José Carlos et al. Inovação E Sustentabilidade: Novos Modelos e Proposições/Innovation And Sustainability: New Models And Propositions/Innovación Y Sostenibilidad: Nuevos Modelos Y Proposiciones. Revista de Administração de Empresas, v. 50, n. 2, p. 146, 2010.

[6] Choi, S. S., Kang, G., Jung, K., Kulvatunyou, B., MORRIS, K.C.: Applications of the factory design and improvement reference activity model. In: I. A. Nääs et al. (Eds.) IFIP 2016: APMS 2016 (2016).

[7] Confederação Nacional da Indústria CNI. Desafios para indústria 4.0 no Brasil. Brasília: CNI, 2016

[8] Coltro, Alex. A gestão da qualidade total e suas influências na competitividade empresarial. Caderno de Pesquisas em Administração, v. 1, n. 2, p. 1-7, 1996.

[9] Correia, Adriano José; RIBEIRO, Gilvan Alves; Ciuccio, Ricardo Luiz. Os desafios para a implantação de sistemas de controle mobile na manutenção industrial. In: XXX Congresso Brasileiro de Manutenção e Gestão de Ativos Expoman 2015. Campinas, SP, 2015.

[10] De Morais, Roberto Ramos; Monteiro, Rogério. A indústria 4.0 e o impacto na área de operações: Um ensaio. In: V SINGEP - Simpósio de Gestão De Projetos, Inovação e Sustentabilidade. São Paulo, 2016.

[11] Elkington, J.: Enter the Triple Bottom Line. In: Henriques, A. and Richardson J. (Org.). The

\section{AGRADECIMENTOS}

Agradecemos a Coordenação de Aperfeiçoamento de Pessoal de Nível Superior (CAPES), fundação do Ministério da Educação (MEC), pela bolsa que propiciou esta pesquisa.

Triple Bottom Line, Does it All Add up? Assessing the Sustainability of Business and CSR. Earthscan, Londres, 1-16, 2004.

[12] Engeman. O Sistema de Manutenção Mais Flexível do Brasil. Disponível em: < http://www.engeman.com.br>. Acesso em: 13 mai. 2016.

[13] European Parliament. Industry 4.0 Digitalisation for productivity and growth. Setembro de 2015. Disponível em: <http://www.europarl.europa.eu/RegData/etudes/B RIE/2015/568337/

EPRS_BRI(2015)568337_EN.pdf>. Acesso em: 14 abr. 2016.

[14] Federação das Indústrias do Estado do Rio de Janeiro - Firjan. Panorama da inovação Indústria 4.0. Cadernos SENAI de Inovação. Rio de Janeiro: 2016.

[15] Hermann, M; Pentek, T; Otto, B. Design Principles for Industrie 4.0 Scenarios: A Literature Review. 2015. Disponível

[16] em: <http://www.snom.mb.tudortmund.de/cms/de/forschung/Arbeitsberichte/De sign-Principles-for-Industrie-4_0-Scenarios.pdf > .

Acesso em: 14 abr. 2016.

[17] Kagermann, H., Wahlster, H., Helbig, J. Securing the future of German manufacturing industry: Recommendations for implementing the strategic initiative Industrie 4.0 - Final Report of the Industrie 4.0 working group. Acatech - National Academy of Science and Engineering, 1-82 (2013). [18] Martins, G. A; Theóphilo, C. R. Metodologia da investigação científica para ciências sociais aplicadas. 2. ed. São Paulo: Atlas, 2009.

[19] Mendes, Rafael B.; Sampaio, Renelson Ribeiro. Internet das coisas e physical web aplicados a plataformas multilaterais físicas. In: Workshop de Gestão, Tecnologia Industrial e Modelagem Computacional. 2016.

[20] Pinto, João Paulo. Manutenção Lean. Lisboa: 2013.

[21] Sellitto, Miguel Afonso. Formulação estratégica da manutenção industrial com base na confiabilidade dos equipamentos. Revista Produção, v. 15, n. 1, p. 44-59, 2005.

[22] Sousa, Saymon Ricardo de Oliveira; AGOSTINO, Ícaro Romolo Sousa; DAHER Ricardo Oliveira; CUTRIM; Rialberth Matos; MELO JR; José Samuel de Miranda. A implantação de um sistema de informações para o monitoramento e análise de falhas: Um estudo aplicado ao processo de 
manutenção industrial de equipamentos móveis. Revista Espacios, v. 37 (23), p. 21, 2016.
[23] Souza, Valdir Cardoso de. Organização e Gerência de Manutenção. São Paulo: All Print, 2009. 


\section{Gapítulo 10}

\section{APLICAÇ̃̃O DA TECNOLOGIA DE FEATURES DA PECA PARA SIMULAÇÃO DE UM SISTEMA DE PRODUÇÃO}

\section{Heráclito Lopes Jaguaribe Pontes \\ Marcos Ronaldo Albertin \\ Marcos Charles Pinheiro Baltazar}

Resumo: Este capítulo detalha a simulação de sistemas de produção a partir da aplicação da tecnologia de features geométricas inseridas na peça em estudo. Essa forma de análise proporciona ao gestor de um sistema produtivo tomar decisões mais precisas, aarretando menores erros e possíveis melhorias no processo. A simulação baseada em features das peças possibilita uma maior confiança e robustez nas análises, pois os dados de entrada da simulação são as características da peça a ser simulada. O trabalho foi estruturado a partir de revisões das literaturas sobre os conceitos de Sistemas de Produção, Tecnologia de Features e Simulação. O objetivo do trabalho foi realizar um estudo num sistema de produção específico utilizando o conceito de simulação baseada nas features da peça para analisar detalhadamente a eficiência de um recurso de produção envolvendo um processo-chave do sistema em estudo. No estudo de caso foi simulada uma peça que compõe um corrimão (guarda corpo) de uma empresa metalúrgica composto por quatro features circulares: quatro furos. O cenário proposto na simulação proporcionou uma redução no tempo e no custo de processamento das features em torno de $10,11 \%$ e $11,39 \%$, respectivamente. Os resultados mostraram que a inserção de uma nova máquina no cenário proposto gerou uma redução de $31,75 \%$ no tempo de fabricação por furo e uma redução de $35,08 \%$ no custo de fabricação por furo. Considerando que a peça em estudo é composta por quatro furos e tem uma produção total de trezentas peças mensais houve uma redução de tempo de 560,32 minutos por mês e uma redução de custos de $\mathrm{R} \$ 241,42$ reais por mês com o novo cenário.

Palavras Chave: Sistema de Produção; Tecnologia de Features; Simulação. 


\section{INTRODUÇÃO}

Atualmente, a crescente busca pelo diferencial competitivo nas empresas gera a necessidade de ter sistemas de produção que atendam fatores como o aumento do número e variedade de produtos; a queda do tamanho do lote de produção; minimização de estoques; menores tolerâncias a erros; aumento na quantidade de materiais complexos; aumento dos custos de materiais; e a diminuição entre o tempo de concepção do projeto e o produto fabricado.

A função Produção, na maior parte das empresas, representa a maior parte do seu ativo e do seu pessoal. A produção são os ossos, os nervos e os músculos da empresa. Uma produção saudável dá à empresa a força para suportar a concorrência, mantém o melhoramento no desempenho competitivo e proporciona a versatilidade operacional que pode responder aos mercados crescentemente voláteis (SLACK, 1993).

Para se obter sistemas de produção competitivos é necessário que as empresas conheçam muito bem seus sistemas. Para isso a simulação computacional pode ser utilizada como ferramenta. De acordo com Perera e Lyanage (2000), a simulação é uma ferramenta de suporte à decisão na produção. Ela é muito utilizada em sistemas de produção para realizar projeções sem alterar o cotidiano da empresa. Através da simulação é possível ter uma visão geral do sistema, assim como obter respostas para questões do tipo "o que aconteceria se...?". Complementa O'kane et al. (2000) dizendo que a simulação é uma das técnicas mais populares para se analisar problemas em produção.

A simulação pode ser utilizada como um laboratório de testes para sistemas de produção gerando vantagens como: facilidade de uso, custo e tempo menores do que a experimentação no sistema real.

Nesse trabalho a premissa utilizada para o desenvolvimento da simulação são as features constantes nas peças a serem fabricadas. As features relacionam um conjunto de informações referentes aos aspectos do projeto de um produto com a produção. As features correspondem a uma forma de representar o significado de engenharia (projeto) numa peça através de entidades geométricas. Shah e Mantÿla (1995) afirmam que as features são formas geométricas definidas por um conjunto de parâmetros que têm significado especial para engenheiros de projeto e fabricação.

As features das peças em conjunto com a simulação possibilitam aos gestores uma maior confiança e robustez nas análises, pois os dados de entrada da simulação são as características da peça a ser simulada. Assim, as features descrevem um modelo de produto de maneira mais inteligente do que a geometria explícita.

Nos últimos anos, a tecnologia de features vem sendo muito utilizada nos sistemas CAD (Projeto Assistido por Computador) interligados aos sistemas CAM (Manufatura Assistida por Computador) gerando automatização desde o estágio de projeto até à produção de um produto. Apesar do sucesso dos sistemas CAD/CAM, existe uma carência na literatura de análises e simulações de sistemas de fabricação a partir da tecnologia de features.

Com isso, este trabalho propõe como objetivo a realização de um estudo num sistema de fabricação específico utilizando o conceito de simulação baseada nas features da peça para analisar detalhadamente a eficiência de um recurso de fabricação envolvendo um processo-chave do sistema em estudo.

Este trabalho está estruturado em quatro seções. A primeira seção busca prover informações para a compreensão do trabalho realizado, onde são definidos o contexto em que está inserido o trabalho e a justificativa, além do objetivo. A segunda seção apresenta o aporte teórico necessário à discussão do tema em estudo. São abordados os temas: Sistemas de Produção, Tecnologia de Features e Simulação. A terceira seção apresenta um estudo de caso a partir da aplicação do modelo num sistema de produção real. $\mathrm{Na}$ quarta seção são apresentadas as conclusões obtidas com o estudo, buscando responder o objetivo proposto.

\section{REVISÃO BIBLIOGRÁFICA}

\subsection{SISTEMAS DE PRODUÇÃO}

Segundo Moreira (2008) um sistema de produção é um conjunto de atividades e operações necessárias para a produção de produtos envolvendo os seguintes elementos: insumos, o processo de transformação e os produtos fabricados.

Um sistema de produção é composto de vários subsistemas como transportadores, 
células de produção, máquinas operatrizes, inspeção de controle da qualidade no qual cada subsistema realiza uma determinada operação produtiva, a qual pode ser uma transformação física ou um deslocamento físico ou uma inspeção. Uma característica básica destes subsistemas é que por eles fluem diversos itens como peças, materiais, que passam sequencialmente pelos subsistemas, onde transformações apropriadas são realizadas até obter o produto final requerido de acordo com especificações da qualidade (PALOMINO, 2001).

Um sistema de produção é composto por processos de fabricação. Um procedimento ou atividade dedicada à produção de uma ou de um grupo de peças denomina-se processo de fabricação. Os processos de fabricação têm como objetivo a modificação de um material com o fim de the conferir uma forma definida (AGOSTINHO et al., 2004).

Cada processo de fabricação possui características específicas que o torna particular no que concerne às formas como trata os materiais. Conforme Resende (1993), a conveniência da escolha de um processo de fabricação está relacionada com a forma da peça a ser trabalhada, o que determina a utilização de máquinas que combinem movimentos corretos para a peça.

De acordo com Resende (1993), os principais processos para fabricação de peças brutas ou acabadas podem ser divididos em dois grupos: processos com remoção de material (usinagem) e processos sem remoção de material (fundição, metalurgia do pó, conformação mecânica e soldagem). A usinagem é dividida em convencional e não convencional.

De acordo com Halevi e Weill (1995), aproximadamente $80 \%$ dos processos efetuados nas indústrias são processos de redução de massa de materiais sólidos, ou seja, processos de usinagem. Além disso, esses processos têm uma grande flexibilidade, permitindo ao usuário conseguir uma larga escala de aplicações, com um número muito grande de soluções possíveis.

Este trabalho aprofundou-se nos processos de usinagem convencional. Segundo Ferraresi (1985), os processos de usinagem convencional compreendem aqueles que, ao conferir à peça a forma, as dimensões, o acabamento, ou ainda uma combinação qualquer destes três itens, produzem cavaco.
Entende-se por cavaco a porção de material da peça retirada pela ferramenta, caracterizando-se por apresentar, em geral, uma forma geométrica irregular.

De acordo com Agostinho et al. (2004), as principais condições para que ocorra o processo de usinagem são:

- Movimento de corte: movimento entre a peça e a ferramenta, o qual sem 0 movimento de avanço origina somente uma única remoção de cavaco, durante uma volta ou curso;

- Movimento de avanço: movimento entre a peça e a ferramenta que, juntamente com o movimento de corte, origina um levantamento repetido ou contínuo do cavaco durante várias revoluções ou cursos;

- $\quad$ Direção de corte: direção instantânea do movimento de corte;

- Direção de avanço: direção instantânea do movimento de avanço;

- Plano de trabalho: plano que contém as direções de corte e avanço;

- Velocidade de corte: velocidade instantânea de um ponto qualquer da aresta cortante de um ponto de referência, segundo a direção e sentido do corte;

- $\quad$ Avanço: é a distância percorrida pela ferramenta seguindo a direção de avanço em uma volta ou curso;

- Profundidade de corte: é a profundidade de penetração da aresta de corte, medida numa direção perpendicular ao plano de trabalho.

Ferraresi (1985) e Diniz et al. (2001) dividem os custos de usinagem em três parcelas que são os custos relativos à mão-de-obra, à máquina-ferramenta e à ferramenta. Com relação ao tempo da usinagem, Ferraresi (1985) o definiu como sendo o tempo gasto em todas as etapas da usinagem de uma peça ou de um lote de peças, que se constitui nas seguintes fases: colocação e fixação da peça em bruto ou semi-acabada na máquinaferramenta; aproximação ou posicionamento da ferramenta para o início do corte; corte propriamente dito; afastamento da ferramenta e; inspeção e retirada da peça usinada. 


\subsection{TECNOLOGIA DE FEATURES}

Segundo Lee (2004), a feature pode ser definida de diversos pontos de vista, tais como, projeto, análise, montagem, ou diversas funções relativas à produção. De acordo com Shah e Mantyla (1995), features são formas geométricas definidas por um conjunto de parâmetros que têm significado especial para engenheiros de projeto e fabricação.

Bhandarkar et al. (2000) afirmam que as features permitiram o sucesso na ligação entre os sistemas CAD/CAM que foi um passo fundamental para a automatização do desenvolvimento do produto desde o estágio de projeto até à produção.
As features são usadas para dar um significado ao produto com relação aos seus atributos e sua geometria e melhoram a comunicação entre o projeto e a fabricação (GAO et al., 2004). Através das features, pode-se compor uma estrutura de dados para representar uma peça ou uma montagem em termos dos seus constituintes, onde: cada feature tem uma identidade única e; a forma pode ser expressa em termos de: parâmetros dimensionais; enumeração geométrica; relações e entidades topológicas; etapas de construção para produzir a geometria das features (BENAVENTE, 2007). A Figura 1 mostra exemplos de features.

Figura 1 - Exemplo de features em peças

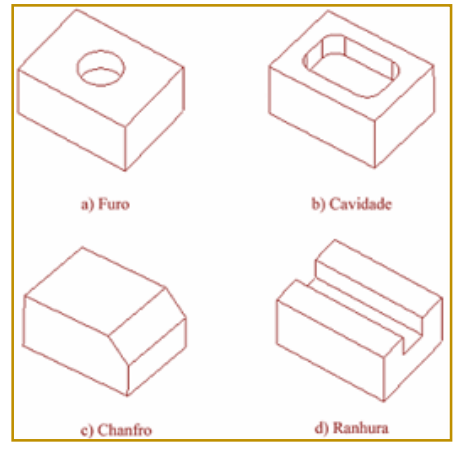

Fonte: Benavente, (2007)

Segundo Maziero (1998), a principal vantagem da utilização de features é a maior rapidez em produzir um projeto e na interligação com a fabricação, havendo, redução do custo final do produto. Outras vantagens são: não induz a erros ou distorções de interpretação pelo sistema, pois o objeto modelado sempre corresponderá a uma representação validada pelo próprio usuário e possibilita o desenvolvimento de aplicações que verificam as condições de produção, de forma a validar o modelo geométrico antes da produção.

De acordo com Shah e Mantyla (1995), as características das features asseguram algumas vantagens: os modelos podem ser descritos usando entidades de alto nível definidos como abstrações genéricas de formas recorrentes. Os relacionamentos entre as entidades caracterizam parâmetros e restrições e disponibilizam uma base para a propagação de alterações no modelo; conduzem à descrição do projeto em termos de entidades orientadas para a aplicação; conduzem a uma interface melhorada para manipulação de geometrias de projeto e; as features podem realizar um trabalho de validação de alterações muito melhor, uma vez que carregam a intenção do projeto.

Numa modelagem baseada em features, o usuário somente pode utilizar aquelas features que estão definidas na biblioteca, o que leva a uma limitação quanto ao universo a ser utilizado. Outra limitação da utilização das features é quanto a especialização de sistemas de produção. Quanto mais simples (alto nível) for a forma geométrica da feature, maior a flexibilidade de modelagem, porém menor a especialização do sistema (MAZIEIRO, 1998).

Segundo Lui e Wang (2007), features de produção ou manufatura são definidas como o volume retirado na operação de fabricação. Esse volume corresponde ao material que é removido na operação de usinagem. Essas features de produção têm uma forma padrão a partir de um conjunto de informações sobre 
como fabricar, ou seja, fornecem uma indicação quanto ao tipo de operação e às ferramentas que serão necessárias para fabricar a feature.

Jung (2002) classifica as features de manufatura em quatro classes que são: rotacional; prismática; cavidade e; circular. Para cada classe de features utiliza-se processos de usinagem deferentes como, por exemplo, na feature circular furo utiliza-se o processo de fabricação furação ou alargamento.

De acordo com Álvares (2005), associado às features de manufatura, no caso de processos de fabricação com remoção de material, temse as features de usinagem. Uma feature de usinagem é constituída por: features volumétricas que é o volume de material removido pela operação de usinagem para transformar a peça bruta em peça acabada.

Cada feature de usinagem é definida por uma coleção de parâmetros e combinação de fronteira. Do ponto de vista da usinagem, a forma como a remoção de material é feita depende do movimento de corte, do movimento de avanço, da forma do corte e dos parâmetros de configuração. As principais formas de features de usinagem são torneamento, fresamento, furação (ZHANG et al., 1999).

\subsubsection{TEMPO E CUSTO DE PRODUÇÃO DAS FEATURES}

Segundo Jung (2002), a vantagem de calcular o custo de fabricação baseado na tecnologia de features é a possibilidade de lidar com um número infinito de formas geométricas da peça manufaturada a partir das informações fornecidas pelas features. Estimar custos através do cálculo das operações de usinagem para fabricação da feature é um paradigma recente em comparação com a estimativa tradicional de experiência na área de usinagem.

O cálculo do custo de produção é baseado no tempo de usinagem e no custo do material. O tempo de usinagem é composto pelo tempo de operação e tempo de não operação. $O$ cálculo do tempo e custo de produção são realizados de acordo com as equações 1 e 2 (JUNG, 2002).

$$
\begin{aligned}
& T_{f}=T_{o t}+T_{n o} \\
& C_{f}=\left(\frac{S_{h}}{60}\right) \times T_{f}+\left(\frac{S_{m}}{60}\right) \times T_{f}+C_{f r}
\end{aligned}
$$

Onde: $T_{f}-$ tempo de fabricação (min); $T_{\text {ot }}-$ tempo total de operação (min); $T_{\text {no }}$ - tempo total de não-operação (min); $C_{f}-$ custo de fabricação (R\$/peça); $S_{h}$ - salário do operador ( $R \$ /$ hora); $S_{m}$ - salário da máquina ( $R \$ /$ hora); $\mathrm{C}_{\mathrm{fr}}$ - custo da ferramenta (R\$/peça).
Segundo Jung et al. (2000), o tempo operacional é composto pelo tempo de corte (desbaste), o tempo de acabamento e o tempo de aproximação da ferramenta na equação:

$$
T_{o t}=\sum_{i=0}^{n} T r_{i}+\sum_{i=0}^{n} T f_{i}+\sum_{j=0}^{m} T a_{j}
$$

Onde: $T_{\text {ot }}$ - tempo total de operação (min); $T r_{i}$ - tempo de desbaste da feature (min); $\mathrm{Tf}_{\mathrm{i}}$ tempo de acabamento da feature (min); $\mathrm{Ta}_{\mathrm{j}}-$ tempo de aproximação da ferramenta (min); $\mathrm{n}$ - quantidade de features na peça (unid); m quantidade de ferramentas utilizadas (unid).

O tempo de desbaste é proporcional ao volume removido na usinagem da peça. $O$ volume de usinagem removido é diretamente proporcional ao volume das features de manufatura que pode ser obtido através de cálculos matemáticos. Assume-se que o tempo de corte é calculado para a máxima potência da máquina e que a máquina possui força suficiente para cortar o material. Conforme Jung (2002), o tempo de desbaste é calculado de acordo com a equação: 


$$
\begin{gathered}
T_{r}=\frac{V_{r}}{M R R} \\
V_{r}=\pi \times\left(\text { Diametro }^{2}\left(\frac{\text { Altura }}{4}\right)\right) \\
M R R_{c i}=d \times D \times v
\end{gathered}
$$

Onde: $V_{r}$ - volume do material removido para o feature circular $\left(\mathrm{mm}^{3}\right)$; $\mathrm{MRR}_{\mathrm{ci}}$ - taxa de remoção do material de features circulares $\left(\mathrm{mm}^{3} / \mathrm{min}\right) ; \mathrm{d}$ - profundidade do corte $(\mathrm{mm}) ; \mathrm{D}$ - diâmetro do corte $(\mathrm{mm}) ; \mathrm{v}$ - velocidade de avanço $(\mathrm{mm} / \mathrm{min})$.

Além da operação de desbaste outro tipo de operação realizada na usinagem é o acabamento. Esta operação não está fortemente associada à remoção de material da peça, mas à precisão dimensional, à rugosidade da superfície e desvios geométricos. O tempo de acabamento é proporcional à área de corte das features. Ele é obtido a partir da equação (JUNG, 2002).

$$
\begin{gathered}
T_{f}=\frac{A_{f}}{R_{t}} \\
A_{f}=\pi \times \text { Diametro } \times \text { Altura }
\end{gathered}
$$

Onde: $A_{f}$ - área da feature furo $\left(\mathrm{mm}^{2}\right)$ e; $R_{t}-$ taxa de remoção da área da feature $\left(\mathrm{mm}^{2} / \mathrm{min}\right)$.

Segundo Jung et al. (2000), o tempo de aproximação da ferramenta varia de acordo com o tipo de máquina, o diâmetro da peça e localização de repouso da ferramenta. Geralmente, o tempo de aproximação é muito pequeno comparado com o tempo de corte, sendo em muitas situações estimado baseado no tempo de corte.
O tempo de não operação ou tempo improdutivo foi definido por Diniz et al. (2001) como sendo o tempo referente à colocação, inspeção e retirada da peça, setup, substituição da ferramenta e preparo da máquina para usinagem de um lote, que é independente da velocidade de corte. Esse tempo pode ser obtido pelas seguintes equações:

$$
\begin{aligned}
& T_{n o}=T_{i}+T_{f r} \\
& T_{i}=T_{c} \times\left(\frac{P_{i}}{100}\right) \\
& T_{f r}=\left(\frac{T_{c}}{T}-\frac{1}{Z}\right) T_{f t}
\end{aligned}
$$

Onde: $\mathrm{T}_{\mathrm{i}}$ - tempo improdutivo ( $\left.\mathrm{min}\right) ; \mathrm{T}_{\mathrm{fr}}-$ tempo de troca da ferramenta (min); $P_{i}-$ percentual de tempo improdutivo (\%); $\mathrm{T}_{\text {- }}$ tempo de vida da ferramenta (min); Z número de peças do lote (unid); $T_{\mathrm{ft}}$ - tempo de troca de ferramenta (min)

\subsection{SIMULAÇÃO}

Simulação é um termo amplo e, basicamente, pode ser definido como o processo de elaboração de um modelo de um sistema real (ou hipotético) e a condução de experimentos com a finalidade de entender o comportamento de um sistema ou avaliar sua operação (SHANNON, 1998). Complementa Banks et al. (2009) dizendo que a simulação é a imitação de uma operação de um processo real ou sistema.

Segundo Freitas Filho (2008), a simulação permite ao analista realizar estudos sobre os correspondentes sistemas para responder a 
questões do tipo "O que aconteceria se". O principal apelo ao uso desta ferramenta é que tais questões podem ser respondidas sem que os sistemas sob investigação sofram qualquer perturbação, uma vez que os estudos são realizados no computador. A simulação permite também que tais estudos sejam realizados sobre sistemas que ainda não existem, levando ao desenvolvimento de projetos eficientes antes que qualquer mudança física tenha sido iniciada.

O uso de simulação na produção tem aumentado significativamente nos últimos anos. Existem várias razões para este crescimento, dentre elas, a busca para aumentar a qualidade e produtividade, reduzindo, consequentemente, os custos. Outro fator importante é a popularização da utilização da simulação nas empresas, assim como o aumento da capacidade de recursos (hardware e software) para realização da simulação (PONTES, 2012).

Segundo Lopes et al. (2011), simulação é uma abordagem para o estudo de problemas complexos, para os quais a solução analítica é excessivamente complexa ou restritiva em relação às características do problema real. Num contexto mais amplo, a simulação refere-se à construção de modelos de qualquer natureza (físicos, matemáticos, lógicos, idealizados) e na condução de experimentos com estes modelos para o estudo de uma ou mais variáveis de interesse.

\subsubsection{SIMULAÇÃO EM SISTEMAS DE PRODUÇÃO}

A simulação tem se tornado uma das técnicas mais populares para se analisar problemas complexos da produção. Os sistemas de produção atuais consistem em muitas operações que ocorrem aleatórias e não linearmente, dessa forma, a modelagem por simulação torna-se um dos mais populares e eficientes meios de análise desses sistemas (O'KANE et al., 2000).

Segundo Law e Mccomas (1999), a produção é uma das maiores aplicações da simulação, tendo como benefícios destacar a necessidade e quantidade de maquinário e/ou funcionários extras, avaliação de desempenho e avaliação dos procedimentos operacionais.

Para Pegden et al. (1990), a simulação é utilizada na produção de três formas distintas: como ferramenta de projeto e análise de layouts, de compra de máquinas, de avaliação de políticas alternativas; como ferramenta de planejamento, pois o seu uso permite ao tomador de decisão explorar, planejar e avaliar mudanças no planejamento a fim de obter a otimização do mesmo; como parte de sistemas em tempo real com ou sem a intervenção humana.

Abdul-Kader e Gharbi (2002) utilizaram a simulação para estimar a capacidade de linhas produtivas que produzem diversos produtos diferentes. A simulação permitiu a representação no modelo de fatores como tempo de setup, tempo de reparo de falhas, tempo entre falhas.

Braghirolli (2009), desenvolveu um estudo comparativo entre a aderência do comportamento linear da mão-de-obra para as células de manufatura previsto na literatura e o comportamento observado nas implementações em empresas do setor metalmecânico, através do uso da simulação computacional.

Miranda et al. (2010), desenvolveram um projeto de simulação com o objetivo de responder qual o melhor método de trabalho para a realização de setup (preparação) em uma célula de manufatura de uma empresa de autopeças do sul de Minas Gerais.

De acordo com Porto e Palma (2000) algumas vantagens da aplicação da simulação na produção são: novas políticas, procedimentos operacionais, regras de projetos, fluxo de informação, procedimentos organizacionais podem ser explorados sem perturbar a continuidade das operações do sistema real; hipóteses de "como" e "por que" certos fenômenos ocorrem podem ser testadas para verificar a viabilidade; tempo pode ser comprimido ou expandido permitindo o aumento ou a redução da velocidade do fenômeno da investigação; estudo da simulação pode ajudar o entendimento de como o sistema opera em vez de como os indivíduos pensam que o sistema opera.

\section{APLICAÇÃO DA TECNOLOGIA DE FEATURES PARA SIMULAÇÃO DE UM SISTEMA DE PRODUÇÃO}

\subsection{CARACTERIZAÇÃO DO ESTUDO}

O estudo foi desenvolvido baseado num sistema de produção de uma empresa do setor metalúrgico que trabalha a vinte anos com o desenvolvimento de produtos como 
escadas, cadeiras, mesas, corrimãos e cobertura metálicas para os setores residenciais e comerciais.

O desenvolvimento do estudo consiste em utilizar a peça como referência para simulação de sistemas de produção. A peça é composta de features que são características geométricas que dão forma à peça. Cada feature possui um volume e uma área que são utilizados como base para os cálculos de tempos e custos de fabricação da peça. O volume da feature é utilizado como base para o cálculo do tempo de desbaste e a área da feature como base para o tempo de acabamento. Os custos são calculados baseados nos tempos de processamento de cada recurso.

A peça em estudo faz parte de um corrimão (guarda corpo) detalhado na amostra da Figura 2. Esse corrimão é comercializado para utilização em áreas internas ou externas tendo como a principal função a segurança de seus usuários. Ele é composto de três peças diferentes (base de fixação, montante, parte superior) que são soldadas formando o produto final. Cada peça do corrimão é manufaturada em processos de fabricação separados realizados em paralelo. A altura do corrimão depende do tamanho do montante e a largura do montante define o tamanho da base de fixação.

Figura 2 - Amostra do corrimão da peça em estudo

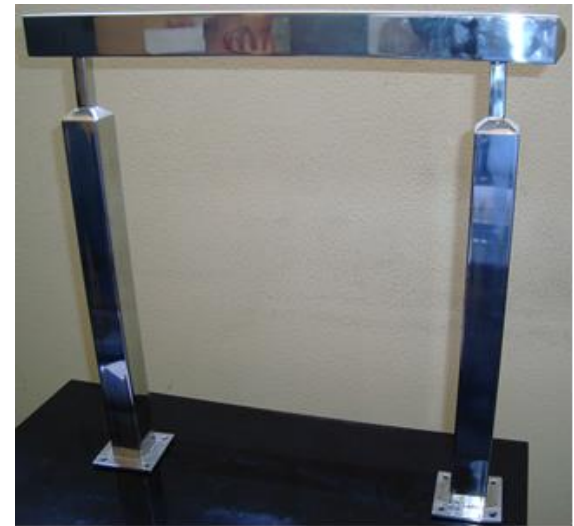

A peça em estudo é a base de fixação do corrimão. Essa base pode ser quadrada ou circular dependendo da necessidade do usuário. A peça (base) é soldada no montante de acordo com a Figura 2 para dar sustentação ao corrimão. A peça é composta de quatro furos (features) onde são inseridos os parafusos como na Figura 3.

Figura 3 - A peça em estudo

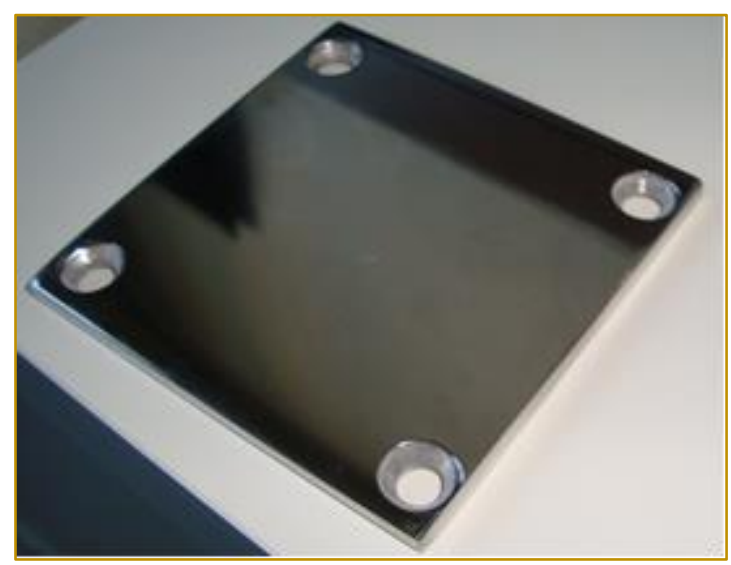




\subsection{ANÁLISE DO SISTEMA DE PRODUÇÃO}

Para a fabricação das features o sistema de produção da empresa, mostrado na figura 4 , é composto de uma serra, uma furadeira e uma politriz.

Figura 4 - Sistema de produção da peça em estudo

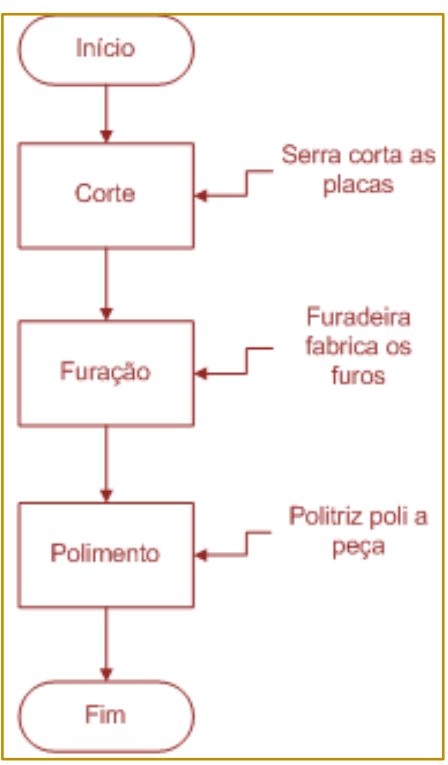

O primeiro processo do sistema de produção é o corte da placa. O material da placa é aço inoxidável (esse material é muito utilizado em corrimãos devido à sua resistência à corrosão, às suas propriedades higiénicas e estéticas). A empresa compra a matéria-prima em barras de seis metros de comprimento e corta de acordo com as medidas do projeto da peça. Esse processo é realizado numa máquina de corte industrial. Em seguida, a peça cortada é encaminhada para o processo de furação. Esse processo é único que produz features, o furo e tem o maior tempo de processamento. Esse processo é fundamental para a peça, pois permite fixação do corrimão na superfície para sustentação do mesmo. O último processo é o polimento da barra. Esse processo dar o brilho/proteção à peça e utiliza grãos abrasivos numa máquina politriz.
A peça em estudo foi escolhida devido a um problema exposto pelo gerente da empresa em estudo no momento da visita técnica. A máquina (furadeira) que produz as features furos na peça é antiga, tendo sido comprada no início do funcionamento da empresa a vinte anos atrás. Com isso, gerou-se uma dúvida com relação a eficiência dessa máquina, ou seja, de acordo com a produção mensal da peça e os tempos e custos de produção da máquina atual, vale a pena comprar uma nova máquina ou continuar produzindo com a atual.

Para o desenvolvimento do modelo foi realizada a coleta de dados mostrada nas Tabelas 1, 2, 3 e 4. Os dados coletados são: as dimensões da peça, as dimensões e as localizações das features, os parâmetros de tempo e de custo do recurso furadeira atual, a quantidade de peças produzidas por mês e o tempo entre chegada de peças no sistema. 
Tabela 1 - Parâmetros de entrada do sistema

\begin{tabular}{c|c} 
Tempo Entre Chegada de Peças (min) & Quantidade de Peças Produzidas (mês) \\
2,0 & 300 \\
\hline
\end{tabular}

Tabela 2 - Parâmetros da peça

\begin{tabular}{|c|c|c|c|c|}
\hline Descrição & Material & Comprimento $(\mathrm{mm})$ & Largura $(\mathrm{mm})$ & Altura $(\mathrm{mm})$ \\
\hline Base de Fixação & Aço Inoxidável & 75 & 75 & 5 \\
\hline
\end{tabular}

Tabela 3 - Parâmetros das features

\begin{tabular}{|c|c|c|c|c|c|}
\hline \multicolumn{6}{|c|}{$\begin{array}{c}\text { Features } \\
\text { Furos }\end{array}$} \\
\hline Diâmetro(mm) & Altura (mm) & Pos. X & Pos. Y & Pos. Z & Orientação \\
\hline 10 & 5 & 0,10 & 0,0 & 0,90 & 1 (Face XZ) \\
\hline 10 & 5 & 0,10 & 0,0 & 0,10 & 1 (Face XZ) \\
\hline 10 & 5 & 0,90 & 0,0 & 0,90 & 1 (Face XZ) \\
\hline 10 & 5 & 0,90 & 0,0 & 0,10 & 1 (Face XZ) \\
\hline
\end{tabular}

Tabela 4 - Parâmetros do recurso atual

\begin{tabular}{|c|c|}
\hline \multicolumn{1}{|c|}{ Parâmetros } & Furadeira \\
\hline Salário Operador $(\mathrm{R} \$ /$ hora $)$ & 4,30 \\
\hline Salário Máquina $(\mathrm{R} \$ /$ hora) & 15,00 \\
\hline Custo Ferramenta $\left(\mathrm{R} \$ \mathrm{~mm}^{3}\right)$ & 0,10 \\
\hline Diâmetro de Corte $(\mathrm{mm})$ & 10,00 \\
\hline Profundidade de Corte $(\mathrm{mm})$ & 5,00 \\
\hline Velocidade de Avanço $(\mathrm{mm} / \mathrm{min})$ & 6,50 \\
\hline Tempo Improdutivo $(\%)$ & 20,00 \\
\hline Tempo Vida Ferramenta (min) & 15,00 \\
\hline Tempo Troca Ferramenta (min) & 0,52 \\
\hline
\end{tabular}

\subsection{PROPOSTA DE UM NOVO CENÁRIO E EXPERIMENTAÇÃO}

Foi proposto um novo cenário para o recurso furadeira para observar a alteração no sistema de fabricação como um todo. O cenário foi definido a partir da alteração dos parâmetros do recurso furadeira. Para isso, foi realizada uma pesquisa em empresas especializadas na comercialização de furadeiras industriais. A Tabela 5 detalha os parâmetros da furadeira do cenário proposto.

Tabela 5 - Parâmetros do novo cenário

\begin{tabular}{|c|c|}
\hline \multicolumn{1}{|c|}{ Parâmetros } & Furadeira \\
\hline Salário Operador $(\mathrm{R} \$ /$ hora $)$ & 4,30 \\
\hline Salário Máquina $(\mathrm{R} \$ / \mathrm{hora})$ & 12,00 \\
\hline Custo Ferramenta $\left(\mathrm{R} \$ / \mathrm{mm}^{3}\right)$ & 0,10 \\
\hline Diâmetro de Corte $(\mathrm{mm})$ & 10,00 \\
\hline Profundidade de Corte $(\mathrm{mm})$ & 5,00 \\
\hline Velocidade de Avanço $(\mathrm{mm} / \mathrm{min})$ & 9,00 \\
\hline Tempo Improdutivo $(\%)$ & 15,00 \\
\hline Tempo Vida Ferramenta $(\mathrm{min})$ & 20,00 \\
\hline Tempo Troca Ferramenta $(\mathrm{min})$ & 0,48 \\
\hline
\end{tabular}

A experimentação do novo cenário foi realizada utilizando o ambiente virtual para simulação de sistema de produção baseada em features desenvolvido por Pontes (2012), que é um ambiente voltado para a simulação de sistemas de fabricação a partir das features contidas nas peças que permite 
analisar a dinâmica do sistema de forma sistêmica.

O ambiente virtual possui a flexibilidade e a versatilidade da simulação computacional com a coerência da descrição detalhada da geometria fornecida pelas features. Ela possibilita realizar simulações a partir do projeto da peça com as features, o que torna confiável a simulação, porém não tira a possibilidade de desenvolvimento de diferentes cenários para uma melhor tomada de decisão.

\subsection{ANÁLISES DOS RESULTADOS}

A última parte do estudo foi a análise dos resultados da simulação do cenário atual em relação ao proposto. A Tabela 6 detalha 0 comparativo dos resultados entre os cenários para a produção de 300 peças por mês. Para se obter os resultados dos indicadores, o ambiente de simulação utilizado na experimentação realiza os cálculos utilizando os dados das tabelas de 1 a 5 e as equações de 1 a 10 do capitulo anterior.

Tabela 6 - Comparativo dos resultados da simulação dos cenários

\begin{tabular}{|c|c|c|}
\hline Indicadores & Cenário Atual & Cenário Proposto \\
\hline Tempo Fabricação por Furo (min) & 1,48 & 1,01 \\
\hline Custo Fabricação por Furo $(\mathrm{R} \$)$ & 0,57 & 0,37 \\
\hline Tempo Fabricação por Furo Mensal $(\min )$ & 445,98 & 305,90 \\
\hline Custo Fabricação por Furo Mensal $(\mathrm{R} \$)$ & 173,45 & 113,104 \\
\hline Tempo Total de Produção Peça $(\min )$ & $1.783,93$ & $1.223,61$ \\
\hline Custo Total de Produção Peça $(\mathrm{R} \$)$ & 693,83 & 452,41 \\
\hline
\end{tabular}

A partir dos resultados acima foi realizada uma análise. Os resultados mostram que a inserção de uma nova máquina no cenário proposto gerou uma redução de 31,75\% no tempo de fabricação por furo e uma redução de $35,08 \%$ no custo de fabricação por furo. Considerando quatro furos e a produção total de trezentas peças houve uma redução de tempo de 560,32 minutos por mês e uma redução de custos de $\mathrm{R} \$ 241,42$ reais por mês.

Essa melhoria é devido à nova furadeira proporcionar uma redução no tempo improdutivo ficando menos tempo em manutenção corretiva, consequentemente, reduzindo o salário máquina. Há também uma redução no tempo de troca de ferramenta devido a dispositivos modernos já acoplados à nova furadeira e um aumento no tempo de vida da ferramenta. Outro fator importante é o aumento do avanço por minuto gerado a partir de uma maior rotação por minuto (rpm) do motor da nova furadeira

Apesar das melhorias mostradas, para comprar uma nova furadeira é necessário desembolsar em torno de $\mathrm{R} \$ 8.000,00$. De acordo com o responsável pelo sistema de produção, a furadeira atual pode ser vendida por $\mathrm{R} \$ 3.000,00$, sendo assim necessário desembolsar $\mathrm{R} \$ 5.000,00$. Com os resultados obtidos na simulação foi possível analisar o ganho por mês relativo ao tempo e ao custo para cada peça a ser fabricada na furadeira e comparar com o valor a ser gasto, gerando uma tomada de decisão com maior acuracidade.

\section{CONCLUSÃO}

Pode-se afirmar que o objetivo proposto para o artigo "analisar a compra ou não de um novo recurso de fabricação a partir da simulação das features contidas na peça", foi plenamente atingido. Essa abordagem permite simular com confiabilidade, rapidez, baixo custo e com alta qualidade da informação de entrada a partir da geometria da peça simulada.

A aplicação realizada possibilitou a visualização detalhada da utilização das features como base para análise de quais recursos selecionar na fabricação de uma peça específica. A utilização das features permitiu a flexibilidade para realização de testes e experimentos com recursos de fabricação com diferentes parâmetros sem alterar o dia-a-dia da empresa.

Algumas limitações da abordagem são: a necessidade de conhecimentos na interpretação de projetos mecânicos de peças e de conhecimento do sistema de fabricação e; durante a simulação foram considerados os tempos de setup e os tempos de falhas dos recursos como tempo improdutivo não fazendo distinção entre eles. 


\section{AGRADECIMENTOS}

Os autores agradecem ao CNPq pelo apoio que permitiram a realização desse trabalho.

\section{REFERÊNCIAS}

[1] Abdul-Kader, W.; Gharbi, A. Capacity estimation of a multi-product unreliable production line. International Journal of Production Research, 40(18), 4815-4834. 2002.

[2] Agostinho, L. O.; Vilella, R. C.; Button, S. T. Processos de fabricação e planejamento de processos. Apostila da Disciplina Introdução à Engenharia de Fabricação da Engenharia Mecânica da Unicamp, 2004.

[3] Álvares, A. J. Uma metodologia para integração CAD/CAPP/CAM voltada para manufatura remota de peças rotacionais baseada na internet. Tese de Doutorado. Programa de PósGraduação em Engenharia Mecânica da Universidade Federal de Santa Catarina, 2005.

[4] Banks, J.; Carlson, J. S.; Nelson, B. L.; Nicol, D. M. Discrete-event system simulation. 5a.ed New Jersey: Prentice-Hall, 2009.

[5] Benavente, J. C. T. Um sistema para o projeto e fabricação remota de peças prismáticas via internet. Dissertação de Mestrado. Programa de Pós-Graduação em Engenharia Mecânica da Universidade Federal de Santa Catarina, 2007.

[6] Bhandarkar, M. P.; Downie, B.; Hardwick, M.; NAGI, R. Migrating from IGES to STEP: one to one translation of IGES drawing to STEP drafting data. Computers in Industry, v. 41 n.3, pp.261-277, 2000.

[7] Braghirolli, L. F. Estudo da linearidade da produção em células de manufatura através de simulação a eventos discretos. Dissertação de mestrado. Programa de Pós-Graduação em Engenharia de Produção da Universidade Federal do Rio Grande do Sul. 2009.

[8] Diniz, A. E.; Marcondes, F. C.; Coppini, N. L. Tecnologia de usinagem dos materiais. 3a ed. São Paulo: MM Editora, 2001.

[9] Ferraresi, D. Fundamentos da usinagem dos metais. São Paulo: Edgard Blucher, 1985.

[10] Freitas-Filho, P. J. Introdução à modelagem e simulação de sistemas: com aplicação em Arena. $2^{\underline{a}}$ ed, Florianópolis: Visual Books, 2008.

[11] Gao, J.; Zheng, D.; Gindy, N. Mathematical representation of feature conversion for CAD/CAM system integration. Computer Integrated Manufacturing. n.20, p.457-467, 2004.

[12] Halevi, G.; Weill, R. D. Principles of process planning: a logical approach. Chapman \& Hall. 1995

[13] Jung, J. Y. Manufacturing cost estimation for machined parts based on manufacturing features. Journal of Intelligent Manufacturing, $p$. 227-238, 2002.

[14] Jung, J. Y.; Choi, S. J.; Moon, D. H. Cost estimating system for machined parts. Proceedings of International Conference on Production Research. Bangkok, Thailand, 2000.

[15] Law, A. M.; Mccomas, M. G. Simulation of manufacturing systems. Proceedings of the 1999 Winter Simulation Conference, 1999.

[16] Lee, H. Rule-based process planning by grouping features. KSME International Journal. v.18, n.12, p.2095-2103, 2004.

[17] Lopes, H. S.; Carmo, B. B. T.; Dutra, N. G. S.; Pontes, H. L. J. Simulação do transporte de minério de ferro na hidrovia do Araguaia-tocantis. Revista Gestão Industrial. v. 07, n.01:p.43-71, 2011. [18] Lui, Z.; WANG, L. Sequencing of interacting prismatic machining features for process planning. Computers in Industry. n.58. pp. 295-303, 2007.

[19] Maziero, N. L. Um sistema computacional inteligente de suporte ao projeto, manufatura e montagem de peças baseado em features: uma abordagem com sistemas especialistas. Tese de Doutorado. Programa de Pós-Graduação em Engenharia Mecânica da Universidade Federal de Santa Catarina, 1998.

[20] Miranda, R. C.; Fernandes, B. C.; Ribeiro, J. R. Montevechi, A. B.; Pinho, A. F. Avaliação da operação de setup em um célula de manufatura de um indústria de autopeças através da simulação a eventos discreto. Revista Gestão Industrial, v.06, n.03:p.01-21, 2010.

[21] Moreira, D. A. Administração da produção e operações. 2. ed. São Paulo: Cengage Learning. 2008.

[22] O'kane, J. F.; Spenceley, J. R.; Taylor, R. Simulation as an essential tool for advanced manufacturing technology problems. Journal of Materials Processing Technology, v.107, p.412424, 2000

[23] Pegden, C. D.; Shannon, R. E.; Sadowski, R. P. Introduction to simulation using siman. New York: Mcgraw-Hill, 1990.

[24] Palomino, R. C. Um modelo baseado em redes de petri para o planejamento e a programação da produção em ambientes do tipo job shop. Tese apresentada ao Programa de PósGraduação em Engenharia de Produção da Universidade Federal de Santa Catarina. 2001.

[25] Perera, T.; Liyanage, K. Methodology for rapid identification and collection of input data in the simulation of the manufacturing systems. Simulation Practice and Theory, n.7, p.645-56. 2000.

[26] Pontes, H. L. J. Desenvolvimento de um ambiente para simulação da manufatura baseado em features e realidade virtual. Tese de Doutorado. Programa de Pós-Graduação em Engenharia Mecânica/Manufatura da Universidade São Paulo, 2012. 
[27] Porto, A. J. V.; Palma, J. G. Da Manufatura Virtual à Simulação e à Realidade Virtual. In: Fábrica do Futuro: entenda hoje como sua indústria vai ser amanhã, ed. Banas, 2000.

[28] Resende, M. O. Princípios de processos de produção. Volume 1 e 2. Apostila do Departamento de Engenharia Mecânica. São Carlos: Universidade de São Paulo, 1993.

[29] Shah, J. J.;Mantyla, M. Parametric and Feature-Based CAD/CAM: Concepts, Techniques, and Applications. New York: John Wiley Songs Inc, 1995.
[30] Shannon, R. E. Introduction to the art and science of simulation. In: Proceedings of the 1998 Winter Simulation Conference, p.07-14, 1998.

[31] Slack, N. Vantagem Competitiva em Manufatura: atingindo competitividade nas operações industriais. São Paulo: Atlas. 1993.

[32] Zhang, F.; Huaming, L.; Chunhua, S. The disposal to face-based representation of design/manufacturing feature integration. Vehicle Electronics Conference. Proceedings of the IEEE International, v.1, p. 414-417, 1999. 


\section{Bapítulo 11}

\section{ESTUDO DE CASO DA IMPLEMENTAČ̃̃O DO MÉTODO SMED NO PROCESSO DE COMPRESSÃO DE UMA INDÚSTRIA FARMACÊUTICA}

\section{Andrei Gustavo Kozan de Souza}

\section{Edson Minoru Yajima}

Resumo: O presente artigo aborda a questão da efetividade da aplicação do SMED, que consiste em uma metodologia que busca a redução do tempo de setup, em um processo de compressão de comprimidos sólidos de uma indústria farmacêutica localizada no estado do Paraná. O objetivo almejado neste artigo é compreender os detalhes de um projeto já implementado para então, analisar criticamente as ações tomadas, comparando-as com a teoria acerca do SMED. Os resultados evidenciam que alguns conceitos da metodologia já eram utilizados na empresa. Contudo também é possível concluir que o potencial de redução do tempo de setup não foi explorado por completo, pois a redução do tempo de setup ao final do projeto foi de $27 \%$, mas como algumas ações implementadas não se sustentaram, a redução total foi de $16 \%$, sem mencionar as ações não implementadas devido à alta regulamentação presente na indústria farmacêutica. 


\section{INTRODUÇÃO}

Com as grandes transformações que vêm ocorrendo nas organizações industriais, o nível de competitividade tende a ser cada vez mais acirrado, sendo necessária uma busca contínua pela melhoria da qualidade e produtividade nos processos. Historicamente, a qualidade tem atravessado diversas eras (GARVIN, 1992).

A era do modelo japonês, criado a partir das necessidades do período pós II Guerra Mundial, trouxe vários elementos novos à gestão da qualidade. Segundo Carvalho \& Paladini (2012) esse modelo ficou conhecido como Toyota Production System - TPS (do inglês, Sistema Toyota de Produção - STP), ou ainda Produção Enxuta (Lean Manufacturing), e influenciou o estudo da qualidade, sobretudo, pela aversão ao desperdício ou muda, termo em japonês.

Contudo, alterar a estratégia de produção para o Lean Manufacturing requer também uma mudança cultural. Por esse motivo o Pensamento Lean é uma filosofia e não apenas uma nova abordagem metodológica para a melhoria. A cultura de uma organização é a forma e o clima no qual as pessoas realizam seu trabalho diariamente. Portanto, alcançar a mudança cultural é algo complexo, pois requer uma visão do processo sob um diferente ponto de vista (DINERO, 2005).

Um fator complicador abordado neste artigo é a alta regulamentação na qual a indústria farmacêutica está inserida. Um exemplo de sistema de regulamentação é o CGMP Current Good Manufacturing Practices (do inglês, BPF - Boas Práticas de Fabricação) que dispõe os requisitos mínimos para as instalações, equipamentos e procedimentos utilizados na produção, embalagem e análise de medicamentos. Essas regras visam à segurança do paciente e a eficiência do produto (U.S. FOOD AND DRUG ADMINISTRATION, 2017).

Ferrari (2013) ainda aponta um paradigma ao dizer que a indústria farmacêutica se difere dos outros segmentos no sentido de resistência às mudanças. Sempre que há uma iniciativa de implementar alterações simples nos processos, mas que melhorariam muito a produtividade dos processos farmacêuticos os processos, existe uma cultura de receio de deixar de atender às CGMP.
Um exemplo desses processos é o setup, que costuma ser uma grande oportunidade de melhoria, pois um setup mais rápido acarreta maior tempo de produção disponível e, consequentemente, maior produtividade. Nesse contexto, estudos que buscam a redução do tempo de setup são de extrema importância em qualquer segmento industrial, incluindo a indústria farmacêutica que segue rígidos padrões de qualidade. Um método que têm se mostrado eficiente na redução dos tempos de setup é o SMED - Single Minute Exchange of Die (do inglês, Troca Rápida de Ferramentas) e que possui suas raízes na filosofia Lean.

O objetivo geral deste trabalho foi estudar um projeto de redução de tempo de setup realizado em uma determinada indústria farmacêutica localizada no Paraná que já possuía os conceitos de SMED disseminados em seus processos de manufatura e analisar criticamente as ações tomadas comparandoas com a metodologia proposta pela teoria acerca do SMED ressaltando pontos positivos e negativos.

\section{REFERENCIAL TEÓRICO}

\subsection{MANUFATURA ENXUTA - LEAN MANUFACTURING}

Como mencionado na introdução, o lean manufacturing busca a eliminação dos desperdícios. Ohno (1997) divide desperdícios da indústria em sete categorias:

- Superprodução;

- Espera;

- Transporte;

- Superprocessamento;

- Movimentação;

- Produtos defeituosos;

- Estoques.

Segundo Carvalho \& Paladini (2012), um conceito fundamental do modelo japonês é o da melhoria contínua em busca da perfeição, traduzido da palavra japonesa, kaizen, introduzida por Maasaki Imai. Outro programa que serviu como pilar-base para o Lean Manufacturing e que também foi difundido pelo Japão nessa época é o 5S, que de acordo com Werkema (2011) mobiliza colaboradores e promove mudança de cultura através das seguintes vertentes: 
- Seiri: organização, utilização e descarte;

- Seiton: arrumação e ordenação;

- Seisou: limpeza e higiene;

- Seiketsu: padronização;

- Shitsuke: disciplina.

\subsection{SMED - SINGLE MINUTE EXCHANGE OF DIE}

Shigeo Shingo (2000) também teve uma contribuição importante para eliminação dos desperdícios da qualidade com a proposição de seu modelo de Troca Rápida de Ferramentas (TRF) ou ainda, do inglês, Single Minute Exchange of Die (SMED), que contribuiu para uma revolução nos sistemas produtivos.

De acordo com Shingo (2000), podemos classificar as operações industriais em operações principais e etapas de preparação e ajustes. As operações principais são realizadas em cada peça produzida, dividindo-se em operações essenciais, que tratam do processamento real do material, operações auxiliares, incluindo a alimentação e remoção de peças das máquinas e folgas marginais que são aquelas ações que ocorrem de forma irregular como esperas decorrentes da indisponibilidade da máquina ou do operador. As etapas de preparação e ajustes podem ser caracterizadas como operações que ocorrem apenas uma vez, antes e após do processamento de cada lote, também chamadas de setup.

De acordo com Burger (2004), o setup pode ser definido como todas as tarefas necessárias desde o momento em que se tenha completado a última peça boa do lote anterior até o momento da produção da primeira peça boa do lote seguinte, ou seja, que atenda as especificações de qualidade. Durante o tempo de setup, temos a execução de uma série de tarefas que reduzem a produtividade devido a não disponibilização do recurso produtivo. Entre elas temos: retirada do produto finalizado da célula e/ou linha de manufatura, desmontagem e limpeza do equipamento, troca de ferramental específico para cada produto, remontagem do equipamento, alimentação com novo lote de matéria-prima, testes e ajustes no equipamento e testes com a matéria-prima do novo lote.

Segundo Shingo (2000) na metodologia para aplicação do SMED, existem quatro estágios conceituais. No estágio preliminar, não há nenhuma distinção entre setup interno e setup externo. No primeiro estágio, é feita a separação das operações de setup interno e externo. No segundo estágio, as atividades consideradas setup interno são convertidas para setup externo. Por fim, no terceiro estágio, examinam-se as operações de setup interno e setup externo a fim de se observar eventuais oportunidades de melhoria, assim como a padronização de ajustes estabelecidos. A Figura 1 ilustra a metodologia de Shingo (2000), englobando ainda a possibilidade de haver atividades de setup externo antes do início do setup e não apenas atividades externas depois do fim do setup. Em ambos os casos, tais atividades são, em sua maioria, preparação e verificação de materiais (matérias-primas e produto semiacabado) bem como organização de peças e ferramentas:

Figura 1 - Estágios para aplicação da TRF

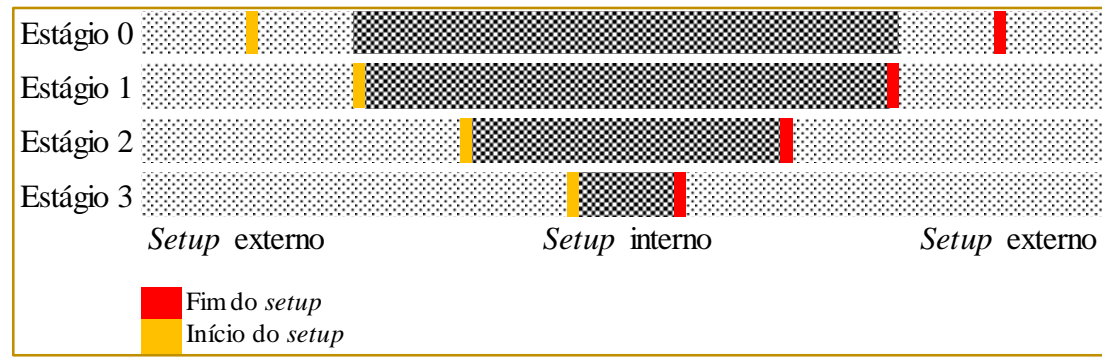

Fonte: Adaptado de Shingo, 2000. 
Dinero (2005) ainda preconiza quatro passos para a implementação de um setup rápido em sua metodologia TWI (Training Within Industry), que foi o início do Lean Manufacturing:

- Registro: evitar interferência do observador e envolver as pessoas através de formulário e gráfico spaghetti (para mapear e posteriormente otimizar as movimentações);

- Análise: classificar as atividades registradas em internas (executadas com a máquina parada) e externas (executadas com a máquina produzindo);

- Aplicação do ECRS: buscar oportunidades para eliminar, combinar, reduzir ou simplificar as atividades internas priorizando atacar com a abordagem que gerará a melhor redução de tempo;

- Padronização: transferir o conhecimento às pessoas, exigir uma nova metodologia e postura de trabalho para que a redução se sustente;

\section{ESTUDO DE CASO}

\subsection{METODOLOGIA}

A metodologia aplicada nesta pesquisa foi baseada em revisões bibliográficas de artigos científicos, livros e sites relacionados, podendo se classificar como um estudo de caso, pois abrange o problema por completo utilizando-se de abordagens específicas de coleta de análise de dados que garantem um amplo e detalhado conhecimento sobre o mesmo (GIL, 2012).

Inicialmente foi selecionado um projeto de SMED já finalizado em uma determinada indústria farmacêutica. Entende-se que o problema é avaliar como o SMED vem sendo implementado nas empresas, pois, seus benefícios são evidentes, mas é importante analisar as dificuldades e barreiras na implementação de um projeto como esse. A partir de então foi estruturada uma coleta de dados na empresa, bem como um plano de revisão bibliográfica. Tendo os dados coletados, foi preciso realizar uma classificação e organização para análise no trabalho. Por fim, o produto do trabalho, foi explicitar os pontos positivos e negativos encontrados nos registros históricos do projeto selecionado e comparar estes pontos com o conhecimento teórico acerca do tema a fim de propor melhorias e apontar lições aprendidas para a empresa.

\subsection{DESCRITIVO DA EMPRESA E DO PROCESSO}

Com relação à empresa, pertence a um grupo multinacional do ramo segmento farmacêutico, sendo o segundo maior fabricante mundial de fármacos. Na planta em questão, localizada no estado do Paraná, são produzidos medicamentos genéricos, ou seja, medicamentos isentos de patente. É considerada pelo grupo uma planta média de produção de comprimidos orais sólidos e um polo mundial para a produção de produtos hormonais.

Na produção da empresa em questão existem seis grandes setores: pesagem mistura granulação, compressão e revestimento.

Na pesagem, todas as matérias primas (pós e líquidos) eram pesadas e alocadas em um container de aço inox chamado bin que possuía entre 150 e 1200 litros e era movimentado entre os processos através de empilhadeira, paleteira manual hidráulica ou coluna de elevação.

Na mistura, o container era acoplado a um equipamento e rotacionado, realizando a homogeneização das matérias primas em seu interior.

No processo de granulação, características físico-químicas do pó eram alteradas por meio de fases de spray da solução granulante, secagem e calibração para permitir a compressão do pó no processo seguinte.

$\mathrm{Na}$ compressão, o pó era alimentado por gravidade, pois o bin ficava posicionado acima da compressora rotativa (Figura 2) que é preparada com punções e matrizes montados no rotor, de acordo com o formato do comprimido desejado. As matrizes eram preenchidas com o pó através de um sistema de hélices chamado conjunto fill-o-matic. Após, sofriam pressão proveniente da punção. Uma compressora possuía em média 30 punções juntamente com um retentor, que são peças plásticas utilizadas para conter a lubrificação do ferramental e evitar o contato com os comprimidos. A pressão exercida pela punção no interior da matriz reduz o espaço físico, aumentando o atrito inter-particular e removendo o ar entre o material particulado. Assim, o movimento das partículas ficava impedido e o comprimido sólido é formado.

Por fim, no setor de revestimento os comprimidos eram revestidos com uma 
solução aglutinante aplicada uniformemente por meio de um jato uniforme em uma câmara rotativa.

Figura 2 - Compressora rotativa de comprimidos de médio porte e seu painel IHM

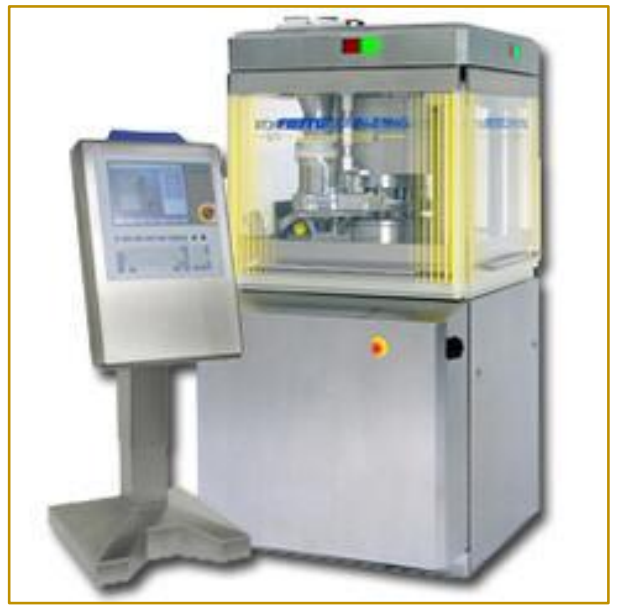

Fonte: Pharmaceutical Online, 2017.

\subsection{RESULTADOS}

\subsubsection{APRESENTAÇÃO DO SMED NA EMPRESA CITADA}

O setor de compressão possuía quatro tipos de setup classificados de acordo com a complexidade das atividades de cada um. Neste trabalho será explorado o setup Tipo A, que acontece entre trocas de lote do mesmo produto. O tempo médio para execução de um setup Tipo A antes do início do projeto era de $1 \mathrm{~h}$ 42min e ele acontece cerca de duas vezes ao dia em cada compressora.

O procedimento operacional padrão (POP) do setup não possuía organização com referência de tempo, nem de padronização de atividades ou sequenciamento detalhado de atividades. Assim, o diagnóstico realizado através da análise do vídeo do setup ficou comprometido, pois cada operador realizava as tarefas de acordo com sua experiência pessoal.

Tendo em vista este problema, foi elaborado um sequenciamento padrão de atividades a ser implementado em todo o setor. Os resultados são apresentados na Tabela $1 \mathrm{e}$ Tabela 3. Na Tabela 2 são apresentados também os tempos de um setup, estimados com base em uma filmagem das câmeras de segurança já instaladas em uma sala produtiva do setor de compressão, para evitar influência do observador sobre o operador, evitando com que ele realizasse as atividades de forma não usual.

Tabela 1 - Atividades do setup externo (pré setup interno)

\begin{tabular}{|cccc|}
\hline$\#$ & Tipo & \multicolumn{1}{c}{ Atividade do Setup } & Tempo (hh:mm) \\
\hline 1 & & Alocar bin e documento do novo lote próximo à sala & N/A \\
2 & & Conferir documento do novo lote & N/A \\
3 & & Alocar: pallet com barricas limpas, etiquetas e saco plástico & N/A \\
4 & & Coletar amostra do final do lote & N/A \\
5 & Analisar friabilidade de final de lote & N/A \\
6 & analisar desintegração de final de lote & N/A \\
7 & & Alocar o pallet com produto para fora da sala (corredor) & N/A \\
8 & Alocar o bin do novo lote na coluna de elevação & N/A \\
9 & Limpar o bin & N/A \\
10 & Alocar o bin para fora da sala (corredor) & N/A \\
\hline \hline
\end{tabular}

Fonte: Empresa estudada, 2017. 
Tabela 2 - Atividades do setup interno

\begin{tabular}{|c|c|c|c|}
\hline \# & Tipo & Atividade do Setup & Tempo (hhmm) \\
\hline 11 & \multirow{4}{*}{ 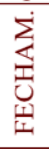 } & Coletar amostras (teste microbiológico) & $0: 01$ \\
\hline 12 & & Realizar o fechamento da última barrica & 0:02 \\
\hline 13 & & Preencher documentação (diário e IP) & 0:04 \\
\hline 14 & & Alocar documentação na sala de liderança & 0:02 \\
\hline 15 & \multirow{7}{*}{ 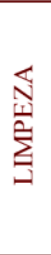 } & Limpar fill-o-matic & $0: 06$ \\
\hline 16 & & Limpar o raspador de pó & 0:04 \\
\hline 17 & & Montar retentores dos punções (troca) & 0:05 \\
\hline 18 & & Limpar a base da compressora, matrizes e punções & $0: 03$ \\
\hline 19 & & Montar o raspador de pó e fill-o-matic & $0: 06$ \\
\hline 20 & & Limpar portas laterais e proteções da compressora & $0: 03$ \\
\hline 21 & & Montar portas laterais e proteções da compressora & 0:02 \\
\hline 22 & \multirow{11}{*}{ 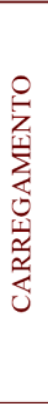 } & Preencher fechamento da documentação & $0: 02$ \\
\hline 23 & & Alocar o bin do novo produto na sala & 0:03 \\
\hline 24 & & Preencher identificação da sala (porta) & 0:01 \\
\hline 25 & & Preencher diário de equipamento e etiquetas & 0:02 \\
\hline 26 & & Preencher documentação do novo lote & 0:02 \\
\hline 27 & & Inserir novo lote na IHM & $0: 01$ \\
\hline 28 & & Inserir comandos de liberação do lote na IHM & 0:02 \\
\hline 29 & & Realizar abertura do bin & 0:02 \\
\hline 30 & & Inserir o bin na compressora (posicionamento) & $0: 03$ \\
\hline 31 & & Coletar amostra para teste de umidade pelo fill-o-matic & 0:02 \\
\hline 32 & & Inserir parâmetros para ajuste de variáveis de processo & $0: 03$ \\
\hline 33 & \multirow{9}{*}{ 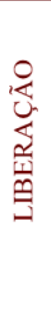 } & Coletar amostra para liberação & 0:02 \\
\hline 34 & & Analisar friabilidade & $0: 05$ \\
\hline 35 & & Analisar desintegração & $0: 05$ \\
\hline 36 & & Analisar peso médio & $0: 04$ \\
\hline 37 & & Analisar altura & $0: 05$ \\
\hline 38 & & Analisar dureza & 0:04 \\
\hline 39 & & Preencher os dados nos relatórios e na IP & $0: 03$ \\
\hline 40 & & Conferir setup & 0:02 \\
\hline & & & 1:31 \\
\hline
\end{tabular}

Fonte: Empresa estudada, 2017.

Tabela 3 - Atividades do setup externo (pós setup interno)

\begin{tabular}{|cclc|}
\hline$\#$ & Tipo & \multicolumn{1}{c}{ Atividades do Setup } & Tempo (hh:mm) \\
\hline 41 & \multirow{2}{*}{ Analisar umidade } & N/A \\
42 & O & Alocar o produto na área de estoque intermediário & N/A \\
43 & \multirow{2}{*}{} & Alocar o bin na área de lavagem/pesagem & N/A \\
\hline
\end{tabular}

Fonte: Empresa estudada, 2017.

Foi selecionado um setup após a implantação do sequenciamento padrão de atividades com todos os operadores e após a eliminação e análise de causas especiais - os outliers. Os resultados imediatos foram a redução de $1 \mathrm{~h}$ 42min para 1 h $31 \mathrm{~min}$, conforme apontado na Tabela 2 (redução de 10,8\%).

A empresa optou por envolver todos os colaboradores na implementação do SMED por meio de divisão em grupos. Assim, todos poderiam participar, de forma focada, sem parar totalmente a produção no setor ou despender muitos recursos por meio de reuniões alternadas semanalmente.
Também foi possível visualizar os tipos de atividade que mais demandavam tempo para sua execução e realizar uma classificação geral de atividades que auxiliaria o operador a manter o foco no setup interno, são elas: fechamento, limpeza, carregamento e liberação. As atividades foram classificadas de acordo com sua finalidade específica e divididas entre os grupos para o brainstorm, conforme o impacto em minutos totais que tais atividades causavam no setup, conforme mostra a Tabela 4. 
Tabela 4 - Classificação das atividades do setup

\begin{tabular}{|clccc|}
\hline Atividade & \multicolumn{1}{c}{ Descriçao } & Impacto & \multicolumn{1}{c}{ Grupo } \\
\hline Analisar & $\begin{array}{l}\text { Teste de qualidade realizado em equipamento } \\
\text { específico da sala de CEP }\end{array}$ & 23 & Sequenciamento \\
Limpar & $\begin{array}{l}\text { Limpeza realizada conforme POP (pano } \\
\text { descartável, gaspilhão, aspirador) }\end{array}$ & 22 & Grupo 5S / Fluxo \\
Preencher & $\begin{array}{l}\text { Preenchimento de documento à mão conforme } \\
\text { POP e regras de BPF } \\
\text { Inserir }\end{array}$ & $\begin{array}{l}\text { Atividade dependente de IHM (interface homem- } \\
\text { máquina) }\end{array}$ & 11 & Grupo Documentação \\
Montar & $\begin{array}{l}\text { Montagem de componentes mecânicos feita com } \\
\text { auxilio de ferramentas }\end{array}$ & 11 & Gequenciamento \\
Alocar & $\begin{array}{l}\text { Movimentação de materiais (carregamento, } \\
\text { posicionamento ou descarga) }\end{array}$ & 6 & Grupo 5S / Fluxo \\
Coletar & $\begin{array}{l}\text { Atividade manual conforme POP } \\
\text { Retirada de amostra conforme POP para teste } \\
\text { posterior } \\
\text { Check ou conferência padronizada por POP } \\
\text { (realizada pela liderança) }\end{array}$ & 5 & Grupo Documentação \\
\hline
\end{tabular}

Fonte: Empresa estudada, 2017.

\subsubsection{PLANO DE AÇÃO}

Como produto das reuniões dos grupos, estabeleceu-se um plano de ação em que as principais ações, que foram investigadas na fase de coleta de dados, são apresentadas nos próximos seis subitens. Por fim será apresentado o resultado ao final do projeto, bem como a situação atual do tempo de setup no setor de compressão.

\subsubsection{MONTAGEM DE RETENTORES (ATIVIDADE \#17)}

Durante o setup os retentores exigiam desmontagem, limpeza / troca e remontagem. A saída encontrada foi garantir que houvesse sempre um jogo de retentores reserva sanitizado, completo e pronto para uso dentro da sala produtiva. Assim o operador não precisaria ir até a área de lavagem realizar a sanitização de tais peças. Então foi alinhado entre a área de compressão e área de lavagem um fluxo para que sempre houvesse um jogo reserva disponível conforme apresentado na Figura 3.

Figura 3 - Jogo de retentor limpo, organizado e pronto para utilização

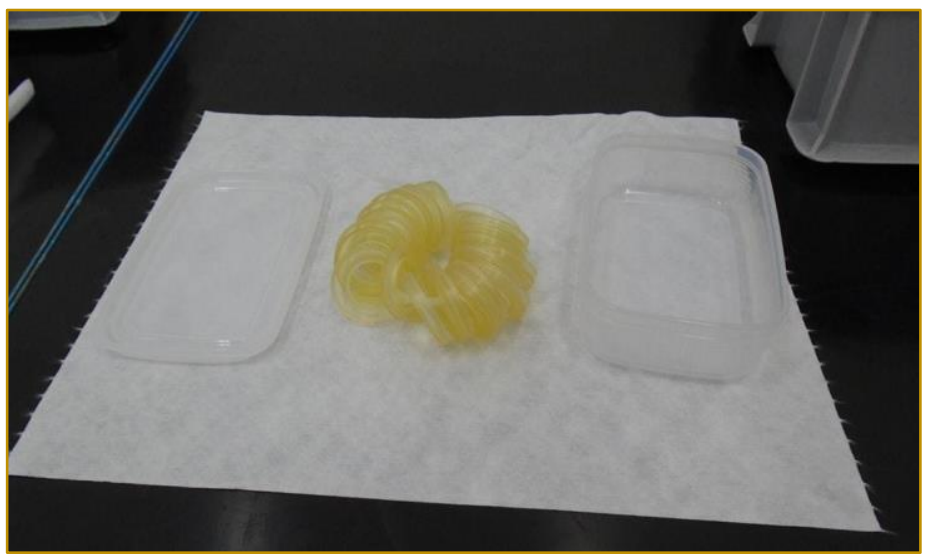

Fonte: O Autor, 2017. 


\subsubsection{MONTAGEM DO CONJUNTO FILL-O- MATIC (ATIVIDADES \#15 E \#19)}

Durante o setup, o procedimento operacional padrão exigia a remoção e desmontagem de todo o conjunto fill-o-matic (Figura 4) para limpeza de qualquer resquício de pó do lote anterior que pudesse ter ficado ali depositado após a parada da compressora. Contudo, investigando o fluxo de todo o setor de produção, percebeu-se que na etapa de granulação uma pequena quantidade de pó que ficava armazenado no equipamento de um lote para outro e não impactava a qualidade do produto, pois tratava-se de um setup Tipo A, para um mesmo composto e de mesma concentração. Com esse argumento foi possível conseguir a liberação para eliminar a limpeza do conjunto fill-o-matic junto ao departamento de qualidade. Contudo o grupo sequenciamento encontrou dificuldades e resistências por parte dos operadores e analistas de processo para mudar o procedimento e cancelou a ação.

Figura 4 - Conjunto fill-o-matic (vistas lateral e frontal)

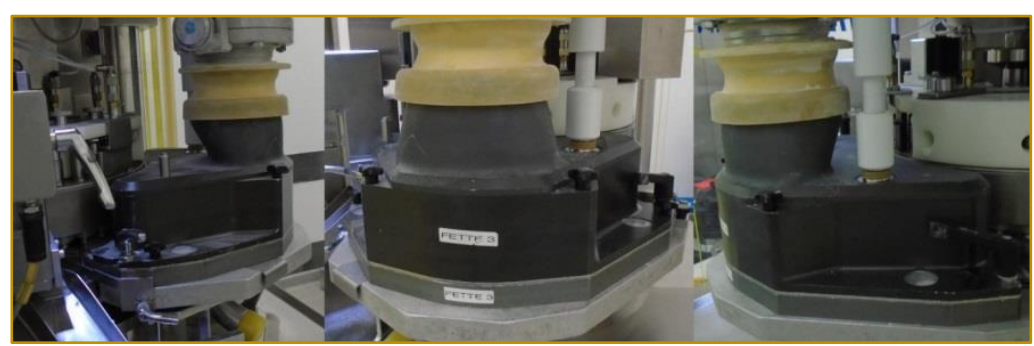

Fonte: O Autor, 2017.

\subsubsection{ANÁLISES DE FRIABILIDADE E DESINTEGRAÇÃO (ATIVIDADES \#35 E \#36)}

As análises de friabilidade e desintegração são testes obrigatórios em todos os lotes de acordo com as normas de CGMP, contudo durante a observação do processo feitas pelas equipes constatou-se que para a liberação de processo de um lote após o setup era preciso apenas as análises de peso médio do comprimido, análise de dureza e análise de altura. Ou seja, as análises de friabilidade e desintegração (Figura 5) não são parâmetros críticos e poderiam ser feitas após a liberação do processo e ser transferidos para setup externo. Avaliando tal oportunidade com o time de qualidade, a proposta foi aprovada, porém no momento da operacionalização da mudança houve resistência por parte do próprio grupo de sequenciamento no momento da execução da ação com o argumento de que eram atividades que não despendiam muito tempo e que podiam ser feitas em paralelo.

Figura 5 - Friabilômetro e desintegrador utilizados nas análises

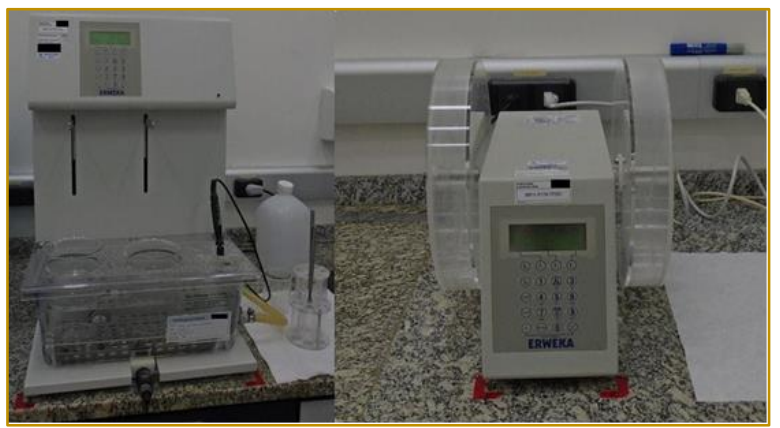

Fonte: O Autor, 2017. 


\subsubsection{PADRONIZAÇÃO DE MONTAGENS (ATIVIDADES \#17, \#19 E \#21)}

As montagens necessitavam de ferramentas especiais que ficavam misturadas em uma caixa abaixo do balcão de preenchimento de documentos. Após um levantamento da posição dos parafusos e das ferramentas utilizadas verificou-se que na maioria dos casos utilizava-se chave allen, portanto concluiu-se que era possível substituir todos por manípulos conforme indicado na Figura 6, eliminando $o$ uso das chaves e, consequentemente, a necessidade de procurar e armazenar tais chaves na sala produtiva. A ação foi planejada e executada pela equipe de manutenção, com 0 acompanhamento do grupo 5S / fluxo.

Figura 6 - Manípulos utilizados para padronizar parafusos

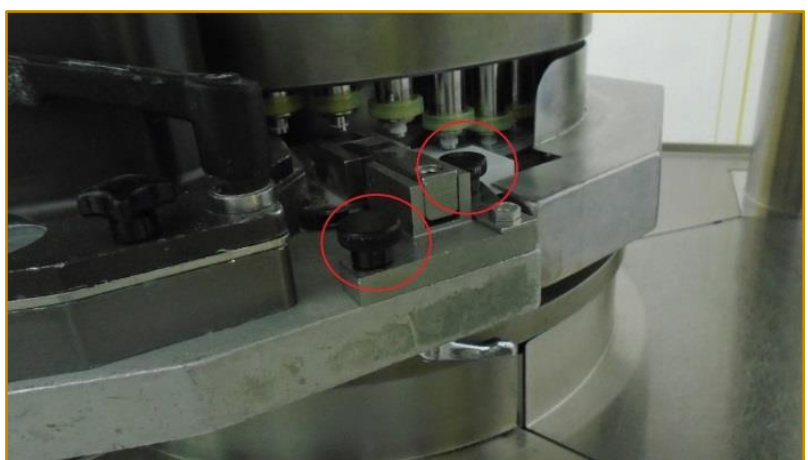

Fonte: O Autor, 2017.

\subsubsection{AÇÃO: MOVIMENTAÇÃO DE BINS E PALLETS NO CORREDOR (ATIVIDADES \#1, \#3, \#7 E \#10)}

Havia uma demanda para mais demarcações e áreas de alocação intermediária que ficavam nos corredores, pois quando havia várias compressoras em setup, faltava espaço físico. Para tal, foi preciso a organização das áreas com a aplicação de 5S, removendo quadros e informações desnecessárias/ duplicadas e também reposicionamento de outros itens. Assim, foi possível liberar espaço para criar novas demarcações para posicionamento de peças, bins e pallets, fora das salas produtivas durante as atividades do setup, conforme Figura 7. A ação foi então implementada pelo grupo 5S / fluxo.

Figura 7 - Algumas das demarcações realizadas no setor de compressão

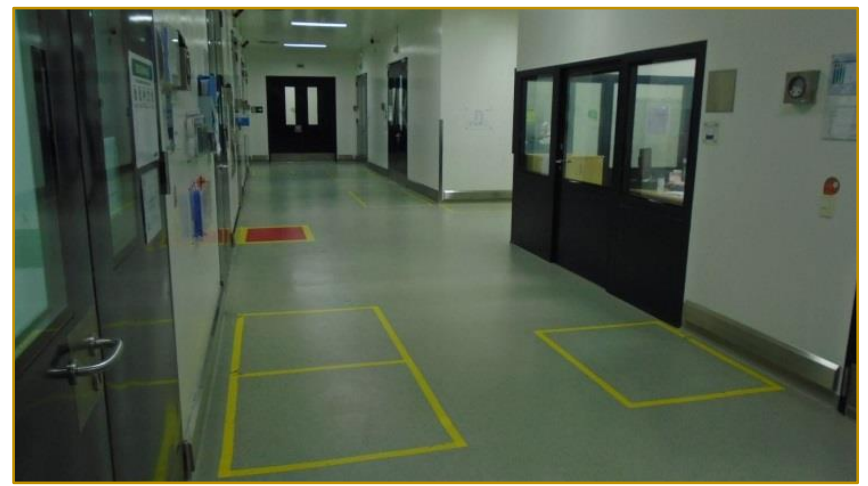

Fonte: O Autor, 2017. 


\subsubsection{MOVIMENTAÇÃO NO PREPARO DE CONSUMÍVEIS (ATIVIDADE \#3)}

Nessa atividade o operador deslocava-se até uma sala de armazenamento de materiais consumíveis (sacos plásticos, etiquetas, barricas limpas, entre outros) comum para todo o departamento de produção e, logo, também utilizada pelos outros setores. A proposta foi criar uma sala de armazenamento menor e próxima das salas das compressoras, que atendesse somente o setor de compressão, reduzindo o deslocamento do operador pela fábrica, conforme o diagrama de spaghetti elaborado nas reuniões do grupo de 5S / fluxo e apresentado na Figura 8.

Figura 8 - Diagrama de spaghetti com o fluxo antes (laranja) e depois (verde)

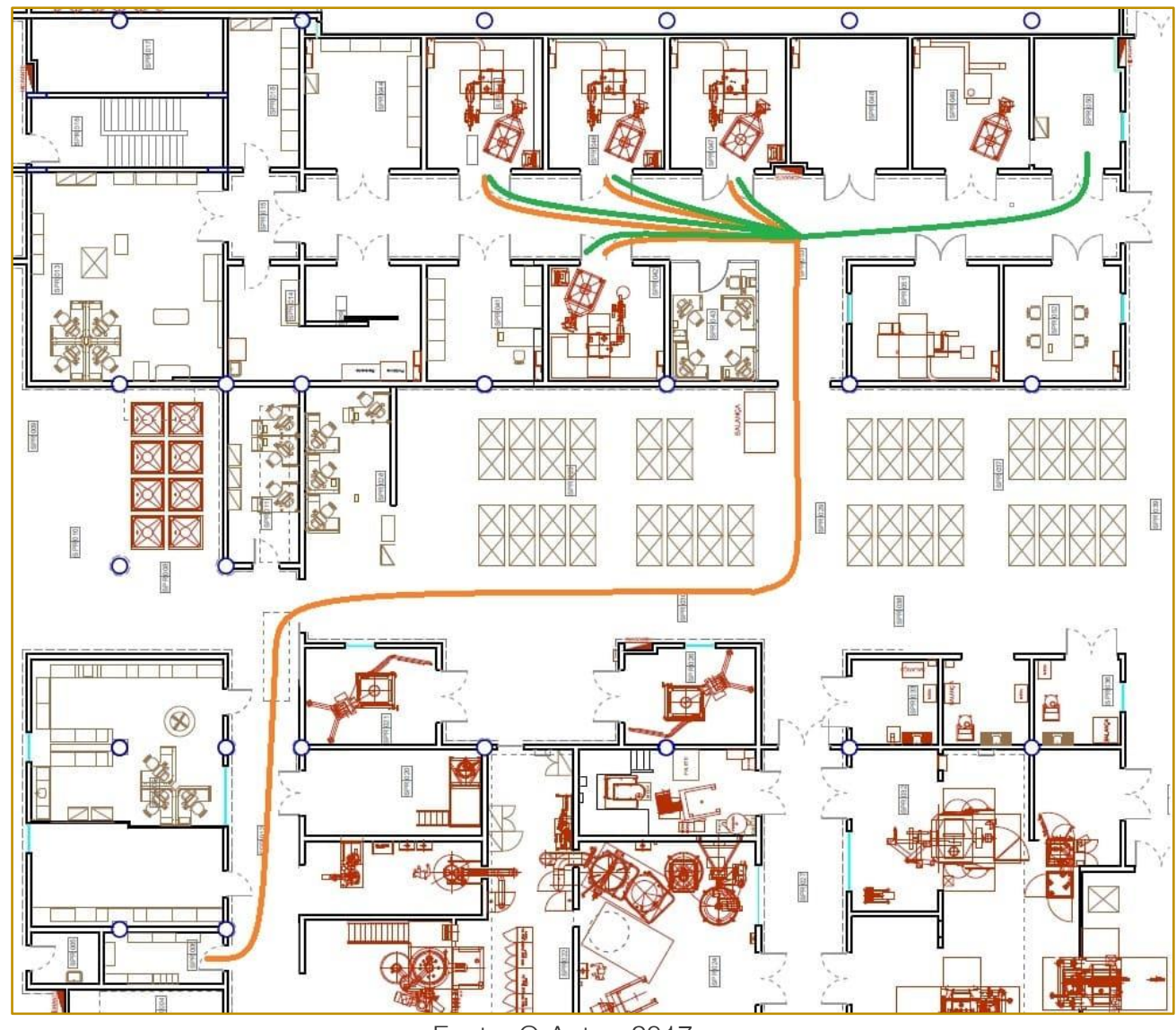

Fonte: O Autor, 2017.

\subsubsection{ANÁLISE CRONOLÓGICA DO TEMPO DE SETUP}

Após o pleno entendimento e a finalização da análise de todo o material coletado na empresa acerca do projeto, foi possível visualizar os tempos médios do setup considerando amostras com três setups realizados em turnos e compressoras diferentes. Tais tempos médios foram separados em antes, durante, ao final do projeto e no momento da coleta de dados, três meses após a conclusão do projeto. 
Figura 9 - Evolução do tempo médio de setup em relação às fases do projeto

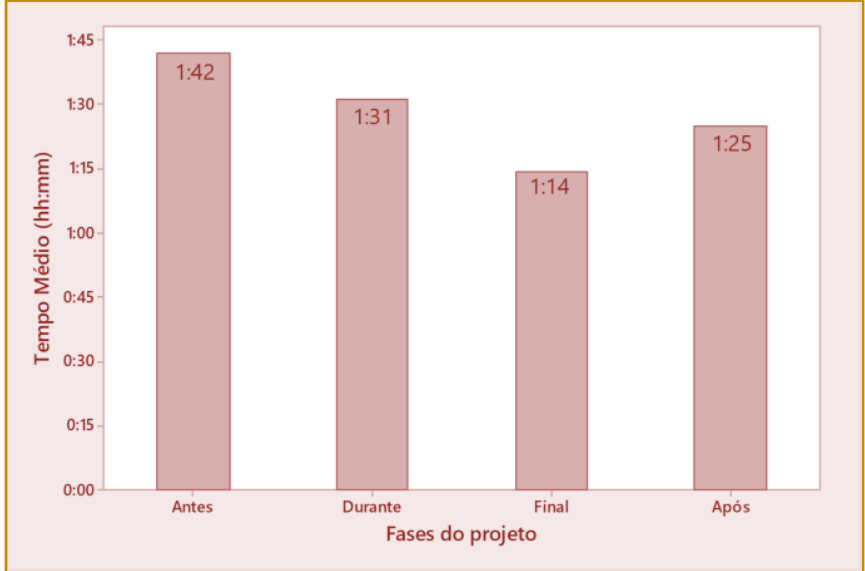

Fonte: O Autor, 2017

\section{DISCUSSÃO}

A empresa em questão fez escolhas acertadas nas etapas de planejamento, onde envolveu o chão-de-fábrica por meio de trabalho em grupo para participar do SMED. Um segundo ponto observado foi que a empresa não realizava plenamente a separação entre setup interno e externo no caso específico do setup do setor de compressão, que é o estágio preliminar apontado pela metodologia do SMED.

Após essa discussão a empresa buscou oficializar a separação entre setup interno e setup externo, que já era parcialmente feita pelos próprios operadores, o que foi um ponto positivo. Esta prática é o primeiro estágio indicado na metodologia do SMED. Um ponto negativo desta prática é que não era feita de forma padronizada e obrigatória entre os operadores, pois quando havia revezamento para refeições, reuniões, treinamentos ou troca de turno, o setup externo nem sempre era feito. Uma evidência disso é que muitas vezes os próprios operadores não sabiam justificar a causa raiz do atraso no setup nos formulários, quando de fato era a falta da execução de setup externo que gerava um acúmulo de atividades no setup interno e que, mesmo realizando com pressa, não era possível atingir o tempo almejado.

Em relação às possíveis melhorias para os próximos projetos de SMED na empresa estudada, foi organizado um quadro de Lições Aprendidas conforme apresentado na Tabela 5, com base nos conceitos definidos por Shingo (2000) para a implantação do SMED e classificando as ações conforme a análise ECRS. Vale lembrar que as oportunidades foram listadas com base em um diagnóstico realizado cerca de três meses após a conclusão do projeto.

Tabela 5 - Lições Aprendidas

\begin{tabular}{|c|c|c|c|}
\hline Ações & ECRS & Avaliação & Oportunidade \\
\hline $\begin{array}{l}\text { - Organização de jogos } \\
\text { reserva de retentores }\end{array}$ & $\mathrm{R}$ & $\begin{array}{l}\text { Não havia jogos reservas para todas as } \\
\text { compressoras no momento da avaliação. }\end{array}$ & $\begin{array}{l}\text { Planejar auditorias internas para } \\
\text { garantir a sustentação. }\end{array}$ \\
\hline $\begin{array}{l}\text { - Montagem do Fill-o-matic } \\
\text { - Análises de Friabilidade e } \\
\text { Desintegração }\end{array}$ & $\mathrm{E}$ & $\begin{array}{l}\text { Transferir para setup externo traria } 22 \\
\text { minutos de ganho. }\end{array}$ & $\begin{array}{l}\text { Deve-se propor um projeto bem } \\
\text { estruturado e com recursos alocados } \\
\text { a fim de executar estas ações. }\end{array}$ \\
\hline - Montagens & $\mathrm{S}$ & $\begin{array}{l}\text { Não se sustentaram: não havia peças de } \\
\text { reposição para manípulos perdidos, } \\
\text { espanados ou danificados. }\end{array}$ & $\begin{array}{l}\text { Incluir spare parts no plano de } \\
\text { manutenção preventiva. }\end{array}$ \\
\hline - Movimentações & N/A & $\begin{array}{l}\text { Falta de conhecimento técnico sobre TRF } \\
\text { nos grupos (reduzir atividades do setup } \\
\text { externo não impacta o tempo total) }\end{array}$ & $\begin{array}{l}\text { Ministrar treinamentos técnicos para } \\
\text { nivelar conhecimento no início dos } \\
\text { projetos. }\end{array}$ \\
\hline
\end{tabular}

Fonte: O autor, 2017 
Um motivo em comum para que as ações descritas na Tabela 5 culminassem em tais avaliações foi a falta de padronização da metodologia SMED. Seria necessário um plano estruturado para a fase de sustentação do projeto e não apenas para as fases de planejamento e execução, como foi feito. Isso fez com o que o resultado final do projeto fosse positivo, contudo com potencial de manutenção do menor tempo de setup atingido ao final da implementação do SMED, comparado ao tempo de setup constatado após três meses da implantação das ações.

\section{CONCLUSÃO}

Por meio do presente trabalho é evidenciado o potencial de aumento de disponibilidade de equipamento por meio da aplicação da técnica SMED mesmo em um processo produtivo de uma indústria que atua no ramo farmacêutico, levando em conta à resistência frente às mudanças e os altos níveis de regulamentação, característicos neste segmento.

Portanto pode-se dizer que os objetivos deste trabalho foram alcançados, pois foi possível organizar os dados fornecidos pela empresa através da aplicação de ferramentas e assim compreender as escolhas tomadas ao aplicar um projeto de SMED.

Por outro lado, também foi possível apontar

\section{REFERÊNCIAS}

[1] Burger, Marcos Guilherme. O balanced scorecard no monitoramento do desempenho do processo de implementação da produção enxuta: um estudo de caso. Universidade Federal de Pernambuco, 2004.

[2] Carvalho, Marly Monteiro de; Paladini, Edson Pacheco. Gestão da qualidade. 2. ed. Rio de Janeiro: Elsevier, 2012.

[3] Dinero, Donald A. Training within industry: the foundation of lean. Nova lorque: Productivity Press, 2005

[4] Ferrari, M. Lean na Indústria Farmacêutica Quebrando paradigmas. Disponível em: $<$ http://www.lean.org.br/artigos/229/lean-naindustria-farmaceutica---quebrandoparadigmas.aspx>. Acesso em: 20 abr. 2017.

[5] Garvin, David A. Gerenciando a qualidade: a visão estratégica e competitiva. Rio de Janeiro: Qualitymark, 1992.

[6] Gil, Antonio Carlos. Como elaborar projetos de pesquisa, 5 ed. São Paulo: Atlas, 2012. pontos de melhoria na metodologia adotada pela empresa, sendo o principal deles a necessidade de incentivo à mudança de cultura e um aumento na exigência de execução e padronização das melhorias. Isso porque houveram ações propostas não implementadas por "receio" de que houvesse impacto na qualidade do produto, sem avaliar o custo da não qualidade. Tal comportamento também pode ser explicado pelo alto nível de regulamentação exigido na indústria farmacêutica, contudo para que a implantação do Lean obtenha sucesso a mudança cultural é decisiva e deve ser implementada no sentido da diretoria para o chão-de-fábrica.

Sendo assim, embora a empresa já tivesse algumas ações que fazem parte do método SMED implementadas, conclui-se que o tempo mínimo possível para o setup Tipo A no setor de compressão é menor que 1:14, pois algumas ações não foram implementadas. Por outro lado, também é crucial uma maior manutenção dos resultados obtidos, pois se atingiu um tempo mínimo em um primeiro momento, contudo houve um aumento no tempo médio após três meses.

De qualquer forma, ficou evidente que o método SMED é uma ferramenta eficaz para redução dos desperdícios e busca contínua pela perfeição nos processos, pois o projeto estudado teve resultado positivo, porém ainda existem oportunidades de melhoria.

[7] Minitab. User' Guide Release 17.1.0, Microsoft Windows, 2013.

[8] Ohno, Taiichi. O sistema Toyota de produção: além da produção em larga escala. Porto Alegre: Bookman, 1997.

[9] Pharmaceutical Online. Fette America Tablet Press Medium 1200i 0002. Disponível em: $<$ https://www.pharmaceuticalonline.com/doc/fetteamerica-tablet-press-medium-1200i-0002>. Acesso em: 23 abr. 2017.

[10] Shingo, S. Sistema de Troca Rápida de Ferramenta. Porto Alegre. Bookman, 2000.

[11] U.S. Food And Drug Administration. CGMP Regulations. Disponível em: <https://www.fda.gov/Drugs/DevelopmentApproval Process/Manufacturing/ucm090016.htm>. Acesso em: 19 abr. 2017.

[12] Werkema, Maria C. C. Lean Seis Sigma: Introdução as ferramentas do lean manufacturing. 2. ed. Rio de Janeiro: Elsevier, 2011. 


\section{Bapítulo 12}

\section{PROPOSTA DO PROJETO DE UNIDADE PRODUTIVA EM UMA MICROEMPRESA DE CONFECCZÃO NO MUNICÍPIO DE ITACOATIARA/AM}

\section{Alafan Jeferson da Costa Lima}

\section{Alessandra Ferreira Reis}

\section{Ricardo Lopes de Almeida Junior}

Rayson Rawkem da Silva Santos

\section{Agberto de Castro Marinho Júnior}

Resumo: Este trabalho consiste em avaliar as ações de planejamento de unidades produtivas em uma microempresa de confecção localizada na cidade de Itacoatiara/Am. Quanto a abordagem do problema, trata-se de uma pesquisa quantitativa. Quanto ao procedimento técnico, o trabalho caracteriza-se como estudo de caso propondo a aplicação de algumas ferramentas de análise de custo, capacidade de produção e previsão de demanda. Finalizando, a empresa poderá racionalizar os recursos, oferecendo produtos competitivos e lucratividade. Ao colaborador maior satisfação, segurança e saúde no ambiente de trabalho.

Palavras-chave: Arranjo físico, produtividade, confecção de roupas, gestão de custo. 


\section{INTRODUÇÃO}

O planejamento das atividades industriais tem grande importância para o sucesso de qualquer organização. Esse planejamento, quando ligados a fatores estratégicos, que impactam diretamente a produtividade da empresa, deve ser analisado cuidadosamente. Planejar o processo produtivo não é uma tarefa simples, principalmente por conta das exigências frente aos consumidores.

No desenvolvimento do projeto de uma unidade produtiva, as decisões de localização, capacidade produtiva e arranjo físico são, extremamente, importantes, pois interferem na produtividade, nos custos e em todo o fluxo da operação. Desta forma, verifica-se que o principal objetivo do planejamento, de uma unidade industrial, está na administração eficiente dos recursos físicos, por meio, do dimensionamento correto dos fatores de produção.

De acordo com Chiavenato (1991), o Planejamento e Controle da Produção age sobre os meios de produção para aumentar a eficiência (produzir mais, racionalizando os recursos), cuida para que os objetivos sejam plenamente alcançados e garanta a eficácia.

A relevância desta pesquisa consiste na apresentação e adoção de um modelo apresentado por Camorotto (2006), com um roteiro estruturado, A estratégia de produção foi elaborada de forma que fosse simples o suficiente para ser aplicado pela própria empresa, com o objetivo de torná-las mais competitivas por meio da análise da unidade produtiva.

Este artigo consiste em analisar o arranjo físico as ações relacionadas a planejamento de unidade produtiva, dentro de uma organização localizada na cidade de Itacoatiara-AM. Para realização e compreensão da estrutura deste trabalho, dividiram-se em cinco partes: (1) Introdução; (2) Revisão da literatura, tratando ramos de confecções, roupas e Capacidade de produção (3) Metodologia; e (4) Apresentação, discussão e resultados; (5) Conclusão; e referências.

\section{REVISÃO DA LITERATURA}

\subsection{RAMOS DE CONFECÇÕES, ROUPAS}

O objetivo primordial da indústria de confecção é a produção de roupas. A confecção dá forma aos tecidos, possibilitando a utilização direta do produto final por parte do consumidor. (ANDRADE e SANTOS, 1980)

Comparada às outras indústrias, a organização racional da indústria de confecção está atrasada. Isto se dá por ainda existir um grande número de firmas pequenas e de indústria de caráter especulativo e de curta duração (ANDRADE e SANTOS, 1980). Dessa forma, a informalidade e falta de conhecimento administrativo, levam pequenas empresas de confecções ter um ciclo de vida curto no mercado.

\subsection{ARRANJO FÍSICO: ARRANJO FUNCIONAL}

O arranjo físico influencia diretamente nos resultados da Gestão do Processo, refletidos na produtividade e no custo do produto. A distribuição física do ambiente deve estar de acordo com a sequência operacional, reduzindo as perdas por deslocamento de materiais e de pessoal e contribuindo com a gestão visual. (BIERMANN, 2007)

$\mathrm{Na}$ Empresa leves confecções é utilizado atualmente o arranjo físico funcional, onde é caracterizado pelo agrupamento de equipamentos e máquinas que desempenham o mesmo processo em um mesmo espaço físico denominado seção ou departamento. O material em transformação percorrerá um roteiro de uma seção a outra para que as operações necessárias à sua transformação sejam realizadas. (SLACK; JOHNSTON; CHAMBERS, 2007).

\subsection{CAPACIDADE DE PRODUÇÃO}

Para Slack (1999), a capacidade produtiva de uma operação é o nível máximo de atividade de valor adicionado que pode ser conseguida em condições normais de operação durante determinado período de tempo.

De acordo com Andrade e Santos (1980) a etapa de planejamento da coleção é a etapa em que a empresa deve desenvolver os seus produtos de acordo com a necessidade do mercado e dimensionar as quantidades de modelos de acordo com a capacidade de produção da empresa.

Segundo Biermann (2007) a maneira mais adequada para otimizar a produção em relação aos pedidos recebidos é planejar lotes 
somando a quantidade de peças vendidas de cada modelo e que serão entregues em uma determinada data, para ser aumentado gradativamente. Todos os materiais, tecidos e aviamentos necessários para a produção, das referências que estiverem no lote, devem estar à disposição, evitando pendências que atrasarão toda a entrega.

Além disso Favaretto (2001) afirma que questões relacionadas ao pessoal, tempo, equipamentos e materiais são importantes no contexto da manufatura e devem ser considerados no planejamento das capacidades.

\subsection{PREVISÃO DE DEMANDA}

Kotler (1991) define a demanda de mercado para um produto como sendo o "volume total que seria comprado por um grupo de clientes definido, em uma área geográfica definida, em um período definido, em um ambiente de marketing definido e sob um programa de marketing definido.

Segundo Oishi (1995), as verificações de demanda auxiliam na verificação antecipada das necessidades de produção, principalmente referente aos recursos a serem utilizados, tais como equipamentos, máquinas e mão de obra. Quando a demanda não ocorre de maneira contínua e de forma isolada, a produção também deve ser ajustada.

O planejamento das operações deverá ocorrer em diferentes níveis, pois uma única previsão dificilmente servirá para diferentes problema. Além disso, não se trata de uma ferramenta para resolução de problemas imediato, entretanto deve-se olhar na direção de um futuro mais distante para prover novas capacidades ou ovos tipos de capacidade e o momento em que elas serão necessárias (BUFFA, 1997).

\subsection{CUSTOS}

Analisar os custos é de extrema importância para acompanhar as constantes evoluções que ocorrem diariamente na empresa, adotando a melhor decisão que favoreça a entidade, escolhendo alternativas de estratégias que garantam o crescimento e sobrevivência no mercado competitivo (HANSEN; MOWEN, 2010).

Segundo Teixeira (2003) a boa disposição dos móveis, equipamentos e maquinários resultam em uma maior eficiência de fluxos de trabalho e uma melhoria na aparência do ambiente. O projeto de arranjo físico busca minimizar custos de movimentação, reduzindo o congestionamento de materiais e pessoas, incrementando a segurança, o moral e a comunicação, aumentar a eficiência de máquinas e mão-de obra. A eficiência no processo tornará a empresa mais competitiva, melhorando a qualidade, reduzindo tempos médios de entrega, aumentando a produtividade e diminuindo custos.

Tanto em casos de excesso como também em situações de capacidade produtiva insuficiente, os custos extras e indesejáveis acabam aparecendo, gerando assim várias desvantagens (CORRÊA, 2001).

Em trabalho, Leone (2000) define os termos de custos fixos e variáveis, explicou que são geralmente usados para descrever como um custo reage às mudanças na atividade. Um custo variável é um custo que tem seu valor aumentado ou diminuído em relação ao nível da produção realizada e um custo fixo é sempre constante em seu total, na faixa de volume relevante da atividade esperada que esteja sendo considerada.

A relação entre os custos fixos e varáveis consiste em importante etapa na análise de formação de preços e projeção de lucros obtidos a diversos níveis possíveis de produção e vendas (BRUNI, 2002).

\section{METODOLOGIA}

\subsection{DESIGN DA PESQUISA}

Quanto à abordagem do problema a pesquisa é quantitativa, pois, considera que tudo pode ser quantificável, o que significa traduzir em números, opiniões e informações para classificá-las e analisá-las (SILVA \& MENEZES, 2005). Quanto aos objetivos, a pesquisa é exploratória. O pesquisador levanta informações de um objeto de estudo com delimitado campo de trabalho (SEVERINO, 2007).

Para o procedimento técnico, o trabalho é um estudo de caso, cujo interesse é proporcionar uma visão global do problema ou de identificar possíveis fatores que o influenciam ou por ele são influenciados (GIL, 2002). 


\subsection{ABORDAGEM UTILIZADA}

Este estudo segue a abordagem apresentada por Camorotto (2006), com um roteiro estruturado, a elaboração e análise de projetos de unidades produtivas. As categorias analisadas apresentam os sistemas de produção, a organização física dos recursos, a competitividade e o dimensionamento dos fatores de produção.

\subsection{PROCEDIMENTOS DE COLETA DE DADOS}

A amostragem pesquisada, foi de caráter não probabilística intencional (MARCONI \& LAKATOS, 1990). As técnicas de pesquisa utilizadas foram: (1) a documentação indireta; (2) a observação direta intensiva e (3) a observação extensiva.

Nesta pesquisa, foram utilizadas entrevistas estruturadas abertas individuais (VERGARA, 2007). A partir de um formulário, onde se identificaram informações fundamentais e complementares aplicados à empresa estudada.

\subsection{PROCEDIMENTOS PARA ANÁLISE DE DADOS}

Para análise de dados, utilizou-se a análise do discurso. Além de aprender como uma mensagem é transmitida, ajuda a explorar o seu sentido.

\section{RESULTADOS - ANÁLISE DA UNIDADE PRODUTIVA}

\subsection{CARACTERIZAÇÃO DA EMPRESA}

O estudo se desenvolveu na microempresa Leves Confecções, situada na cidade de Itacoatiara-Amazonas e que atua no ramo de confecção de calcinhas, pijamas, cuecas e blusas. A organização, de característica familiar, está em atividade há, aproximadamente, 5 anos no mercado de produção de roupas. Além disso, possui uma loja própria onde são realizadas as vendas dos bens produzidos.

A escolha da localização do negócio, no município de Itacoatiara, teve como fatores estratégicos, além do crescimento do setor na região, há possibilidade de tornar-se a principal empresa no ramo de confecções da cidade. De acordo com a proprietária da
Leves Confecções, o empreendimento localizado no bairro Santa Luzia, mais especificamente, na Rua Uatumã possui uma infraestrutura que permite o fluxo de clientes, visibilidade dos produtos ofertados, segurança, limpeza, facilidade de acesso e proximidade de clientes.

Os principais fornecedores, da matéria prima, consumida no processo, encontram-se em Manaus, pois os preços dos fornecedores do próprio município, são considerados elevados e se tornam inviáveis para o negócio, uma vez que, refletirá no preço final de venda dos produtos.

A estrutura física básica do prédio, onde acorre toda operação, dispõe de redes de esgoto, água encanada, boa iluminação, livres de ruídos e ambiente higienizado.

\subsection{CARACTERIZAÇÃO DO SISTEMA DE PRODUÇÃO}

O processo de fabricação da microempresa Leves Confecções caracteriza-se pelo volume médio de bens produzidos e padronizados em lotes, baseado em uma série de operações que necessitam ser programadas à medida que são realizadas. É relativamente flexível, emprega equipamentos simples e mão de obra polivalente, visando atender diferentes pedidos dos clientes e flutuações da demanda. Os equipamentos normalmente apresentam alterações frequente de trabalho, devido à alta variedade de produtos encomendados e dos tamanhos dos lotes fabricados. Em resumo, os clientes apresentam um pedido com especificações únicas, necessitando de uma resposta rápida do processo produtivo para atender a demanda. A Tecnologia empregada para fabricar a variedade de produtos são utilizados diferentes equipamentos (maquina galoneira, máquina de costura overlock, máquina de costura zig-zag, ferros a vapor, mesa de corte, mesa de passar roupas) no processo.

A produção, mostrada na figura 1, para os quatro produtos, não segue um fluxo préestabelecido, o que torna o processo desordenado e lento. Esse é um fator enfrentado pela organização que impede de atender a demanda e haver queda nas vendas. 
Figura 1- Processo de produção desordenado

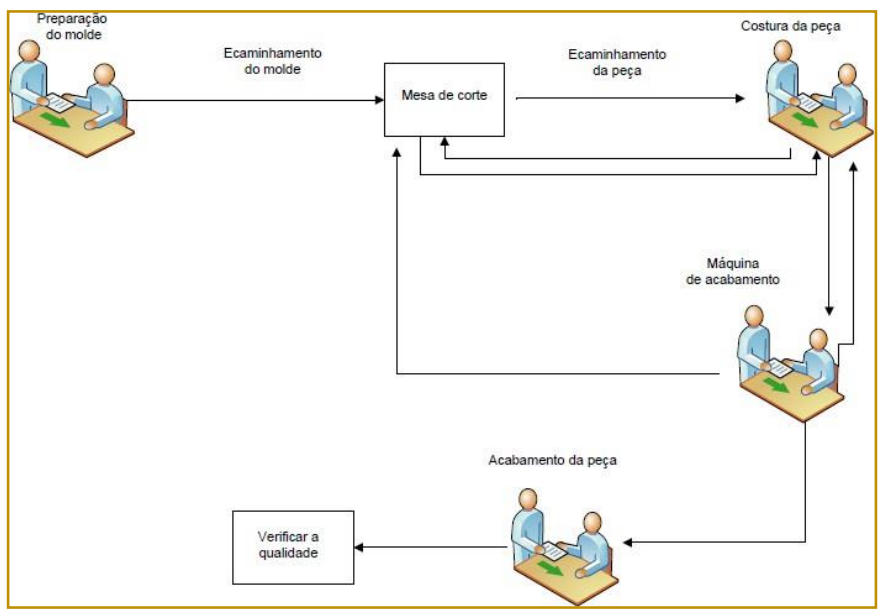

Fonte: próprios autores

Quadro 1- Processo de produção

\begin{tabular}{|c|c|}
\hline $\begin{array}{l}\text { Recebimento de } \\
\text { matéria-prima }\end{array}$ & $\begin{array}{l}\text { 1. A matéria-prima é recebida e estocada no deposito. } \\
\text { 2. Em conformidade com a ordem de produção (com destaque do qualitativo a } \\
\text { ser produzido) a matéria-prima é enviada para produção. }\end{array}$ \\
\hline $\begin{array}{l}\text { Execução de } \\
\text { corte }\end{array}$ & $\begin{array}{l}\text { 3. O tecido é colocado na mesa de corte. } \\
\text { 4. Verificar a qualidade observando eventuais defeitos. } \\
\text { 5. Ajustar aos moldes elaborados pelo modelista sobre o tecido e executar o } \\
\text { corte com a máquina elétrica apropriada. }\end{array}$ \\
\hline $\begin{array}{l}\text { Costura das } \\
\text { peças e costura } \\
\text { do produto }\end{array}$ & $\begin{array}{l}\text { 6. Separação e codificação das peças e envio para costura. } \\
\text { 7. Montagem das peças. } \\
\text { 8. As partes são cortadas são costuradas e composta em conformidade com o } \\
\text { modelo definido. }\end{array}$ \\
\hline Acabamento & $\begin{array}{l}\text { 9. Arremate e limpeza de linhas. } \\
\text { 10. Controle de qualidade. }\end{array}$ \\
\hline
\end{tabular}

Fonte: próprios autores

$\mathrm{Na}$ atualidade é necessário traçar uma linha de base, para se escolher as melhores estratégias, para atingir os objetivos. Assim, foram formuladas as seguintes bases para a empresa Leves confecções.

\subsection{DETERMINAÇÃO DA CAPACIDADE DISPONÍVEL}

A empresa em estudo trabalha 6 horas/dia, em apenas um turno, sendo 24 dias/mês com parada de 2 horas para o almoço. Os colaboradores realizam múltiplas atividades, desde o recebimento do pedido, preparação da matéria prima, corte, costura até a distribuição e venda do produto final.

A partir de visitas e observações feitas in loco foram definidas as operações, o mix de produtos existentes, bem como foram levantados os tempos de produção para cada produto em diferentes fases do processo (ver Tabela 1). 
Tabela 1- tempo de produção

\begin{tabular}{|lccrc|}
\hline \multicolumn{5}{c}{ Tempo de operação (minutos) } \\
\hline Processo/Produto & Cueca & Calcinha & Pijama & Blusa \\
\hline Corte & 2 & 2 & 3,2 & 2,8 \\
\hline Costura & 3 & 3 & 7,7 & 6,3 \\
\hline Acabamento & 2,5 & 2,5 & 4,2 & 3,8 \\
\hline Espera & 5,5 & 5,5 & 5,5 & 5,5 \\
\hline Total & 13 & 13 & 20,6 & 18,4 \\
\hline
\end{tabular}

Fonte: próprios autores

A tabela 1 mostra o tempo médio de produção da empresa Leves Confecções. No entanto esse tempo de produção não condiz com o que se produz por mês, visto que, há muitas paradas durante a produção como: começar um dia e terminar no outro, ausências, falta de tecido etc., mas o principal fator é a "não sequência" das operações. Com isso, são apresentados na tabela 2 a produção mensal atual da empresa com base nos dados levantados.

Tabela 2- de Produção mensal da Empresa

\begin{tabular}{|lcc|}
\hline \multicolumn{3}{|c|}{ Capacidade de Produção (mês) } \\
\hline Produto & Quantidade & Tempo (horas) \\
\hline Calcinha & 80 & 2 \\
\hline Cueca & 80 & 3 \\
\hline Pijama & 40 & 2,5 \\
\hline Blusa & 20 & 5,5 \\
\hline Total & 220 & 13 \\
\hline
\end{tabular}

Fonte: próprios autores

Analisando os dados da tabela 1 e 2, é possível observar que para os produtos, cueca e calcinha, é necessário de aproximadamente 40 minutos para produzir uma unidade por hora, enquanto que para produzir um pijama são necessários aproximadamente 55 minutos. A empresa gastaria praticamente um dia para produzir uma única blusa. Desta forma conclui-se que o sistema está desbalanceado, com muitos gargalos presentes na empresa, estações de trabalhos ociosos e dados inconsistentes que influenciam na medição da capacidade.

\subsection{ANÁLISE DE CUSTOS FIXOS E VARIÁVEIS}

Este estudo propõe a aplicação de algumas ferramentas de análise de custo, como o custeio por absorção que estabelece que todos os gastos produtivos, inclusive os indiretos que devem ser incorporados ao valor dos estoques, e a análise do ponto de equilíbrio. Ao elaborar a formação do preço de venda, faz se necessário identificar os custos fixos e variáveis incorridos em um determinado período. Mediante esta informação é exposto nesta seção os valores referentes aos custos mensais da empresa.

As tabelas 3 e 4 mostram os valores desembolsados pela empresa, os quais originam os custos variáveis de cada produto. 
Tabelas 3- de Produção mensal da Empresa (custos variáveis)

\begin{tabular}{|c|c|c|c|c|c|c|c|}
\hline \multicolumn{2}{|c|}{ PRODUT0 1: Calcinha } & \multicolumn{2}{|c|}{ PRODUTO 2: Cueca } & \multicolumn{2}{|c|}{ PRODUTO 3: Pijama (Babydool) } & \multicolumn{2}{|c|}{ PRODUTO 4: Blusa } \\
\hline \multicolumn{8}{|c|}{ Materiais de Produçäo } \\
\hline Descrição & Valor & Descrição & Valor & Descrição & Valor & Descriçāo & Valor \\
\hline Elástico $(1,60 \mathrm{~m})$ & $R \$ 0,35$ & Elástico (Grosso) & $\mathrm{R} \$ 2,00$ & Elastico $(0,80 \mathrm{~m})$ & $R \$ 0,20$ & Molde & $R \$ 1,00$ \\
\hline Linha & $R \$ 0,20$ & Linha & $\mathrm{R} \$ 0,20$ & Linha & $R \$ 0,30$ & Linha & $\mathrm{R} \$ 0,30$ \\
\hline Tecido & $R \$ 2,20$ & Tecido & $\mathrm{R} \$ 2,50$ & Tecido (1m) & $R \$ 9,00$ & Tecido $(0,80 \mathrm{~m})$ & $R \$ 7,50$ \\
\hline Lacinho & $R \$ 0,10$ & Etiqueta & $\mathrm{R} \$ 0,10$ & Etiqueta (papel) & $R \$ 0,50$ & Etiqueta (papel) & $R \$ 0,50$ \\
\hline Etiqueta & $R \$ 0,10$ & Molde & $\mathrm{R} \$ 1,00$ & Etiqueta (lateral) & $R \$ 0,10$ & Etiqueta (Dourado) & $\mathrm{R} \$ 0,10$ \\
\hline \multirow[t]{2}{*}{ Molde } & $R \$ 1,00$ & & & Etiqueta (Tamanho) & $R \$ 0,10$ & Etiqueta (Tamanho) & $\mathrm{R} \$ 0,10$ \\
\hline & & & & & & Enfeites (gripe) & $R \$ 10,00$ \\
\hline TOTAL & $R \$ 3,95$ & & $R \$ 5,80$ & & $R \$ 10,20$ & & $R \$ 19,50$ \\
\hline
\end{tabular}

Fonte: próprios autores

Após serem demonstrados os custos variáveis e fixos existentes na empresa, ilustra-se o demonstrativo do resultado do exercício calculando o custo unitário de cada produto pelo rateio. É a partir desta ferramenta contábil, confrontando as receita, despesas e custos que se verifica a formação do resultado líquido de um determinado período pelo custeio por absorção.

Tabela 4- Rateio dos custos (fixos e variáveis)

\begin{tabular}{|lccccccr|}
\hline \multicolumn{7}{c|}{ Rateio dos Custos (Fixos e rariáreis) e Cálculo do Custo Total } \\
\hline \multicolumn{7}{c}{ Custos fixos } & \multicolumn{7}{c|}{ Custo (rariárel) produçăo } & \multicolumn{3}{c|}{ Rateio Fixos } \\
\hline \multicolumn{1}{|c|}{ Despesas } & ralor & Produto & ralor & $\%$ & ralor & Custo Total & Custo Unitário \\
Funcionário & $\mathrm{R} \$ 440,00$ & Calcinha & $\mathrm{R} \$ 316,00$ & $20 \%$ & $\mathrm{R} \$ 150,59$ & $\mathrm{R} \$ 466,59$ & $\mathrm{R} \$ 5,83$ \\
Água & $\mathrm{R} \$ 21,00$ & Cueca & $\mathrm{R} \$ 464,00$ & $29 \%$ & $\mathrm{R} \$ 221,12$ & $\mathrm{R} \$ 685,12$ & $\mathrm{R} \$ 8,56$ \\
Luz & $\mathrm{R} \$ 150,00$ Pijama(Babydool) & $\mathrm{R} \$ 408,00$ & $26 \%$ & $\mathrm{R} \$ 194,43$ & $\mathrm{R} \$ 602,43$ & $\mathrm{R} \$ 15,06$ \\
Telefone & $\mathrm{R} \$ 40,00$ & Blusa & $\mathrm{R} \$ 390,00$ & $25 \%$ & $\mathrm{R} \$ 185,86$ & $\mathrm{R} \$ 575,86$ & $\mathrm{R} \$ 28,79$ \\
Impostos & $\mathrm{R} \$ 100,00$ & & & & & & \\
Total & $\mathrm{R} \$ 752,00$ & & $\mathrm{R} \$ 1.578,00$ & $100 \%$ & $\mathrm{R} \$ 752,00$ & $\mathrm{R} \$ 2.330,00$ & - \\
\hline
\end{tabular}

Fonte: Próprios Autores

\subsubsection{LUCRO LÍQUIDO (CUSTEIO POR ABSORÇÃO)}

De acordo com os dados repassados pela proprietária da empresa Leves Confecções foi possível obter as seguintes informações: a mesma atribui ao lucro $30 \%$ do preço de venda, sendo assim reformulando a equação do lucro temos seguintes resultados (ver tabela 5).

$\mathrm{PV}=\mathrm{CU} / 0,70$ 
Tabela 5- Quantidade produzida e Custeio por Absorção

\begin{tabular}{|c|c|c|c|c|}
\hline \multicolumn{5}{|c|}{ Quantidade produzida vendida (mensalmente) } \\
\hline Descrição & Produto 1 & Produto 2 & Produto 3 & Produto 4 \\
\hline Unidades produzidas: & 80 & 80 & 40 & 20 \\
\hline $\begin{array}{l}\text { Custo variável de } \\
\text { fabricação }\end{array}$ & 316 & 464 & 408 & 390 \\
\hline Custo Fixo & 752 & 752 & 752 & 752 \\
\hline Unidades vendidas: & 80 & 80 & 40 & 20 \\
\hline Preço de venda: & 8,32 & 12,22 & 21,51 & 41,12 \\
\hline \multicolumn{5}{|c|}{ Custeio por absorção } \\
\hline & Produtol & Produto2 & Produto 3 & Produto 4 \\
\hline Venda bruta & RS 715,86 & RS $1.001,96$ & RS $1.001,14$ & RS $1.001,18$ \\
\hline Custo total do produto & RS $1.091,86$ & RS $1.227,56$ & RS $1.226,74$ & RS $1.226,78$ \\
\hline Lucro Bruto & -RS 376,00 & $-\mathrm{R} \$ 225,60$ & -RS 225,60 & RS-225.60 \\
\hline Custo fixo & & & & \\
\hline Lucro Liquido & -R\$ 376,00 & -R\$225,60 & -RS 225,60 & RS -225.60 \\
\hline
\end{tabular}

Fonte: Próprios Autores

Após ser obtido o lucro líquido, foi observado que a empresa estar no prejuízo, visto que a mesma não consegue suprir seus gastos de produção.

\subsubsection{ANÁLISE DO PONTO DE EQUILÍBRIO}

A análise do ponto de equilíbrio identificará onde empresa está no prejuízo e o quanto ela deve produzir e vender para começar a suprir seus custos e mais adiante gerar lucro e a outra ferramenta de análise a ser usada é a margem de contribuição que auxiliará na identificação de quais produtos geram mais sobra financeira e os quais possuem menos participação nas vendas.

Gráfico 1: Ponto de equilíbrio do produto 1

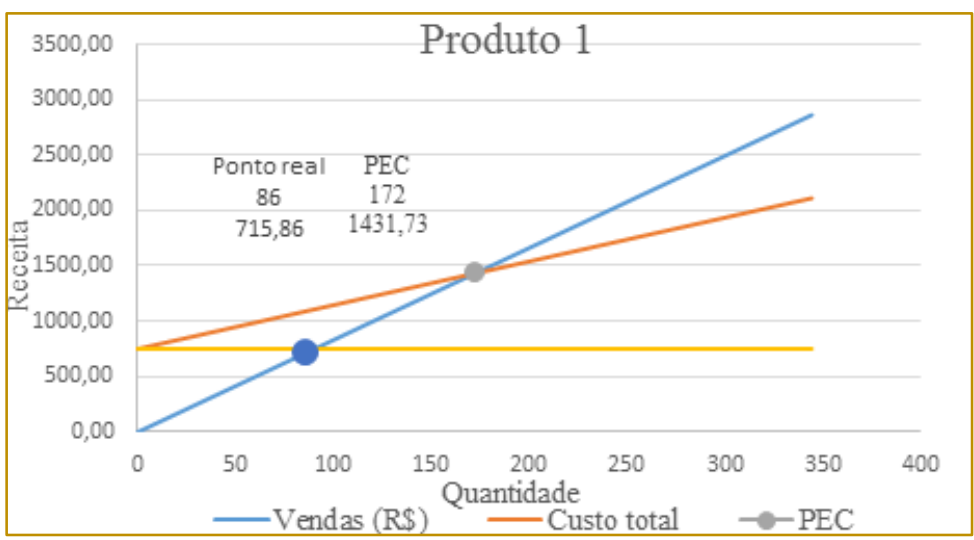

Fonte: próprios autores 
Gráfico 2: Ponto de equilíbrio do produto

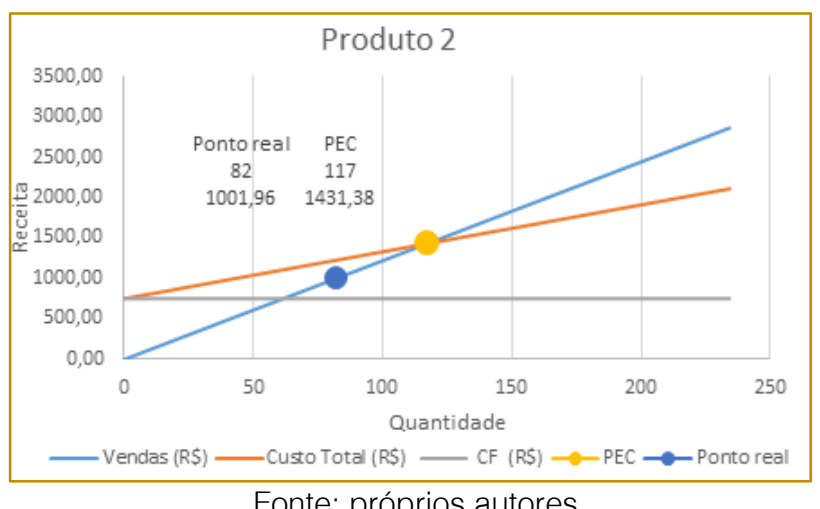

No gráfico 1 é visível que o produto 1 no período de julho/2016 que não há lucro para empresa, pois se encontra abaixo dos custos fixos e assim não contribui significativamente para empresa. No gráfico 2 o cenário é diferente porem as vendas não ultrapassam

os custos totais dessa forma o produto 2 também não agrega valor à empresa.

A situação se repete nos gráficos 3 e 4 onde é analisado que os produtos 3 e 4 não tem venda suficientes para supri os custos totais da empresa.

Gráfico 3: Ponto de equilíbrio do produto 3

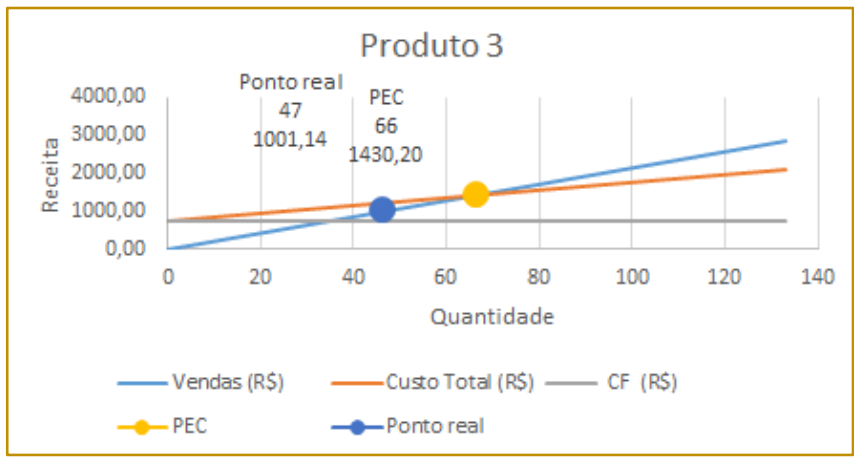

Fonte: próprios autores

Gráfico 4: Ponto de equilíbrio do produto 4

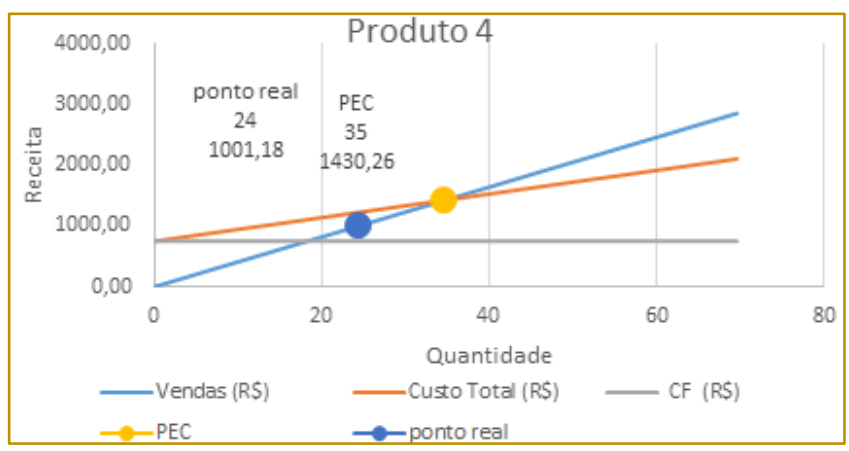

Fonte: próprios autores

Após analisar individualmente cada produto podemos montar um quadro de dados. Assim poderá realizar uma comparação e análise financeira e de produção de cada produto, e 
como esse cenário pode ser melhorado, pois a empresa atualmente estar no prejuízo.

Mediante os resultados negativos que a empresa vem obtendo, o cálculo da margem da contribuição vai ser baseado na produção do ponto de equilíbrio, pois a venda bruta individual de cada produto não supri os custos variáveis assim não sendo possível ter uma sobra financeira.

Assim partir desse ponto de equilíbrio será calculado o quanto cada produto contribui financeiramente para empresa.

\subsubsection{ANÁLISE DA MARGEM DE CONTRIBUIÇÃO DO PRODUTO}

A margem de contribuição é o valor resultante de uma venda após serem deduzidos os custos e despesas variáveis. E contribui para pagar os gastos fixos e gerar lucro do período.

Como a empresa estar no prejuízo não há margem de contribuição de nenhum produto, sendo assim a sobra financeira vai ser calculada partir do ponto de equilíbrio de cada produto ver (tabela 6).

PEQ: Ponto de Equilíbrio; CFT: Custo fixo total; I MC: Margem de Contribuição;

$\mathrm{PEQ}=\mathrm{CFT} / \mathrm{MC}$

Tabela 6: Margem de contribuição de todos produtos

\begin{tabular}{|llccc|}
\hline \multicolumn{5}{c}{ MARGEM DE CONTRIBUIÇA口 } \\
\hline Descrição & Produto1 & Produto2 & Produto 3 & Produto 4 \\
\hline Quantidade vendida & \multicolumn{1}{c}{172} & 117 & 66 & 35 \\
Venda bruta & $\mathrm{R} \$ 1.431,73$ & $\mathrm{R} \$ 1.431,38$ & $\mathrm{R} \$ 1.430,20$ & $\mathrm{R} \$ 1.430,26$ \\
Custo Variável & $\mathrm{R} \$ 679,73$ & $\mathrm{R} \$ 679,38$ & $\mathrm{R} \$ 678,20$ & $\mathrm{R} \$ 678,26$ \\
MC (Unitária) & $\mathrm{R} \$ 752,00$ & $\mathrm{R} \$ 752,00$ & $\mathrm{R} \$ 752,00$ & $\mathrm{R} \$ 752,30$ \\
MC (Unitária \%) & $52,52 \%$ & $52,54 \%$ & $52,58 \%$ & $52,58 \%$ \\
Receita [\%) & $25 \%$ & $25 \%$ & $24,98 \%$ & $25,02 \%$ \\
\hline
\end{tabular}

Fonte: próprios autores

De acordo com os cálculos obtidos da margem de contribuição, observou-se que os quatros produtos contribuem $50 \%$ de sua sobra financeira. Onde os mesmos não são suficientes para suprir os gastos da empresa. Analisando esse cenário, a melhor proposta para empresa é um reajuste de $45 \%$ no valor atual de cada produto e buscar comprar tecidos e outras matérias primas em maiores quantidades, visto que dessa forma é possível negociar com os fornecedores um desconto nos insumos. Dessa forma, haverá lucro.

\subsection{PREVISÃO DE DEMANDA}

A técnica usada na previsão de demanda da unidade produtiva escolhida foi a Técnica de Sazonalidade com Tendência. A Tabela 7 mostrada abaixo, apresenta os dados obtidos de produção e a previsão da demanda até o mês 30. Vale ressaltar que essa demanda prevista obtida com os dados da demanda real não possuem a inserção das melhorias ressaltas no projeto evidenciando que a produção continuará obedecendo o mesmo comportamento até o mês 30.

Portanto a produção se manteve nos valores limites não obtendo nenhum aumento de produção ou declínio, assim concluindo que as perdas de venda mostradas na Tabela 4 continuarão acontecendo se não inserir as melhorias evidenciadas no projeto. 
Tabela 7 - demanda de produção prevista

\begin{tabular}{|c|c|c|c|c|c|c|c|c|}
\hline \multirow{2}{*}{ Período } & \multicolumn{2}{|c|}{ Calcinha } & \multicolumn{2}{|r|}{ Cueca } & \multicolumn{2}{|c|}{ Piiama } & \multicolumn{2}{|c|}{ Blusa } \\
\hline & D. Real & D. Prevista & D. Real & D. Prevista & D. Real & D. Prevista & D. Real & D. Prevists \\
\hline 1 & 76 & 76 & 75 & 75 & 39 & 39 & 19 & 19 \\
\hline 2 & 75 & 75 & 80 & 80 & 39 & 39 & 18 & 18 \\
\hline 3 & 80 & 80 & 76 & 76 & 39 & 39 & 18 & 18 \\
\hline 4 & 80 & 80 & 77 & 77 & 38 & 38 & 20 & 20 \\
\hline 5 & 79 & 79 & 80 & 80 & 38 & 38 & 19 & 19 \\
\hline 6 & 76 & 76 & 77 & 77 & 40 & 40 & 19 & 19 \\
\hline 7 & 80 & 80 & 75 & 75 & 38 & 38 & 20 & 20 \\
\hline 8 & 80 & 80 & 77 & 77 & 38 & 38 & 20 & 20 \\
\hline 9 & 75 & 75 & 78 & 78 & 38 & 38 & 19 & 19 \\
\hline 10 & 76 & 76 & 80 & 80 & 38 & 38 & 20 & 20 \\
\hline 11 & 80 & 80 & 75 & 75 & 40 & 40 & 20 & 20 \\
\hline 12 & 75 & 75 & 76 & 76 & 39 & 39 & 18 & 18 \\
\hline 13 & 76 & 76 & 75 & 75 & 38 & 38 & 19 & 19 \\
\hline 14 & 77 & 77 & 78 & 78 & 40 & 40 & 19 & 19 \\
\hline 15 & 80 & 80 & 77 & 77 & 39 & 39 & 20 & 20 \\
\hline 16 & 79 & 79 & 80 & 80 & 39 & 39 & 18 & 18 \\
\hline 17 & 77 & 77 & 79 & 79 & 39 & 39 & 18 & 18 \\
\hline 18 & 76 & 76 & 75 & 75 & 40 & 40 & 18 & 18 \\
\hline 19 & 75 & 75 & 77 & 77 & 39 & 39 & 19 & 19 \\
\hline 20 & 77 & 77 & 77 & 77 & 38 & 38 & 20 & 20 \\
\hline 21 & 80 & 80 & 79 & 79 & 39 & 39 & 20 & 20 \\
\hline 22 & & 77 & & 78 & & 39 & & 19 \\
\hline 23 & & 78 & & 78 & & 39 & & 19 \\
\hline 24 & & 76 & & 77 & & 39 & & 19 \\
\hline 25 & & 77 & & 78 & & 39 & & 19 \\
\hline 26 & & 78 & & 78 & & 39 & & 19 \\
\hline 27 & & 76 & & 77 & & 40 & & 19 \\
\hline 28 & & 77 & & 78 & & 39 & & 19 \\
\hline 29 & & 78 & & 78 & & 39 & & 19 \\
\hline 30 & & 76 & & 77 & & 40 & & 19 \\
\hline
\end{tabular}

Fonte: próprios autores

Tabela 8- Perdas de Vendas

\begin{tabular}{|c|c|c|c|c|c|c|c|c|c|c|}
\hline \multicolumn{11}{|c|}{ Vendas Perdidas (Calcinha) } \\
\hline Mês & 1 & 2 & 3 & 4 & 5 & 8 & 9 & 10 & 11 & 12 \\
\hline Perdas & -50 & -45 & -49 & -63 & -59 & -30 & -57 & -32 & -36 & -35 \\
\hline Mês & 13 & 14 & 15 & 16 & 17 & 20 & 21 & 22 & 23 & 24 \\
\hline Perdas & -50 & -45 & -49 & -63 & -59 & & & & & \\
\hline \multicolumn{11}{|c|}{ Vendas Perdidas (Cueca) } \\
\hline Mês & 1 & 2 & 3 & 4 & 5 & 8 & 9 & 10 & 11 & 12 \\
\hline Perdas & -49 & -45 & -42 & -37 & -48 & -50 & -41 & -40 & -39 & -39 \\
\hline Mês & 13 & 14 & 15 & 16 & 17 & 20 & 21 & 22 & 23 & 24 \\
\hline Perdas & -49 & -45 & -42 & -37 & -48 & & & & & \\
\hline \multicolumn{11}{|c|}{ Vendas Perdidas (Pijama) } \\
\hline Mês & 1 & 2 & 3 & 4 & 5 & 8 & 9 & 10 & 11 & 12 \\
\hline Perdas & -20 & -20 & -20 & -15 & -10 & -13 & -11 & -16 & -15 & -20 \\
\hline Mês & 13 & 14 & 15 & 16 & 17 & 20 & 21 & 22 & 23 & 24 \\
\hline Perdas & -20 & -20 & -20 & -15 & -10 & & & & & \\
\hline \multicolumn{11}{|c|}{ Vendas Perdidas (Blusa) } \\
\hline Mês & 1 & 2 & 3 & 4 & 5 & 8 & 9 & 10 & 11 & 12 \\
\hline Perdas & -3 & -5 & -6 & -4 & -7 & -5 & -6 & -7 & -8 & -1 \\
\hline Mês & 13 & 14 & 15 & 16 & 17 & 20 & 21 & 22 & 23 & 24 \\
\hline Perdas & -3 & -5 & -6 & -4 & -7 & & & & & \\
\hline
\end{tabular}

Fonte: próprios autores

Os gráficos 5 à 8 abaixo mostram de forma dinâmica a estabilidade de produção com a atual fluxo de produção, onde, a linha mais clara demostra a produção real e a escura mostra a previsão futura de produção. 
Gráfico 5: Produto Calcinha

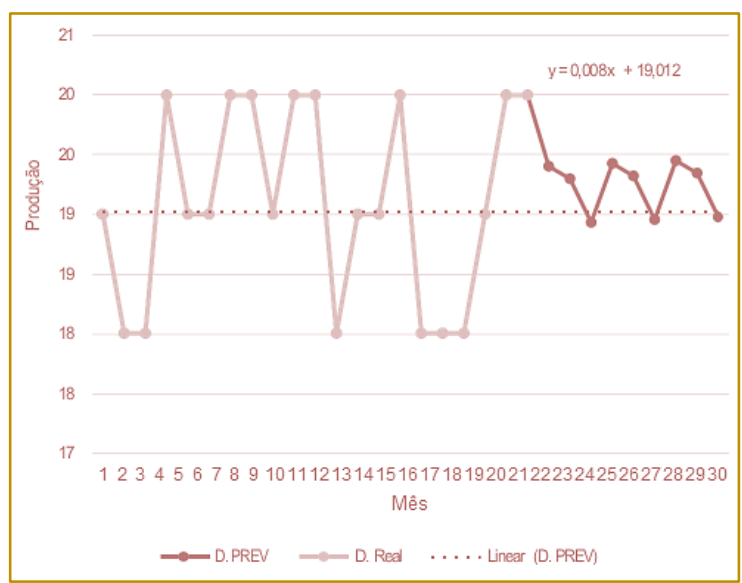

Fonte: próprios autores

Gráfico 6: Produto Cueca

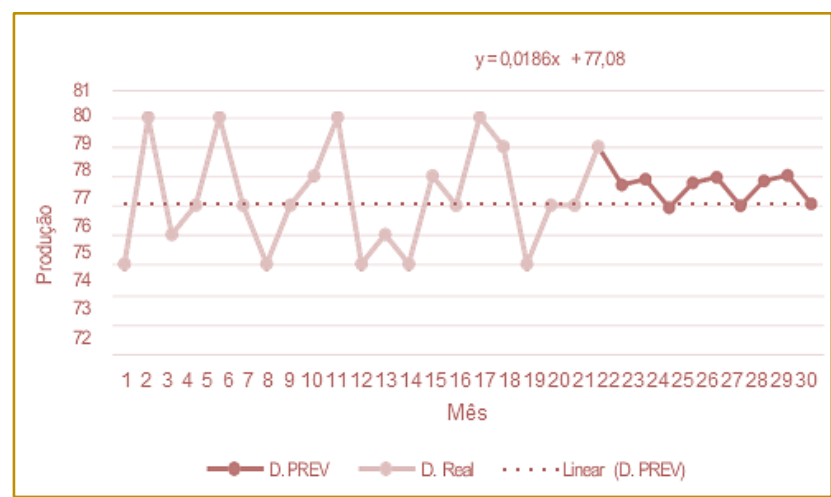

Fonte: próprios autores

Gráfico 7: Produto Pijama

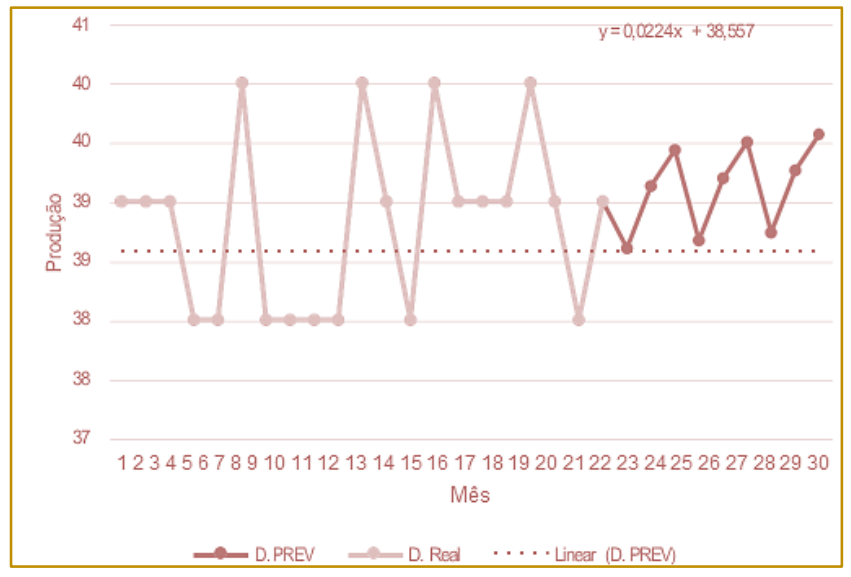

Fonte: próprios autores 
Gráfico 8: Produto Pijama

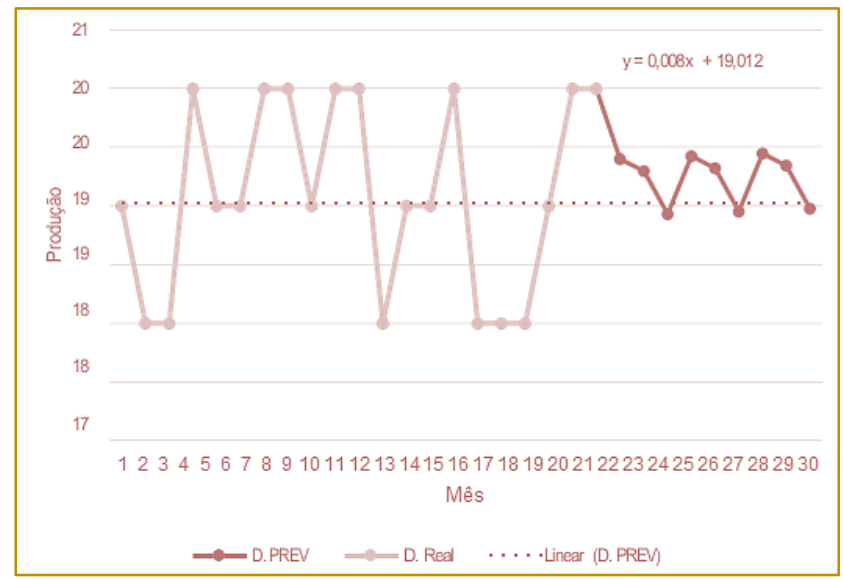

Fonte: próprios autores

Figura 2: Fluxo organizado

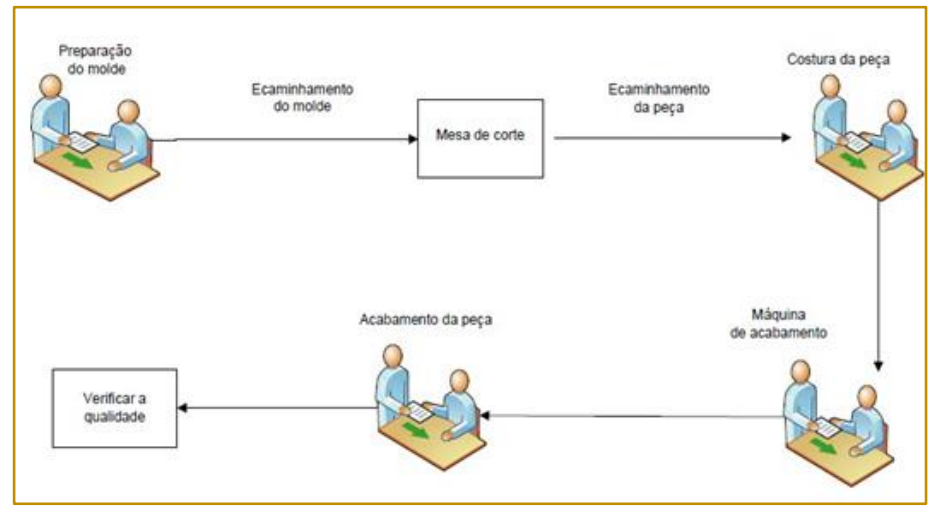

Fonte: próprios autores

\section{CONCLUSÃO}

Conforme foi exposto, para a organização sobreviver e se tornar competitiva no cenário globalizado atual, sua estratégia e objetivos devem ser claros, incluindo os gerenciamentos das melhorias propostas, pois, com o bom conhecimento do inserido na empresa, deve apresentar consequências positivas acarretando assim o sucesso do empreendimento.

A proposta deste artigo foi analisar o funcionamento do sistema produtivo de uma microempresa do setor de confecções localizada na cidade de Itacoatiara/AM, verificando como as ações de planejamento e unidade produtiva ali praticadas têm contribuído para a competitividade organizacional e melhoria no sistema produtivo. Para tanto, tomou-se como base de análise o estudo do Camorotto (2006), dentro desse contexto foi possível aplicar ferramentas como analise de ponto de equilíbrio e a margem de contribuição, capacidade de produção e previsão de demanda.

No entanto, deve-se lembrar que a execução dessas melhorias possuirá maiores chances de sucesso com um gerenciamento adequado, por essa razão, não se deve negligenciar as melhores práticas de gerenciamento da produção.

Os dois processos de elaboração da estratégia e gerenciamento do projeto proposto devem ter igual importância e sinergia. Por um lado, uma vez que propostas que não estão relacionados à estratégia podem levar ao insucesso, diminuição de recursos disponíveis e não atingimento de meta, e por consequência não mais importante a perda no lucro da empresa.

Deste modo, conclui-se que para administrar uma microempresa do ramo de confecções, 
tem-se a necessidade de ter um conhecimento especializado voltado para visualização do mercado e como a empresa está diante seus concorrentes, e a falta de investimentos, planejamento e controlar os

\section{REFERÊNCIAS}

[1] Andrade Filho, J. F. e Santos, L. F. Introdução à tecnologia têxtil. Vol III. Rio de Janeiro: SENAI - Centro de Tecnologia da Indústria Química e Têxtil, 1980.

[2] Biermann, M. J. E. Gestão do processo produtivo. Porto Alegre: SEBRAE/RS, 2007.

[3] Bruni, Adriano Leal, Famá, Rubens. Gestão de Custos e Formação de Preços: com aplicações na calculadora HP 12c e Excel, 1 edição. São Paulo: Atlas, 2002.

[4] Buffa, Elwood S. Modern Production Management. New York: 1997

[5] Camarotto, João Alberto. Universidade de São Carlos - UFSCar : Projeto de Unidades Produtivas. 2006

[6] Corrêa, H. L. et al. Planejamento, Programação e Controle da Produção: MRP II/ERP: conceitos, uso e implantação. 4. ed. São Paulo: Atlas, 2001.

[7] Favaretto, F. Uma contribuição ao processo de gestão da produção pelo uso da coleta automática de dados de chão de fábrica. Tese de doutorado - Escola de Engenharia de São Carlos da Universidade de São Paulo, São Carlos, 2001.

[8] Gil, Antonio Carlos. Como elaborar projetos de pesquisa. 4. ed. São Paulo: Atlas, 2002.

[9] Hansen, Don R.; Maryanne M. Mowen. Gestão de custos: contabilidade e controle/ Don R. tempos de ciclos e minimizar os gastos são fatores que quando bem trabalhados, influenciam para a satisfação e retenção dos clientes, melhoria dos lucros e minimização dos custos da empresa.

Hansen; tradução Robert Brian Taylor. São Paulo: Cengage Learning, 2010.

[10] Kotler, Philip.;Administração de Marketing. Prentice Hall. 10aㅡ edição. p. 140-143. 1991.

[11] Leone, George Sebastião Guerra. Custos Planejamento, Implantação e Controle. 3. ed. São Paulo: Atlas, 2000.

[12] Marconi, M. A.; Lakatos, E. M. Técnicas de pesquisa: planejamento e execução de pesquisas, amostragens e técnicas de pesquisa, elaboração, análise e interpretação de dados. 2a ed. São Paulo: Atlas, 1990.

[13] Oishi, M. Técnicas Integradas na Produção e Serviços. 1. ed. São Paulo: Pioneira, 1995.

[14] Severino, Antônio Joaquim. Metodologia do trabalho científico: 23a Edição revista e atualizada $2^{\text {a }}$ reimpressão. 2007.

[15] Silva Lúcia, Menezes, Estera Muszkat. - 4. ed. rev. atual. - Florianópolis: UFSC, 2005. 138p. SLACK, N. et al. Administração da Produção. 1. ed. São Paulo: Atlas, 1999

[16] Slack, N.; Johnston, R.; Chambers, S. Operations management. Harlow: Pearson Education, 5th.ed.,2007.

[17] Vergara, S. C. Projetos e Relatórios de Pesquisas em Administração, São Paulo: Editora Atlas,

2007. 


\section{Gapítulo 13}

\section{PISCICULTURA NA AMAZÔNIA: PROCESSO PRODUTIVO DO TAMBAQUI (COLOSSOMA MACROPUMUM) CURUMIM}

\section{Pollyanna Menezes de Sousa}

Rute Holanda Lopes

Evandro Menezes de Medeiros

\section{Renata de Oliveira Teixeira}

Marcos Antônio de Souza Queiroz

Kátia Viana Cavalcante

Resumo: Fatores relacionados à produtividade e qualidade estão no foco de pesquisas relacionadas à piscicultura, tendo em vista que a pesca é o terceiro maior sistema produtor do mundo, contribuindo com mais de $60 \%$ da cadeia produtiva global. Neste contexto, o cultivo de tambaqui curumim vendo expressivamente se desenvolvendo de forma comunitária, requerendo um conhecimento técnico, o trabalho conjunto e organização na busca da produção coletiva. Assim, teve-se como objetivo geral analisar o processo produtivo do cultivo de tambaqui curumim na Associação dos Moradores do Santana no município de Manacapuru-AM. A falta de conhecimentos relacionados às diferentes técnicas de manejo tem gerado problemas no cultivo de tambaqui curumim, que perpassam pela necessidade de sistematização das atividades em cada fase para o aumento da produtividade e qualidade do pescado. Dessa forma, o estudo reforça a importância da organização, planejamento e boa execução das técnicas de manejo dentro da atividade de cultivo de tambaqui curumim. Caracterizada assim, pelo agrupamento de conhecimento técnicos científicos relacionados a piscicultura, tendo nessas características o seu grande desafio para que se possa atingir com eficiência o pleno desenvolvimento da criação de peixes na comunidade em análise.

Palavras-chave: Piscicultura; Qualidade; Produtividade. 


\section{INTRODUÇÃO}

Em um cenário econômico altamente competitivo, Corrêa et al. (2001), esclarecem que cada organização tem uma grande necessidade de conhecer detalhadamente seu processo produtivo, a fim de facilitar a identificação de possíveis gargalos existentes no decorrer das operações. Esta competitividade expande-se em todos os setores, inclusive nos produtores de alimentos e criação de animais, entre eles o de peixes.

A pesca tem se posicionado como sendo o terceiro maior sistema produtor do mundo, contribuindo com aproximadamente $64 \%$ da produção mundial, tendo alcançado índices recordes de produção em 2013. Enquanto isso, as exportações atingiram os 136 milhões de dólares, conforme o Subcomitê de Comércio Pesqueiro da Organização das Nações Unidas para a Alimentação e a Agricultura (FAO, 2010).

Vale ressaltar, entretanto, que a pesca extrativa tem demonstrado atingir seu limite máximo sustentável devido à superexploração das espécies de maior valor comercial. Em contrapartida a aquicultura tem avançado com grande potencial para suprir a demanda de pescado pela população mundial (FAO, 2013).

Regionalmente, os sistemas de criação de tambaqui curumim podem ser diversos: em viveiros escavados, em tanques rede e misto, sendo que no misto, viveiros escavados e tanques rede são utilizados em forma de rodízios durante todo o ciclo do cultivo. O que vem chamando a atenção da piscicultura comunitária no Amazonas, é o sistema misto de produção, que de acordo com experimentos feitos na região, o cultivo se torna mais produtivo.

O projeto comunitário de cultivo de tambaqui curumim está localizado na Associação de Moradores do Santana no Manacapuru-AM e vem se desenvolvendo nos últimos anos como alternativa sustentável de trabalho e renda aos associados assim também como aos moradores da comunidade. Tendo como um dos principais entraves à falta de padronização do processo produtivo adotado na Associação, o que por fim resulta na improvisação de determinados processos.

\section{REVISÃO BIBLIOGRÁFICA}

\subsection{PISCICULTURA COMO ATIVIDADE PRODUTIVA}

A demanda mundial por produtos pesqueiros aumenta e segue o desequilíbrio crescente entre a procura e a oferta. Mundialmente, o consumo de pescado por habitante ano é de 16Kg. Nessa conjuntura, a atividade de piscicultura já vem sinalizando alternativa para suprir as deficiências da pesca extrativa. Portanto, a piscicultura tem uma grande oportunidade para o desenvolvimento nas próximas décadas (WURMANN, 2010).

Freitas (2003) sinaliza, entretanto, que o Brasil responde a menos de $1 \%$ do mercado mundial de pescado (entre a captura e o cultivo) que atualmente está em torno de 143 milhões de toneladas. A atividade de piscicultura, no estado do Amazonas, é uma atividade de grande potencial, pois apresenta características substanciais de recursos naturais como parâmetros ecológicos, biológicos e hídricos situado na maior bacia hidrográfica do mundo, a Bacia Amazônica. Contudo, apesar dessas circunstâncias favoráveis, a piscicultura não é, ainda, considerada uma atividade economicamente representativa.

Segundo Petrere (2001), a limitação inicial da piscicultura no Amazonas poderia ser explicada pelo isolamento regional que impossibilitaria o escoamento da produção, já que a distância entre o centro de produção e o de consumo poderia inviabilizar a atividade.

Segundo os piscicultores, a aquisição de alevinos, a falta ou restrição de informações e de técnicos especializados e principalmente o elevado custo da ração e dos insumos para sua fabricação, se constituem nos principais entraves da atividade de piscicultura no estado do Amazonas.

O tambaqui curumim, tipo de pescado de que trata este estudo, não se trata de uma variedade da espécie do tambaqui (Colossoma macropomum), mas se trata do próprio tambaqui, cultivado de maneira intensiva ou superintensiva com o objetivo de consumo ainda na sua fase juvenil (FILHO, 2001).

A produção de tambaqui em pisciculturas do Amazonas, nos últimos anos, está na ordem de 8 mil toneladas por ano, sendo os principais produtores os municípios de Rio Preto da Eva, Iranduba e Manacapuru, 
localizados próximos a Manaus (INOUE e BOIJINK, 2011).

$\mathrm{O}$ sistema misto de produção (intensivo $\mathrm{x}$ superintensivo) vem sendo utilizado na Associação de Moradores do Santana no município de Manacapuru. Esse sistema de produção envolve tanto o viveiro escavado, quanto o tanque-rede. No viveiro escavado e tanque rede os peixes são alimentados com ração balanceada para crescerem e engordarem de maneira satisfatória. O rodízio, nos diferentes tipos de tanques é realizado conforme as necessidades de prática de manejo.

Segundo Souza Filho e Cerqueira (2003), a densidade de estocagem pode ser influenciada conforme o tipo de sistema de produção empregado no cultivo, assim como, como a espécie cultivada, a idade de estocagem, a biomassa e o oxigênio dissolvido na água que se constituem, dessa maneira como os fatores mais relevantes a serem considerados.

Na piscicultura, a alimentação artificial passa a ter uma grande importância, principalmente nos sistemas intensivos e superintensivos. Os cuidados com a qualidade da ração e com manejo alimentar devem ser considerados no planejamento da atividade, antes do inicio do cultivo (EMBRAPA, 2009).

A ração utilizada no cultivo de tambaqui curumim deve ser de acordo com as necessidades nutricionais da espécie, sendo apropriada para cada fase de criação, digestível, estável (não afundar na água) e de boa qualidade para não prejudicar o meio aquático. (EMBRAPA, 2009).

Pedrazzani (2007) nos diz ao citar-se a comercialização do peixe, é de extrema relevância que o produtor possua a ciência de que estar inserido dentro de uma cadeia de produção, tendo que desta forma, estar voltado para os anseios do mercado consumidor local e regional, afim de redirecionar de forma mais eficiente o foco de comercialização, dando grande importante a divulgação, aliada a uma eficiente e otimizada logística de distribuição do pescado.

\subsection{PROCESSO PRODUTIVO NA PISCICULTURA}

Ultimamente, o relevante aumento da concorrência, somado ao instável cenário econômico nacional e mundial, forçam as organizações a repensarem sua estrutura produtiva a fim de responderem mais eficientemente às mudanças que acontecem no mercado. Slack et al. (2002) e Corrêa et al. (2001), afirmam que processos produtivos eficientes têm forte influência sobre os aspectos de desempenho competitivo, por meio da fabricação de produtos sem erros, atendimento rápido ao consumidor, manter confiabilidade, oferecer produtos a preços que possam concorrer no mercado e flexibilidade para adaptar-se as mudanças.

Segundo Valenti (2008), o processo produtivo na piscicultura deve ser entendido como um processo amplo, que envolve todo o conjunto de elementos que se inter-relacionam formando uma rede complexa. Elementos como o suporte técnico, infraestrutura e a conjuntura econômica e legal; os ligados a produção propriamente dita, como os processos biológicos e zootécnicos que compreendem a reprodução, a larvicultura (ou fase equivalente) e a produção dos organismos alvo; e os elementos pósprodução que envolve o beneficiamento do produto, embalagem, conservação, distribuição e venda até atingir o consumidor final.

Se por um lado, a piscicultura vem se desenvolvendo economicamente, por outro, o crescimento faz com que a atividade precise se atentar a esse mercado competitivo, onde o conhecimento de todo o processo produtivo é fundamental e decisivo para o sucesso do negócio e fatores como a oferta e a procura que determinam o preço dos produtos e a redução dos custos passa a ter extrema importância. O amadorismo perde rapidamente o espaço para o profissionalismo (PROCHMANN e MICHELS, 2003).

\section{METODOLOGIA}

Esta pesquisa teve como objeto de estudo o Cultivo do Tambaqui Curumim na Associação dos Moradores do Santana em ManacapuruAM. Desta forma, caracteriza-se como estudo de caso, tem uma tipologia, no que tange aos objetivos, classificada como descritiva e explanatória, pois sua finalidade é descrever e estabelecer relações entre as variáveis qualitativas em estudo (MATTAR, 1999).

$\mathrm{Na}$ maior parte deste estudo, seu desenvolvimento envolve as técnicas de observações no campo e entrevista com as pessoas envolvidas com a problemática da 
pesquisa. Mattar (1999) sinaliza diferentes classificações que podem ser obtidas usando diferentes variáveis relacionadas ao ambiente de pesquisa. Entre elas pode ser definida a pesquisa de campo. Enquanto que Lakatos e Marconi (2005) ressaltam que os meios de investigação de uma pesquisa podem ter várias taxonomias. Em específico, este trabalho se remete ao estudo de caso, com caráter de detalhamento realizado no campo.

A pesquisa de campo sugerida neste trabalho consistiu na observação de fatos ou fenômenos tal como ocorrem espontaneamente, na coleta de dados a ele referente e no registro de variáveis que se presumem relevantes para analisá-los (LAKATOS e MARCONI, 2005). Nesta pesquisa, a observação se deu durante as diversas visitas a Associação, onde foi possível acompanhar as etapas do processo produtivo e entrevistar os Associados e principalmente o presidente da Associação para um melhor entendimento de todo o processo desde a aquisição das larvas até a venda do produto ao consumidor final. A partir dos dados iniciais, foi possível elaborar o layout do sistema produtivo da área estudada, onde se pode observar na Figura 01.

$\mathrm{Na}$ pesquisa bibliográfica houve a busca na literatura sobre os tópicos relevantes neste trabalho, como os índices que afetam a produção na atividade de piscicultura e a cadeia produtiva do tambaqui curumim no estado do Amazonas. As fontes utilizadas foram: livros, artigos, teses, dissertações, relatórios técnicos, boletins informativos, além de outras informações acessíveis na internet. Isso proporcionou um suporte teórico para confrontar com as práticas adotadas na Associação dos Moradores do Santana.

Figura 01 - Associação dos Moradores do Santana

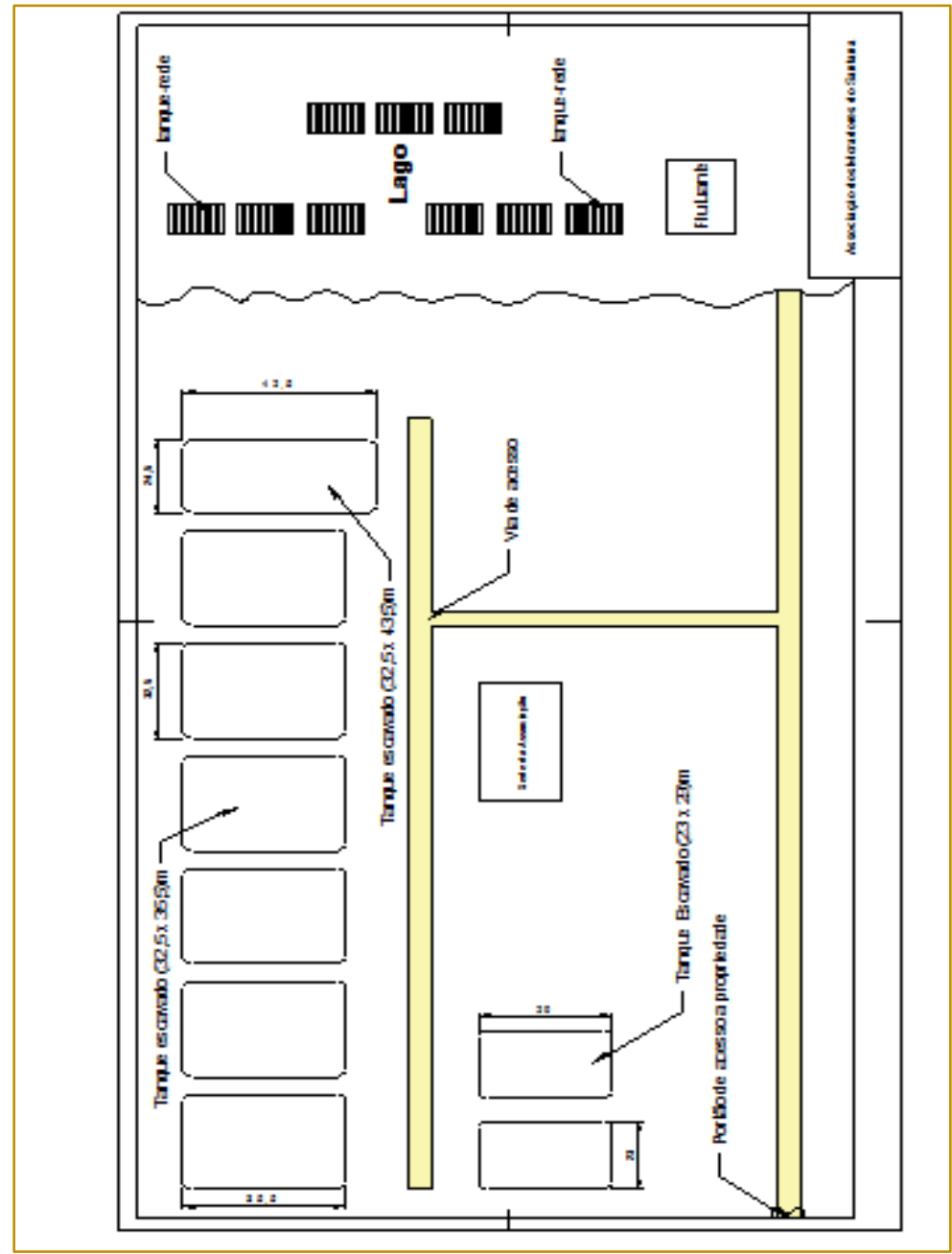

Fonte: Autora, 2016 


\section{RESULTADOS E DISCUSSÃO}

Com o intuito de representar as atividades realizadas na produção criou-se um fluxograma, o qual discrimina as atividades e operações realizadas no cultivo de tambaqui curumim em sistema misto de produção na Associação dos Moradores do Santana, conforme a figura 02, abaixo.

Figura 02 - Fluxograma do processo produtivo

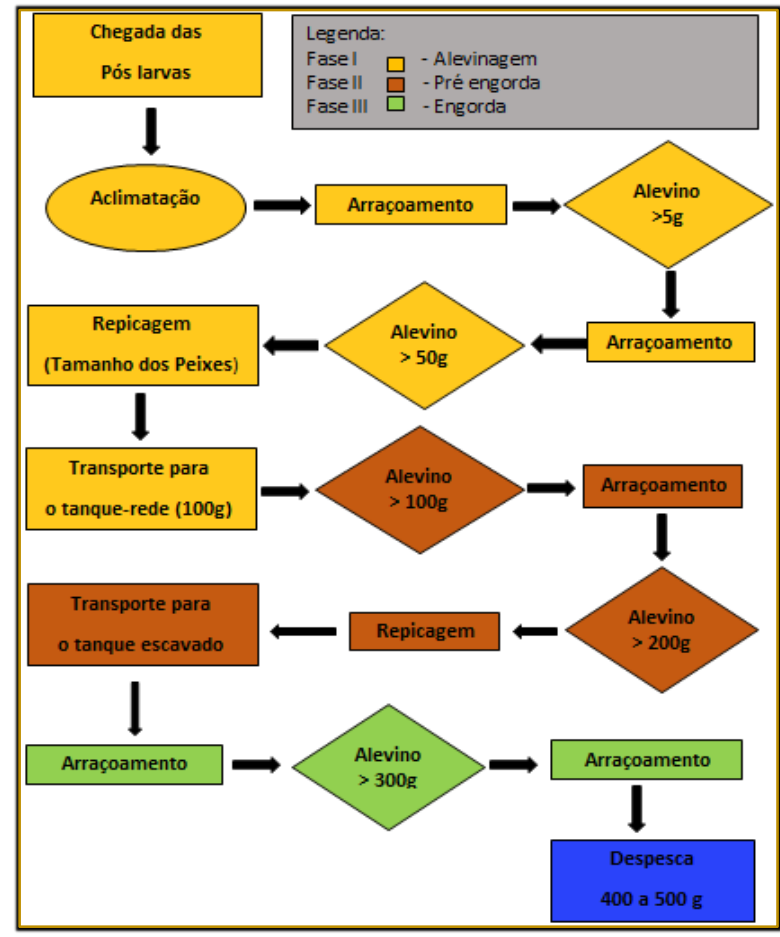

Fonte: elaboração própria, 2016.

O início do processo produtivo do tambaqui curumim na Associação dos Moradores do Santana dá-se com a aquisição de 150 mil pós-larvas que a comunidade adquire junto ao Centro de Tecnologia, Treinamento e Produção em Aquicultura do Amazonas no Município de Presidente Figueiredo. Este centro é uma estação de pesquisa que tem como um de seus objetivos o trabalho de capacitar profissionais na área de piscicultura, além de fazer doações de póslarvas e alevinos dos tipos tambaqui, matrinxã e pirapitinga, para o desenvolvimento da piscicultura no estado do Amazonas.

Assim, após a solicitação do quantitativo de pós-larvas que a comunidade deseja, essa quantidade é enviada da estação de alevinagem na Vila de Balbina município de Presidente Figueiredo, para uma sede em Manaus, onde as pós-larvas aguardam sua retirada pelos comunitários da Associação. As pós-larvas são então transportadas em sacos plásticos de vinte litros e inflados com oxigênio, pela rodovia AM 070 Manaus -
Manacapuru até o $\mathrm{Km} \mathrm{58,} \mathrm{no} \mathrm{Ramal} \mathrm{do}$ Santana, Manacapuru - AM onde está localizada a sede da Associação.

Ao chegar, as pós-larvas são colocadas em um dos noves viveiros escavados, onde foi devidamente preparado e limpo para receber as mesmas. Em seguida, são passadas para os viveiros, onde passam por uma aclimatação, e em seguida são alimentadas com a ração indicada para a fase em que o peixe se encontra. Quando se encontram nessa fase inicial, pós-larva e alevino por volta de dois meses, são alimentados com uma ração em pó. A partir daí, as rações utilizadas são influenciadas pela a fase em que o peixe se encontra, levando-se em conta a porcentagem de proteína bruta necessária e a granulometria, ou seja, tamanho dos grãos da ração.

A Associação possui uma bomba de água que bombeia a água do lago para os viveiros escavados, geralmente uma vez na semana, para repor a água da evaporação. A 
Associação dos Moradores do Santana não tem estrutura para desenvolver essas 150 mil pós-larvas até 0 peso de despesca, aproximadamente $500 \mathrm{~g}$. Então, quando se tornam alevinos, após povoarem todos os viveiros escavados, a Associação vende para piscicultores próximos da região o restante dos peixes. Assim, a arrecadação dessa venda de alevinos aos associados, já ajuda nas despesas e manutenção do processo produtivo dos alevinos que permaneceram na Associação.

Ao atingir determinado tamanho, tamanho mínimo para não passar pela malha do tanque-rede, o peixe é transportado, através de caixas de isopor de 170 litros com uma solução de água e sal, para os tanques-rede e permanecem até atingirem aproximadamente $200 \mathrm{~g}$. Enquanto estão nos tanques-rede, são alimentados rigorosamente duas vezes ao dia, utilizando a ração adequada para a fase que se encontra. Quando estão ocupados por peixes, os tanques-rede são limpos duas vezes na semana, devido ao acumulo de ração e detritos da água. Depois são novamente transportados para o viveiro escavado até atingir o ponto de despesca, onde são tratados e vendidos nas feiras da cidade de Manaus.

Quanto às atividades de manejo realizadas, a primeira é a aclimatação que deve ser bastante cuidadosa, pois o peixe se encontra estressado, por ocasião do seu transporte até o local dessa prática. Deve-se ter o cuidado, também, para igualar a temperatura da água que o peixe se encontra, com a do tanque que vai recebê-lo. O processo segue até que este alevino atinja $5 \mathrm{~g}$ quando será feita a contagem e separação, processo que é feito manualmente pela Associação, onde é indicado um banho de sal para evitar que o peixe tenha contato direto com fungos $e$ bactérias.

Após aproximadamente 60 dias o peixe deve atingir $50 \mathrm{~g}$. Nesse período, é feita a primeira repicagem, ou seja, a separação do peixe que se encontra no tanque, de acordo com seu peso e tamanho. Ao atingirem aproximadamente $100 \mathrm{~g}$ com dois meses e meio a três meses, os peixes são transportados para o tanque-rede.

$\mathrm{Na}$ segunda fase, chamada pré-engorda ou recria inicial, o peixe já se encontra no tanque-rede e a Associação dos Moradores do Santana, atualmente, somente dispõe de um em funcionamento com capacidade de 600 peixes/tanques. Esse juvenil é alimentado até atingir $200 \mathrm{~g}$, onde é transportado novamente para o viveiro escavado, podendo ser realizada mais uma repicagem no período, se necessário.

Quando o tambaqui curumim atingir $300 \mathrm{~g}$ inicia-se a fase de engorda, onde o peixe é alimentado até que se atinja o peso desejado para despesca, que varia entre 400 e $500 \mathrm{~g}$. Depois desta etapa, o peixe é encaminhado ao processamento, apenas tratado e lavado, para posterior comercialização nas feiras da cidade de Manaus.

Ao atingir o peso da despesca, em torno de $500 \mathrm{~g}$, o tambaqui curumim é beneficiado na própria Associação, pelos próprios associados e também pelos comunitários. Esse beneficiamento, que acontece todas as sextas-feiras, consiste na limpeza do peixe e na sua "ticagem", termo utilizado para denominar a atividade de retirada ao máximo das espinhas do peixe.

Em seguida ele é embalado em uma sacola plástica transparente com aproximadamente 1 $\mathrm{kg}$ de tambaqui curumim. É transportado em caixas de isopor com gelo para ser comercializados ainda frescos aos sábados nas feiras da cidade de Manaus. Portanto são comercializados nessas feiras onde a Associação possui um local especifico, uma banca, para expor e venda do produto.

A produção eficiente do tambaqui curumim depende principalmente da qualidade da ração utilizada, ou seja, uma ração com proteína adequada para cada fase que o peixe se encontra e da padronização da produção. Assim, proporcionando um produto de referência capaz de concorrer potencialmente no mercado em que se encontra.

É notável que, o cultivo de tambaqui curumim na Associação dos Moradores do Santana conta com uma estrutura básica, ou seja, a Associação dispõe apenas de estrutura e material indispensável para o processo produtivo. Sem tecnologia avançada alguma, ainda assim, permite uma boa produção, possibilitando atender consideravelmente o mercado consumidor, podendo ser melhorada em diferentes pontos para uma eficiente produção.

Assim, tem-se os fatores que diretamente afetam o ritmo de produção, como baixo rendimento e produtividade que se encontram 
intrinsicamente relacionado a falta de controle no arraçoamento, onde a ração não é administrada corretamente de acordo com cada fase de crescimento, na localidade em estudo.

Com isso, para evitar problemas no criadouro ou viveiro, é preciso que se tome cuidado em relação à qualidade e o tipo de ração. É preciso que se siga com rigor a orientação quanto ao tipo certo de ração para cada fase, pois a ração correta faz o peixe produzir menos fezes, além de proporcionar um melhor aproveitamento da alimentação e, ainda, mantém a água em bom estado.

No sistema de cultivo da Associação de Moradores do Santana, que vai do pós-lava, passando pelo alevino $>5 \mathrm{~g}$, alevino $>50 \mathrm{~g}$, alevino > 100g, alevino > 200g, alevino > $300 \mathrm{~g}$, até a despesca com peixe entre 400 e 500g; cada uma dessas fases precisa de um tipo especifico de ração para que o peixe se desenvolva bem e com qualidade, uma vez que os alevinos dependem deste insumo para atingir o peso esperado pelos comunitários, principalmente quando estão nos tanquesrede.

Apesar da ciência por parte dos comunitários da importância da alimentação, que requer cuidados quanto à quantidade e a qualidade em cada fase, o improviso acaba por comandar a sistematização do processo de arraçoamento.

Outro problema relacionado a ração é a falta de assiduidade no horário de arraçoamento dos alevinos, onde frequentemente a ração é dada em horários meramente oportunos, quando na verdade deveria obedece-se um rigor nos horários de alimentação no transcorrer do dia. Diante desse outro problema, para que se tenham bons resultados no que se refere ao desenvolvimento dos peixes cultivados, o manejo alimentar não pode ser caracterizado apenas pelo número de arraçoamentos diários, mas deve também atender ao melhor horário do dia para administração da ração.

Observou-se na Associação que não há um rigor nós horários, além de ter dias em que os peixes não comem por falta de ração, devido principalmente a falta de um melhor planejamento e controle que possibilite a simples organização do processo produtivo do tambaqui curumim na comunidade estudada.
Outro aspecto observado foi a falta de padronização das embalagens utilizadas para a comercialização do pescado nas feiras. Não há nenhum tipo de rótulo indicando a marca ou a origem do produto. São embalados apenas em sacolas plásticas transparentes sem indicação ao menos do nome da Associação.

Quando lidamos com a comercialização de um produto, vários aspectos devem ser levados em conta e além de uma boa apresentação do produto, conhecer o tipo de consumidor e onde eles estão se torna importante. Já que são pescados adequados para o consumo em restaurantes, ou seja, possuem o tamanho necessário de uma refeição, poderia haver também uma venda direta para tais lugares, assim fidelizariam clientes, com isso agregariam valores ao produto.

Outro fator importante é ter um bom domínio das técnicas da piscicultura. Uma vez que o piscicultor munido de um bom manejo, conseguirá adaptar 0 tanque com as condições climáticas e ambientais, o que consequentemente gera mais lucro em decorrência de uma maior produtividade. Há de se considerar também que o cultivo de espécies nativas é de extrema importância, pois além de permitir um manejo seletivo, evita a introdução de espécies exóticas, que podem ameaçar o equilíbrio ambiental e, consequentemente, a produção pesqueira.

Assim, para que haja uma produção racional, capaz de gerar previsibilidade de condições e antecipação de problemas, a manutenção dos parâmetros de cultivo, tais como: limpeza dos tanques e dos comedouros, comprovação da posição de boias, alinhamento e posicionamento dos tanques quanto à corrente d'água em caso de tanque-rede, além do registro das quantidades diárias de ração fornecida, deve se padronizados e acompanhados diariamente pelos comunitários, afim de fornecer dados capazes de gerar sistematização da cadeia produtiva.

Com isso, a partir de uma padronização pode-se criar um sistema de cultivo que possibilite o povoamento dos tanques, a repicagem e a despesca dentro de um preceito equilibrado entre todas as fases de cultivo, evitando o desfalque na comercialização do pescado, evento que em certas ocasiões acorre na Associação dos Moradores do Santana, acontecendo em geral 
por falta de organização e inconstância no manejo do tambaqui curumim.

Dessa forma, a falta de padronização do sistema misto de produção escolhido pelos comunitários da Associação, gera outro problema que aparece em decorrência de uma busca de maior produtividade na comunidade estudada, que é uma densidade de estocagem inadequada do tambaqui, influindo inteiramente nas definições de boas práticas de manejo (BPM) em sistemas de criação, assim como também na piscicultura em tanques-rede. Assim sendo, é preciso que uma padronização dos parâmetros de cultivo que gere a sistematização tão necessária ao processo produtivo, possibilite o perfeito equilíbrio entre a taxa de concentração de peixe e o crescimento mínimo desejado.

Devemos, entretanto, considerar o fato de que o tambaqui pode ser cultivado utilizando-se diferentes técnicas de manejo, determinado de acordo com o grau de investimento disponível. Contudo, o que geralmente ocorre na Associação dos Moradores do Santana é que uma carência e dificuldades de maiores investimentos geram um manejo irregular, por conseguinte deficiente para atender as demandas de um mercado consumidor sensível a qualidade e a produtividade do pescado consumido.

\section{CONCLUSÃO}

Enfatizando a importância de se analisar detalhadamente as operações realizadas no processo produtivo do tambaqui curumim na Associação dos Moradores do Santana, esta atividade é realmente necessária para que ações de possíveis correções e melhorias possam ser implantadas. No entanto, a identificação de problemas e falhas em

\section{REFERÊNCIAS}

[1] Corrêa, H. L et al. Planejamento, programação e controle da produção. São Paulo: Atlas, 2001

[2] Embrapa. Coleção Criar. Piscicultura em tanques-rede. Brasília, 2009.

[3] Fao. The State of World Fisheries and Aquaculture. Fisheries and Aquaculture Department, 2010

[4] Fao. Pesca e aquicultura batem recorde de produção em 2013. Disponível em: $<$ https://nacoesunidas.org/fao-pesca-e-aquiculturabatem-recorde-de-producao-em-2013> Acesso em: 12 dez. 2015. processos produtivos é fundamental para a formulação e implementação de estratégias, objetivando a otimização dos recursos disponíveis na Associação.

As técnicas de manejo em cada uma das etapas do sistema misto de produção, requer grande atenção em cada uma das fases de cultivo do tambaqui curumim. Este fato acaba por se tornar em um grande obstáculo ao pleno desenvolvimento do sistema de cultivo implantado na Associação dos Moradores do Santana, uma vez que práticas de manejo ultrapassadas falta de padronização do cultivo, tecnologia restrita, carência de um maior envolvimento e responsabilidade dos comunitários, são os fatores que geram uma contraposição ao fato dos abundantes recursos naturais para atividade de piscicultura, a fácil adaptação do tambaqui a alimentação artificial e as diferentes técnicas de manejo existentes.

Assim, por meio da sistematização da informação, também alcançar um maior envolvimento e responsabilidade por parte dos comunitários. Uma vez que se verificou que a falta de padronização do manejo, decorre dos impactos negativos da falta de conhecimento técnico no manejo do tambaqui, que influi na produtividade e qualidade do pescado oferecido aos centros consumidores.

Então, torna se importante a realização de mais pesquisas cientificas relacionados ao processo produtivo da piscicultura, assim como o processo produtivo do cultivo de tambaqui curumim, onde possam auxiliar os piscicultores a racionalizar sua produção, ou seja, uma produção eficiente, sem desperdícios e sem perdas, ao menor custo possível e sem prejudicar ao meio ambiente.

[5] Filho, M. d. Criação de peixes em tanquesrede. SENAR- Sindicato Rural, 2001

[6] Freitas, C.E.C. Recursos pesqueiros amazônicos: status atual da exploração e perspectiva de desenvolvimento do extrativismo e da piscicultura. In: Mello, A.F. (org.). O futuro da Amazônia: dilemas, oportunidades e desafios no limiar do século XXI. Belém. EDUFPA. 2003, p. 101129.

[7] Inoue, L. A.; Boijink, C. D. Manaus a capital do tambaqui. 2011. Disponível em: <http://www.infobibos.com/Artigos/2011_1/tambaq ui/index.htm>. Acesso em: 27 mai. 2016.

[8] Lakatos, E. M.; Marconi, M. A.. 
Fundamentos de metodologia científica. São Paulo: Atlas, 2005.

[9] Mattar, F. N. Pesquisa de marketing: metodologia, planejamento. 5. ed. São Paulo: Atlas, 1999. 225p.

[10] Pedrazzani, A. S.; Molento, C. F. M.; Carneiro, P. C. F.; Castilho, M. F. Sensciência e bem-estar de peixes: uma visão de futuro do mercado consumidor. Panorama da Aquicultura. Rio de Janeiro, 2007. Disponível em: http://www.prp.ufla.br/wpcontent/uploads/2011/08/bem-estar-empeixes.pdf>Acesso em: 9 jan. 2016

[11] Petrere, J. M. Desarrollo Sostenible del Area Amazonica Fronteriza Brasil y Colombia. Rio Claro: Oea/Sinchi/SUDAM, 2001. 89 p.

[12] Prochmann, A. M.; Michels, I. L. Estudo das Cadeias Produtivas de Mato Grosso do Sul Piscicultura. Campo Grande: Governo do Estado do Mato Grosso do Sul, 2003.
[13] Souza-Filho, J.; Cerqueira, V. Influência na densidade de estocagem no cultivo de juvenis de robalo-flecha mantidos em laboratório. Pesquisa Agropecuária Brasileira, Brasilía, v. 38, n. 11, nov. $2003 . \quad$ Disponível em: <http://www.scielo.br/pdf/pab/v38n11/18927.pdf> Acesso em: 25 fev. 2016.

[14] Slack, N. e. Adminstração da Produção. São Paulo: Atlas, 2002.

[15] Valenti, W.C. Aqüicultura sustentável. Apresentado no $12^{\circ}$ Congresso de Zootecnia, Portugal, 2002. Acesso em 10/10/2008. Disponível em:

http://www.caunesp.unesp.br/Publicacoes/Artigos/ Valenti/Aquicultura\%20Sustentavel.PDF> Acesso em: 24 abr. 2016.

[16] Wurmann, C. Situación actual y perpectivas de dessarollo de La acuicultura mundial. FAO. 2010. 


\section{Bapítulo 14}

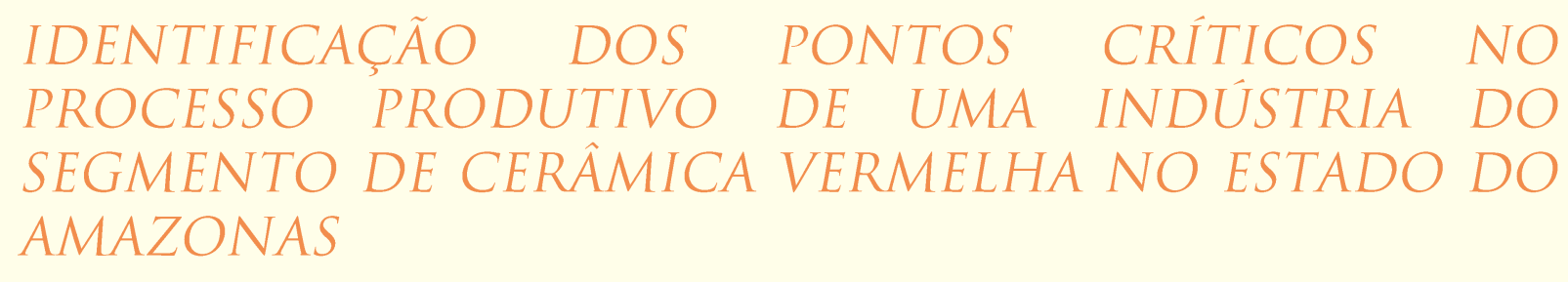

Renata de Oliveira Teixeira

Rute Holanda Lopes

Renato Moreira Teixeira

Júnior Dayanne Alves Lacerda

Roque José Paes Moraes Filho

Carlos André Esteves Leite

Resumo: O presente trabalho teve como objetivo identificar os pontos críticos do processo produtivo em uma indústria do segmento de cerâmica vermelha no Estado do Amazonas, por meio da identificação dos pontos críticos que afetam a produtividade do processo. A indústria de cerâmica destaca-se por exercer um papel importante na economia brasileira, sendo um dos setores mais importantes no fornecimento de insumos para a construção civil. A cerâmica vermelha abrange um grupo de materiais cerâmicos constituído por tijolos, blocos estruturais, telhas, tubos, lajotas, entre outros, geralmente fabricados próximos dos centros consumidores, utilizando matérias-primas locais. No que tange à metodologia, utilizou-se os meios de pesquisa bibliográfica e pesquisa de campo, pois os dados foram coletados no local de estudo, no qual, realizaram-se entrevistas e observações, tendo fins descritivo e exploratório, e de natureza qualitativa. Realizou-se acompanhamentos diários e observações do início ao fim do processo. Assim, possibilitando a descrição de todas as etapas necessárias para o processo produtivo dos produtos. A partir da análise identificaram-se pontos críticos, fatores que prejudicam o adequado fluxo da produção gerando perda de produtividade e desperdícios de matéria-prima. De modo geral, observou-se que a aplicação de ferramentas da qualidade e a realização de investimento em mão de obra qualificada auxiliarão na otimização do processo produtivo.

Palavras-chave: Indústria de cerâmica vermelha; Processo produtivo; Pontos críticos. 


\section{INTRODUÇÃO}

A competitividade tem gerado constantes mudanças no mercado de produtos e serviços em geral, impondo a necessidade de se aperfeiçoar, mesmo em mercados tradicionais, motivando o desenvolvimento de bens e serviços diferenciados pela qualidade e/ou preço na busca por obter vantagens competitivas. Diante dessa realidade, as empresas precisam buscar um modelo de processo adequado e compatível com sua visão estratégica (ROCHA; PALMA, 2011).

Nessa perspectiva, possuir um processo produtivo planejado e controlado, torna-se uma vantagem estratégica no ramo empresarial e industrial, assim possibilitando a implantação de futuras inovações. No segmento de cerâmica vermelha não é diferente, pois se apresenta com significativa relevância no desenvolvimento socioeconômico do País, por meio da geração de emprego e renda nos âmbitos industrial e comercial, pois se têm na cerâmica vermelha como um produto de ampla utilização na sociedade desde as civilizações antigas. E, atualmente, ainda há uma forte demanda da cerâmica vermelha no abastecimento do setor da construção civil.

Os autores Bustamante e Bressiani (2000), descrevem que a produção dos produtos da indústria de cerâmica vermelha abrange todos os materiais que possuem coloração avermelhada empregados no setor de edificações, que se torna indispensável para o mercado, por ser uma atividade de base que possibilita a construção civil em geral, desde a mais simples a mais sofisticada, é o segmento responsável pela produção de tijolos furados, tijolos maciços, lajes, blocos de vedação e estruturais, telhas, manilhas, pisos rústicos etc.

Segundo dados da Associação Nacional da Indústria Cerâmica - ANICER (2016), a Indústria de Cerâmica Vermelha possui uma atuação muito significativa na economia do País, com participação expressiva no Produto Interno Bruto que corresponde por $1 \%$ do PIB brasileiro, responsável por 293 mil empregos diretos e 900 mil de empregos indiretos, gerados por 6.903 mil empresas, sendo entre elas de micro, pequenas e médio porte.

De acordo com o Instituto Nacional de Tecnologia - INT (2012), a região norte possui 884 empresas e com uma produção de 165 mil milheiros/mês, onde o setor encontra-se em desenvolvimento em relação ao quantitativo mensal das regiões sul e sudeste. O estado do Amazonas possui uma média de 100 empresas, boa parte das empresas do setor no estado encontra-se instalada em local privilegiado com abundância de matériaprima, próximo ao centro consumidor, a maior concentração nos municípios de Iranduba, Manacapuru e Itacoatiara.

O presente trabalho tem como objetivo identificar os pontos críticos do processo produtivo dos principais produtos cerâmicos (tijolos, blocos e telhas) em uma indústria do segmento de cerâmica vermelha no Estado do Amazonas, por meio da identificação dos pontos críticos que afetam a produtividade do processo.

\section{REFERENCIAL TEÓRICO}

\subsection{A INDÚSTRIA DE CERÂMICA VERMELHA}

De acordo com Challoner (2010), foi na antiguidade que a técnica de produção cerâmica passou a ser empregada para fabricação de produtos voltados para a construção civil, principalmente em regiões onde as pedras eram mais escassas, tendo em vista que antes da alvenaria, as edificações eram feitas de pedra.

A indústria de cerâmica vermelha é um dos mais importantes fornecedores de insumos para a construção civil. Tijolos, blocos, lajotas e telhas cerâmicas constituem as paredes e telhados das construções, apresentando baixo custo e boas propriedades isolantes, térmica e acústica, sendo por isso consumido em larga escala. (LIRA; ALARCON, 2004).

No Brasil, foi desenvolvido em 2007 o Programa de Aceleração do Crescimento PAC, voltado aos investimentos em obras de infraestrutura econômica e social, e o Programa Minha Casa, Minha Vida em parceria com o Governo Federal, em 2009, no qual proporcionou um crescimento significativo no setor de construção civil.

O setor de cerâmica vermelha no Brasil é extremamente pulverizado, com empresas localizadas nas diversas regiões do país, no qual o fator determinante para a localização dessas empresas é, principalmente, a disponibilidade de matéria-prima, ou seja, a proximidade em que se encontram as jazidas de argila. (BUSTAMANTE; BRESSIANI, 2000).

Nos últimos anos, a fabricação e comercialização dos produtos cerâmicos, em especial os produtos de cerâmica vermelha, 
passaram por grandes modificações. O que era feito de maneira artesanal, vem ganhando técnica e confiabilidade, porém mesmo diante de um crescimento expressivo, o setor necessita de adequações para melhoria. (MEDEIROS et al., 2015).

No entanto, uma boa parte das indústrias, ainda possuem fortes relações com o setor primário e manual, pois as mesmas necessitam do uso de recursos naturais tais como: lenha que é utilizada como combustível e a argila que é a principal matéria-prima e o processo manual de movimentação do produto no processo. (SILVESTRE, 2001).

As indústrias de fabricação de cerâmicas são importantes para 0 desenvolvimento econômico das regiões onde atuam, no entanto, apesar de sua importância e dos benefícios trazidos por esse setor, a maioria tem dificuldade em utilizar novas técnicas e tecnologias propostas, ficando as margens dos avanços tecnológicos do mercado. Devido à maioria das organizações serem constituídas de cunho familiar, estas sofrem pela rotina rústica implantada pelos seus patriarcas, como forte presença da economia informal, com processos produtivos e tecnologia, em muitos casos, defasados. (ANICER, 2010).

Segundo a Associação Brasileira de Cerâmica - ABC (2011) pode-se destacar algumas dificuldades que o segmento enfrenta, tais como: processos produtivos ultrapassados, defasagem tecnológica e obsolescência de maquinário, falta de conhecimento técnico para preparação da argila, ausência de critérios para dosagem de resíduos, falha no processo de extrusão, falta de regulagem na moldagem, ou seja, falta de padronização no processo. Para tanto, se faz necessário uma visão detalhada do processo produtivo, a fim de identificar essas dificuldades, localizar desperdícios de resíduos do processo, assim, podendo diagnosticar os possíveis pontos críticos.

O estado do Amazonas encontra-se em processo de desenvolvimento, segundo o Sindicato da Indústria da Construção Civil do Amazonas (2012), que inclui uma parcela de $50 \%$ de instalações de pequena escala de produção, algumas delas localizadas pelo imenso território do Estado. A maior parte da produção se refere a tijolos de oito furos, telhas e de forma menos intensa blocos cerâmicos especiais e revestimento rústico para pisos.
De acordo com Pinheiro (2015), as empresas do Estado do Amazonas vêm inserindo tecnologia na fabricação dos seus produtos, apesar de serem a passos lentos, várias atividades já estão se modificando. Como exemplo, o acréscimo de um novo tipo de combustível para os fornos, na etapa de queima dos produtos, com a utilização de pó de serragem, cavaco de restos de toras de madeira, caroços de açaí ou ainda resíduos de madeira oriunda de construção civil.

\subsection{PROCESSO PRODUTIVO}

Para Maciel e Freitas (2013), o ser humano utiliza inúmeros bens e produtos para atender suas diversas necessidades. Neste sentido, grande parte do que é utilizado no dia-dia é resultado de um processo produtivo o qual faz uso de fatores como: recursos naturais, trabalho e capital. Sendo assim, o processo produtivo está diretamente interligado à cadeia de valor, fazendo com que a empresa esteja constantemente interagindo com 0 ambiente interno e externo da mesma.

$\mathrm{Na}$ procura de otimizar processos e crescimento econômico, tem-se a busca em minimizar insumos, racionalizar custo e reduzir impactos, fazendo com que as empresas tornem-se competitivas e a cadeia de valor passe a ser o elemento chave, pois a gestão da produção é de grande importância em qualquer empresa, seja ela de pequeno, médio ou grande porte (SILVA, SOUZA E COSTA, 2015).

Costa, et al (1997), descrevem a análise do processo produtivo, como o pleno entendimento do mesmo, levando em consideração seu consumidor imediato em termos de custo e valor agregado ao produto. Tratando-se de um plano de ação e avaliação das informações obtidas na fase anterior para que se possa alcançar a melhoria, pois ao identificar todas as etapas de cada processo, bem como seu consumidor e fornecedor, é possível analisar os pontos críticos e conhecer a raiz do problema, promovendo a melhoria no desempenho do processo. Assim, proporcionando uma melhora na produtividade, na qual corresponde ao volume de produto obtido por unidade de fatores de produção utilizados, para um dado período de tempo.

Os processos produtivos dos produtos cerâmicos em geral ocorrem de maneira semelhante, pois possuem fases em comuns 
para todos os tipos de produtos, no qual vão desde a retirada da argila das jazidas, ao transporte para a empresa, moldagem $e$ secagem, até a queima dos produtos nos fornos, sendo esta última fase a que requer melhor conhecimento e habilidade, uma vez que pode comprometer todas as etapas anteriores. Todas as etapas do processo possuem a duração em média, de 8 a 14 dias, levando em consideração a época do ano, por ter uma influencia significativa, fazendo com que no período de chuvas a secagem seja mais demorada, até duas vezes mais que no verão (GOMES, 2009).

\section{METODOLOGIA}

Este estudo foi desenvolvido em uma indústria do segmento de cerâmica vermelha no município do Estado do Amazonas, durante o período de 45 dias (180 horas), nos meses de Junho, Julho e Agosto de 2015, onde se buscou analisar e compreender como é executada a produção dos produtos com o objetivo secundário de analisar cada etapa necessária do processo produtivo do produto e por fim apontar os pontos críticos identificados na análise.

A metodologia empregada para realizar tal análise foi o procedimento técnico estudo de caso, que proporciona um maior aprofundamento da pesquisa ao se deter em um objeto predeterminado, no embasamento teórico utilizou-se os meios de pesquisa bibliográfica e para a melhor compreensão do estudo empregou-se a pesquisa de campo, tendo como técnicas de pesquisa, entrevistas e observações, e para a melhor concepção da análise fez-se uso das pesquisas descritiva, exploratória e abordagem qualitativa.

Para a compreensão inicial do estudo, fez-se necessário a realização de pesquisa bibliográfica em complemento realizou-se a pesquisa de campo para coleta de dados relacionados ao estudo de caso. Para isso, utilizou-se para a coleta dos dados as técnicas de observação (participante e não participante) e de entrevistas (não estruturada), como detalha-se a seguir.

A pesquisa caracterizou-se como estudo de caso por acompanhar todo o processo de produção de uma indústria de cerâmica vermelha no Estado do Amazonas. Os autores Diehl e Tatim (2004), abordam o estudo de caso como um método de pesquisa que engloba um conjunto de dados que descrevem uma fase ou a totalidade do processo social de uma unidade em diversas relações internas. Com isso, ao utilizar o estudo de caso, a coleta e análise de dados tornam-se procedimentos simples, os quais ocorreram por meio de entrevistas e acompanhamento diário do processo produtivo da produção.

Os autores Diehl e Tatim (2004), afirmam que a observação é uma técnica para conseguir informações, não consistindo em apenas ver ou ouvir, mas também em examinar fatos ou fenômenos que se deseja estudar, tornando-a científica a alcance que é planejada sistematicamente e registrada metodicamente. Neste estudo, foram realizadas entrevistas com os funcionários e gestores responsáveis de cada setor, categorizada de entrevista não estruturada, por não possuir roteiro possibilitou que o entrevistador tivesse a liberdade para desenvolver a direção da entrevista, por meio de perguntas abertas.

$\mathrm{Na}$ fase de averiguação dos dados, a pesquisa tornou-se exploratória à medida que o tema é pouco abordado na região e buscou por meio da literatura e de dados coletados na pesquisa de campo expor as problemáticas identificadas. No estudo, a pesquisa teve o foco descritivo, no decorrer da procura em observar, registrar e interpretar o processo produtivo da indústria em questão, desde a extração da argila até a expedição do produto final para pontos de vendas, com - relato de cada etapa necessária para produção do produto.

Quanto à natureza do estudo, a abordagem da pesquisa é qualitativa, pois serão descritas todas as etapas necessárias do processo produtivo, assim, coletando e analisando os dados. Por fim, identificando seus problemas por meio da análise do processo, com o auxílio de um fluxograma, sem o uso de dados estatísticos, para que possa ser estudada com certo grau de liberdade.

\section{RESULTADOS}

\subsection{PROCESSO PRODUTIVO DOS PRODUTOS CERÂMICOS}

Para a fabricação dos produtos de cerâmica vermelha, tais como Tijolos (de 4, 6 e 8 furos), blocos estruturais, telhas, cobogós, pisos e lajotas, têm-se as etapas do processo produtivo semelhantes, detalhes que 
distingues um produto ou outro, seguem a sequência apresentada na Figura 01.

Figura 01- Processo Produtivo da empresa

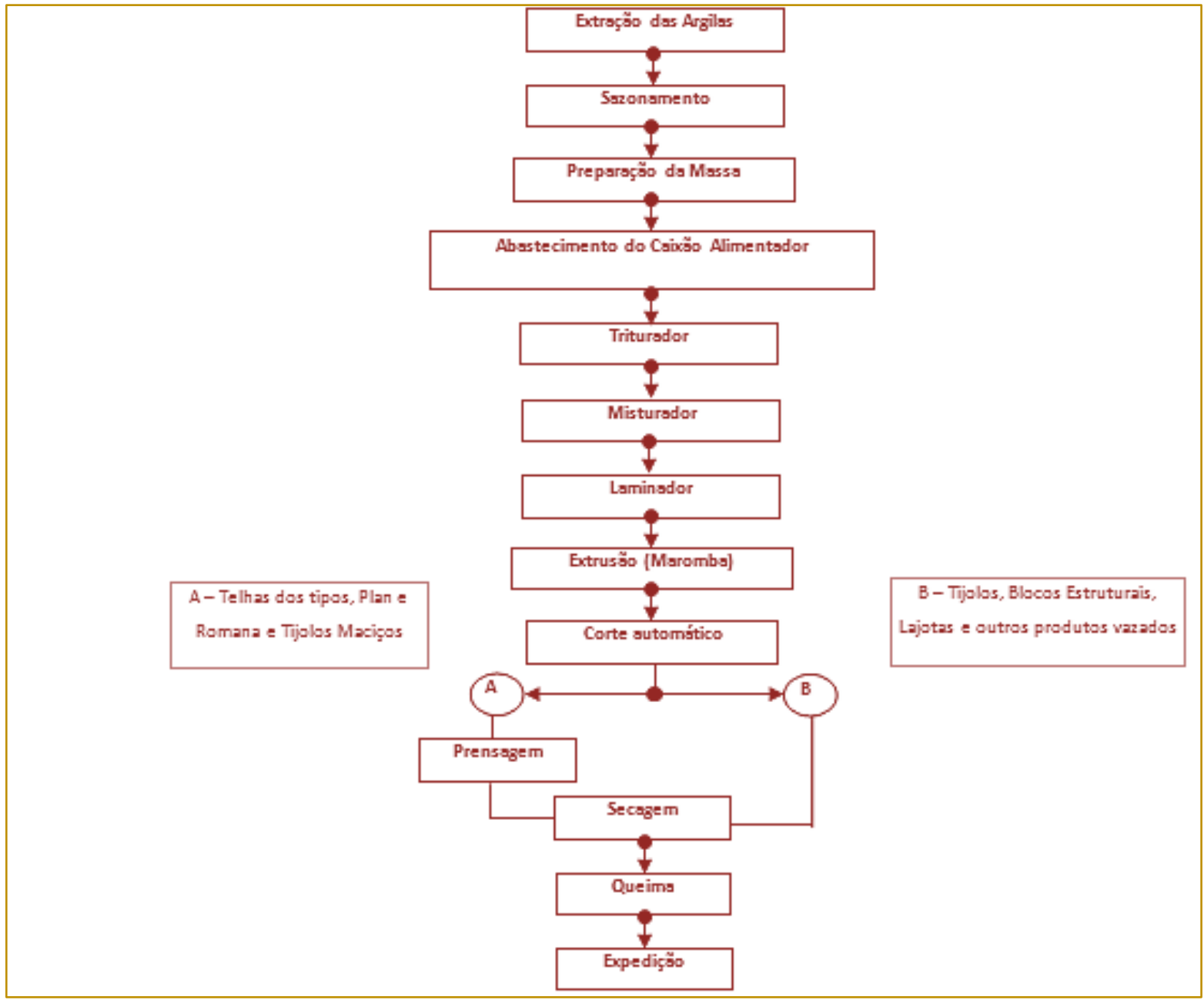

Fonte: Autores, 2017.

Assim, pode-se melhor compreender cada etapa do processo da empresa estudada, nos tópicos seguintes:

- Extração da matéria-prima: uma vez ao ano, realiza-se a extração de 3 (três) tipos de argila com quantidade e profundidade de extração previamente calculada através de tratores do tipo retroescavadeira e transportados por caminhões caçamba até o pátio da empresa.

- Sazonamento ou estocagem da argila: a matéria-prima é depositada ao ar livre, em um período de um ano, onde as argilas ficam "descansando", para que ocorra decomposição dos componentes orgânicos pela ação de agentes atmosféricos, com intuito de melhoram sua plasticidade e homogeneízam a umidade.
- Mistura: a mistura da massa ocorre pela combinação da argila tipo gorda (de alta plasticidade, granulometria fina e composição essencialmente de argilominerais) com a argila do tipo magra (rica em quartzo e menos plástica, podendo ser caracterizada também como um material redutor de plasticidade). (COUVIGNOU, 2007).

- Conformação ou Extrusão: é a etapa que constitui os passos, abastecimento do caixão alimentador, triturador, misturador, laminação e finaliza a etapa na extrusora. Quando a massa é homogeneizada e transferida para a máquina chamada de extrusora, também conhecida por maromba, que é responsável pela moldagem dessa massa cerâmica, por meio do aquecimento da mesma e prensada em um molde, de nome boquilha, que 
proporciona o formato desejado da peça, no qual faz com o que saia nas dimensões do produto final e em seguida é cortada no comprimento devidamente padronizado do produto.

- Prensagem: essa etapa é destinada somente aos produtos telhas e tijolos maciços, pois quando os mesmos saem da etapa de extrusora, são cortadas em formato específico e em seguida são submetidas a uma prensagem em moldes, de acordo com o modelo de telha que se deseja produzir, e em seguida seguem o processo normalmente. (SEBRAE, 2008).

- Secagem: é a etapa que se trata da retirar do teor de umidade do produto, de forma lenta e gradual, realizada em estufas, constituídas de ventiladores e ar quente que se reaproveita dos fornos, após o processo de queima. A secagem é realizada para que não se tenha a geração de tensões, assim, não ocasionando defeitos na próxima etapa do processo.

Queima: nessa etapa é onde se realiza o processo de cozimento da massa cerâmica, alterando as suas propriedades física e química, tornando-os com as características adequadas para uso. Para efetuar esta etapa, faz necessária a utilização de fornos especiais, que desempenham o trabalho de atingir elevadas temperaturas para que se realize o processo adequadamente.

- Expedição: após o término do processo de queima, realiza-se a inspeção visual dos produtos conformes e não conforme, as peças conformes são encaminhadas para setor de expedição que possui duas maneiras de enviar o produto ao cliente, sendo a granel, onde as peças seguem para o cliente soltas no caminhão e seu carregamento e descarregamento é realizado de maneira manualmente; ou em pallets, onde são embalados com certa quantidade de unidades e alocados em caminhões com o auxílio da empilhadeira e os produtos não conforme são descartados.

\subsection{IDENTIFICAÇÃO DOS PONTOS CRÍTICOS}

Ponto crítico é apontado como qualquer circunstancia que pode colocar ou representar risco em partes ou em todo um processo realizado. E a partir dos dados obtidos nas visitas, entrevistas e observação direta, foi feita uma análise das ações, os pontos críticos que prejudicam o fluxo do processo produtivo de cada setor e quais medidas podem ser tomadas, expostas na tabela 01.

Tabela 01 - Resumo dos principais problemas identificados e sugestões de melhoria.

\begin{tabular}{|c|c|c|c|}
\hline Setor & $\begin{array}{l}\text { Etapa do processo } \\
\text { produtivo }\end{array}$ & $\begin{array}{l}\text { Principais problemas } \\
\text { encontrados }\end{array}$ & Sugestões de Melhoria \\
\hline $\begin{array}{l}\text { Mistura } \\
\text { Massa }\end{array}$ & $\begin{array}{l}\text { Mistura dos } 3 \text { tipos de } \\
\text { argila }\end{array}$ & $\begin{array}{l}\text { Resíduos na matéria- } \\
\text { prima }\end{array}$ & $\begin{array}{l}\text { Trator de uso exclusivo ao setor } \\
\text { de conformação }\end{array}$ \\
\hline Conformação & Alimentar o caixão & $\begin{array}{l}\text { Falta de matéria-prima } \\
\text { no abastecimento do } \\
\text { caixão alimentador }\end{array}$ & $\begin{array}{l}\text { Trator de uso exclusivo ao setor } \\
\text { de conformação }\end{array}$ \\
\hline Conformação & Laminação & $\begin{array}{l}\text { Baixa umidade da massa } \\
\text { cerâmica }\end{array}$ & $\begin{array}{l}\text { Instalação de sensores de } \\
\text { medição da passagem de } \\
\text { matéria-prima e adição de água. }\end{array}$ \\
\hline Conform & $\begin{array}{l}\text { Transporte do } \\
\text { laminador a extrusora }\end{array}$ & $\begin{array}{l}\text { Desperdícios de matéria- } \\
\text { prima }\end{array}$ & $\begin{array}{l}\text { Limpeza periódica dos rolos } \\
\text { transportador das esteiras }\end{array}$ \\
\hline Conform & Corte automático & $\begin{array}{l}\text { Ruptura do cabo de aço } \\
\text { da cortadeira automática }\end{array}$ & $\begin{array}{l}\text { Avaliar o tempo de vida útil dos } \\
\text { cabos e realizar trocas } \\
\text { periódicas }\end{array}$ \\
\hline Conformação & $\begin{array}{l}\text { Extrusora e corte } \\
\text { automático }\end{array}$ & $\begin{array}{l}\text { Desperdícios de matéria- } \\
\text { prima }\end{array}$ & $\begin{array}{l}\text { Ao iniciar o processo produtivo, } \\
\text { realizar vistoria nos maquinários } \\
\text { e calibragem da cortadeira }\end{array}$ \\
\hline Secagem & $\begin{array}{l}\text { Retirada de água dos } \\
\text { produtos }\end{array}$ & $\begin{array}{l}\text { Falta de controle da } \\
\text { extração de umidade do } \\
\text { produto }\end{array}$ & $\begin{array}{l}\text { Instalação de sensores de } \\
\text { medição do grau de umidade }\end{array}$ \\
\hline Queima & $\begin{array}{l}\text { Cozimento da massa } \\
\text { cerâmica }\end{array}$ & Controle da temperatura & $\begin{array}{l}\text { Instalação de sensores de } \\
\text { medição de temperatura e } \\
\text { adoção de gás na queima }\end{array}$ \\
\hline
\end{tabular}

Fonte: Autores, 2017. 
O setor conformação foi identificado como responsável pelo maior número de queda de produtividade, por meio do acompanhamento diário e pôde-se identificar os maiores índices de motivo de paradas, pode-se constatar que possuem uma planilha de controle de produção ineficiente na ótica da análise dos dados para realizar a otimização do sistema, pois não se registra no real momento todas as paradas. Assim, deixando uma deficiência nos registros e nos controles da empresa o que impossibilita o dimensionamento do problema pelos gestores.

Recomenda-se realizar vistorias e manutenção preventiva dos maquinários, determinar funções para um funcionário fixo, pois demanda um alto tempo para iniciar-se a produção e um grande volume de desperdício de matéria prima.

O setor de secagem da empresa encontra-se a frente de muitas outras que trabalham no segmento de cerâmica vermelha, em comparação as existentes no estado do Amazonas, por utilizar o processo de secagem artificial com o emprego de secadores intermitentes.

No entanto, nessa etapa a empresa não possui o controle de umidade do produto, pois não possuem painel de indicação de temperatura e nem sensores de medição do grau de umidade, pois a empresa só possui o controle da quantidade de entrada/saída e tempo de permanência dos produtos na estufa, isso não permite uma boa avaliação da condição de umidade do produto, pois o clima da região que é instalada a indústria há grandes variações de temperaturas, assim influenciando no processo de eliminação da água dos produtos.

De tal modo, a proporcionar futuros defeitos no processo seguinte, a queima, pois quando o produto encontrasse com a concentração de água elevada, durante o período de ebulição da mesma, originam-se trincas e quebras, assim perdendo produtos. E quando se tem a lesão do produto final, é necessária a realização de retrabalho para repor o produto na demanda pendente.

O setor da queima é um dos mais importantes do processo de produção, pois depois dele o produto não pode ser reaproveitado ou retornar ao processo. Prontamente, deve-se ter um cuidado minucioso do tempo e da temperatura de funcionamento dos fornos. A empresa possui dois tipos de forno, o modelo abóbodas que possuem termômetros malconservados localizados na região superior e inferior do forno, disponibilizando o avanço da temperatura ao longo do tempo, enquanto, que os fornos Hoffmann não possuem nenhum demonstrativo de temperatura, somente a atividade de alimentação dos combustíveis (lenha) realizada de hora e hora.

Ambos os fornos possuem boa eficiência, no entanto, o controle do processo de queima ainda é realizado de maneira rústica, pois a avaliação do processo é julgada pelos sentidos visuais, na qual disponibilizam uma área de observação dos produtos que se encontram no interior dos fornos em atividade, assim avaliando os níveis de temperatura do processo de queima de maneira empírica, por meio da observação da tonalidade que o produto apresenta, até que se avalie o fim do processo.

Recomenda-se ao setor da queima, que a empresa invista na aquisição de dispositivos e sensores de controle de temperatura adequado ao modelo de cada tipo de forno, para que se possa ter uma melhor avaliação e acompanhamento da evolução da temperatura durante o processo de queima dos produtos ou também se pode realizar a adaptação dos fornos a gás, no qual irá diminuir a utilização da lenha que é usada como combustível, assim, proporcionar uma produção mais eficiente e controlada.

\section{CONCLUSÃO}

No decorrer das análises, observações e acompanhamento do processo produtivo, identificaram-se pontos considerados realmente críticos, fatores que prejudicam o adequado fluxo do processo produtivo, gerando perda de produtividade e desperdícios de matéria-prima. Desta forma, ao compreender o processo como um todo, foi possível propor possíveis melhorias, revelando a importância de se ter uma adequada gestão dos processos, para que sejam capazes de identificar e nortear os problemas e futuramente solucioná-los.

De modo geral, observou-se que a empresa em todo o seu processo produtivo necessita de aplicação de ferramentas da qualidade, na qual podem proporcionar uma visão mais ampla e conhecimento para resolver questões na identificação e norteamento para a solução de problemas e também para propor um plano de ação que atingisse de forma pontual os itens levantados como problema-raiz para ser trabalhado.

Outro ponto que contribuirá para otimização do processo de produção é o investimento em 
mão de obra com qualificação profissional, ou seja, com formação técnica específica, onde contribuirá no fator da redução dos índices de defeito, produtos padronizados, além de realização de treinamento com os funcionários, pois uma das maiores deficiência das organizações desse segmento é a carência de mão-de-obra qualificada e com a indústria em questão não é diferente.

Após alcançar, desenvolvimento tecnológico

\section{REFERÊNCIAS}

[1] ABC - Associação Brasileira de Cerâmica: ABCERAM. Informações diversas. São Paulo 2011. Disponível em: < abceram.org.br/>. Acesso em: 22 de Abril de 2017.

[2] Anicer - Associação Nacional da Indústria Cerâmica. Informações diversas. 2010. Disponível em: <http://www.anicer.com.br>. Acesso em: 22 de Janeiro de 2017.

[3] Cenário da Indústria de cerâmica vermelha no país. 2016. Disponível em: $<$ http://www.anicer.com.br>. Acesso em: 22 de Janeiro de 2017.

[4] Bustamante, G.M; Bressiani, J.C. A Indústria Cerâmica Brasileira. Revista Cerâmica Industrial, 5(3) (Mai/Jun), 2000. Disponível em: <http://ceramicaindustrial.org.br/pdf/v05n03/v5n3_ 5.pdf>. Acesso em: 10 de Fevereiro de 2017.

[5] Challoner, Jack. 1001 invenções que mudaram o mundo. Tradução de Carolina Alfaro, Pedro Jorgensen e Paulo Polzonoff Junior. Rio de Janeiro: Sextante, 2010.

[6] Costa, N. A. A.; et al. Gerenciamento de processos - metodologia base para a melhoria contínua. In: Encontro Nacional de Engenharia de Produção - ENEGEP, Florianópolis - SC, 1997. Disponível em: <http://www.abepro.org.br/biblioteca/ENEGEP1997 _T4109.PDF>. Acesso em: 29 de Fevereiro de 2017.

[7] Couvignou, Eliana Macêdo. Análise da Conformidade e Caracterização da Matéria- Prima Empregada na Fabricação de Blocos Cerâmicos na Região Metropolitana de Salvador. 2007. 104 f. Dissertação (Mestrado em Tecnologia de Materiais; Projetos Mecânicos; Termociências) - Universidade Federal do Rio Grande do Norte (UFRN), Natal-RN, 2007.

[8] Diehl, Astor Antônio; Tatim, Denise Carvalho. Pesquisa em ciências sociais aplicadas: métodos e técnicas. São Paulo: Prentice Hall, 2004. [9] Gomes, D. R. Mapeamento de Processos como Ferramenta de Avaliação de Processo Produtivo. Trabalho conclusão de curso (Bacharel em Engenharia de Produção) - Universidade Estadual do Norte Fluminense (UENF), Campos-RJ, 2009. Disponivel em http://www.uenf.br/Uenf/Downloads/LEPROD_6958 _1251232430.pdf>. Acesso em: 29 de Fevereiro de 2017. e mão-de-obra qualificada, sugere-se que a empresa trabalhe para conquistar a certificação de qualidade do INMETRO, trabalhando dentro dos padrões da norma brasileira, pois já exige uma série de adequações e normatizações que irá refletir na qualidade do produto final, consequentemente, melhorando a produção e sua confiabilidade no mercado regional.

[10] INT - Instituto Nacional de Tecnologia. Informações diversas. Disponível em: $<w w w . i n t . g o v . b r />$. Acesso em: 27 de Março de 2017.

[11] Lira, Claúdia; Alarcon, Orestes. Manual da qualidade e produtividade para indústria cerâmica. Controle do processo de fabricação. Arranjo Produtivo Local (APL). FINEP, FAPES, SEBRAE, 2004.

[12] Maciel, D. dos S. C.; Freitas, L. S. de. Análise do processo produtivo de uma empresa do segmento de cerâmica vermelha à luz da produção mais limpa. Revista Produção Online, Florianópolis, SC, v.13, n. 4, p. 1355-1380, out./dez. 2013. Disponível em: $<$ http://producaoonline.org.br/rpo/article/viewFile/13 96/1079 > . Acesso em: 29 de Fevereiro de 2017

[13] Medeiros, L. D. D. et al. Proposta de elaboração de um plano de manutenção em uma empresa cerâmica. XXXV Encontro Nacional de Engenharia de Produção, Fortaleza - CE, 2015. Disponível em: <http://www.abepro.org.br/biblioteca/TN_STO_206_ 224_27641.pdf>. Acesso em: 29 de Fevereiro de 2017.

[14] Pinheiro, H. A. OLEIROS DA VIDA, TRABALHO, AMBIENTE E O FUTURO DOS TRABALHADORES DO BARRO EM IRANDUBA (AM). TESE (Doutorado EM Ciências do Ambiente E Sustentabilidade NA Amazônia) - Universidade Federal do Amazonas (UFAM), Manaus-AM, 2015.

[15] Rocha, A. F. da; Palma, M. A. M. Inovação tecnológica e capacidade competitiva: uma análise não paramétrica no setor cerâmico de Campos dos Goytacazes - RJ. Anais do XXXI Encontro Nacional de Engenharia de Produção, Belo Horizonte - MG, 2011.

[16] Sebrae. Serviço Brasileiro de Apoio às Micro e Pequenas Empresas. Cerâmica vermelha para construção: telhas, tijolos e tubos. Relatório Completo. Estudos de mercado SEBRAE/ESPM, Setembro, 2008. Disponível em: <http://www.sebraemercados.com.br/wpcontent/uploads/2015/09/ESTUDO-CERAMICA VERMELHA.pdf>. Acesso em: 22 de Janeiro de 2017.

[17] Silva, Taisa Pereira da; Souza, Simone Almeida de; Costa, Marcelo Neves. Produção mais limpa: eficiência ambiental na produção das indústrias de cerâmica vermelha em Guanambi Bahia. XXXV Encontro Nacional De Engenharia De Produção. Fortaleza, CE, Brasil, 13 a 16 de outubro 
de 2015. Disponível em: < http://www.abepro.org.br/biblioteca/TN_STO_214_2 68_27650.pdf>. Acesso em: 22 de Janeiro de 2017.

[18] Silvestre, B.S. Uma Análise Competitiva do Setor Ceramista de Campos dos Goytacazes. Dissertação de Mestrado em Engenharia de Produção - Campos dos Goytacazes-RJ.
Universidade Estadual do Norte Fluminense UENF. 109p, 2001.

[19] Sinduscon-AM. Sindicato da Indústria da Construção Civil do Amazonas. Olarias no amazonas. 2012. Disponível em: $<$ http://www.sindicatodaindustria.com.br>. Acesso em: 26 de Fevereiro de 2017. 


\section{Bapítulo 15}

\section{FILOSOFIA KAIZEN APLICADA AO PROCESSO PRODUTIVO EM INDUSTRIA QUIMICA: UM ESTUDO DE CASO}

\section{Camila Machado}

\section{Felipe Morais Menezes}

\section{Fabiano de Lima Nunes}

Tiago dos Santos Antunes

Resumo: A melhoria contínua dos processos, com base em práticas enxutas, tornase uma alternativa aplicada às empresas que objetivam competir em mercados globais. O Kaizen, filosofia baseada na eliminação de desperdícios por meio de soluções otimizadas e econômicas, apresenta resultados rapidamente visíveis. Essa filosofia estimula o engajamento em toda a organização, sendo amplamente utilizada na busca pela melhoria contínua de processos dentro das empresas. Esse artigo tem como objetivo avaliar a aplicação do kaizen e seu impactos acerca dos resultados de produtividade e qualidade na área de produção em uma empresa de manufatura na região do Vale dos Sinos - RS. Através do Mapeamento do Fluxo de Valor (MFV) descreve-se o estado atual do processo estudado, discute-se as causas identificadas, propõem-se soluções potenciais e, por fim, apresenta-se o estado futuro do processo. Também se apresenta, a perspectiva da elevação do indicador uptime de $30 \%$ para $45 \%$. Os ganhos apresentados têm como base avanços na padronização da área, acesso visual às informações, o controle dos tempos de produção para diagnóstico de seus pontos críticos e na redução dos desperdícios, com ênfase nas esperas ao longo do processo.

Palavras-chave: Kaizen, Mapeamento do Fluxo de Valor (MFV), Manufatura, Aplicação. 


\section{INTRODUÇÃO}

A melhoria gradual e contínua dos processos, com base em práticas enxutas, torna-se uma alternativa aplicada às empresas preocupadas com sua participação em mercados globais. Otimizar os recursos e disseminar a cultura da qualidade são ações essenciais às organizações que buscam um diferencial competitivo e a consolidação de seus negócios. O cenário requer, portanto, uma gestão orientada para a eliminação dos desperdícios, princípio sobre o qual é erigido o Sistema Toyota de Produção (STP), cujos métodos popularizaram-se mundialmente (NUNES; VACCARO; ANTUNES JÚNIOR, 2017). Junto ao STP, difunde-se o kaizen, filosofia que representa uma poderosa prática de melhoria sem maiores investimentos (SINGH; SINGH, 2009).

Assim, o kaizen entrega resultados rapidamente visíveis e estimula a participação daqueles que realizam as atividades no cotidiano. Apresenta uma abordagem pontual na resolução de problemas no curto prazo, articulada por equipes multifuncionais que procuram compreender os estados vigentes para proposição de mudanças focadas na cadeia de valor (MARKSBERRY et al., 2010).

A partir deste contexto, o presente artigo delimita-se à prática do kaizen e seus resultados no setor produtivo de uma indústria no ano de 2015. Atuante no ramo de termoplásticos, a empresa segue uma tendência mundial ao estruturar, em todos os seus níveis, projetos kaizen orientados para a mudança e a capacitação. Desta forma, o estudo visa responder à seguinte questão de pesquisa: como o uso do kaizen influencia a produtividade e a qualidade dos processos produtivos?. O objetivo geral é avaliar a aplicação da metodologia kaizen e seu impacto sobre os resultados de produtividade e qualidade na área de produção desta empresa de manufatura localizada na região do Vale do Sinos - RS.

\section{FUNDAMENTAÇÃO TEÓRICA}

A sessão que segue trata do embasamento bibliográfico oportuno para entendimento dos conceitos de manufatura enxuta e kaizen.

\subsection{MANUFATURA ENXUTA E KAIZEN}

A base do STP é a absoluta eliminação do desperdício- inconsistências e excessos que geram custos sem, no entanto, agregar valor (SHINGO, 1996; OHNO, 1997). Otimizar ao máximo os recursos é o principal objetivo deste método, cuja sustentação depende de dois pilares (LIKER, 2005):

a) just in time: uma unidade é produzida por vez à razão da demanda do cliente, remoção ao máximo possível dos estoques;

b) autonomação: o processo é interrompido em situações anormais para impedir a fabricação de produtos defeituosos, para-se a linha para investigação e correção do problema.

O ponto de partida do pensamento enxuto é a definição de valor, presumindo o alinhamento das atividades aos requisitos do cliente e àquilo que este se dispõe a pagar. Assim, para a geração de lucro, as ineficiências dos processos exigem ações contundentes de eliminação de perdas (CHAVES FILHO, 2010).

\subsection{FERRAMENTAS DA MANUFATURA ENXUTA}

Presente em uma proporção menor do que desejável, o trabalho que agrega valor tratase do processamento que transforma a matéria-prima ou a informação em componente, produto ou serviço (OHNO, 1997).

As perdas são categorizadas em sete tipos, uma classificação usada como ferramenta de identificação, sendo elas: 1) excesso de produção (itens produzidos além da demanda e antes do necessário), 2) tempo sem trabalho (funcionários ou produtos em espera), 3) transporte (movimentação extra, ineficiente ou desnecessária de material ou informação), 4) superprocessamento (processos e passos desnecessários ou ineficientes), 5) inventário (excesso de matérias-primas, produtos acabados e semi-acabados), 6) movimento (qualquer movimento inútil de funcionários) e 7) defeitos (produtos que não atingem os requisitos de qualidade, correções ou informações imprecisas) (LIKER, 2005; GALLAS; NUNES, 2016).

A perspectiva do valor oportuniza a projeção das melhorias (LIKER, 2005). Para isso, o mapeamento do fluxo de valor (MFV) é utilizado como técnica para coleta de dados, expressando visualmente a sequência das operações como forma de diagnóstico e planejamento. O MFV fornece uma visão do comportamento de materiais e informações à 
medida que fluem, seu objetivo é identificar as oportunidades de redução das perdas, estabelecendo um estado atual, de acordo com a situação real do processo. Conforme expressa a Figura 1, o mapa ilustra tempos de ciclos, troca de ferramentas, paradas, movimentação de pessoas, estoques e requisitos de entrega (ROTHER, SHOOK, 2003; ORTIZ, 2010).

\section{Figura 1- Exemplo de MFV}

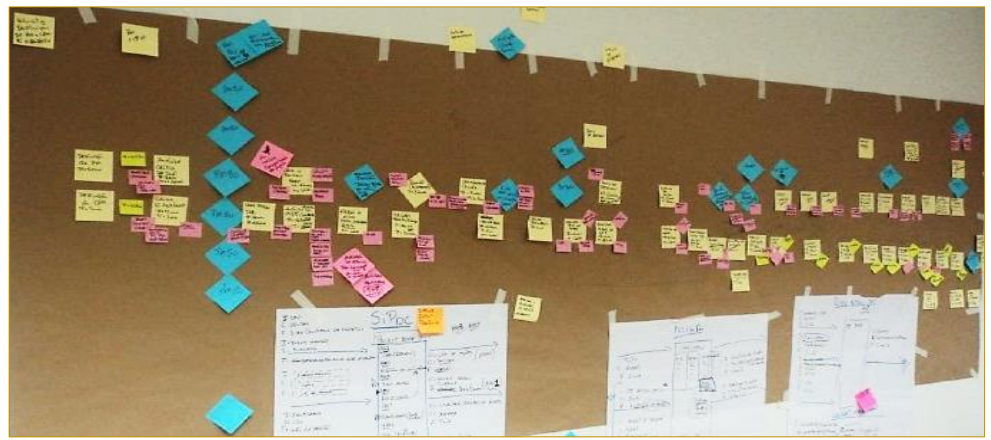

Fonte: Rossitti (2014, p. 39)

O entendimento dos processos por meio do MFV se dá, sobretudo, por conta da percepção visual. Técnica estabelecida integralmente em sistemas enxutos, a gestão visual é compreendida como a prática de exibir informações de maneira clara para que todas as atividades sejam assimiladas rapidamente (BARBOZA, 2011). Tornar os desvios evidentes e esclarecer as metas são os principais objetivos, de acordo com Imai (2014, p. 100): "A gestão visual é um método para se determinar quando tudo está sob controle e para se gerar um alerta no momento em que um problema é detectado".

Quando implementados os dispositivos adequados, esta comunicação contribui para o desempenho adequado do trabalho, a redução do esforço e das perdas, além de figurar como um grande apoio à segurança $e$ à padronização. Por fim, pode-se afirmar que "a gestão bem sucedida das atividades cotidianas resume-se a um preceito: manter e melhorar os padrões" (IMAI, 2014, p. 49). Na prática, a padronização consiste de folhas de processo que, quando apresentadas com clareza, permitem aos usuários proceder de modo a evitar retrabalhos, variabilidade, defeitos e acidentes (OHNO, 1997).

\subsection{KAIZEN}

Em japonês, kaizen significa "melhoria contínua". O termo popularizou-se no ocidente como conceito guarda-chuva das práticas de produção enxuta. Essencialmente, trata-se de uma filosofia que pressupõe a evolução constante do ser humano. Para as organizações, configura uma abordagem de bom senso e baixo custo que garante mudanças pequenas e progressivas, cujos resultados mostram-se compensatórios no longo prazo (IMAI, 2014).

Orientado para os processos, de maneira a realinhar a forma como as pessoas desempenham suas atividades, os objetivos do kaizen alinham-se às estratégias do negócio. Traduzida esta afirmação em propósitos para a fábrica, estabelece: elevar os níveis de produtividade e qualidade, reduzir o tempo e cortar custos pela eliminação de desperdícios (SHINGO, 2010; ORTIZ, 2010, NUNES; MENEZES, 2014).

\subsection{FASES DO KAIZEN}

Em essência, o kaizen tem escopo estreito e bem definido, sendo dividido em três momentos: pré-evento (preparação), evento (análise e implementação das mudanças) e pós-evento (manutenção, controle e execução de itens incompletos).

O pré-evento ocorre quatro semanas antes do evento, constituindo de período destinado à preparação de cronogramas e suprimentos, ao estudo de tempos e movimentos e à definição dos participantes (ORTIZ, 2010). Com vistas a auxiliar o entendimento, dividese o pré-evento em: 1) definição clara do escopo; 2) definição de objetivos factíveis, arrojados e mensuráveis; 3) criação do MFV atual e 4) levantamento de documentação (LIKER, 2005). 
A fase dois do kaizen é o evento em si que dura cerca de cinco dias (ORTIZ, 2010). Primeiramente é exigido que o líder ministre algum treinamento à equipe sobre manufatura enxuta e práticas específicas aplicáveis (CHAVES FILHO, 2010). A sequência das demais ações é sintetizada em cinco passos (LIKER, 2005):

a) A equipe observa e identifica as etapas do processo, definindo quais as que agregam valor;

b) O MFV atual é analisado de forma detalhada e, se necessário, modificado. Após, algumas medidas são calculadas, tais como: lead time, produtividade e percentual de defeitos ou correções;

c) Todas as ideias são lançadas e uma nova visão do processo é projetada em um MFV futuro. Os tempos de ciclo e esperas do processo sugerido são estimados e comparados ao estado atual para, assim, quantificar os ganhos esperados;

d) O estado futuro é colocado em prática, a partir de um plano de ação que inclui: organização da área, redistribuição das tarefas e revisão de procedimentos e formulários;

e) Definição dos indicadores para controle do novo fluxo, com vistas a sustentar os ganhos alcançados no longo prazo.

O pós-evento, terceira fase, de acordo com Chaves Filho (2010, p. 66), compreende em: "manutenção dos novos padrões, conclusão das questões técnicas e de todas as atividades pendentes do evento e aplicação das ferramentas para melhoria contínua". Avaliar a assimilação da nova prática e sua consistência exige uma coleta de dados reais, como: percentual de atendimento ao cliente, produtividade, qualidade, giros de estoque, realização do cronograma de produção e eficiência das linhas (IMAI, 2014).

\section{METODOLOGIA}

A metodologia utilizada neste artigo trata-se de uma pesquisa aplicada e descritiva, classificada como estudo de caso, pois este se caracteriza como um trabalho de caráter empírico que investiga um determinado fenômeno dentro de um contexto atual e real, por meio de uma investigação dos objetos de estudo (GIL, 2010). Quanto à abordagem do problema, é qualitativa e quantitativa. A condução do processo investigativo recorre a um conjunto de proposições teóricas e diversificadas fontes, destacando-se as técnicas para coleta de dados (PRODANOV; FREITAS, 2013).

O método de trabalho se dá pela observação direta participante, levantamento documental e entrevistas com série pré-determinada de perguntas, que devem ser respondidas por escrito pelo informante (PRODANOV; FREITAS, 2013). Nesse sentido as entrevistas foram conduzidas de forma espontânea onde o entrevistador pode tanto indagar dos respondentes-chaves os fatos relacionados a um assunto, quanto pedir a opinião deles sobre determinados eventos (YIN, 2005). Além destas técnicas, este trabalho faz uso de ferramentas descritivas, medidas de síntese, constatação causa-efeito e relação entre a bibliografia e a observação (PRODANOV; FREITAS, 2013).

\section{OBJETO DE ESTUDO}

A pesquisa tem como objeto de estudo uma empresa familiar, localizada na região do Vale do Sinos - RS, que iniciou suas atividades nos anos 1980 com a produção de concentrados de cores destinados à indústria calçadista. Ao longo dos anos, ampliou sua atuação para o segmento de plásticos injetados e aditivos. As aplicações de seus produtos são distintas, como, por exemplo: solados, embalagens, brinquedos, painéis de automóveis e cabos elétricos. Essencialmente, as matérias-primas utilizadas são pigmentos, auxiliares de processo, aditivos e polímeros. As etapas para a obtenção do produto final são: pesagem mistura e extrusão.

\subsection{PROPOSTA DE KAIZEN}

A demonstração do estado atual do processo se dá através do uptime, relação entre o tempo em atividade das máquinas e o tempo disponível em um turno de trabalho. Atualmente, o uptime médio é de 30\%. Também é atribuído ao projeto o monitoramento de indicadores secundários que, entende-se, poderão ser afetados pelo projeto. A situação destas medidas está colocada no Quadro 1. 
Quadro 1- Indicadores de desempenho do processo atual

\begin{tabular}{|c|c|c|c|c|c|c|c|}
\hline \multirow{2}{*}{} & Indicador & Mês 1 & Mês 2 & Mês 3 & Mês 4 & Mês 5 & Média \\
\cline { 2 - 8 } & Uptime & $31 \%$ & $23 \%$ & $39 \%$ & $25 \%$ & $31 \%$ & $30 \%$ \\
\cline { 2 - 7 } & $\begin{array}{c}\text { Atendimento da } \\
\text { programação }\end{array}$ & $87 \%$ & $94 \%$ & $94 \%$ & $87 \%$ & $82 \%$ & $89 \%$ \\
\cline { 2 - 7 } & Taxa de retrabalho & $24 \%$ & $14 \%$ & $16 \%$ & $24 \%$ & $38 \%$ & $23 \%$ \\
\cline { 2 - 7 } & $\begin{array}{c}\text { Materiais } \\
\text { consumidos } \\
\text { em limpeza de } \\
\text { máquina }\end{array}$ & $\begin{array}{c}0,1 \mathrm{Kg} / \\
\mathrm{Kg} \text { de } \\
\text { produto } \\
\text { acabado }\end{array}$ & $\begin{array}{c}0,091 \mathrm{Kg} / \\
\mathrm{Kg} \text { de } \\
\text { produto } \\
\text { acabado }\end{array}$ & $\begin{array}{c}0,092 \mathrm{Kg} / \\
\mathrm{Kg} \text { de } \\
\text { produto } \\
\text { acabado }\end{array}$ & $\begin{array}{c}0,045 \mathrm{Kg} / \\
\mathrm{Kg} \text { de } \\
\text { produto } \\
\text { acabado }\end{array}$ & $\begin{array}{c}0,085 \mathrm{Kg} / \\
\mathrm{Kg} \text { de } \\
\text { produto } \\
\text { acabado }\end{array}$ & $\begin{array}{c}0,083 \mathrm{Kg} / \\
\mathrm{Kg} \text { de } \\
\text { produto } \\
\text { acabado }\end{array}$ \\
\hline
\end{tabular}

Fonte: Objeto de estudo

As paradas de produção consistem de outra métrica primária. A Figura 2 ordena a frequência destas ocorrências da maior para a menor, sendo as paradas representadas em laranja e o tempo de máquina rodando/produzindo em verde.

Figura 2- Eventos de produção pré-evento kaizen
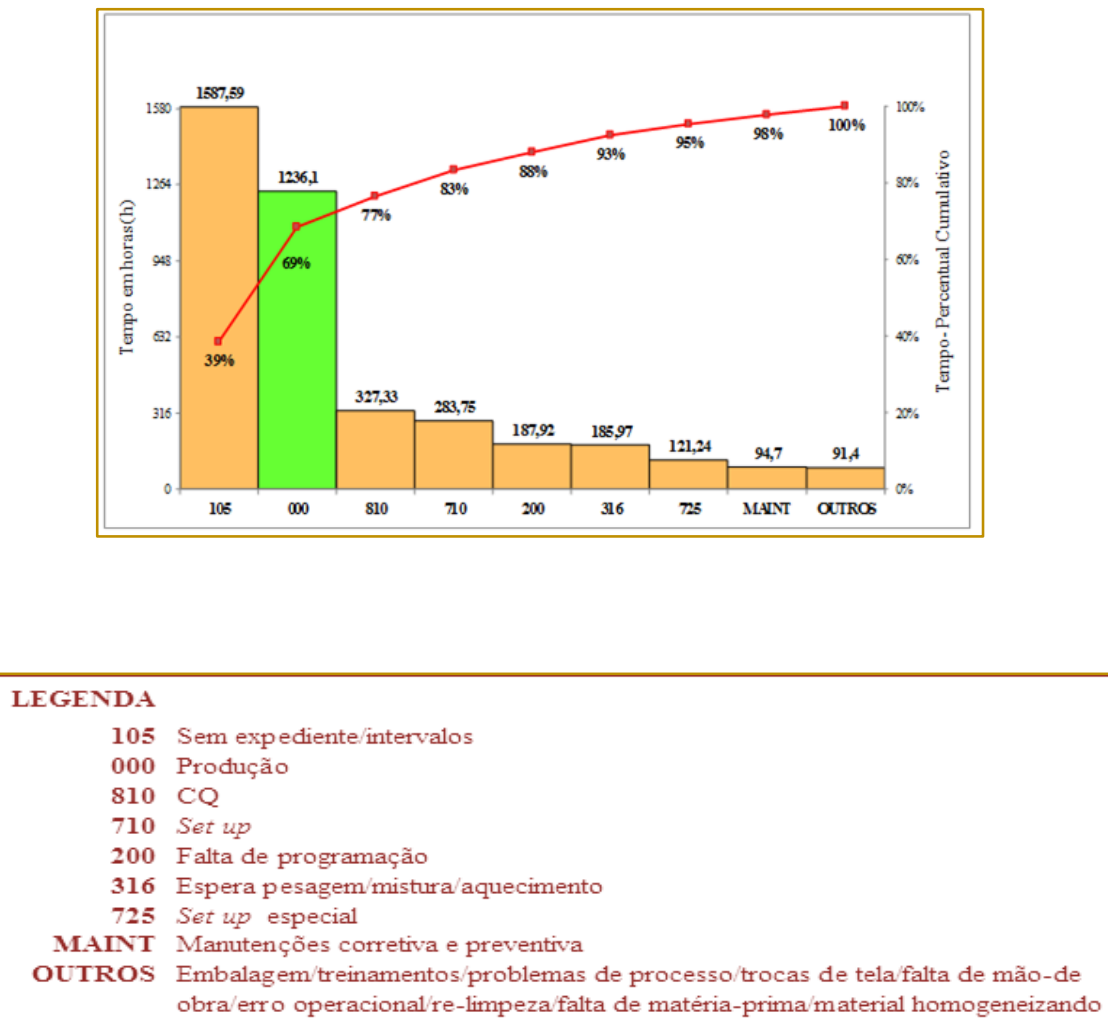

Fonte: Objeto de estudo

O kaizen proposto estabelece como objetivo melhorar em $50 \%$ o tempo de produção das linhas, alçando o uptime de $30 \%$ para $45 \%$.

\subsection{PRÉ-EVENTO KAIZEN}

O pré-evento inicia com a reunião dos componentes da equipe para apresentação do projeto e cronograma de atividades pela líder que, em seguida, ministra treinamento sobre a base da manufatura enxuta e algumas de suas ferramentas. A primeira tarefa prática trata de uma visita à produção para identificação de perdas e melhorias em organização, mensuração de tempos e coleta de informações. Desta caminhada, juntamente à base conceitual, surge à percepção 
requerida para o mapeamento do fluxo de valor, como mostra a Figura 3.

Figura 3- MFV do processo atual

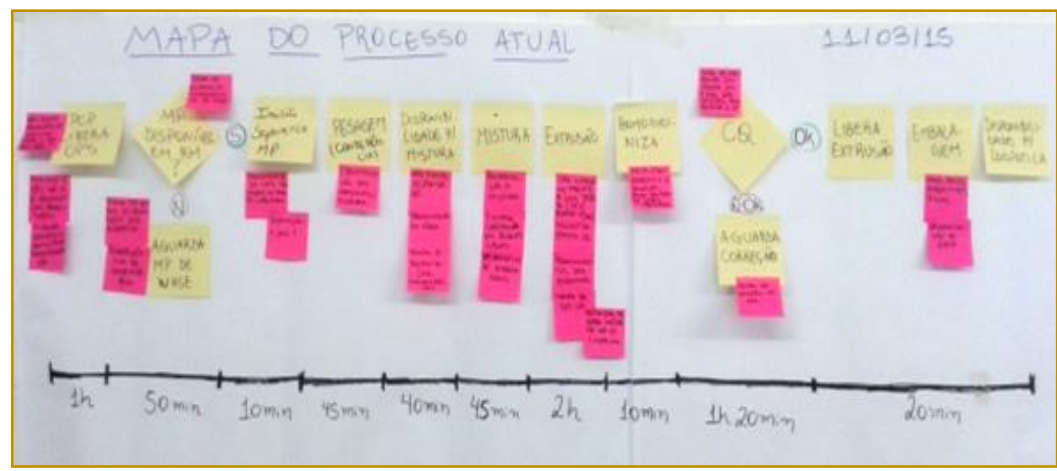

Fonte: Objeto de estudo

Validadas as métricas primária e secundárias pelo grupo, parte-se para a avaliação atenta do MFV e a discussão das causas e soluções potenciais para o baixo uptime. Posto isto, é feito o esboço do mapa futuro, registrado na Figura 4.

Figura 4- Proposta de MFV futuro

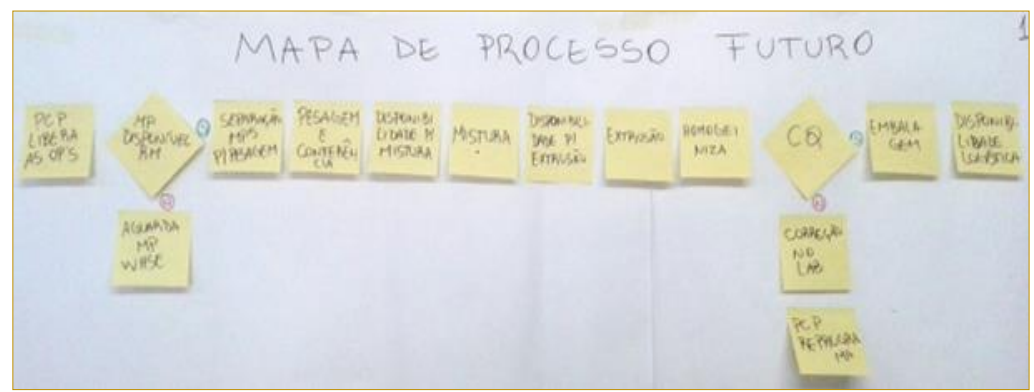

Fonte: Objeto de estudo

Como fechamento do pré-evento, a equipe determina algumas tarefas que entende serem preparatórias para a próxima fase: organizar as áreas; descartar insumos expirados e sem identificação; refazer demarcações; treinar operadores e auxiliares sobre a conferência de seu trabalho e a conservação de matérias-primas e produtos.

\subsection{EVENTO KAIZEN}

Quatro semanas após o pré-evento, ocorre o evento kaizen. Primeiramente, todas as ideias levantadas são traduzidas em ações, chegando-se a um consenso sobre:

- Gestão visual da programação diária, divulgando-a não somente à extrusão, mas também às áreas de pesagem, mistura e controle de qualidade (CQ);
- Identificação de produtos em elaboração: formulário que identifique os semi-acabados ao longo do processo;

- Revisão dos horários de trabalho dos operadores: pela manhã, um operador trinta minutos mais cedo para aquecimento dos equipamentos; intervalos de almoço intercalados, de modo que duas linhas permaneçam operando no período das 11:30 às 13:30;

- Revisão do formulário de tempos de produção: utilizado pelos operadores para anotação dos tempos de início e fim das ocorrências do processo, atualmente, há um formulário anexado por ordem de produção (OP). A equipe considera o uso de planilha única disponibilizada por máquina;

- Revisão dos códigos de eventos de linha: para preenchimento do formulário acima, os 
operadores consultam uma lista com trinta códigos que correspondem aos eventos possíveis para a linha de produção. Após avaliação, a equipe reduz a relação a um total de treze códigos;

- Mistura e extrusão não aguardam CQ: independentemente da disponibilidade de resultado do $\mathrm{CQ}$ sobre o produto em andamento, as OP's programadas devem ser misturadas e extrusadas em sequência e identificadas como produtos em elaboração até disposição.

Os dois dias seguintes do evento são dedicados à aplicação destas ações. Primeiramente, como forma de gestão visual, são aplicados os novos documentos descritos a seguir:

- Sequenciamento diário das linhas de produção, conforme Figura 5, divulgado aos setores de pesagem, mistura, CQ e extrusão.

Figura 5- Sequenciamento diário das linhas de produção

\begin{tabular}{|c|c|c|c|c|c|c|}
\hline \multirow{2}{*}{\multicolumn{2}{|c|}{$\underset{\text { SEQUÊNCIA }}{\text { Iogoti }}$}} & 0 & \multicolumn{4}{|c|}{$\begin{array}{l}\text { PROGRAMAÇÃO DE PRODUÇÃO } \\
\text { DIA: }{ }^{15}{ }^{\prime}{ }^{\prime}{ }^{04}{ }^{\prime}{ }^{\prime}{ }^{15}+\end{array}$} \\
\hline & & A2 & A3 & A4 & A7 & COMENTÁRIO \\
\hline \multirow{5}{*}{1} & CÓDIGO & XX0001275025 & XX1023367810 & XX1020555910 & & \\
\hline & COR & MARROM & CINZA & BEGE & & \\
\hline & OP & 4075264 & 4084607 & 4068189 & & \\
\hline & RESINA & $\mathrm{PE}$ & $\mathrm{PE}$ & PC & & \\
\hline & QUANTIDADE & 300 & 100 & 100 & & \\
\hline \multirow{5}{*}{2} & CÓDIGO & XX1019918910 & XX0105021610 & & & \\
\hline & COR & MARROM & CINZA & & & \\
\hline & OP & 4085015 & 4086454 & & & \\
\hline & RESINA & PE & PVC & & & \\
\hline & QUANTIDADE & 200 & 25 & & & \\
\hline
\end{tabular}

Fonte: Objeto de estudo

- Formulário de eventos de linha, disponível na Figura 6. Inclui os códigos e suas descrições, é disponibilizado pelo PCP, diariamente, em cada extrusora.

Figura 6- Formulário de eventos de linha

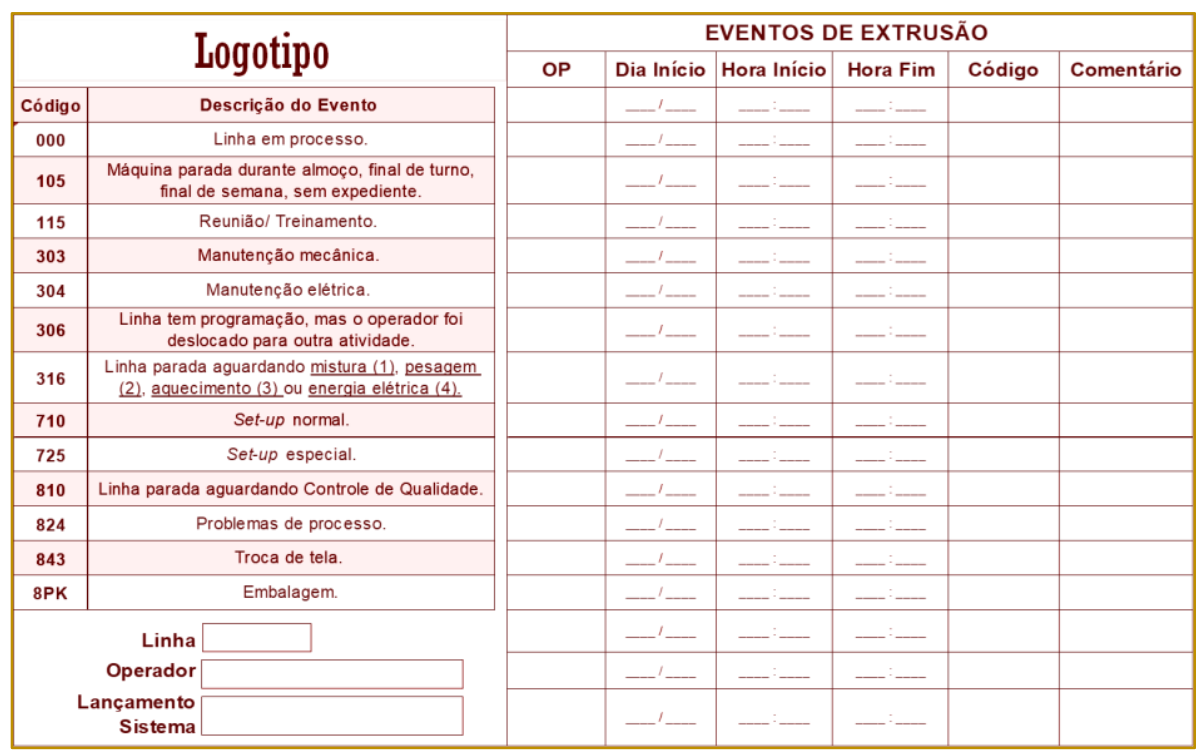

Fonte: Objeto de estudo 
- Formulário para identificação de produtos que aguardam resultado do $\mathrm{CQ}$ ou reprogramação para ajuste, conforme Figura 7.

Figura 7- Formulário para produtos em elaboração

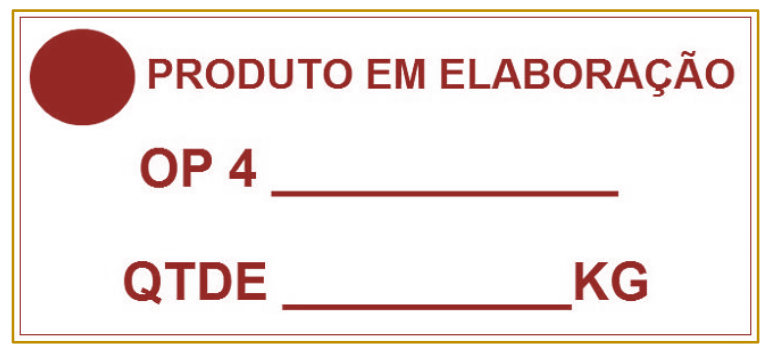

Fonte: Objeto de estudo

As demais ações também são colocadas em prática: operador às 06:30 para aquecimento dos equipamentos, sem paradas para resultado do $C Q$, pesagem e mistura antecipadas ou ocorrendo juntamente à extrusão, alternância dos horários de almoço para operação de duas linhas (simultaneamente mais de uma máquina em processo ou em preparação).

Finalizados os testes, a equipe avalia os resultados e decide manter o fluxo proposto, como mostra a Figura 8.

Figura 8- Fluxograma do novo processo

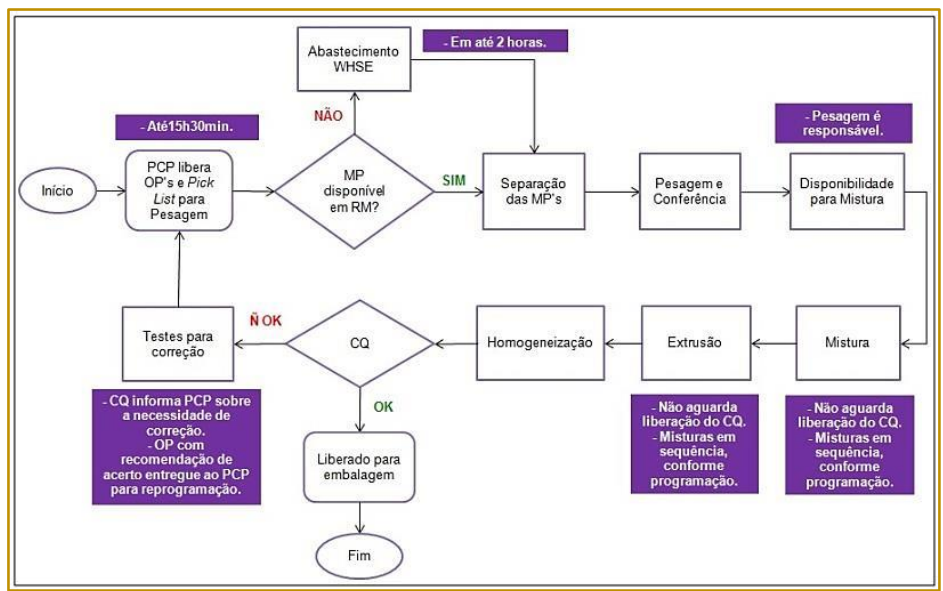

Fonte: Objeto de estudo

Como etapa final do evento, é estruturado um plano para ações futuras que, em suma, resume-se em: padronização das folhas de processo e capacitação das pessoas para que entendam suas novas responsabilidades.

\subsection{PÓS-EVENTO KAIZEN}

Com o fluxo projetado vigorando, o uptime não atinge a meta esperada de $45 \%$, considerado o acumulado do período pósevento. A mudança é pouco expressiva, dos iniciais $30 \%$ para $36 \%$.

Quanto ao percentual de atendimento à programação, os níveis mantêm-se próximos a $90 \%$, pelo fato de o novo fluxo estimular o mínimo de paradas, e, certamente, em razão de uma notável redução nas vendas. Quanto ao retrabalho, além da perda por defeito, as correções geram estoques excedentes e indesejados. Ademais, observa-se 0 superprocessamento como uma das fontes do retrabalho- a conclusão dos lotes é retardada por níveis desnecessários de detalhamento e de repetições no CQ. Por outro lado, a ausência de inspeções preventivas que evitem a repetição de uma mesma correção também figura como causa. Neste sentido, os resultados do pós-evento reforçam o status de instabilidade deste indicador. 
A última métrica monitorada é a razão entre os quilos de material de limpeza consumidos e os quilos de produtos acabados fabricados. A medida mantém-se estável e, comparada aos meses de maior consumo do contexto passado, reduzida, enxugando os custos.

A síntese dos resultados de todas as métricas no pós-evento está expressa no Quadro 2.

Quadro 2- Indicadores de desempenho do processo proposto

\begin{tabular}{|c|c|c|c|c|c|c|c|}
\hline & Indicador & Mês 1 & Mês 2 & Mês 3 & Mês 4 & Mês 5 & Média \\
\hline & Uptime & $40 \%$ & $30 \%$ & $36 \%$ & $40 \%$ & - & $36 \%$ \\
\hline$a^{2} e^{n}$ & $\begin{array}{l}\text { Atendimento da } \\
\text { programação }\end{array}$ & $90 \%$ & $88 \%$ & $95 \%$ & $88 \%$ & - & $90 \%$ \\
\hline & Taxa de retrabalho & $19 \%$ & $34 \%$ & $26 \%$ & $35 \%$ & - & $29 \%$ \\
\hline $6, e^{2}$ & $\begin{array}{c}\text { Materiais } \\
\text { consumidos } \\
\text { em limpeza de } \\
\text { máquina }\end{array}$ & $\begin{array}{l}0,062 \mathrm{Kg} / \\
\mathrm{Kg} \mathrm{de} \\
\text { produto } \\
\text { acabado }\end{array}$ & $\begin{array}{l}0,064 \mathrm{Kg} / \\
\mathrm{Kg} \mathrm{de} \\
\text { produto } \\
\text { acabado }\end{array}$ & $\begin{array}{c}0,068 \mathrm{Kg} / \\
\mathrm{Kg} \text { de } \\
\text { produto } \\
\text { acabado }\end{array}$ & $\begin{array}{l}0,07 \mathrm{Kg} / \\
\mathrm{Kg} \text { de } \\
\text { produto } \\
\text { acabado }\end{array}$ & - & $\begin{array}{l}0,066 \mathrm{Kg} / \\
\mathrm{Kg} \text { de } \\
\text { produto } \\
\text { acabado }\end{array}$ \\
\hline
\end{tabular}

Fonte: Objeto de estudo

Em comparação com o estado anterior, a fim de identificar a interferência do kaizen sobre as alterações graficamente visíveis na Figura 9, a análise das ocorrências de produção pós-evento norteia as seguintes constatações:

- O código 000 (produção ou uptime) passa a figurar como item mais frequente;

- Os tempos de espera em processo (316) mantêm-se em patamares similares à situação passada;

- O CQ (810), até então principal motivo para as paradas de máquina, sofre queda considerável, da terceira para a sexta colocação, em virtude de o novo fluxo não prever o aguardo por resultados de inspeções para prosseguimento da programação;

- Elevação do 200 (falta de pedidos) e agregação do 105 (intervalos e turnos sem expediente) às incidências menores, em consequência da adequação do uso destes códigos durante o kaizen, revelada a falta de clareza para sua correta aplicação e a generalização pelo emprego do 105 em situações às quais, de fato, não é aplicável.

Figura 9- Eventos de produção pós-evento kaizen

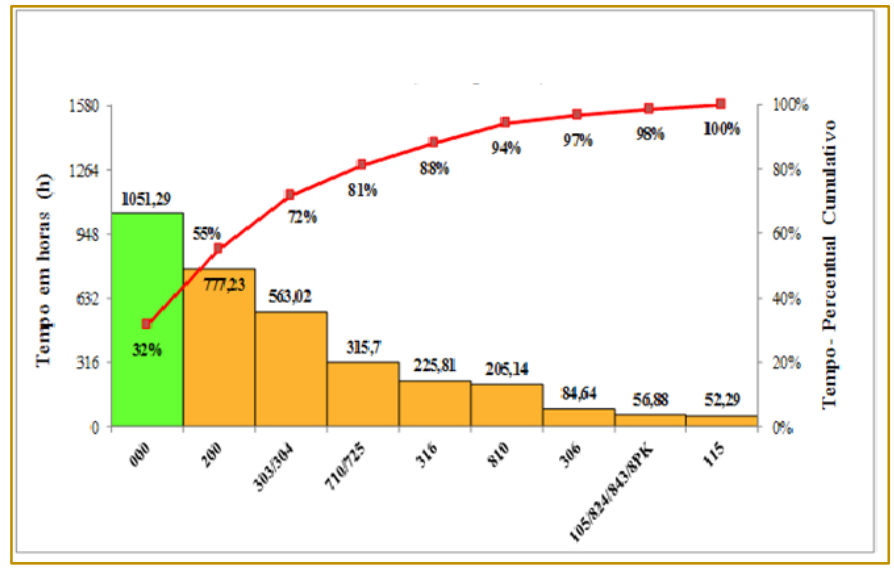




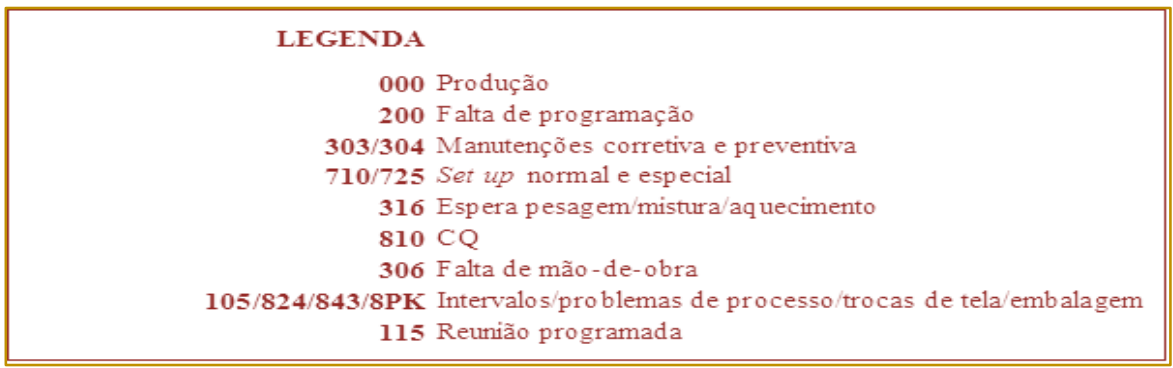

Fonte: Objeto de estudo

São pontos a destacar deste projeto a elucidação das dúvidas referentes aos códigos de eventos de linha e a simplificação de seu preenchimento, ações que contribuem para a composição de uma base fidedigna de dados. Ademais, com o advento da planilha única, por recurso, os registros ocorrem em sequência, evitando lacunas de tempo.

A divulgação da programação diária a todas as áreas envolvidas com a execução da produção deixa explícito e compreensível o sequenciamento das linhas. Atualizada, estabelece o fluxo de comunicação entre PCP e fábrica.

Neste sentido, por sua vez, a identificação de produtos em elaboração foi assimilada de modo a estender seu uso como forma de reconhecimento além da OP. Em suma, tem sido utilizada em situações de aguardo por uma próxima etapa.

Além disso, o fluxo proposto estabelece para PCP e armazém, dois fornecedores internos da extrusão, limites para a conclusão de suas atividades.

Por fim, espera-se da planta a produção mínima de 35 toneladas/ mês, logo, uma avaliação pertinente é a da produtividade: divisão das unidades produzidas pelo número de horas trabalhadas. A Tabela 1 apresenta o volume mensal produzido no estado inicial do processo, bem como o total de tempo disponível. Visíveis são, portanto, a produção abaixo do nível pretendido e uma vasta ociosidade das máquinas que, em um mês regular, atingiriam uma produtividade de, em torno, $45 \mathrm{Kg} / \mathrm{hora}$.

Tabela 1- Kg/hora produzidos Ago-Dez/2014

\begin{tabular}{|c|c|c|c|}
\hline Mês & Produção (Kg) & Totalde horas & $\begin{array}{c}\text { Produtividade } \\
\text { (Kg/hora) }\end{array}$ \\
\hline Ago/14 & 25919,60 & 823,20 & 31,49 \\
Set/14 & 21002,00 & 862,40 & 24,35 \\
Out14 & 29802,90 & 901,60 & 33,06 \\
Nov/14 & 16315,80 & 784,00 & 20,81 \\
Dez/14 & 20227,28 & 744,80 & 27,16 \\
\hline \hline
\end{tabular}

Fonte: Objeto de estudo

A tendência de queda das demandas em 2015 é evidenciada na Tabela 2, já no pósevento. Devido às mudanças promovidas pelo projeto, no sentido de tornar os apontamentos mais precisos, é possível visualizar as paradas por falta de pedidos (código 200) e sua influência sobre o cálculo da produtividade. Desconsiderado este tempo, torna-se admissível firmar a capacidade da planta em galgar uma produtividade próxima ao mínimo projetado, como ilustra a última coluna dos meses de julho e agosto a seguir. 
Tabela 2- Kg/hora produzidos Mai-Ago/2015

\begin{tabular}{|ccccccc|}
\hline Mês & $\begin{array}{c}\text { Produção } \\
\text { (Kg) }\end{array}$ & $\begin{array}{c}\text { Total de } \\
\text { horas }\end{array}$ & $\begin{array}{c}\text { Produtividade } \\
\text { (Kg/hora) }\end{array}$ & $\begin{array}{c}\text { Código 200 } \\
\text { (h) }\end{array}$ & $\begin{array}{c}\text { Total de } \\
\text { horas } \\
\text { sem 200 }\end{array}$ & $\begin{array}{c}\text { Produtividade } \\
\text { sem 200 } \\
\text { (Kg/hora) }\end{array}$ \\
\hline Mai 15 & 17261,80 & 744,80 & 23,18 & 63,21 & 681,59 & 25,33 \\
Jun115 & 19866,60 & 862,40 & 23,04 & 293,28 & 569,12 & 34,91 \\
Jul115 & 21856,10 & 676,20 & 32,32 & 217,83 & 458,37 & 47,68 \\
Ago/15 & 18591,05 & 617,40 & 30,11 & 202,91 & 414,49 & 44,85 \\
\hline \hline
\end{tabular}

Fonte: Objeto de estudo

Com efeito, a capacidade produtiva não é preenchida pelo volume de vendas, além de haver uma tendência de mercado por quantidades menores de uma maior variedade de cores, condições que afetam substancialmente o sequenciamento e a viabilidade do fluxo proposto: em momentos de baixa, os lotes acabam por aguardar os resultados de $C Q$ devido à falta de um próximo item a produzir ou à complexidade do set up envolvido.

\section{CONSIDERAÇÕES FINAIS}

Este artigo tem como objetivo geral avaliar a aplicação da metodologia kaizen e seu impacto sobre os resultados de produtividade e qualidade na área de produção em uma empresa de manufatura na região do Vale do Sinos - RS. Como conclusões, percebe-se que o método promovido pela empresa difere ao da literatura, sobretudo no que se refere à distribuição das atividades ao longo das fases, de maneira que o evento se concentre na experimentação e na validação das mudanças. As três fases do projeto são compreendidas, respectivamente, como: preparação, execução e consolidação dos resultados.

A meta projetada de incremento em $50 \%$ do uptime não foi atingida, os indicadores monitorados não apresentam alteração

\section{REFERÊNCIAS}

[1] Barboza, Fabio Gonzales. Melhoria de processo produtivo pela aplicação de conceitos lean: um estudo de caso. São Carlos: USP, 2011. Disponível em: <http://www.tcc.sc.usp.br/tce/disponiveis/18/18083 0/tce-01032012-160603/?\&lang=br>. Acesso em: 31 ago. 2015.

[2] Chaves Filho, José Geraldo Batista. Melhores práticas para garantia de sustentabilidade de melhorias obtidas através de positiva significante, todavia, não há indícios de que o kaizen os tenha influenciado negativamente. Os ganhos, sobremaneira, constituem de avanços em padronização da área, no acesso visual às informações, no controle dos tempos de produção para diagnóstico de seus pontos críticos e na redução das esperas.

Para uma resposta com alto grau de aceitabilidade quanto às mudanças promovidas, faz-se necessário atacar variáveis que interferem diretamente no novo fluxo proposto, como o alto índice de retrabalho e a queda das demandas que inviabilizam um planejamento de produção efetivo. Os benefícios constatados demonstram como o método interfere sobre a produtividade e a qualidade dos processos produtivos.

De fato, o evento kaizen, no objeto de estudo, configura-se como uma quebra na resistência para o amadurecimento da prática. Como sugestões para trabalhos futuros, sugere-se considerar treinamentos dinâmicos, com práticas de experimentação para maior assimilação, além de uma comunicação regular, de maneira a permitir a discussão de novas oportunidades de melhorias, bem como a análise de novos eventos para fins comparativos e de mensuração da melhoria contínua no processo.

eventos kaizen. 2010. 149 f. Dissertação de Mestrado- Programa de Pós-Graduação em Engenharia de Produção, Escola de Engenharia de São Carlos, Universidade de São Paulo, São Carlos, 2010. Disponível em: <http://www.teses.usp.br/teses/disponiveis/18/1815 6/tde-07022011-150332/pt-br.php>. Acesso em: 01 jun. 2015.

[3] Gallas, Cristiano André; de Lima Nunes, Fabiano. Redução de perdas a partir de uma proposta de alteração de layout em uma empresa prestadora de serviços: Um estudo de 
caso. Revista ESPACIOSI Vol. 37 (№ 11) Año 2016 , 2016.

[4] Gil, Antonio Carlos. Como Elaborar Projetos de Pesquisa. 5a ed. São Paulo: Atlas, 2010.

[5] Imai, Masaaki. Gemba Kaizen: uma abordagem de bom senso à estratégia de melhoria contínua. Porto Alegre: Bookman, 2014.

[6] Liker, Jeffrey K. O Modelo Toyota: 14 princípios de gestão do maior fabricante do mundo. Porto Alegre: Bookman, 2005.

[7] Marksberry, Phillip et al. Management directed kaizen: Toyota's Jishuken process for management development. Journal of Manufacturing Technology Management, v. 21, n. 6, p. 670-686, 2010.

[8] Nunes, Fabiano de Lima; MENEZES, Felipe Morais. SISTEMA HYUNDAI DE PRODUÇÃO E SISTEMA TOYOTA DE PRODUÇÃO: SUAS INTERAÇÕES E DIFERENÇAS. Revista Acadêmica São Marcos, v. 4, n. 2, p. 101-120, 2015.

[9] Nunes, Fabiano; Vaccaro, Guilherme Luís Roehe; ANTUNES JÚNIOR, José Antônio Valle. The development of the Hyundai Production System: The historical evolution. Journal of Manufacturing Systems, v. 43, p. 47-57, 2017.

[10] Ohno, Taiichi. O Sistema Toyota de Produção: além da produção em larga escala. Porto Alegre: Bookman, 1997.
[11] Ortiz, Chris A. Kaizen e implementação de eventos kaizen. Porto Alegre: Bookman, 2010.

[12] Prodanov, Cleber Cristiano; Freitas, Ernani Cesar de. Metodologia do Trabalho Científico: Métodos e Técnicas da Pesquisa e do Trabalho Acadêmico. 2. ed. Novo Hamburgo: Feevale, 2013. Disponível em:

https://www.feevale.br/cultura/editora-

feevale/metodologia-do-trabalho-cientifico---2edicao>. Acesso em: 20 out. 2015.

[13] Rossitti, Beatriz Souza. Melhoria de processo por meio do Lean Project Management. São Carlos: USP, 2014. Disponível em: <http://www.tcc.sc.usp.br/tce/disponiveis/18/18083 0/tce-09012015-151001/ >. Acesso em: 24 out. 2015.

[14] Rother, Mike; Shook, John. Learning to see: value stream mapping to add value and eliminate muda. Lean Enterprise Institute, 2003.

[15] Singh, Jagdeep; SINGH, Harwinder. Kaizen philosophy: a review of literature. IUP Journal of Operations Management, v. 8, n. 2, p. 51, 2009.

[16] Shingo, Shigeo. O Sistema Toyota de Produção do ponto de vista da Engenharia de Produção. 2. ed. Porto Alegre: Bookman, 1996.

[17] Yin, Robert K. Estudo de caso planejamento e métodos. 3 ed. São Paulo: Bookman, 2005. 


\section{Gapítulo 16}

\section{MELHORIA DA PRODUTIVIDADE COM A REDUCÃO DO TEMPO DE SETUP EM UMA MÁQUINA FLEXOGRÁFICA DE UMA EMPRESA DE EMBALAGENS INDUSTRIAIS}

\section{Eduardo Oliveira Paes}

Hendrick Brian Rodrigues

Jeane Aparecida Castro

Mariane Merchiori

Resumo: O presente estudo de caso tem por objetivo diminuir o tempo de Setup de equipamentos de flexografia em uma empresa de médio porte fabricante de embalagens industriais, localizada no Paraná. O desenvolvimento desse trabalho foi constituído em 3 estágios: O primeiro estágio consistiu da realização de medição de tempo das regulagens das máquinas, tendo em vista que não existia dados relevantes para o desenvolvimento do projeto. Em seguida foram realizadas pesquisas bibliográficas, tendo como referência o Lean Thinking, estando dessa forma de acordo com a abordagem do trabalho. Na sequência, foi realizado um brainstorm com os funcionários do setor, a fim de obter informações relevantes e sugestões para otimização do tempo. Seguindo essa ordem constatou-se que seria possível a redução do tempo de Setup em praticamente 25\%. Através dessa melhoria haverá redução de gargalo, diminuindo atrasos na entrega de produtos, e por consequência, elevando o nível competitivo da empresa, mostrando dessa forma a importância de se adotar uma mentalidade enxuta nos processos produtivos.

Palavras-Chave: Setup; Flexografia; Melhoria; Produtividade. 


\section{INTRODUÇÃO}

A crescente competição do mercado nos dias atuais origina a necessidade contínua do aperfeiçoamento nos processos produtivos, gerada pelo estudo da produção, a fim de reduzir custos e aumentar sua produtividade. Uma das abordagens mais eficientes para cumprir tais metas é o Lean Manufacturing, ou seja, o conceito da manufatura enxuta. Para SELEME (2009) o "Lean" é uma estratégia de negócios para aumentar a satisfação dos clientes através da melhor utilização dos recursos. Aplicando os conceitos da produção enxuta, é possível definir os sete desperdícios encontrados no processo produtivo. RODRIGUES (2014) cita o foco permanente do Pensamento Lean como suporte principal a eliminação de mudas (desperdícios) em todas as etapas e em todos os níveis do processo produtivo por meio da otimização ou de mudanças das ações que as geram. Um dos desperdícios citados por RODRIGUES é o de espera ou de tempo disponível - períodos de ociosidade de pessoas, peças e informações. Diante disso, nota-se o desperdício de tempo gerado em processos de Setup (regulagem de máquina), onde longos ajustes podem interromper a produção, causando gargalos no processo produtivo. Porém, é possível a redução do tempo de Setup utilizando-se de várias metodologias, entre elas o SMED (Single Minute Exchange of Die). O SMED foi uma metodologia desenvolvida pelo então engenheiro da Toyota Shingeo Shingo entre os anos de 1950 e 1960, devido a constantes desperdícios de tempo na linha de produção. Shingo (2005) afirma que o primeiro passo para a aplicação do SMED, consiste na separação das atividades em Setup Interno e Setup Externo. Sendo possível assim uma visão holística do processo em si. O SMED ainda engloba outras 7 importantes técnicas para a redução de Setup, que foram abordadas nesse estudo de caso. O presente artigo visa analisar os tempos de Setup no setor de flexografia em uma fábrica de médio porte que fabrica embalagens industriais. Após a análise e estudos sobre o processo foi possível identificar significativos pontos de melhorias, que poderão reduzir consideravelmente o tempo de troca de ferramentas em questão, gerando aumento da produtividade e do faturamento da empresa.

\section{FUNDAMENTAÇÃO TEÓRICA}

\subsection{O QUE É REDUÇÃO DE SETUP?}

Segundo Cristina (2012), a redução de setup é a redução do tempo necessário para a troca da fabricação de um tipo de produto para outro. O método também é conhecido pela sigla SMED (Single Minute Exchange of Die), que se refere ao objetivo de redução dos tempos de troca para menos de 10 minutos, ou seja, para um único dígito. O método foi criado nas décadas de 1950 e 1960, por Shigeo Shingo, consultor da Toyota, que separou os procedimentos de setup nas duas categorias abaixo: Procedimentos Internos somente podem ser realizados quando a operação do equipamento é interrompida, tais como a fixação e a remoção de matrizes; Procedimentos externos - Podem ser executados quando o equipamento está em atividade, tais como o transporte de matrizes da estocagem à montagem e a procura de ferramentas.

\subsection{AS OITO TÉCNICAS PARA A REDUÇÃO DE SETUP}

Em 1970, enquanto Shingo (2005) dava sugestões para o gerente de sessão de carrocerias da Toyota para a redução de tempo de setup de uma prensa de 1.000 toneladas, ele criou 8 técnicas para a redução de tempo de setup. São elas:

- Técnica 1 - Separação das atividades de setup interno e externo: Identifique claramente quais operações atuais devem ser executadas enquanto a máquina está parada ( setup Interno) e quais podem ser realizadas com a máquina funcionando (setup Externo). Por exemplo, toda a preparação e transportes de matrizes, gabaritos e dispositivos de fixação, ferramentas e materiais podem ser feitos durante o funcionamento da máquina. setup interno deve estar limitado a remoção da matriz ou ferramenta anterior e fixação da nova (SHINGO, 2005 p.82);

- Técnica 2 - Converter setup interno em setup externo: Este é o princípio mais poderoso da TRF (Troca rápida de ferramentas). Sem ele não poderiam ser atingidos os tempos de setup inferiores a 10 minutos. Fazer essa conversão envolve o reexame das operações para verificar se qualquer das etapas foi equivocadamente tomada como interna e encontrar maneiras de 
converter estes setups internos em externos (SHINGO,2005, p.82);

- Técnica 3 - Padronizar a função, não a forma: A padronização da forma e do tamanho das matrizes pode reduzir os tempos de setup consideravelmente. A padronização da forma, porém é uma perda, porque todas as matrizes teriam de adequar-se ao maior tamanho utilizado, o que aumentaria os custos desnecessariamente. A padronização da função, por outro lado, requer apenas a uniformidade nas peças necessárias à operação de setup. Por exemplo, acrescentar uma placa ou bloco à borda de fixação da matriz padroniza as dimensões somente daquela peça e faz com que seja possível utilizar os mesmos grampos em setups diferentes. (SHINGO 2005, pg.82);

- Técnica 4 - Utilizar grampos funcionais ou eliminar grampos: Shingo (2005) fala sobre a eficiência de fixadores. Ele explica que, embora o parafuso seja o mecanismo de fixação mais comum, ele não é eficiente ao passo que demanda muito mais movimento do que é realmente necessário para se fixar algo. Em um parafuso, somente a última rosca é a que realmente fixa enquanto os demais são um desperdício. Do mesmo modo, somente a primeira rosca é que liberta o objeto, enquanto as demais são um desperdício de movimento. Para ser eficiente o parafuso deveria ser um fixador de um único giro;

- Técnica 5 - Usar dispositivos intermediários: Nesta técnica Shingo (2005) fala sobre como reduzir os tempos gastos com a fase de acerto do setup: "enquanto a peça presa a um dispositivo está sendo processada, a próxima é presa em um outro". Deste modo, na hora do setup é possivel trocar somente os dispositivos, com as peças presas nele, ao invés de trocar as peças e ter de fixa-las e fazer todos os ajustes com a máquina parada. Para instalar os dispositivos de forma rápida e fácil, usam-se os grampos;

- Técnica 6 - Adotar operações paralelas: Shingo (2005) menciona sobre os Setups que envolvem operações em diferentes partes de uma máquina, envolvendo invariavelmente, trabalho de setup nas duas laterais ou nas partes frontal e posterior. Se apenas um operário executar essas operações, muito tempo e movimento são desperdiçados com o seu deslocamento em torno da máquina. Mas quando duas pessoas realizam as operações paralelas simultaneamente, o tempo de setup é geralmente reduzido em mais de 50\%, devido a economia de movimentos. Uma operação, por exemplo, que leva 30 minutos para ser executada por um trabalhador pode levar apenas 10 minutos com dois (SHINGO, 2005);

- Técnica 7- Eliminar ajustes: Tipicamente, ajustes e testes piloto são responsáveis por 50 a $70 \%$ do setup interno. A eliminação destes tempos traz formidáveis economias de tempo. Os ajustes podem ser eliminados, se um padrão for empregado para determinar com precisão a posição correta do interruptor de fim de curso. Por conseguinte, a preparação será a única operação necessária (SHINGO, 2005);

- Técnica 8- Mecanização: A mecanização deve ser considerada somente após haver sido feito todo o esforço possível para melhorar os setups utilizando as técnicas descritas. Os 7 primeiros princípios podem reduzir em um setup de 2 horas para 3 minutos e a mecanização irá reduzir esse tempo em apenas 1 minuto.

A TRF é uma abordagem analítica para a melhoria do setup da qual a mecanização é apenas um componente. Empreender tal melhoria com a mecanização pode reduzir o tempo de Setup em um primeiro momento, mas não irá remediar as ineficiências básicas de um processo de setup mal planejado. É muito melhor mecanizar setups após sua total linearização com a aplicação dos princípios da TRF (SHINGO, 2005).

\subsection{CRONOANÁLISE}

O estudo de tempos, também conhecido como cronoanálise, é uma forma de mensurar o trabalho por meio de métodos estatísticos, permitindo calcular o tempo padrão que é utilizado para determinar a capacidade produtiva da empresa, elaborar programas de produção e determinar o valor da mão-deobra direta no cálculo do custo do produto vendido, dentre outras aplicações. (PEINADO E GRAEM, 2007).

Segundo SELEME (2009), as organizações que mantém um registro de seus métodos e tempos de produção obtêm um diferencial estratégico, pois assim é possível conhecer exatamente qual é a sua capacidade de produção. Além disso, o estudo de tempos tem diversas utilidades para a organização, o que caracteriza a sua importância. 
Os primeiros indícios de tentativa de estudar e organizar este método de trabalho ocorreram em 1760 por Perronet, mas a primeira grande contribuição ocorreu em 1900 por Frederick Taylor que produziu experiências para 0 estudo de tempos e, a partir delas, projetou os melhores métodos para a realização de tarefas, estabelecendo analiticamente os métodos de trabalho. Os métodos de Taylor visavam o aumento da produtividade do trabalho e consideravam o estímulo humano, idealizando uma forma de premiação por produtividade chamada de sistema de tarifas diferenciadas, na qual o funcionário que produzisse mais ganharia mais (SELEME, 2009).

PEINADO E GRAEM (2007) citam que para a realização da cronoanálise é necessário que se façam várias tomadas de tempo obtendo uma média aritmética destes tempos. O número de ciclos a serem cronometrados $(\mathrm{N})$ é determinado através de um cálculo, dado na fórmula abaixo.

$$
\mathrm{N}=\left(\frac{Z * R}{E r * d_{2} * \bar{x}}\right)^{2}
$$

Onde:

$\mathrm{N}=$ número de ciclos a serem cronometrados

$Z$ = coeficiente de distribuição normal para uma probabilidade determinada

$\mathrm{R}=$ amplitude da amostra

$\mathrm{Er}=$ Erro relativo da medida

$d_{2}=$ coeficiente em função do número de cronometragens realizadas preliminarmente $\bar{x}=$ média dos valores das observações

Os valores para Z (coeficiente de distribuição normal para uma probabilidade determinada) e D2 (coeficiente em função do número de cronometragens realizadas preliminarmente) são dados na figura 1 e 2 , respectivamente.

Figura 1 - Valores para Z (coeficiente de distribuição normal para uma probabilidade determinada)

\begin{tabular}{c|c|c|c|c|c|c|c|c|c|c}
\hline Probabilidade & $90 \%$ & $91 \%$ & $92 \%$ & $93 \%$ & $94 \%$ & $95 \%$ & $96 \%$ & $97 \%$ & $98 \%$ & $99 \%$ \\
\hline Z & 1,65 & 1,70 & 1,75 & 1,81 & 1,88 & 1,96 & 2,05 & 2,17 & 2,33 & 2,58 \\
\hline
\end{tabular}

Fonte: PEINARDO E GRAEM, 2007, p. 98

Figura 2 - Valores para D2 (coeficiente em função do número de cronometragens realizadas preliminarmente)

\begin{tabular}{|c|c|c|c|c|c|c|c|c|c|}
\hline \hline $\mathrm{N}$ & 2 & 3 & 4 & 5 & 6 & 7 & 8 & 9 & 10 \\
\hline $\mathrm{Z}$ & 1,128 & 1,693 & 2,059 & 2,326 & 2,534 & 2,704 & 2,847 & 2,970 & 3,078 \\
\hline
\end{tabular}

Fonte: PEINARDO E GRAEM, 2007, p. 98

SELEME (2009) evidencia o erro relativo (Er) como a precisão nas leituras e medidas realizadas. Normalmente o erro relativo é considerado entre $5 \%$ e $10 \%$.

Para PEINADO E GRAEM (2007) o estudo de tempos, movimentos e métodos mantém estreito vínculo com três importantes definições do vocabulário empresarial: A engenharia de métodos, projeto de trabalho e ergonomia. $\mathrm{Na}$ engenharia de métodos preocupa-se em estabelecer o método de trabalho mais eficiente, ou seja, procura otimizar o local de trabalho com relação a ajuste de máquinas, manuseio e movimentação de materiais, leiaute, ferramentas e dispositivos específicos, medição de tempos e racionalização de movimentos. 


\section{CARACTERIZAÇÃO DA EMPRESA} PESQUISADA

O estudo foi realizado em uma empresa de médio porte de embalagens industriais, a qual fabrica sacarias, tecidos, lonas e big bags e possui uma linha completa de produção de ráfia.
O setor analisado foi a flexografia, local onde é feita a impressão rápida na sacaria de marcas ou mensagens definidas pelo cliente. O processo de produção desde a fase inicial até se tornar sacaria é apresentado na figura 3.

Figura 3 - Etapas do processo produtivo da sacaria de ráfia

\begin{tabular}{|l|l|}
\hline \multicolumn{1}{|c|}{ ETAPAS } & \multicolumn{1}{c|}{ DECRIÇÃO } \\
\hline 1. Setor de extrusão & $\begin{array}{l}\text { Inicio do processo produtivo, transformação } \\
\text { do polipropileno e do polietileno em fitas de } \\
\text { ráfia. }\end{array}$ \\
\hline 2. Tecelagem circular & $\begin{array}{l}\text { As fitas de ráfia são introduzidas no tear } \\
\text { circular e são trançadas para garantir a } \\
\text { re sistência máxima, formando um extenso } \\
\text { tecido tubular que será utilizado na } \\
\text { produção de sacos. }\end{array}$ \\
\hline 3. Laminadora & $\begin{array}{l}\text { O tecido rec ebe uma camada extra de } \\
\text { polipropileno e polietileno tornando-se } \\
\text { impermeáveis. }\end{array}$ \\
\hline 4. Flexografia & $\begin{array}{l}\text { O tecido rec ebe a impressão de sejada e o } \\
\text { processo termina com o tratamento corona } \\
\text { que oferece melhor aderência ao que foi } \\
\text { impresso }\end{array}$ \\
\hline 5. Acabamento & $\begin{array}{l}\text { O tecido com a marca impressa e já laminado, } \\
\text { é cortado e passa por um proce sso de fusão } \\
\text { para gerar os sacos de ráfía }\end{array}$ \\
\hline
\end{tabular}

Fonte: Informações coletadas na empresa analisada

O PCP (planejamento e controle da produção) envia a OP (ordem de produção) para o setor de artes, onde a arte impressa na sacaria será analisada, e se aprovada, a OP segue para o setor de flexografia para então ser realizada a mistura da tinta conforme o pedido e ser ajustado em máquina. Nesse momento a máquina é ajustada conforme as especificações da OP, colocado os cilindros, tintas, o tecido, engrenagens, ajustando a pressão e realizando a limpeza dos componentes e do maquinário.

\section{METODOLOGIA DA PESQUISA}

\subsection{TIPO DE PESQUISA}

O método de trabalho seguido nessa atividade teve os seguintes estágios: Cronoanálise da regulagem de máquina, visto que a empresa analisada não obtinha esses dados relevantes para o desenvolvimento do trabalho. A cronoanálise foi realizada no período do dia 1 a 23 de dezembro de 2016, foram cronometrados todos os tipos de regulagem, os quais diferem de pedido para pedido, obtendo os parâmetros para a maioria deles. As medições de tempo permitiram o cálculo do tempo observado (TO) da operação. Esse tempo observado estima quanto tempo o trabalhador que participou do estudo leva em média para executar cada elemento. Após, foi realizada pesquisa bibliográfica do assunto de setup em flexografia e brainstorm com os funcionários e supervisora do setor, a fim de entender as maiores dificuldades no setup.

Outro estágio foi a discussão entre os membros da equipe e a pesquisa das formas de redução de setup na flexografia, de modo que não obtivessem um elevado custo para a empresa e fossem de rápida aplicação.

\subsection{MATERIAIS E MÉTODOS}

A empresa em questão possui o setor de flexografia, o mesmo conta com 4 máquinas produtivas, das 4, uma delas foi adquirida recentemente e contém tecnologia de ponta, as outras 3 são máquinas mais antigas, porém, possuem uma boa produtividade, dessas 3, a flexográfica que tem uma produção maior é a Colorflex e tem um setup 
maior comparado a outras, pois ela possui capacidade para até 6 tipos de cores para impressão, motivo que demanda mais tempo para a regulagem e limpeza da máquina. Sendo assim, essa foi a máquina escolhida para estudo de redução do setup.

Nos 23 dias foram coletados os dados para os diferentes tipos de regulagem, os quais se diferenciam na quantidade de cilindros, tinta, faca e clichê, basicamente. A figura 4 apresenta esses valores médios, com o tempo estimado para cada tipo de regulagem.
Sendo a regulagem de máquina todos os outros fatores não citados nos itens do quadro, como pequenos ajustes. A troca de cilindro, do contra, de tintas e do clichê, variam de acordo com o pedido do cliente. A limpeza de facas refere-se a retirada do conjunto de facas (doctor blade) de máquina e limpeza do mesmo. A limpeza das bombas diz respeito as bombas que abastecem a flexografia com a tinta, sendo que a cada regulagem é realizada a limpeza desse conjunto.

Figura 4 - Valores médios para etapas de regulagem de máquina

\begin{tabular}{|l|c|}
\hline \multicolumn{1}{|c|}{ Evento } & $\begin{array}{c}\text { Valor médio de } \\
\text { regulagem (min) }\end{array}$ \\
\hline REGULAGEM DE MÁQUINA & 2050 \\
\hline TROCA DE 1 CIIINDRO & 140 \\
\hline TROCA DE 2 CIIINDRO & 190 \\
\hline TROCA DE 3 CIIINDRO & 340 \\
\hline TROCA DE 4 CIIINDRO & 430 \\
\hline TROCA DE 5 CIIINDRO & 540 \\
\hline TROCA DE 6 CIIINDRO & 720 \\
\hline TROCA DE CONTRA (VERSO) & 305 \\
\hline TROCA DE 1 TINTA & 30 \\
\hline TROCA DE 3 TINTAS & 45 \\
\hline TROCA DE 4 TINTAS & 80 \\
\hline TROCA DE 5 TINTAS & 95 \\
\hline TROCA DE 6 TINTAS & 115 \\
\hline LIMPEZA DE FACAS & 740 \\
\hline TROCA DE 1 CLICHÊ & 60 \\
\hline TROCA DE 3 CLICHÊS & 120 \\
\hline TROCA DE 4 CLICHÊS & 170 \\
\hline TROCA DE 5 CLICHÊS & 260 \\
\hline TROCA DE 6 CLICHÊS & 275 \\
\hline LIMPEZA DAS BOMBAS & 1516 \\
\hline TOTAL & 8221 \\
\hline
\end{tabular}

Fonte: Dados obtidos através da cronoanálise

Através dessas informações, foi consultado o tempo total de trabalho durante os 23 dias, e com esse valor, foi estipulado o tempo total, em percentual, que a flexografia estudada ficou parada somente para regulagem de máquina, desconsiderando outros fatores de setup, conforme apresentam as figuras 5 e 6 .

Figura 5: Setup para regulagem no píodo de 1 a 23/12

\begin{tabular}{|ccc|}
\hline $\begin{array}{c}\text { Total trabalhado } \\
(\mathrm{min})\end{array}$ & $\begin{array}{c}\text { Total de setup } \\
\text { para regulagem } \\
(\mathrm{min})\end{array}$ & Percentual \\
\hline 24020 & 8221 & $34,2 \%$ \\
\hline
\end{tabular}

Fonte: Dados obtidos através da cronoanálise 
Figura 6 - Setup para regulagem por dia

\begin{tabular}{|lccc|}
\hline $\begin{array}{c}\text { Total trabalhado por } \\
\text { dia }\end{array}$ & $\begin{array}{c}\text { Total de setup para } \\
\text { regulagem por dia }\end{array}$ & Percentual \\
\cline { 1 - 3 } Minutos & 1044 & 357 & \multirow{3}{*}{$34,2 \%$} \\
\hline Horas & 17,4 & 5,95 & \\
\hline
\end{tabular}

Fonte: Dados obtidos através da cronoanálise

\section{RESULTADOS E DISCUSSÕES}

De acordo com os dados coletados, verificouse que a Colorflex apresentava um elevado índice de setup para regulagem de máquina na troca de pedidos, ocasionando uma perda de capacidade de produção do equipamento, sendo assim, tornando um gargalo no processo produtivo da empresa e, consequentemente, atrasando a entrega do produto ao cliente.

A partir dessas informações coletadas e observações realizadas e em busca da solução que reduziria o setup e ao mesmo tempo aumentaria a produtividade do equipamento, começamos a estudar as possibilidades para reduzir o tempo de regulagem.

Primeiramente, foram observados três processos que podem ser alterados a fim de reduzir consideravelmente esse tempo.

O primeiro processo utiliza as técnicas 1 e 2 da redução de setup (separação de setup interno e externo), que diz respeito a separação antecipada do tecido a ser utilizado para impressão. Hoje, a empresa finaliza um pedido, inicia a regulagem da máquina para então o tecido a ser impresso ser retirado do estoque, e nesse momento, o tecido pode não estar finalizado na laminadora e não estar disponível no estoque, sendo assim, é proposto que o tecido seja separado antes mesmo de iniciar a regulagem de máquina, pois, se ele não estiver disponível, outro pedido é regulado e assim não terá tempo desperdiçado. Esse é um processo denominado como setup externo, atividade que pode ser realizada ainda com a máquina em funcionamento. Outras atividades, como separação dos cilindros e das engrenagens já são realizadas com a máquina funcionando, as demais atividades da regulagem não são recomendadas serem realizadas como setup externo, pois oferecem risco aos operadores.
Em relação aos processos de regulagem da máquina, foram propostas duas melhorias. No momento em que é feita a regulagem, a flexografia dispõe de um conjunto doctor blade (conjunto de lâminas) para realizar o corte no tecido. No momento da regulagem, esse conjunto é retirado e o mesmo operador que realiza a regulagem, precisa limpar lâmina por lamina para então colocar o conjunto novamente na máquina, sendo que deve ser limpo com cuidado para que o operador não se machuque e deve ter uma limpeza eficaz, pois se não estiver bem limpo, pode alterar o pedido que entrará em sequência, por esses motivos, é elevado o setup para a limpeza do conjunto. Dessa forma, é proposta a compra de um conjunto reserva doctor blade, pois assim, o operador retira o conjunto sujo e imediatamente coloca o limpo, sendo que o que estava sujo será limpo no momento em que o pedido já estiver rodando em máquina, não interferindo no tempo de setup. Não é recomendado direcionar uma mão de obra apenas para essa limpeza, pois são 4 flexografias que possuem esse conjunto e caso ocorra das 4 pararem ao mesmo tempo, um auxiliar não conseguiria limpar todos os conjuntos a tempo de coloca-los novamente na máquina.

Outra melhoria proposta à empresa iguala-se ao conjunto reserva de doctor blade, porém, propomos a compra de um conjunto reserva de bombas. A bomba localiza-se em cima do suporte de tinta que abastece a flexografia e novamente, a empresa possui apenas um conjunto por máquina, o que faz com que o conjunto seja limpo durante a regulagem para então ser colocado novamente em máquina, lembrando que, assim como o conjunto de lâminas, o de bombas, também deve ser bem limpo para não alterar as cores do próximo pedido que entrará em máquina.

A seguir, a figura 7 apresenta 0 ganho em redução de setup para regulagem de máquina, aplicando tais melhorias. 
Figura 7 - Redução de setup por dia com a aplicação das melhorias propostas

\begin{tabular}{|lccc|}
\hline & $\begin{array}{c}\text { Total trabalhado por } \\
\text { dia }\end{array}$ & $\begin{array}{c}\text { Total de setup para } \\
\text { regulagem por dia }\end{array}$ & Percentual \\
\cline { 1 - 3 } Minutos & 1044 & 260 & \multirow{2}{*}{$24,9 \%$} \\
\hline Horas & 17,4 & 4,3 & \\
\hline
\end{tabular}

Fonte: Dados obtidos através da cronoanálise

Para chegar ao tempo de 260 min por dia, foram retirados os tempos de limpeza de facas e limpeza de bombas, referidos no quadro 2, os quais não serão mais contabilizados se conjuntos reservas de doctor blade e de bombas forem adquiridos. Dessa forma, percebe-se na tabela 3, que por dia será reduzido, aproximadamente, em 2 hora o setup de regulagem, extremamente significante para ganho da empresa. Levando em consideração, que o tempo desperdiçado quando uma máquina é regulada e o tecido não está disponível em estoque, não está sendo contabilizado, ou seja, a redução de setup pode alcançar valores superiores a $2 \mathrm{~h}$. Também é importante ressaltar que estes valores foram obtidos através de cronoanálise, ou seja, o operador fazia a atividade mais rapidamente pois sabia que estava sendo analisado, em conversa com a supervisora do setor, ela informou que esse tempo de troca de facas e de bombas pode ser ainda maior do que foi cronometrado.

Para uma melhor visualização do ganho real, a figura 8 demonstra o ganho em reais em 24 dias (média de dias trabalhados no setor de flexografia). A flexografia analisada possui uma capacidade de 5000 sacos por hora, aplicando o que foi proposto, será reduzido, em média, 2 horas de setup de máquina, a sacaria possui um valor médio de $R \$ 1,24$ a unidade, pois há sacarias com o preço elevado e com o preço mais reduzido, dependendo das especificações do cliente, isso equivale a um ganho bruto de $\mathrm{R} \$ 6200$ a hora e $\mathrm{R} \$ 297600$ durante 24 dias.

Figura 8 - Ganho em reais com a aplicação das melhorias propostas

\begin{tabular}{|cccc|}
\hline $\begin{array}{c}\text { Capacidade da máquina } \\
\text { por hora (em sacos) }\end{array}$ & $\begin{array}{c}\text { Valor médio por } \\
\text { sacaria (R\$̦) }\end{array}$ & $\begin{array}{c}\text { Ganho por } \\
\text { hora (R\$) }\end{array}$ & $\begin{array}{c}\text { Ganho mensal } \\
\text { (R\$̦) }\end{array}$ \\
\hline 5000 & 1,24 & 6200 & 297600 \\
\hline
\end{tabular}

Fonte: Dados obtidos na empresa estudada

\section{CONSIDERAÇÕES FINAIS}

Manter-se competitivo no mercado deixou de ser o foco das empresas, hoje elas precisam ir além, pois o objetivo passa a ser a referência ou liderança no mercado de atuação. No intuito de contribuir com este objetivo estudou-se o setup de regulagem de máquina de uma fábrica de embalagens industriais com 0 intuito de apresentar alternativas de melhorias. Após identificar que com a compra de conjuntos reservas de doctor blade e de bombas e com a separação de algumas atividades de setup externo e interno, é possível prever que haverá uma redução significativa nos tempos de setup e, consequentemente, elevando o tempo disponível para produção, gerando um melhor aproveitamento da capacidade produtiva. Com o resultado apresentado chega-se à conclusão que a separação de setup externo e interno e o pensamento Lean proporcionam a redução de custos dentro do processo produtivo, oferecendo flexibilidade à empresa, podendo atender melhor e de forma mais rápida os seus clientes e com isso se diferenciando no mercado. Dessa forma, é possível afirmar que a utilização dessas práticas no processo estudado é totalmente viável. 


\section{REFERENCIAS}

[1] Peinado, J; Graeml, R. A. (2007) Administração da produção: operações industriais e de serviços - Curitiba: Unicenp

[2] Seleme, R (2009) Métodos e tempos: racionalizando a produção de bens e serviços $-1^{\circ}$ Ed - Curitiba: Ibpex

[3] Shingo, S. (2005) O Sistema Toyota de Produção do ponto de vista da Engenharia de
Produção. Trad. Eduardo Schaan - $2^{\circ}$ Ed. - Porto Alegre: Artes Médicas. Editora Bookman

[4] Slack, N; Chambers, S; Johnston, R (2002) Administração da produção - $2^{\circ}$ Ed - São Paulo: Editora Atlas S. A

[5] Werkema,C (2012) LeanSix Sigma Introdução as Ferramentas do Lean Manufacturing $-2^{\circ}$ Ed. - Rio de Janeiro: Editora Campus 


\section{Gapítulo 17}

\section{ANÁLISE E PROPOSTA DE MELHORIA NO PROCESSO DE PLANEJAMENTO DE MATERIAIS: UM ESTUDO DE CASO EM UMA DISTRIBUIDORA DE ENERGIA ELÉTRICA DA REGIÃO SUL DO PAÍS}

\section{Manoel Sebastião Camargo}

Tiago dos Santos Antunes

Fabio Antonio Sartori Piran

Resumo: Este artigo busca identificar a diferença entre o planejamento e a demanda de materiais de rede do setor elétrico, assim como propor mudanças em processos para reduzir ou eliminar as faltas de materiais em uma distribuidora de energia elétrica do sul do país. Para isso foram selecionados processos-chave da cadeia de valor, mapeado o processo atual de previsão de demanda e planejamento de materiais para utilização em rede de energia elétrica, o que propiciou o entendimento da interação entre processos na empresa, possibilitando identificar oportunidades de melhorias. Através do Business Process Management (BPM), pode-se realizar o mapeamento dos processos chaves o que possibilitou a construção de uma visão de futuro contemplando as melhorias identificadas no mapeamento.

Palavras-chave: Business Process Management (BPM); Distribuidora de Energia Elétrica; Planejamento de Materiais. 


\section{INTRODUÇÃO}

O cenário organizacional é caracterizado pela competitividade e instabilidade, fazendo com que as organizações busquem melhorar seus processos e entregar produtos de melhor qualidade para seus clientes internos ou externos. Para que isso ocorra, as empresas precisam ter conhecimento e domínio sobre seus processos para que possam entender em que momentos estão sendo eficientes e em que momentos não estão. Assim é possível evitar custos desnecessários e/ou tarefas que não agregam valor para o cliente. Essa compreensão dos níveis de maturidade dos processos pode auxiliar na proteção da organização, quanto a problemas oriundos da falta de alinhamento e comunicação em diversos níveis. A partir da utilização dos mais variados sistemas de informação, surgem abordagens e métodos que podem ajudar as empresas na melhoria dos seus processos (GONÇALVES; RAMOS; SANTOS, 2009).

Nas empresas Distribuidoras de Energia Elétrica o principal produto é a distribuição e entrega de energia elétrica para o usuário final (ANEEL, 2016b). Para que isso ocorra, uma série de outras atividades devem ser realizadas, como o planejamento de materiais. Sendo assim, são feitas previsões para consumos futuros, que em alguns casos, devem prever antecipadamente a quantidade necessária, o tempo para confecção do item específico para o local a ser instalado (fabricação), prever o tempo de deslocamento (logística). Além disso, é necessário respeitar a legislação para a correta remuneração pelo órgão regulador (retorno sobre investimento), treinamento do técnico que irá realizar a instalação (capacitação) e, por fim, monitorar a satisfação do cliente final, que em caso de falhas, ficará sem um dos principais insumos do mundo moderno, a energia elétrica.

Nesse sentido, ter uma gestão por processos é fundamental para manter-se competitivo no mercado e atender as expectativas dos clientes. A gestão por processos, conhecida também por Business Process Management (BPM), é uma ferramenta de gestão voltada para gerenciar os negócios da empresa de modo integrado (RIBEIRO et al, 2015). No BPM, destaca-se a modelagem de processos, que podem ser os já existentes, os que ainda estão em planejamento ou sendo previstos e entre outros (CAPOTE, 2011). A partir dessa modelagem é possível se ter uma visão ampla do negócio como um todo, identificando possíveis problemas, analisa-los e implementar soluções necessárias para resolvê-los (RIBEIRO et al, 2015), bem como identificar oportunidades de melhorias.

Diante deste contexto, o objetivo geral deste trabalho é identificar oportunidades de melhoria no processo de planejamento de materiais de uma distribuidora de energia elétrica utilizando as práticas de BPM. Para atender o objetivo geral, serão adotados os seguintes passos:

a - Mapear o estado atual ("AS $I S$ ") do processo de planejamento de materiais com vista à previsão de demanda da operação da empresa;

b - Desenhar o estado futuro ("TO BE") do processo de planejamento de materiais com vista à previsão de demanda da operação da empresa;

C - Apresentar propostas de melhoria.

Além desta introdução, é apresentado o referencial teórico e análise dos resultados obtidos. E, por fim, apresentam-se as considerações finais e recomendações para pesquisas futuras.

\section{REFERENCIAL TEÓRICO}

Este capítulo tem o objetivo de apresentar os principais pilares do conhecimento necessários para o desenvolvimento deste trabalho. São apresentados aspectos e características importantes relacionados a "distribuição de energia elétrica", "business process management (bpm)", "cadeia de valor" e "indicadores de desempenho".

\subsection{DISTRIBUIÇÃO DE ENERGIA ELÉTRICA}

O setor elétrico tanto no âmbito técnico como regulatório é de grande complexidade sendo - Governo Federal quem regulamenta a utilização e exploração dos serviços de energia elétrica pelos agentes do setor, pelos consumidores cativos e livres, produtores independentes e autoprodutores (ANEEL, 2015b). A abrangência de interação da Agencia Nacional de Energia Elétrica (ANEEL) abrange três modalidades de regulação, a saber: i) a regulação técnica de padrões de serviço (geração, transmissão, distribuição e comercialização); ii) a regulação econômica (tarifas e mercado); e, iii) a dos projetos de pesquisa e desenvolvimento (P\&D) e eficiência energética. Este estudo terá como pano de fundo a distribuição de energia 
elétrica realizada pelas Distribuidoras de Energia.

A Distribuidora de Energia Elétrica é a empresa que detém a concessão ou permissão de distribuir energia elétrica para o consumidor final. Todo processo de conexão, atendimento e a entrega efetiva de energia elétrica ao consumidor ocorrem por parte das distribuidoras de energia (ABRADEE, 2016a). Esse sistema de distribuição é composto por fios condutores, transformadores e equipamentos diversos de medição, controle e proteção das redes elétricas (ANEEL, 2015b). Portanto, o sistema de distribuição é muito extenso e ramificado, pois deve chegar aos domicílios e endereços de todos os seus consumidores (ABRADEE, 2016a).

\subsection{BUSINESS PROCESS MANAGEMENT (BPM)}

A Gestão de Processos de Negócios ou Business Process Management (BPM) é uma ferramenta de gestão voltada para gerenciar os negócios da empresa de modo integrado (RIBEIRO et al, 2015), ou seja, é uma abordagem de gestão holística (TOOR; DHIR, 2011; DRAGHICl et al., 2012; FURLAN, 2013) que compreende todo o trabalho executado por uma organização para entregar o produto ou serviço do processo, independentemente de quais áreas funcionais ou locações estejam envolvidas (ABPMP, 2013). Para tanto, torna-se necessário o mapeamento e a modelagem das atividades que compõem estes processos (JESUS; RODRIGUES;
TORRES, 2014). Na modelagem é realizada a identificação das funções e atividades que a compõem e seus principais fluxos de trabalhos (GONÇALVES, 2000) deixando claro e de forma visível como o processo funciona (BALDAM, 2007). O BPM constitui um conjunto instrumental de negócio para identificar, desenhar, executar, documentar, medir, monitorar, controlar e melhorar processos de negócio, automatizados ou não, para alcançar resultados consistentes e alinhados com os objetivos estratégicos da organização (ABPMP, 2013). Para Megard (2002) uma das funcionalidades mais relevantes da metodologia consiste na própria definição do processo, no monitoramento das atividades e na análise de performance através de indicadores de processos.

A modelagem convencionada neste trabalho é a BPMN (Business Process Model and Notation) que integra uma simbologia simples e compreensível por todos (FURLAN, 2013; OMG, 2011). Esta simbologia ainda permite inserir regras de negócio (FURLAN, 2013). O BPMN é um padrão da Object Management Group (OMG) para as formas e símbolos utilizados no processo de diagramas de modelagem, e sua semântica associados, conforme mostrado na figura 1. Surgiu como o padrão importante no BPM, especialmente quando a intenção do usuário é seguir modelagem para documentação e análise, com um desenho de implementação do processo (SILVER, 2014).

Figura 1 - Elementos básicos da notação BPMN

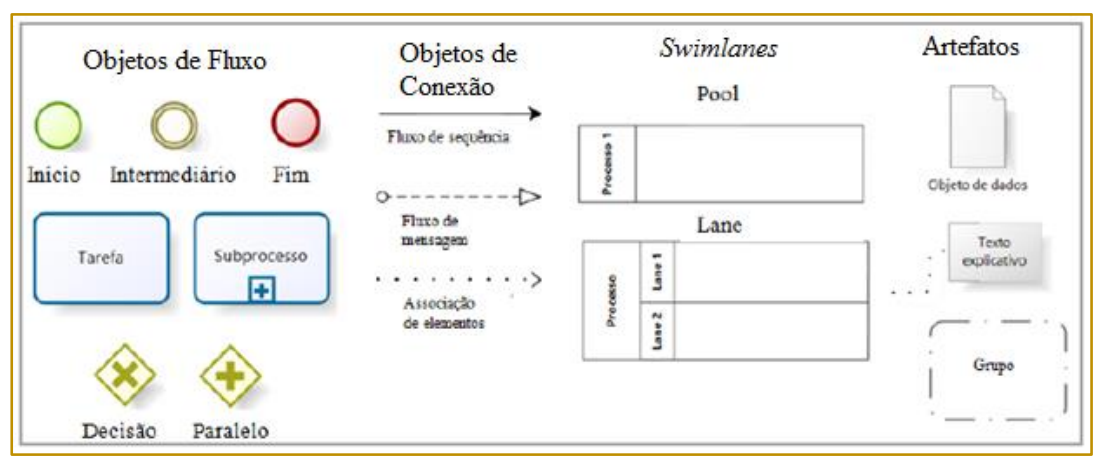

Fonte: Mendoza et al. (2012) 
A partir deste mapeamento é possível identificar todas as conexões do processo de forma ampla, permitindo enxergar o negócio de ponta a ponta. Qualquer ponto em um processo onde o trabalho ou a informação passa de uma função para outra é um handoff nesse processo. Handoffs podem resultar em desconexões de processos e devem ser analisados com cuidado (FURLAN, 2013).

\subsection{PLANEJAMENTO DE MATERIAIS}

O planejamento de materiais consiste basicamente em antever a necessidade dos materiais e tem o intuito diminuir incertezas no processo de ressuprimento. Pode-se considerar três requisitos para previsão de demanda: ser expressa em termos úteis para o planejamento dos materiais, ser tão exata quanto possível e dar uma indicação da incerteza relativa (SLACK, 2002). Como o planejamento consiste em uma previsão de futuro em um horizonte de tempo, essa incerteza relativa é inevitável (HUBBARD, 2008). Para minimizar essa incerteza é preciso que as diferenças entre consumo e planejamento sejam mensuradas. Dias (2010) apresenta alguns exemplos de técnicas quantitativas para a previsão de consumo:

a) Método do último período: consiste em considerar como verdade que o consumo do próximo período será igual ao consumo do último período;

b) Método da média móvel: consiste em realizar a média de um montante de períodos e a cada novo período acrescenta-se o novo período e realiza-se a exclusão do período mais antigo.

c) Método de média móvel ponderada: consiste na aplicação de média móvel, mas considerado peso maior para as amostras mais recentes;

d) Método da média com ponderação exponencial: consiste em prever o consumo com base na sua tendência, atribuindo parte da diferença entre o consumo atual e o previsto a uma mudança de tendência e o restante a parte aleatória.

\subsection{INDICADORES DE DESEMPENHO}

Os indicadores de desempenho permitem demonstrar, sinalizar, comunicar, indicar e informar sobre um tema qualquer, eles representam um conjunto de medidas focadas no desempenho organizacional, apresentando os pontos críticos para 0 sucesso da organização (PARMENTER, 2010). Nesse sentido, os indicadores têm várias características que os definem, a saber: i) quantificam a informação, tornando seu significado mais aparente; ii) simplificam a informação para facilitar a comunicação; iii) são descritivos, não explicativos; iv) representam um modelo empírico da realidade, não a realidade em si (MIRANDA, 2002). Um indicador deve, ainda, facilitar a comparação de forma quantitativa, para que seu uso possa servir como um direcionador conectando a estratégia à realidade (PALADINI, 2005).

\section{METODOLOGIA DE PESQUISA}

O método de pesquisa utilizado neste trabalho é o de estudo de caso, pois este se caracteriza como um trabalho de caráter empírico que investiga um determinado fenômeno dentro de um contexto atual e real, por meio de uma investigação dos objetos de estudo (GIL, 2010). O foco deste método é de relatar, descrever situações e fatos e proporcionar conhecimento acerca do fenômeno estudado e verificar efeitos ou relações presentes no caso (MIGUEL et. al., 2012).

Como ferramentas de investigação, utilizou-se a pesquisa bibliográfica e documental. A pesquisa bibliográfica é caracterizada por abranger estudos já tornados públicos em relação ao tema, constituído principalmente de livros, artigos de periódicos e com material disponibilizado na Internet (MINAYO, 2010). Por outro lado, a pesquisa documental é caracterizada por ser feita com base na análise de documentos conservados dentro das organizações de qualquer natureza (VERGARA, 2009).

A coleta de dados foi realizada através de observação direta dos processos e de entrevistas semiestruturadas, com seis profissionais da empresa foco de estudo, a saber: i) coordenador; ii) analista, e; iii) técnico. A partir dos dados das entrevistas e análise dos documentos, foram desenhados os processos com notação BPMN (Business Process Model and Notation), o qual possibilitou a abordagem do processo atual e construção do processo com visão de futuro com base nas melhorias identificadas. Por fim, é importante citar que a modelagem dos processos foi realizada com o uso do software 
Bizagi Process Modeler, que é o software mais popularmente usado (CHINOSI; TROMBETTA, 2012).

\subsection{ESTUDO DE CASO}

A empresa alvo deste trabalho é uma distribuidora de energia elétrica localizada no rio grande do sul, com mais de $99 \mathrm{mil} \mathrm{km}^{2}$ de área de concessão, aproximadamente 2 mil colaboradores e próximo de 1 milhão e 300 mil clientes. O estudo de caso desenvolvido e apresentado atuou diretamente com os processos que têm relação com materiais de rede elétrica para consumo da operação, que são consumidos por equipes multitarefa, veículos leves com dois eletricistas (camionete e cestos aéreos) de atendimento emergencial, que executam ordens de serviço comerciais como ligação de energia, corte e entre outras, bem como ordens de manutenção na rede elétrica.

\section{RESULTADOS}

Neste capítulo serão apresentados os processos-chave da cadeia de valor, os processos em uma visão ponta a ponta que estão relacionados com materiais até o nível de entrega para as equipes, o mapeamento da situação atual ("as is") dos processos com influências no planejamento de materiais, abordagem do desempenho atual diante da problemática, propostas de melhoria e o mapeamento como proposta de estudo futuro ("to be").

Para alcançar o objetivo de identificar oportunidades de melhoria no processo de planejamento de materiais a figura 2, apresenta uma adaptação com base nos dados da empresa, mostrando de forma macro a cadeia de valor do setor de distribuição de energia elétrica, sendo apresentados os processos-chave no escopo estratégico, negócio e suporte.

Figura 2 - Visão sistêmica da cadeia de valor e seus processos

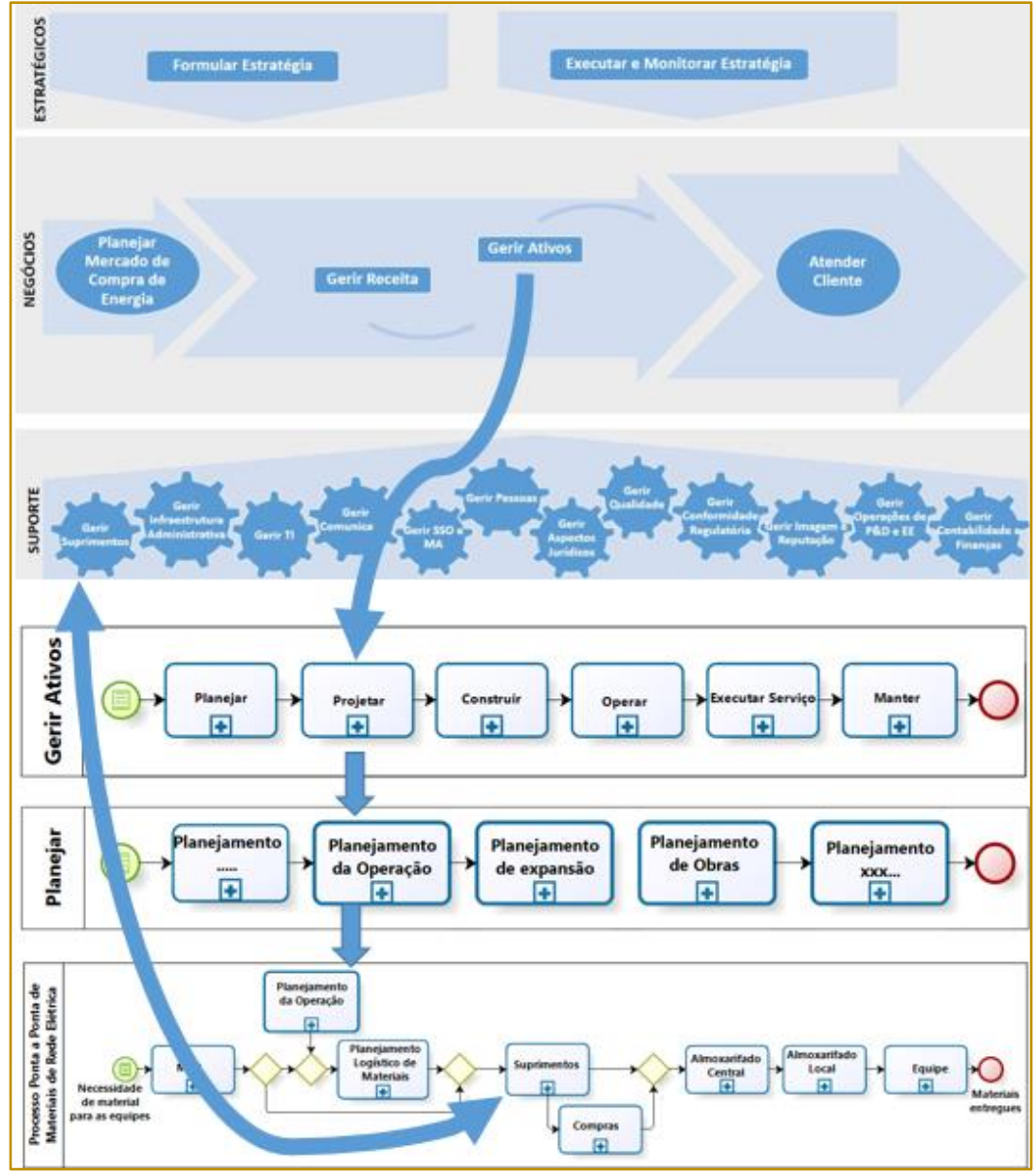

Fonte: elaborado pelos autores com base nos dados da empresa 
Observa-se ainda que o macroprocesso "planejamento da operação" faz parte do âmbito de negócio da cadeia de valor e é parte do processo ponta a ponta de materiais, assim como "suprimentos" e "planejamento logístico de materiais" que fazem parte do processo ponta a ponta de materiais e são parte do processo "gerir suprimentos", que está presente na cadeia de valor como processo de suporte.

\subsection{ESTADO ATUAL "AS IS"}

$\mathrm{Na}$ figura 3 são apresentados os processos que se relacionam com materiais, em uma visão ponta a ponta, desde a necessidade à entrega. Esses processo ajudam na compreensão dos motivos das diferenças entre o planejado e a demanda de materiais de rede do setor elétrico

Figura 3 - Mapeamento de macroprocessos ponta a ponta de materiais

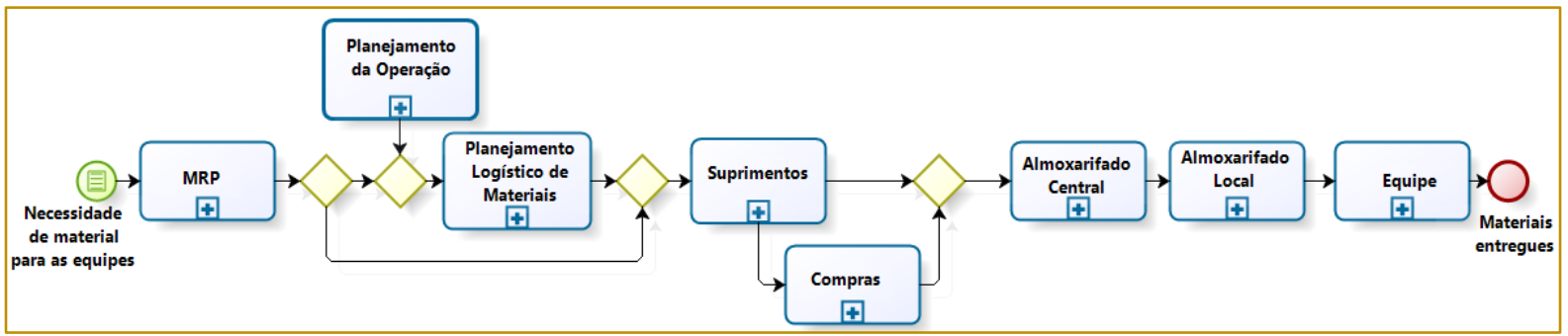

Fonte: elaborado pelos autores com base nos dados da empresa

O mapeamento contemplou os macroprocessos de planejamento da operação, processos de materiais de forma geral (gerador de informações) e o planejamento logístico de materiais, como mostrado abaixo nas figuras 4, 5 e 6 .

Figura 4 - Planejamento Da Operação ("As /s")

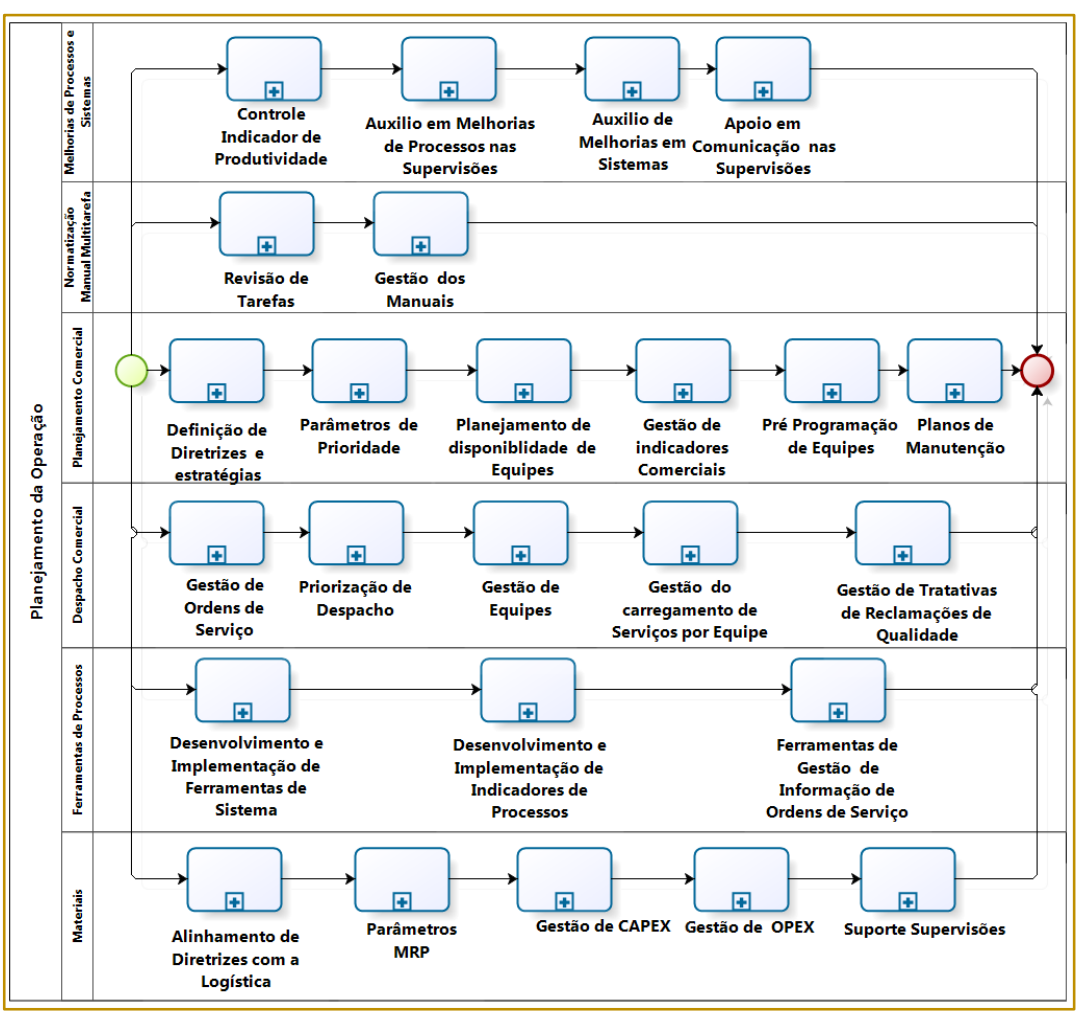

Fonte: elaborado pelos autores com base nos dados da empresa 
Figura 52 - Processo Geral Materiais (Gerador De Informações) ("As /s")

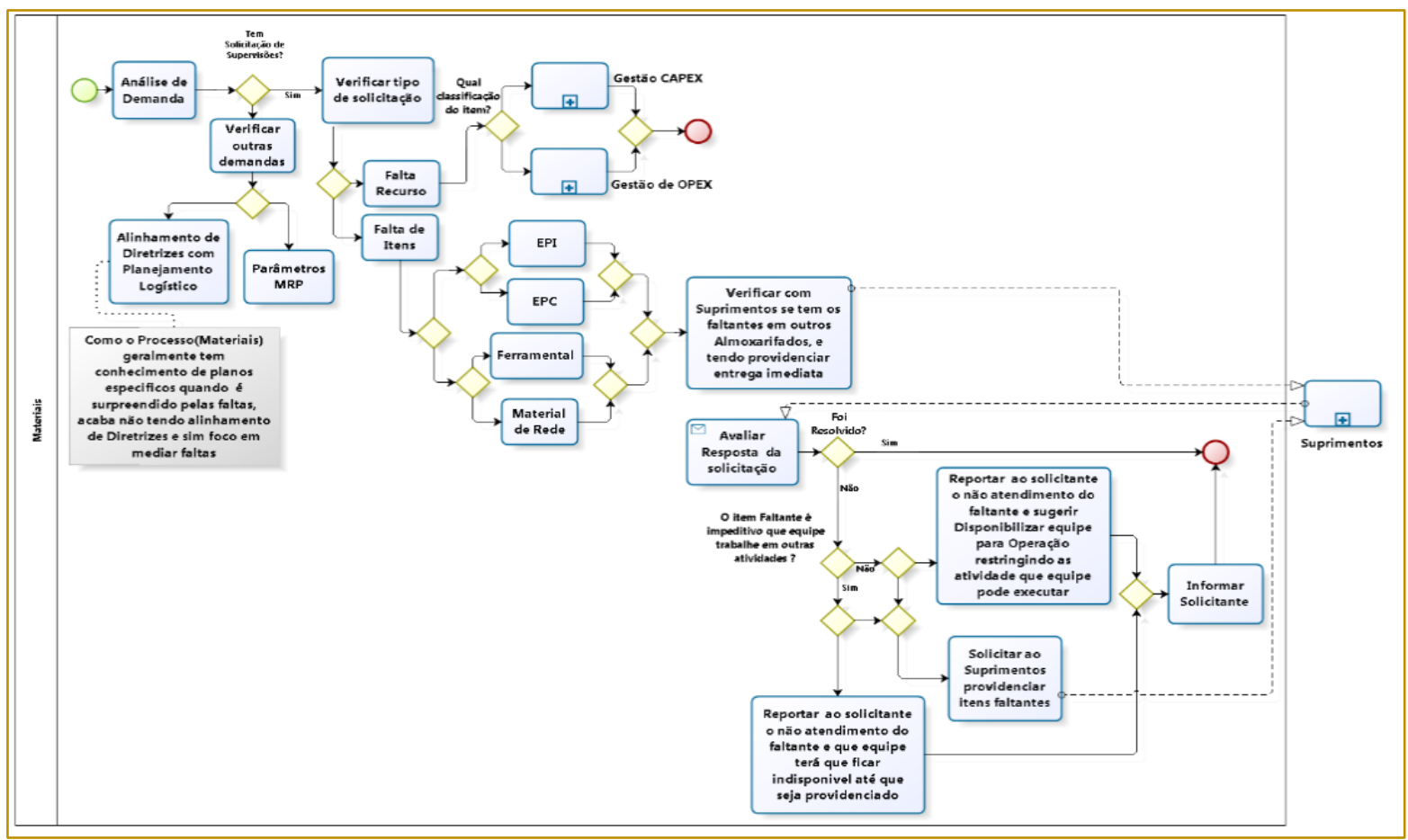

Fonte: elaborado pelos autores com base nos dados da empresa

Figura 6 - Processo Planejamento Logístico De Materiais (" $A s$ /s")

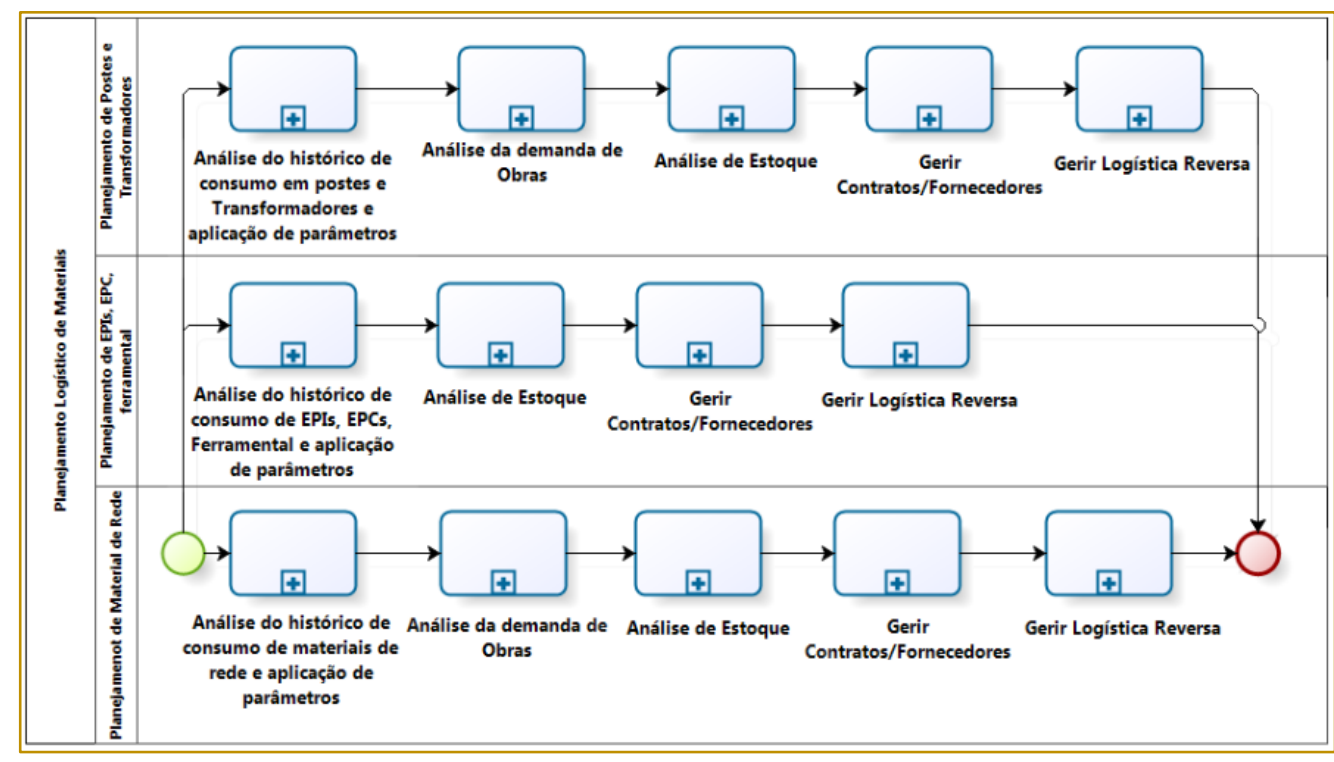

Fonte: elaborado pelos autores com base nos dados da empresa 
A seguir serão mostrados os principais achados referente ao estado atual ("as is") do processo de planejamento de materiais, como fatos que contribuíram para o aumento do consumo e da demanda dos materiais bem como suas causas e efeitos.

\subsection{DESEMPENHO ATUAL DO ESTADO "AS IS"}

Após o mapeamento do estado atual, pode-se observar que $17 \%$ da lista de materiais está em falta e que destes, $79 \%$ são de faltas de materiais até o limite de $10 \%$ da quantidade necessária e os outros $21 \%$ são de faltas superiores a $10 \%$ da quantidade necessária. Os $79 \%$ de itens em falta com diferença de até $10 \%$ da quantidade necessária com base no montante faltante de $17 \%$ representam $13,43 \%$ do total de itens de consumo da operação. Já os $21 \%$ de itens com diferença maior do que $10 \%$ da quantidade necessária com base no montante faltante de $17 \%$ representam $3,57 \%$ do total de itens de consumo da operação e são decorrentes dos planos de manutenção que a empresa intensificou, como mostra a figura 7.

Figura 7 - Status dos materiais por item de consumo pela operação

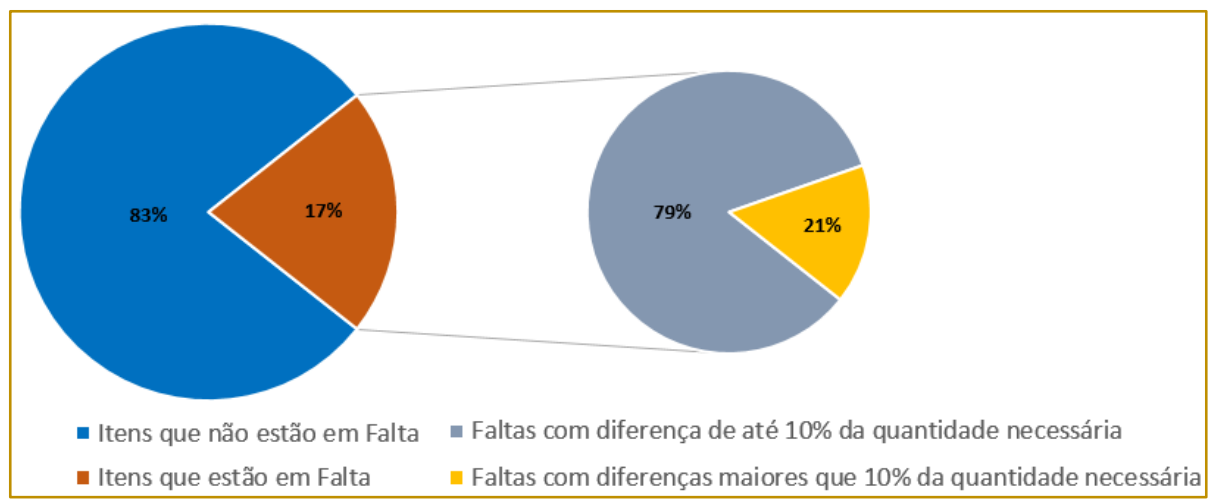

Fonte: elaborado pelos autores com base nos dados da empresa.

Observou-se que algumas das mudanças tiveram impacto na demanda de materiais, entre outros recursos que não estão atrelados a este trabalho, como mostra o quadro 1:

Quadro 1 - Oportunidades identificadas

\begin{tabular}{|c|c|c|}
\hline \multicolumn{3}{|c|}{ Outros impactos nas demandas de materiais } \\
\hline $\begin{array}{c}\text { Primarização (tomar o serviço terceiro em próprio) de } \\
\text { todas as equipes multitarefa da operação: } 70 \% \text { das } \\
\text { equipes da operação eram terceirizadas (a empresa } \\
\text { em estudo, gerenciava e fornecia os materiais de rede } \\
\text { para a prestadora de serviços), mas a primarização } \\
\text { resultou em maior produtividade e assim propiciando } \\
\text { maior número de intervenções na rede elétrica, } \\
\text { acarretando em maior consumo de materiais. }\end{array}$ & $\begin{array}{c}\text { Incremento de equipes especificas para realização de } \\
\text { manutenções na rede elétrica: o que resultou no } \\
\text { aumento de consumo de materiais. }\end{array}$ & $\begin{array}{l}\text { Aumento do efetivo operacional: o que possibilitou } \\
\text { que a empresa em questão disponibilizasse } \\
\text { quantidade considerável de equipes por } 24 \text { horas por } \\
\text { dia, o que também elevou o consumo de materiais. }\end{array}$ \\
\hline
\end{tabular}

Fonte: Elaborado pelos autores com base nos dados da empresa. 
A partir do mapeamento os pesquisadores se reuniram com o coordenador, analistas e técnicos para uma análise de causa e efeito com o diagrama de ishikawa com o objetivo de identificar as possíveis variáveis que podem estar contribuindo para o planejado em materiais ser diferente da demanda elencando prioridades através da matriz gut, por fim analisando a principal recorrência de causa com a análise dos 5 por quês, como mostrado abaixo.

\subsubsection{ANÁLISE DE CAUSA DAS FALTAS DE MATERIAIS}

Figura 9 - Análise de causa da falta de materiais (Matriz GUT).

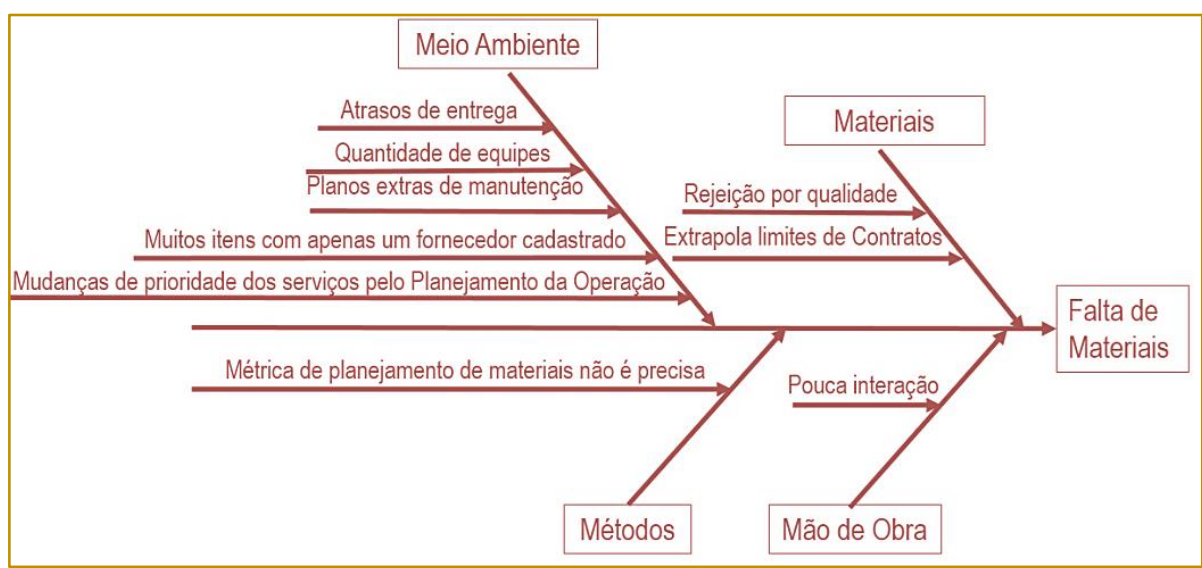

Fonte: Elaborado pelos autores com base nos dados da empresa.

Tabela 1 - Matriz de prioridade (Matriz GUT)

\begin{tabular}{|c|c|c|c|c|c|}
\hline Problema & G & $\mathbf{U}$ & $\mathrm{T}$ & GXUxT & Classificaçäc \\
\hline Métrica de planejamento de materiais não é precisa & 5 & 5 & 4 & 100 & 1 \\
\hline Extrapola Limites dos contratos & 5 & 4 & 4 & 80 & 2 \\
\hline $\begin{array}{l}\text { Mudanças de prioridade dos serviços pelo Planejamento da } \\
\text { Operação }\end{array}$ & 4 & 4 & 5 & 80 & 3 \\
\hline Muitos itens com apenas um fomecedor cadastrado & 4 & 4 & 4 & 64 & 4 \\
\hline Atraso de entrega dos materiais & 5 & 4 & 3 & 60 & 5 \\
\hline Rejeição por qualidade & 4 & 4 & 3 & 48 & 6 \\
\hline Quantidade de equipes & 4 & 3 & 3 & 36 & 7 \\
\hline Planos extras de manutenção & 4 & 3 & 3 & 36 & 8 \\
\hline Pouca interação & 3 & 3 & 3 & 27 & 9 \\
\hline
\end{tabular}

Fonte: elaborado pelos autores com base nos dados da empresa. 


\subsubsection{ANÁLISE DE CAUSA DO EXCESSO DE MATERIAIS}

Figura 10 - Análise de causa de excesso de materiais

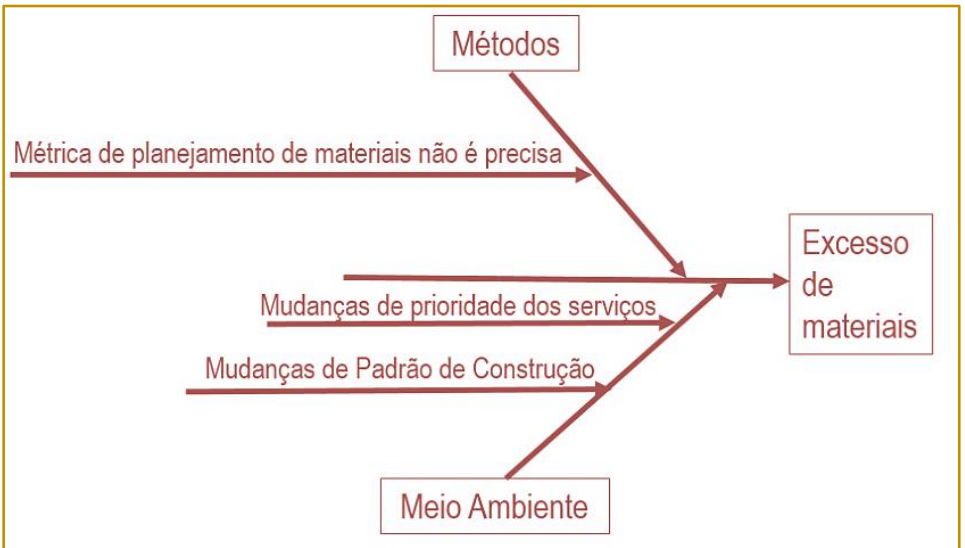

Fonte: Elaborado pelos autores com base nos dados da empresa.

Tabela 2 - Prioridade das causas do excesso de materiais (Matriz GUT)

\begin{tabular}{|l|c|c|c|c|c|}
\hline \multicolumn{1}{|c|}{ Problema } & G & U & T & GxUxT & Classificação \\
\hline Mudanças de prioridade dos serviços & 5 & 4 & 4 & 80 & 1 \\
Métrica de planejamento de materiais não é precisa & 5 & 4 & 3 & 60 & 2 \\
Mudança do padrão de construção & 4 & 4 & 3 & 48 & 3 \\
\hline
\end{tabular}

Fonte: Elaborado pelos autores com base nos dados da empresa.

\subsubsection{ANÁLISE DE CAUSA DA DIFERENÇA \\ ENTRE PLANEJADO E DEMANDA}

Figura 11 - Análise de causa da diferença entre planejado e demanda

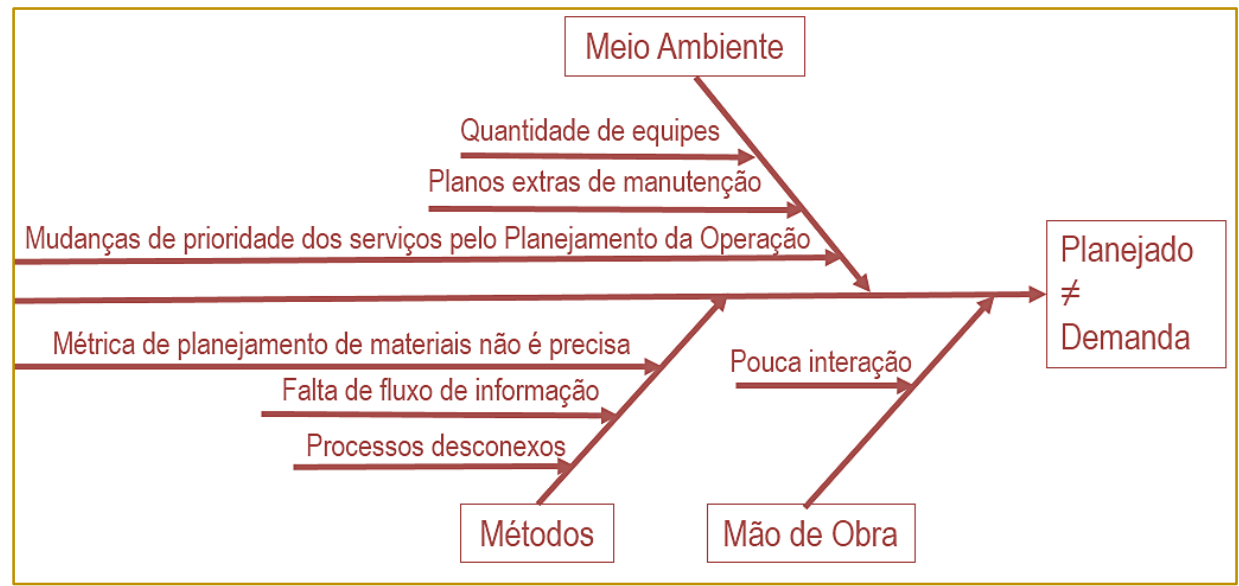

Fonte: Elaborado pelos autores com base nos dados da empresa. 
Tabela 3 - Prioridade das Causas da Diferença entre Planejado e Demanda (Matriz GUT)

\begin{tabular}{|l|c|c|c|c|c|}
\hline \multicolumn{1}{|c}{ Problema } & G & U & T & GxUxT & Classificação \\
\hline Métrica de planejamento de materiais não é precisa & 5 & 5 & 5 & 125 & 1 \\
Falta de Fluxo de informação & 4 & 5 & 4 & 80 & 2 \\
Planos extras de manutenção & 4 & 4 & 4 & 64 & 3 \\
Mudanças de prioridade dos serviços pelo & 5 & 3 & 4 & 60 & 4 \\
Planejamento da Operação & 4 & 3 & 4 & 48 & 5 \\
Processos desconexos & 4 & 3 & 3 & 36 & 6 \\
Quantidade de equipes & 3 & 3 & 3 & 27 & 7 \\
Pouca interação & &
\end{tabular}

Fonte: Elaborado pelos autores com base nos dados da empresa

\subsubsection{ANÁLISE DOS 5 POR QUÊS}

Figura 12 - Análise dos 5 por quês

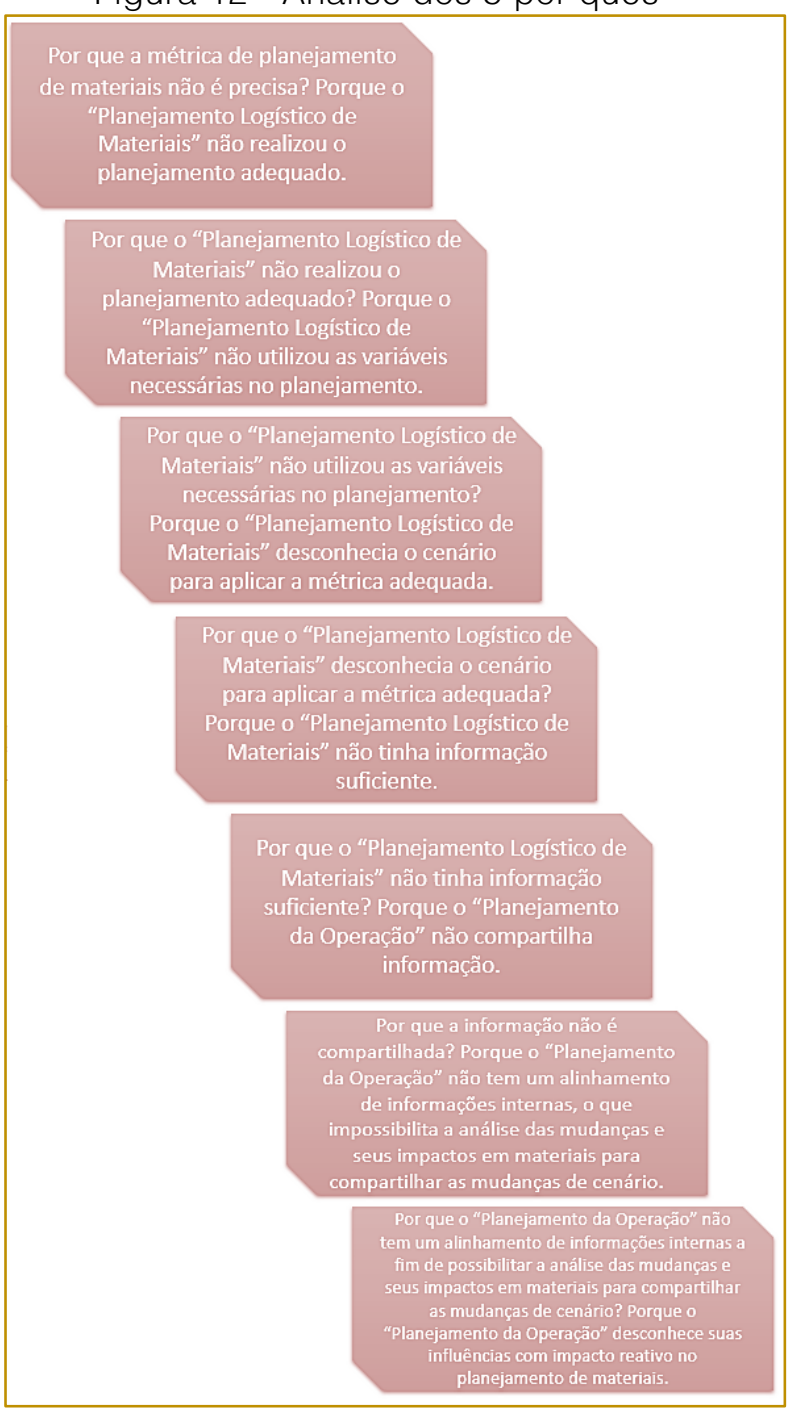

Fonte: Elaborado pelos autores com base nos dados da empresa. 
Com o mapeamento do estado atual (" $A S$ $\left(S^{\prime \prime}\right)$ pode-se analisar as principais causas que impactam no planejamento de materiais sendo a métrica de planejamento a causa mais recorrente. A partir dela foi realizada a análise dos 5 por quês que identificaram como causa raiz do problema desconexões entre os processos, o que a teoria define como handoffs.

\subsubsection{OPORTUNIDADES IDENTIFICADAS}

No quadro 2 são sintetizadas as principais oportunidades de melhoria identificadas no estado atual (" $A S / S$ ").
Com base no estado atual (" $A S / S$ ") e nos pontos de melhorias identificados, foi possível realizar o redesenho com visão de Futuro ("TO BE") comtemplando na simplicidade práticas transformadoras.

\subsection{ESTADO FUTURO "TO BE"}

Com uma visão ponta a ponta de materiais de rede, o processo de planejamento da operação está sendo representado como tendo interação no contexto de planejamento de materiais, pois sempre que ocorrer alguma mudança com impacto na demanda, ele fornecerá informações complementares ao processo planejamento logístico de materiais, conforme mostrado na figura 13.

Figura 13 - Processo ponta a ponta de materiais de rede ("TO BE")

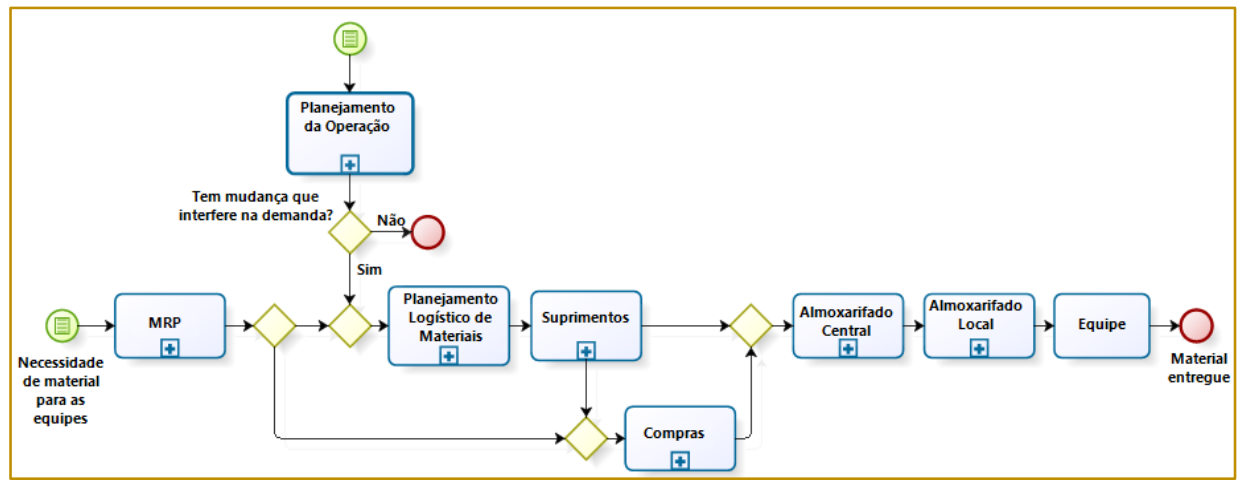

Fonte: Elaborado pelos autores com base nos dados da empresa. 
O redesenho com visão de futuro propõe a eliminação dos handoffs fazendo com que as transferências de informações entre os processos garantam os insumos necessários para gerar a mudança transformadora através de um planejamento mais preciso, como mostra a figura 14.

Figura 14 - Planejamento da operação ("TO BE")

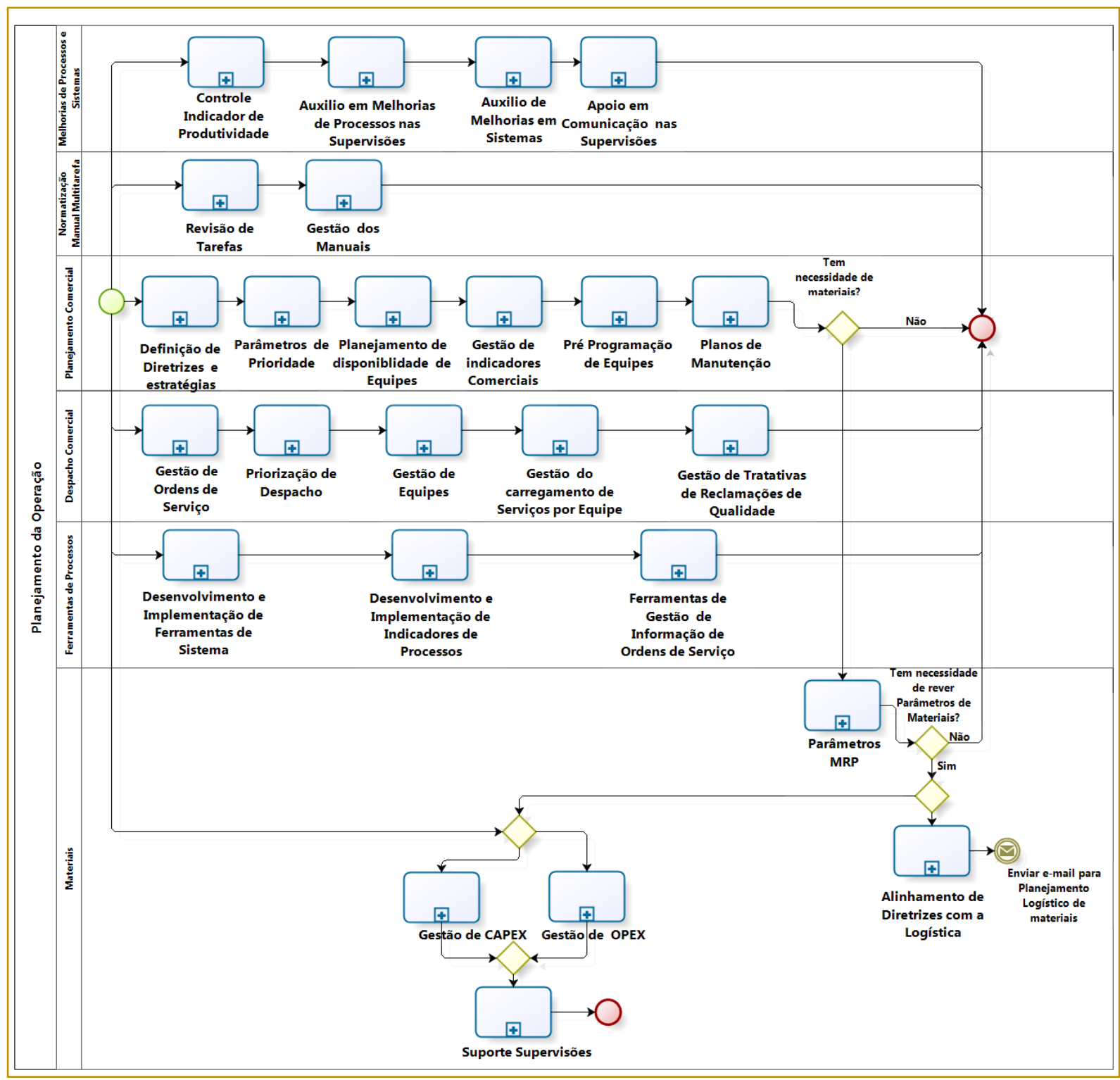

Fonte: Elaborado pelos autores com base nos dados da empresa.

$\mathrm{Na}$ figura 15 pode-se ver o mapeamento proposto com visão de futuro ("to be") do processo geral de materiais pela abordagem de atividades, para orientar o esperado de cada participante que tenha interação no processo. 
Figura 15 - Processo geral materiais (gerador de informações) ("TO BE")

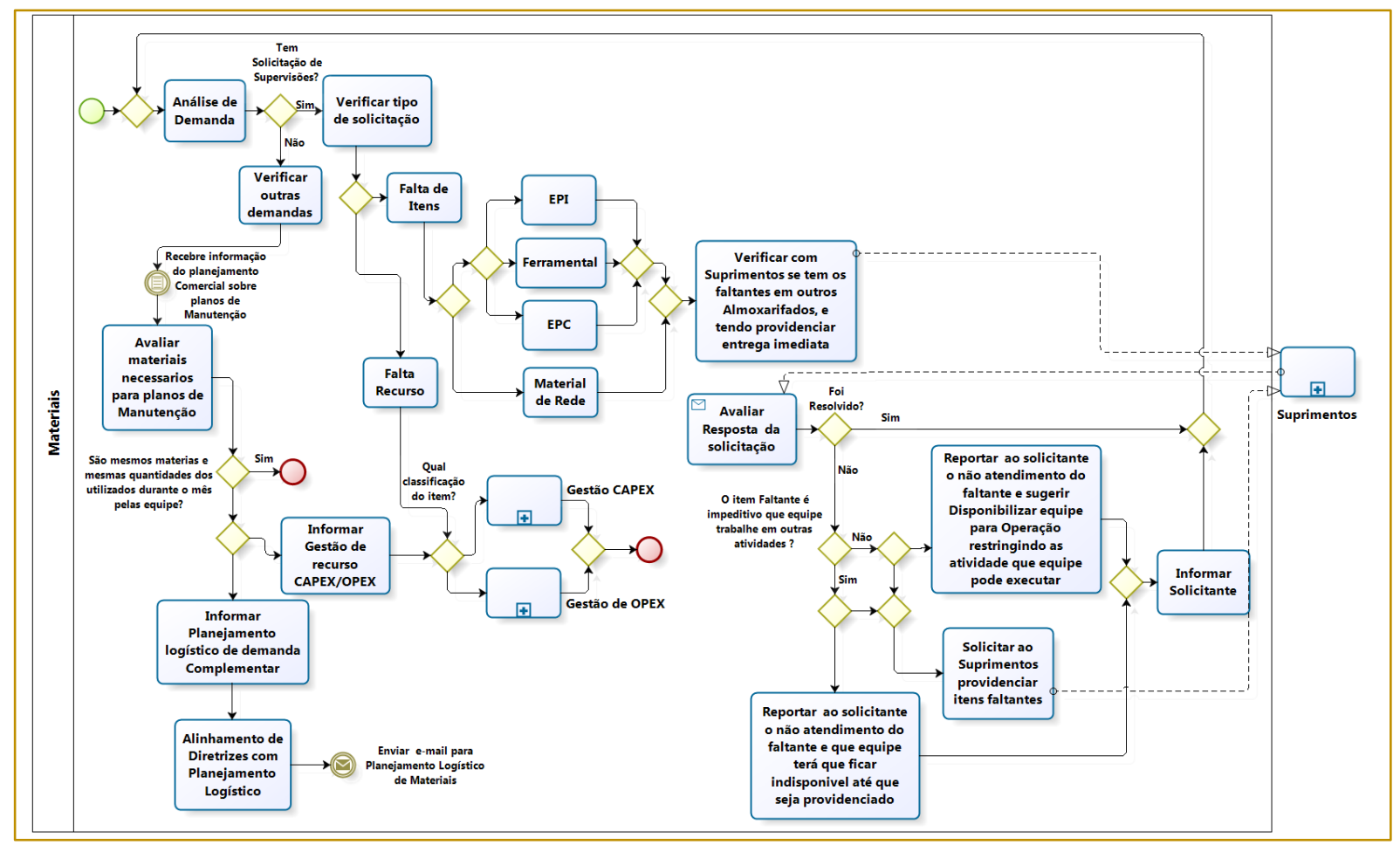

Fonte: elaborado pelos autores com base nos dados da empresa.

A seguir, na figura 16, pode-se ver 0 mapeamento proposto com visão de futuro ("TO BE") do processo planejamento logístico de materiais em abordagem de macroprocesso, mas contemplando a interação através do canal de comunicação (e-mail) com planejamento da operação a fim de que o planejamento de materiais de rede tenha as informações necessárias para o planejamento mais eficiente.

Figura 16 - Planejamento logístico de materiais ("TO BE")

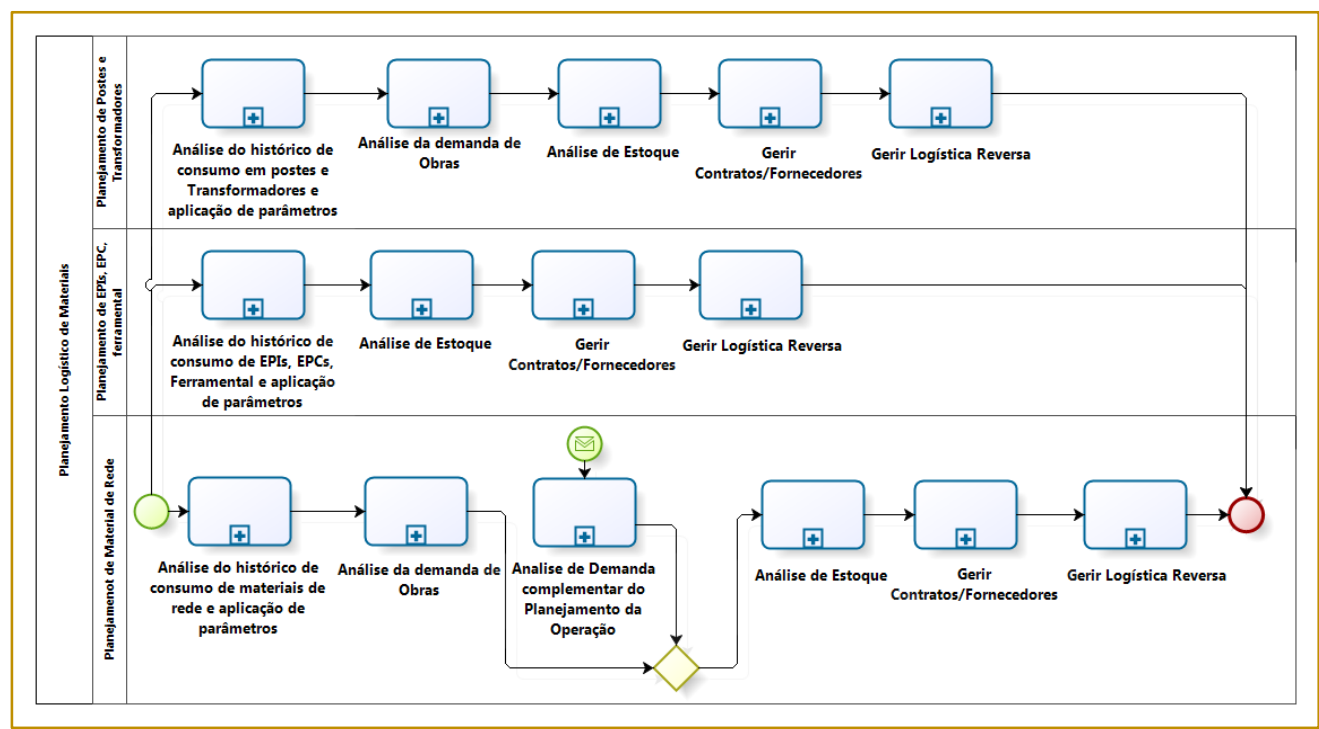

Fonte: Elaborado pelos autores com base nos dados da empresa. 
A figura 16 mostra que os processos interagem de acordo com os acontecimentos, sendo que se no planejamento comercial ocorrer alguma mudança com impacto em materiais, ele irá interagir com o processo "parâmetro", que analisará a mudança, e se realmente tiver impacto em demanda, fará a interação com os processos de recurso ("gestão de capex" e "gestão de opex") e fará o alinhamento com planejamento logístico de materiais mostrado na figura 14 .

\section{CONCLUSÃO}

O trabalho objetiva identificar oportunidades de melhoria no processo de planejamento de materiais em uma distribuidora de energia elétrica utilizando práticas de bpm mapeando o estado atual ("as is") dos processos, identificando pontos chaves de melhoria e, por fim, desenhando o estado futuro ("to be") implementando as oportunidades identificadas. Através dessa uma abordagem com visão ponta a ponta foi possível entender o papel de cada processo e suas relações no planejamento de materiais (capote, 2011). A visão sistêmica na abordagem do estudo e os métodos aplicados possibilitaram identificar o principal motivo de rompimento no plano de abastecimento de materiais da empresa foco de estudo. O principal motivo identificado foi a desconexão entre os processos, chamado de handoffs (furlan, 2013).

Com a apresentação de propostas de melhorias descritas a seguir está sendo atendido o último objetivo específico definido para este trabalho. Com o mapeamento do estado atual do planejamento de materiais também foi possível propor sugestões melhorias no processo, conforme mostrado no quadro 3.

Quadro 3 - Sugestão de melhorias

\begin{tabular}{|c|c|c|}
\hline \multicolumn{3}{|c|}{ Sugestão de melhorias } \\
\hline $\begin{array}{l}\text { Aplicar o proposto no redesenho dos processos com visão } \\
\text { de futuro, devido à necessidade de mudança em decorrência } \\
\text { dos handoffs provenientes de desconexões entre os } \\
\text { processos, para que tenham a interação em fluxo de } \\
\text { informação e, como o objeto de abordagem foi material de } \\
\text { rede elétrica, então que toda mudança que tenha } \\
\text { envolvimento com materiais desta categoria e que contenha } \\
\text { como consequência impacto em aumento ou diminuiçäo de } \\
\text { demanda, que essas informações sejam reportadas aos } \\
\text { processos de planejamento de materiais. }\end{array}$ & $\begin{array}{c}\text { Revisão da métrica de planejamento de materiais para a rede } \\
\text { elétrica adotada pelo processo de planejamento logistico de } \\
\text { materiais, onde sugere-se que a métrica seja flexivel e } \\
\text { interativa com as mudanças. }\end{array}$ & $\begin{array}{l}\text { Utilização de um sistema de BI (Business } \\
\text { Intelligence - Inteligência de Negócios) para que } \\
\text { seja realizada a coleta, organização, análise, } \\
\text { compartilhamento e monitoramento de } \\
\text { informações que ofereçam suporte à gestão na } \\
\text { tomada de decisão e que contemple histórico de } \\
\text { consumo de materiais completo entre revisões } \\
\text { tarifärias, para que seja analisado o } \\
\text { comportamento do consumo ano a ano após a } \\
\text { revisão, comparando com o periodo atual, como } \\
\text { também análises de periodos menores e } \\
\text { contemplando como variáveis as mudanças. }\end{array}$ \\
\hline
\end{tabular}

Fonte: elaborado pelos autores com base nos dados da empresa.

Por fim, destaca-se a importância destas modelagens, já que elas proporcionaram um melhor entendimento dos processos, permitindo que qualquer colaborador da organização visualize os fluxos e atores envolvidos, e compreenda o comportamento do sistema, inferindo na melhor gestão dos processos de negócios. Para trabalhos futuros

\section{REFERÊNCIAS}

[1] ABPMP. Guia para o Gerenciamento de Processos de Negócio - Corpo Comum de Conhecimento - (bpm cbok®). Versão 3.0. 2013.

[2] Agência Nacional de Energia Elétrica (aneel). Regulação do Setor Elétrico, 01 dez. 2015b. Disponível em: $<$ http://www.aneel.gov.br/Regulacao-do-setoreletrico >. Acesso em: 22 jan 2017.

[3] Agência Nacional de Energia Elétrica (aneel). Distribuição de Energia Elétrica. 2016b. Disponível sugere-se o mapeamento detalhado de todas as atividades do processo ponta a ponta de materiais, assim como realizar a análise de otimização do consumo, considerando as saídas de materiais para as equipes e compará-las com os materiais que realmente são necessários para cada serviço o que foi um limitante deste trabalho.

$<$ http://www2.aneel.gov.br/area.cfm?ldarea=77\&id perfil=2> . Acesso em: 05 jan 2017.

[4] Baldam R. L. Et al. Gerenciamento de Processos de Negócios: Bpm - Business Process Management. 2. Ed. São Paulo: Érica, 2007.

[5] Capote, G. Guia para Formação de Analistas de Processos. Rio de Janeiro: Gart Capote, 2011. V.1.

[6] Chinosi, M.; trombetta, a. Bpmn: An Introduction to the Standard. Computer Standards \& Interfaces, v. 34, n. 1, p. 124-134, 2012. 
[7] Dias, Marco Aurélio p. Administração de Materiais: uma Abordagem Logística. 5. Ed. São Paulo: Atlas, 2010.

[8] Draghici, A.; Draghici, G.; Olariu, C.; Canda, A. Romanian Market Acceptance For Business Process Management skills Development. Procedia Technology, v. 5, p. 537-546, 2012.

[9] Furlan, J. D. Et al. Abpmp BPM CBOK: Business Process Management Common Body of Knowledge. Abpmp, 2013. (v. 3: primeira liberação em português).

[10] Gil, Antonio Carlos. Como Elaborar Projetos de Pesquisa. 5ํㅡㄹ. EÃO PAULO: ATLAS, 2010

[11] Gonçalves, C. O.; Ramos, D. S. F.; Santos, M. S. Gestão do Conhecimento e Comunicação Organizacional: Estudo da Aplicação de um Modelo de Comunicação Organizacional para Disseminação do Conhecimento. 2009. 83f. Trabalho de Conclusão de Curso (Especialização em Gestão do Conhecimento e Inteligência Empresarial) - Universidade Federal do Rio de Janeiro, Rio de Janeiro, 2009.

[12] Hubbard, D. W. Como mensurar qualquer coisa. Rio de janeiro: qualitymark editora Itda, 2008 .

[13] Jesus, P.; A.; S.; Rodrigues, M.; S.; T.; Torres, J.; B. Proposta de Mapeamento de Processos de Armazenagem em Centro de Distribuição de Supermercados de Fortaleza/ce Utilizando Bpmn. XXII Simpep, nov. 2014. Disponível em Http://Www.Simpep.Feb.Unesp.Br/Anais_Simpep.P hp?E=7. Acesso em: 19 mar. 2017.

[14] Megard, Patrick. Business Process Management: Don't Neglect the User! P. 14 - 17, Eai Journal, 2002.

[15] Mendoza, Luis e.; Capel, Manuel I.; Perez, María a. Conceptual Framework For Business Processes Compositional Verification. Information And Software Technology, v. 54, p. 149-161, 2012.
[16] Minayo, M. C. S. Pesquisa Social: Teoria, Método e Criatividade. 29. Ed. Petrópolis, Rj: Vozes, 2010.

[17] Miranda, E.C. Avaliação de Perdas em Sistemas de Abastecimento de Água - Indicadores de Perdas e Metodologias para Análise de Confiabilidade. Unb: Dissertação de Mestrado. Brasília, 200 f. 2002.

[18] Object Management Group. Business Process Model And Notation, Needham, 2011. Disponível em: <http://www.omg.org/spec/bpmn/2.0/>, Acesso em: 19 mar. 2017.

[19] Paladini, e. P. Qualidade total na prática. São Paulo: Editora atlas, 2005.

[20] Parmenter, d. Key Performance Indicators: Developing, Implementing, And Using Winning Kpis. John Wiley \& Sons, 2010.

[21] Ribeiro, t. O.; drumond, g. M.; méxas, m. P.; costa, h. G. Benefícios do bpm na modelagem dos processos: um estudo exploratório. Xxii simpep, nov. 2015. Disponível em http://www.simpep.feb.unesp.br/anais_simpep.php $? \mathrm{e}=7$. Acesso em: 18 mar. 2017.

[22] Silver, Bruce; Bpms Watch: How Much Bpmn do You Need?; Bpm Institute http://www.Bpminstitute.Org/Resources/Articles/Bp ms-Watch-How-Much-Bpmn-do-You-Need. Acesso em: Mar. 2017.

[23] Slack, N. Chambers, S.; Johnston, R. Administração da Produção. Tradução de Mara Teres a Corrêa de Oliveira; Fabio Alher; Revisão Técnica Henrique Luiz Corrêa. 2 Ed. São Paulo: Atlas, 2002. $7474 \mathrm{p}$.

[24] Toor, T. P. S.; Dhir, t. Benefits Of Integrated Business Planning, Forecasting, And Process Management. Business strategy series, $v$. 12, n. 6, p. 275-288, 2011.

[25] Vergara s. C. Métodos de Coleta de Dados no Campo. São Paulo: atlas, 2009.

[26] Yin, Robert k. Estudo de Caso Planejamento e Métodos. 3 ed. São Paulo: Bookman, 2005. 


\section{Bapítulo 18}

\section{INDÚSTRIA 4.0: PROPOSTA DE MAPA CONCEITUAL}

\section{Renan Mathias Ferreira Saltiel}

Ana Claudia Silva da Silva

\section{Fabiano de Lima Nunes}

\section{Fabio Antonio Sartori Piran}

Felipe Morais Menezes

Resumo: A Indústria 4.0 é considerada por muitos pesquisadores a quarta grande revolução industrial. Aliando modernas tecnologias de informação e automatização, a Indústria 4.0 possibilita a existência de fábricas inteligentes, com máquinas, produtos e equipamentos trabalhando de forma autônoma. Este estudo teve como objetivo propor um mapa conceitual, identificando os principais constructos e conceitos da Indústria 4.0 e suas relações. O método utilizado foi a pesquisa bibliográfica. Como resultados, observou-se que, para a aplicação da Indústria 4.0, é necessário por parte da administração que os investimentos sejam realizados de forma equitativa, pois a Indústria 4.0 é um conjunto, que necessita que todas as áreas da empresa disponham de estrutura e pessoal qualificado para o êxito da operação. Após a definição dos constructos principais, de acordo com os materiais estudados, a proposta de mapa conceitual foi elaborada, nos quais se identificam como principais constructos da Indústria 4.0, a Internet das Coisas (IoT), os Sistemas Ciber-físicos (CPS) e as fábricas inteligentes (Smart Factories).

Palavras-chave: Indústria 4.0. Mapa Conceitual. Tecnologia. 


\section{INTRODUÇÃO}

O crescimento e o desenvolvimento social da humanidade estão ocorrendo de forma exponencial, desde o século passado. Este crescimento dá-se devido ao avanço tecnológico. Em conjunto a estes avanços, a criação de sistemas de produção resulta em desenvolvimentos econômicos sustentáveis a sociedade (BRYNJOLFSSON; MCAFEE, 2014). Para atender estas demandas, as empresas, principalmente de manufatura, perceberam a necessidade de ajustes mais rápidos e eficientes em seus processos produtivos. Com o intuito de suprir essa necessidade, em meados de 2011, surge na Alemanha, um movimento denominado de Indústria 4.0 (BRETTEL et al., 2014). A denominação de indústria 4.0, é referente a uma possível quarta revolução industrial. As revoluções anteriores foram a partir da mecanização (1르 Revolução), uso e aplicação da eletricidade ( $2^{\mathrm{a}}$ Revolução) e a inserção da automação e da tecnologia de informação (3a Revolução), junto aos ambientes produtivos. (ROBLEK et al., 2016).

A Indústria 4.0 possui elevado potencial de aplicação, pois sua plataforma faz com que produtos, ferramentas e os meios de produção troquem informações, a partir da utilização de sensores e chips embarcados com a tecnologia de RFID. Com essas tecnologias, torna-se possível que essa troca de informações inclusive fora dos limites das organizações, sejam gerenciadas de forma integrada com as funções de desenvolvimento de produtos e serviços, produção, vendas, logística e operações (RUSSWURM, 2014; SCHRÖDER et al., 2015).

O conceito da Indústria 4.0 surge com força, em relação aos sistemas produtivos, pois os atuais sistemas não contemplam ferramentas que possibilitem a análise rápida das informações para a tomada de decisões, principalmente no tocante às melhorias de produtividade das organizações. E a partir da elevada inserção da tecnologia de informação, a indústria 4.0, torna-se um fator de competitividade devida a sua conectividade junto aos processos que afetam diretamente aos clientes e consumidores, inclusive integrada às redes sociais, impactando na percepção de valor destes atores (LEE; BAGHERI; KAO, 2015; LEE; KAO; YANG, 2014).

Os estudos e as pesquisas sobre a Indústria 4.0 são recentes (ALMADA-LOBO, 2016;
BRETTEL et al., 2014; GORECKY et al., 2014; LASI et al., 2014; ROBLEK et al., 2016; RUSSWURM, 2014; SCHLECHTENDAHL et al., 2014; SCHRÖDER et al., 2015; SCHUH et al., 2014; SOMMER, 2015). Procurando estender as investigações acerca do tema, esse artigo visa responder a seguinte pergunta de pesquisa: "como os conceitos que compõem a Indústria 4.0 e as suas relações, podem ser representados em forma de um mapa conceitual?". Para responder essa questão, esse artigo tem como objetivo propor um mapa conceitual para a representação conceitual da Indústria 4.0 e as suas relações entre seus constructos. Como objetivos específicos, essa pesquisa tem como: (a) elaborar uma pesquisa em bases de dados científicas, para a busca de publicações acerca do tema da indústria 4.0 e (b) apresentar as relações entre os construtos que compõem a Indústria 4.0.

Este artigo está dividido em cinco capítulos: (a) o primeiro refere-se à introdução; (b) o segundo, apresenta a fundamentação teórica utilizada nessa pesquisa; (c) o terceiro capítulo apresenta a metodologia de pesquisa aplicada na condução desse artigo; (d) o quarto, apresenta as análises e discussões desta pesquisa e; (e) o quinto e final capítulo apresenta as considerações finais, conclusões e sugestões de pesquisas futuras.

\section{REVISÃO TEÓRICA}

\subsection{INDÚSTRIA 4.0}

Existe a demanda, por parte dos consumidores, de produtos de qualidade cada vez mais exclusivos e acessíveis. Assim, o mercado, principalmente as indústrias, são pressionadas a se adequar a este ambiente, desenvolvendo soluções flexíveis, dinâmicas e economicamente viáveis as necessidades da sociedade moderna. Combinando tecnologia avançada de informação e automação, assim como sistemas ciber-físicos (SCF) e produtos e máquinas inteligentes, a Indústria 4.0 (14.0) permite a criação de fábricas inteligentes, com grande potencial de produtividade e aplicabilidade (BRETTEL et al., 2014; ROBLEK et al., 2016; RUSSWURM, 2014).

A 14.0, caracterizada como a quarta revolução industrial, surge com o avanço da tecnologia de informação e comunicação, aplicadas no contexto industrial. É a convergência entre estas bases que proporciona a 14.0 um 
potencial ainda desconhecido, tamanha sua aplicabilidade. A 14.0 utiliza tecnologias avançadas em transmissão e análise de informações, assim como tecnologia de armazenamento nas nuvens, sistemas inteligentes de monitoramento e correção de falhas no ambiente fabril e modernas tecnologias de automação. É a primeira vez que uma revolução industrial é caracterizada antes de seu desenvolvimento completo, e não observada posteriormente. $O$ impacto econômico da 14.0 é projetado como enorme, tamanho seu potencial de desenvolvimento, assim como as oportunidades de novos modelos de negócios são extensas (HERMANN; PENTEK; OTTO, 2016).

Em 2013, o Industry 4.0 Working Group, grupo de referência em pesquisa sobre o assunto, publicou o "Relatório Final de Implementação da Indústria 4.0". Esse material apresentou três componentes-chaves da 14. 0: Internet das coisas (Internet of Things - IoT), sistemas ciber-físicos (SCF) e as fábricas inteligentes (Smart Factories) (HENNING, KAGERMANN WOLFGANG, WAHLSTER JOHANNES, 2013).

A IOT conecta todos os elementos da fábrica, propiciando a integração de dispositivos móveis, máquinas, produtos e sistemas, coletando dados e gerando informações e instruções em tempo real. Os SCF permitem a conexão entre os mundos virtual e físico, com a integração entre processos físicos e computação. Através de sensores e dispositivos embutidos e conectados aos equipamentos, realiza-se o monitoramento e correção dos processos físicos, assim como a adequação dos processos e equipamentos aos parâmetros de qualidade e produtividade almejados pela organização. Os equipamentos da fábrica tornam-se sistemas de produção ciber-físicos (SPCF), com a capacidade das máquinas aumentada com o auxílio de softwares, aproveitando uma vasta gama de sensores, atuadores e softwares embutidos. Um SCPF sabe sua capacidade de produção, seu estado e suas diferentes opções de configuração e produção, permitindo a tomada de decisões autônomas. (ALMADA-LOBO, 2016; HERMANN; PENTEK; OTTO, 2016; ROBLEK et al., 2016; RUSSWURM, 2014).

As fábricas inteligentes (Smart Factories) são a convergência entre todas as tecnologias e sistemas presentes nas empresas. Os produtos, por meio de chips RFID, possuem todas as informações necessárias para a sua fabricação, movimentação e armazenamento.
Caso existam equipamentos defeituosos, a própria máquina realiza a manutenção ou transmite informações para o equipamento necessário, corrigindo os desvios no processo produtivo e eliminando perdas com manutenção e peças de reposição. Com o auxílio de sensores e sistemas embutidos em todas as áreas do processo, os produtos podem definir a melhor maneira de serem produzidos, comunicando-se com todas as máquinas e equipamentos presentes na linha de produção. (ALMADA-LOBO, 2016; HERMANN; PENTEK; OTTO, 2016; RUSSWURM, 2014).

Outro fator importante são as máquinas existentes no processo produtivo, que são capazes de gerar e receber informações, realizar análises e tomar decisões com base na situação existente na fábrica, sem a necessidade de interrupções e perdas de tempo e produtividade. (HERMANN; PENTEK; OTTO, 2016; RUSSWURM, 2014).

A transparência de informação é um fator importante no contexto da 14.0. Com uma vasta gama de objetos e equipamentos conectados, trabalhando em sintonia e gerando informações em tempo real, é necessário que padrões de comunicação e transmissão sejam eficientemente gerenciados, de forma que informações e dados importantes sejam sempre priorizados. Paralelamente a isto, com informações sigilosas das empresas sendo compartilhadas entre as partes do processo, é importante que as tecnologias de segurança da informação sejam devidamente implantadas e aperfeiçoadas, de forma a proporcionar um ambiente seguro para o desenvolvimento das organizações. (HERMANN; PENTEK; OTTO, 2016; ROBLEK et al., 2016).

Em um ambiente altamente flexível e autônomo, as decisões devem ser descentralizadas para o correto funcionamento do sistema. Todos os objetos, equipamentos e pessoas são conectados pela IOT e os SCF, tendo uma rede completa de transparência de informação e simulação de dados e situações disponíveis para tomada de decisão. Todas as partes do processo devem ser tão autônomas quanto possível, possibilitando o aproveitamento total da tecnologia disponível no ambiente da fábrica. Apenas as situações mais complexas e decisivas devem ser levadas aos níveis superiores (ALMADA-LOBO, 2016; HERMANN; PENTEK; OTTO, 2016; SCHUH et al., 2014). 
A partir da utilização de sistemas inteligentes e tecnologias avançadas de monitoramento e controle de produção, a 14.0 tem como uma de suas características principais a autonomia de máquinas e equipamentos dentro do ambiente da fábrica inteligente. Assim, com as máquinas tomando decisões e organizando-se de forma autônoma, diferentes cenários de produção cada vez mais complexos podem surgir no contexto da 14. 0. No entanto, o movimento não é de eliminação do fator humano dentro das empresas. Com uma vasta gama de tecnologias e equipamentos, o trabalho humano será de constituído fundamentalmente de "trabalho mental", com atividades de planejamento, desenvolvimento, controle e supervisão de equipamentos, softwares, máquinas e produtos. $O$ fator humano tem importância destacada, com um ambiente propício ao aprendizado e desenvolvimento de habilidades, permitindo o aproveitamento total das capacidades do capital humano, muitas vezes desperdiçado com trabalhos físicos e repetitivos (GORECKY et al., 2014; RUSSWURM, 2014)

\subsection{MAPAS CONCEITUAIS}

Os mapas conceituais foram desenvolvidos com o intuito de propor uma forma de instrumentalização da teoria da aprendizagem significativa (NOVAK, 2010; NOVAK; CAÑAS, 2008; NOVAK; GOWIN, 1984). Os mapeamentos conceituais envolvem a identificação de conceitos ou ideias pertencentes a um tema, e a descrição das relações existentes entre essas ideias a partir de uma forma representada por um desenho esquemático. (RUIZ-PRIMO; ARACELI; SHAVELSON, 1996; SHERRATT; SCHLABACH, 1990). A partir da compilação das relações de construtos, torna-se possível a elaboração de um mapa conceitual, com o intuito de apresentar de forma clara e direta essas relações(NUNES, 2015), conforme ilustra a Figura 1.

Figura 1 - Exemplo de mapa conceitual.

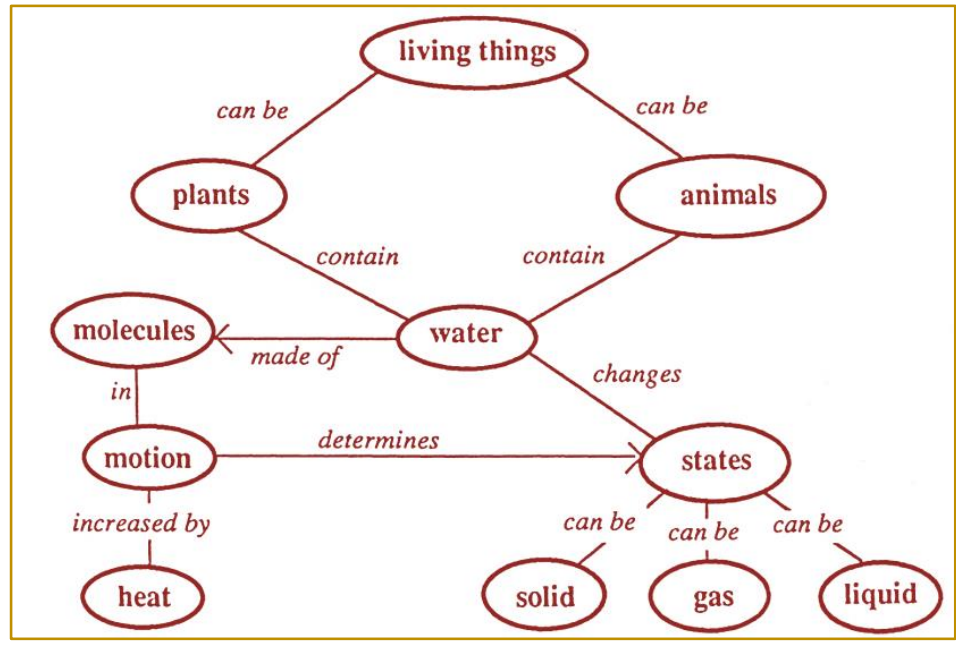

Fonte: Sherratt e Schlabach (1990)

Após a apresentação do referencial teórico o próximo capítulo apresenta os aspectos metodológicos utilizados no desenvolvimento da pesquisa.

\section{METODOLOGIA}

A metodologia científica orienta o pesquisador com o intuito da obtenção dos objetivos propostos em sua pesquisa. Em relação a sua natureza, essa pesquisa caracteriza-se como aplicada e com fins e objetivos exploratórios. No que tange aos procedimentos técnicos, aplicou-se a pesquisa bibliográfica. Esse tipo de procedimento visa o aprofundamento acerca de um tema, a partir de fontes de dados já organizados e analisados como informação. Nas quais devem ser referenciadas por fontes bibliográficas (ZUPIC, CATER, 2015). Para a elaboração dessa pesquisa foram verificados materiais já publicados (livros, publicações em periódicos, artigos científicos, monografias, dissertações, dentre outros) (GIL, 2010; MIGUEL, 2012; PROVDANOV; FREITAS, 2013) Como método de trabalho, adaptou-se o método aplicado por Nunes e Menezes (2014) 
Figura 2 - Método de trabalho aplicado na condução da pesquisa.

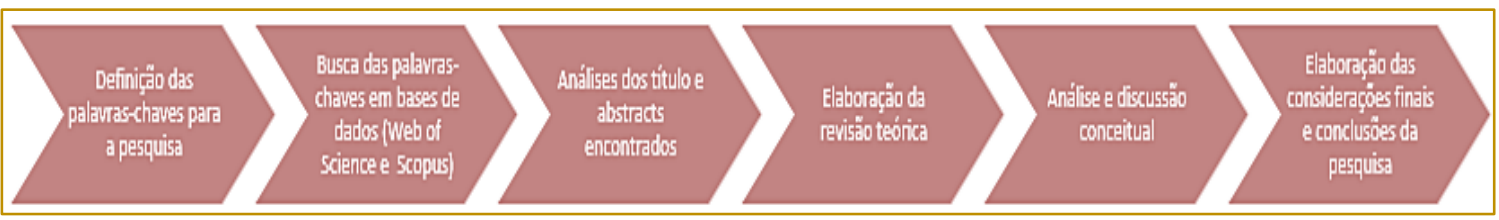

Fonte: adaptado de Nunes e Menezes (2014) e Tomaszewki et al. (2013)

Foram efetuadas pesquisas nas bases de dados Web of Science e Scopus, com o objetivo de elaborar uma pesquisa bibliométrica e uma revisão sistemática da literatura com as seguintes palavras-chave. (NUNES; MENEZES, 2014; PIRAN et al., 2015): Indústria 4.0; Sistemas de Manufatura Digital; Sistemas Ciber Físicos; Indústria 4.0 "E" Sistemas de Manufatura Digital; Indústria 4.0 "E" Sistemas Ciber Físicos; Sistemas de Manufatura Digital "E" Sistemas Ciber Físicos e; Indústria 4.0 "E" Sistemas de Manufatura Digital "E" Sistemas Ciber Físicos, bem como a pesquisa dessas palavras traduzidas na língua inglesa. A Web of Science é uma base de dados da editora Thomson Reuters. Essa base revê anualmente entre 3.000 a 4.000 journals de artigos científicos, para incluí-los em sua base. Esses artigos são disponibilizados em mais de 9.200 títulos de periódicos (THOMSON REUTERS, 2016). A base Scopus foi lançada em 2004 pela editora Elsevier e contém resumos e citações de literatura científica revisada por pares, totalizando mais de 21.500 revistas e jornais científico (ELSEVIER, 2016). Os resultados apurados nas bases são apresentados na Tabela 1.

Tabela 2: Resultados da busca de palavras-chaves sobre Indústria 4.0, nas bases Web of Science e Scopus, no período dos anos 1960 e 2017

\begin{tabular}{|l|c|c|}
\multicolumn{1}{|c|}{ Palavras-chaves } & Web of science & Scopus \\
\hline Indústria 4.0 & 1 & 2 \\
\hline Industry 4.0 & 1428 & 1761 \\
\hline Sistemas de Manufatura Digital & 0 & 0 \\
\hline Digital Manufacturing Systems & 1217 & 2370 \\
\hline Sistemas Ciber Físicos & 0 & 0 \\
\hline Cyber Physical Systems & 1230 & 1657 \\
\hline Indústria 4.0 "E" Manufatura Digital & 0 & 2 \\
\hline Industry 4.0 "AND" Digital Manufacturing Systems & 7 & 1761 \\
\hline Indústria 4.0 "E" Sistemas Ciber Físicos & 0 & 2 \\
\hline Industry 4.0 "AND" Cyber-physical Systems & 40 & 0 \\
\hline Sistemas de Manufatura Digital "E" Sistemas Ciber Físicos & 0 & 2370 \\
\hline Digital Manufacturing Systems "AND" Cyber-physical Systems & 5 & 0 \\
\hline $\begin{array}{l}\text { Indústria 4.0 "E" Sistemas de Manufatura Digital "E" Sistemas } \\
\text { Ciber Físicos }\end{array}$ & 0 & 1761 \\
\hline $\begin{array}{l}\text { Industry 4.0 "AND" Digital Manufacturing Systems "AND" Cyber- } \\
\text { physical Systems }\end{array}$ & 10 & \\
\hline
\end{tabular}

Fonte: Autores 
A partir dos artigos encontrados, dados foram analisados seus títulos e seus abstracts e verificados quais destes artigos possuíam aderência à pesquisa. Estes foram utilizados na elaboração da revisão teórica acerca do tema da Indústria 4.0. Após essa etapa, foi realizada a análise $e$ as discussões conceituais da Indústria 4.0, com o intuito de elaborar o framework referente ao tema, de acordo com o objetivo proposto dessa pesquisa. Após, foram elaboradas as considerações finais e as conclusões desse artigo.

\section{ANÁLISE E DISCUSSÃO DOS RESULTADOS}

A Indústria 4.0 (BRETTEL et al., 2014; GORECKY et al., 2014; LASI et al., 2014; LEE; KAO; YANG, 2014; RUSSWURM, 2014; SCHLECHTENDAHL et al., 2014; SCHUH et al., 2014; LEE; BAGHERI; KAO, 2015; HERMANN; SCHRÖDER et al., 2015; SOMMER, 2015; ALMADA-LOBO, 2016a; PENTEK; OTTO, 2016; ROBLEK et al., 2016) utiliza a internet das coisas (LEE; KAO; YANG, 2014; SOMMER, 2015; (ALMADA-LOBO, 2016; HERMANN; PENTEK; OTTO, 2016; SCHUH et al., 2014) para integrar equipamentos, dispositivos móveis e sistemas, para realizar a correção de desvios no processo, a manutenção seja realizada pela própria máquina, através de uma tomada de decisão autônoma. (LEE; KAO; YANG, 2014); (ROBLEK et al., 2016). Além disso, RFID é utilizado para obter informações de movimentação e armazenagem em tempo real, que também acarretará uma tomada de decisão autônoma. (LEE; KAO; YANG, 2014; ALMADA-LOBO, 2016; ROBLEK et al., 2016). A IOT também está relacionada com os sistemas ciber físicos (LEE; KAO; YANG, 2014; SCHRÖDER et al., 2015; ALMADALOBO, 2016) através dos quais, pode-se coletar e analisar dados para gerar informações e instruções em tempo real. Os sistemas de produção ciber físicos transformam as indústrias em fábricas inteligentes (BRETTEL et al., 2014; HERMANN; PENTEK; OTTO, 2016; ROBLEK et al., 2016).

As fábricas inteligentes aproveitam ao máximo o capital humano (GORECKY et al., 2014; RUSSWURM, 2014), para que os cenários de produção complexos, gerados pela tecnologia, sejam desenvolvidos, planejados e controlados, garantindo uma alta qualidade e rentabilidade (LEE; BAGHERI; KAO, 2015; SOMMER, 2015), tornando seus produtos diferenciados (BRETTEL et al., 2014; SOMMER, 2015). A Tabela 2 apresenta as principais relações e interrelações da 14. 0.

Tabela 3: Relações da indústria 4.0 e os autores que as suportam

\begin{tabular}{|l|l|l|}
\hline \multicolumn{1}{|c|}{ Principais Construtos da } & \multicolumn{1}{|c|}{ Relações e Inter-relações } \\
\hline I4.0 & $\begin{array}{l}\text { Integrar máquinas, dispositivos móveis e } \\
\text { sistemas } \\
\text { Utilização de RFID obtendo informações de } \\
\text { movimentação e armazenagem em tempo } \\
\text { Internet das Coisas } \\
\text { Correção de desvios no processo e e } \\
\text { manutenção realizada pela própria máquina }\end{array}$ & $\begin{array}{l}\text { (Lee; kao; Yang, 2014; Sommer, } \\
\text { 2015; Almada-Lobo, 2016; } \\
\text { Hermann; Pentek; Otto, 2016; } \\
\text { Schuh et al., 2014) }\end{array}$ \\
\hline Sistemas Cyber Físicos & $\begin{array}{l}\text { Coletar e analisar dados para gerar } \\
\text { informações e instruções em tempo real } \\
\text { Integrar softwares aos processos físicos } \\
\text { Tomada de decisão autônoma }\end{array}$ & $\begin{array}{l}\text { (Brettel Et Al., 2014; Hermann; } \\
\text { Pentek; Otto, 2016; Roblek Et } \\
\text { Al., 2016). }\end{array}$ \\
\hline Fábricas Inteligentes & $\begin{array}{l}\text { Alta qualidade e rentabilidade } \\
\text { Utilização elevada do capital humano } \\
\text { Entrega de produtos diferenciados } \\
\text { Desenvolvimento, planejamento e controle de } \\
\text { cenários complexos } \\
\text { Desenvolvimento sustentável, com redução } \\
\text { de resíduos e utilização de energias } \\
\text { renováveis. }\end{array}$ & $\begin{array}{l}\text { (Brettel Et Al., 2014; Gorecky Et } \\
\text { Al., 2014; Russwurm, 2014; Lee; } \\
\text { Bagheri; Kao, 2015; Sommer, } \\
\text { 2015, Roblek Et Al., 2016) }\end{array}$ \\
\hline
\end{tabular}


Com base nas relações e inter-relações identificadas através de uma revisão sistemática da literatura, foi elaborado o mapa conceitual da indústria 4.0. Os construtos e suas relações estão destacados de formas diferentes, conforme a legenda apresentada na Figura 3.

Figura 3: Legenda do mapa conceitual

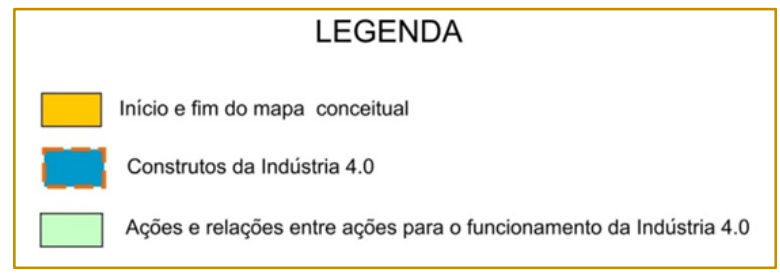

Fonte: autores

A Figura 5 apresenta a proposta de um mapa conceitual, elaborado a partir das análises

efetuadas na pesquisa.

Figura 3: Mapa conceitual da Indústria 4.0

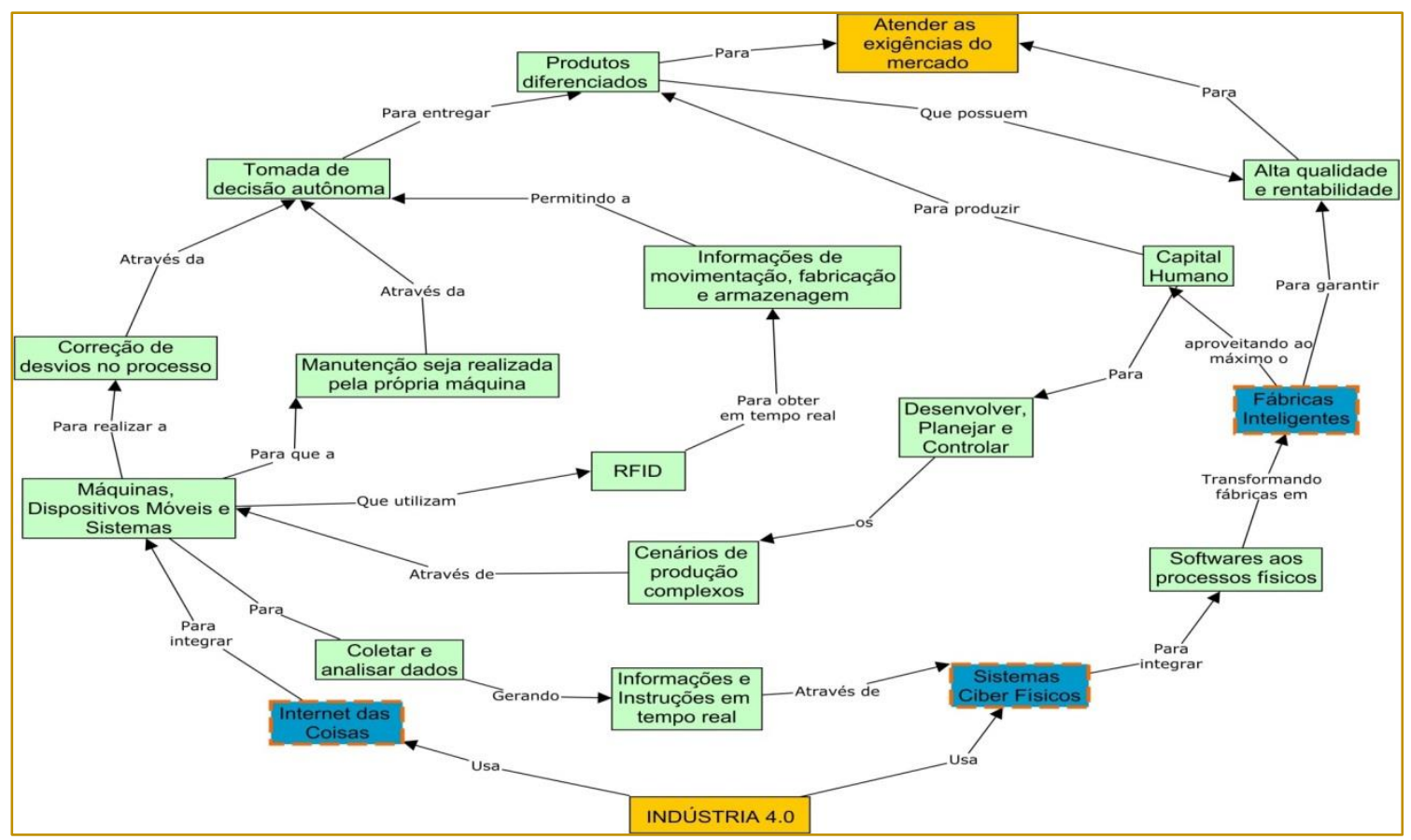

Fonte: autores

A partir da apresentação da proposta do Mapa Conceitual, é possível perceber as interações entre os construtos que compõem a Indústria 4.0.

\section{CONSIDERAÇÕES FINAIS}

Este artigo teve como objetivo, a proposição de um mapa conceitual para a representação conceitual da Indústria 4.0 e as relações entre seus construtos. Essa pesquisa visa contribuir na apresentação dos constructos, considerados pela literatura, como os pilares norteadores da Indústria 4.0. Esses constructos são: Internet das Coisas (IOT), Sistemas Ciber Físicos (Cyber-Physical Systems) e Fábricas Inteligentes (Smart Factories).

A proposta de mapa conceitual mostra as relações e inter-relações entre os constructos. A partir dessas informações evidencia-se que as interações não são isoladas e que os 
constructos se relacionam entre si, dando suporte ao objetivo principal da Indústria 4.0 que é atender as exigências de um mercado cada vez mais dinâmico e incerto. Além disso, percebe-se que para obter sucesso na implantação dos conceitos da indústria 4.0 as empresas precisam desenvolver os conceitos e efetuar os investimentos de forma equitativa. Não é possível desenvolver uma fábrica inteligente sem a utilização da Internet das Coisas e dos Sistemas Ciber Físicos, por exemplo.

Por fim, entende-se que a proposição do mapa conceitual irá contribuir no

\section{REFERÊNCIAS}

[1] Almada-lobo, F. The Industry 4.0 Revolution And The FUTURE of Manufacturing Execution Systems (mes). Journal of Innovation Management, v. 3, n. 4, p. 17, 2016.

[2] Brettel, M. Et al. How virtualization, Decentrazliation And Network Building Change The Manufacturing Landscape: an Industry 4.0 Perspective. International Journal of Mechanical, Aerospace, Industrial, Mechatronic and Manufacturing Engineering, v. 8, n. 1, p. 37-44, 2014

[3] Brynjolfsson, e.; Mcafee, a. THE Second Machine Age: Work, Progress, And Prosperity In a Time Of Brilliant Technologies. WW Norton \& Company., p. 420-421, 2014.

[4] Gil, a. C. Como elaborar Projetos de Pesquisa. São Paulo: atlas, 2010.

[5] Gorecky, D. Et al. Human-MachineInteraction In The Industry 4.0 era. Proceedings 2014 12th leee International Conference on Industrial Informatics, Indin 2014, p. 289-294, 2014.

[6] Henning, kagermann Wolfgang, Wahlster Johannes, h. Recommendations for Implementing The Strategic Initiative Industrie 4.0. Final report of the industrie $4.0 \mathrm{wg}, \mathrm{n}$. April, p. 82, 2013.

[7] Hermann, m.; pentek, t.; otto, b. Design principles for industrie 4.0 scenarios. Proceedings of the annual hawaii international conference on system sciences, v. 2016-march, p. 3928-3937, 2016.

[8] Lasi, h. Et al. Industry 4.0. Business and information systems engineering, v. 6, n. 4, p. 239242, 2014

[9] Lee, J.; Bagheri, B.; Kao, H. A. A CyberPhysical Systems Architecture For Industry 4.0Based Manufacturing Systems. Manufacturing Letters, v. 3, n. December, p. 18-23, 2015. entendimento dos conceitos da 4 ㅇ Revolução Industrial que ainda são incipientes na literatura. Essa estrutura proposta em forma de mapa conceitual facilita o entendimento dos gestores e pode servir para auxiliar nas discussões empíricas realizadas nas empresas. O mapa proposto pode ser um ponto de partida para realização de melhorias e novas construções por parte do corpo acadêmico. Assim, sugere-se pesquisas futuras buscando melhorias no artefato proposto, bem como a inclusão de novas relações e interpelações entre os constructos identificados.

[10] Lee, j.; kao, h. A.; Yang, s. Service Innovation And Smart Analytics For Industry 4.0 And Big Data Environment. Procedia Cirp, v. 16, p. 3-8, 2014

[11] Miguel, P. A. C. Metodologia de Pesquisa em Engenharia de Produção e Gestão de Operações. Rio de Janeiro: Elsevier: Abepro, 2012.

[12] Novak, j. D. Learning, creating, And Using Knowledge: Concept Maps As Facilitative Tools In Schools And Corporations. Journal Of e-Learning And Knowledge Society, v. 6, n. 3, p. 21-30, 2010.

[13] Novak, j. D.; Cañas, A J. THE Theory Underlying Concept Maps And How To Construct and Use Them. Florida Institute for Human And Machine Cognition, p. 1-36, 2008.

[14] Novak, J. D.; Gowin, D. B. LEARNING How To Learn. [s.l.] Cambridge University Press., 1984.

[15] Nunes, f. L. De. Sistema hyundai de produção: uma proposição de modelo conceitual. N. Dissertação: mestrado em engenharia de produção e sistemas-unisinos, 2015.

[16] Nunes, F. L. De; Menezes, F. M. Sistema Hyundai de Produção e Sistema Toyota de Produção: Suas Interações e Diferenças. Revista Acadêmica São Marcos, v. 4, n. 2, p. 101-120, 2014.

[17] Piran, f. A. S. Et al. Modularization Strategy: Analysis Of Published Articles On Production And Operations Management (1999 to 2013). International Journal of Advanced Manufacturing Technology, p. 1-13, 2015.

[18] Provdanov, C. C.; Freitas, E. C. De. Metodologia do Trabalho Científico: Métodos e Técnicas da Pesquisa e do Trabalho Acadêmico. [s.l: s.n.].

[19] Roblek, V. Et Al. A complex View Of Industry 4.0. Sage Open, v. 6, n. 2, p. 16-21, 2016. 
[20] Ruiz-primo; Araceli, M.; shavelson, R. J. Problems And Issues In The Use Of Concept Maps In Science assessmentjournal of research in science teaching, 1996.

[21] Russwurm, s. Industry 4.0 - From Vision to Reality. Background Information, p. 1, 2014.

[22] Schlechtendahl, J. Et al. Making Existing Production Systems Industry 4.0-Ready: Holistic Approach To The Integration of Existing Production Systems In Industry 4.0 Environments. Production Engineering, v. 9, n. 1, p. 143-148, 2014.

[23] Schröder, r. Et al. Análise da implantação de um processo automatizado em uma empresa calçadista: um estudo de caso a luz do sistema hyundai de produção e a indústria 4.0. Revista espacios caracas, v. 36, n. 18, p. 19, 2015.
[24] Schuh, g. Et al. Collaboration mechanisms to increase productivity in the context of industrie 4.0. Procedia cirp, v. 19, n. C, p. 51-56, 2014.

[25] Sherratt, C. S.; Schlabach, M. L. The Applications Of Concept Mapping in Reference And INFORMATION services. Rq, v. 30, n. 1, p. 6069, 1990.

[26] Sommer, I. Industrial Revolution - Industry 4.0: Are German Manufacturing Smes The First Victims of This Revolution? Journal of Industrial Engineering And Management, v. 8, n. 5, p. 15121532, 2015.

[27] Tomaszewki, I. A. Et al. Comparando os Sistemas de Produção: uma Perspectiva do Sistema Toyota de Produção x Sistema Hyundai de Produção. Anais do xxiii - Encontro Nacional de Engenharia de Produção - Enegep, 2013. 


\section{Bapítulo 19}

\section{BENEFICIOS DA UTILIZAÇÃO DA MINERAÇÃO DE PROCESSOS}

\section{Roquemar de Lima Baldam \\ Luciana de França Pestana \\ Paulo Cezar Thiebaut \\ Lourenço Costa \\ Thalmo de Paiva Coelho Junior}

Resumo: A mineração de processos é um tema que tem apresentado relevância nos últimos anos, tendo em vista a constante necessidade de melhoria de processos de negócios em ambientes competitivos. Assim, num contexto em que se busca melhorias de eficiência, a presente pesquisa objetiva identificar os principais benefícios resultantes da utilização de mineração de processos nas organizações. Para se alcançar o objetivo proposto pelo estudo, foi realizada uma revisão sistemática de literatura, proposta por Cooper (1984), objetivando, a partir da pesquisa e análise dos estudos primários, realizar a discussão e a síntese dos resultados. A partir da metodologia utilizada, foram selecionados estudos primários que dispunham sobre os benefícios decorrentes da aplicação da mineração de processos. Foram identificados diversos benefícios decorrentes da utilização da técnica nas organizações, classificados em 14 modalidades distintas. O presente estudo se justifica pela relevância do tema e pela falta de achados, na literatura, de estudos que abordem, de forma sistemática, os benefícios identificados por pesquisas primárias, decorrentes da aplicação da mineração de processos.

Palavras-chave: Mineração de processos, benefícios, gerenciamento de processos de negócios, logs de eventos. 


\section{INTRODUÇÃO}

A melhoria de processos de negócios é um tema de crescente preocupação e um fator crítico de sucesso para organizações (REBUGE et al, 2012). O gerenciamento, o controle e o planejamento de processos de negócios são de grande valia para que o resultado esperado seja efetivamente alcançado.

A necessidade de melhorar processos de negócio em ambientes competitivos e de rápida evolução (VOJTECH, 2012) proporciona um interesse no estudo na área de mineração de processos (VAN DER AALST et al, 2003), tendo em vista que a mesma permite às organizações atender suas necessidades de aprender sobre seus próprios processos (TIWARI, 2014). Nesse contexto, embora exista um grande número de contribuições para a literatura de mineração ao longo da última década, o número de estudos que demonstram, na prática, a aplicabilidade e o valor destas técnicas, na prática, é limitado (WEERDT, 2013).

As técnicas de mineração de processos estão orientadas para extrair conhecimento a partir de registros de eventos (logs), frequentemente disponíveis nos sistemas de informação atualmente existentes. Estas técnicas oferecem novos meios para descobrir, monitorizar e melhorar processos num vasto domínio de aplicações (VAN DER AALST et al, 2012). Informações como atividades do processo, recursos humanos envolvidos na execução das atividades, período em que as atividades foram realizadas e eventos que desencadearam uma atividade, são alguns exemplos de informações que podem ser extraídas por meio da técnica. A idéia básica da mineração de processos é diagnosticar o conhecimento do processo de negócio por meio dos logs de eventos (VAN DER AASLT e MEDEIROS, 2004).

Assim, com o intuito de abordar possibilidades de melhorias de eficiência, o presente estudo concentra-se em realizar uma análise dos principais benefícios adquiridos por uma organização com a utilização da mineração de processos. Para tanto, será realizada uma revisão sistemática de literatura, utilizando a metodologia preconizada por Cooper (1984), que envolve as etapas de formulação do problema; coleta, avaliação e análise dos dados; e apresentação dos resultados.

As seções deste artigo estão dispostas da seguinte forma: na seção 2, é disposto um quadro conceitual através da revisão da literatura sobre Mineração de Processos. A seção 3 apresenta a metodologia utilizada e na seção 4 são apresentados os resultados da pesquisa realizada.

\section{REVISÃO DE LITERATURA}

A maioria das organizações tem algum tipo de sistema de informação orientada para o processo que mantém o controle e armazenamento dos eventos de negócios eventos realizados (WEERDT, 2013). Gestão de processos de negócios (BPM - Business Process Management) inclui métodos e técnicas e ferramentas para apoiar o projeto, a realização, o acompanhamento e a melhoria de processos de negócios - ou workflows de negócios (VAN DER AALST et al., 2003). Por outro lado, a mineração de dados consiste na extração ou mineração de conhecimento a partir de grandes quantidades de dados $(\mathrm{H}$. JIAWEI E M. KAMBER, 2010). Na junção das duas áreas - BPM e mineração de dados -, um novo campo de estudo é estabelecido, chamado mineração de processos de negócios (VAN DER AALST, 2011). Assim, a mineração de processos se situa entre a mineração de dados e aprendizado de máquina, de um lado e a modelagem e a análise de processo de negócios de outro, proporcionando uma importante interligação entre eles. (VAN DER AALST et al, 2011).

Nesse sentido, a mineração de processos busca descobrir, monitorar, otimizar processos reais, por meio da extração do conhecimento existentes nos registros de eventos dos processos gerados pelos sistemas de informação. Ela também pode ser utilizada para monitorar sistemas ou processos operacionais, como descritos em Medeiros et al. (2007). Além disso, técnicas de mineração de processos disponibilizam meios mais rigorosos para verificação de conformidade e averiguação da validade e confiabilidade da informação acerca dos processos centrais das organizações. (VAN DER AALST et al, 2011).

A avaliação da qualidade dos modelos de processo descobertos é um elemento essencial, tanto para a realização do 
processo de pesquisa de mineração, bem como para a utilização do processo de exploração mineira, na prática (WEERDT, 2012). A partir do modelo de processo elaborado, poderá haver uma estruturação do conhecimento organizacional com o objetivo de entender o funcionamento holístico de uma empresa ou um processo do negócio (BUBENKO et al., 1998).

O segundo tipo de mineração de processos, a conformidade é utilizada para comparar um modelo de processo existente com o log de eventos do mesmo processo. A comparação mostra as diferenças existentes entre 0 verdadeiro processo e o processo modelado, podendo quantificar as diferenças de nível de conformidade entre eles.
A verificação de conformidade é altamente relevante para a auditoria (VASARHELYI , 2004) e análise de risco dos processos (HULSTIJN, 2010).

O terceiro tipo de mineração de processo é o aprimoramento. Essa técnica objetiva estender ou aprimorar um modelo de processo a partir da utilização da informação existente sobre o processo real gravado em algum log de eventos. Considerando as medidas de controle de conformidade do alinhamento entre modelo e realidade, esse tipo de mineração visa, a priori, alterar ou ampliar o modelo do processo. Por exemplo, usando timestamps no log de eventos podese estender o modelo para mostrar pontos de estrangulamento, níveis de serviço, tempos de produção e frequências.

Figura 01 - Tipos básicos de mineração de processos em termo de entradas e saídas: (a) descoberta, (2) conformidade e (3) aprimoramento.

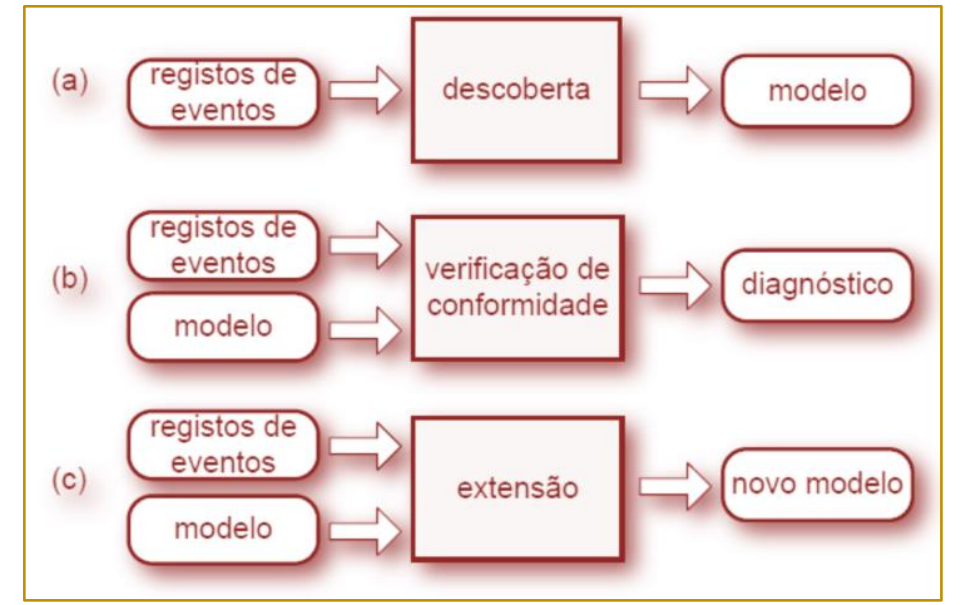

\section{METODOLOGIA}

O método utilizado nesse artigo consiste em uma pesquisa na literatura, com o objetivo de reunir subsídios para a investigação dos benefícios da mineração de processos. Buscou-se identificar os casos de mineração de processos e reunir as principais vantagens obtidas através da utilização da técnica, bem como sintetizar conhecimentos relacionados ao tema, para ganhar uma nova perspectiva.

A revisão sistemática de literatura empreendida nessa pesquisa baseou-se no protocolo estabelecido por Cooper (1984), que inclui as seguintes etapas: (1) formulação do problema; (2) coleta de dados; (3) avaliação dos dados; (4) análise e Gestão da Produção em Foco - Volume 20 interpretação; e (5) apresentação dos resultados. Ela objetivou identificar contribuições relevantes sobre a utilização de mineração de processos em organizações. Publicações relevantes foram identificadas através de uma estratégia de busca estruturada e iterativa, selecionando palavraschave e incorporando outros termos de pesquisa à medida que artigos relevantes foram identificados. Uma visão geral do protocolo utilizado, baseado na proposição de Cooper (1984), é apresentado na figura 02 e descrito em detalhes a seguir.

A primeira etapa, de formulação do problema, envolveu a definição do objetivo que se desejava alcançar através da revisão de 
literatura. Isso permitiu a distinção entre o que era e o que não era relevante para o estudo. Nesse caso, o foco principal de interesse foi a identificação de referências que dispusessem sobre a mineração de processos e sobre os benefícios de sua utilização.

Fig. 02 - Visão geral da revisão sistemática de literatura

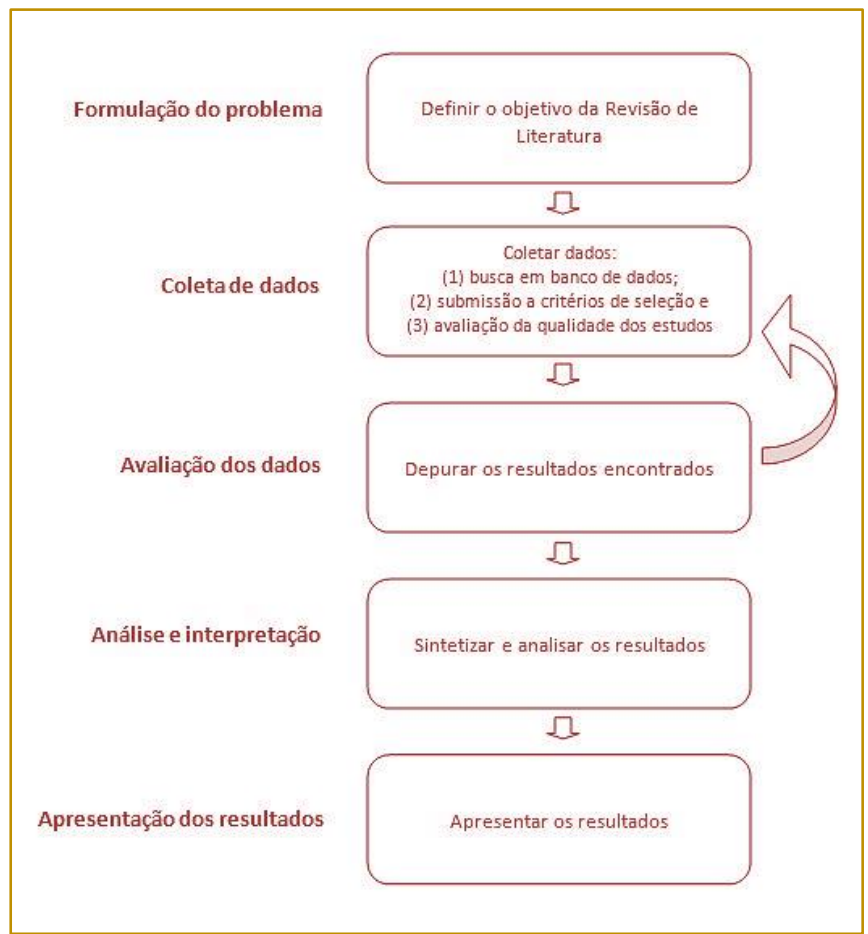

A coleta de dados envolveu as atividades de seleção dos bancos de dados de publicações, escolha das palavras-chaves de busca e realização das buscas. O critério adotado para a escolha da base de dados a ser investigada foi em nível internacional na área de pesquisa, no portal da CAPES, tendo em vista a disponibilidade e grande variedade de material técnico. Os principais termos e palavras-chave (e suas variantes) utilizados nas buscas foram os seguintes: "process mining", "benefits" "business process management", "case study", combinados entre si. Objetivando uma elaboração de pesquisa atualizada, a busca se restringiu a artigos produzidos entre os anos de 2010 a 2015.

Além disso, artigos secundários encontrados a partir da busca principal, também foram considerados para a pesquisa, tendo em vista que tinham conteúdo semelhante ao da busca primária. Nesses, não houve critério de restrição temporal, para suas seleções.
A etapa de avaliação de dados envolve o julgamento sobre a inclusão ou não de um artigo na revisão de literatura. O investigador deve examinar todas as potenciais evidências que podem tornar um artigo irrelevante para o problema que está sob análise (COOPER, 1984).

Nessa etapa, realizou-se uma depuração dos resultados obtidos nas buscas e os estudos foram selecionados com base em sua relevância quanto ao tema pesquisado. A avaliação baseou-se na leitura do título e do resumo de cada trabalho. Caso essa leitura não fosse suficiente para o julgamento sobre a inclusão ou não de um determinado estudo, esse era lido por inteiro.

Nesse trabalho, optou-se por não utilizar fichas de codificação; as publicações selecionadas foram cadastradas e armazenadas no banco de dados de uma planilha.

As etapas de coleta e avaliação dos dados foram realizadas iterativamente, variando e 
combinando as palavras-chave em cada nova busca, até que fosse observado um estresse nas buscas, com repetição das publicações já encontradas.

Os artigos em que não se conseguiu ter acesso ao texto integral, seja por restrição de acesso ou por se tratar de documentos pagos, foram excluídos da revisão.

A etapa de análise e interpretação dos dados abrange a determinação da informação que deve ser extraída e a preparação de uma síntese dos estudos incluídos na revisão sistemática de literatura. O propósito da análise é reduzir os dados para uma forma inteligível e interpretável, enquanto na interpretação são feitas inferências pertinentes aos temas pesquisados e são retiradas conclusões a respeito do assunto (COOPER, 1984).

\section{RESULTADOS E DISCUSSÕES}

Esta seção apresenta uma visão geral dos resultados produzidos pela realização desta Revisão Sistemática de Literatura. O Gráfico 01 mostra os principais benefícios identificados nos estudos primários.

Gráfico 01 - Benefícios identificados nos estudos primários.

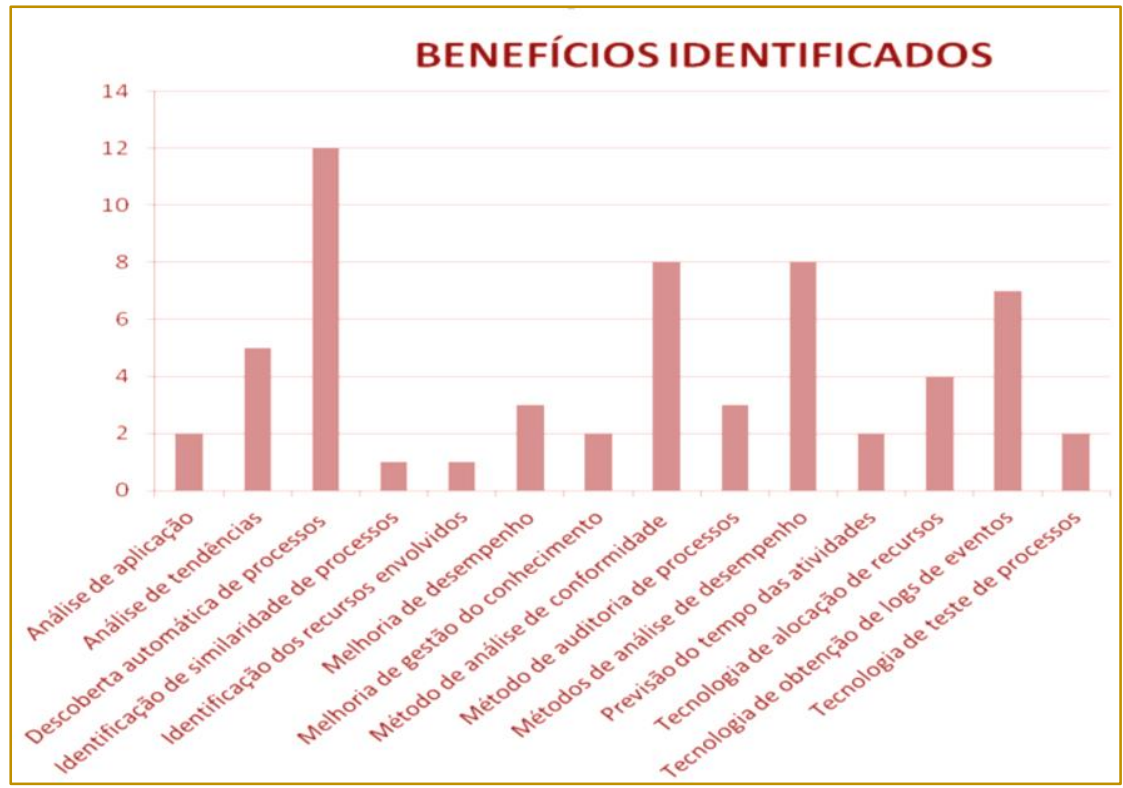

1. Análise de aplicação: A mineração de processos possibilita a análise de aplicação de ferramentas relacionadas à técnica, em casos específicos, bem como a apresentação dos eventuais resultados obtidos. O benefício da análise de aplicação foi citado por 02 artigos.

2. Análise de tendências: A análise de tendências oferece uma visão da evolução das pesquisas em áreas definidas, buscando avaliar os estudos já realizados nessas áreas e os eventuais benefícios alcançados, bem como as potencialidades decorrentes de novos trabalhos. O benefício da análise de tendências foi identificado em três artigos.
3. Descoberta automática de modelos de processos: A descoberta automática de modelos de processos foi um benefício citado por um total de 12 artigos. A mineração de processos possibilita a descoberta dos processos da organização, exigindo-se, para tanto, o tratamento dos logs de eventos, de maneira que se possa obter, após a sua organização e unificação, a identificação dos processos em execução, dos recursos envolvidos em cada fase dessa execução, dos períodos de tempo decorridos em cada fase e da cronologia dessas fases, de forma a possibilitar a criação de um "mapa" de cada processo. 
4. Identificação da similaridade dos processos: A identificação de similaridade dos processos mediante o uso da ferramenta dos gráficos de dependência temporal - "time dependency graph" ou TDG foi um benefício citado por Yinglong Ma, Xiaolan Zhang, e Ke Lu, em 01 artigo. O benefício decorreu do desenvolvimento dos gráficos de dependência temporal - "time dependency graph" ou TDG - para identificar similaridade entre processos formalmente diferentes, mas que tenham exigências, tarefas/serviços e funções semelhantes.

5. Identificação dos recursos envolvidos: $A$ mineração de processos permite a identificação dos agentes e das áreas da organização que participaram de cada fase do processo, sendo até mesmo possível identificar a função exercida por esses recursos para a obtenção do resultado final dos processos.

6. Melhoria do desempenho: A possibilidade de melhoria de desempenho na execução de processos foi um benefício decorrente da mineração citada por W.M.P. van der Aalst, M.H. Schonenberg e M. Song, de Deirdre C. Kelleher, MD, R.P. Jagadeesh Chandra Bose, $\mathrm{PhD}$, Lauren J. Waterhouse, BS, Elizabeth A. Carter, PhD, MPH, Randall S. Burd, MD, PhD e FACS, e, 03 artigos.

7. Melhoria na gestão do conhecimento: A possibilidade de melhoria na gestão do conhecimento foi um benefício citado por Vaclav Slavicek, Rosemary Francisco e Eduardo A. Portela Santos, em 02 artigos. A mineração de processos permite a transformação de dados em informações úteis para a geração do conhecimento organizacional. A utilização da técnica permitiria reduzir a complexidade no levantamento de informações a respeito do fluxo de trabalho dos processos e possibilitaria maior tempo e agilidade para as tomadas de decisão em relação à melhoria contínua dos processos implementados.

8. Métodos de análise de conformidade: A utilização da mineração de processos como método de análise de conformidade, foi um benefício citado por total de 08 artigos. 0 estabelecimento de fluxos de trabalho nas organizações tem a finalidade de definir o itinerário de cada modalidade de processo e os recursos a serem envolvidos em cada fase de sua execução. No entanto, por se tratarem de atividades que envolvem a atuação de seres humanos, há a possibilidade de que os fluxos de trabalho estabelecidos não estejam sendo seguidos, seja qual for a razão.

9. Métodos de análises de desempenho: A utilização da mineração de processos como método de análise de desempenho de processos, foi um benefício citado por um total de 08 artigos. Os itinerários seguidos pelos processos em uma organização na qual não há fluxos de trabalho definidos são regidos pela aleatoriedade ou pelas relações de poder existentes nas organizações. Esses fluxos naturais nem sempre resultam em melhor desempenho, mas atendem, em regra, os interesses das pessoas que exercem suas funções na organização.

10. Método de auditoria de processos: A utilização da mineração de processos como método de auditoria de processos, contemplando a possibilidade de identificação de fraudes e de registro de violação de processos, foi um benefício citado por W.M.P. van der Aalst, H.A. Reijers, A.J.M.M. Weijters, B.F. van Dongen, A.K. Alves de Medeiros, M. Songa, H.M.W. Verbeek, Mieke Jans, Jan Martijn van der Werf, Nadine Lybaert, Koen Vanhoof, Mieke Jans, Michael Alles e Miklos Vasarhelyi, num total de 03 artigos. A mineração de processos possibilita a constatação de irregularidades por meio da identificação de itinerários não previstos nos modelos de processos, em desconformidade com os regulamentos existentes.

11. Previsão do tempo restante das atividades: A possibilidade de previsibilidade do tempo de execução das atividades de um processo foi um benefício citado em dois artigos, um deles de autoria de W.M.P. van der Aalst, M.H. Schonenberg, M. Song, e outro de autoria de Arik Senderovich, Matthias Weidlich, Avigdor Gal e Avishai Mandelbaumem. A mineração de processos possibilita a previsão do tempo necessário para a execução de atividades em processos.

12. Tecnologia de alocação de recursos: $A$ promoção de tecnologia de alocação de recursos foi um benefício citado por Suriadi Suriadi, Chun Ouyang, Wil M.P. van der Aalst, Arthur H.M. ter Hofstede, Zhengxing Huang, Xudong Lu, Huilong Duan, Schahram Dustdar, Weidong Zhao, Haitao Liu, Weihui Dai, Jian $\mathrm{Ma}$, num total de 04 artigos. Assim, a análise do comportamento dos recursos sob as perspectivas acima demonstradas, pode 
gerar benefícios ao gerenciamento de processos, permitindo a alocação dos recursos conforme o perfil necessário para cada situação, na medida em que objetiva alocar o recurso certo à atividade certa, no tempo certo.

13. Tecnologia de obtenção de logs de eventos: A promoção de tecnologia de obtenção de logs de eventos foi um benefício citado por um total de 07 artigos. Os dados relativos às transações realizadas nos sistemas de uma organização - logs de eventos - são armazenados de diversas formas, apresentam diferentes estruturas e variados conjuntos de informações, especialmente quando a organização ainda não implementou nenhuma estrutura de controle de processos ou adota diferentes aplicativos e sistemas para controlar suas operações.

14. Tecnologia de teste de processos: desenvolvimento das tecnologias de testes de processos foi um benefício citado por 02 artigos. Os benefícios mais identificados nos estudos primários resultantes da pesquisa foram a descoberta automática dos modelos de processo, referenciado em 13 artigos e a utilização da mineração de processos como método de análise de desempenho e de conformidade de processos, ambos referenciados em 08 estudos.

\section{CONCLUSÕES}

Este artigo apresentou uma abordagem pragmática acerca de estudos sobre mineração de processos e possibilitou a elaboração de um gráfico de análise com os benefícios, encontrados na literatura, provenientes da aplicabilidade da técnica.

Foi possível a identificação de 14 (quatorze) vantagens potencialmente obtidas a partir da mineração de processos. São elas: a

\section{REFERÊNCIAS}

[1] Borrego D.; Barba I. Conformance checking and diagnosis for declarative business process models in data-aware scenarios. Expert Systems with Applications. v.41, p.5340-5352, 2014

[2] Bubenko, J.R., Stima, J.; Brash, D. User Guide. Departamento of computer and systems sciences. Stockholm: Royal Institute of Technology. 1998. possibilidade de melhoria do desempenho do processo, a possibilidade de melhoria da gestão do conhecimento, a identificação dos recursos envolvidos, a possibilidade de melhoria da alocação dos mesmos na execução processual, a possibilidade de utilização da técnica como método de auditoria, a identificação de similaridade entre os processos, a possibilidade de previsão do tempo de execução das atividades no processo, a detecção automática do modelo de processos, a promoção do desenvolvimento de tecnologias para a obtenção de logs de eventos e para a análise de processos, a possibilidade de utilização da técnica como análise de desempenho do processo e de conformidade do processo, a possibilidade de análise das aplicações dos processos e das tendências dos mesmos.

Diante dos resultados, pôde-se observar que a mineração de processos é útil para as organizações, sob aspectos que variam desde a detecção de modelos de processos até análises quanto à melhor alocação de recursos para cada fase do processo e a previsão do tempo de conclusão das atividades, características que geram efetividade no contexto organizacional. Além disso, a natureza empírica da mineração auxilia os gestores, consultores e analistas de processos a compreenderem melhor o "tecido de processos de negócios reais" (VAN DER AALST, 2011), e permite, portanto, que os mesmos possam tomar decisões acertadas, objetivando a melhoria dos processos e da gestão das organizações.

Trabalhos futuros com abordagens específicas de cada um dos benefícios identificados com a utilização da mineração de processos, ampliando a pesquisa acerca de cada tema individualmente, são necessários para a elaboração da produção científica acerca do assunto, considerando-se a relevância do tema.

[3] Cantidio, Sandro. Padronização do Processo. Disponível no site: http://www.administradores.com.br/informese/artigos/padronizacao-do-processo, acesso em 24 jun. 2012.

[4] Caron F., Vanthienen J.A., Baesens B. Comprehensive rule-based compliance checking and risk management with process mining. Decision Support Systems, v. 54 , p. 1357-1369, 2013. 
[5] Chunguang Bai a, Joseph Sarkis, A greybased DEMATEL model for evaluating business process management critical success factors, Int. J. Production Economics, V.146 (2013) 281-292

[6] Claes, J.; Poels, G. Merging event logs for process mining: A rule based merging method and rule suggestion algorithm. Expert Systems with Applications v.41 7291-7306, 2014.

[7] Dijkman R, Dumas M, VaN Dongen B, Käärik R, Mendling, J. 2011. Similarity of business process models: Metrics and evaluation. Information Systems, 36 (2): 498-516.

[8] Dijkman, R.; LA Rosa, M..; Reijers, H. A. Managing large collections of business process models-Current techniques and challenges. Computers in Industry, v. 63, p. 91-97, nov. 2012.

[9] Geetika T., Khalaf R. Leveraging Process Mining Tecniques. IEEE Computer Society, v. 15209202, 2013.

[10] Goedertier, S.; Weerdt J.D.; Martens, D.; Vanthienen J.; Baesens, B. Process discovery in event logs: An application in the telecom industry, Applied Soft Computing, v.11 p. 1697-1710, 2011.

[11] Harrington, H. J., Esseling, E.K.C., Nimwegen, H.V. "Business Process Improvement: New York: McGraHill, 1997.

[12] Hulstijn J., Gordijn J., Risk analysis for inter-organizational controls, in: Proceedings of the 12th International Conference on Enterprise Information System (ICEIS2010), SciTePress, 2010, pp.314-320.

[13] jans M., Martijn J., Van Der Aalst, W. M. P, Werf B, Nadine L. A, Vanhoof K.A. A business process mining application for internal transaction fraud mitigation. Expert Systems with Applications, v. 38, p. 13.351-13.359, 2011.

[14] Lee, J., SEO, W., Kim, K., \& Kim, C.-H. An owl-based ontological approach to rad modeling of human interactions for business collaboration. Expert Systems with Applications, 37(6), 41284138, 2010.

[15] Leoni, M. D.; Maggi, F. M.; Van Der Aalst, W. M. P. An alignment-based framework to check the conformance of declarative process models and to preprocess event-log data. Information Systems. v. 47, p. 258-277, 2015.

[16] LIU Y.A., Zhang H. B., LI C.B., Jianxin R.J. Workflow simulation for operational decision support using event graph through process mining. Decision Support Systems, v. 52, p. 685-697, 2012.

[17] Liu, J; Liu, P; Liu, S. Handover optimization in business processes via prediction. Kybernetes, Vol. 42 pp. 1101 - 112, 2013.

[18] Maita, A.R.C., Estudo da aplicação de técnicas inteligentes em mineração de processos de negócio. Workshop de Teses e Dissertações em Sistemas de Informação, 2015.

[19] Medeiros, A.K.A.; Guzzo, A.; Greco, G.; Aalst, W.M.P.; Weijters, A.J.M.M.; Dongen, B. and Saccà, D. Process Mining Based on Clustering: A Quest for Precision. In Proceedings of Business Process Management Workshops, 2007.

[20] Pamponet, Arnaud Velloso Como Entender Os Processos Organizacionais, http://www.administradores.com.br/artigos/economi a-e-financas/como-entender-os-processosorganizacionais/30037/ 2009.

[21] Pyon, C. U., Woo, J. Y., \& Park, S. C. Service improvement by business process management using customer complaints in financial service industry. Expert Systems with Applications, 38(4), 3267-3279, 2011.

[22] Pyon, C. U.; Woo J. Y., Park, S. C.Service improvement by business process management using customer complaints in financial service industry. Expert Systems with Applications V 38 3267-3279, 2011.

[23] Rebuge A., Ferreira D. Business process analysis in healthcare environments: A methodology based on process mining. Information Systems, v.37, p. 99-116, 2012.

[24] Tiwari A., Turner C. J., Majeed, B. A review of business process mining: State-of-the-art and future trends. Business Process Management Journal, 2014.

[25] Van Der Aalst, ter Arthur Hofstede, and M. Weske. Business process management: A survey, June 2003.

[26] Van Der Aalst, W. M. P, Process Mining: Discovery, Conformance, and Enhancement of Business Processes, Springer, 2011.

[27] Van der Aalst, W. M. P, The Process Mining Manifesto-An interview with Wil van der Aalst, Information System, v. 37, p. 288-290, 2012.

[28] Van Der Aalst, W. M. P, Wen L.,Mining process models with prime invisible tasks, Data \& Knowledge Engineering. V. 69, p 999-1021, 2010.

[29] Van Der Aalst, W. M. P. Service Mining: Using Process Mining to Discover, Check, and Improve Service Behavior. leee Transactions on Services Computing, V. 06, p. 525-535, 2013.

[30] Van Der Aalst, W. M. P.; Bose, R.P.J.C., Process diagnostics using trace alignment: Opportunities, issues, and challenges, Information Systems, V. 37, 117-141, 2012.

[31] Van Der Aalst, W. M. P.; Dustdar, S. Process Mining Put Into Context. leee Internet Computing, v. p. 82-86, 2012.

[32] Van Der Aalst, W. M. P.; What makes a good model? Software and Systems Modeling, v. 11 , p. $557-569,2012$ 
[33] van der Aalst, W. M. P; Reijers H.A., Weijters A.J.M.M., Business process mining: An industrial application, Information System, v.32, 713-732, 2011.

[34] II Der Aalst, W. M. P; Schonenberg M.H.; Song, M. Time Prediction Based On Process MINING. Information Systems. V.36, P. 450-475, 2011

[35] Van Nuffel, D.; DE Backe, M. Multiabstraction layered business process modeling. Computers in Industry, v. 63, p. 131-147, 2012.

[36] Vasarhelyi, M., M.Alles, A.Kogan, Principles of analytic monitoring for continuous assurance, J.Emerg.Technol. Account.1(1)(2004)121.

[37] Vojtech H., Process Mining: Discovery, Conformance and Enhancement of Business Processes. Journal of Biomedical Informatics. V. 45, p. 1018-1019, 2012.

[38] Wang, D.; GE, J., Discovering process models from event multiset. Expert Systems with Applications v.39 p.11970-11978, 2012.

[39] Weerdt J. D.; Schupp, A.; Vanderloock, A.; Baesens, B. Process Mining for the multi-faceted analysis of business processes - A case study in a financial services organization. Computers in Industry. V. 64, p. 57-67, 2013.

[40] Weerdt, J. A multi-dimensional quality assessment of state-of-the-art process discovery algorithms using real-life event logs, Information Systems, V. 34, 654-676, 2012.

[41] Winarjo, H., Petri-net integration - An approach to support multi-agent process mining. Expert Systems with Applications V. 38 4039-4051, 2011.

[42] Wortmann, H. Discovery and analysis of email-driven business processes, Information Systems, V.37, 142-168, 2012.

[43] Zhengxing $\mathrm{H}_{\text {.; }}$ Xudong L.; Huilong D. Mining association rules to support resource allocation in business process management. Expert Systems with Applications. V. 38, p.9483-9490, 2011.

[44] Zhengxing $\mathrm{H}_{\text {.; }}$ Xudong L.; Huilong D. Resource behavior measure and application in business process management. Expert Systems with Applications, v. 39, p. 6458-6468, 2012. 


\section{Bapítulo 20}

\section{MELHORIA DO ARRANJO FISICO DE UM RESTAURANTE: UM ESTUDO DE CASO}

\section{Adriele Braga da Mota}

\section{Camila Pereira}

\section{Ingrid Moreno de Lima}

Vinicius Gomes Figueiredo

Resumo: O arranjo físico refere-se ao posicionamento das instalações, máquinas, equipamentos e pessoas, visando o aumento da produtividade, bem como a redução de custos, riscos, movimentações e esforços. Diante disso, o presente trabalho foi realizado em um restaurante localizado na cidade de Lorena-SP, que apresenta algumas dificuldades quanto à utilização de seu espaço físico. O principal objetivo consistiu em propor um modelo de layout eficaz que promovesse melhor movimentação interna de clientes dentro do restaurante por meio do estudo de caso. Inicialmente, diagnosticaram-se eventuais problemas e aspectos a serem melhorados no espaço disponível do restaurante, e então foram estudadas formas de mudança do layout e criadas propostas de melhoria viáveis de serem realizadas. Por fim, foi proposto um arranjo físico funcional, que possibilitará uma melhor movimentação de clientes e funcionários e, consequentemente, um ambiente mais agradável dentro do estabelecimento.

Palavras-chave: Arranjo Físico Funcional, Layout e Restaurante. 


\section{INTRODUÇÃO}

A decisão acerca do correto posicionamento do arranjo físico de um estabelecimento é de suma importância, pois envolve diversas características não apenas operacionais, os quais determinam o sucesso ou fracasso de um empreendimento, afetando os custos e a eficácia como um todo. De acordo com Guimarães et al.(2011):

"No âmbito empresarial, o - "layout" pode ser sinônimo de "arranjo físico", ou seja, o modo como estão organizados os equipamentos, máquinas, ferramentas, produtos finalizados e mão de obra dentro da empresa. Um bom "layout" pode ter um efeito na produtividade da empresa, podendo também reduzir os custos (por significar menos desperdícios) e perda de tempo".

Assim, percebe-se que um layout adequado influencia no aumento da produtividade e na redução de custos, riscos e esforços para a movimentação, possibilitando, assim, um diferencial e, por consequência, uma maior competitividade no mercado.

No caso do layout em um restaurante, é de extrema relevância levar-se em consideração fatores como: flexibilidade, velocidade do atendimento, facilidade de acesso ao Buffet, disposição das mesas, ambiente interno agradável; e o fluxo de pessoas. Isso tudo, com intuito de acarretar um melhor aproveitamento do espaço físico, tornando-o visualmente mais claro para o cliente, facilitando seu acesso às diversas áreas do estabelecimento e proporcionando um maior conforto tanto físico como visual; além de aperfeiçoar a organização dos produtos. Como cita Carsten, (2015) "Organizações empresariais com estudos de layouts bem elaborados e arranjos físicos claramente definidos são mais dinâmicas e têm seus processos organizacionais mais eficazes e eficientes".

O estudo a seguir trata de um restaurante localizado no centro da cidade de Lorena-SP, chamado D\&A Restaurante, que atualmente tem apresentado um baixo fluxo de clientes. Através da análise de sua estrutura física e da observação da movimentação e alocação de pessoas, busca-se compreender como as deficiências em seu layout podem interferir diretamente no seu bom funcionamento, e quais aspectos podem ser ajustados e adaptados para a otimização do ambiente.
Sendo assim, um dos objetivos do projeto é identificar as principais problemáticas envolvidas no layout, compreendendo seus pontos fracos. Além de essa análise promover sugestões de melhorias, ela permite aumentar o número de clientes e o tempo de permanência dos mesmos no restaurante D\&A. Através de mudanças em seu espaço físico, melhora-se o fluxo de pessoas, o armazenamento dos produtos e a facilidade de acesso, proporcionando maior lucro ao proprietário e uma opção de lazer agradável e acessível aos moradores do centro e visitantes.

\section{REVISÃO BIBLIOGRÁFICA}

\subsection{DEFINIÇÃO DE ARRANJO FÍSICO}

Para Neumann e Fogliatto (2013), os ambientes de trabalho devem procurar uma otimização do espaço juntando colaboradores, máquinas e equipamentos, materiais, dentre outros, pois são de extrema importância.

Pode-se considerar essa organização como arranjo físico ou layout. Conforme Slack (2006), arranjo físico é decidir onde colocar todas as instalações, máquinas, equipamentos e pessoal da produção.

Um bom layout pode ter um efeito direto na produtividade da empresa, podendo reduzir os custos (por significar menos desperdícios) e perda de tempo. De acordo com Moreira (2011), planejar o arranjo físico de uma instalação constitui tomar decisões sobre a forma como serão dispostos os centros de trabalho, de maneira a tornar mais fácil e suave o movimento, por meio do sistema, quer esse movimento se relacione ao fluxo de pessoas ou de materiais.

A concepção do arranjo físico deve ser baseada em alguns fatores como: o tamanho das instalações físicas; os fluxos de materiais, informações e pessoas; necessidade de estocagem; perspectiva de ampliação futura; questões ergonômicas e segurança das pessoas; leis trabalhistas, entre outros fatores. Slack (2009) diz que o arranjo físico de uma operação ou processo é como seus recursos principais são posicionados uns em relação aos outros e como as múltiplas tarefas da operação serão alocadas a esses recursos.

A decisão do tipo de layout a ser escolhido por uma empresa é influenciada pelas características já citadas. Como mostra a 
Figura 1, determinado o tipo de processo produtivo, alinham-se os objetivos de atuação estratégica definidas pela empresa para que se decida sobre qual tipo básico de arranjo físico melhor se adequa às necessidades operacionais. Uma vez definido como os recursos serão arrumados uns em relação aos outros, delimita-se precisamente a posição de cada um dos recursos abrangidos na operação.

Figura 4 - Modelo de decisão para se definir o tipo de layout

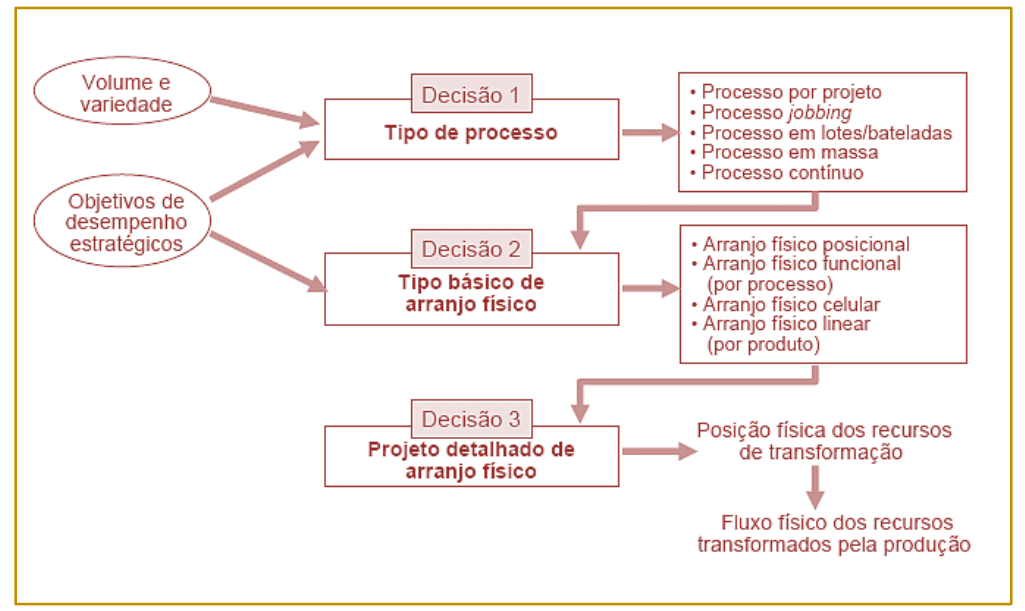

Fonte: Slack et al (1999)

\subsection{TIPOS DE PROCESSOS}

"Um processo é um grupo de atividades realizadas numa sequência lógica com o objetivo de produzir um bem ou um serviço que tem valor para um grupo específico de clientes". (GONÇALVES, 2000)

Nas empresas existem distinções entre as operações desempenhadas, de acordo com a estratégia de produção implementada. Dessa forma, na manufatura é possível elencar cinco processos, os quais são listados a seguir (Slack e Stuart, 2009):

a) Processos de projetos: é caracterizado por um baixo volume e um grau elevado de customização.

b) Processos de jobbing: apresentam variedade alta e volumes baixos e os recursos são partilhados entre todas as unidades.

c) Processos em lotes ou bateladas: os produtos são fabricados em lotes, possuindo como característica alto volume e baixa variedade.

d) Processos de produção em massa: são aqueles que fabricam um alto volume de produtos e pequena variedade.

e) Processos contínuos: possuem alta eficiência e inflexibilidade intensa. Normalmente funcionam por períodos de tempo longos, com alto volume e variedade de produtos baixíssima.

Em relação às operações de serviços, existem três tipos de processos (Slack e Stuart, 2009):

a) Serviços profissionais: proporcionam altos níveis de customização e o processo todo tem a intenção de atender e satisfazer às necessidades particulares dos consumidores.

b) Serviços em massa: são baseados em equipamentos e não em pessoas, sendo que provavelmente tenham uma divisão do trabalho precisamente definida.

c) Lojas de serviços: o serviço é prestado por meio de combinações de atividades de pessoas do escritório e da linha de frente, e o destaque passa a ser no produto e no processo de produção.

\subsection{TIPOS DE ARRANJO FÍSICO}

Segundo Slack (1999) existem quatro tipos de arranjos físicos: arranjo físico posicional, arranjo físico funcional ou por processo, arranjo físico por produto e arranjo físico celular.

a) Arranjo posicional ou por posição fixa: $O$ produto a ser trabalhado permanece fixo enquanto os trabalhadores e ferramentas movimentam-se em torno, além de ser 
caracterizado pela existência da pequena variedade de produtos em pequenas quantidades. Isso ocorre em casos onde todo o processo produtivo se desenvolve em uma área restrita, como na construção de navios, aviões e equipamentos de grande porte;

a) Arranjo físico funcional ou por processo: Os recursos são organizados de acordo com as funções que desempenham e de suas necessidades comuns. Assim, existe uma grande variedade de produtos em pequenas quantidades. As peças se movimentam de acordo com as operações, o que permite a existência de departamentos com as operações do mesmo tipo feitas na mesma área;

b) Arranjo físico linear ou por produto: Os equipamentos são montados com a sequência de processamento, o que facilita o controle do processo e minimiza o manejo de materiais, dessa forma o material passa pelas operações e existe um único produto feito em grande quantidade; e.

c) Arranjo físico celular: O material em processo é direcionado para onde ocorrerão várias etapas de seu processamento. A célula concentra todos os recursos necessários e pode ter os seus equipamentos organizados por processo ou produto.

"A direção final sobre a escolha do arranjo físico é influenciada tanto pelos custos quanto pela análise das vantagens e desvantagens de cada um para determinado processo, frente aos objetivos de desempenho estratégicos da empresa. O desempenho das instalações depende fortemente dos seus tipos de layouts. No entanto, a otimização simultânea de outros critérios também é essencial na obtenção de um eficaz arranjo" (BOZORGI; ABEDZADEH; ZEINALI, 2015).

Além disso, D'Agostini et al. (2014) descreve que o objetivo do arranjo físico é um melhor aproveitamento dos ambientes existentes, proporcionando um fluxo de comunicação entre as unidades organizacionais. Desse modo, a tomada de decisão acerca do posicionamento correto do arranjo físico de um processo produtivo é de fundamental relevância, pois envolve diversos aspectos não apenas operacionais, os quais determinam o sucesso ou fracasso de uma empresa.

\subsection{SWEET HOME 3D}

Sweet Home 3D é um programa relativamente simples, onde é montada a "planta" da casa, projetando os espaços e também a decoração de cada cômodo. Ele ainda oferece uma série de recursos e ferramentas para a criação de ambientes tridimensionais. Assim, a Figura 2 apresenta a imagem da página principal do programa.

Figura 5 - Layout do Programa

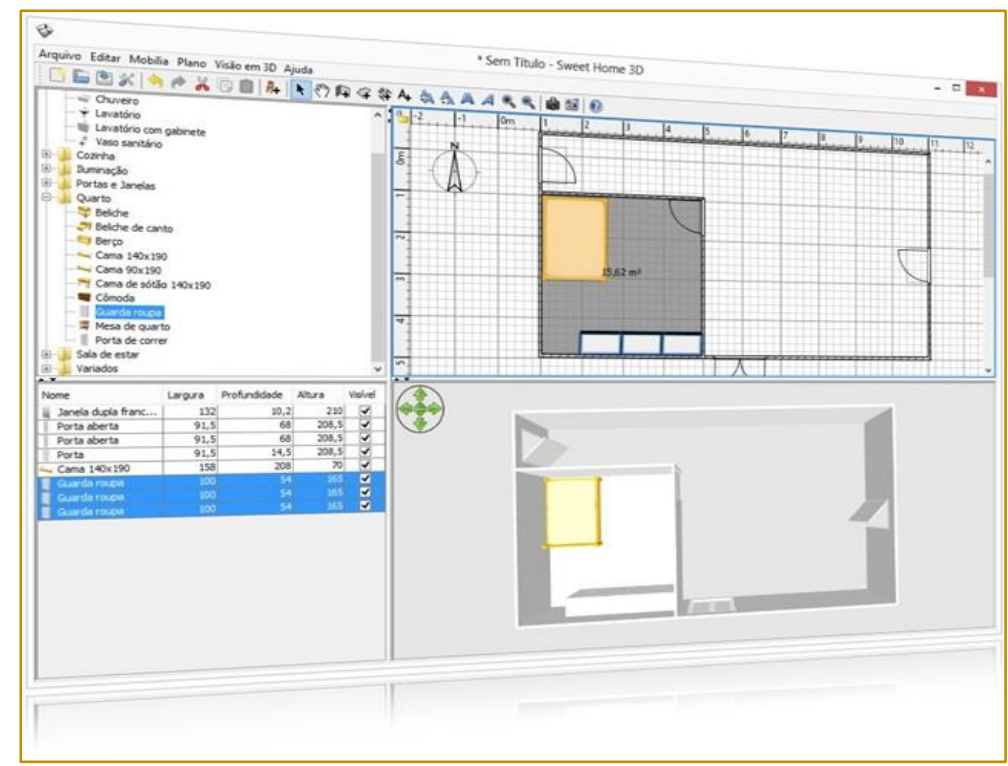

Fonte: Sweet Home 3D (2016) 
O Sweet Home 3D organiza as tarefas em quatro espaços, sendo: banco de dados de objetos; informações mais precisas sobre cada item adicionado à tela de desenho; a tela de desenho em si; e a projeção tridimensional de tudo o que é criado.

\section{METODOLOGIA}

\subsection{MÉTODO DE PESQUISA}

Para alcançar os objetivos definidos, foi empregado sob abordagem qualitativa 0 método de estudo de caso, uma vez que tal metodologia se mostra eficiente na observação da realidade quando em comparação aos estudos teóricos. "Estudo de caso é uma inquirição empírica que investiga um fenômeno contemporâneo dentro de um contexto da vida real, quando a fronteira entre o fenômeno e o contexto não é claramente evidente e onde múltiplas fontes de evidência são utilizadas" (Yin, 1989).

O estudo de caso tem um contexto interessado não num padrão universal ou generalizado, mas sim na possibilidade de aprofundamento de um conhecimento já estruturado (no caso, o layout que já existe). Assim sendo, o Estudo de Caso objetiva proporcionar vivência de situações reais e aplicar técnicas aprendidas para a solução de problemas e/ou obtenção de conclusões acerca das mesmas, com foco na melhoria e no aprendizado contínuo (Miguel, 2007).

Com as bases teóricas já definidas, seguiu-se o projeto através de etapas:

a) Análise e sugestão de uma melhoria;

b) Levantamento bibliográfico;

c) Definição de um método e adaptação do mesmo;

d) Estudo do layout atual entendendo as causas da disposição (os profissionais envolvidos na operação foram interrogados sobre as dificuldades que o layout impõe na operação) e observando possíveis falhas e, também, prevendo possíveis melhorias;

e) Coleta de dados e visitas para a observação dos fluxos (de pessoas, de produtos e de demanda);

f) Construção da planta atual do estabelecimento e seu layout através do software Sweet Home 3D; e

g) Sugestão de alternativas viáveis de layout otimizado.

A Figura 3 esquematiza a tomada de decisão para a criação de propostas de melhoria.

Figura 6 - Fluxograma Da Tomada De Decisão

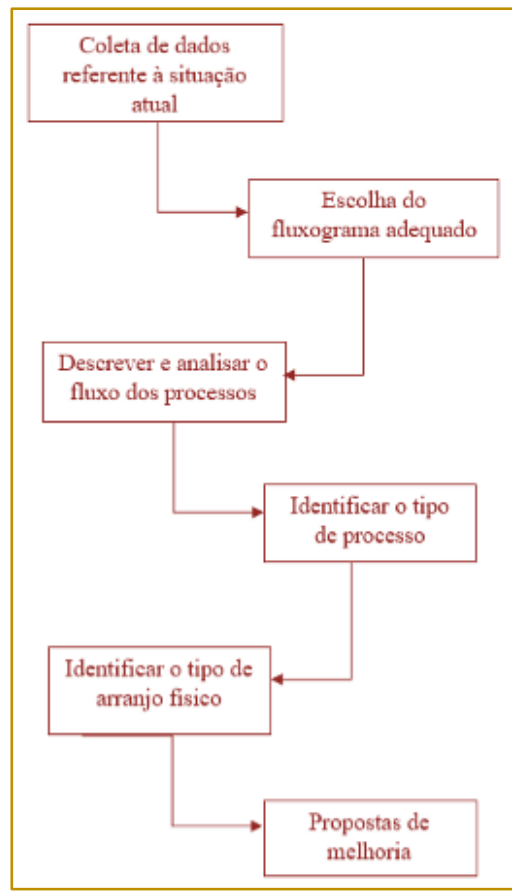

Fonte: NEVES, Renato Martins et al (2016) 
O presente estudo buscou otimizar o layout de uma parte do estabelecimento para que tal arranjo físico comporte os processamentos realizados, buscando também trazer conforto e eficiência de serviços aos clientes do estabelecimento. Visto a relação do material que é movimentado e o período em que isso acontece com maior veemência, a área de produção foi dividida em fluxo de preparação da operação e fluxo da operação durante o atendimento. Porém, esse trabalho só mexerá com a parte de fluxo da operação durante o atendimento.

Assim, depois dos estudos realizados sobre a literatura foi observado que a correta utilização do espaço físico é um fator importante para o seu bom funcionamento, já que estabelece a sua organização. Dessa maneira, seguindo o diagrama indicado na Figura 3, tomou-se a decisão de usar o arranjo físico funcional, pois neste arranjo as atividades são agrupadas de acordo com a sua função. A razão é que juntas elas podem atender diferentes necessidades de produtos/serviços distintos, trazendo flexibilidade.

\subsection{OBJETO DE PESQUISA}

A empresa estudada está voltada para o ramo alimentício no segmento de massas, salgados e refeições. Fundada há três anos, o D\&A Restaurante está localizado na Rua Major de Oliveira Borges, № 26, na cidade Lorena-SP. O dono da empresa possui uma experiência de trinta anos no ramo alimentício, porém o seu comércio anterior não possuía o foco na parte de restaurantes.

O restaurante em questão possui uma área de aproximadamente $1340 \mathrm{~m}^{2}$, entretanto, o presente trabalho só irá abordar o espaço que compreende o salão principal e um possível depósito de bebidas.

\section{RESULTADOS E DISCUSSÕES}

Atualmente, o espaço físico é limitado,
composto por mesas dispostas aleatoriamente por todo o ambiente, expositores de bebidas e sorvetes na entrada do estabelecimento (Figura 4), Buffet selfservice ao lado do banheiro e fechando a passagem até a cozinha (Figura 5), caixas de bebidas acumuladas na única área de sol do ambiente e inúmeros pôsteres colados por todo estabelecimento.

Figura 7 - Bebidas e Sorvete na entrada

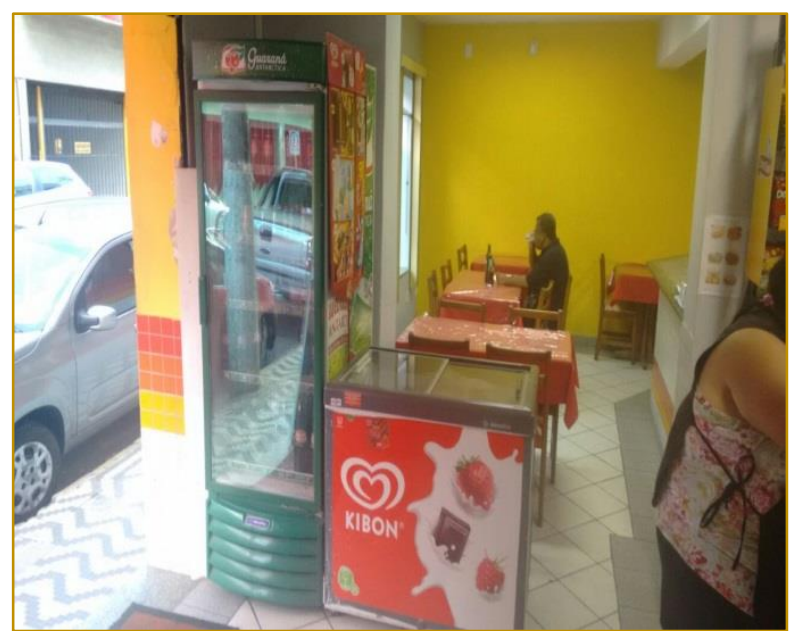

Fonte: Autores 
Figura 8 - Buffet próximo ao banheiro

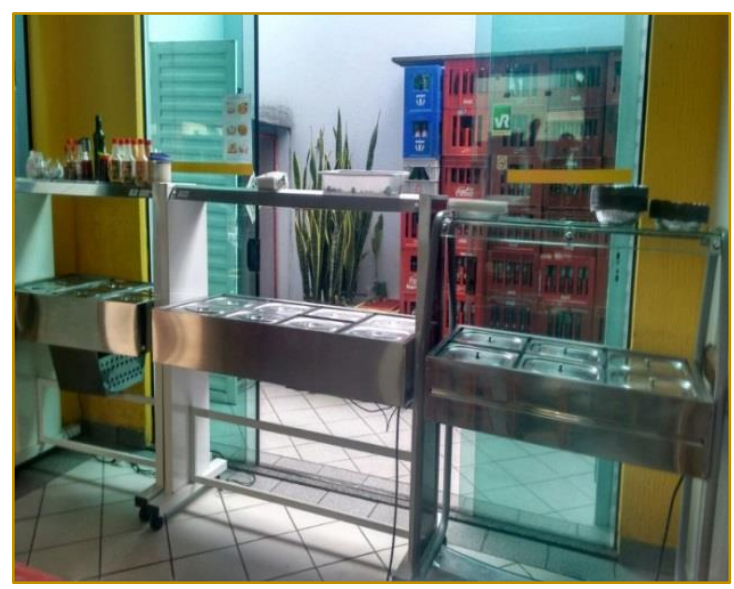

Fonte: Autores

Avaliando o layout do estabelecimento fica evidente que não houve um planejamento na disposição dos objetos neste espaço físico, sendo alocados de maneira desordenada. A consequência desta falta de planejamento é a poluição visual, falta de higiene e limitação do espaço de movimentação dos clientes.

Diante disso, a primeira etapa consistiu nas observações de como funcionava o fluxo de pessoas dentro do estabelecimento e quais as principais dificuldades que os clientes encontravam ao adentrar o local. Assim, notou-se que a distribuição incorreta dos produtos, como a geladeira e o Buffet, acarretavam num problema de higiene, visto que a comida se localiza perto do banheiro, e problema de fluxo, pois a geladeira na porta interrompe a visualização do almoço que está sendo servido do lado de dentro. Na Figura 6, pode-se ver como é o atual layout do Restaurante.

Figura 6 - Layout Atual

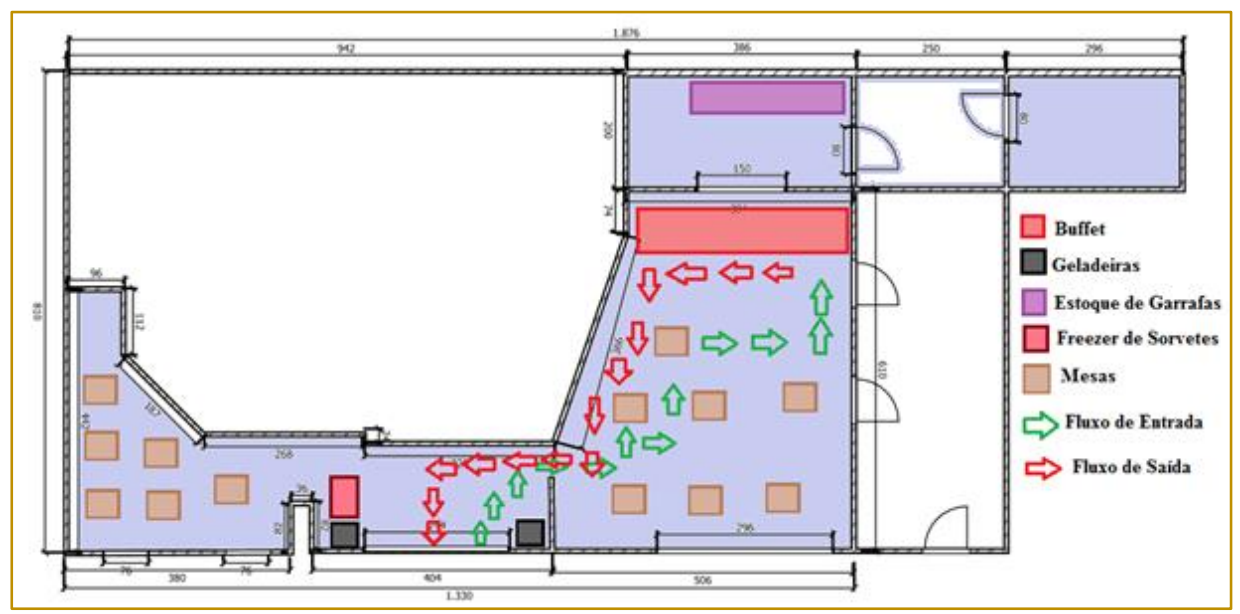

Fonte: Autores

Dessa forma, a segunda e terceira etapa demandaram a escolha do fluxograma adequado e a descrição e análise dos fluxos dos processos mais importantes do estabelecimento.

$\mathrm{Na}$ quarta etapa realizou-se o diagnóstico sobre qual seria o melhor processo, sendo escolhido o jobbing, o qual é caracterizado pelo baixo volume e alta variedade, mas enquanto que em processos de projeto cada produto possui recursos especificamente para ele.

$\mathrm{Na}$ etapa cinco, foi identificado que o tipo de layout mais adequado é o funcional. Isso significa que, quando clientes, informações e produtos correrem através da operação, eles 
cursarão um roteiro de processo a processo, de acordo com as suas necessidades.

\subsection{PROPOSTA DE MELHORIA}

Diante da situação, foram observados alguns pontos e, a partir disso, apontaram-se melhorias. No Quadro 1, é possível notar quais foram os pontos observados:

Quadro 4 - Propostas de Melhorias

\begin{tabular}{|c|c|c|c|}
\hline & Arranjo Físico Atual & $\begin{array}{l}\text { Modelo Arranjo Físico } \\
\text { Funcional }\end{array}$ & $\begin{array}{c}\text { Vantagens da } \\
\text { Implementação do Modelo }\end{array}$ \\
\hline Sinalização & $\begin{array}{l}\text { Grande quantidade de } \\
\text { panfletos e cartazes } \\
\text { localizados próximos uns } \\
\text { aos outros. }\end{array}$ & $\begin{array}{l}\text { Retirada de alguns } \\
\text { panfletos desnecessários, } \\
\text { melhor distribuição dos } \\
\text { mesmos e proposta de } \\
\text { criação de banners com } \\
\text { figuras mais atrativas. }\end{array}$ & $\begin{array}{l}\text { Ambiente menos poluído e } \\
\text { com melhor visualização } \\
\text { dos produtos oferecidos } \\
\text { pelo restaurante. }\end{array}$ \\
\hline Geladeiras & $\begin{array}{l}\text { Localizadas próximas à } \\
\text { porta de entrada do } \\
\text { restaurante. }\end{array}$ & $\begin{array}{l}\text { Deslocar uma das } \\
\text { geladeiras para o lado das } \\
\text { mesas. }\end{array}$ & $\begin{array}{ll}\text { Melhor visualização } & \text { do } \\
\text { ambiente interno } & \text { do } \\
\text { restaurante. } & \end{array}$ \\
\hline Buffet & $\begin{array}{l}\text { Localizado próximo ao } \\
\text { banheiro. }\end{array}$ & $\begin{array}{l}\text { Localizar no canto } \\
\text { esquerdo do restaurante, } \\
\text { distante do banheiro. }\end{array}$ & $\begin{array}{l}\text { Melhor condição } \text { de } \\
\text { higiene } \\
\text { comodidade aos clientes. }\end{array}$ \\
\hline Estoque de garrafas & $\begin{array}{l}\text { Localizado em uma área } \\
\text { aberta no fundo do } \\
\text { restaurante. }\end{array}$ & $\begin{array}{l}\text { Armazenar em um cômodo } \\
\text { no fundo do restaurante, } \\
\text { onde antes se guardava } \\
\text { produtos de limpeza. }\end{array}$ & $\begin{array}{l}\text { Evita que as garrafas } \\
\text { fiquem expostas ao sol, } \\
\text { além de ganhar espaço } \\
\text { físico; possibilitando o } \\
\text { aumento do número de } \\
\text { mesas. }\end{array}$ \\
\hline
\end{tabular}

Fonte: Autores

A partir dessa análise foi proposto para o dono do estabelecimento um novo tipo de layout, como o ilustrado na Figura 7.

Figura 9 - Layout Proposto

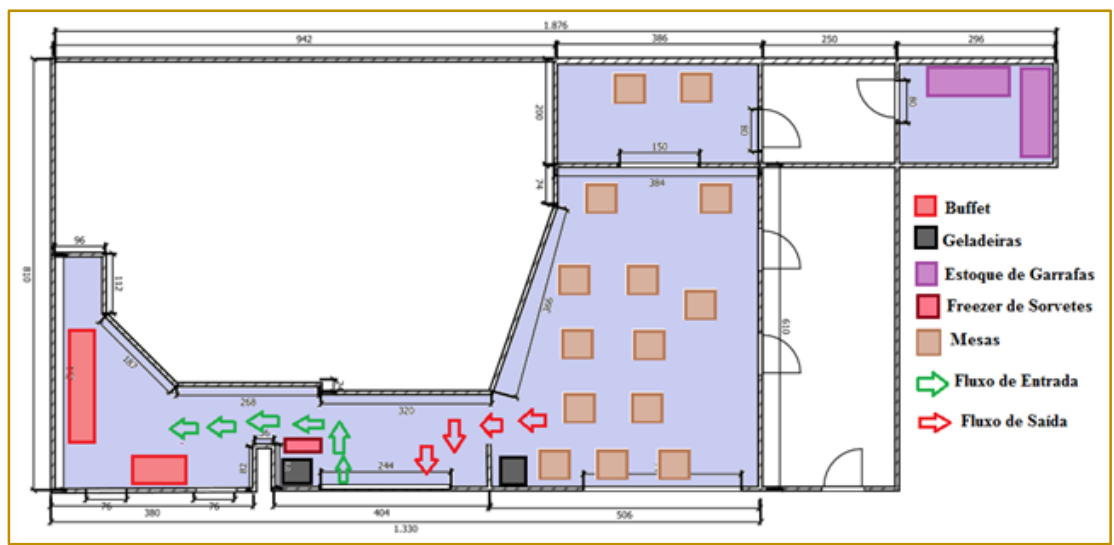

Fonte: Autores

Dentre as 4 propostas de melhorias, 3 delas foram implementadas, as quais foram: sinalização, buffet e o estoque de garrafas.
Na figura 8 e 9 é possível observar a nova distribuição do layout. 
Figura 10 - Vista da porta sem o buffet e o estoque de garrafas

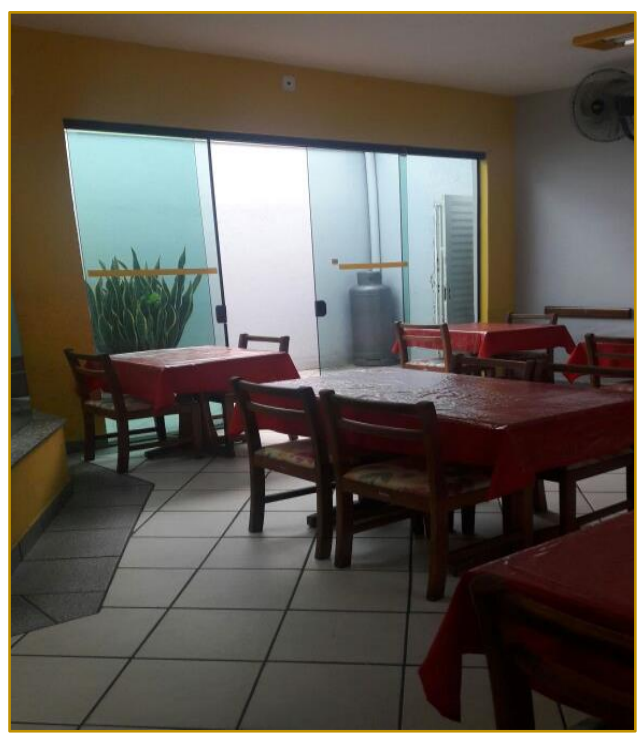

Fonte: Autores

Figura 9 - Novo local do buffet

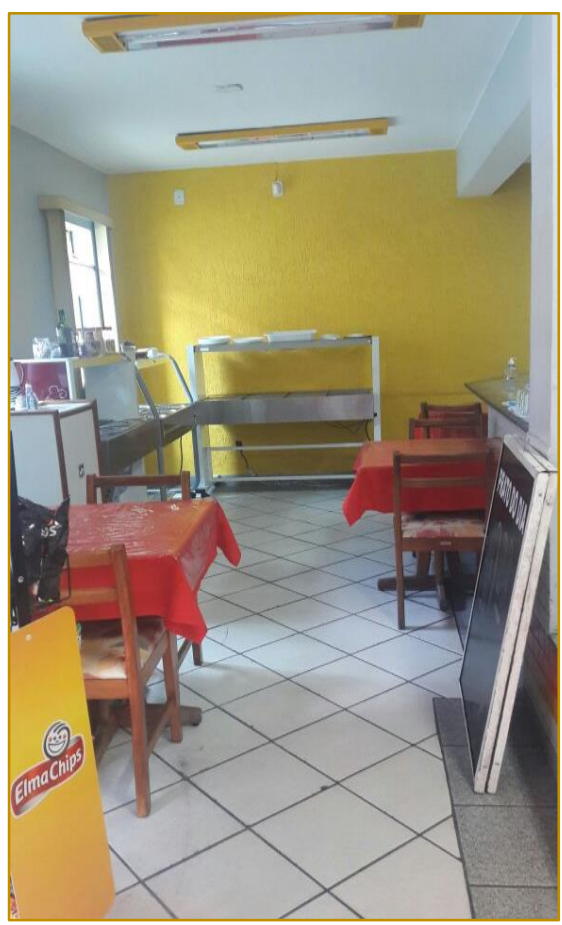

Fonte: Autores

\section{CONSIDERAÇÕES FINAIS}

Com a execução deste trabalho percebe-se que um bom layout é aquele que disponibiliza total acesso à área, bom fluxo de produtos e de pessoas, fazendo isso de forma abrangente, ou seja, atingindo a todos. Assim, a reestruturação do arranjo físico no
D\&A Restaurante, objetivo geral deste projeto, foi proposta com simplicidade e qualidade, tornando o ambiente mais agradável e competitivo no mercado.

Dessa forma, as propostas elaboradas para o atual layout, com base nos estudos dos processos, tiveram por finalidade propor 
melhorias, dentre essas mencionam-se: a criação de um depósito para armazenar bebidas, a mudança do buffet para longe dos banheiros e a correção da sinalização no ambiente.

\section{REFERÊNCIAS}

[1] Bozorgi, N.; Abedzadeh, M.; Zeinali, M. Tabu search heuristic for efficiency of dynamic facility layout problem. The International Journal of Advanced Manufacturing Technology, v. 77, n. 1-4, p. 689-703, 2015.

[2] D'agostini, M.; Sartor, R. S.; Tisott, P. B.; Tondolo, V. A. G.; Camargo, M. E. Escolha do arranjo físico de produção: o caso da Metalices Indústria Metalmecância. Revista ALCANCE Eletrônica ISSN: 1983-716X. v. 21; n. 02 Abr./Jun.2014. Disponível em http://goo.gl/OyY5AE. Acesso em 27 de out. de 2016.

[3] Carsten, Everton. Bal. ECR Consultoria: Otimizando seus movimentos. 2015. Disponível em: $<$ http://www.ecrconsultoria.com.br/consultorias/are a-de-atuacao/layout-de-producao-e-linhas-defabricao> Acesso em: 05 nov. 2016.

[4] Guimarães, Dilva; CABRAL, Paulo. Significados: Significado de layout. 2011. Disponível em $<$ http://www.significados.com.br/layout/> Acesso em: 05 nov. 2016.

[5] Gonçalves, José Ernesto Lima. As Empresas São Grandes Coleções de Processos. Revista de Administração de Empresas, São Paulo, v. 40, p.9-19, 1 jan. 2000. Bimestral.

[6] Neumann, Carla S.R.; Fogliatto, Flávio S. Sistemática para avaliação e melhoria da flexibilidade de layout em ambientes dinâmicos.
Assim, espera-se que os resultados acarretem uma boa gestão das mercadorias e uma melhor movimentação de clientes.

Gest. Prod., São Carlos, v. 20, n. 2, p. 235-254, 2013. Acesso: 20 out. 2016. Disponível em: http://www.scielo.br/pdf/gp/v20n2/v20n2a01.pdf

[7] Neves, Renato Martins das et al. Análise do arranjo físico no almoxarifado de uma organização militar: um estudo de caso. João Pessoa: Enegep, 2016. 17 p.

[8] Miguel, P. A. C. Estudo de caso na engenharia de produção: estruturação e recomendações para sua condução. Produção, v. 17, n. 1, p.216-229, Jan./Abr. 2007.

[9] Moreira, D. A. Administração da Produção e Operações. 2. ed. São Paulo: Cengage Learning, 2011.

[10] Rocha, Roberto; Germano, Lucas. Sweet Home 3D. $2017 . \quad$ Disponível em: <http://www.sweethome3d.com/pt/>. Acesso em: 12 out. 2016

[11] Slack, Nigel. Administração da produção. São Paulo: Atlas, 1999.

[12] Slack, Nigel et al. Administração da Produção. 1.ed. - 10. reimpr. - São Paulo: Atlas, 2006.

[13] Slack, Nigel; Chambers, Stuart; Jonhnston, Robert. Administração da Produção. 3. ed. São Paulo: Atlas, 2009

[14] Yin, Robert K. Case study research design and methods. 5. ed. EUA: Sage Publications, 1989. 


\section{Gapítulo 21}

\section{ESTUDO DE CASO: APLICAČ̃O O MÉTODO RKW EM UMA MICRO EMPRESA, UMA BARBEARIA NA CIDADE DE MOSSORO-RN}

\section{Antonio Jaem Estigarriga Menescal Neto}

Lucas Medeiros Bezerra

Jose Helton de Azevedo

Jaine Joyce Moreira Marinho

Thiara Monik Silva Costa

Resumo: Saber quanto é custo de cada serviço da empresa é essencial para competividade da mesma no mercado, pensando nisso esse trabalho trata de uma aplicação do método de custeio RKW em uma barbearia da cidade de Mossoró no Rio Grande do Norte. Com esse estudo, pode-se mostrar quais os serviços que geram mais e menos lucro a empresa. Analisando os resultados, foi observado que o centro que gera mais lucro é o centro de cabelo, em contrapartida o centro de estética possui um valor elevado de custos e é o menos lucrativo, em algumas atividades causam até prejuízos. Com essas informações em mãos, pode facilitar a tomada de decisão do gerente, e assim poder traçar melhores estratégias de gerenciamento da empresa e tornando-a mais competitiva no mercado.

Palavras-chave: RKW, Método de custeio, Barbearia 


\section{INTRODUÇÃO}

Em um ambiente cada vez mais competitivo, as organizações são obrigadas a evoluir e apreender constantemente, além de se empenhar na busca de melhores informações para o gerenciamento de seus custos. A necessidade de uma maior acurácia de informações dos custos operacionais e gerenciais só é possível com uma escolha correta de ferramentas, é busca de uma técnica que melhor represente a realidade organizacional. Diante do exposto os sistemas de custeio mostram seu valor, sua relevância, pois sem os quais não é possível conhecer a situação da organização e muito menor controlar.

De acordo com William Edwards Deming, "Não se gerencia o que não se mede, não se mede o que não se define, não se define o que não se entende, e não há sucesso no que não se gerencia". Portanto, os sistemas de custeio são de suma importância para um posicionamento estratégico da empresa, sem os quais não é possível gerenciar o negocio.

Logo, a determinação dos custos de produção é fundamental para a administração econômico- financeira de uma empresa. Além disso, a escolha de um método de custeio compatível com as características dela não só resulta em custos finais acurados, mas também proporciona ferramentas e conhecimentos diferenciais para a tomada de decisões estratégicas e aumentar o seu nível de competitividade (BORNIA, 2010).

O objetivo deste trabalho é analisar os custos de uma barbearia da cidade de Mossoró no Rio Grande do Norte, identificando quais os serviços mais e menos lucrativos para a empresa, utilizando o método de custeio RKW.

\section{REFERENCIAL TEÓRICO}

No intuito de tornassem mais competitivas as empresas necessitam conhecer seus processos e compreender os gastos relacionados a produção de bens e serviços para otimizar seu sistema de produção e criar estratégias para gerencia os mesmo. Dessa forma, os sistemas de custos apresentam-se como alternativas para a mensuração e análise de dados que visam proporcionar melhor entendimento aos gestores. (PIMENTEL et al., 2013)

\subsection{GESTÃO DE CUSTOS}

A preocupação com o gerenciamento de custo relaciona-se ao século XVIII com advento da revolução industrial. Atualmente devido a globalização da economia, o estudo dos custos tornou-se instrumento para criar vantagens competitivas que deve fazer parte do setor estratégico da empresa. (DUBOIS, KULPA, SOLUZA; 2009).

De acordo com Hansen e Mowen (2003, p.28) mencionam que "a gestão de custos identifica, coleta, mensura, classifica e relatam informações que são úteis aos gestores para o custeio (determinar quanto algo custa), planejamento, controle e tomadas de decisão ".

É necessário antes de tudo definir o significado de custo. Padoveze (2006, p.6) define custo como a "mensuração econômica dos recursos (produtos, serviços e direitos) adquiridos para obtenção e venda dos produtos e serviços da empresa". De acordo com Dutra (2009) "custo é o valor aceito pelo comprador pata adquirir um bem ou é a soma de todos os valores agregados ao bem desde sua aquisição, até que ele atinja o estágio de comercialização. Outros autores afirmam que custo é todo gasto (ato de adquirir um bem ou serviço que tem como consequência um desembolso para a empresa) relacionado a aquisição de bens e/ou serviço para a produção de outros bens ou serviços. (DUBOIS, KULPA, SOLUZA; 2009).

No que se refere ao sistema de custeio observa-se a necessidade de aplicações em todos os tipos de empresa: comercial, industrial ou prestadora de serviço. (ANDRADE, 2013). Pode-se encarar um sistema de custos de duas maneiras: No que se refere ao princípio, que direciona a forma com serão tratadas as informações e ao método, que proporciona a aplicação do princípio. (BORNIA, 2010).

Ressalta-se que antes da implantação de um sistema de custeio é necessário entender quais as informações e fatores são relevantes para o gerenciamento das atividades e qual o nível de detalhamento e a frequência com que essas informações deveram ser produzidas. Pois quanto mais fiel a realidade for o sistema maior a possibilidade de se extrair boas informações. (DUBOIS, KULPA, SOLUZA; 2009). 


\subsection{MÉTODO DE CUSTEIO RKW}

Método de custeio RKW é "um dos grandes e primeiros modelos de sistema de custo é o de centro de custos surgido no início do século XX na Alemanha". PIMENTEL et al., 2013).

De acordo com Bornia (2010) o método RKW ou método dos centos de custos ou das seções homogenias, trata apenas dos centros indiretos não considerando os custos relacionados a matéria-prima e aos demais custos diretos.

A característica principal desse método citase a divisão da organização em "centros de custos". Nesse método os custos são designados aos centros de custos, por bases de distribuição e, em seguida, transferidos aos produtos por unidade de trabalho. Podemos separar os centros de custos em diretos e indiretos. Os centros diretos são aqueles que lidam com o produto diretamente já os custos indiretos são aqueles que dão suporte aos centros de custos diretos e a empresa em geral (BORNIA, 2010).

No que tange as etapas desse método podese sintetiza-las em cinco: "Separação dos custos em itens, divisão da empresa em centros de custos, identificação dos custos com os centros (distribuição primaria), distribuição dos custos dos centros indiretos até os diretos (distribuição secundaria). Distribuição dos custos dos centros diretos aos produtos." (BORNIA, 2010).

Kliemann Neto (2007) afirma que são três os tipos de centros de custos que são divididos conforme a função que desempenham. Centros comuns: relaciona-se com a função de diretoria e contabilidade, centros auxiliares: relacionam-se a funções como engenharia e manutenção e centros operacionais: referente ao setor de execução.

\section{METODOLOGIA}

Quanto aos procedimentos metodológicos, realizou-se primeiramente uma pesquisa bibliográfica sobre o método de custeio RKW. Quanto a esse tipo de pesquisa, Gil (2002, p.44) diz que ela "é desenvolvida com base em material já elaborado, constituído principalmente de livros e artigos científicos".

Em relação ao método de pesquisa, realizouse um estudo de caso que de acordo com Acevedo e Nohara (2007, p. 50) "caracteriza- se pela análise em profundidade de um objeto ou grupo de objetos, que podem ser indivíduos ou organizações. "Neste caso, a análise em profundidade foi realizada com o proprietário da barberaria, que preferiu não ter o nome citado.

Além disso, foi realizada uma visita "in loco" para verificar o sistema do serviço oferecido pela empresa, além de colher as informações presentes nesse artigo com uma conversa com o proprietário, dados como com o fim de levantar informações inerentes aos custos do serviço. Com os dados em mãos calculamos os custos de cada serviço oferecido, utilizando o método de custeio RKW.

\section{EMPRESA}

\subsection{CARACTERIZAÇÃO DA EMPRESA}

O Salão de beleza participante do estudo de caso, para a elaboração deste artigo, foi constituído em 2013 e tem seus serviços voltados a sua maioria para o público masculino no segmento da beleza.

Sua missão é alcançar o público masculino que queiram se cuidar melhor, tendo este mercado crescendo a cada dia, pois o público masculino estar se torando cada dia mais metrossexual. O salão se localiza em Mossoró-RN, mais precisamente no bairro doze anos.

O dono do seu estabelecimento tem uma política voltada para a qualidade, tem como principais clientes pessoas da classe $B$ e $A$ da cidade, para conquistar este espaço no mercado o mesmo participou de vários cursos e treinamentos em diversos locais do Nordeste. Atualmente, a empresa possui 2 (dois) empregados, o primeiro, responsável pelo atendimento inicial dos clientes, a recepção, onde fica determinado a sua função de fazer a reserva de horários para atendimento e a limpeza quando necessário. O segundo é um ajudante do cabelereiro e empreendedor do salão, onde fica a função deste lavar o cabelo dos clientes e/ou fazer os atendimentos de estética do salão, todos possuem registro em Carteira de Trabalho Profissional.

A partir dessas características principais atribuídas ao salão de beleza, foi elaborado um organograma representativo apresentado na Figura 1 a seguir: 
Figura 1: Organograma da Barbearia

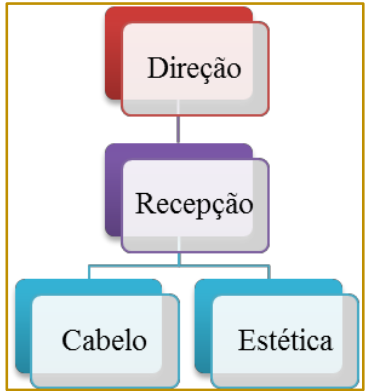

Fonte: Dados da pesquisa (2016)

\subsection{SERVIÇOS PRESTADOS PELA EMPRESA}

A empresa oferece vários serviços que estão divididos em dois setores o setor de cabelo e o outro setor de estética. Nos quadros 1 e 2, a seguir mostra como os setores estão organizados além dos preços pelos serviços, o tempo gasto em cada atividade e quantidade de serviços feitos por mês.

Quadro 1 - Setor cabelo

\begin{tabular}{|cc|c|c|}
\hline \multicolumn{4}{c}{ Cabelo } \\
Atividade & Quantidade & Preço & Tempo (min) \\
Corte & 380 & $R \$ 40,00$ & 30 \\
\hline Escovinha & 95 & $\mathrm{R} \$ 20,00$ & 20 \\
\hline Hidratação & 80 & $\mathrm{R} \$ 40,00$ & 30 \\
\hline Pintura & 25 & $\mathrm{R} \$ 60,00$ & 80 \\
\hline Luzes & 70 & $\mathrm{R} \$ 60,00$ & 90 \\
\hline
\end{tabular}

Fonte: Dados da pesquisa (2016)

Quadro 2 - Setor estética

\begin{tabular}{cc|c|c|}
\hline \multirow{4}{*}{ Estética } \\
Atividade & Quantidade & Preço & Tempo (min) \\
Maquiagem & 10 & $\mathrm{R} \$ 75,00$ & 60 \\
\hline Sobrancelha & 60 & $\mathrm{R} \$ 10,00$ & 30 \\
\hline Barba & 96 & $\mathrm{R} \$ 10,00$ & 20 \\
\hline
\end{tabular}

Fonte: Dados da pesquisa (2016)

Como visto dos quadros 1 e 2, o setor de cabelo as atividades exercidas são cortes, escovinha, hidratação, pintura e luzes. Já no setor de estética as atividades são barba, sobrancelha e maquiagem.

\section{RESULTADOS}

\subsection{APLICAÇÃO DO RKW}

\subsubsection{FATURAMENTO MENSAL DE CADA ATIVIDADE}

Com base nos dados dos quadros 1 e 2 podemos calcular o faturamento mensal das atividades. Calculamos o faturamento mensal de cada atividade. Como mostra o quadro 3. 
Quadro 3 - Faturamento mensal em cada atividade

\begin{tabular}{|c|c|}
\hline Atividade & Faturamento Mensal \\
\hline Corte & $\mathrm{R} \$ 15.200,00$ \\
\hline Escovinha & $\mathrm{R} \$ 1.900,00$ \\
\hline Hidratação & $\mathrm{R} \$ 3.200,00$ \\
\hline Pintura & $\mathrm{R} \$ 1.500,00$ \\
\hline Luzes & $\mathrm{R} \$ 4.200,00$ \\
\hline Maquiagem & $\mathrm{R} \$ 750,00$ \\
\hline Sobrancelha & $\mathrm{R} \$ 600,00$ \\
\hline Barba & $\mathrm{R} \$ 960,00$ \\
\hline Total & $\mathrm{R} \$ 28.310,00$ \\
\hline
\end{tabular}

Fonte: Dados da pesquisa (2016)

No quadro 3 , mostra que a atividade que mais fatura por mês é o corte de cabelo que equivale a $54 \%$ do faturamento total do salão e a atividade que menos fatura é a sobrancelha que é referente a $2 \%$ do total.

\subsubsection{ELABORAÇÃO DOS CUSTOS DA EMPRESA}

Com base nos dados obtidos na empresa. $\mathrm{O}$ quadro 4, apresenta todos os custos indiretos e mão de obra que a empresa necessita para funcionar.

Quadro 4 - Custo total

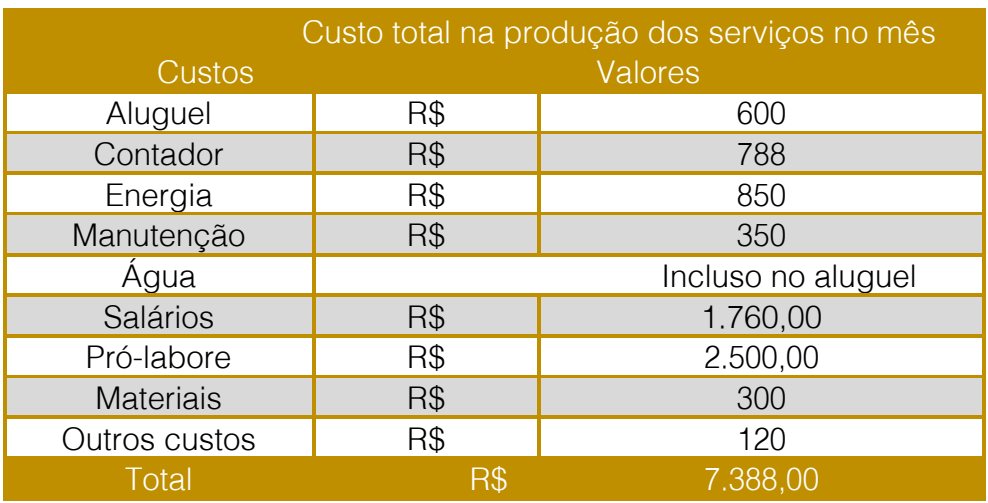

Fonte: Dados da pesquisa (2016)

Outros dados foram obtidos pela observação da empresa, através disso observamos como a empresa está dividida. Ela se divide em quatro centros que são administração, atendimento ao cliente, cabelo e estética. Com esses dados e as observações foi montada o quadro 5 .

Quadro 5 - Organização dos centros em relação a alguns custos

\begin{tabular}{|c|c|c|c|c|}
\hline & Adm. & Atendimento & Cabelo & Estética \\
\hline \multirow{2}{*}{$\begin{array}{c}\text { Funcionários } \\
\text { Área }\end{array}$} & & 1 & & 1 \\
\hline & 100 & 100 & 150 & 50 \\
\hline Materiais & 100 & 200 & & \\
\hline Manutenção & & $5 \%$ & $90 \%$ & $5 \%$ \\
\hline Pró-labore & $20 \%$ & & $80 \%$ & \\
\hline Energia & 200 & 300 & 1000 & 200 \\
\hline
\end{tabular}

Fonte: Dados de pesquisa (2016)

O quadro 5, apresenta como estão distribuídos alguns custos em cada setor. Alguns custos que não estão no quadro 5 foram distribuídos nas seguintes formas: o custo com contador foi diretamente para o setor de administração e os outros custos foram distribuídos igualmente.

\subsubsection{RATEIO DOS CUSTOS}

Utilizando os dados o quadro foi feito o rateio de cada um dos setores. Como se pode observar no quadro 6. 
Quadro 6 - Distribuição dos custos

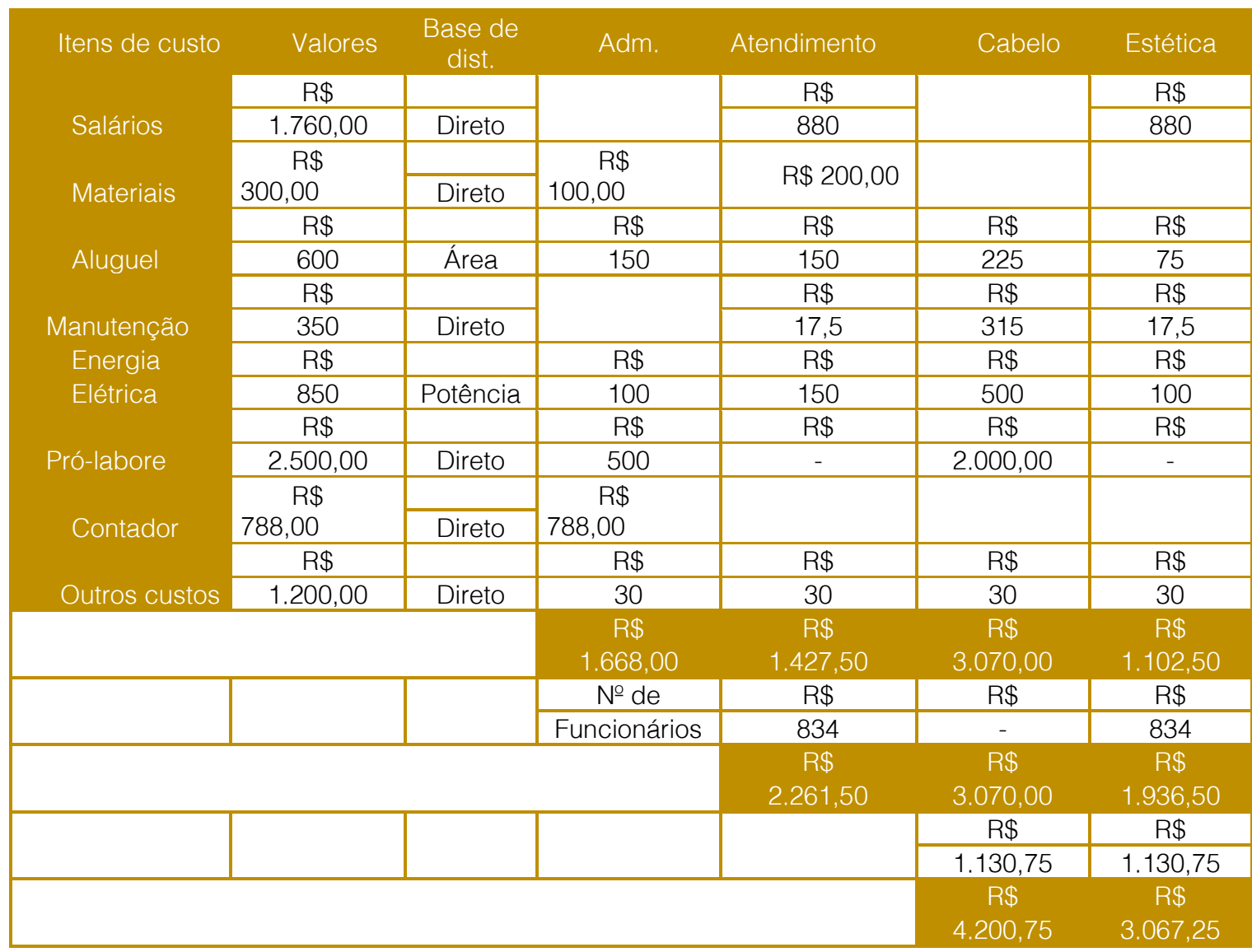

Fonte: Dados da pesquisa (2016)

Nesse processo os setores da administração e do atendimento do cliente foram rateados para os setores de Cabelo e Estéticas. O primeiro setor a ser distribuído foi o setor de administração, distribuído pelo número de funcionários para as áreas de atendimento, cabelo e estética. Já atendimento ao cliente foi distribuído igualmente para as outras áreas.

\subsubsection{CALCULANDO OS CUSTOS PARA CADA CENTRO}

Depois da distribuição dos custos nos centros diretos do processo, calculamos a os custos para cada centro, no quadro 7 , apresenta o custo por hora que cada setor precisa para funcionar. Para calcular, usamos o custo total para cada setor de dividimos pela quantidade de horas desse mesmo setor.

Quadro 7 - Custo por hora de cada centro

\begin{tabular}{|c|c|c|c|c|}
\hline & \multicolumn{3}{c}{ Cabelo } & \multicolumn{2}{c|}{ Estética } \\
$\begin{array}{c}\text { Custo para cada centro } \\
\text { Custo por hora em cada } \\
\text { centro }\end{array}$ & $\mathrm{R} \$$ & $4.200,75$ & $\mathrm{R} \$$ & $3.067,25$ \\
\hline \begin{tabular}{c} 
con \\
\hline
\end{tabular} & $\mathrm{R}$ & 10,5 & $\mathrm{R} \$$ & 42,6 \\
\hline
\end{tabular}

Fonte: Dados da pesquisa (2016)

Com os dados do quadro 7 , podemos calcular os custos indiretos e com mão-deobra de cada uma das atividades. Para fazer isso, usamos o tempo de cada atividade e multiplicamos por cada atividade, observe o quadro 8. No quadro 9, possui o custo da matéria-prima, o custo total que foi calculada e o lucro para cada atividade. Os dois quadros estão a seguir: 
Quadro 8 - Custos por cada uma realizada atividade

\begin{tabular}{|c|c|c|c|c|c|c|c|c|}
\hline Atividade & Corte & Escovinha & Hidratação & Pintura & Luzes & Maquiagem & Sobrancelha & Barba \\
\hline Tempo (horas) & 0,5 & 0,33 & 0,5 & 1,33 & 1,5 & 1 & 0,5 & 0,33 \\
\hline & $\mathrm{R} \$$ & $\mathrm{R} \$$ & $\mathrm{R} \$$ & $\mathrm{R} \$$ & $\mathrm{R} \$$ & $\mathrm{R} \$$ & $\mathrm{R} \$$ & $\mathrm{R} \$$ \\
\hline $\begin{array}{c}\text { Custo por cada } \\
\text { ativ. }\end{array}$ & 5,25 & 3,5 & 5,25 & 14 & 15,75 & 42,6 & 21,3 & 14,2 \\
\hline
\end{tabular}

Fonte: Dados da pesquisa (2016)

Quadro 9 - Lucro de cada atividade

\begin{tabular}{|c|c|c|c|c|c|c|c|c|}
\hline \multirow{4}{*}{$\begin{array}{c}\text { Custo por cada } \\
\text { ativ. }\end{array}$} & Corte & Escovinha & Hidratação & Pintura & Luzes & Maquiagem & Sobrancelha & Barba \\
\hline & $\mathrm{R} \$$ & $\mathrm{R} \$$ & $\mathrm{R} \$$ & $\mathrm{R} \$$ & $\mathrm{R} \$$ & $\mathrm{R} \$$ & $\mathrm{R} \$$ & $\mathrm{R} \$$ \\
\hline & 5,25 & 3,5 & 5,25 & 14 & 15,75 & 42,6 & 21,3 & 14,2 \\
\hline & $\mathrm{R} \$$ & $\mathrm{R} \$$ & $\mathrm{R} \$$ & $\mathrm{R} \$$ & $\mathrm{R} \$$ & $\mathrm{R} \$$ & $\mathrm{R} \$$ & $\mathrm{R} \$$ \\
\hline \multirow{2}{*}{$\begin{array}{l}\text { Custo com } \\
\text { matéria-prima }\end{array}$} & 1,27 & 1,27 & 1,27 & 18,86 & 8,33 & 6,27 & 0,5 & 0,3 \\
\hline & $\mathrm{R} \$$ & $\mathrm{R} \$$ & $\mathrm{R} \$$ & $\mathrm{R} \$$ & $\mathrm{R} \$$ & $\mathrm{R} \$$ & $\mathrm{R} \$$ & $\mathrm{R} \$$ \\
\hline \multirow[t]{2}{*}{ Custo total } & 6,52 & 4,77 & 6,52 & 32,86 & 24,08 & 48,87 & 21,8 & 14,5 \\
\hline & $\mathrm{R} \$$ & $\mathrm{R} \$$ & $\mathrm{R} \$$ & $\mathrm{R} \$$ & $\mathrm{R} \$$ & $\mathrm{R} \$$ & $\mathrm{R} \$$ & $\mathrm{R} \$$ \\
\hline \multirow[t]{2}{*}{ Preço } & 40 & 20 & 40 & 60 & 60 & 75 & 10 & 10 \\
\hline & $\mathrm{R} \$$ & $\mathrm{R} \$$ & $\mathrm{R} \$$ & $\mathrm{R} \$$ & $R \$$ & $\mathrm{R} \$$ & $-R \$$ & $-R \$$ \\
\hline Lucro & 33,48 & 15,23 & 33,48 & 27,14 & 35,92 & 26,13 & 11,8 & 4,5 \\
\hline
\end{tabular}

O quadro 8, nos indica quais as atividades que possuem um custo (indireto e com mãode- obra) mais elevado. Podendo analisar se é realmente viável oferecer esse serviço. Como não foi possível obter os custos de matérias-primas, buscamos em outros trabalhos acadêmicos um preço base para a matéria-prima.

No quadro 9, pode-se observar qual o lucro de cada serviço da empresa e assim analisar quais os serviços devem continuar a oferecer e quais não deve. No caso da desse salão

\section{CONCLUSÃO}

De acordo com a revisão de literatura, a determinação dos custos de produção é fundamental para a administração econômicofinanceira de uma empresa. Com a implementação do método de custeio RKW na empresa estudada, obtendo os custos dos serviços, propiciou-se a análise da situação econômica do empreendimento e a busca por oportunidades de melhorias, tanto nas decisões competitivas ante ao mercado de concorrência, quanto nas decisões internas aos processos da prestação de serviço.

Com podemos observar vários pontos importantes que a empresa deve estar ciente quanto a situação dos seus serviços. Observamos que no centro de custo estética observou um prejuízo nas atividades sobrancelha e barba. Esse prejuízo se deu mais pelos custos no centro de estética que é relativamente mais alto que o de cabelo. Isso porque quantidade melhor de horas trabalhadas.

Observa-se também que as atividades que estão rendendo mais lucro para a empresa são as luzes, o corte de cabelo e hidratação. Portanto a empresa deve investir mais nestes serviços para lucrar mais.

possui um valor elevado de para seu funcionamento, como é um centro que possui menos horas de atividade, isso gera em alguns serviços desse centro alguns prejuízos que devem ser estudados, que são eles sobrancelha e barba.

Outros elementos observados foram os serviços que geram mais lucro para a empresa, eles pertencem ao centro de cabelo que são luzes, corte de cabelo e hidratação. Mostrando que esses produtos devem ter mais importância para empresa.

Assim, os objetivos propostos para esse trabalho foram alcançados, abrem-se oportunidades para futuros estudos, visando sempre a melhoria contínua. 


\section{REFERÊNCIAS}

[1] Acevedo, Claudia Rosa; NOHARA, Jouliana Jordan. Monografia no Curso de Administração: guia completo de conteúdo e forma. 3aㅡ ed. São Paulo: Atlas, 2007.

[2] Gil, Antônio Carlos. Como Elaborar Projetos de Pesquisa. 4aa ed. São Paulo: Atlas, 2002.

[3] Andrade, Maria do Socorro Martins de. Sistema de custeio RKW, 2013. Disponível em:<http://www. portaleducacao.com.br/contabilidade lartigos/31375/sistema-de-custeio-rkw\%20\%20!1\#!5>. Acesso em: 01 de julho 2016.

[4] Bornia, Antonio Cezar. Análise Gerencial de Custos: Aplicação em empresas modernas. 3. ed. São Paulo: Atlas, 2010. 214 p.

[5] Cogan, Samuel. Custos e Formação de Preços: Análise e Prática. São Paulo: Atlas, 2013. 189 p. Dubois, Alexy; Kulpa, Luciana; Souza, Luiz Eurico de. Gestão de Custos e Formação de Preços:

[6] Conceitos, Modelos e Intrumentos: Abordagem do Capital de Giro e da Margem de Competitividade. 3. ed. São Paulo: Atlas, 2009. 250 p.
[7] Dutra, René Gomes. Custos: Uma Abordagem Prática. 6. ed. São Paulo: Atlas, 2009. $473 \mathrm{p}$.

[8] Kliemann Neto, F. J. Custos Industriais. Apostila da Disciplina de Custos Industriais. UFRGS, Porto Alegre, 2007.

[9] Hansen, Don R.; Mowen, Maryanne M. Gestão de custos: contabilidade e controle. Tradução da Robert Brian Taylor. São Paulo: Pioneira Thomson Lear ning, 2003.

[10] Nóbrega, Rodrigo et al. Elaboração do Mapa DE Localização DE Custos em Um Salão DE Beleza do Município DE João Pessoa - PB Através da Aplicação do Método de Custeio RKW. In: SEPRONE, 7., 2012, Mossoró. Anais. Mossoro: Seprone, 2012. p. 1 - 12.

[11] Padoveze, Clóvis Luís. Curso básico gerencial de custos. $2^{\mathrm{a}}$. ed. rev. e ampl. 2003.

[12] Pimentel, Ana Carolina Lima et al. Aplicação do Método dos Centros de Custos em uma Indústria Jornalística. In: Encontro Nacional DE Engenharia de Produção, 33., 2013, Salvador, Ba. :

[13] Abepro, 2013 Disponível em: <http://www.abepro.org.br/biblioteca/enegep2013_ tn_stp_179_021_23241.pdf>. Acesso em: 01 jun 2016. São Paulo: Pioneira Thomson Learning, 2006. 


$$
\text { Alutary }
$$




\section{ADRIANO JOSE CORREIA}

Possui formação em Tecnólogo de manutenção industrial pela Faculdade de Tecnologia SENAI Roberto Simonsen (2015), pós Graduado e especialista em Gestão de manutenção e Ativos pela Faculdade Educacional Inaciana Padre Saboia de Medeiros - FEI (2017), Atualmente é programador de manutenção em uma grande indústria do segmento químico e farmacêutico, tem experiência na área de gestão de ativos com ênfase em planejamento e controle de manutenção onde atua a cerca de 7 anos implementando novas técnicas e ferramentas de controle para a indústria.

\section{ADRIELE BRAGA DA MOTA}

Graduanda em Engenharia Química pela Universidade de São Paulo. Participou da mesa redonda "Mulheres na matemática e nas ciências tecnológicas" na Semana de Ciência e Tecnologia da UNIFESP -SJC. Participou do II Simpósio Acadêmico de Engenharia de Produção - EEL USP.

\section{AGBERTO DE CASTRO MARINHO JUNIOR}

Graduado em Engenharia de Produção pela Universidade Federal do Amazonas (UFAM). Tem como interesse as áreas de Planejamento Estratégico, Lean Manufacturing, Controle de Processos Produtivos, Manufatura enxuta (Mapeamento de fluxo de valor e fluxo contínuo), Gestão da Qualidade, Gestão de Custo, Gestão Mercadológica, Pesquisa Operacional (Modelagem e Simulação da Produção)

\section{ALAFAN JEFERSON DA COSTA LIMA}

Graduado em Engenharia de Produção pela Universidade Federal do Amazonas (UFAM). Tem como interesse as áreas de Planejamento Estrategico, Lean Manufacturing, Controle de Processos Produtivos, Manufatura enxuta (Mapeamento de fluxo de valor e fluxo contínuo), Gestão da Qualidade, Gestão Mercadológica, Pesquisa Operacional (Modelagem e Simulação da Produção)

\section{ALESSANDRA FERREIRA REIS}

Graduada em Engenharia de Produção pela Universidade Federal do Amazonas (UFAM). Tem como interesse as áreas de Planejamento e Controle da Produção, logística, Gestão de Custo, Gestão Mercadológica, marketing, Gestão de pessoas, Controle Estatístico da Qualidade, Qualidade em Serviços, Gestão da inovação

\section{ALEXANDRE PARANHOS BASTOS}

Consultor e professor de gestão operacional e projetos, formado em Engenharia de Produção pelo Centro Federal de Educação Tecnológica Celso Suckow da Fonseca, e com mestrado em Gestão e Estratégica em Negócios pela Universidade Federal Rural do Rio de Janeiro.

\section{AMANDA DE CAMPOS}

É Engenheira de Produção pela Universidade do Extremo Sul Catarinense (UNESC). Atualmente trabalha na Empresa Glasstem, localizada na cidade de Criciúma-SC.

\section{ANA CLAUDIA SILVA DA SILVA}

Graduada em Engenharia de Produção pela Universidade Feevale. Experiência empresarial em planejamento e programação da produção, mapeamento e análise de processos, gestão de equipe em indústria nacional do ramo metal mecânico. 


\section{ANDREI GUSTAVO KOZAN DE SOUZA}

Graduado em Engenharia de Produção pela Pontifícia Universidade Católica do Paraná (PUCPR), com graduação sanduíche em Engenharia Industrial pela Universidade Estadual do Mississipi (EUA), sendo bolsista no programa Ciência sem Fronteiras. Atuou como pesquisador convidado pelo Instituto de Tecnologia de Illinois em Chicago (EUA). Trabalha há 3 anos no grupo Novartis Biociências, com foco em processos de manufatura de sólidos e embalagem em blister.

\section{ANTONIO JAEM ESTIGARRIGA MENESCAL NETO}

Engenheiro de Produção, graduado pela Universidade Federal Rural do Semi Árido

\section{CAMILA MACHADO}

Pós-graduanda do MBA em Gestão Estratégica de Pessoas da Universidade do Vale do Rio dos Sinos - Unisinos. Bacharel em Administração de Empresas pela Universidade Feevale. Técnica em Química pela Fundação Liberato Salzano Vieira da Cunha. Atua há 16 anos na indústria química nas áreas de planejamento, programação e controle de produção, controle de qualidade e desenvolvimento de produtos.

\section{CAMILA PEREIRA}

Graduanda em Engenharia Química pela Universidade Estadual de São Paulo, campus Lorena-SP. Conhecimento técnico em Engenharia da Qualidade devido ao estágio em uma empresa do setor moveleiro e Planejamento e Controle da Produção devido ao estágio em uma indústria farmacêutica.

\section{CARLOS ANDRÉ ESTEVES LEITE}

Mestrando do Programa de Pós-graduação em Ciências e Meio Ambiente área de Concentração em Recursos Naturais e Sustentabilidade pela Universidade Federal do Pará UFPA. Especialista em Engenharia de Segurança do Trabalho pela Universidade do Norte Uni Norte (2015), bacharel em Engenharia de Produção pela Universidade do Norte - Uni Norte (2013) e Bacharel em Tecnologia Mecânica pela Universidade Estadual do Amazonas UEA (2003). Atualmente é Engenheiro de Segurança do Trabalho, Líder Ambiental e de Cumprimentos Legais da Procter \& Gamble do Brasil S/A.

\section{CAROLINA SCHERER FINKLER}

Graduada em Engenharia de Produção pela Universidade La Salle (2017) e pós-graduação em andamento de Gestão Estratégica da Tecnologia da Informação pela Universidade Estácio de Sá. Trabalha como analista de sistemas na Confederação Sicredi e possui experiência nas áreas de suporte técnico de sistemas e manutenção/configuração de equipamentos de ponto eletrônico.

\section{CHRISTIANE WENCK NOGUEIRA FERNANDES}

Possui Graduação em Matemática pela Universidade Federal de Santa Catarina (1999), Mestrado em Engenharia de Produção pela Universidade Federal de Santa Catarina (2002), Doutorado em Engenharia de Produção pela Universidade Federal de Santa Catarina(2010). Atualmente é Professora Adjunto IV do Departamento de Engenharias da Mobilidade da Universidade Federal de Santa Catarina. Tem experiência na área de Engenharia de Transportes, Pesquisa Operacional e Logística. 


\section{CRISTINA KEIKO YAMAGUCHI}

Doutora em Engenharia e Gestão do Conhecimento - EGC da Universidade Federal de Santa Catarina - UFSC, área de concentração: Gestão do Conhecimento e Linha de Pesquisa: Gestão da Sustentabilidade Ambiental e Organizacional. Mestre em Administração - Área de Concentração: Gestão Estratégica das Organizações pela Universidade do Estado de Santa Catarina. MBA em Administração Global pela Universidade Independente de Lisboa e da Universidade de Santa Catarina - UDESC/ESAG. Especialista em Produtividade e Qualidade Total. Graduada em Ciências Contábeis e Bacharel em Administração.

\section{DANILO VENTURI}

Engenheiro Mecânico com experiência no desenvolvimento de produtos e processos e na gestão e no desenvolvimento de projetos. Com mais de 10 anos de experiência, tive a oportunidade de trabalhar nas áreas de Engenharia Industrial (Processos), Marketing Estratégico e na elaboração de projetos (Projetista) em três empresas multinacionais.

\section{DAYANNE ALVES LACERDA}

Bacharel em Engenharia de Produção pela Universidade Federal do Amazonas (2015). Pósgraduada em Engenharia da Qualidade pelo Instituto Superior de Educação Ibituruna - ISEIB (2018), em Gerenciamento de Projetos pela Faculdade Dom Bosco (2016) e em Gestão Pública pela Faculdade AVM (2016). Possui experiência em consultoria empresarial e têm trabalhos publicados em congressos e revistas nacionais.

\section{EDSON MINORU YAJIIMA}

Doutorado em Engenharia Química (UEM), mestrado em Engenharia de Materiais (UTFPR) e graduação em Engenharia Química (UEM). Possui ainda cursos de especialização em Gestão da Qualidade (UEM), Engenharia de Segurança (UTFPR), Gestão Ambiental (UFPR) e MBA em Gestão Estratégica (USP).Atua como professor associado no curso de Engenharia de Produção da Pontifícia Universidade Católica do Paraná.

\section{EDSON PEREIRA DA SILVA}

Possui graduação em Automação Industrial pela Universidade Paulista (2012), Mestrando em Engenharia de Produção pela Universidade Paulista (bolsa CAPES), Especialização em Gerenciamento da Manutenção pelo Centro Universitário da FEI (2013) e Licenciatura em Matemática pela Universidade de Franca (2016). Tem experiência na área de Engenharia Mecânica, com ênfase em Manutenção Industrial onde possui experiência desde 1991 em grandes e médias empresas no setor Metalúrgico Automotivo, Madeireiro e de Alimentos como Técnico e Gestor de Manutenção Mecânica e Docência no Ensino Superior na Faculdade de Tecnologia SENAI Roberto Simonsen no curso Superior em Manutenção Industrial, na Faculdade de Engenharia e Arquitetura do Centro Universitário Nossa Senhora do Patrocínio nos cursos de Engenharia de Produção e Automação e Controle e na Fundação Indaiatubana de Educação e Cultura FIEC como Professor nos cursos Técnicos em Mecânica e Mecatrônica no Programa Mediotec do Ministério da Educação.

\section{EDUARDO OLIVEIRA PAES}

Graduando em Engenharia de Produção pela Universidade Positivo-PR , atualmente atua no ramo de empreendedorismo na área de refrigeração, possui 2 artigos publicados e apresentados no ENEGEP (Encontro Nacional de Engenharia de Produção) e projetos voltados para gestão de produção durante o período de graduação. 


\section{ELYELTON CESAR DE SOUZA LIMA}

Graduando em Engenharia de Transportes e Logística pela Universidade Federal de Santa Catarina. Atualmente trabalha como estagiário na Associação dos Municípios do Nordeste de Santa Catarina em Joinville - SC, atuando no auxílio à sistematização das etapas de elaboração de Planos de Mobilidade Urbana de oito municípios do nordeste catarinense. Tem interesse na área de Engenharia de Transportes, Pesquisa Operacional e Logística.

\section{EVANDRO MENEZES DE MEDEIROS}

Graduado em Engenharia de Pesca pela Universidade Federal rural de Pernambuco- UFRPR (1991). Especialização em Gestão Pública pela Universidade estadual do Amazonas-UEA (2011). Já atuou na Gerência da Estação de Piscicultura de Balbina por 10 anos, 1996-2006. Atualmente, atua como Engenheiro de Pesca concursado da Suframa.

\section{FABIANO DE LIMA NUNES}

Doutorando em Engenharia de Produção e Sistemas, na Unisinos. Sócio-Consultor da Opperatio Consultoria e co-fundador do Mokeru Institute. Professor nos cursos de Logística, Gestão da Produção Industrial, Administração de Empresas, Gestão da Manutenção, Engenharia de Produção e Engenharia Mecânica da Universidade Feevale e em Cursos de Pós-Graduação da Universidade Feevale. Mestre em Engenharia de Produção e Sistemas pela Unisinos, possui MBA em Gestão Empresarial pela FGV, Pós-Graduação em Gestão Estratégica da Produção e Logística (Lean Thinking) e Graduação em Gestão da Produção pela Universidade Feevale e em Logística pela UNISINOS.

\section{FABIO ANTONIO SARTORI PIRAN}

Doutorando em Engenharia de Produção e Sistemas pela Universidades do Vale do Rio dos Sinos - Unisinos. Mestre em Engenharia de Produção e Sistemas pela Universidades do Vale do Rio dos Sinos - Unisinos. Graduado em Logística pela Universidades do Vale do Rio dos Sinos - Unisinos. Formação Superior em Gestão de Produção pela Universidade Feevale. Pesquisador no Gmap-Unisinos. Sócio consultor na HP Custos assessoria empresarial, empresa prestadora de Consultoria e Treinamentos nas áreas de Gestão de operações, Sistemas de produção, Mapeamento de processos, Gestão de custos e Controladoria.

\section{FELIPE MORAIS MENEZES}

Fundador da WTF! School, uma escola livre com foco em experiências transformadoras. Engenheiro (mas tem coração) e entusiasta de futurismo, é coordenador de curso, professor universitário e palestrante. Pai do Pedro e do Lucas, adora tecnologia, mas mora num sítio. Curte filosofar, mas também bota a mão na massa. Tem uma relação bem próxima com startups: já fundou uma e quebrou outras. Acredita que pode mudar o mundo através da educação. Professor e Coordenador do Curso na Universidade Feevale. Co-fundador da WTF! SCHOOL. Mentor da Feevale Techpark. Co-fundador da Startup TKS!. Mestrado em Engenharia de Produção e Sistemas. Graduação em Engenharia de Produção Mecânica.

\section{FERNANDO CÉSAR CERRI}

Graduando em Engenharia de Produção pela Escola de Engenharia de Lorena - EEL/USP. Tem artigos publicados nos Anais ENEGEP. Participação em projetos com indústrias de pequeno e médio porte da região do Vale do Paraíba. 


\section{GABRIEL HOFIG DE CASTILHO}

Técnico Mecânico formado no Colégio Técnico Industrial de Guaratinguetá - UNESP e cursando o oitavo período do curso de Engenharia de Produção na Escola de Engenharia de Lorena - USP. Atualmente servidor público estadual na Faculdade de Engenharia de Guaratinguetá - UNESP, área de atuação Mecânica, com cinco anos de experiência. Quatro anos de participação na Equipe EEL Racing de Fórmula SAE, categoria a combustão, e três participações na competição Fórmula SAE Brasil pela mesma Equipe. Participante de préiniciação cientifica durante o ensino médio na área de dinâmica orbital e uma apresentação de artigo no Encontro Nacional de Engenharia de Produção em 2017.

\section{GABRIELA YUKIE TANAKA SHIBAO}

Graduanda Engenharia de Produção pela Escola de Engenharia de Lorena da Universidade de São Paulo (EEL - USP). Participou do Encontro Nacional de Engenharia de Produção (ENEGEP) em 2017, apresentando um artigo fruto de um de seus trabalhos do segundo semestre da graduação. Três anos de participação na organização Enactus EEL USP, tendo como trajetória a liderança de Gestão de Talentos, bem como a do Projeto João de Barro. Participa do Centro Acadêmico de Engenharia de Produção atuando como assessora de eventos.

\section{GERMANO AUGUSTO METZNER DE ANDRADE}

Graduando em Engenharia de Transportes e Logística pela Universidade Federal de Santa Catarina. Atualmente trabalha como estagiário de Logística Corporativa na Tigre S/A. Experiência em Excel VBA, C++ e SAP ERP. Possui interesse nas áreas de simulação, pesquisa operacional e otimização.

\section{GHISLAINE LURY TESTONI}

Graduada em Engenharia de Transportes e Logística pela Universidade Federal de Santa Catarina. Atualmente exerce o cargo de Assistente Operacional na Aliança Transporte Multimodal, Itapoá - SC. Interessa-se em Pesquisa Operacional, Simulações e Processos.

\section{GILVAN ALVES RIBEIRO}

Possui formação em Tecnólogo de manutenção industrial pela faculdade de Tecnologia SENAI Roberto Simonsen (2015), atuando a 13 anos como supervisor de manutenção de Trens metropolitano, tem experiência na área de gestão de ativos com ênfase em planejamento e controle de manutenção, prestou serviço a uma das maiores empresas Canadense onde atuou em projetos de desenvolvimento tecnológico: Controle de Trens Baseado em Comunicação (CBTC).

\section{GLAUBER ARAUJO ALENCAR CARTAXO}

Possui graduação em Engenharia de Produção Mecânica (2003), mestrado em Engenharia Ambiental Urbana (Construção Civil) pela Universidade Federal da Bahia (2011) e especialização em Docência do Ensino Superior (2009) como também especialização em Tecnologia e Gerenciamento de Obras (2012). Atuou como Engenheiro de Produção na área de Engenharia de Produção, com ênfase em Planejamento, Projeto e Controle de Sistemas de Produção, Desenvolvimento de Produtos, Logística e Logística reversa. Atualmente é Coordenador da Agência de Inovação da Universidade Salvador/UNIFACS, atuando como Professor Adjunto na Universidade Salvador - UNIFACS/Laureate International Universities. Tem experiência na Área Inovação Tecnológica, Marketing aplicado, Área de Planejamento e Controle da Produção, Gestão de Projetos, Sistemas de Gestão da Qualidade, Gestão e Mediação, Programa de Gerenciamento de Resíduos, Gestão Sustentável do Ambiente Construído. 


\section{GUSTAVO LUIZ MACEDO DA SILVA}

Engenheiro Mecânico (2010) e mestre em Engenharia Mecânica (2012) pela Universidade Federal de Santa Catarina (UFSC). Atuou na empresa Embraco (Joinville/SC) como Engenheiro-Pesquisador entre 2013 e 2015, na área de pesquisa e desenvolvimento. Atualmente é coordenador do curso de Engenharia Mecânica do Centro Universitário Católica de Santa Catarina em Jaraguá do Sul/SC. Atua na mesma instituição como professor ministrando disciplinas da área de Ciências Térmicas para os cursos de Engenharia Mecânica, Engenharia Elétrica e Engenharia de Produção.

\section{HENDRICK BRIAN DOS SANTOS RODRIGUES}

Graduando de Engenharia de Produção pela Universidade Positivo-PR, com artigos publicados em congressos nacionais ao longo da graduação. Profissionalmente atuando no ramo de reposição automotiva para montadoras.

\section{HERACLITO LOPES JAGUARIBE PONTES}

Formado em Engenharia de Produção Mecânica pela Universidade Federal do Ceará - UFC (2004). Possui Especialização em Gestão da Produção pela Universidade Federal de São Carlos - UFSCAR (2006), Mestrado em Engenharia Mecânica (área de concentração Manufatura) pela Universidade de São Paulo - USP (2006) e Doutorado em Engenharia Mecânica (área de concentração Manufatura) pela Universidade de São Paulo - USP (2012). Atualmente é Professor Adjunto III do Curso de Engenharia de Produção Mecânica da Universidade Federal do Ceará (UFC), Coordenador do Laboratório Observatório Tecnológico (OT) e Tutor do Programa de Educação Tutorial (PET). Tem experiência na área de Engenharia de Produção, com ênfase em Logística, Gestão da Produção e Pesquisa Operacional.

\section{INGRID MORENO DE LIMA}

Graduando em Engenharia de Produção pela Universidade de São Paulo, campus Lorena-SP. Técnico em Logística pela Etec Emílio Hernandez Aguilar-SP.

\section{JAINEJOYCE MOREIRA MARINHO}

Engenheira de Produção, graduada pela Universidade Federal Rural do Semi Árido

\section{JAIR RODRIGUES DE SIQUEIRA NETO}

Engenheiro de Produção graduado pela Universidade do Estado do Pará (2017). Publicou artigos nos principais congressos nacionais voltados à Engenharia de Produção nas áreas de Gestão da Produção, com foco em Gestão de Sistemas de Produção.

\section{JEANE APARECIDA CASTRO}

Graduanda de Engenharia de Produção na Universidade Positivo-PR, atualmente atua como Coordenadora de PCP (Planejamento e Controle da Produção). Durante a graduação desenvolveu trabalhos acadêmicos voltados para resolução de problemas industrias, os quais resultaram na publicação de dois artigos no ENEGEP (Encontro Nacional de Engenharia de Produção). 


\section{JOSE BENEDITO SACOMANO}

Possui graduação em Engenharia Civil pela Universidade de São Paulo (1968), mestrado em Engenharia Mecânica pela Universidade de São Paulo (1983) e doutorado em Engenharia Mecânica pela Universidade de São Paulo (1990). Atualmente é professor titular da Universidade Paulista. Tem experiência na área de Engenharia de Produção, com ênfase em Planejamento, Projeto e Controle de Sistemas de Produção, atuando principalmente nos seguintes temas: planejamento, qualidade, construção civil, administração da produção e engenharia de produção.

\section{JOSE HELTON DE AZEVEDO}

Engenheiro de Produção, graduado pela Universidade Federal Rural do Semi Árido

\section{KÁTIA VIANA CAVALCANTE}

Doutora em Desenvolvimento Sustentável, área de Política e Gestão Ambiental pelo Centro de Desenvolvimento Sustentável da Universidade de Brasília CDS/UnB (2013). Mestre em Comunicação e Semiótica pela Pontifícia Universidade Católica de São Paulo PUC-SP (1998). Especialista em Ciência da Computação pelo Convênio Técnico da Universidade Federal do Amazonas e IBM Brasil - Indústria, Máquinas e Serviços Ltda. (1992). Atualmente é professora na Universidade Federal do Amazonas e do quadro permanente do Mestrado Profissional em Rede Nacional para o Ensino das Ciências Ambientais - PROFCIAMB. Responsável pela Divisão de Análise Ambiental do Centro de Ciências do Ambiente da Universidade Federal do Amazonas - CCA/UFA

\section{KRISTIAN MADEIRA}

É Doutor em Ciências da Saúde (2015), Mestre em Educação (2009), Especialista em Educação Matemática (2004) e Licenciado em Ciências e Matemática (2001) pela Universidade do Extremo Sul Catarinense (UNESC). Professor e Pesquisador da Universidade do Extremo Sul Catarinense (UNESC), onde atua nos cursos de Graduação e Especialização. Membro do Projeto Associado em Rede Interdisciplinar em Sistemas Produtivos - PPGISP, (UNIPLAC/UNESC/UNIVILLE/UNIFEBE/UNIARP/UNIBAVE) submetido à avaliação da CAPES. Sua pesquisa, produção técnica e tecnológica estão focadas na aplicação de Métodos Quantitativos para a produção de conhecimento nas áreas de Educação, Saúde e Sistemas Produtivos.

\section{LARISSA DOS SANTOS ROSA}

Estudante de Engenharia de Produção na Universidade Estácio de Sá. Consultora Independente de Mapeamento de Processos. Possui experiência com otimização produtiva, gestão de projetos, planejamento estratégico e controle de dados.

\section{LAYRA GABRIELA GONCALVES}

Graduanda em engenharia de produção, com experiência em gestão de rotinas, ferramentas da qualidade, análise e melhoria de processos, gestão da melhoria contínua e transformação lean. Foi monitora de matemática elementar e voluntária do diretório acadêmico do curso de engenharia de produção da Universidade La Salle.

\section{LEONARDO RODRIGUES DE FREITAS}

Engenheiro de produção formado pela Universidade do Estado do Pará (2017). Publicou artigos no principal congresso nacional de Engenharia de Produção nas áreas de gestão da qualidade e gestão de manutenção. Possui experiência profissional na área de gestão de processos e segurança no trabalho. 


\section{LEOPOLDO PEDRO GUIMARAES FILHO}

Doutor em Ciências Ambientais - Universidade do Extremo Sul Catarinense (UNESC). Mestre em Engenharia de Produção - Universidade Federal de Santa Catarina (UFSC). Graduado em Engenharia de Produção Civil - Universidade Federal de Santa Catarina (UFSC). Coordenador e docente do curso de Engenharia de Produção na Universidade do Extremo Sul Catarinense (UNESC). Membro do Projeto Associado em Rede Interdisciplinar em Sistemas Produtivos PPGISP, (UNIPLAC/ UNESC/ UNIVILLE/ UNIFEBE/ UNIARP/ UNIBAVE) submetido à avaliação da CAPES. Atua em pesquisas nas seguintes áreas: resíduos sólidos de construção civil, gerenciamento de custos, gestão da qualidade, sistemas produtivos.

\section{LETICIA DA SILVA PIRES}

Engenheira de Produção graduada pela Universidade do Estado do Pará (2017). Publicou artigos nos principais congressos nacionais voltados à Engenharia de Produção nas áreas de Gestão da Produção, com foco em Gestão de Sistemas de Produção. E, atualmente, atua como Analista de Logística em uma grande empresa distribuidora de produtos no Estado do Pará.

\section{LOURENÇO COSTA}

Possui Graduação em Engenharia Mecânica pela Universidade Federal do Espírito Santo, Especialização e Mestrado em Engenharia de Produção pela Universidade Tecnológica Federal do Paraná e Doutorado em Engenharia de Produção pela Universidade Federal do Rio de Janeiro. É professor titular do Instituto Federal do Espírito Santo, com experiência de atuação nas áreas de Expressão Gráfica, Gestão de Processos de Negócio e Sustentabilidade Corporativa. É autor de diversos livros sobre a ferramenta AutoCAD "Utilizando Totalmente o AutoCAD".

\section{LUCAS MEDEIROS BEZERRA}

Graduando em Engenharia de Produção pela Universidade Federal Rural do Semi Árido e Pós graduando em Gestão de Projetos pelo Centro Universitário de Maringá.

\section{LUCIANA DE FRANÇA PESTANA}

Graduada em Odontologia pela FAESA - Faculdades Integradas Espírito Santenses. Especialista em Gestão da Clínica, pelo Hospital Sírio Libanês, especialista em Gestão em Saúde, pela Fundação Getúlio Vargas - FGV, especialista em Direito Público, pela Faculdade São Geraldo e Mestra em Gestão Pública, pela Universidade Federal do Espírito Santo - UFES.

\section{LUIS CLAUDIO RAGASSON}

Graduado em Engenharia de Produção com foco em melhoria contínua, qualidade, desenvolvimento de projetos. Estudo realizado sobre o Recall no setor automotivo brasileiro, perpassando o processo, avaliando causas e propondo melhorias. Profissional com vivência em plantas industriais de médio e grande porte do segmento petroquímico e petrolífero em terceirizadas de construção e montagens. Experiência no planejamento e programação de produção, aplicação de técnicas de medição e ensaios que visam melhoria de produtos e serviços da planta industrial, bem como processos de auditorias internas e externas. Vivência também na área de meio ambiente industrial com gestão e gerenciamento de resíduos, com formação e atuação técnica. 


\section{MANOEL SEBASTIAO CAMARGO}

MBA em BPM - Business Process Management pela Universidade do Vale do Rio dos Sinos Unisinos, Formado em Processos Gerencias Pela Uninter - Centro Universitário Internacional e Técnico em Eletrotécnica pela Escola Estadual Monteiro Lobato. Coordenador de Unidade de Obras e Manutenção na Sirtec Sistemas Elétricos LTDA, com mais de 13 anos de experiência atuando no sistema elétrico de potência (Distribuição de Energia Elétrica) e Consultor Especialista de BPM - Business Process Management.

\section{MARCELA CRISTINA DE OLIVEIRA REY}

Graduanda em Engenharia de Produção pela Universidade de São Paulo - Escola de Engenharia de Lorena (EEL/USP). Experiência em Gestão de Pessoas no Centro Acadêmico de Engenharia de Produção (CAEP). Além de desenvolvimento de projetos socioambientais em hospitais de pequeno porte no Vale do Paraíba e realização de pesquisa na área de Planejamento Estratégico para o agronegócio. Tem artigos publicados nos Anais COBENGE e ENEGEP.

\section{MARCOS ANTÔNIO DE SOUZA QUEIROZ}

Graduação em andamento em Engenheira de Produção na Universidade Federal do Amazonas - UFAM.

\section{MARCOS CHARLES PINHEIRO BALTAZAR}

Professor na área de Logística do Instituto Federal de Alagoas. Mestre em Logística e Pesquisa Operacional pela Universidade Federal do Ceará (2015). Possui graduação em Telemática pela Universidade Estácio de Sá (2011). Possui experiência com implantação de sistema empresarial (ERP) na área de Suprimentos, Finanças, Controladoria e Mercado. Atualmente participa do grupo de pesquisa Observatório Tecnológico da Universidade Federal do Ceará com pesquisas voltadas a desempenho empresarial e práticas empresariais.

\section{MARCOS RONALDO ALBERTIN}

Possui graduação em Engenharia Mecânica pela Pontifícia Universidade Católica do Rio Grande do Sul (1983), mestrado em Engenharia Industrial - FH-Bochum Universität (1993) e doutorado em Engenharia de Produção pela URGS (2003). Atualmente é Prof. Associado e Chefe do Departamento de Engenharia de Produção do Centro de Tecnologia da Universidade Federal do Ceará. Trabalhou em empresas como: Mangels, Zahnrad Fabrik, OPEL, Marcopolo e DANA. Possui experiência em ISO 9001, TS 16949, STP e Gestão da Qualidade. Pós-doutorado no Bremer Institut für Produktion und Logistik (2009) em Monitoramento de Sistemas Produtivos. Pós-doutorado no IPK - Fraunhofer no tema Benchmarking (2013). Extensão universitária em garantia da qualidade para o ensino superior Vienna University of Technology (2016).

\section{MARIANE MERCHIORI}

Graduanda do último ano de Engenharia de Produção, atualmente trabalha com Gestão da Qualidade (SGQ). Possui dois artigos publicados e apresentados no ENEGEP (Programa de Engenharia de Produção) e demais contribuições com projetos aplicados na área fabril. 


\section{MATEUS LEITE DE OLIVEIRA}

Possui graduação em Engenharia de Produção (2015), MBA em Gestão Financeira: Auditoria e Controladoria pela Fundação Getúlio Vargas (2018). Atuou como estagiário na área de Engenharia de Produção, com ênfase em Planejamento, Programação e Controle da Produção, Desenvolvimento em Projeto de Melhoria Contínua e Produtos. Atualmente é SócioDiretor de uma empresa que presta assessoria na área financeira. Tem experiência na Área de Planejamento, Programação e Controle da Produção, Desenvolvimento de Produtos, Gestão Financeira, Gestão de Projetos.

\section{MERISANDRA CORTES DE MATTOS}

Doutora em Engenharia Elétrica pela Universidade Federal de Santa Catarina (2015) na área de conhecimento em Engenharia Biomédica. Possui Mestrado em Ciências da Computação pela Universidade Federal de Santa Catarina (2001) na área de Sistemas do Conhecimento. Desde fevereiro de 2001 é professora da Unidade Acadêmica de Ciências, Engenharias e Tecnologias da Universidade do Extremo Sul Catarinense (UNESC) em Criciúma-SC. Atua nas áreas de Inteligência Computacional e Engenharia Biomédica, principalmente nas linhas de Ferramentas Inteligentes de Suporte à Decisão, Engenharia e Gestão do Conhecimento.

\section{PAULO CEZAR THIEBAUT}

Graduado em Ciências Contábeis e Direito e Mestrando em Gestão Pública, pela Universidade Federal do Espírito Santo - UFES. Auditor Federal de Finanças e Controle da Controladoria-Geral da União - CGU.

\section{PEDRO ALVIM DE AZEVEDO SANTOS}

Phd Fellow na Universidade Técnica da Dinamarca (DTU), onde atua com P\&D em distintas áreas em energia eólica, com foco para micrometeorologia, sensoriamento remoto com tecnologia lidar, avaliação do recurso eólico e turbulência atmosférica. m.sc. em engenharia mecânica para UFSC, atuou como consultor na Weg equipamentos elétricos S.A. (2015) e professor no centro universitário católica de Santa Catarina (2015-2017).

\section{POLLYANNA MENEZES DE SOUSA}

Bacharel em Engenheira de Produção pela Universidade Federal do Amazonas - UFAM (2016). Já atou como supervisora de projetos, área de gestão de piscicultura, na Secretaria Executiva de Pesca e Aquicultura-SEPA. Atualmente, atua como Assessora no Gabinete da Superintendência do IBAMA - AM.

\section{RAYSON RAWKEM DA SILVA SANTOS}

Graduado em Engenharia de Produção pela Universidade Federal do Amazonas (UFAM), PósGraduado em Lean Manufacturing pela Fundação Centro de Apoio à Pesquisa e Inovação Tecnológica (FUCAPI). Na indústria, possui experiência com processo de fabricação por injeção plástica e Gestão de Custos. Atuou como professor do curso de Engenharia de Produção na Universidade Federal do Amazonas (UFAM), ministrando disciplinas nos seguintes temas: Tecnologia de Fabricação, Elementos de Máquinas. Projeto de Unidades Produtivas, Gestão de Custos e Gestão de Operações.

\section{RENAN MATHIAS FERREIRA SALTIÉL}

Graduando em Engenharia de Produção pela Universidade Feevale. 


\section{RENATA DE OLIVEIRA TEIXEIRA}

Bacharel em Engenheira de Produção pela Universidade Federal do Amazonas (2016), com especialização em andamento em Segurança do Trabalho e Gestão Ambiental pela Universidade Candido Mendes. Técnica em Mecânica pelo Instituto Federal de Educação, Ciência e Tecnologia do Amazonas (2008). Atualmente ocupa o cargo de Técnica dos Laboratórios de Engenharia do Instituto de Ciências Exatas e Tecnologia da UFAM.

\section{RENATA RIBEIRO SILVA}

Carreira desenvolvida na área de Engenharia de Produção e Ferramentas Lean com experiência no acompanhamento, planejamento e controle de processos, elaboração de cronograma físico-financeiro, desenvolvimento de indicadores de desempenho, gestão de projetos e marketing do produto.

\section{RENATO MOREIRA TEIXEIRA JUNIOR}

Bacharelando em Engenheira de Materiais pela Universidade do Estado do Amazonas. Técnico em Eletrotécnica pelo Instituto Federal de Educação, Ciência e Tecnologia do Amazonas (2016).

\section{RICARDO LOPES DE ALMEIDA JUNIOR}

Ricardo, tem 24 anos, é graduado em Engenharia de Produção pela Universidade Federal do Amazonas (UFAM), é natural do estado do amazonas, nasceu na cidade de Itacoatiara. Tem como interesse as áreas de Planejamento e Controle da Produção, Sistemas Lean, Manufatura enxuta (Mapeamento de fluxo de valor e fluxo contínuo), Gestão da Qualidade, Gestão de Custo, Gestão Mercadológica, Pesquisa Operacional (Modelagem de sistemas e processos estocásticos).

\section{RICARDO LUIZ CIUCCO}

Possui graduação em Licenciatura Plena em Matemática pela Universidade Guarulhos (2003), Bacharelado em Matemática pela Universidade Guarulhos (2004), graduação em ENGENHARIA DE PRODUÇÃO pela Universidade Guarulhos (2009), especialista em Educação Matemática pela Universidade Guarulhos (2005) e MBA em direção de empresas pela Faculdade Armando Alvares Penteado (2007). Mestre em Engenharia Mecânica pela Universidade de Taubaté (2013). Atualmente é professor titular da Faculdade SENAI Roberto Simonsen e do Centro Universitário SENAC nos cursos de Tecnologia em Manutenção Industrial e Engenharia de Produção. Tem experiência na área de Engenharia de Produção, com ênfase em Engenharia de Processo, atuando principalmente nos seguintes temas: processos de fabricação, desenvolvimento de produto, usinagem. Atualmente atua com desenvolvimento de novos produtos e processos no setor de implantodontia odontológica.

\section{ROQUE JOSÉ PAES MORAES FILHO}

Bacharelando em Engenharia de Produção pela Universidade Federal do Amazonas - UFAM. Tecnólogo em Gestão de Tecnologia da Informação pela Universidade Leonardo da Vinci UNIASSELVI (2018) e Técnico em Segurança do Trabalho pelo Centro de Ensino Técnico CENTEC (2017). Atualmente é Técnico de Segurança do Trabalho, no Sistema de Segurança e Saúde Ocupacional ou do Trabalho - SST da Saldanha Rodrigues Ltda. 


\section{ROQUEMAR DE LIMA BALDAM}

Doutorado em Engenharia de Produção. Tem experiência prática na implantação em organizações Privadas e Públicas, nas áreas de Pesquisa, Processos, Projetos, Gerenciamento Eletrônico de Informação, Gestão do Conhecimento, Ferramentas para racionalização do trabalho. Certificado PMP (Project Management Professional), CBPP (Certified Business Process Professional) e CDIA+ (Certified Document Imaging Architect+). Gestor Regional da ABPMP Brasil.

\section{RUTE HOLANDA LOPES}

Doutora em Ciências do Ambiente e Sustentabilidade da Amazônia pela Universidade Federal do Amazonas - UFAM (2015). Mestra em Desenvolvimento Regional pela Universidade Federal do Amazonas - UFAM (2008). MBA em Empresas e Negócios pelo Centro Integrado de Ensino Superior do Amazonas - CIESA (2003). Bacharel em Ciências Econômicas pelo Centro Integrado de Ensino Superior do Amazonas - CIESA (2001). Pesquisas na área de: Sustentabilidade, Economia Regional, Engenharia de Produção, Produção Agrícola, Cadeias Produtivas Locais e Agricultura Familiar. Atualmente é professora adjunto da Universidade Federal do Amazonas - UFAM/ ICET, coordenadora do Curso de Engenharia de Produção e Vice coordenadora do COMEXI - Comitê de Extensão do ICET e Tecnologia, Gestão e Inovação, além de Coordenadora Administrativa da Incubadora do ICET - ICETech.

\section{SARA SANTOS PEREIRA}

Cursando o ensino superior em Engenharia de Produção pela Escola de Engenharia de Lorena da Universidade de São Paulo (EEL-USP). Experiência como voluntaria na área de gestão de pessoas e marketing em projetos sociais. Utilização de ferramentas do Lean Manufactoring em organização do Vale do Paraíba. Participação em projeto de inovação da Universidade de São Paulo, com certificado de primeiro lugar e artigo apresentado no Congresso de Engenharia de Produção - ENEGEP - em 2017. Proativa, com facilidade para trabalhar em equipe e com grande vontade de crescimento profissional.

\section{SILVIA LOPES DE SENA TAGLIALENHA}

Professora da Universidade Federal de Santa Catarina, Centro Tecnológico de Joinville. Possui Licenciatura em Matemática, com habilitação em Física - UNESP - Faculdade de Ciências e Tecnologia - Júlio de Mesquita Filho, Mestrado em Matemática Pura (Análise) ICMC-USP Universidade de São Paulo - São Carlos e Doutorado em Engenharia Elétrica (Automação) - UNESP - Faculdade de Engenharia de Ilha Solteira. Atua principalmente nos seguintes temas: programação linear inteira, problemas de transporte e logística, meta heurísticas e planejamento da expansão de sistemas de transmissão de energia elétrica.

\section{TAIS OLIVEIRA DA SILVA}

Graduanda em Engenharia de Produção e atualmente Analista de Projetos na Universidade La Salle. Pesquisa sobretudo tópicos sobre Gestão de Projetos, Liderança, e Mapeamento de Processos. Foi voluntária no diretório acadêmico do curso de Engenharia de Produção da Universidade La Salle, da empresa júnior Sinergia e do evento TED x Unilasalle Canoas (2016).

\section{THAIS MARTINS SOUZA}

Engenheira de Produção graduada pela Universidade do Estado do Pará (2017), Pós Graduanda em Engenharia e Gestão da Qualidade de Projetos pela Estácio - IESAM. Publicou artigos nos principais congressos nacionais voltados à Engenharia de Produção nas áreas de Gestão da Qualidade, com foco em Qualidade em serviços; Logística; Gestão da Produção; e Gestão de Custos. Também possui experiência profissional em Gestão de Processos e, 
atualmente, atua como Analista de Inteligência de Vendas em uma grande empresa distribuidora de produtos no Estado do Pará.

\section{THALMO DE PAIVA COELHO JUNIOR}

Professor Titular do Instituto Federal de Educação, Ciência e Tecnologia do Espírito Santo (IFES) e docente permanente no Programa de Pós-Graduação em Gestão Pública da Universidade Federal do Espírito Santo (UFES), é Doutor em Engenharia de Produção pela COPPE/UFRJ2003 (Coordenação dos Programas de Pós-Graduação em Engenharia da Universidade Federal do Rio de Janeiro), Mestre em Engenharia Metalúrgica e de Materiais pela COPPE/UFRJ 1997 e Especialista em Educação Tecnológica pela UFES'1997 (Universidade Federal do Espírito Santo), bem como Especialista em Didática e Pedagogia pela UFES'1993. Graduou-se em Engenharia Metalúrgica pela Universidade Federal Fluminense (1988).

\section{THIARA MONIK SILVA COSTA}

Graduanda em Engenharia de Produção pela Universidade Federal Rural do Semi Árido

\section{TIAGO DOS SANTOS ANTUNES}

Mestrando em Engenharia de Produção e Sistemas pela Universidades do Vale do Rio dos Sinos - Unisinos. Engenheiro de Produção pela Universidade Feevale. Pesquisador no GmapUnisinos. Técnico em Eletrotécnica pela Instituito Federal IFSUL. Atua há 12 anos no ramo de serviços nas áreas de Operações, Planejamento, Programação e Controle de Produção.

\section{TIAGO LISBOA MATTOS}

Engenheiro de Produção pela Universidade Estácio de Sá, Project Management Professional, amante de Planejamento, Risco e Produtividade, possui mais de 15 anos de experiência em projetos de alta complexidade como construções de Petroquímicas, Refinarias, Plataformas e Navios, sempre atento aos processos buscando otimiza-los com foco na tomada de decisão.

\section{VINICIUS GOMES FIGUEIREDO}

Graduando em Engenharia Química pela Universidade Estadual de São Paulo, campus Lorena-SP. Conhecimento operacional e estratégico de plataformas digitais e suas respectivas vendas devido à realização de um estágio numa empresa de varejo farmacêutico.

\section{WILLIAM NUNES BITTENCOURT}

É graduado em Processos Gerenciais, pós-graduado em Gestão Industrial Logística, Gestão de pessoas, Gestão Financeira e Custos, Educação Profissional e Mestre em Tecnologia de Informação e Comunicação na linha de pesquisa educacional. Atualmente é professor universitário na Faculdade SENAC/ SC nos níveis técnico, graduação e pós-graduação atuando com disciplinas voltadas para a Gestão de Negócios, como: Logística, Marketing e Pessoas. Possui atribuições como Coach de Carreira e Propósito, consultor de gestão empresarial para pequenas e médias empresas e palestrante em treinamentos de formação de equipes e lideranças. É também empreendedor franqueado de uma empresa de vendas diretas. 
Agência Brasileira do ISBN ISBN 978-85-93729-96-6

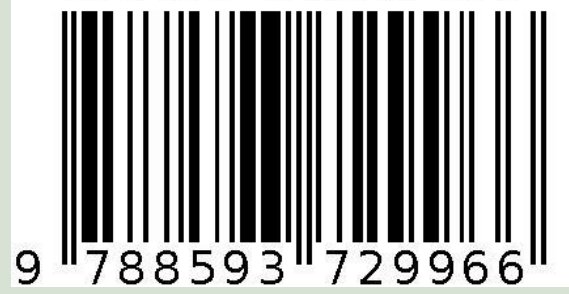

